\title{
nanomaterials
}

Advances

in Emerging

Solar Cells

Edited by

Munkhbayar Batmunkh

Printed Edition of the Special Issue Published in Nanomaterials 
Advances in Emerging Solar Cells 



\section{Advances in Emerging Solar Cells}

Special Issue Editor

Munkhbayar Batmunkh

MDPI • Basel • Beijing $\bullet$ Wuhan $\bullet$ Barcelona $\bullet$ Belgrade $\bullet$ Manchester $\bullet$ Tokyo $\bullet$ Cluj $\bullet$ Tianjin

\section{MDPI}


Special Issue Editor

Munkhbayar Batmunkh

Griffith University

Australia

Editorial Office

MDPI

St. Alban-Anlage 66

4052 Basel, Switzerland

This is a reprint of articles from the Special Issue published online in the open access journal Nanomaterials (ISSN 2079-4991) (available at: https://www.mdpi.com/journal/nanomaterials/ special_issues/nano_solar_cells).

For citation purposes, cite each article independently as indicated on the article page online and as indicated below:

LastName, A.A.; LastName, B.B.; LastName, C.C. Article Title. Journal Name Year, Article Number, Page Range.

ISBN 978-3-03928-979-0 (Hbk)

ISBN 978-3-03928-980-6 (PDF)

(C) 2020 by the authors. Articles in this book are Open Access and distributed under the Creative Commons Attribution (CC BY) license, which allows users to download, copy and build upon published articles, as long as the author and publisher are properly credited, which ensures maximum dissemination and a wider impact of our publications.

The book as a whole is distributed by MDPI under the terms and conditions of the Creative Commons license CC BY-NC-ND. 


\section{Contents}

About the Special Issue Editor $\ldots \ldots \ldots \ldots \ldots \ldots \ldots$ vii

Munkhbayar Batmunkh

Advances in Emerging Solar Cells

Reprinted from: Nanomaterials 2020, 10, 534, doi:10.3390/nano10030534 . . . . . . . . . . . . 1

Calum McDonald, Chengsheng Ni, Paul Maguire, Paul Connor, John T. S. Irvine,

Davide Mariotti and Vladimir Svrcek

Nanostructured Perovskite Solar Cells

Reprinted from: Nanomaterials 2019, 9, 1481, doi:10.3390/nano9101481 _ . . . . . . . . . . 5

Jia-Ren Wu, Diksha Thakur, Shou-En Chiang, Anjali Chandel, Jyh-Shyang Wang, Kuan-Cheng Chiu and Sheng Hsiung Chang

The Way to Pursue Truly High-Performance Perovskite Solar Cells

Reprinted from: Nanomaterials 2019, 9, 1269, doi:10.3390/nano9091269 _ . . . . . . . . . . . 33

Xianglin Mei, Bin Wu, Xiuzhen Guo, Xiaolin Liu, Zhitao Rong, Songwei Liu, Yanru Chen, Donghuan Qin, Wei Xu, Lintao Hou and Bingchang Chen

Efficient CdTe Nanocrystal/ $\mathrm{TiO}_{2}$ Hetero-Junction Solar Cells with Open Circuit Voltage Breaking $0.8 \mathrm{~V}$ by Incorporating A Thin Layer of CdS Nanocrystal

Reprinted from: Nanomaterials 2018, 8, 614, doi:10.3390/nano8080614

Hang Dong, Shangzheng Pang, Yi Zhang, Dazheng Chen, Weidong Zhu, He Xi,

Jingjing Chang, Jincheng Zhang, Chunfu Zhang and Yue Hao

Improving Electron Extraction Ability and Device Stability of Perovskite Solar Cells Using a

Compatible PCBM/AZO Electron Transporting Bilayer

Reprinted from: Nanomaterials 2018, 8, 720, doi:10.3390/nano8090720 . . . . . . . . . . . . 61

Hongye Chen, Min Li, Xiaoyan Wen, Yingping Yang, Daping He, Wallace C. H. Choy and Haifei Lu

Enhanced Silver Nanowire Composite Window Electrode Protected by Large Size Graphene

Oxide Sheets for Perovskite Solar Cells

Reprinted from: Nanomaterials 2019, 9, 193, doi:10.3390/nano90201935 _ . . . . . . . . . . 7

Guixia Yang, Yuanlong Pang, Yuqing Yang, Jianyong Liu, Shuming Peng, Gang Chen, Ming Jiang, Xiaotao Zu, Xuan Fang, Hongbin Zhao, Liang Qiao and Haiyan Xiao

High-Dose Electron Radiation and Unexpected Room-Temperature Self-Healing of Epitaxial SiC Schottky Barrier Diodes

Reprinted from: Nanomaterials 2019, 9, 194, doi:10.3390/nano9020194 _ . . . . . . . . . . . 8

Hsuan-Ta Wu, Yu-Ting Cheng, Ching-Chich Leu, Shih-Hsiung Wu and Chuan-Feng Shih Improving Two-Step Prepared $\mathrm{CH}_{3} \mathrm{NH}_{3} \mathrm{PbI}_{3}$ Perovskite Solar Cells by Co-Doping Potassium Halide and Water in $\mathrm{PbI}_{2}$ Layer

Reprinted from: Nanomaterials 2019, 9, 666, doi:10.3390/nano9050666 . . . . . . . . . . . . 99

Dazheng Chen, Gang Fan, Hongxiao Zhang, Long Zhou, Weidong Zhu, He Xi, Hang Dong, Shangzheng Pang, Xiaoning He, Zhenhua Lin, Jincheng Zhang, Chunfu Zhang and Yue Hao Efficient Ni/Au Mesh Transparent Electrodes for ITO-Free Planar Perovskite Solar Cells Reprinted from: Nanomaterials 2019, 9, 932, doi:10.3390/nano9070932 . . . . . . . . . . . . . . 111 
Kai Wang, Haoran Chen, Tingting Niu, Shan Wang, Xiao Guo and Hong Wang

Dopant-Free Hole Transport Materials with a Long Alkyl Chain for Stable Perovskite Solar Cells Reprinted from: Nanomaterials 2019, 9,935, doi:10.3390/nano9070935 . . . . . . . . . . . . . . . 125

Madeshwaran Sekkarapatti Ramasamy, Ka Yeon Ryu, Ju Won Lim, Asia Bibi, Hannah Kwon, Ji-Eun Lee, Dong Ha Kim and Kyungkon Kim

Solution-Processed PEDOT:PSS/ $\mathrm{MoS}_{2}$ Nanocomposites as Efficient Hole-Transporting Layers for Organic Solar Cells

Reprinted from: Nanomaterials 2019, 9, 1328, doi:10.3390/nano9091328 . . . . . . . . . . . . . . 135

Filip Ambroz, Joanna L. Donnelly, Jonathan D. Wilden, Thomas J. Macdonald and

Ivan P. Parkin

Carboxylic Acid Functionalization at the Meso-Position of the Bodipy Core and Its Influence on Photovoltaic Performance

Reprinted from: Nanomaterials 2019, 9, 1346, doi:10.3390/nano9101346 . . . . . . . . . . . . . . 147

Mariem Naffeti, Pablo Aitor Postigo, Radhouane Chtourou and Mohamed Ali Zaïbi

Elucidating the Effect of Etching Time Key-Parameter toward Optically and Electrically-Active Silicon Nanowires

Reprinted from: Nanomaterials 2020, 10, 404, doi:10.3390/nano10030404 . . . . . . . . . . . . . . . 159 


\section{About the Special Issue Editor}

Munkhbayar Batmunkh is currently a research fellow at Centre for Clean Environment and Energy (CCEE) at Griffith University, Australia. Dr. Munkhbayar Batmunkh also worked at the University of Queensland (2018-2019) and the Flinders University of South Australia (2017-2018), and was a visiting scholar at Virginia Tech, USA. He completed his Ph.D. study in the School of Chemical Engineering at the University of Adelaide, Australia, in 2017. He obtained his M.Eng. degree from Gyeongsang National University, South Korea, in 2012. He completed his B.S. in Chemistry at the National University of Mongolia, Mongolia, in 2010. Dr. Munkhbayar Batmunkh's research interests focus on the production of functional nanomaterials (e.g., nanocarbons and 2D materials) for energy-related applications such as solar cells and catalysis. He has contributed to the fields by publishing more than 70 refereed journal articles in top-ranking journals. 



\title{
Editorial
}

\section{Advances in Emerging Solar Cells}

\author{
Munkhbayar Batmunkh \\ Centre for Clean Environment and Energy, Griffith University, Gold Coast, Queensland 4222, Australia; \\ m.batmunkh@griffith.edu.au
}

Received: 4 March 2020; Accepted: 12 March 2020; Published: 17 March 2020

There has been a continuous increase in the world's electricity generation and consumption over the years. Today's energy requirements are principally met by burning fossil fuels. However, in addition to increasing fuel prices, greenhouse gas emissions caused by the fuel-burning process have become a serious issue. As such, the development of renewable and sustainable energy technologies is of great importance. Direct conversion of the sunlight into electricity using photovoltaic (PV) devices is now considered as a mainstream renewable energy source. According to the international energy agency (IEA) [1], the world's total renewable-based power capacity is expected to grow by $50 \%$ between 2019 and 2024. Interestingly, solar PV accounts for more than 50\% of this rise.

The PV market is currently dominated by technologies based on crystalline (poly + single) silicon. These silicon-based solar cells are a mature technology and can deliver a power conversion efficiency (PCE) of approximately $20 \%$ under full-sun illumination. Although significant reductions in the price of silicon PV cells have been observed, these technologies still suffer from high installation costs. Many scientists and researchers in the field of PV have paid particular attention to the development of a viable alternative PV technology. In this regard, emerging solar cells have received intense attention because these classes of solar cells, in comparison to traditional silicon PVs, promise to be less expensive, lighter, more flexible, and portable. Despite these great features, there are several challenges that restrict the possible commercialization of these technologies. This has led to significant efforts being focused on addressing issues associated with emerging solar cells. This Special Issue presents twelve excellent articles, ten research and two review papers, covering perovskite solar cells (PSCs) [2-8], heterojunction solar cells (HJSCs) [9], organic solar cells (OSCs) [10], dye-sensitized solar cells (DSSCs) [11], and PV materials [12,13].

The first report on organic-inorganic hybrid perovskite for solar cells was published in 2009 by Kojima et al. [14], and achieved a PCE of 3.8\%. Since then, excellent achievements have been made in the PSC field and the certified efficiency of PSCs has now exceeded $25 \%$, making them the fastest advancing PV technology. In this Special Issue, McDonald et al. [8] provided an excellent overview of PSCs and outlined the recent advances that have been made in nanoscale perovskites such as low-dimensional perovskites, perovskite quantum dots, and perovskite-nanocrystal based solar cells. Chang et al. [7] discussed the hot-carrier characteristics of perovskite light absorbers, which play a critical role in high efficiency PSCs. They also pointed out the practical issues hindering the development of highly efficient perovskite-based hot-carrier solar cells. The authors presented their own perspective on the future development of hot-carrier PSCs.

Although PSCs are very attractive and highly efficient, they suffer from several serious limitations. A typical PSC is fabricated using a transparent conductive electrode such as indium-tin oxide (ITO) and fluorine-doped tin oxide (FTO). However, these transparent electrodes are expensive and have natural brittleness and poor mechanical robustness. Two research articles in this Special Issue reported alternative transparent electrodes to the conventional ITO/FTO. Lu and colleagues [3] demonstrated that the composite electrode of silver nanowires and large area graphene oxide (Ag NWs/LGO) can exhibit comparable device performance to the standard ITO based PSCs. Chen et al. [5] designed a hexagonal $\mathrm{Ni}(30 \mathrm{~nm}) / \mathrm{Au}(10 \mathrm{~nm})$ mesh that showed a transmittance close to $80 \%$ in the visible light 
region and a sheet resistance lower than $16.9 \Omega / \mathrm{sq}$. This metal mesh, when used in device fabrication, displayed a PCE of $13.88 \%$, which was comparable to that of the ITO-based PSC.

Phenyl-C61-butyric acid methyl ester (PCBM) is the mostly commonly used electron transporting material in the p-i-n type (inverted) PSCs. However, the energy barrier at the interface between the PCBM layer and metal electrode limits the photogenerated charge extraction and thus results in reduced device efficiencies. In order to tackle this issue, Dong et al. [2] used a room temperature, solution processed Al-doped $\mathrm{ZnO}(\mathrm{AZO})$ as an interlayer between the PCBM and Ag electrode. The PSC device fabricated with an AZO interlayer not only exhibited a promising PV efficiency, but also showed excellent device stability. Incorporating additives into the perovskite has been proven to be a promising strategy to enhance the efficiency of PSCs. Wu et al. [4] explored the influence of adding water and potassium halides $(\mathrm{KCl}, \mathrm{KBr}$, and $\mathrm{KI})$ into the $\mathrm{PbI}_{2}$ precursor solutions on the $\mathrm{PV}$ performance of PSCs. By co-doping with KI and water, they significantly improved the efficiency of $\mathrm{CH}_{3} \mathrm{NH}_{3} \mathrm{PbI}_{3}$ perovskite based solar cells. In PSCs, hole transporting materials (HTMs) play a critical role in selecting holes and transporting them to the conductive electrodes. High efficiency PSCs rely on expensive HTMs such as 2,2' $, 7,7^{\prime}$-Tetrakis[ $N, N$-di(4-methoxyphenyl)amino]-9, $9^{\prime}$-spirobifluorene (Spiro-OMeTAD) and poly[bis(4-phenyl)(2,4,6-trimethylphenyl)amine] (PTAA). In addition to their high costs, the devices fabricated using these HMTs suffer from poor stability in ambient conditions. Therefore, developing a novel HMT is of great interest. Wang et al. [6] designed a new type of HTM, named 4,4'-(9-methyl-9H-carbazole-3,6-diyl)bis( $N, N$-bis(4-methoxyphenyl)aniline) (CZTPA), as an alternative to the traditional Spiro-OMeTAD. This new HTM based PSC achieved a PCE of $11.79 \%$, which was comparable to that $(11.74 \%)$ of the non-doped Spiro-OMeTAD, while showing better stability in ambient conditions.

Solution-processed CdTe based HJSCs have attracted a great deal of attention from the PV community. However, the efficiencies of this class of HJSCs are still very limited. Mei et al. [9] developed an efficient approach to enhance the efficiency of $\mathrm{CdTe} / \mathrm{TiO}_{2} \mathrm{HJSC}$ s by inserting a thin layer of CdS nanocrystal between the $\mathrm{CdTe}$ and $\mathrm{TiO}_{2}$ layers. OSCs have many attractive properties such as high flexibility, solution processability, light weight, and simple manufacturing. In a typical OSC, poly(3,4-ethylenedioxythiophene):poly(styrenesulfonate) (PEDOT:PSS) is used as a HTM. However, the major drawback in using PEDOT:PSS in OSCs is the surface energy mismatch between the PEDOT:PSS and the active layer. To overcome this issue, Ramasamy et al. [10] used oleylamine-functionalized $\mathrm{MoS}_{2}$ in the PEDOT:PSS layer. By using this strategy, they observed a $15.08 \%$ enhancement in the device performance. DSSCs are an attractive emerging PV due to their eco-friendliness, ease of fabrication, and cost effectiveness. Designing a new type of dye molecule as a light harvesting material is still a hot area of research. Ambroz et al. [11] developed two bodipy dyes with different carboxylic acids on the meso-position of the bodipy core and used them to sensitize $\mathrm{TiO}_{2}$ photoelectrodes for DSSCs.

Exploring new synthesis methods, properties, and functionalization of PV materials is of great importance. Yang et al. [12] studied the electrical properties of $4 \mathrm{H}$-silicon carbide (SiC) Schottky barrier diodes (SBDs) under high-dose electron irradiation. They used in-situ noise diagnostic analysis to demonstrate the correlation of irradiation-induced defects and microscopic electronic properties. Semiconductor $\mathrm{SiC}$ is widely used in electronic devices such as inverters, which deliver energy from $\mathrm{PV}$ arrays to the electric grids and other applications. Furthermore, Naffeti et al. [13] used a facile, reliable, and cost-effective metal assisted chemical etching method to fabricate highly crystalline vertically aligned silicon nanowires (SiNWs). SiNWs are widely used not only in solar cells, but also in other applications including lithium-ion batteries, sensors, electronics, and catalysis. SiNWs fabricated in this work [13] showed a strong decrease in the reflectance, demonstrating that these SiNWs are an excellent candidate for PV cells.

Finally, I believe that these articles will be of wide interest for the broad readership of the journal (Nanomaterials).

Funding: This research received no external funding. 
Acknowledgments: The Guest Editor would like to thank all authors for submitting their work to the Special Issue. Special thanks also go to all the reviewers for their prompt responses and for making constructive suggestions that enhance the publication quality and impact. I am also grateful to Sandra Ma and the editorial assistants who made the Special Issue creation a smooth and efficient process.

Conflicts of Interest: The author declares no conflicts of interest.

\section{References}

1. International Energy Agency. 2019. Available online: https://www.iea.org/reports/renewables-2019 (accessed on 3 March 2020).

2. Dong, H.; Pang, S.; Zhang, Y.; Chen, D.; Zhu, W.; Xi, H.; Chang, J.; Zhang, J.; Zhang, C.; Hao, Y. Improving Electron Extraction Ability and Device Stability of Perovskite Solar Cells Using a Compatible PCBM/AZO Electron Transporting Bilayer. Nanomaterials 2018, 8, 720. [CrossRef] [PubMed]

3. Chen, H.; Li, M.; Wen, X.; Yang, Y.; He, D.; Choy, W.C.H.; Lu, H. Enhanced Silver Nanowire Composite Window Electrode Protected by Large Size Graphene Oxide Sheets for Perovskite Solar Cells. Nanomaterials 2019, 9, 193. [CrossRef] [PubMed]

4. Wu, H.-T.; Cheng, Y.-T.; Leu, C.-C.; Wu, S.-H.; Shih, C.-F. Improving Two-Step Prepared CH3NH3PbI3 Perovskite Solar Cells by Co-Doping Potassium Halide and Water in PbI2 Layer. Nanomaterials 2019, 9, 666. [CrossRef] [PubMed]

5. Chen, D.; Fan, G.; Zhang, H.; Zhou, L.; Zhu, W.; Xi, H.; Dong, H.; Pang, S.; He, X.; Lin, Z.; et al. Efficient Ni/Au Mesh Transparent Electrodes for ITO-Free Planar Perovskite Solar Cells. Nanomaterials 2019, 9, 932. [CrossRef] [PubMed]

6. Wang, K.; Chen, H.; Niu, T.; Wang, S.; Guo, X.; Wang, H. Dopant-Free Hole Transport Materials with a Long Alkyl Chain for Stable Perovskite Solar Cells. Nanomaterials 2019, 9, 935. [CrossRef] [PubMed]

7. Wu, J.-R.; Thakur, D.; Chiang, S.-E.; Chandel, A.; Wang, J.-S.; Chiu, K.-C.; Chang, S.H. The Way to Pursue Truly High-Performance Perovskite Solar Cells. Nanomaterials 2019, 9, 1269. [CrossRef] [PubMed]

8. McDonald, C.; Ni, C.; Maguire, P.; Connor, P.; Irvine, J.T.S.; Mariotti, D.; Svrcek, V. Nanostructured Perovskite Solar Cells. Nanomaterials 2019, 9, 1481. [CrossRef] [PubMed]

9. Mei, X.; Wu, B.; Guo, X.; Liu, X.; Rong, Z.; Liu, S.; Chen, Y.; Qin, D.; Xu, W.; Hou, L.; et al. Efficient CdTe Nanocrystal/TiO2 Hetero-Junction Solar Cells with Open Circuit Voltage Breaking $0.8 \mathrm{~V}$ by Incorporating A Thin Layer of CdS Nanocrystal. Nanomaterials 2018, 8, 614. [CrossRef] [PubMed]

10. Ramasamy, M.S.; Ryu, K.Y.; Lim, J.W.; Bibi, A.; Kwon, H.; Lee, J.-E.; Kim, D.H.; Kim, K. Solution-Processed PEDOT:PSS/MoS2 Nanocomposites as Efficient Hole-Transporting Layers for Organic Solar Cells. Nanomaterials 2019, 9, 1328. [CrossRef] [PubMed]

11. Ambroz, F.; Donnelly, J.L.; Wilden, J.D.; Macdonald, T.J.; Parkin, I.P. Carboxylic Acid Functionalization at the Meso-Position of the Bodipy Core and Its Influence on Photovoltaic Performance. Nanomaterials 2019, 9, 1346. [CrossRef] [PubMed]

12. Yang, G.; Pang, Y.; Yang, Y.; Liu, J.; Peng, S.; Chen, G.; Jiang, M.; Zu, X.; Fang, X.; Zhao, H.; et al. High-Dose Electron Radiation and Unexpected Room-Temperature Self-Healing of Epitaxial SiC Schottky Barrier Diodes. Nanomaterials 2019, 9, 194. [CrossRef] [PubMed]

13. Naffeti, M.; Postigo, P.A.; Chtourou, R.; Zaibi, M.A. Elucidating the Effect of Etching Time Key-Parameter toward Optically and Electrically-Active Silicon Nanowires. Nanomaterials 2020, 10, 404. [CrossRef] [PubMed]

14. Kojima, A.; Teshima, K.; Shirai, Y.; Miyasaka, T. Organometal Halide Perovskites as Visible-Light Sensitizers for Photovoltaic Cells. J. Am. Chem. Soc. 2009, 131, 6050-6051. [CrossRef] [PubMed]

(C) 2020 by the author. Licensee MDPI, Basel, Switzerland. This article is an open access article distributed under the terms and conditions of the Creative Commons Attribution (CC BY) license (http://creativecommons.org/licenses/by/4.0/). 



\title{
Review
}

\section{Nanostructured Perovskite Solar Cells}

\author{
Calum McDonald ${ }^{1, *}$, Chengsheng $\mathrm{Ni}^{2}$, Paul Maguire ${ }^{3}$, Paul Connor ${ }^{4}$, John T. S. Irvine ${ }^{4}$, \\ Davide Mariotti ${ }^{3}$ and Vladimir Svrcek ${ }^{1}$ \\ 1 Research Center for Photovoltaics, National Institute of Advanced Industrial Science and Technology (AIST), \\ Tsukuba, Ibaraki 305-8568, Japan; vladimir.svrcek@aist.go.jp \\ 2 College of Resources and Environment, Southwest University, Beibei, Chongqing 400715, China; \\ nichengsheg@163.com \\ 3 School of Engineering, Ulster University, Newtownabbey BT37 0QB, UK; pd.maguire@ulster.ac.uk (P.M.); \\ d.mariotti@ulster.ac.uk (D.M.) \\ 4 School of Chemistry, University of St Andrews, North Haugh, St Andrews KY16 9AJ, UK; \\ pac5@st-andrews.ac.uk (P.C.); jtsi@st-andrews.ac.uk (J.T.S.I.) \\ * Correspondence: calummcdonaldpv@gmail.com
}

Received: 26 September 2019; Accepted: 12 October 2019; Published: 18 October 2019

\begin{abstract}
Over the past decade, lead halide perovskites have emerged as one of the leading photovoltaic materials due to their long carrier lifetimes, high absorption coefficients, high tolerance to defects, and facile processing methods. With a bandgap of $\sim 1.6 \mathrm{eV}$, lead halide perovskite solar cells have achieved power conversion efficiencies in excess of $25 \%$. Despite this, poor material stability along with lead contamination remains a significant barrier to commercialization. Recently, low-dimensional perovskites, where at least one of the structural dimensions is measured on the nanoscale, have demonstrated significantly higher stabilities, and although their power conversion efficiencies are slightly lower, these materials also open up the possibility of quantum-confinement effects such as carrier multiplication. Furthermore, both bulk perovskites and low-dimensional perovskites have been demonstrated to form hybrids with silicon nanocrystals, where numerous device architectures can be exploited to improve efficiency. In this review, we provide an overview of perovskite solar cells, and report the current progress in nanoscale perovskites, such as low-dimensional perovskites, perovskite quantum dots, and perovskite-nanocrystal hybrid solar cells.
\end{abstract}

Keywords: solar cells; perovskites; perovskite nanocrystals; perovskite quantum dots; low-dimensional perovskites; nanocrystal solar cells; organic-inorganic hybrid solar cells; lead halide solar cells; hybrid solar cells

\section{Introduction}

In the search of high-efficiency, low-cost solar cells, a multitude of new materials and architectures are currently being explored. Over the past decade, organometal halide perovskites (OHPs) have emerged as a highly promising photovoltaic material and have been demonstrated as the active layer in perovskite solar cells (PSCs) with efficiencies over $25 \%$ for laboratory-based devices $\left(\sim 0.1 \mathrm{~cm}^{2}\right)$ [1] and around $10-15 \%$ in modules [2] and are recently being employed in high-efficiency tandem devices [3]. The performance of PSCs has seen a meteoric rise over the past decade and they are already comparable with or superior to well-established photovoltaic technologies [1]. OHPs are attractive particularly due to their ease of processing [4], large absorption coefficients [5], long carrier diffusion lengths [6], low exciton binding energies [7], and low non-radiative recombination rates [8]. These properties also make OHPs an attractive material for various other optoelectronic devices, such as light emitting diodes [9], lasers [10,11], and photodetectors [12].

$\mathrm{OHPs}$ have a perovskite crystal structure with the general stoichiometry $\mathrm{ABX}_{3}$ as shown in Figure 1. The A-site is occupied by a monovalent cation e.g., methylammonium ( $\mathrm{MA}, \mathrm{CH}_{3} \mathrm{NH}_{3}{ }^{+}$), 
formamidinium (FA, $\left.\mathrm{CH}_{3}\left(\mathrm{NH}_{2}\right)_{2}{ }^{+}\right), \mathrm{Cs}^{+}$etc. The B-site is usually occupied by a $\mathrm{Pb}^{2+}$ divalent metal cation and can be substituted by a similarly-sized divalent cation such as $\mathrm{Sn}^{2+}$. The $\mathrm{X}$-site is usually occupied by a halide anion e.g., $\mathrm{I}^{-}, \mathrm{Cl}^{-}, \mathrm{Br}^{-}$. OHPs with mixed cations and/or anions are now the standard for high efficiency cells, particularly due to improved structural stability [13-15]. Their high compositional tunability, whereby the bandgap can be easily modified through ion substitution [16] and low-cost facile deposition procedures [17] makes OHPs excellent candidates for tandem solar cells, where two materials of different bandgaps are employed in conjunction to absorb different parts of the solar spectrum. OHPs can be employed either as the top cell in a tandem device (with e.g., silicon, cadmium telluride, copper indium gallium diselenide etc. bottom cell) or in a stacked perovskite-perovskite tandem device. The successful fabrication of tandem cells with OHPs has the potential to achieve efficiencies in excess of $40 \%$ [3].
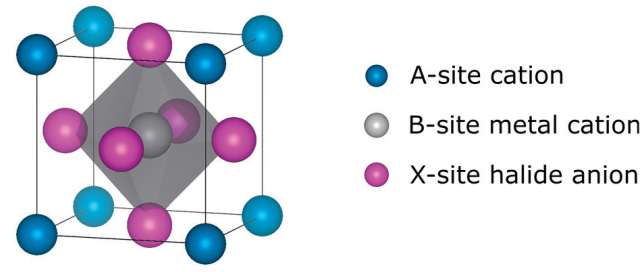

Figure 1. Cubic perovskite unit cell.

While OHPs have demonstrated remarkable efficiencies in laboratory solar cells, there remains significant challenges regarding long-term suitability and feasibility of commercialization [18]. OHPs are extremely susceptible to moisture-induced degradation, and therefore devices must be fabricated in controlled nitrogen atmospheres to avoid trapped moisture in the active layer. Furthermore, devices must be sufficiently encapsulated to prevent external moisture ingress, and the fragility of OHPs along with weak inter-layer adhesion may demand rigid glass substrates to avoid delamination or fractures in the OHP. Even so, heat and light cycling can still induce degradation in encapsulated devices due to thermal mismatch [19]. The use of encapsulants, which can be expensive, along with rigid glass supports, makes OHPs less attractive due to increased costs [3]. It is therefore highly desirable to develop perovskite materials which are stable and tolerant to moisture and other environmental stresses.

Forming nanostructured OHPs (also referred to as low-dimensional OHPs) can be a potential route towards increasing the stability. So far, various types of low-dimensional OHPs have been demonstrated in solar cells, and typically show far superior stability to bulk OHPs [20-22]. This is achieved particularly due to higher formation energies of the low-dimensional perovskite structure and the possibility of encapsulating low-dimensional OHPs in long-chain polymers, essentially providing a protective barrier to moisture [22]. However, carrier transport tends to be restricted in nanostructured perovskites due to the presence of potential barriers within the nanostructured OHP, while quantum confinement also tends to widen the bandgap towards values typically in excess of $2 \mathrm{eV}$. This therefore comes at a cost to the performance, with the best nanostructured OHPs performing between 10-18\% [20-24].

Considering the recent advances in nanostructured perovskites, here we will provide an insight into the important developments and progress in photovoltaics. First, an introduction to the use of bulk OHPs in solar cells will be provided while discussing the challenges and issues facing these materials in order to provide a context for the recent direction towards nanostructured perovskites. This review will then provide a perspective into nanostructured perovskite solar cells as a possible route towards overcoming the issues pertaining to bulk OHPs. Furthermore, hybrid devices formed with OHPs and nanocrystals (NCs) will be discussed, along with high-stability metal oxide perovskite 
nanocrystals. We hope this will provide the reader with a basis for understanding the current status of PSCs and the potential opportunities of stable, low-dimensional perovskites.

\section{Overview of Bulk Perovskite Solar Cells}

PSCs were initially inspired by the dye-sensitized solar cell (DSSC), where simply replacing the dye in a DSSC with an OHP immediately yielded efficiencies of $\sim 3 \%$ [25]. The OHPs used were either $\mathrm{MAPbI}_{3}$ or $\mathrm{MAPbBr}_{3}$, where $\mathrm{MA}$ is the small organic cation methylammonium $\left(\mathrm{CH}_{3} \mathrm{NH}_{3}{ }^{+}\right)$. Since the liquid electrolyte, which is used in DSSCs as a redox mediator, dissolved the OHP, these devices had very short lifetimes on the order of seconds. The rapid dissolution of the OHP was overcome by replacing the liquid electrolyte with a polymer which did not dissolve the OHP. Subsequently, devices were reported using the polymer spiro-MeOTAD for hole transport, quickly achieving efficiencies of $\sim 10 \%$ with improved device lifetime [26,27]. It was demonstrated that electron and hole transport occurs in the OHP, indicating that free-carriers are generated in the OHP with long diffusion lengths and lifetimes, contrary to suspicion that photocarriers would be excitonic as for organic solar cells, and therefore the sensitized architecture was in fact not necessary [26].

The main PSC device architectures are shown in Figure 2. The OHP is sandwiched between two selective contacts, an electron transport layer (ETL) such as $\mathrm{TiO}_{2}$, and a hole transport layer (HTL) such as spiro-OMeTAD. Metallic contacts are formed on either side of the transport layers: a window contact is formed using a transparent conducting oxide (TCO) such as indium-doped tin oxide (ITO), and a back contact is formed using either gold, silver, aluminum etc. The first architecture employed in the research timeline was the sensitized architecture using a thick mesoporous layer of $\mathrm{TiO}_{2}$ (Figure 2a). This was quickly replaced with bi-layer devices, where the mesoporous- $\mathrm{TiO}_{2}$ was reduced in thickness and a thicker OHP layer was deposited to allow for greater absorption of light and longer crystalline order with larger grain sizes (Figure 2b). A planar device architecture can also be used, with either n-i-p configuration (Figure 2c) or p-i-n configuration (Figure 2d). The planar device eliminates the necessity for the mesoporous $\mathrm{TiO}_{2}$ layer, further reducing fabrication costs and complexity. Planar devices show greater potential for low-cost roll-to-roll printing of PSCs at low temperatures due to the elimination of mesoporous- $\mathrm{TiO}_{2}$ which must typically be annealed at high temperatures during device fabrication $\left(\sim 500{ }^{\circ} \mathrm{C}\right)$ for high-efficiency PCSs, and is therefore unattractive for large-scale production while also eliminating the possibility of fabricating devices on flexible plastic substrates. Furthermore, the high-temperature annealing of $\mathrm{TiO}_{2}$ is not suitable for the fabrication of tandem devices with silicon or perovskite bottom cells since such high-temperature annealing process will damage the silicon bottom cell [3]. Planar devices using an $\mathrm{SnO}_{2}$ electron transport layer can be fabricated via low-temperature methods and demonstrate superior stability to mesoporous- $\mathrm{TiO}_{2}$ devices, however the best efficiency of $21.6 \%$ is somewhat lower than mesoporous- $\mathrm{TiO}_{2}$ devices $(25.2 \%)$ [1,28]. Since PSCs employing mesoporous- $\mathrm{TiO}_{2}$ transport layers have shown greater efficiencies than planar devices thus far [29], ideally low-temperature fabrication techniques should be developed for mesoporous- $\mathrm{TiO}_{2}$ transport layers to enable their incorporation into tandem devices.

(a) sensitized

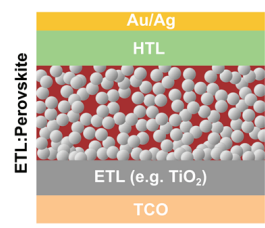

(b) bi-layer

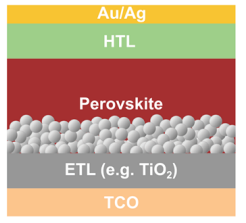

(c) n-i-p planar

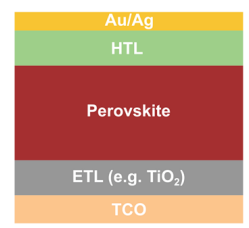

(d) p-i-n planar

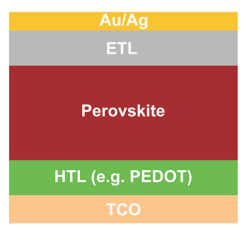

Figure 2. Various device architectures for organometal trihalide perovskite solar cells. (a) Mesoporous sensitized, (b) bi-layer, (c) n-i-p planar and (d) p-i-n planar. ETL, HTL, and TCO stand for electron transport layer, hole transport layer, and transparent conducting oxide, respectively. 


\subsection{Stability of Perovskite Solar Cells}

While exceptional efficiencies have been demonstrated with Pb-based perovskites [13-15], significant challenges exist such as poor stability, toxicity, and rate-dependent current-voltage hysteresis. Stability is an important consideration when assessing commercialization viability of new materials given that silicon solar cells can easily operate for $>25$ years, even when exposed to a broad range of temperatures and intense solar irradiance. OHPs tend to degrade rapidly in open air conditions and must be fabricated in controlled atmospheres to avoid moisture contamination. The rapid degradation of $\mathrm{MAPbI}_{3}$ in open-air conditions is shown in Figure 3, where the majority of the $\mathrm{MAPbI}_{3}$ layer degraded to $\mathrm{PbI}_{2}$ within 13 days [30]. Although the exact mechanism of degradation remains unclear; it is generally understood that an intermediate phase is first formed via hydration of the OHP [31,32]. Considering the decomposition of $\mathrm{MAPbI}_{3}$, the hydration of $\mathrm{MAPbI}_{3}$ leads to its conversion to $\mathrm{MA}_{4} \mathrm{PbI}_{6} \cdot 2 \mathrm{H}_{2} \mathrm{O}$ and $\mathrm{PbI}_{2}$, followed by phase separation and the subsequent loss of $\mathrm{MA}$, with the final products being $\mathrm{CH}_{3} \mathrm{NH}_{3} \mathrm{I}, \mathrm{PbI}_{2}$, and $\mathrm{H}_{2} \mathrm{O}$ [31]. The degradation has been shown first to occur at the grain boundaries and is assisted by the presence of trapped charges which usually exist at defect sites, surfaces, and grain boundaries [33]. Ions can easily migrate within OHPs, causing charge accumulation, phase segregation, lattice distortions, and strain in the perovskite structure [34-38]. The degradation of OHPs is enhanced under illumination, and degradation can be accelerated even under moderate temperatures of $\sim 60{ }^{\circ} \mathrm{C}[39,40]$. Furthermore, $I_{2}$, which is generated within the OHP due to exposure to moisture, can easily migrate and leads to the self-sustaining and irreversible degradation of the $\mathrm{OHP}$ [41]. The degradation of OHPs leads to the release of the gaseous products $\mathrm{CH}_{3} \mathrm{NH}_{2}, \mathrm{HX}, \mathrm{CH}_{3} \mathrm{X}$, and $\mathrm{NH}_{3}$ (where $\mathrm{X}$ is a halide), and the release of these gases can be observed at temperatures below $70{ }^{\circ} \mathrm{C}[42]$.

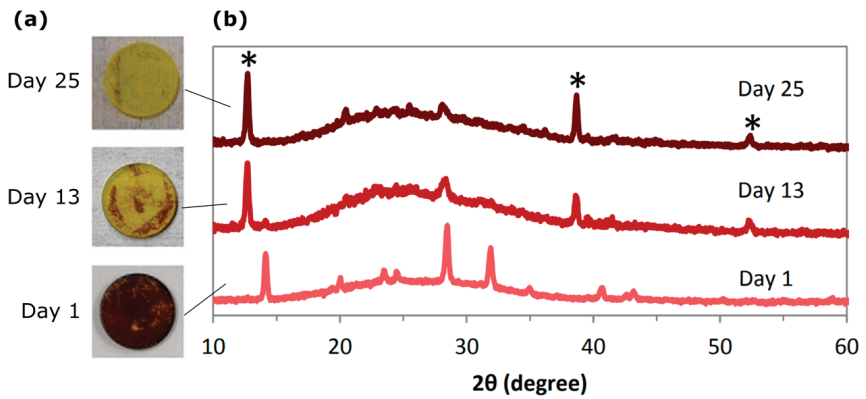

Figure 3. Degradation of $\mathrm{MAPbI}_{3}$. (a) Photographs of $\mathrm{MAPbI}_{3}$ degradation and (b) corresponding X-ray diffraction (XRD) spectra of the same samples after 1, 13, and 26 days stored in ambient conditions. The starred peaks in the XRD spectra correspond to $\mathrm{PbI}_{2}$. Reproduced from ref. [30], with permission from John Wiley and Sons, 2016.

Due to the high susceptibility of OHPs to degrade when exposed to moisture, it is therefore necessary to carefully control the atmosphere during fabrication. Entire device encapsulation is necessary to prevent exposure to moisture and mechanical fractures. For encapsulated devices, the formation of bubbles has been observed in the encapsulant layer due to the release of gaseous species. Encapsulation prevents gaseous products from escaping, creating a thermodynamically enclosed system which is expected to reduce the rate of degradation [42]. Encapsulation is therefore essential for several reasons: to prevent the ingress of moisture; to prevent the release of gases; and to prevent the release of toxic materials to the environment. However, due to the thermal expansion coefficient mismatch between the various layers, including the encapsulant, temperature cycling of the PSC (i.e., day and night temperature variations) can lead to significant delamination and device failure. Careful selection of the encapsulant and various device layers is therefore necessary to minimize delamination caused by temperature cycling. This eliminates the possibility of flexible, low-weight 
modules, and the low stability and Pb-contamination necessitates careful recycling of PSCs. In spite of these measures, the question of whether the lifetime of OHPs can match silicon PV remains dubious.

\subsection{Toxicity of Perouskite Solar Cells}

$\mathrm{Pb}$-containing OHPs' decomposition results in the formation of Pb-halide compounds, metallic $\mathrm{Pb}$, and various carbonated molecules [43]. Although PSCs contain small amounts of $\mathrm{Pb}\left(\sim 0.4 \mathrm{~g} / \mathrm{m}^{2}\right.$ for a $400 \mu \mathrm{m}$-thick OHP layer) [44], the harmful Pb-halides generated via degradation are highly water-soluble and therefore pose a significant risk to the environment [45]. The contamination of $\mathrm{Pb}$ can be addressed either by replacing $\mathrm{Pb}$ with other non-toxic elements or by stabilizing the structure of the perovskite so as to avoid the formation of $\mathrm{PbI}_{2}$. Unfortunately, computational studies have suggested that there is no viable alternative to Pb in PSCs to achieve the similarly high efficiencies which are in excess of $20 \%$ [46]. The high efficiencies of OHPs is attributed to the favorable $\mathrm{Pb}^{2+}$ orbital hybridization with $\mathrm{I}^{-}$and $\mathrm{Br}^{-}$halide ions which results in high absorption coefficients and long carrier diffusion lengths [47]. $\mathrm{Sn}$ is a potential alternative to $\mathrm{Pb}$, and whilst still toxic to animals and humans, it is less harmful than $\mathrm{Pb}$. [43] $\mathrm{Sn}-\mathrm{OHPs}$ have been produced by the direct replacement of $\mathrm{Pb}$ with $\mathrm{Sn}$, but the best efficiency achieved to date is $7.14 \%$ [23]. In addition, the stability of Sn-based devices is usually worse than $\mathrm{Pb}-\mathrm{OHPs}$ due to the tendency of tin to easily oxidize from $\mathrm{Sn}^{2+}$ to $\mathrm{Sn}^{4+}$. This can be mitigated to some extent by the addition of $\mathrm{SnF}_{2}$ and ethylenediammonium during fabrication to inhibit the formation of $\mathrm{Sn}^{4+}[23,48]$. While pure Sn-OHPs are unstable, the oxidation of $\mathrm{Sn}^{2+}$ becomes less energetically favorable when less than $50 \%$ of the B-site in the perovskite structure is occupied by $\mathrm{Sn}^{2+}$ (i.e., $\mathrm{MAPb}_{\geq 0.5} \mathrm{Sn}_{\leq 0.5} \mathrm{I}_{3}$ ) and the stability is significantly improved [49]. Notably, $\mathrm{Zn}$, which is a 2+ ion with a slightly smaller ionic radius than $\mathrm{Pb}$, has also been investigated for the partial replacement of $\mathrm{Pb}$ and has demonstrated an improvement in the power conversion efficiency (PCE) for small amounts of $\mathrm{Zn}(\sim 1 \%$ to $5 \%)$. The introduction of $\mathrm{Zn}$ into $\mathrm{MAPbI}_{3}$ leads to the formation of larger grains which are more homogeneous, and layers which are more compact and with fewer pinholes. This is achieved through a lattice contraction induced by the smaller $\mathrm{Zn}$ ion, along with stronger coordination with the organic cation, leading to a reduction in the amount of point defects [50-53]. However, this work only serves to reduce $\mathrm{Pb}$ contamination without eliminating it entirely, and the contamination of toxic $\mathrm{Pb}$ and $\mathrm{Sn}$ remains and degradation is still observed [49].

\subsection{Hysteresis in PSCs}

A common issue exhibited by nearly all PSCs is a hysteresis present during solar cell characterization. Hysteresis, defined as the dependence of the state of a system on its history, is frequently observed during current density-voltage $(\mathrm{J}-\mathrm{V})$ measurements, where a change in the voltage scan direction between forward and backward results in a differing J-V response, as shown in Figure 4a. A device without J-V hysteresis is shown in Figure $4 \mathrm{~b}$. The observed hysteresis is largely attributed to ion mobility within the OHP [54-56], whilst other mechanisms have also been proposed, see reference [57]. Hysteresis is problematic as it primarily introduces difficulties in accurately measuring device performance, but can also be indicative of stability issues $[41,58]$. Recent work $[13,15]$ has shown that high-efficiency mesoscopic devices possess low hysteresis in the forward and backward $\mathrm{J}-\mathrm{V}$ scans with the same scan rates from $10 \mathrm{mV} / \mathrm{s}$ to $50 \mathrm{mV} / \mathrm{s}$; however, hysteresis is still well observed particularly for fast scans $[56,59,60]$. Selecting appropriate contacts and forming high-quality OHP layers appears to negate most of the hysteresis observed during standard performance measurements with slow scan speeds; however, the J-V character for fast scans is often unreported and ionic motion and charge accumulation are still likely to be present in the perovskite layer. Furthermore, hysteresis is often intensified as devices are scaled to active areas over $1 \mathrm{~cm}^{2}$, particularly due to issues with controlling morphology when depositing OHPs over larger areas [61]. The hysteresis observed in OHPs depends on various measurement conditions during the J-V characterization, in particular: the voltage scan rate and scan range [56,62]; the delay time between applying the bias voltage and measuring the current [63]; and the poling voltage prior to measurement [57]. Hysteresis has also 
been shown to vary with the grain size of the perovskite [57,64], the A-site cation [65], and device architecture $[62,63]$.
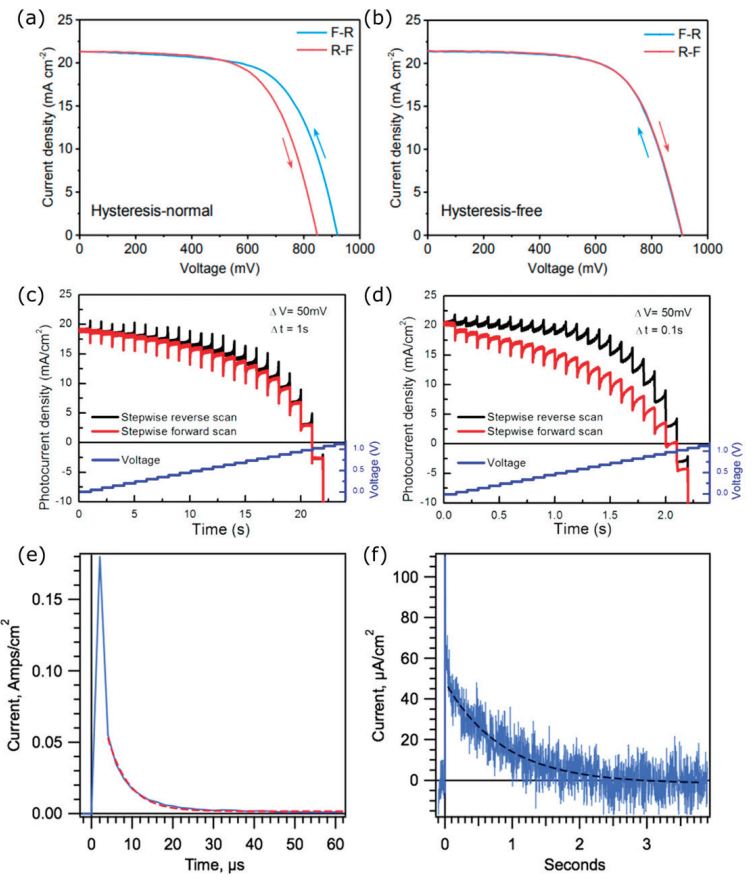

Figure 4. (a,b) Current density-voltage curves with forward (R-F) and reverse (F-R) voltage scan direction for a device with hysteresis (a) and without (b). Reproduced from ref. [66], with permission from The Royal Society of Chemistry, 2017. (c,d) Time-dependent photocurrent response under reverse and forward stepped scans with (b) $1 \mathrm{~s}$ step time and (c) $0.1 \mathrm{~s}$ step time. Reproduced from ref. [67], with permission from American Chemical Society, 2015. (e,f) Current decay after removing device from illumination showing two discharging events occurring over different timescales. Reproduced from ref. [68], with permission from American Chemical Society, 2015.

The hysteresis is well-described by Figure 4c,d whereby the voltage is scanned forward and backward in a stepwise fashion with different delay times between the steps: $1 \mathrm{~s}$ in Figure $4 \mathrm{c}$ and $0.1 \mathrm{~s}$ in Figure 4d [67]. It is clear that at least two processes are involved: one is an ultrafast process which leads to an almost instantaneous (microsecond) change in photocurrent, followed by a slower response on the timescale of milliseconds to seconds. There is a large difference in the forward and reverse $\mathrm{J}-\mathrm{V}$ scans observed for a $0.1 \mathrm{~s}$ voltage step time: this arises because when the step speed is too fast, the photocurrent is not able to stabilize and there is a remnant charge stored in the device. This was further investigated and it was shown that there are at least two ways in which charge is stored in OHPs (Figure 4e,f) [68]. After removing an OHP device from illumination, the photogenerated current decayed from $180 \mathrm{~mA} / \mathrm{cm}^{2}$ to less than $50 \mu \mathrm{A} / \mathrm{cm}^{2}$ within $50 \mu$ s (Figure $4 \mathrm{e}$ ). This was followed by a second, longer decay event which occurred over the next $\sim 3 \mathrm{~s}$ (Figure $4 \mathrm{f}$ ). Although the peak current in the second decay event $\left(\sim 50 \mu \mathrm{A} / \mathrm{cm}^{2}\right)$ accounted for less than $1 \%$ of the initial photocurrent $\left(\sim 180 \mathrm{~mA} / \mathrm{cm}^{2}\right)$, the lifetime of the second current was far longer and therefore the total charge associated with this slower decay was calculated to be $\sim 50$ times larger than the charge associated with the initial microsecond-discharge event. Therefore, at least two types of capacitive electronic charges were confirmed in OHPs: the first one is small $\left(\sim 0.2 \mu \mathrm{C} \mathrm{cm}^{-2}\right)$ and likely due to charge trapping; and the second one is much larger $\left(\sim 40 \mu \mathrm{C} \mathrm{cm}^{-2}\right)$, which could be the result of mobile ions or dipole 
realignment [68]. Furthermore, it is also known that large differences in the carrier mobility of the electron and hole transport layers can lead to charge accumulation resulting in hysteresis [68].

Understanding the origin and mechanism of hysteresis could lead to the improvement of the performance and stability of PSCs. The main mechanisms which have been proposed to contribute to the effect are: ion migration [56,67,69], charge trapping and accumulation [70,71], and polarization of dipoles $[57,62,72]$. These mechanisms are represented in Figure 5 and are described briefly in order of the legend:

1. Charge traps: Charges can become trapped at defects on surfaces or at grain boundaries and induce recombination, reducing the photocurrent.

2. Ferroelectric dipoles: Some reports have indicated that $\mathrm{OHPs}$ such as $\mathrm{MAPbI}_{3}$ are ferroelectric, and the polarization of domains would modify carrier transport through the perovskite, resulting in the observed hysteresis [62,73-75].

3. Electrons and holes: Similar to charge trapping, electrons and holes can accumulate in transport layers due to defects or imbalances in the carrier mobilities of the electron and hole transport layers.

4. Ion migration: Iodide ions and methylammonium ions can migrate to interfaces under applied bias and alter the internal field reducing the efficiency of carrier separation.

5. Interfacial electrode polarization: A capacitive polarization may arise due to the accumulation of charges or ions at interfaces and cause an energy barrier to carrier extraction.

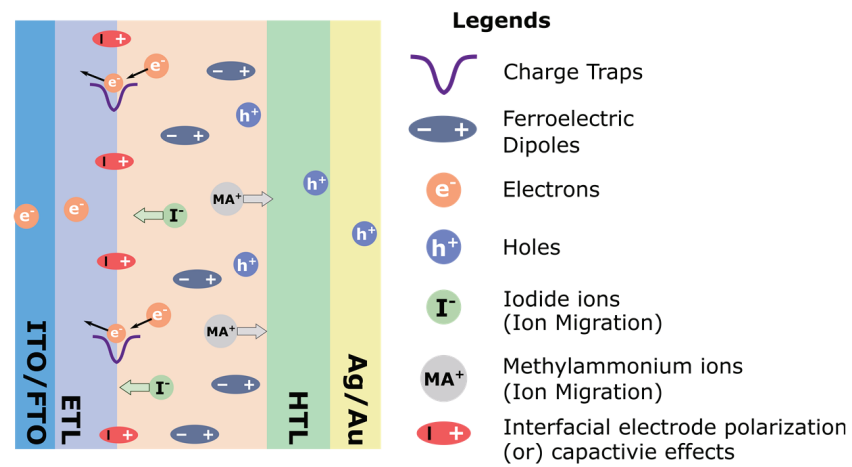

Figure 5. Schematic of the proposed contributions to hysteresis. ITO, FTO, ETL and HTL stand for indium-doped tin oxide, fluorine-doped tin oxide, electron transport layer, and hole transport layer, respectively. Reproduced from ref. [76], with permission from Elsevier, 2016.

These processes may occur simultaneously, and each process will have a different impact on the hysteresis depending on various parameters such as the device structure, interfacial quality, and the properties of the perovskite layer (grain size, defect density, composition etc.), amongst others.

\section{Nanostructured Perovskite Absorbers}

\subsection{Introduction}

Non-toxic and/or stable materials with similar properties to bulk $\mathrm{Pb}-\mathrm{OHPs}$ are a high priority and are currently being explored, such as the replacement of $\mathrm{Pb}$ with $\mathrm{Sn}$ or $\mathrm{Bi}$ [23,77], lead-free halide double perovskites [78], and low-dimensional materials [22]. The efficiencies of these solar cells are often far lower than bulk $\mathrm{Pb}-\mathrm{OHPs}$ and a large amount of development is still required. Nanostructured perovskites include perovskite quantum dots, nanoparticles, nanosheets, nanorods, and perovskites with nanoscale internal ordering. These materials are often termed low-dimensional 
perovskites (LDPs) and can generally be envisioned by reducing the bulk perovskite structure to the nanoscale in at least one structural dimension.

Figure 6 shows schematically how a bulk perovskite with $\mathrm{ABX}_{3}$ structure transforms from a three-dimensional perovskite (3DP) to an LDP. In 3DPs, i.e., the typical bulk perovskites used in record-efficiency devices, each $\mathrm{BX}_{6}{ }^{4-}$ octahedra is connected along all three axes and is anisotropic. It is rather important that this octahedral structure is mostly preserved since the orbital hybridization of $\mathrm{B}$ and $X$ sites is responsible for many of the favorable optoelectronic properties of OHPs. For two-dimensional perovskites (2DPs), e.g., nanoplatelets and nanosheets, the $\mathrm{BX}_{6}{ }^{4-}$ octahedra is connected along two axes and consists of 2D slabs of octahedra with the organic cation occupying the A-site in the voids between slabs. Surrounding the nanosheets are organic 'barrier' molecules which prevent the sheets from crystallizing into a larger 3D structure whilst also providing encapsulation and protection against degradation. For one-dimensional perovskites (1DPs), e.g., nanowires and nanorods, the $\mathrm{BX}_{6}{ }^{4-}$ octahedral network extends along only one axis and is encapsulated with organic barrier molecules. For 1DPs and 2DPs, various organic barriers can be selected, and a wide range of choices exist. Hydrophobic organic barriers can be selected which protect the structure against moisture. For zero-dimensional perovskites (0DPs), the $\mathrm{BX}_{6}{ }^{4-}$ octahedra is disconnected in all directions and consists of isolated octahedral clusters stabilized by a cationic sublattice. A distinction is often made between 0DPs and quantum dots (QDs), where for a perovskite QD (PQD), the $\mathrm{BX}_{6}{ }^{4-}$ octahedra remains connected in all three axes and the radius of the particle is below the Bohr exciton radius, whereas for a 0DP each octahedra is completely disconnected from adjacent octahedra, as shown in Figure 6.

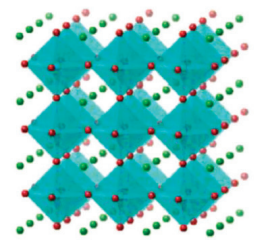

3D

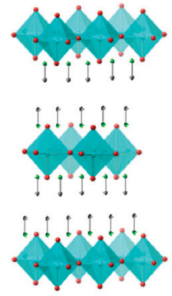

2D

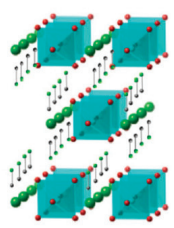

1D

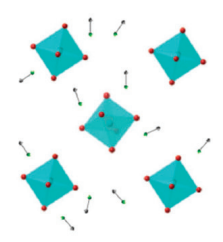

OD

Figure 6. Overview of the different perovskite dimensionalities. Reproduced from ref. [79], with permission from John Wiley and Sons, 2015.

Low-dimensional materials can also be produced which are not strictly perovskites yet follow a similar set of design rules; being based on a large heavy metal ion bonded ionically with halide ions, and stabilized by a sublattice of $1+$ cations: For example, B-site $3+$ cations such as $\mathrm{Bi}^{3+}$ form $\mathrm{B}_{2} \mathrm{X}_{9}{ }^{3-}$ bioctahedra instead of a $\mathrm{BX}_{6}{ }^{4-}$ octahedra for $2+$ cations, forming the 0DP material $\left(\mathrm{CH}_{3} \mathrm{NH}_{3}\right)_{3} \mathrm{Bi}_{2} \mathrm{I}_{9}$. These materials, which can be produced very similarly to standard perovskites (i.e., from solution) whilst also possessing similar properties, are discussed later. The perovskite term is used loosely to describe these materials, as in some cases the perovskite structure is disturbed.

LDPs exhibit quantum confinement effects which are particularly noticeable through a widening of the bandgap [22]. Although 3DPs already have a bandgap close to the optimum value of $\sim 1.4 \mathrm{eV} \mathrm{for}$ a single junction solar cell, a wider bandgap is advantageous for forming tandem devices or for indoor photovoltaics [80]. Furthermore, quantum confinement effects introduce the possibility to reduce losses via carrier multiplication which has already been demonstrated in $\mathrm{CsPbI}_{3}$ quantum dots [81] and in the 0DP material $\left(\mathrm{CH}_{3} \mathrm{NH}_{3}\right)_{3} \mathrm{Bi}_{2} \mathrm{I}_{9}$ [82]. The effective use of carrier multiplication in a single-junction solar cell can potentially increase efficiency to $44 \%$ [83], far beyond the Shockley-Queisser (SQ) efficiency limit for a single junction cell of $\sim 33 \%$ [84]. In addition, both 3DPs and LDPs are capable of incorporating a low concentration of inorganic nanocrystals into their lattice to form internal energy 
band alignments which can be used to increase carrier collection and absorption. These hybrid devices can potentially harvest a wide range of the solar spectrum through quantum confinement effects without significantly altering the device architecture, and will be discussed later $[85,86]$.

LDPs often exhibit excitonic behavior as carriers become localized. Since LDPs are often stabilized with organic barriers or a cationic sub-lattice which behaves as an insulating spacer layer, this results in a potential barrier surrounding the individual sheets, rods, or clusters. Carriers therefore become localized on the sheets, rods, or clusters, which often inhibits carrier extraction. The strength of the exciton binding energy is strongly dependent on the dimensionality, with 0DPs usually exhibiting the highest exciton binding energies [87,88].

\subsection{One-and Two-Dimensional Perovskites}

Along with PQDs, perovskite nanosheets and nanorods are the most successful types of LDPs demonstrating the highest efficiencies in photovoltaic devices. The main advantage of reduced dimensionality is that the $\mathrm{OHP}$ can be encapsulated with a more stable long chain organic molecule which reduces the rate of degradation. In reference [22] it was shown via simulations that the stability of $\mathrm{MAPbI}_{3}$ perovskites can be improved by producing a 2D perovskite encapsulated by larger cations. Further to the benefit of the protective ligands, the 2D perovskite structure has a higher formation energy, which therefore yields a more stable perovskite material. A single 2D slab of the perovskite structure, i.e., a monolayer, encapsulated with organic barrier, is termed $n=1$, as shown in Figure 7. The bandgap is strongly dependent on the number of perovskite slabs $(n)$; as $n$ increases, the bandgap narrows and the strength of quantum confinement reduces, and the dimensionality tends towards a quasi-2D structure $(n>\sim 10)$, while for very large values of $n$ the perovskite tends towards a 3D structure.

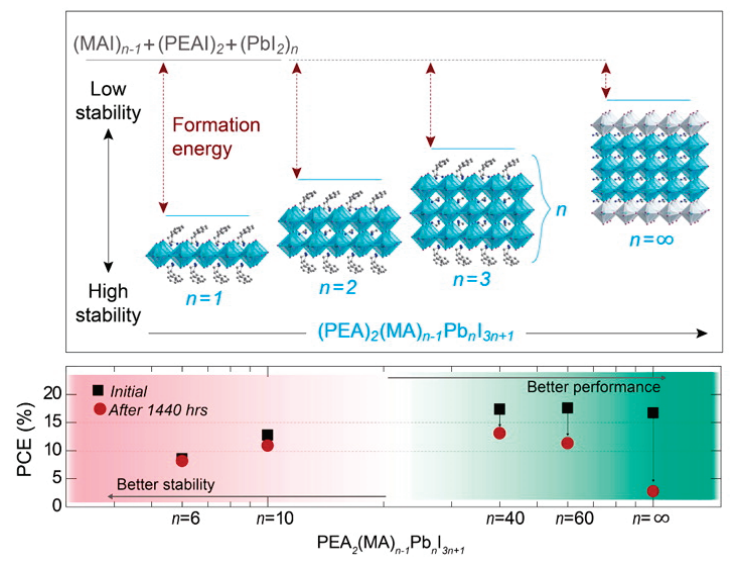

Figure 7. Reducing the dimensionality of organometal halide perovskites leads to higher stability, but lower device performance. Reproduced from ref. [22], with permission from American Chemical Society, 2016

There are a very large number of organic molecules which can potentially be used as the barrier layer, however thus far only a limited number of molecules have been investigated, e.g.: phenylethyl ammonium $\left(\mathrm{C}_{8} \mathrm{H}_{9} \mathrm{NH}_{3}, \mathrm{PEA}\right)$ [22], benzyl ammonium $\left(\mathrm{C}_{6} \mathrm{H}_{5} \mathrm{CH}_{2} \mathrm{NH}_{3}, \mathrm{BA}\right)$ [89], 2-iodoethylammonium $\left(\mathrm{IC}_{2} \mathrm{H}_{4} \mathrm{NH}_{3}\right)$ [90], polyethylenimine $\left(\left(\mathrm{C}_{2} \mathrm{H}_{5} \mathrm{~N}\right)_{\mathrm{n}}, \mathrm{PEI}\right)$ [91], 2-thiophenemethylammonium $\left(\mathrm{C}_{5} \mathrm{H}_{7} \mathrm{NS}\right.$, ThMA) [92], and 3-bromobenzylammonium iodide $\left(\mathrm{BrC}_{6} \mathrm{H}_{4} \mathrm{CH}_{2} \mathrm{NH}_{2}\right.$. HI, 3BBA) [24]. The absorption spectra of 2DPs is weakly associated with the selection of the barrier molecule; optical properties are far more dependent on the $n$ value [93]. As $n$ tends towards lower values, the stability of the 2DP increases [22], yet the device performance tends to decrease dramatically due to the widening of the 
band gap and the higher proportion of insulating barrier molecules which have a detrimental effect on carrier transport. Whilst the high in-plane mobility of bulk OHPs is retained along the nanosheets and nanorods, the transport between nanosheets/rods is restricted due to the potential barrier created by the insulating organic barriers which reduces the overall carrier mobility [88]. However, this can be mitigated somewhat by using shorter barrier molecules [94].

In reference [22], the $\mathrm{MAPbI}_{3}$ perovskite was reduced to a 2DP and a quasi-2DP structure using PEA barriers with varying $n$ values. A quasi-2DP with $n=40$ was capable of achieving $15 \%$ efficiency, however the stability of quasi-2DPs is still rather poor. Reducing the $n$ value to 6 provided high stability, yet the efficiency fell towards $\sim 5 \%$. It is likely that the low efficiency was due to the disordered nature of the sheets which are not aligned perpendicular to the contacts, inhibiting charge transfer. This is shown schematically in Figure 8a. When nanosheets are oriented horizontally, i.e., parallel to the contacts, the charge carrier transfer is restricted in the vertical direction, and charge carrier extraction in inhibited because the long organic barriers separating the LDP sheets inhibit transfer between the layers.

(a) In-plane alignment

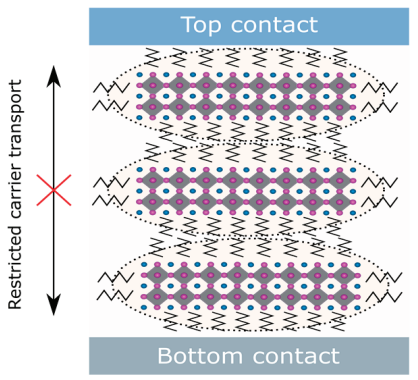

(b) Out-of-plane alignment

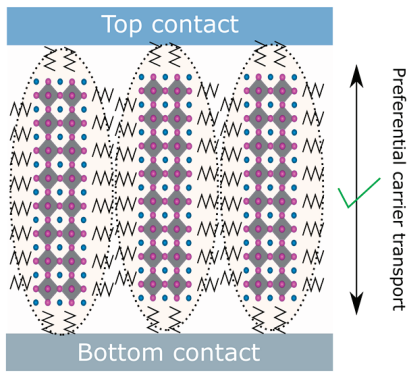

Figure 8. Solar cells based on a perovskite absorber with a two-dimensional network. (a) Sheets align parallel with the contacts resulting in low carrier mobility between the contacts and (b) sheets align perpendicular to the contacts resulting in favorable out-of-plane mobility between contacts.

Higher efficiencies can be achieved by vertically orientating the inorganic sheets, as shown schematically in Figure 8b, whereby charge transport is less restricted. If the nanosheets/rods are orientated vertically, i.e., perpendicular to the contacts (out-of-plane), charge transport is predominantly along the perovskite structure and carrier extraction is therefore far more efficient since carriers must overcome fewer potential barriers. This was initially demonstrated in BA-capped 2DPs with $n=3$ and the efficiency was increased to over $12 \%$ using a hot casting deposition technique to achieve out-of-plane alignment of the 2D sheets [23]. However, these devices still showed rather poor stability when exposed to $65 \%$ relative humidity without encapsulation, while fully encapsulated devices demonstrated impressive stability. This has also been demonstrated in perovskite nanorods, with an increase in efficiency from $1.74 \%$ to over $15 \%$ following out-of-plane alignment [92]. This was achieved by using a methylammonium chloride $(\mathrm{MACl})$ assisted film formation technique which resulted in vertically aligned perovskite nanorods, demonstrating far improved stability over 3D perovskite. Disordered (unaligned) 2DPs usually show significant hysteresis [95], which is likely due to a bias-voltage induced charging effect caused by the insulating organic molecules and poor charge transport when the 2DP sheets are not vertically aligned. However, the hysteresis is mostly eliminated when the nanosheets are aligned out-of-plane with respect to the contacts since charge transport is less restricted [23].

A problem which must be overcome in 2DPs is a stacking misalignment of the 2DP grains which reduces carrier mobility. It was shown that even when 2DPs are aligned with favorable out-of-plane alignment, stacking misalignments between grains restricts charge transfer between vertically aligned 
sheets [83]. In order to improve device performance, it is important to minimize stacking misalignment between grains. In addition, it was recently demonstrated that it is essential to use LDPs with at least $n>2$, as it has been shown that exciton dissociation occurs within the nanosheets of 2DPs due to the presence of lower energy states at the edges of the nanosheets which exit only for nanosheets with $n>2$ [96]. While these edge states are present for 2DPs with $n>2$, for $n \leq 2$, edge-state exciton dissociation was not observed, and the device performance was significantly lower. These lower energy states exist at the edge of 2DPs and provide a favorable energy pathway for excitons to dissociate into free-carriers with longer lifetimes, which was demonstrated to significantly improve device performance. This work demonstrated that it is imperative to synthesize 2DPs with at least $n=3$ in order to benefit from the favorable exciton dissociation mechanism, even though thinner nanosheets $(n \leq 2)$ can provide higher stability.

Recent work demonstrated that mixed $n$ value 2D perovskites can achieve both favorable carrier transport and band alignment introduced via a unique nanostructuring of the 2D perovskite film, achieving a PCE of $18.2 \%$ [24]. The introduction of the barrier molecule 3-bromobenzylammonium iodide (3BBA) leads to the oriented growth of small $n$ value 2D perovskites perpendicular to the substrate $(n \approx 1-4)$, followed by the crystallization of large $n$ value quasi-2D perovskites in the bulk of the film, shown schematically in Figure $9 a$ and the overall device structure in Figure $9 b$. This structure also introduces a favorable band alignment as shown in Figure $9 \mathrm{c}$ whereby the larger bandgap of the mixed low $n$ value 2DPs provides a potential energy gradient driving carriers to the desirable extraction contacts. This demonstrates the remarkable tunability that can be achieved through nanostructuring perovskites to achieve favorable energy band alignment. The devices also showed impressive stability: Unencapsulated devices stored in a dark oven between measurements under $\approx 40 \%$ relative humidity retained $80 \%$ of the original PCE after $2400 \mathrm{~h}$. The device could also be submerged underwater for $60 \mathrm{~s}$ without any immediate negative effect on the efficiency. It was stipulated that the hydrophobicity due to the presence of iodine in 3BBA results in the enhanced moisture durability of these 2DPs.In general, 2DPs have not been optimized yet via cation engineering to the same extent as 3DPs, which has led to the high performance and improved stability of 3DPs today [13]. Recently, $5 \% \mathrm{Cs}^{+}$doping in a 2DP demonstrated an efficiency increase from $12.3 \%$ to $13.7 \%$, which was attributed to improved crystal quality and low trap defects, increased grain size, and improved carrier transport [97]. Since most 2DPs with low $n$ values show wide bandgaps, it is important to engineer 2DPs which absorb in the visible spectrum. Material engineering and optimization as such demonstrates that there is still great potential for work on improving the 2DPs' material properties.

Finally, 2DPs may also find use in improving the stability of 3DPs by acting as a protective capping layer. A 2DP was demonstrated as the capping layer in a 3DP solar cell and displayed over 19\% efficiency, along with improved stability over the 3DP alone [98]. Further work in this area showed that the deposition of a hydrophobic 2D perovskite on top of a 3D perovskite not only protects against moisture, but also improves carrier extraction. The formation of the 2D perovskite on the surface of the 3D perovskite consumes detrimental and undesirable non-perovskite phases present at the surface of the 3D perovskite and resulted in faster injection of holes into the HTL [99]. More recently, an ammonium salt post-treatment of a 3D OHP film increased the PCE from $20.5 \%$ to $22.3 \%$ via the formation of a 1DP passivation layer [100]. Devices retained $95 \%$ of the initial PCE after continuous illumination for $550 \mathrm{~h}$. This area of work presents a route towards avoiding the necessity for encapsulants in PSCs, therefore reducing costs and avoiding issues pertaining to thermal expansion mismatch.

\subsection{Zero-Dimensional Perouskites}

$\mathrm{Pb}$-based 0DPs have been previously studied but so far seem unsuitable for photovoltaics [101,102]. For example, when the typical perovskite $\mathrm{MAPbI}_{3}$ is transformed into a $0 \mathrm{DP}$ with the chemical formula $\left(\mathrm{CH}_{3} \mathrm{NH}_{3}\right)_{4} \mathrm{PbI}_{6}$, the structure is extremely unstable [101]. Alternatively, more stable inorganic $\mathrm{Pb}$-based ODPs can be produced such as $\mathrm{Cs}_{4} \mathrm{PbBr}_{6}$, however, the bandgap is very large: $\mathrm{Pb}$ - based 0DPs tend to 
have very large bandgaps which are unsuitable for photovoltaics, typically in the UV-range, irrespective of the halide anion selected [102].

(a) $\mathrm{PC}_{61} \mathrm{BM}$
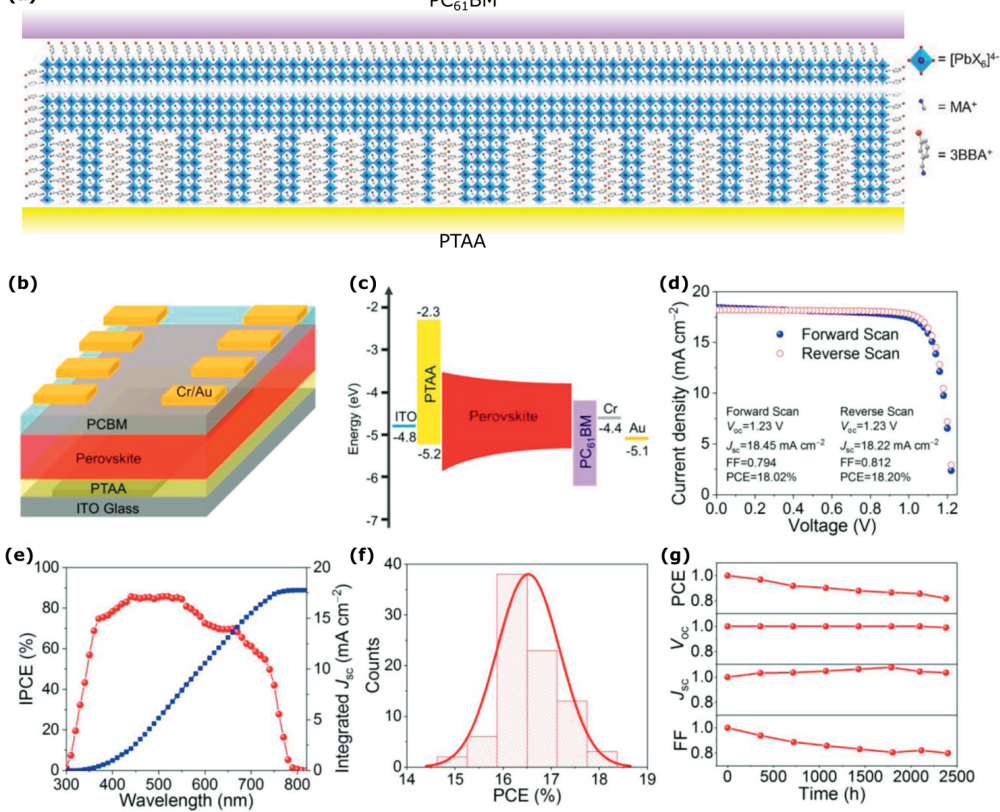

Figure 9. 2D perovskite solar cells using 3-bromobenzylammonium iodide barrier molecule. (a) Schematic of the device nanostructuring, (b) schematic of the device architecture, (c) energy band alignment relative to the vacuum level in $\mathrm{eV}$, (d) current density-voltage measurement, (e) incident photon conversion efficiency (ICPE), (f) histogram showing reproducibility of the power conversion efficiency (PCE) and (g) solar cell stability for devices stored in the dark between measurements under $\approx 40$ relative humidity. Reproduced with modifications for clarity from ref. [24], with permission from John Wiley and Sons, 2018.

Alternatively, Bi-based 0DPs have bandgaps closer to $2 \mathrm{eV}$ and have been demonstrated as the absorber in photovoltaic cells [86,103-105]. Bi, which is adjacent to $\mathrm{Pb}$ in the periodic table, has a similar atomic radius to $\mathrm{Pb}$ yet with one additional valence electron yielding $3+$ instead of $2+$, resulting in a $\mathrm{B}_{2} \mathrm{X}_{9}{ }^{3-}$ bioctahedral structure rather than the $\mathrm{BX}_{6}{ }^{4-}$ octahedral structure. These perovskite structures have the formula $A_{3} B_{2} X_{9}$, but can also be expressed as $A_{2 / 3} X_{3}$, i.e., a metal-deficient perovskite. Figure 10 shows the structure of a ODP with the chemical formula $\left(\mathrm{CH}_{3} \mathrm{NH}_{3}\right)_{3} \mathrm{Bi}_{2} \mathrm{I}_{9}$, where $\mathrm{Bi}_{2} \mathrm{I}_{9}{ }^{3-}$ clusters are separated by a $\mathrm{CH}_{3} \mathrm{NH}_{3}{ }^{+}$cationic lattice. Here, $\mathrm{CH}_{3} \mathrm{NH}_{3}{ }^{+}$can be replaced with a range of organic and inorganic cations. Whilst these materials are often referred to as 'perovskites', their crystallographic structure is slightly different to the perovskite structure, whereby the $\mathrm{BX}_{6}{ }^{4-}$ octahedra is instead replaced with a $\mathrm{B}_{2} \mathrm{X}_{9}{ }^{3-}$ bioctahedra.

Bi-0DPs have been studied and the best devices have achieved efficiencies of $1.64 \%$ [105]. These materials, with bandgaps of $\sim 2 \mathrm{eV}$, generally exhibit high exciton binding energies $(\sim 300 \mathrm{meV})$ and high effective masses for carriers [88]. Because of the excitonic nature of these materials with quantum confinement effects, 0DPs have been shown to exhibit carrier multiplication [82]. However, due to the high exciton binding energy, the rates of electron-hole recombination is high which limits device performance. 0DPs also exhibit anisotropic carrier mobilities if the cluster is non-symmetrical and/or if the spacing between clusters varies between planes [88]. It is therefore necessary to try to overcome the high exciton binding energy and carrier transport issues by a range of possible methods, 
such as modifying the cationic sub-lattice, using semiconducting polymers which enhance carrier mobility between the clusters, or by forming hybrids with inorganic nanocrystals which assist in exciton dissociation.

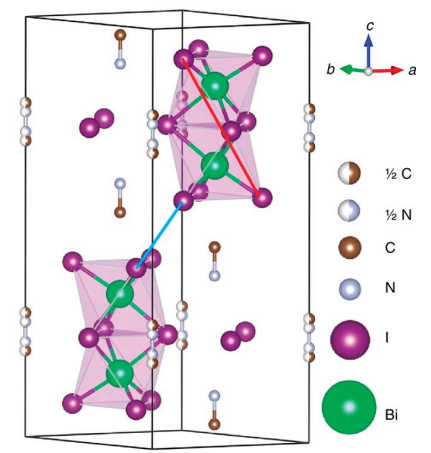

Figure 10. Schematic of the structure of $\left(\mathrm{CH}_{3} \mathrm{NH}_{3}\right)_{3} \mathrm{Bi}_{2} \mathrm{I}_{9}$ which forms a zero-dimensional network. $\mathrm{Bi}_{2} \mathrm{I}_{9}{ }^{3-}$ clusters are stabilized within a $\left(\mathrm{CH}_{3} \mathrm{NH}_{3}\right)^{+}$ionic lattice. Reproduced from ref. [82], with permission from Springer Nature, 2017.

$\left(\mathrm{CH}_{3} \mathrm{NH}_{3}\right)_{3} \mathrm{Bi}_{2} \mathrm{I}_{9}$ solar cells can be processed and stored entirely in ambient conditions and have demonstrated far superior stability to 3DPs, likely due to the formation of a native surface layer of $\mathrm{Bi}_{2} \mathrm{O}_{3} / \mathrm{BiOI}$ which provides self-encapsulation of the perovskite [30]. This layer does not inhibit carrier extraction, and is also likely responsible for the negligible hysteresis observed in these devices [86]. If ODPs were employed as the wide-bandgap top cell in a tandem solar cell, their high stability can provide encapsulation for the less-stable OHP bottom cell to prevent moisture ingress. Furthermore, the absorption can be modified by incorporating optically active organic molecules or forming hybrids with nanocrystals with suitable band alignment [86], and the large bandgap of $2 \mathrm{eV}$ can be reduced to values as low as $1.45 \mathrm{eV}$ through doping and/or changing the A-site cation [106-108].

Sb-based 0DPs have also been demonstrated with the formula $\left(\mathrm{CH}_{3} \mathrm{NH}_{3}\right)_{3} \mathrm{Sb}_{2} \mathrm{I}_{9}$ and have so far achieved higher efficiencies than Bi-0DPs, with the best devices so far achieving $2.77 \%$ efficiency [109]. The higher efficiencies of these devices is likely due to the intrinsically lower exciton binding energy of $\mathrm{Sb}-0 \mathrm{DPs}$ [110]. Since the bandgap of Sb-0DPs is still quite large $(\sim 1.9 \mathrm{eV})$, researchers have attempted to lower the bandgap through Sn-doping, and successfully reduced the bandgap to $1.53 \mathrm{eV}$ with $40 \%$ replacement of $\mathrm{Sb}$ with $\mathrm{Sn}$ to form $\left(\mathrm{CH}_{3} \mathrm{NH}_{3}\right)_{3} \mathrm{Sb}_{0.6} \mathrm{Sn}_{0.4} \mathrm{I}_{9}$. Doping with $\mathrm{Sn}$ increased the efficiency of the devices from $0.57 \%$ (without $\mathrm{Sn}$, bandgap $=2.0 \mathrm{eV}$ ) to $2.7 \%(40 \% \mathrm{Sn}$, bandgap $=1.53 \mathrm{eV})$. Since the starting efficiency of the undoped Sb-0DP reference device was quite low $(0.57 \%)$ compared to the highest reported in the literature $(\sim 2.77 \%)$, it is likely that through device optimization of the Sn-doped Sb-0DP will quickly lead to higher efficiencies in the near future, likely exceeding $5 \%$. These Sn-doped Sb-0DPs demonstrated impressive stability with no change in the XRD spectra after 15 days of exposure to ambient conditions. Although inorganic 0DPs have also been produced with the formula $\mathrm{Cs}_{3} \mathrm{Sb}_{2} \mathrm{I}_{9}$ and $\mathrm{Cs}_{3} \mathrm{Bi}_{2} \mathrm{I}_{9}$, these devices tend to show very low efficiencies below $0.1 \%$ [111,112], likely due to their large bandgaps and high exciton binding energy, and have therefore not been pursued to the same extent.

\subsection{Perovskite Quantum Dot Solar Cells}

High exciton binding energies and inefficient charge transfer are significant issues associated with LDPs which limit carrier extraction, therefore inhibiting device performance. This can potentially be overcome in PQDs through close-packing with electronic coupling between QDs. Colloidal PQDs can be readily synthesized from solution using organic capping molecules, such as oleic acid, oleylamine, octadecene, etc. which prevent the perovskite from forming into a larger crystal [113]. These long chain 
molecules must be removed during device fabrication for efficient solar cell performance. However, PQDs with organic A-site cations are often highly unstable, and it is therefore not possible to remove these barrier molecules as they are essential for preventing rapid degradation. As discussed previously, the issue of long chain organic barrier molecules in perovskite nanorods and nanosheets can be overcome by aligning the sheets and rods perpendicular to the contacts, minimizing the number of potential barriers that must be overcome by charge carriers. However, due to the spherical shape of QDs, this type of favorable alignment is not possible, and researchers must therefore look towards inorganic PQDs which do not require encapsulation in protective organic barriers or use a different architecture $[85,114]$.

All-inorganic perovskites can be formed by replacing the A-site with an inorganic cation, such as $\mathrm{Cs}^{+}$, e.g., $\mathrm{CsPbI}_{3}$. Inorganic $\mathrm{PQDs}$ such as $\mathrm{CsPbI}_{3}$ are the most favorable perovskite material since the bandgap of bulk $\mathrm{CsPbI}_{3}$ is the smallest of the inorganic perovskites (1.73 eV for the cubic phase) [115]. However, accessing the desired cubic phase of $\mathrm{CsPb}_{3}$ is challenging: For bulk $\mathrm{CsPbI}_{3}$, the orthorhombic phase is thermodynamically preferred at room temperature, but the large bandgap of $2.82 \mathrm{eV}$ renders orthorhombic $\mathrm{CsPbI}_{3}$ unsuitable for photovoltaics [115]. The cubic phase exhibits a more favorable bandgap of $1.73 \mathrm{eV}$; however, this phase is unstable at room temperature. Forming $\mathrm{CsPbI}_{3}$ quantum dots enabled researchers to achieve the cubic phase at room temperature, as the contribution of the surface energy for $\mathrm{CsPb}_{3}$ quantum dots was shown to retain the favorable cubic perovskite phase [114].

$\mathrm{CsPbI}_{3} \mathrm{PQD}$ solar cells were fabricated with $10.77 \%$ efficiency [114]. These devices could be fabricated at ambient conditions and showed impressive stability when stored in a desiccator, with no decrease in performance after 60 days. However, when stored in relative humidity of 40-60\% there was a significant decrease in the device performance after just 2 days, although QD devices demonstrated improved stability over bulk $\mathrm{CsPbI}_{3}$. Furthermore, $\mathrm{CsPbI}_{3} \mathrm{QD}$ devices showed significant hysteresis, likely due to difficulties associated with charge transfer between quantum dots, ion migration, and charge trapping at QD surfaces.

These devices were later improved by a post treatment of the $\mathrm{CsPbI}_{3}$ QDs, and increased the efficiency to $13.43 \%$, as shown in Figure 11 [21]. This was achieved through efficient QD coupling via a post-treatment of the film, allowing improved change transfer between the QDs in the film. The post-treatment involved soaking the $\mathrm{CsPbI}_{3} \mathrm{QD}$ thin film in a formamidinium iodide in ethyl acetate solution for $10 \mathrm{~s}$. The post-treatment creates a coating on the $\mathrm{CsPbI}_{3}$ QDs and does not alter their nanocrystalline character. It was confirmed that the post-treatment improved the carrier mobility from 0.23 to $0.50 \mathrm{~cm}^{2} \mathrm{~V}^{-1} \mathrm{~s}^{-1}$. However, the poor stability of $\mathrm{CsPbI}_{3}$ at ambient conditions has not yet been addressed, and it is likely that these materials will require encapsulation. Alternatively, a Cs- salt post-treatment was reported achieving PCE of $14.1 \%$ [116]. The Cs-salt treatment is performed after the removal of ligands from the $\mathrm{CsPbI}_{3}$ QDs. When the ligands are removed, Cs vacancies are left behind on the $\mathrm{CsPbI}_{3}$ QDs. These vacancies are filled by Cs via a Cs-salt post treatment, resulting in improved free carrier mobility, lifetime, and diffusion length, as well as greater stability over untreated $\mathrm{CsPbI}_{3}$ QDs.

One of the advantages of $\mathrm{CsPbI}_{3}$ QDs is the possibility of carrier multiplication, which has already been demonstrated in $\mathrm{CsPbI}_{3}$ QDs with a high carrier multiplication quantum yield of $98 \%$ [81]. While the bandgap for quantum confined materials scales as $E_{\mathrm{g}} \sim \frac{1}{r}$ where $r$ is the radius, the rate of Auger recombination scales as $\frac{1}{r^{6}}$ and therefore forming smaller QDs is more favorable for carrier multiplication. The average radius of the QDs in this work was $5.75 \mathrm{~nm}$ and the exciton Bohr radius for $\mathrm{CsPbI}_{3}$ QDs is $6 \mathrm{~nm}$. The QDs are therefore in the weak quantum confinement regime, yet still exhibited highly efficient carrier multiplication indicating that strong quantum confinement is not necessary in these materials for carrier multiplication [81]. 


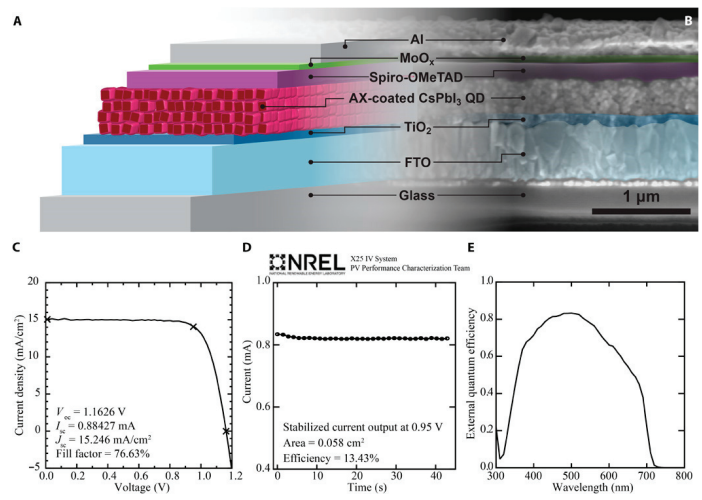

Figure 11. $\mathrm{CsPbI}_{3}$ quantum dot solar cells. (A) Schematic of the device structure, (B) cross-sectional scanning electron microscopy image, (C) current density-voltage scans under solar simulated light, (D) stabilized current at a constant voltage of $0.95 \mathrm{~V}$, and (E) external quantum efficiency. Reproduced from ref. [21], with permission from AAAS, 2017.

The band energy structure of the active layer can be tuned to achieve improved carrier extraction by using PQDs with varying condition band, valence band, and Fermi level positions. The sequential deposition of PQDs with varying band energy positions has been shown to improve carrier extraction [117] and is reproduced in Figure 12. A schematic of the sequential deposition of PQDs is shown in Figure 12a and the band energy positions of the PQDs studied in this work are shown in Figure 12b. PQDs were synthesized in the series $\mathrm{Cs}_{\mathrm{x}} \mathrm{FA}_{1-\mathrm{x}} \mathrm{PbI}_{3}$ and $\mathrm{PQD}$ heterojunction devices were fabricated with the structure $\mathrm{ITO} / \mathrm{TiO}_{2} / \mathrm{PQDs} \mathrm{I} / \mathrm{PQDs} \mathrm{II} /$ spiro-MeOTAD/MoO $/ \mathrm{Al}$. The best device performance was obtained using either $\mathrm{Cs}_{0.5} \mathrm{FA}_{0.5} \mathrm{PbI}_{3}$ or $\mathrm{Cs}_{0.25} \mathrm{FA}_{0.75} \mathrm{PbI}_{3}$ as the bottom layer and $\mathrm{CsPbI}_{3}$ on the top. Devices based on a $\mathrm{Cs}_{0.25} \mathrm{FA}_{0.75} \mathrm{PbI}_{3}: \mathrm{CsPbI}_{3}$ heterojunction were investigated further for optimization. Figure 12c shows the SEM cross section of the device and Figure 12d shows the effect of varying the thickness ratio of $\mathrm{Cs}_{0.25} \mathrm{FA}_{0.75} \mathrm{PbI}_{3}: \mathrm{CsPbI}_{3}$ on the EQE spectra. A ratio of 1:3 $\left(\mathrm{Cs}_{0.25} \mathrm{FA}_{0.75} \mathrm{PbI}_{3}: \mathrm{CsPbI}_{3}\right)$ retained most of the short wavelength EQE contribution from $\mathrm{CsPbI}_{3}$ whilst also red-shifting the EQE onset slightly. Higher proportions of $\mathrm{Cs}_{0.25} \mathrm{FA}_{0.75} \mathrm{PbI}_{3}$ lead to a fall in EQE at shorter wavelengths, despite red-shifting the EQE onset more. Figure 12e shows that varying the bottom layer composition, i.e., by fabricating devices with the structure $\mathrm{ITO} / \mathrm{TiO}_{2} / \mathrm{Cs}_{\mathrm{x}} \mathrm{FA}_{1-\mathrm{x}} \mathrm{PbI}_{3} / \mathrm{CsPbI}_{3} /$ spiro-MeOTAD/MoO $/ \mathrm{Al}$ for $\mathrm{x}=0.25,0.5$ and 0.75 leads to a similar red-shift in the EQE as the bandgap of the $\mathrm{Cs}_{\mathrm{x}} \mathrm{FA}_{1-\mathrm{x}} \mathrm{PbI}_{3} \mathrm{PQDs}$ is decreased. The J-V characteristics are shown in Figure 12f, and ratios of 1:3 and 2:2 achieve the highest PCEs, however due to the large hysteresis present in these devices, the SPO was also presented and revealed that devices with a $1: 3$ ratio of $\mathrm{Cs}_{0.25} \mathrm{FA}_{0.75} \mathrm{PbI}_{3}: \mathrm{CsPbI}_{3}$ achieved the highest $\mathrm{SPO}$ at $15.52 \%$. Finally, bulk heterojunction architecture devices were also fabricated by mixing the PQDs. These devices did not exhibit the same enhanced performance confirming that a bi-layer heterojunction of PQDs is essential for achieving improved carrier collection.

A summary has been provided in Table 1 comparing a selection of the most notable results since 2018 for 0D, 1D, 2D and QD perovskites, as well as also including some of the notable heterojunctions formed between 3D perovskites and LDPs. This table also provides a summary of the stability of the solar cell devices, noting the storage conditions and the solar cell J-V measurement type (i.e. continuous or intermittent, where continuous measurements typically involve the device remaining under constant solar simulated light, whilst for intermittent measurements the device is removed from illumination and stored in specified storage conditions between measurements). 


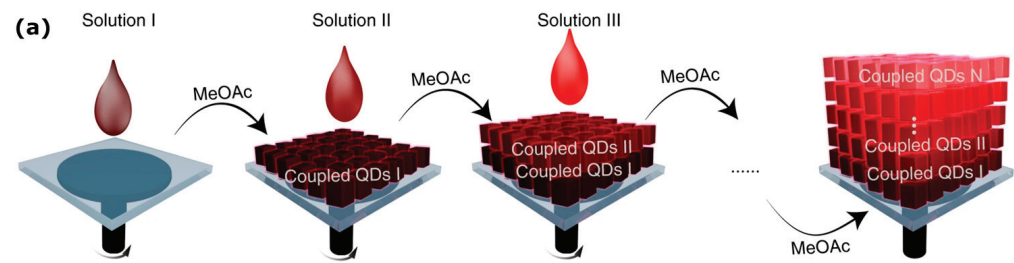

(b)

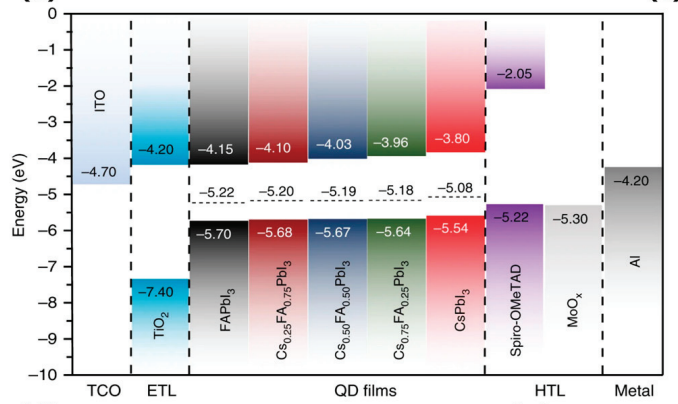

(c)

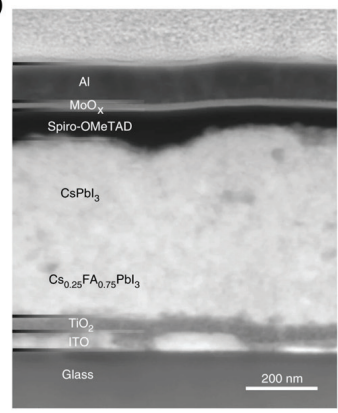

(e)

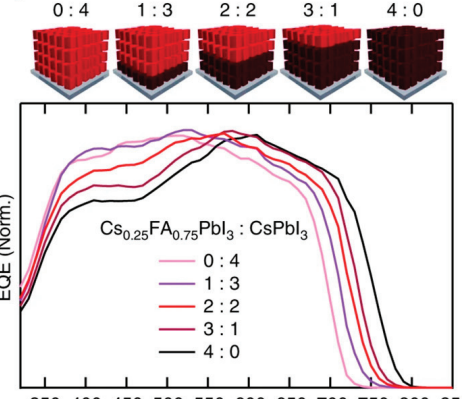

(f)

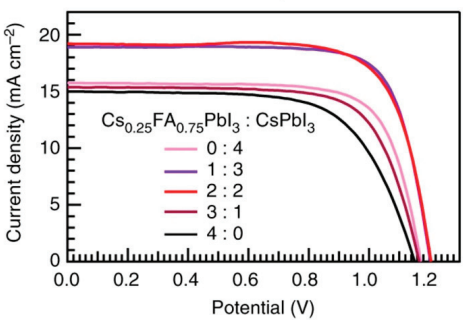

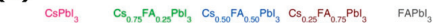

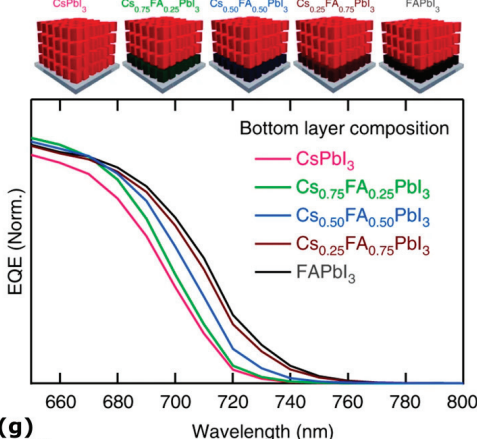

(g)

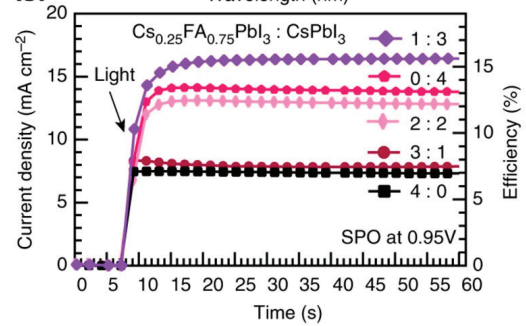

Figure 12. Perovskite quantum dot (PQD) solar cells with charge separating heterostructure. (a) Schematic of the device fabrication via spin coating, (b) energy band structure of the various PQDs used in the study, (c) cross-sectional scanning electron microscope of a typical device, (d) the external quantum efficiency (EQE) of solar cells made with various ratios of $\mathrm{Cs}_{0.25} \mathrm{Fa}_{0.75} \mathrm{PbI}_{3}$ to $\mathrm{CsPbI}_{3}$ quantum dots, (e) EQE at the absorption edge of various quantum dots in the series $\mathrm{Cs}_{\mathrm{x}} \mathrm{FA}_{1-\mathrm{x}} \mathrm{PbI}_{3}$ as the bottom layer. (f) current density-voltage (JV) curves for the devices shown in (d) and (g) stabilized power output (SPO) of the varying compositions shown in (f). Reproduced from ref. [117], with permission from Springer Nature, 2019. 
Table 1. A selection of notable reports on low-dimensional perovskite solar cells. QDs, PCE, RT, and RH stand for quantum dots, power conversion efficiency, room temperature, relative humidity, respectively.

\begin{tabular}{|c|c|c|c|c|}
\hline Dimensionality & Material ( $n$ Value) ${ }^{1}$ & PCE (\%) & Stability & $\begin{array}{l}\text { Reference } \\
\text { (Year) }\end{array}$ \\
\hline OD & $\left(\mathrm{CH}_{3} \mathrm{NH}_{3}\right)_{3} \mathrm{Sb}_{2} \mathrm{I}_{9}$ & 2.77 & $\begin{array}{l}\text { Retained } 80 \% \text { of initial PCE after } 3 \mathrm{~h} \text { under } \\
\text { constant illumination, ambient } \\
\text { conditions, encapsulated. }\end{array}$ & $\begin{array}{c}{[109]} \\
(2018)\end{array}$ \\
\hline OD & $\mathrm{Cs}_{3} \mathrm{Sb}_{2} \mathrm{I}_{9}$ & 1.21 & $\begin{array}{l}\text { Retained 95\% of initial PCE after } 60 \text { days, } \\
\text { intermittent measurements, stored at RT, } \\
50 \% \mathrm{RH} \text {, unencapsulated. }\end{array}$ & $\begin{array}{c}{[118]} \\
(2019)\end{array}$ \\
\hline OD & $\mathrm{Cs}_{3} \mathrm{Sb}_{2} \mathrm{I}_{9}$ & 1.49 & $\begin{array}{c}\text { Retained }>80 \% \text { of initial PCE after } 30 \text { days, } \\
\text { intermittent measurements, storage } \\
\text { conditions unspecified. }\end{array}$ & $\begin{array}{c}{[119]} \\
(2018)\end{array}$ \\
\hline $1 \mathrm{D}$ & $\begin{array}{l}(\mathrm{ThMA})_{2}(\mathrm{MA})_{\mathrm{n}-1} \mathrm{~Pb}_{\mathrm{n}} \mathrm{I}_{3 \mathrm{n}+1} \\
(n=3)\end{array}$ & 15.42 & $\begin{array}{c}\text { Retained } 90 \% \text { of initial PCE after } 100 \mathrm{~h} \text {, } \\
\text { intermittent, stored in } \mathrm{N}_{2} \text { in the dark, } \\
\text { unencapsulated. }\end{array}$ & $\begin{array}{c}{[92]} \\
(2018)\end{array}$ \\
\hline $\begin{array}{l}\text { 1D, mixed with 3D } \\
\qquad \mathrm{MAPbI}_{3}\end{array}$ & $\begin{array}{l}\text { 1,4-benzene } \\
\text { diammonium } \\
(\mathrm{BDA})-\mathrm{PbI}_{4} \\
(n=1)\end{array}$ & 14.1 & $\begin{array}{l}\text { Retained } 95 \% \text { of original PCE after }>1000 \mathrm{~h} \text {, } \\
\text { intermittent measurement, stored in dark at } \\
\text { RT, } 85 \% \text { RH, encapsulated. }\end{array}$ & $\begin{array}{l}{[120]} \\
(2019)\end{array}$ \\
\hline $\begin{array}{c}1 \mathrm{D} / 3 \mathrm{D} \\
\text { heterostructure }\end{array}$ & $\begin{array}{l}\text { ethylammonium } \\
\text { iodide (EAI)-treated } \\
\mathrm{FA}_{0.93} \mathrm{Cs}_{0.07} \mathrm{PbI}_{3}\end{array}$ & 22.3 & $\begin{array}{c}\text { Retained } 95 \% \text { of initial PCE after } 550 \mathrm{~h} \text {, } \\
\text { continuous measurement under constant } \\
\text { illumination in } \mathrm{N}_{2} \text { atmosphere at RT, } \\
\text { unencapsulated. }\end{array}$ & $\begin{array}{c}{[100]} \\
(2019)\end{array}$ \\
\hline $2 \mathrm{D}$ & $\begin{array}{c}(\mathrm{FPEA})_{2} \mathrm{MA}_{4} \mathrm{~Pb}_{5} \mathrm{I}_{16} \\
(n=5)\end{array}$ & 13.64 & $\begin{array}{l}\text { Retained } 65 \% \text { of initial PCE after } 576 \mathrm{~h} \text {, } \\
\text { ambient air at } 70{ }^{\circ} \mathrm{C} \text { unencapsulated. }\end{array}$ & $\begin{array}{c}{[121]} \\
(2019)\end{array}$ \\
\hline $2 \mathrm{D}$ & $\begin{array}{c}(\mathrm{BzDA}) \mathrm{A}_{9} \mathrm{~Pb}_{10} \\
\left(\mathrm{I}_{0.93} \mathrm{Br}_{0.07}\right)_{31} \\
(n=10)\end{array}$ & 15.6 & $\begin{array}{c}\text { Retained } 80 \% \text { of initial PCE after } 84 \mathrm{~h} \text {, } \\
\text { intermittent measurements, kept in dark at } \\
\text { RT in ambient air, } \mathrm{RH}=20-50 \% \\
\text { unencapsulated. }\end{array}$ & $\begin{array}{c}{[122]} \\
(2019)\end{array}$ \\
\hline Quasi-2D & $\begin{array}{l}\text { 3-bromobenzylammonium } \\
\text { iodide (BBAI)- } \\
(n=2)\end{array}$ & 18.2 & $\begin{array}{l}\text { Retained } 82 \% \text { of initial PCE after } 2400 \mathrm{~h} \text {, } \\
\text { intermittent measurements, stored in dark } \\
\text { at RT, } \sim 40 \% \text { RH, unencapsulated. }\end{array}$ & $\begin{array}{c}{[24]} \\
(2018)\end{array}$ \\
\hline Quasi-2D & $\begin{array}{l}(\mathrm{BE})_{2}(\mathrm{FA})_{8} \mathrm{~Pb}_{9} \mathrm{I}_{28} \\
(n \text { value not } \\
\text { reported })\end{array}$ & 17.4 & $\begin{array}{l}\text { Retained } 80 \% \text { of initial PCE after } 50 \mathrm{~h}, \\
\text { stored in the dark at RT, RH }=80 \%, \\
\text { unencapsulated. }\end{array}$ & $\begin{array}{c}{[123]} \\
(2018)\end{array}$ \\
\hline QDs & $\mathrm{CsPbI}_{3}$ & 14.1 & $\begin{array}{l}\text { Retained } 70 \% \text { of initial PCE after } 50 \mathrm{~h} \text {, } \\
\text { intermittent measurements, stored in the } \\
\text { dark at RT and } 40 \% \text { RH, unencapsulated. }\end{array}$ & $\begin{array}{l}{[116]} \\
(2019)\end{array}$ \\
\hline QDs & $\mathrm{CsPbI}_{3}: \mathrm{Cs}_{0.25} \mathrm{FA}_{0.75} \mathrm{PbI}_{3}$ & 17.4 & $\begin{array}{c}\text { Retained } 80 \% \text { of initial PCE after } 10 \mathrm{~h} \text {, } \\
\text { intermittent measurements under constant } \\
\text { illumination at } 40^{\circ} \mathrm{C} \text { and } 25 \% \mathrm{RH}, \\
\text { encapsulated. }\end{array}$ & $\begin{array}{l}{[117]} \\
(2019)\end{array}$ \\
\hline
\end{tabular}

\subsection{Perovskite-Nanocrystal Hybrid Devices}

The formation of hybrid layers and devices through incorporating nanocrystals into the OHP layer have also been explored, both in bulk 3DPs [85] and in 0DPs [86]. The introduction of quantum-confined NCs to bulk 3D OHPs enables the possibility of carrier multiplication. Thus far, SiNCs have been primarily studied in this context, since most nanocrystals studied for organic-inorganic hybrid photovoltaics are toxic $\mathrm{Pb}$ - or Cd-based [20], and it would be counterintuitive to add a toxic material to a lead-free perovskite. SiNCs are an environmentally-friendly material which are non-toxic and can be synthesized through a wide variety of methods $[124,125]$. The properties of SiNCs can also be easily modified by surface engineering and the absorption and emission properties can be influenced by the surface terminations [125-127]. Surface engineering can also improve carrier transport in SiNCs by passivating surface defects [128]. While SiNCs do present their own challenges, they represent an important model NC material. 
It was previously demonstrated that the incorporation of silicon nanocrystals (SiNCs) into the 0DP with the formula $\left(\mathrm{CH}_{3} \mathrm{NH}_{3}\right)_{3} \mathrm{Bi}_{2} \mathrm{I}_{9}$ led to an enhancement in the device performance [86]. It was proposed that the SiNCs may act as a dissociation pathway for tightly-bound excitons on the nanoclusters of $\mathrm{Bi}_{2} \mathrm{I}_{9}{ }^{3-}$ bioctahedra. An electronic junction formed between the perovskite material and the inorganic nanocrystal can provide an energetically favorable pathway for excitons to overcome the potential barrier created by the cationic sublattice, providing exciton dissociation before the carrier recombines. Once the exciton is dissociated it becomes a free-carrier which can be extracted. This is commonly employed in organic-inorganic hybrid solar cells using SiNCs to enhance exciton dissociation [129]. These types of hybrids may present a route towards significantly improving the efficiency of LDPs.

Hybrid $\mathrm{MAPbI}_{3}-\mathrm{SiNC}$ devices also exhibit improved device performance and stability [85]. X-ray photoelectron spectroscopy (XPS) indicated that $\mathrm{MAPbI}_{3}$ bonds with $\mathrm{SiNCs}$ via intermediate oxide bonds with nitrogen in methylammonium (N-O-Si). The oxidation of SiNCs was also observed in XPS and is likely responsible for the improved stability, whereby SiNCs may act as a 'sponge' absorbing oxidizing species in the $\mathrm{MAPbI}_{3}$ layer resulting in slight oxidation of the SiNCs. Furthermore, hybrid devices with SiNCs exhibited improved device performance after light soaking for 8 min (Figure 13), whilst the performance of $\mathrm{MAPbI}_{3}$-only devices decreased. This is commonly observed in $\mathrm{MAPbI}_{3}$ devices and is attributed to light-activated trap states with inhibited photocarrier extraction [130]. The observation of the inverse behavior in hybrid devices suggests that SiNCs may inhibit defect migration possibly via bonding with the perovskite structure.

a)

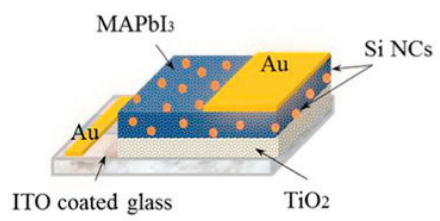

c)

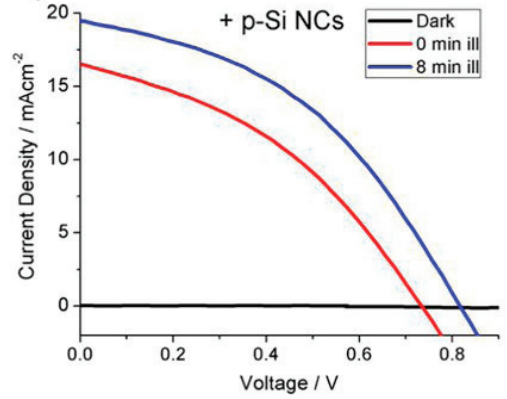

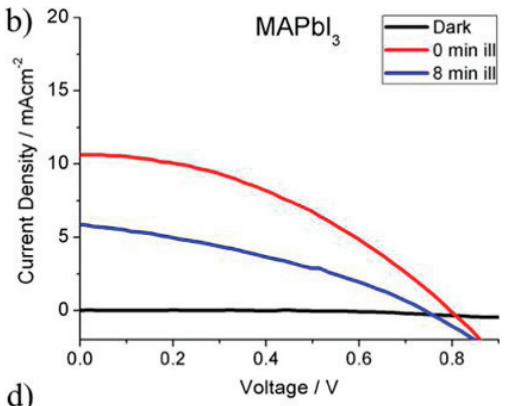

d)

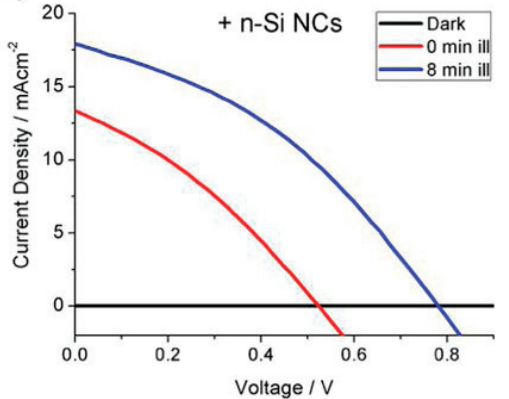

Figure 13. Perovskite-silicon nanocrystal (SiNC) hybrid solar cells show improved device performance especially after light-soaking. (a) Schematic of device structure, and current-density voltage (JV) curves for (b) $\mathrm{MAPbI}_{3}$ alone, (c) $\mathrm{MAPbI}_{3}$ with p-type SiNCs, and (d) n-type SiNCs. Reported from ref. [85], with permission from Elsevier, 2018.

In addition, incorporating nanocrystals into OHPs presents the opportunity to create various types of favorable band alignment between the OHP and the nanocrystal. Coupling the properties of nanocrystals with perovskites can lead to improvements in device performance and opens up an 
avenue of possibilities to exceed the SQ-limit. Forming an inverted type-I junction can potentially improve carrier collection either through optical coupling or electronic coupling. $\mathrm{MAPbI}_{3}-\mathrm{SiNC}$ hybrid devices form an inverted type-I band alignment (Figure 14), where wider-bandgap SiNCs were incorporated into the perovskite layer with electronic and/or optical coupling with the OHP, depending on whether or not the SiNCs are oxidized [85]. In an electronically coupled inverted type- I junction, the absorption in the wider-bandgap nanocrystal generates carriers which can be transferred into the adjacent conduction and valence bands of the smaller bandgap perovskite. In an optically coupled system, the nanocrystal behaves as a 'interpenetrated' down converter for high energy photons, where radiative carrier recombination via photoluminescence (PL) results in excitations in the narrow bandgap perovskite. It is therefore important that the peak PL emission is tailored to the bandgap of the perovskite to maximize the conversion efficiency. In $\mathrm{MAPbI}_{3}: \mathrm{SiNC}$ hybrid devices, it is expected that the structure initially forms an electronically coupled junction whereby carriers generated in the SiNCs can transfer into the OHP. After oxidation, carriers generated in SiNCs are trapped by the oxide potential barrier and recombine via photoluminescence, thus generating an optically coupled junction. It was found using Kelvin probe and XPS that the type-I band alignment is preserved even after the SiNCs became oxidized [85]. These new architectures represent new opportunities for exploring different combinations of materials with perovskite structures.

(a) Electronic-coupling

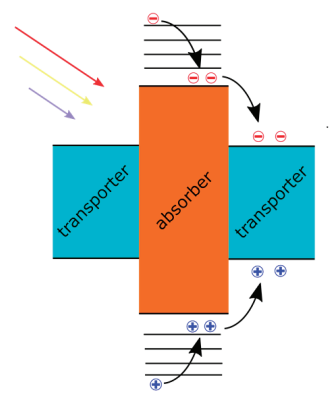

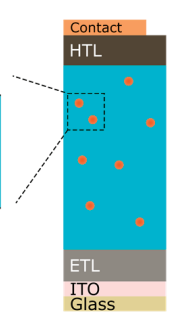

(b) Optical-coupling

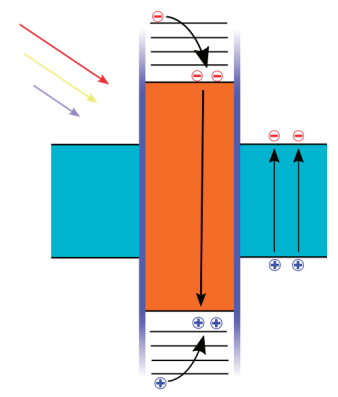

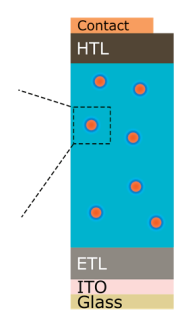

Figure 14. Inverted type-I band alignment: (a) electronically coupled and (b) optically coupled. Reproduced from ref. [85], with permission from Elsevier, 2018..

\subsection{Perouskite Oxide Nanoparticles}

Perovskite oxides $\left(\mathrm{ABO}_{3}\right)$ are attractive materials for photovoltaics because of the possibility of low-cost, non-toxic photovoltaics with high stability [131]. However, most semiconducting perovskite oxides have large bandgaps $(\sim 3-5 \mathrm{eV})$ due to oxygen-metal transitions with large differences in their electronegativities [132,133], and are therefore generally unsuitable for absorbing light within the solar spectral range. Attempts to reduce the bandgap of perovskite oxides include doping [134], intrinsic defects [135], forming oxynitrides [136], solid solutions [137], and cationic ordering [132].

Perovskite oxides and their derivatives (layered perovskite oxides) represent a large family of materials which exhibit a multitude of properties, and have been investigated for applications including photovoltaics [138]. Perovskite oxides possess a high-degree of flexibility given that $90 \%$ of the metallic natural elements in the periodic table can adopt a stable perovskite-type oxide structure [139]. There remains a significant opportunity for exploring the use of metal oxides in photovoltaics to achieve affordable solar cell devices with high efficiency and tunability, whilst easily meeting the often elusive requirement of high stability. The use of metal oxides with highly-tunable absorption properties via the introduction of vacancies [135] and doping [140] would allow for the facile fabrication of multi-junction devices with high stability. 
Ferroelectric perovskite oxides have been demonstrated in photovoltaics [133], however they tend to possess large bandgaps $(\sim 3-5 \mathrm{eV})$ and low conductivities, and therefore efficiencies are low $(\sim 1 \%)$. Plasmonic perovskite oxides have not been explored to the same extent for photovoltaics. Perovskite oxides can be heavily doped to be plasmonic or can be achieved through structural vacancies to strongly modify electronic properties [140]. However, one of the issues associated with plasmonic materials is carrier extraction, and therefore forming extremely thin absorber layers using nano-sized plasmonic oxides is necessary to rapidly extract carriers before recombining.

The perovskite oxide $\mathrm{CaMnO}_{3}$ is an orthorhombic perovskite, and upon reduction in flowing $\mathrm{Ar}$ gas the structure can be transformed to an oxygen-deficient perovskite with the structure $\mathrm{CaMnO}_{2.5}$. The structure of $\mathrm{CaMnO}_{2.5}$ is essentially an orthorhombic perovskite with an internal 1D nanostructure ordering as shown in Figure 15a. The introduction of oxygen vacancies removes one oxygen atom from each $\mathrm{MnO}_{6}$ octahedra and results in a square pyramid of $\mathrm{MnO}_{5}$. This structural transformation reveals many interesting properties, such as plasmonic behavior and significantly improved electrocatayltic and photocatalytic activity [141]. $\mathrm{CaMnO}_{2.5}$ can be described as an orthorhombic perovskite because the $\mathrm{Ca}$ and $\mathrm{Mn}$ perovskite sub-lattice is preserved. Since the resulting powder is phase pure, the oxygen vacancies are expected to be ordered resulting in $1 \mathrm{D}$ chains of $\mathrm{MnO}_{5}$ square pyramids [141]. The $\mathrm{MnO}_{5}$ square pyramids are connected along a one- dimensional network extending through the crystal connected by oxygen atoms, which may be favorable for carrier extraction. This oxygen deficiency creates an internal molecular level porosity. The one-dimensional network of $\mathrm{MnO}_{5}$ pyramids may also enhance charge transport and enable efficient carrier separation whereby photoexcited carriers are transported along segregated $\mathrm{Mn}-\mathrm{O}$ carrier transport channels. $\mathrm{CaMnO}_{2.5}$ displays broad absorption of light from the infra-red through to the visible region of the solar spectrum. Nanoparticles of $\mathrm{CaMnO}_{2.5}$ can be easily produced via a sol-gel process followed by reductive annealing, and then deposited as an ultrathin film either by spray coating or spin coating. The shape and size of the $\mathrm{CaMnO}_{2.5}$ nanoparticles is shown in Figure 15b. $\mathrm{CaMnO}_{2.5}$ nanoparticles have been successfully used to fabricate a photovoltaic cell, and the device performance is shown in Figure 15c. While initial device performance was low, this work serves as a proof of concept and it is likely that the efficiency can be significantly improved, primarily through optimization of the layer thickness and interfacial engineering to improve coupling between $\mathrm{CaMnO}_{2.5}$ nanoparticles and transport layers.

(a)

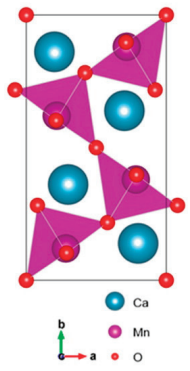

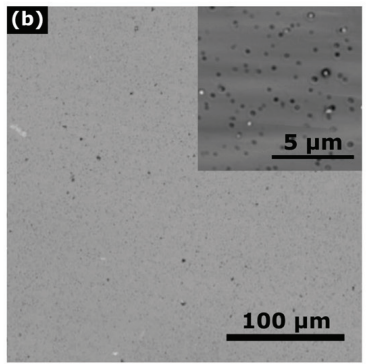

(c)

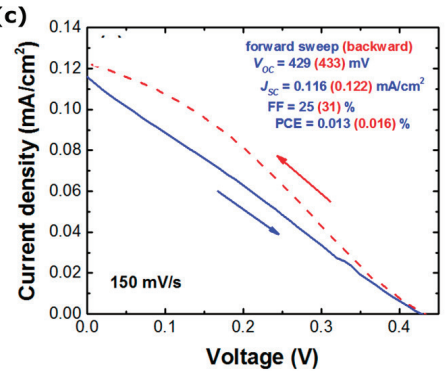

Figure 15. (a) Structure of $\mathrm{CaMnO}_{2.5}$ reproduced from ref. [141], with permission from American Chemical Society, 2014, (b) optical microscope images of $\mathrm{CaMnO}_{2.5}$ after laser fragmentation, the inset shows a high-magnification optical microscope image, and (c) current density-voltage characteristic of a $\mathrm{CaMnO}_{2.5}$ solar cell under solar simulated light.

\section{Conclusions and Outlook}

This review article has provided a summary of 3D bulk OHPs and an overview of the recent direction and progress towards LDPs. To date, 1DPs and 2DPs have shown the highest efficiencies, yet it is unclear whether these materials will suffer the same long-term stability issues as bulk OHPs. Nanosheets with $n \leq 2$ tend to show impressive stabilities but suffer from low performance issues, 
particularly due to their very large bandgaps. It is still unclear whether 2DPs and 1DPs with $n>2$ can demonstrate the long-term stability required for commercialization. Furthermore, the issue of stacking faults between grains, which inhibits charge transfer through the layer, must be overcome to increase the efficiency towards $20 \%$. Exploring conductive organic barriers could be a possible route towards overcoming carrier transport issues.

0DPs tend to be highly stable, however their efficiencies are often very low due to issues associated with carrier extraction, where excitons tend to be strongly localized on $\mathrm{BX}_{6}{ }^{4-}$ or $\mathrm{B}_{2} \mathrm{X}_{9}{ }^{3-}$ clusters. Methods to enhance exciton dissociation and carrier transport need to be further explored if these materials are to demonstrate noteworthy efficiencies in photovoltaics, particularly through forming hybrids with nanocrystals to promote exciton dissociation, and by exploring various ion substitutions at the A-site to lower the exciton binding energy. Provided that these challenges can be overcome, ODPs with large bandgaps can be incorporated as a top cell in a tandem solar cell. For use in single junction cells, it is important to explore doping along with varying the A-site ion with the aim of discovering 0DPs with smaller bandgaps, which are currently often $>2 \mathrm{eV}$.

PQDs have shown impressive performance so far, yet the choice of materials is rather limited due to the poor stability of organometal PQDs, which are unstable unless capped with long chain organic barriers which inhibit carrier transport. Inorganic $\mathrm{CsPbI}_{3}$ QDs do not require capping molecules and have demonstrated improved short-term stability along with impressive solar cell efficiencies over $13 \%$. Despite this, $\mathrm{CsPbI}_{3}$ QDs are highly unstable in ambient conditions and encapsulation of the entire solar cell device is essential. As research in this field is still in its infancy, there are limited studies on the stability of $\mathrm{CsPbI}_{3}$ QDs and the extent to which the stability can be improved remains unclear. It is therefore currently difficult to predict the potential for $\mathrm{CsPbI}_{3}$ QDs in photovoltaics.

Hybrid devices can be formed by adding NCs to bulk 3DPs or 0DPs. These hybrid device architectures have been explored using SiNCs, demonstrating an improvement in the device performance due to the possibility of a type-I band alignment which can be optically and/or electronically coupled to improve carrier collection. Furthermore, adding SiNCs indicates a route towards extending the device lifetime, whereby SiNCs are oxidized by the residual moisture in the layer rather than degrading the OHP. This was shown to preserve the favorable type-I band alignment without affecting the device performance.

Due to the significant stability issues suffered by OHPs, occurring both in bulk and lowdimensional forms, we have also briefly introduced the field of perovskite oxide nanomaterials, studying the oxygen-deficient perovskite $\mathrm{CaMnO}_{2.5}$. This material, which absorbs a broad range of light in the solar spectrum from infrared to ultra-violet, has a one-dimensional internal structure which may promote carrier transport. Although the efficiency of the solar cell device is low, there remains significant opportunities for tuning the properties, optimizing devices, and exploring doping to improve device performance.

Finally, while the efficiencies of LDPs are still often far lower than bulk-OHPs, it is encouraging that higher device efficiencies are continually being reported. Provided that these devices can be fabricated with efficiencies of $>20 \%$, it is likely that they will be attractive to the market assuming they can be produced at very low cost and with far superior stability to 3D OHPs.

Funding: This work was supported by the Japanese Society for the Promotion of Science (JSPS) (17F17815), EPSRC (EP/K022237/1, EP/M024938/1 and EP/R023638/1), the EPSRC Supergen SuperSolar Hub, the Department for Employment and Learning (DEL) of Northern Ireland Studentship, and by the New Energy and Industrial Technology Development Organization (NEDO).

Conflicts of Interest: The authors declare no conflict of interest.

\section{References}

1. National Renewable Energy Laboratory Best Research-Cell Efficiency Chart. Available online: https: //www.nrel.gov/pv/assets/pdfs/best-research-cell-efficiencies.20190923.pdf (accessed on 25 September 2019). 
2. Green, M.A.; Hishikawa, Y.; Dunlop, E.D.; Levi, D.H.; Hohl-Ebinger, J.; Ho-Baillie, A.W.Y. Solar cell efficiency tables (version 52). Prog. Photovolt. Res. Appl. 2018, 26, 427-436. [CrossRef]

3. Leijtens, T.; Bush, K.A.; Prasanna, R.; McGehee, M.D. Opportunities and challenges for tandem solar cells using metal halide perovskite semiconductors. Nat. Energy 2018, 1-11. [CrossRef]

4. Jung, H.S.; Park, N.-G. Perovskite Solar Cells: From Materials to Devices. Small 2015, 11, 10-25. [CrossRef] [PubMed]

5. Xing, G.; Mathews, N.; Sun, S.; Lim, S.S.; Lam, Y.M.; Gratzel, M.; Mhaisalkar, S.; Sum, T.C. Long-Range Balanced Electron- and Hole-Transport Lengths in Organic-Inorganic $\mathrm{CH}_{3} \mathrm{NH}_{3} \mathrm{PbI}_{3}$. Science 2013, 342, 344-347. [CrossRef] [PubMed]

6. Stranks, S.D.; Eperon, G.E.; Grancini, G.; Menelaou, C.; Alcocer, M.J.P.; Leijtens, T.; Herz, L.M.; Petrozza, A.; Snaith, H.J. Electron-hole diffusion lengths exceeding 1 micrometer in an organometal trihalide perovskite absorber. Science 2013, 342, 341-344. [CrossRef] [PubMed]

7. Lin, Q.; Armin, A.; Nagiri, R.C.R.; Burn, P.L.; Meredith, P. Electro-optics of perovskite solar cells. Nat. Photonics 2014, 9, 106-112. [CrossRef]

8. Xing, G.; Mathews, N.; Lim, S.S.; Yantara, N.; Liu, X.; Sabba, D.; Grätzel, M.; Mhaisalkar, S.; Sum, T.C. Low-temperature solution-processed wavelength-tunable perovskites for lasing. Nat. Mater. 2014, 13, 476-480. [CrossRef]

9. Xing, J.; Zhao, Y.; Askerka, M.; Quan, L.N.; Gong, X.; Zhao, W.; Zhao, J.; Tan, H.; Long, G.; Gao, L.; et al. Color-stable highly luminescent sky-blue perovskite light-emitting diodes. Nat. Commun. 2018, 9. [CrossRef]

10. Li, Z.; Moon, J.; Gharajeh, A.; Haroldson, R.; Hawkins, R.; Hu, W.; Zakhidov, A.; Gu, Q. Room-temperature continuous-wave operation of organometal halide perovskite lasers. ACS Nano 2018, 12, 10968-10976. [CrossRef]

11. Wang, K.; Wang, S.; Xiao, S.; Song, Q. Recent Advances in Perovskite Micro- and Nanolasers. Adv. Opt. Mater. 2018, 6, 1800278. [CrossRef]

12. Feng, J.; Gong, C.; Gao, H.; Wen, W.; Gong, Y.; Jiang, X.; Zhang, B.; Wu, Y.; Wu, Y.; Fu, H.; et al. Single-crystalline layered metal-halide perovskite nanowires for ultrasensitive photodetectors. Nat. Electron. 2018, 1, 404-410. [CrossRef]

13. Saliba, M.; Matsui, T.; Seo, J.-Y.; Domanski, K.; Correa-Baena, J.-P.; Mohammad, K.N.; Zakeeruddin, S.M.; Tress, W.; Abate, A.; Hagfeldt, A.; et al. Cesium-containing Triple Cation Perovskite Solar Cells: Improved Stability, Reproducibility and High Efficiency. Energy Environ. Sci. 2016, 9, 1989-1997. [CrossRef] [PubMed]

14. Jeon, N.J.; Noh, J.H.; Yang, W.S.; Kim, Y.C.; Ryu, S.; Seo, J.; Seok, S. Il Compositional engineering of perovskite materials for high-performance solar cells. Nature 2015, 517, 476-480. [CrossRef] [PubMed]

15. Li, X.; Bi, D.; Yi, C.; Decoppet, J.-D.; Luo, J.; Zakeeruddin, S.M.; Hagfeldt, A.; Gratzel, M. A vacuum flash-assisted solution process for high-efficiency large-area perovskite solar cells. Science 2016, 353, 58-62. [CrossRef] [PubMed]

16. Eperon, G.E.; Stranks, S.D.; Menelaou, C.; Johnston, M.B.; Herz, L.M.; Snaith, H.J. Formamidinium lead trihalide: A broadly tunable perovskite for efficient planar heterojunction solar cells. Energy Environ. Sci. 2014, 7, 982-988. [CrossRef]

17. Seok, S.I.; Grätzel, M.; Park, N.G. Methodologies toward Highly Efficient Perovskite Solar Cells. Small 2018, 14. [CrossRef]

18. Huang, F.; Li, M.; Siffalovic, P.; Cao, G.; Tian, J. From scalable solution fabrication of perovskite films towards commercialization of solar cells. Energy Environ. Sci. 2019, 12, 518-549. [CrossRef]

19. Cheacharoen, R.; Rolston, N.; Harwood, D.; Bush, K.A.; Dauskardt, R.H.; McGehee, M.D. Design and understanding of encapsulated perovskite solar cells to withstand temperature cycling. Energy Environ. Sci. 2018, 11, 144-150. [CrossRef]

20. Fan, X.; Zhang, M.; Wang, X.; Yang, F.; Meng, X.; Chen, C.W.M.; Tang, C.Y.; Chen, C.W.M.; Cao, J.; Wang, Z.G.; et al. Recent progress in organic-inorganic hybrid solar cells. 2013, 1, 8694-8709. J. Mater. Chem. A 2013, 1, 8694-8709. [CrossRef]

21. Sanehira, E.M.; Marshall, A.R.; Christians, J.A.; Harvey, S.P.; Ciesielski, P.N.; Wheeler, L.M.; Schulz, P.; Lin, L.Y.; Beard, M.C.; Luther, J.M. Enhanced mobility $\mathrm{CsPbI}_{3}$ quantum dot arrays for record-efficiency, high-voltage photovoltaic cells. Sci. Adv. 2017, 3, eaao4204. [CrossRef] 
22. Quan, L.N.; Yuan, M.; Comin, R.; Voznyy, O.; Beauregard, E.M.; Hoogland, S.; Buin, A.; Kirmani, A.R.; Zhao, K.; Amassian, A.; et al. Ligand-Stabilized Reduced-Dimensionality Perovskites. J. Am. Chem. Soc. 2016, 138, 2649-2655. [CrossRef] [PubMed]

23. Tsai, H.; Nie, W.; Blancon, J.-C.; Stoumpos, C.C.; Asadpour, R.; Harutyunyan, B.; Neukirch, A.J.; Verduzco, R.; Crochet, J.J.; Tretiak, S.; et al. High-efficiency two-dimensional Ruddlesden-Popper perovskite solar cells. Nature 2016, 536, 312-316. [CrossRef] [PubMed]

24. Yang, R.; Li, R.; Cao, Y.; Wei, Y.; Miao, Y.; Tan, W.L.; Jiao, X.; Chen, H.; Zhang, L.; Chen, Q.; et al. Oriented Quasi-2D Perovskites for High Performance Optoelectronic Devices. Adv. Mater. 2018, 30, 1804771. [CrossRef] [PubMed]

25. Kim, M.R.; Ma, D. Quantum-Dot-Based Solar Cells: Recent Advances, Strategies, and Challenges. J. Phys. Chem. Lett. 2015, 6, 85-99. [CrossRef]

26. Lee, M.M.; Teuscher, J.; Miyasaka, T.; Murakami, T.N.; Snaith, H.J. Efficient hybrid solar cells based on meso-superstructured organometal halide perovskites. Science 2012, 338, 643-647. [CrossRef]

27. Kim, H.-S.; Lee, C.-R.; Im, J.-H.; Lee, K.-B.; Moehl, T.; Marchioro, A.; Moon, S.-J.; Humphry-Baker, R.; Yum, J.-H.; Moser, J.E.; et al. Lead Iodide Perovskite Sensitized All-Solid-State Submicron Thin Film Mesoscopic Solar Cell with Efficiency Exceeding 9\%. Sci. Rep. 2012, 2, 591. [CrossRef]

28. Xiong, L.; Guo, Y.; Wen, J.; Liu, H.; Yang, G.; Qin, P.; Fang, G. Review on the Application of SnO2 in Perovskite Solar Cells. Adv. Funct. Mater. 2018, 28. [CrossRef]

29. Yang, W.S.; Park, B.-W.; Jung, E.H.; Jeon, N.J.; Kim, Y.C.; Lee, D.U.; Shin, S.S.; Seo, J.; Kim, E.K.; Noh, J.H.; et al. Iodide management in formamidinium-lead-halide-based perovskite layers for efficient solar cells. Science 2017, 356, 1376-1379. [CrossRef]

30. Hoye, R.L.Z.; Brandt, R.E.; Osherov, A.; Stevanovic, V.; Stranks, S.D.; Wilson, M.W.B.; Kim, H.; Akey, A.J.; Perkins, J.D.; Kurchin, R.C.; et al. Methylammonium Bismuth Iodide as a Lead-Free, Stable Hybrid Organic-Inorganic Solar Absorber. Chem. A Eur. J. 2016, 22, 2605-2610. [CrossRef]

31. Zhang, L.; Ju, M.-G.; Liang, W. The effect of moisture on the structures and properties of lead halide perovskites: A first-principles theoretical investigation. Phys. Chem. Chem. Phys. 2016, 18, 23174-23183. [CrossRef]

32. Rocks, C.; Svrcek, V.; Maguire, P.; Mariotti, D. Understanding Surface Chemistry During $\mathrm{MAPbI}_{3} \mathrm{Spray}$ Deposition and its Effect on Photovoltaic Performance. J. Mater. Chem. C 2017, 5, 902-916. [CrossRef]

33. Ahn, N.; Kwak, K.; Jang, M.S.; Yoon, H.; Lee, B.Y.; Lee, J.-K.; Pikhitsa, P.V.; Byun, J.; Choi, M. Trapped charge-driven degradation of perovskite solar cells. Nat. Commun. 2016, 7, 13422. [CrossRef] [PubMed]

34. Hoke, E.T.; Slotcavage, D.J.; Dohner, E.R.; Bowring, A.R.; Karunadasa, H.I.; McGehee, M.D. Reversible photo-induced trap formation in mixed-halide hybrid perovskites for photovoltaics. Chem. Sci. 2015, 6, 613-617. [CrossRef] [PubMed]

35. Wu, B.; Fu, K.; Yantara, N.; Xing, G.; Sun, S.; Sum, T.C.; Mathews, N. Charge Accumulation and Hysteresis in Perovskite-Based Solar Cells: An Electro-Optical Analysis. Adv. Energy Mater. 2015, 5, 1500829. [CrossRef]

36. deQuilettes, D.W.; Zhang, W.; Burlakov, V.M.; Graham, D.J.; Leijtens, T.; Osherov, A.; Bulović, V.; Snaith, H.J.; Ginger, D.S.; Stranks, S.D. Photo-induced halide redistribution in organic-inorganic perovskite films. Nat. Commun. 2016, 7, 11683. [CrossRef]

37. Choi, J.J.; Yang, X.; Norman, Z.M.; Billinge, S.J.L.; Owen, J.S. Structure of Methylammonium Lead Iodide Within Mesoporous Titanium Dioxide: Active Material in High-Performance Perovskite Solar Cells. Nano Lett. 2014, 14, 127-133. [CrossRef]

38. Jeon, N.J.; Noh, J.H.; Kim, Y.C.; Yang, W.S.; Ryu, S.; Seok, S. Il Solvent engineering for high-performance inorganic-organic hybrid perovskite solar cells. Nat. Mater. 2014, 13, 897-903. [CrossRef]

39. Misra, R.K.; Aharon, S.; Li, B.; Mogilyansky, D.; Visoly-Fisher, I.; Etgar, L.; Katz, E.A. Temperature- and Component-Dependent Degradation of Perovskite Photovoltaic Materials under Concentrated Sunlight. J. Phys. Chem. Lett. 2015, 6, 326-330. [CrossRef]

40. Bush, K.A.; Palmstrom, A.F.; Yu, Z.J.; Boccard, M.; Cheacharoen, R.; Mailoa, J.P.; McMeekin, D.P.; Hoye, R.L.Z.; Bailie, C.D.; Leijtens, T.; et al. 23.6\%-efficient monolithic perovskite/silicon tandem solar cells with improved stability. Nat. Energy 2017, 2, 17009. [CrossRef]

41. Wang, S.; Jiang, Y.; Juarez-Perez, E.J.; Ono, L.K.; Qi, Y. Accelerated degradation of methylammonium lead iodide perovskites induced by exposure to iodine vapour. Nat. Energy 2016, 2, 395-398. [CrossRef] 
42. Juarez-Perez, E.J.; Ono, L.K.; Maeda, M.; Jiang, Y.; Hawash, Z.; Qi, Y. Photodecomposition and thermal decomposition in methylammonium halide lead perovskites and inferred design principles to increase photovoltaic device stability. J. Mater. Chem. A 2018, 6, 9604-9612. [CrossRef]

43. Babayigit, A.; Ethirajan, A.; Muller, M.; Conings, B. Toxicity of organometal halide perovskite solar cells. Nat. Mater. 2016, 15, 247-251. [CrossRef] [PubMed]

44. Park, N.-G.; Grätzel, M.; Miyasaka, T.; Zhu, K.; Emery, K. Towards stable and commercially available perovskite solar cells. Nat. Energy 2016, 1, 16152. [CrossRef]

45. Clever, H.L.; Johnston, F.J. The solubility of some sparingly soluble lead salts: An evaluation of the solubility in water and aqueous electrolyte solution. J. Phys. Chem. Ref. Data 1982, 9, 751-784. [CrossRef]

46. Filip, M.R.; Giustino, F. Computational Screening of Homovalent Lead Substitution in Organic-Inorganic Halide Perovskites. J. Phys. Chem. C 2016, 120, 166-173. [CrossRef]

47. Yin, W.J.; Shi, T.; Yan, Y. Unique properties of halide perovskites as possible origins of the superior solar cell performance. Adv. Mater. 2014, 26, 4653-4658. [CrossRef] [PubMed]

48. Lee, S.J.; Shin, S.S.; Kim, Y.C.; Kim, D.; Ahn, T.K.; Noh, J.H.; Seo, J.; Seok, S. Il Fabrication of Efficient Formamidinium Tin Iodide Perovskite Solar Cells through $\mathrm{SnF}_{2}-$ Pyrazine Complex. J. Am. Chem. Soc. 2016, 138, 3974-3977. [CrossRef]

49. Leijtens, T.; Prasanna, R.; Gold-Parker, A.; Toney, M.F.; McGehee, M.D. Mechanism of Tin Oxidation and Stabilization by Lead Substitution in Tin Halide Perovskites. ACS Energy Lett. 2017, 2, 2159-2165. [CrossRef]

50. Muscarella, L.A.; Petrova, D.; Jorge Cervasio, R.; Farawar, A.; Lugier, O.; McLure, C.; Slaman, M.J.; Wang, J.; Ehrler, B.; Von Hauff, E.; et al. Air-Stable and Oriented Mixed Lead Halide Perovskite (FA/MA) by the One-Step Deposition Method Using Zinc Iodide and an Alkylammonium Additive. ACS Appl. Mater. Interfaces 2019, 11, 17555-17562. [CrossRef]

51. Chen, R.; Hou, D.; Lu, C.; Zhang, J.; Liu, P.; Tian, H.; Zeng, Z.; Xiong, Q.; Hu, Z.; Zhu, Y.; et al. Zinc ion as effective film morphology controller in perovskite solar cells. Sustain. Energy Fuels 2018, 2, 1093-1100. [CrossRef]

52. Kooijman; Muscarella; Williams Perovskite Thin Film Materials Stabilized and Enhanced by Zinc(II) Doping. Appl. Sci. 2019, 9, 1678. [CrossRef]

53. Shai, X.; Wang, J.; Sun, P.; Huang, W.; Liao, P.; Cheng, F.; Zhu, B.; Chang, S.Y.; Yao, E.P.; Shen, Y.; et al. Achieving ordered and stable binary metal perovskite via strain engineering. Nano Energy 2018, 48, 117-127. [CrossRef]

54. Eames, C.; Frost, J.M.; Barnes, P.R.F.; O’Regan, B.C.; Walsh, A.; Islam, M.S. Ionic transport in hybrid lead iodide perovskite solar cells. Nat. Commun. 2015, 6, 7497. [CrossRef] [PubMed]

55. Meloni, S.; Moehl, T.; Tress, W.; Franckevičius, M.; Saliba, M.; Lee, Y.H.; Gao, P.; Nazeeruddin, M.K.; Zakeeruddin, S.M.; Rothlisberger, U.; et al. Ionic polarization-induced current-voltage hysteresis in $\mathrm{CH}_{3} \mathrm{NH}_{3} \mathrm{PbX}_{3}$ perovskite solar cells. Nat. Commun. 2016, 7, 10334. [CrossRef]

56. Tress, W.; Marinova, N.; Moehl, T.; Zakeeruddin, S.M.; Nazeeruddin, M.K.; Grätzel, M. Understanding the rate-dependent $\mathrm{J}-\mathrm{V}$ hysteresis, slow time component, and aging in $\mathrm{CH}_{3} \mathrm{NH}_{3} \mathrm{PbI}_{3}$ perovskite solar cells: The role of a compensated electric field. Energy Environ. Sci. 2015, 8, 995-1004. [CrossRef]

57. Cao, X.; Li, Y.; Li, C.; Fang, F.; Yao, Y.; Cui, X.; Wei, J. Modulating Hysteresis of Perovskite Solar Cells by a Poling Voltage. J. Phys. Chem. C 2016, 120, 22784-22792. [CrossRef]

58. Yuan, Y.; Huang, J. Ion Migration in Organometal Trihalide Perovskite and Its Impact on Photovoltaic Efficiency and Stability. Acc. Chem. Res. 2016, 49, 286-293. [CrossRef]

59. Levine, I.; Nayak, P.K.; Wang, J.T.-W.; Sakai, N.; Van Reenen, S.; Brenner, T.M.; Mukhopadhyay, S.; Snaith, H.J.; Hodes, G.; Cahen, D. Temperature-dependent Hysteresis in $\mathrm{MAPbI}_{3}$ Solar Cells. J. Phys. Chem. C 2016. [CrossRef]

60. Mei, A.; Li, X.; Liu, L.; Ku, Z.; Liu, T.; Rong, Y.; Xu, M.; Hu, M.; Chen, J.; Yang, Y.; et al. A hole-conductor-free, fully printable mesoscopic perovskite solar cell with high stability. Science 2014, 345, 295-298. [CrossRef]

61. Ko, Y.; Kim, Y.; Lee, C.; Kim, Y.; Jun, Y. Investigation of Hole-Transporting Poly(triarylamine) on Aggregation and Charge Transport for Hysteresisless Scalable Planar Perovskite Solar Cells. ACS Appl. Mater. Interfaces 2018, 10, 11633-11641. [CrossRef]

62. Wei, J.; Zhao, Y.; Li, H.; Li, G.; Pan, J.; Xu, D.; Zhao, Q.; Yu, D. Hysteresis Analysis Based on the Ferroelectric Effect in Hybrid Perovskite Solar Cells. J. Phys. Chem. Lett. 2014, 5, 3937-3945. [CrossRef] [PubMed] 
63. Unger, E.L.; Hoke, E.T.; Bailie, C.D.; Nguyen, W.H.; Bowring, A.R.; Heumüller, T.; Christoforo, M.G.; McGehee, M.D.; Pullerits, T.; Stepanov, A.; et al. Hysteresis and transient behavior in current-voltage measurements of hybrid-perovskite absorber solar cells. Energy Environ. Sci. 2014, 7, 3690-3698. [CrossRef]

64. Kim, H.S.; Park, N.G. Parameters affecting I-V hysteresis of $\mathrm{CH}_{3} \mathrm{NH}_{3} \mathrm{PbI}_{3}$ perovskite solar cells: Effects of perovskite crystal size and mesoporous $\mathrm{TiO}_{2}$ layer. J. Phys. Chem. Lett. 2014, 5, 2927-2934. [CrossRef] [PubMed]

65. Sanchez, R.S.; Gonzalez-Pedro, V.; Lee, J.-W.; Park, N.-G.; Kang, Y.S.; Mora-Sero, I.; Bisquert, J. Slow Dynamic Processes in Lead Halide Perovskite Solar Cells. Characteristic Times and Hysteresis. J. Phys. Chem. Lett. 2014, 5, 2357-2363. [CrossRef]

66. Rong, Y.; Hu, Y.; Ravishankar, S.; Liu, H.; Hou, X.; Sheng, Y.; Mei, A.; Wang, Q.; Li, D.; Xu, M.; et al. Tunable hysteresis effect for perovskite solar cells. Energy Environ. Sci. 2017, 10, 2383-2391. [CrossRef]

67. Chen, B.; Yang, M.; Zheng, X.; Wu, C.; Li, W.; Yan, Y.; Bisquert, J.; Garcia-Belmonte, G.; Zhu, K.; Priya, S. Impact of Capacitive Effect and Ion Migration on the Hysteretic Behavior of Perovskite Solar Cells. J. Phys. Chem. Lett. 2015, 6, 4693-4700. [CrossRef]

68. O'Regan, B.C.; Barnes, P.R.F.; Li, X.; Law, C.; Palomares, E.; Marin-Beloqui, J.M. Optoelectronic studies of methylammonium lead iodide perovskite solar cells with mesoporous $\mathrm{TiO}_{2}$ : Separation of electronic and chemical charge storage, understanding two recombination lifetimes, and the evolution of band offsets during J-V hysteresis. J. Am. Chem. Soc. 2015, 137, 5087-5099. [CrossRef]

69. Richardson, G.; O’Kane, S.E.J.; Niemann, R.G.; Peltola, T.A.; Foster, J.M.; Cameron, P.J.; Walker, A.B.; Pace, G.; Manna, L.; Caironi, M.; et al. Can slow-moving ions explain hysteresis in the current-voltage curves of perovskite solar cells? Energy Environ. Sci. 2016, 9, 1476-1485. [CrossRef]

70. Shao, Y.; Xiao, Z.; Bi, C.; Yuan, Y.; Huang, J. Origin and elimination of photocurrent hysteresis by fullerene passivation in $\mathrm{CH}_{3} \mathrm{NH}_{3} \mathrm{PbI}_{3}$ planar heterojunction solar cells. Nat. Commun. 2014, 5, 5784. [CrossRef]

71. Zheng, F.; Xin, Y.; Huang, W.; Zhang, J.; Wang, X.; Shen, M.; Dong, W.; Fang, L.; Bai, Y.; Shen, X.; et al. Above 1\% Efficiency of a Ferroelectric Solar Cell Based on the $\mathrm{Pb}\left(\{\mathrm{Zr}, \mathrm{Ti}) \mathrm{O}_{3}\right\}$ Film. J. Mater. Chem. A 2013, 2, 1363-1368. [CrossRef]

72. Frost, J.M.; Butler, K.T.; Brivio, F.; Hendon, C.H.; van Schilfgaarde, M.; Walsh, A. Atomistic Origins of High-Performance in Hybrid Halide Perovskite Solar Cells. Nano Lett. 2014, 14, 2584-2590. [CrossRef] [PubMed]

73. Chen, B.; Zheng, X.; Yang, M.; Zhou, Y.; Kundu, S.; Shi, J.; Zhu, K.; Priya, S. Interface band structure engineering by ferroelectric polarization in perovskite solar cells. Nano Energy 2015, 13, 582-591. [CrossRef]

74. Kutes, Y.; Ye, L.; Zhou, Y.; Pang, S.; Huey, B.D.; Padture, N.P. Direct observation of ferroelectric domains in solution-processed $\mathrm{CH}_{3} \mathrm{NH}_{3} \mathrm{PbI}_{3}$ perovskite thin films. J. Phys. Chem. Lett. 2014, 5, 3335-3339. [CrossRef] [PubMed]

75. Kim, H.; Kim, S.K.; Kim, B.J.; Shin, K.; Gupta, M.K.; Jung, H.S.; Kim, S.; Park, N. Ferroelectric Polarization in $\mathrm{CH}_{3} \mathrm{NH}_{3} \mathrm{PbI}_{3}$ Perovskite. J. Phys. Chem. Lett. 2015, 6, 1729-1735. [CrossRef] [PubMed]

76. Elumalai, N.K.; Uddin, A. Hysteresis in organic-inorganic hybrid perovskite solar cells. Sol. Energy Mater. Sol. Cells 2016, 157, 476-509. [CrossRef]

77. Zhang, X.; Wu, G.; Gu, Z.; Guo, B.; Liu, W.; Yang, S.; Ye, T.; Chen, C.; Tu, W.; Chen, H. Active-layer evolution and efficiency improvement of $\left(\mathrm{CH}_{3} \mathrm{NH}_{3}\right)_{3} \mathrm{Bi}_{2} \mathrm{I}_{9}$-based solar cell on $\mathrm{TiO}_{2}$-deposited ITO substrate. Nano Res. 2016, 9, 2921-2930. [CrossRef]

78. Giustino, F.; Snaith, H.J. Towards Lead-free Perovskite Solar Cells. ACS Energy Lett. 2016, 1, 1233-1240. [CrossRef]

79. González-Carrero, S.; Galian, R.E.; Pérez-Prieto, J. Organometal Halide Perovskites: Bulk Low-Dimension Materials and Nanoparticles. Part. Part. Syst. Charact. 2015, 32, 709-720. [CrossRef]

80. Müller, M.F.; Freunek, M.; Reindl, L.M. Maximum efficiencies of indoor photovoltaic devices. IEEE J. Photovoltaics 2013, 3, 59-64.

81. de Weerd, C.; Gomez, L.; Capretti, A.; Lebrun, D.M.; Matsubara, E.; Lin, J.; Ashida, M.; Spoor, F.C.M.; Siebbeles, L.D.A.; Houtepen, A.J.; et al. Efficient carrier multiplication in $\mathrm{CsPbI}_{3}$ perovskite nanocrystals. Nat. Commun. 2018, 9. [CrossRef]

82. Ni, C.; Hedley, G.; Payne, J.; Svrcek, V.; McDonald, C.; Jagadamma, L.K.; Edwards, P.; Martin, R.; Jain, G.; Carolan, D.; et al. Charge carrier localised in zero-dimensional $\left(\mathrm{CH}_{3} \mathrm{NH}_{3}\right)_{3} \mathrm{Bi}_{2} \mathrm{I}_{9}$ clusters. Nat. Commun. 2017, 8. [CrossRef] 
83. Nozik, A.J. Nanoscience and nanostructures for photovoltaics and solar fuels. Nano Lett. 2010, 10, $2735-2741$. [CrossRef] [PubMed]

84. Shockley, W.; Queisser, H.J. Detailed Balance Limit of Efficiency of p-n Junction Solar Cells. J. Appl. Phys. 1961, 32, 510. [CrossRef]

85. Rocks, C.; Svrcek, V.; Velusamy, T.; Macias-Montero, M.; Maguire, P.; Mariotti, D. Type-I alignment in $\mathrm{MAPbI}_{3}$ based solar devices with doped-silicon nanocrystals. Nano Energy 2018, 50, 245-255. [CrossRef]

86. McDonald, C.; Ni, C.; Švrček, V.; Lozac'H, M.; Connor, P.A.; Maguire, P.; Irvine, J.T.S.; Mariotti, D. Zero-dimensional methylammonium iodo bismuthate solar cells and synergistic interactions with silicon nanocrystals. Nanoscale 2017, 9. [CrossRef] [PubMed]

87. Kawai, T.; Shimanuki, S. Optical Studies of $\left(\mathrm{CH}_{3} \mathrm{NH}_{3}\right)_{3} \mathrm{Bi}_{2} \mathrm{I}_{9}$ Single Crystals. Phys. Status Solidi 1993, 177, 43-45. [CrossRef]

88. Pazoki, M.; Johansson, M.B.; Zhu, H.; Broqvist, P.; Edvinsson, T.; Boschloo, G.; Johansson, E.M.J. Bismuth Iodide Perovskite Materials for Solar Cell Applications: Electronic Structure, Optical Transitions, and Directional Charge Transport. J. Phys. Chem. C 2016, 120, 29039-29046. [CrossRef]

89. Cao, D.H.; Stoumpos, C.C.; Farha, O.K.; Hupp, J.T.; Kanatzidis, M.G. 2D Homologous Perovskites as Light-Absorbing Materials for Solar Cell Applications. J. Am. Chem. Soc. 2015, 137, 7843-7850. [CrossRef]

90. Koh, T.M.; Shanmugam, V.; Schlipf, J.; Oesinghaus, L.; Müller-Buschbaum, P.; Ramakrishnan, N.; Swamy, V.; Mathews, N.; Boix, P.P.; Mhaisalkar, S.G. Nanostructuring Mixed-Dimensional Perovskites: A Route Toward Tunable, Efficient Photovoltaics. Adv. Mater. 2016, 28, 3653-3661. [CrossRef]

91. Yao, K.; Wang, X.; Xu, Y.X.; Li, F.; Zhou, L. Multilayered Perovskite Materials Based on Polymeric-Ammonium Cations for Stable Large-Area Solar Cell. Chem. Mater. 2016, 28, 3131-3138. [CrossRef]

92. Lai, H.; Kan, B.; Liu, T.; Zheng, N.; Xie, Z.; Zhou, T.; Wan, X.; Zhang, X.; Liu, Y.; Chen, Y. Two-Dimensional Ruddlesden-Popper Perovskite with Nanorod-like Morphology for Solar Cells with Efficiency Exceeding 15\%. J. Am. Chem. Soc. 2018, 140, 11639-11646. [CrossRef] [PubMed]

93. Cohen, B.E.; Wierzbowska, M.; Etgar, L. High efficiency quasi 2D lead bromide perovskite solar cells using various barrier molecules. Sustain. Energy Fuels 2017, 1, 1935-1943. [CrossRef]

94. Ma, C.; Shen, D.; Ng, T.W.; Lo, M.F.; Lee, C.S. 2D Perovskites with Short Interlayer Distance for High-Performance Solar Cell Application. Adv. Mater. 2018, 30, 1800710. [CrossRef] [PubMed]

95. Smith, I.C.; Hoke, E.T.; Solis-Ibarra, D.; McGehee, M.D.; Karunadasa, H.I. A Layered Hybrid Perovskite Solar-Cell Absorber with Enhanced Moisture Stability. Angew. Chem. Int. Ed. 2014, 53, 11232-11235. [CrossRef]

96. Blancon, J.C.; Tsai, H.; Nie, W.; Stoumpos, C.C.; Pedesseau, L.; Katan, C.; Kepenekian, M.; Soe, C.M.M.; Appavoo, K.; Sfeir, M.Y.; et al. Extremely efficient internal exciton dissociation through edge states in layered 2D perovskites. Science 2017, 355, 1288-1292. [CrossRef]

97. Zhang, X.; Ren, X.; Liu, B.; Munir, R.; Zhu, X.; Yang, D.; Li, J.; Liu, Y.; Smilgies, D.M.; Li, R.; et al. Stable high efficiency two-dimensional perovskite solar cells via cesium doping. Energy Environ. Sci. 2017, 10, 2095-2102. [CrossRef]

98. Liu, G.; Zheng, H.; Xu, X.; Zhu, L.; Alsaedi, A.; Hayat, T.; Pan, X.; Dai, S. Efficient solar cells with enhanced humidity and heat stability based on benzylammonium-caesium-formamidinium mixed-dimensional perovskites. J. Mater. Chem. A 2018, 6, 18067-18074. [CrossRef]

99. Liu, Y.; Akin, S.; Pan, L.; Uchida, R.; Arora, N.; Milić, J.V.; Hinderhofer, A.; Schreiber, F.; Uhl, A.R.; Zakeeruddin, S.M.; et al. Ultrahydrophobic 3D/2D fluoroarene bilayer-based water-resistant perovskite solar cells with efficiencies exceeding 22\%. Sci. Adv. 2019, 5, eaaw2543. [CrossRef]

100. Alharbi, E.A.; Alyamani, A.Y.; Kubicki, D.J.; Uhl, A.R.; Walder, B.J.; Alanazi, A.Q.; Luo, J.; Burgos-Caminal, A.; Albadri, A.; Albrithen, H.; et al. Atomic-level passivation mechanism of ammonium salts enabling highly efficient perovskite solar cells. Nat. Commun. 2019. [CrossRef]

101. Takeoka, Y.; Asai, K.; Rikukawa, M.; Sanui, K. Hydrothermal Synthesis and Structure of Zero-dimensional Organic-inorganic Perovskites. Chem. Lett. 2005, 34, 602-603. [CrossRef]

102. Akkerman, Q.A.; Abdelhady, A.L.; Manna, L. Zero-Dimensional Cesium Lead Halides: History, Properties, and Challenges. J. Phys. Chem. Lett. 2018, 9, 2326-2337. [CrossRef] [PubMed]

103. Park, B.W.; Philippe, B.; Zhang, X.; Rensmo, H.; Boschloo, G.; Johansson, E.M.J. Bismuth Based Hybrid Perovskites $\mathrm{A}_{3} \mathrm{Bi}_{2} \mathrm{I}_{9}$ (A: Methylammonium or Cesium) for Solar Cell Application. Adv. Mater. 2015, 27, 6806-6813. [CrossRef] [PubMed] 
104. Qiu, X.; Jiang, Y.; Zhang, H.; Qiu, Z.; Yuan, S.; Wang, P.; Cao, B. Lead-free mesoscopic $\mathrm{Cs}_{2} \mathrm{SnI}_{6}$ perovskite solar cells using different nanostructured $\mathrm{ZnO}$ nanorods as electron transport layers. Phys. Status Solidi Rapid Res. Lett. 2016, 10, 587-591. [CrossRef]

105. Zhang, Z.; Li, X.; Xia, X.; Wang, Z.; Huang, Z.; Lei, B.; Gao, Y. High-Quality $\left(\mathrm{CH}_{3} \mathrm{NH}_{3}\right)_{3} \mathrm{Bi}_{2} \mathrm{I}_{9}$ Film-Based Solar Cells: Pushing Efficiency up to 1.64\%. J. Phys. Chem. Lett. 2017, 8, 4300-4307. [CrossRef] [PubMed]

106. Zhu, H.; Pan, M.; Johansson, M.B.; Johansson, E.M.J. High Photon-to-Current Conversion in Solar Cells Based on Light-Absorbing Silver Bismuth Iodide. ChemSusChem 2017, 10, 2592-2596. [CrossRef]

107. Vigneshwaran, M.; Ohta, T.; Iikubo, S.; Kapil, G.; Ripolles, T.S.; Ogomi, Y.; Ma, T.; Pandey, S.S.; Shen, Q.; Toyoda, T.; et al. Facile synthesis and characterization of sulfur doped low bandgap bismuth based perovskites by soluble precursor route. Chem. Mater. 2016, 28, 6436-6440. [CrossRef]

108. Kim, Y.; Yang, Z.; Jain, A.; Voznyy, O.; Kim, G.-H.; Liu, M.; Quan, L.N.; García de Arquer, F.P.; Comin, R.; Fan, J.Z.; et al. Pure Cubic-Phase Hybrid Iodobismuthates $\mathrm{AgBi}_{2} \mathrm{I}_{7}$ for Thin-Film Photovoltaics. Angew. Chem. 2016, 128, 9738-9742. [CrossRef]

109. Karuppuswamy, P.; Boopathi, K.M.; Mohapatra, A.; Chen, H.C.; Wong, K.T.; Wang, P.C.; Chu, C.W. Role of a hydrophobic scaffold in controlling the crystallization of methylammonium antimony iodide for efficient lead-free perovskite solar cells. Nano Energy 2018, 45, 330-336. [CrossRef]

110. Chatterjee, S.; Pal, A.J. Tin(IV) Substitution in $\left(\mathrm{CH}_{3} \mathrm{NH}_{3}\right)_{3} \mathrm{Sb}_{2} \mathrm{I}_{9}$ : Toward Low-Band-Gap Defect-Ordered Hybrid Perovskite Solar Cells. ACS Appl. Mater. Interfaces 2018, 10, acsami.8b12018. [CrossRef]

111. Correa-Baena, J.P.; Nienhaus, L.; Kurchin, R.C.; Shin, S.S.; Wieghold, S.; Putri Hartono, N.T.; Layurova, M.; Klein, N.D.; Poindexter, J.R.; Polizzotti, A.; et al. A-Site Cation in Inorganic $\mathrm{A}_{3} \mathrm{Sb}_{2} \mathrm{I}_{9}$ Perovskite Influences Structural Dimensionality, Exciton Binding Energy, and Solar Cell Performance. Chem. Mater. 2018, 30, 3734-3742. [CrossRef]

112. Ghosh, B.; Wu, B.; Mulmudi, H.K.; Guet, C.; Weber, K.; Sum, T.C.; Mhaisalkar, S.; Mathews, N. Limitations of $\mathrm{Cs}_{3} \mathrm{Bi}_{2} \mathrm{I}_{9}$ as Lead-Free Photovoltaic Absorber Materials. ACS Appl. Mater. Interfaces 2018, 10, 35000-35007. [CrossRef] [PubMed]

113. Ha, S.T.; Su, R.; Xing, J.; Zhang, Q.; Xiong, Q. Metal halide perovskite nanomaterials: Synthesis and applications. Chem. Sci. 2017, 8, 2522-2536. [CrossRef] [PubMed]

114. Swarnkar, A.; Marshall, A.R.; Sanehira, E.M.; Chernomordik, B.D.; Moore, D.T.; Christians, J.A.; Chakrabarti, T.; Luther, J.M. Quantum dot-induced phase stabilization of $\alpha-\mathrm{CsPb}_{3}$ perovskite for high-efficiency photovoltaics. Science 2016, 354, 92-95. [CrossRef] [PubMed]

115. Eperon, G.E.; Paternò, G.M.; Sutton, R.J.; Zampetti, A.; Haghighirad, A.A.; Cacialli, F.; Snaith, H.J. Inorganic caesium lead iodide perovskite solar cells. J. Mater. Chem. A 2015, 3, 19688-19695. [CrossRef]

116. Ling, X.; Zhou, S.; Yuan, J.; Shi, J.; Qian, Y.; Larson, B.W.; Zhao, Q.; Qin, C.; Li, F.; Shi, G.; et al. 14.1\% CsPbI3 Perovskite Quantum Dot Solar Cells via Cesium Cation Passivation. Adv. Energy Mater. 2019, 9, 1900721. [CrossRef]

117. Zhao, Q.; Hazarika, A.; Chen, X.; Harvey, S.P.; Larson, B.W.; Teeter, G.R.; Liu, J.; Song, T.; Xiao, C.; Shaw, L.; et al. High efficiency perovskite quantum dot solar cells with charge separating heterostructure. Nat. Commun. 2019, 10, 2842. [CrossRef]

118. Umar, F.; Zhang, J.; Jin, Z.; Muhammad, I.; Yang, X.; Deng, H.; Jahangeer, K.; Hu, Q.; Song, H.; Tang, J. Dimensionality Controlling of $\mathrm{Cs}_{3} \mathrm{Sb}_{2} \mathrm{I}_{9}$ for Efficient All-Inorganic Planar Thin Film Solar Cells by HCl-Assisted Solution Method. Adv. Opt. Mater. 2019, 7, 1801368. [CrossRef]

119. Singh, A.; Boopathi, K.M.; Mohapatra, A.; Chen, Y.F.; Li, G.; Chu, C.W. Photovoltaic Performance of Vapor-Assisted Solution-Processed Layer Polymorph of $\mathrm{Cs}_{3} \mathrm{Sb}_{2} \mathrm{I}_{9}$. ACS Appl. Mater. Interfaces 2018, 10, 2566-2573. [CrossRef]

120. Ma, C.; Shen, D.; Huang, B.; Li, X.; Chen, W.C.; Lo, M.F.; Wang, P.; Hon-Wah Lam, M.; Lu, Y.; Ma, B.; et al. High performance low-dimensional perovskite solar cells based on a one dimensional lead iodide perovskite. J. Mater. Chem. A 2019, 7, 8811-8817. [CrossRef]

121. Zhang, F.; Kim, D.H.; Lu, H.; Park, J.S.; Larson, B.W.; Hu, J.; Gao, L.; Xiao, C.; Reid, O.G.; Chen, X.; et al. Enhanced Charge Transport in 2D Perovskites via Fluorination of Organic Cation. J. Am. Chem. Soc. 2019, 141, 5972-5979. [CrossRef]

122. Cohen, B.E.; Li, Y.; Meng, Q.; Etgar, L. Dion-Jacobson Two-Dimensional Perovskite Solar Cells Based on Benzene Dimethanammonium Cation. Nano Lett. 2019, 19, 2588-2597. [CrossRef] [PubMed] 
123. Zheng, H.; Liu, G.; Zhu, L.; Ye, J.; Zhang, X.; Alsaedi, A.; Hayat, T.; Pan, X.; Dai, S. The Effect of Hydrophobicity of Ammonium Salts on Stability of Quasi-2D Perovskite Materials in Moist Condition. Adv. Energy Mater. 2018, 8. [CrossRef]

124. Liu, J.J.; Erogbogbo, F.; Yong, K.-T.; Ye, L.; Liu, J.J.; Hu, R.; Chen, H.; Hu, Y.; Yang, Y.; Yang, J.; et al. Assessing clinical prospects of silicon quantum dots: Studies in mice and monkeys. ACS Nano 2013, 7, 7303-7310. [CrossRef] [PubMed]

125. Mariotti, D.; Mitra, S.; Švrček, V.; Svrček, V. Surface-engineered silicon nanocrystals. Nanoscale 2013, 5, 1385. [CrossRef]

126. Dasog, M.; Bader, K.; Veinot, J.G.C. Influence of Halides on the Optical Properties of Silicon Quantum Dots. Chem. Mater. 2015, 27, 1153-1156. [CrossRef]

127. Ramos, E.; Monroy, B.M.; Alonso, J.C.; Sansores, L.E.; Salcedo, R.; Mart, A. Theoretical Study of the Electronic Properties of Silicon Nanocrystals Partially Passivated with Cl and F. J. Phys. Chem. C 2012, 36, 3988-3994. [CrossRef]

128. Ding, Y.; Sugaya, M.; Liu, Q.; Zhou, S.; Nozaki, T. Oxygen passivation of silicon nanocrystals: Influences on trap states, electron mobility, and hybrid solar cell performance. Nano Energy 2014, 10, 322-328. [CrossRef]

129. Liu, C.-Y.; Holman, Z.C.; Kortshagen, U.R. Hybrid solar cells from P3HT and silicon nanocrystals. Nano Lett. 2009, 9, 449-452. [CrossRef]

130. Nie, W.; Blancon, J.-C.; Neukirch, A.J.; Appavoo, K.; Tsai, H.; Chhowalla, M.; Alam, M.A.; Sfeir, M.Y.; Katan, C.; Even, J.; et al. Light-activated photocurrent degradation and self-healing in perovskite solar cells. Nat. Commun. 2016, 7, 11574. [CrossRef]

131. Rühle, S.; Anderson, A.Y.; Barad, H.N.; Kupfer, B.; Bouhadana, Y.; Rosh-Hodesh, E.; Zaban, A. All-oxide photovoltaics. J. Phys. Chem. Lett. 2012, 3, 3755-3764. [CrossRef]

132. Nechache, R.; Harnagea, C.; Li, S.; Cardenas, L.; Huang, W.; Chakrabartty, J.; Rosei, F. Bandgap tuning of multiferroic oxide solar cells. Nat. Photonics 2014, 9, 61-67. [CrossRef]

133. Fan, Z.; Sun, K.; Wang, J. Perovskites for photovoltaics: A combined review of organic-inorganic halide perovskites and ferroelectric oxide perovskites. J. Mater. Chem. A 2015, 3, 18809-18828. [CrossRef]

134. Lv, M.; Xie, Y.; Wang, Y.; Sun, X.; Wu, F.; Chen, H.; Wang, S.; Shen, C.; Chen, Z.; Ni, S.; et al. Bismuth and chromium co-doped strontium titanates and their photocatalytic properties under visible light irradiation. Phys. Chem. Chem. Phys. 2015, 17, 26320-26329. [CrossRef] [PubMed]

135. Xu, X.; Randorn, C.; Efstathiou, P.; Irvine, J.T.S. A red metallic oxide photocatalyst. Nat. Mater. 2012, 11, 595-598. [CrossRef] [PubMed]

136. Yashima, M.; Fumi, U.; Nakano, H.; Omoto, K.; Hester, J.R. Crystal Structure, Optical Properties, and Electronic Structure of Calcium Strontium Tungsten Oxynitrides $\mathrm{Ca}_{x} \mathrm{Sr}_{1-\mathrm{x}} \mathrm{WO}_{2}$ N. J. Phys. Chem. C 2013, 117, 18529-18539. [CrossRef]

137. Shi, J.; Ye, J.; Zhou, Z.; Li, M.; Guo, L. Hydrothermal Synthesis of $\mathrm{Na}_{0.5} \mathrm{La}_{0.5} \mathrm{TiO}_{3}-\mathrm{LaCrO}_{3}$ Solid-Solution Single-Crystal Nanocubes for Visible-Light-Driven Photocatalytic $\mathrm{H}_{2}$ Evolution. Chem. A Eur. J. 2011, 17, 7858-7867. [CrossRef]

138. Grinberg, I.; West, D.V.; Torres, M.; Gou, G.; Stein, D.M.; Wu, L.; Chen, G.; Gallo, E.M.; Akbashev, A.R.; Davies, P.K.; et al. Perovskite Oxides for Visible-Light-Absorbing Ferroelectric and Photovoltaic Materials. Nature 2013, 503, 509-512. [CrossRef]

139. Peña, M.A.; Fierro, J.L.G. Chemical Structures and Performance of Perovskite Oxides. Chem. Rev. 2001, 101, 1981-2018.

140. Sun, C.; Searles, D.J. Electronics, Vacancies, Optical Properties, and Band Engineering of Red Photocatalyst $\mathrm{SrNbO}_{3}$ : A Computational Investigation. J. Phys. Chem. C 2014, 118, 11267-11270. [CrossRef]

141. Kim, J.; Yin, X.; Tsao, K.C.; Fang, S.; Yang, H. Ca2Mn2O5 as Oxygen-Deficient Perovskite Electrocatalyst for Oxygen Evolution Reaction. J. Am. Chem. Soc. 2014, 136, 14646-14649. [CrossRef]

(C) 2019 by the authors. Licensee MDPI, Basel, Switzerland. This article is an open access article distributed under the terms and conditions of the Creative Commons Attribution (CC BY) license (http://creativecommons.org/licenses/by/4.0/). 


\title{
The Way to Pursue Truly High-Performance Perovskite Solar Cells
}

\author{
Jia-Ren Wu ${ }^{1,+}$, Diksha Thakur ${ }^{1,+}$, Shou-En Chiang ${ }^{1}$, Anjali Chandel ${ }^{1}$, Jyh-Shyang Wang ${ }^{1,2}$, \\ Kuan-Cheng Chiu ${ }^{1,2}$ and Sheng Hsiung Chang ${ }^{1,2, *}$ \\ 1 Department of Physics, Chung Yuan Christian University, Taoyuan 32023, Taiwan \\ 2 Center for Nano Technology, Chung Yuan Christian University, Taoyuan 32023, Taiwan \\ * Correspondence: shchang@cycu.edu.tw; Tel.: +886-3-265-3208 \\ + These authors contributed equally to this work.
}

Received: 16 August 2019; Accepted: 3 September 2019; Published: 5 September 2019

\begin{abstract}
The power conversion efficiency (PCE) of single-junction solar cells was theoretically predicted to be limited by the Shockley-Queisser limit due to the intrinsic potential loss of the photo-excited electrons in the light absorbing materials. Up to now, the optimized GaAs solar cell has the highest PCE of $29.1 \%$, which is close to the theoretical limit of $\sim 33 \%$. To pursue the perfect photovoltaic performance, it is necessary to extend the lifetimes of the photo-excited carriers (hot electrons and hot holes) and to collect the hot carriers without potential loss. Thanks to the long-lived hot carriers in perovskite crystal materials, it is possible to completely convert the photon energy to electrical power when the hot electrons and hot holes can freely transport in the quantized energy levels of the electron transport layer and hole transport layer, respectively. In order to achieve the ideal PCE, the interactions between photo-excited carriers and phonons in perovskite solar cells has to be completely understood.
\end{abstract}

Keywords: perovskite solar cells; hot-carrier characteristics; quantized electron transport layer; quantized hole transport layer

\section{Introduction}

The bounded electrons of inorganic and organic semiconductors can be efficiently and instantaneously excited from the ground state to the excited state when the photon energy of the incident lightwaves is higher than the absorption bandgap. However, the photo-excited electrons (hot electrons) in the light-absorbing materials (LAMs) have to relax to the meta-stable state (conduction band minimum (CBM) or lowest unoccupied molecular orbital (LUMO)) due to the ultrafast thermallization process [1-4], which results in the intrinsic potential loss and thereby limits the power conversion efficiency (PCE) of single-junction solar cells to be a moderate value of 33.7\% [5]. The physical concept of the Shockley-Queisser (S-Q) limit can be understood as the following descriptions. When then LAM has a large bandgap, the broadband sun light cannot be efficiently absorbed by the wide-bandgap material. Therefore, the photocurrent density of solar cells can be increased with a decrease in the absorption bandgap of the active layer. For example, the photocurrent density of single-crystalline Si solar cells $\left(\sim 42 \mathrm{~mA} / \mathrm{cm}^{2}\right)$ is always higher than that of single-crystalline GaAs solar cells $\left(\sim 29 \mathrm{~mA} / \mathrm{cm}^{2}\right)$ because the absorption bandgap of crystalline $\mathrm{Si}(1.1 \mathrm{eV})$ is lower than that of crystalline GaAs $(1.43 \mathrm{eV})$. When the active layer is a wide-bandgap material, the photo-excited electrons have to relax to the meta-stable state, which indicates that the highest potential difference between the cathode electrode and the anode electrode is equal to $E_{g} / e$. $E_{g}$ and $e$ are the absorption bandgap of the active layer and the electric charge, respectively. Usually, the potential difference between the cathode electrode and the anode electrode equals to the open-circuit voltage $\left(V_{O C}\right)$ which is defined by the current density-voltage $(\mathrm{J}-\mathrm{V})$ curve of solar cells. As we know that the $\mathrm{V}_{\mathrm{OC}}$ of a solar cell is proportional to the absorption bandgap of the active layer. For example, the $\mathrm{V}_{\mathrm{OC}}$ of single-crystalline 
Si solar cells $(\sim 0.738 \mathrm{~V})$ is lower than that of single-crystalline GaAs solar cells ( 1.127 V). According to the $\mathrm{S}-\mathrm{Q}$ limit, it is impossible to simultaneously obtain the high $\mathrm{V}_{\mathrm{OC}}$ and the high photocurrent density (short-circuit current density, JSC), which results in an optimal absorption bandgap of $1.34 \mathrm{eV}$ for the highest PCE of $33.7 \%$.

In the past several decades, physical and chemical scientists were trying to achieve the highest PCE of $33.7 \%$ by using the different types of solar cells. When the exciton binding energy of LAMs is lower than the thermal energy, the planar thin-film structure can be used to construct the high-performance solar cells, such as the crystalline Si [6,7], crystalline GaAs [8,9] and crystalline InP [10,11] solar cells. When the exciton binding energy of the LAMs is higher than the thermal energy, the P:N nanocomposite thin-film structures have to be used to increase the photovoltaic performance, such as the organic bulk-heterojunction solar cells [12-14] and dye-sensitized solar cells (DSSCs) [15-17]. Although the PCE of organic photovoltaics (OPVs) and DSSCs is significantly lower than that of the planar thin-film inorganic semiconductor-based solar cells, the cost-effective OPVs and DSSCs still received a lot of attentions in the past two decades. Thanks to the fundamental investigations on the OPVs and DSSCs, the PCE of perovskite solar cells has dramatically increased from 3.8\% [18] to 25.2\% [19] by using the solution-processed methods.

It is amazing that the high-efficiency perovskite solar cells can be realized by using the low-temperature solution-processed methods because the presence of high-density defects in the active layer [20-22] usually can simultaneously reduce the $\mathrm{V}_{\mathrm{OC}}, \mathrm{J}_{\mathrm{SC}}$ and fill factor (FF) of solar cells. It is well known that high-efficiency perovskite solar cells can be explained mainly due to the large absorption coefficient [23,24], moderate refractive index [25,26], low exciton binding energy [27,28], long exciton (carrier) lifetime [29,30] and long exciton (carrier) diffusion length [31,32]. In addition, the high PCE of perovskite solar cells also relieson the efficient energy transfer at the perovskite/electron transport layer (ETL) and perovskite/hole transport layer (HTL) interfaces. The highest PCE of perovskite solar cells is theoretically predicted to be an attractive value of 31\% [33], which is also limited by the prediction from the S-Q limit.

To pursue truly high-performance solar cells, it is necessary to reduce the intrinsic potential loss via increasing the hot-carrier lifetimes of LAMs. The hot-electron lifetimes of GaAs, Si and InP crystals are 1.5 ps [34], 0.18 ps [35] and 3.4 ns [36], respectively. In general, the lower phonon energy corresponds to the longer hot-electron lifetime [37,38]. The ultrashort hot-electron lifetimes mean that the photo-excited electrons must relax to the meta-stable state to form excitons. In recent reports, the lifetime for the hot electrons in perovskite crystals has been related to the +1 cation [39]. Furthermore, the hot-electron lifetime (diffusion length) of $\mathrm{MAPbI}_{3}$ thin films was determined to be longer than 20 ps (600 nm) by using transient absorbance spectroscopy [40]. The long-lived hot-carrier mediated light emission was also observed in formamidinium tin triiodide perovskites [41]. The existence of long-lived hot electrons means that it is possible to realize truly high-performance solar cells when crystalline perovskite thin films are used as the LAM.

In this review, we discuss the hot-carrier characteristics and the ways for hot-carrier extractions in the energy-space diagrams. A theoretical point of view is proposed in order to understand how the single-junction hot-carrier solar cells can be realized. Finally, the practical issues are discussed in order to assess the possibility for the realization of perovskite-based hot-carrier solar cells.

\section{Light-Materials' Interactions: Excited Bounded Electrons}

Photon energy can be efficiently converted to electrical power by using p-type materials due to the high absorption coefficient. Figure 1 shows the carrier dynamics of photo-excited electrons in an energy-space diagram. When the incident photons are absorbed by a p-type material, the electrons in the ground state can transit to the excited state to form hot carriers. The hot carriers can be viewed as the oscillating charged particles, which can coherently and incoherently collide with the lattice vibrations (photons). The coherent collisions between the hot carriers and phonons can result in Raman scattering emissions. The incoherent collisions between the hot carriers and photons can result 
in the photoluminescence (PL) emissions. In addition, the hot-carrier mediated PL emissions can be observed in the perovskite thin film due to the slow thermalization process [41].

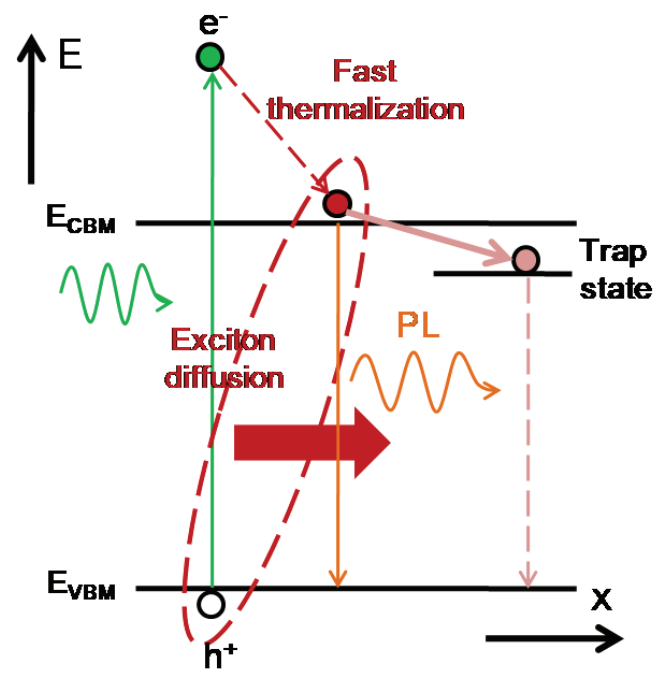

Figure 1. Photo-excited carrier dynamics in an energy-space diagram.

In general, the hot-carrier lifetime of organic LAMs is shorter than $100 \mathrm{fs}$. Therefore, it is not easy to observe the hot-carrier dynamics of organic materials by using the femtosecond time-resolved photoluminescence (FTR-PL) technique due to the limited instrument response function (IRF $\sim 150 \mathrm{fs}$ ) $[42,43]$. The ultrashort hot-carrier lifetime is mainly due to the large optical phonon energy of organic materials [44], which results in an extremely short hot-carrier diffusion length. It means that the hot carriers rapidly decay to the meta-stable state in organic materials via the thermalization (downhill relaxation) process [2,45]. Then, the electrons in the lowest unoccupied molecular orbital (LUMO) and the holes in the highest occupied molecular orbital (HOMO) are mutually attracted to form excitons. In conjugated small organic molecules, the exciton binding energy can be reduced by increasing the conjugation due to the delocalization effect [46]. In general, the exciton-binding energy of organic LAMs can be a wide range from $0.3 \mathrm{eV}$ to $1.0 \mathrm{eV}[47,48]$, which depends on the degree of delocalization of electron-hole pairs. This means that the larger exciton binding energy corresponds to the shorter (smaller) exciton radius (volume). From the concept of allowable excitation density, the smaller exciton volume results in the higher exciton generation rate (absorption coefficient). Due to the high density of excitons, the exciton diffusion length and exciton lifetime of organic materials can be lower than $1 \mathrm{~nm}$ and $1 \mathrm{~ns}$, respectively.

It can be predicted that the hot-carrier lifetime of inorganic materials [34-36] is longer than that of organic materials because the optical phonon energy of inorganic materials $[49,50]$ is lower. The optical phonon energy and hot-carrier lifetime of various materials are listed in Table 1 [34-38,49-53]. During the hot-carrier thermalization process in a polar semiconductor as shown in Figure 2, the energy of the hot carriers has to be firstly transferred to the longitudinal optical (LO) phonons. Then, the transition from the LO phonons to acoustic phonons results in the lattice heating. With the propagation of acoustic phonons, the thermal energy can transfer to the surroundings. This means that there are three ways that can be used to slow down the hot-carrier thermalization process. The energy transfer rate from hot carriers to LO phonons is intrinsic fast in non-polar materials [54,55], such as $\mathrm{Si}$ and $\mathrm{Ge}$. In a polar $\mathrm{CH}_{3} \mathrm{NH}_{3} \mathrm{PbI}_{3}$ $\left(\mathrm{MAPbI}_{3}\right)$ crystal thin film, the energy transfer rate from hot carriers to LO phonons can be delayed due to the formation of hot polarons [55], which results in a long hot-carrier cooling time. As we know that hot polarons are quasiparticles, which describes the interaction between the hot carriers and polar lattices. 
Therefore, the formation of hot polarons can delay the transfer rate from hot carriers to LO phonons. This was firstly explained due to a phonon bottleneck effect [56]. In addition, the propagation of acoustic phonons in perovskite crystals is theoretically predicted to be slow due to the use the insulating organic cation [57], which also can generate the up-conversion of acoustic phonons to re-heat the hot carriers and thereby increases the hot-carrier lifetime [53]. Up to now, the methods to delay the energy transition from LO phonons to acoustic phonons have not yet been proposed for increasing the hot-carrier lifetime in polar perovskite crystals.

Table 1. Optical phonon energies ( $\left.E_{\text {Phonon }}\right)$ and hot-carrier lifetimes $\left(\tau_{\mathrm{hc}}\right)$ of various inorganic materials and organic materials. TPA-TTAR-A: triphenylamine-tetrathienoacene-acceptor.

\begin{tabular}{cccccccc}
\hline Materials & GaAs & $\mathbf{S i}$ & InP & P3HT & TPA-TTAR-A & $\mathbf{C H}_{\mathbf{3}} \mathbf{N H}_{\mathbf{3}} \mathbf{P b I}_{\mathbf{3}}$ & $\mathbf{H C}\left(\mathbf{N H}_{\mathbf{2}} \mathbf{2}_{\mathbf{2}} \mathbf{P b I}_{\mathbf{3}}\right.$ \\
\hline$E_{\text {Phonon }}(\mathrm{meV})$ & 40 & 60 & 42 & None & None & 25 & 11.5 \\
$\tau_{\text {hc }}(\mathrm{ps})$ & 1.5 & 0.18 & 3400 & $<0.1$ & 1.01 & 20 & 124 \\
Ref. & {$[34]$} & {$[35,36]$} & {$[37,38]$} & {$[49]$} & {$[50]$} & {$[40,51]$} & {$[52,53]$} \\
\hline
\end{tabular}

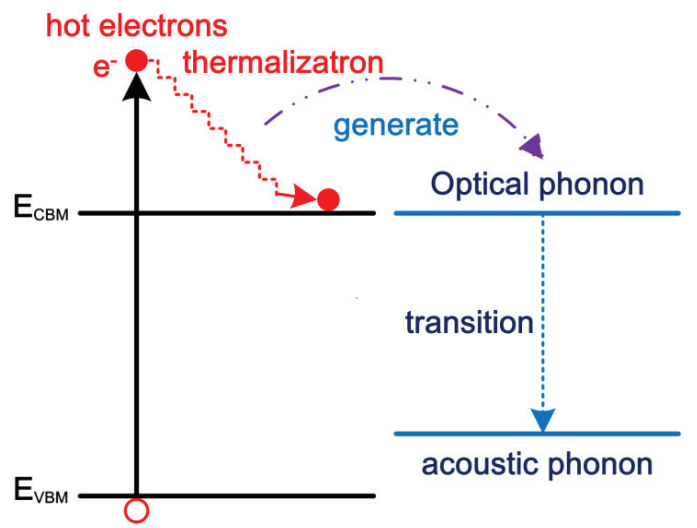

Figure 2. Hot carrier-optical phonon energy transfer and thermalization process.

\section{Hot-Carrier Extraction at a Light-Absorbing Material/Electron Transport Layer (LAM/ETL) Interface}

The hot-electron injection from organic fused thiophene-based dyes to $\mathrm{TiO}_{2}$ nanoparticles (NPs) was investigated for the first time by using a FTR-PL technique [58], which was used to explain the abnormal high $\mathrm{V}_{\mathrm{OC}}$ of $0.93 \mathrm{~V}$ in DSSCs with an iodide/triliodide based electrolyte [50]. The dyes can be adsorbed on the surface of $\mathrm{TiO}_{2}$ NPs due to the electrical attraction between the anchoring group of dyes and the oxygen defect of $\mathrm{TiO}_{2} \mathrm{NPs}$. Therefore, it can be understood that the high $\mathrm{V}_{\mathrm{OC}}$ is due to the hot-electron injection from the dyes to the higher quantized energy levels of the $\mathrm{TiO}_{2} \mathrm{NPs}_{\text {, }}$ as shown in Figure 3. In this study, the average diameter of the $\mathrm{TiO}_{2} \mathrm{NPs}$ is about $10 \mathrm{~nm}$ [59], which is about 3 times of the exciton radius. Therefore, it can be predicted that the quantized energy levels can be created in the $\mathrm{TiO}_{2}$ quantum dots (QDs) [60]. 


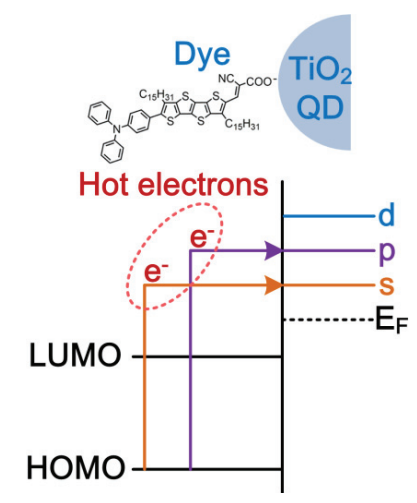

Figure 3. Hot-electron injection from dyes to the quantized energy levels of $\mathrm{TiO}_{2}$ quantum dots (QDs).

The efficient hot-electron extraction in OPVs has not yet been reported in literature, which is probably due to the fact that the diffusion process is needed for the hot carriers to reach the region of charge transfer radius [61,62]. For example, the hot electrons in poly(3-hexylthiophene-2,5,-diyl) (P3HT) polymers is rapidly decayed from the excited state to the LUMO energy level due to the ultrafast self-localization process ( $100 \mathrm{fs}$ ) [2,43], which suppresses the hot-electron diffusion. This means that it is possible to realize organic hot-carrier photovoltaics when the ultrafast self-localization process can be reduced by increasing the delocalization quantum-assisted transport within long polymer chains [46].

The efficient hot-electron extraction in perovskite solar cells has not yet been discussed in literature. However, the abnormal high $\mathrm{V}_{\mathrm{OC}}(=1.61 \mathrm{~V})$ of inverted-type $\mathrm{MAPbBr}_{3}$ based solar cells is probably due to the efficient hot-electron extraction from the $\mathrm{MAPbBr}_{3}$ nano-crystals to the indene- $\mathrm{C}_{60}$-bisadduct (ICBA) ETL [63]. In this study, the poly(3,4-ethylenedioxythiophene):polystyrene sulfonate (PEDOT:PSS $(1: 6 \mathrm{wt} \%))$ thin film and ICBA thin film are used as the HTL and ETL, respectively. The Fermi level of PEDOT:PSS thin film and the LUMO energy level of ICBA thin film are $-5.1 \mathrm{eV}[64,65]$ and $-3.9 \mathrm{eV}[66,67]$, respectively, which results in a S.-Q limited $\mathrm{V}_{\mathrm{OC}}$ of $1.2 \mathrm{eV}$. The high $\mathrm{V}_{\mathrm{OC}}$ of $\mathrm{MAPbBr}_{3}$ based solar cells means that the hot electrons have to be extracted by the LUMO+1 and/or LUMO+2 of the ICBA thin film because the PEDOT:PSS thin film is a metal-like conductive polymer [68]. The photovoltaic performances of high-V $\mathrm{V}_{\text {OC }}$ perovskite based solar cells are listed in Table $2[63,69,70]$. The three types of perovskite solar cells both contain bromide elements in the active layer, which suggests that the bromide-based perovskite thin films probably have longer hot-carrier lifetimes. In addition, the long hot-carrier lifetime and diffusion length were observed in a $\mathrm{MAPbI}_{3}$ perovskite thin film by using transient absorbance spectroscopy [40], which means that the realization of high-performance hot-carrier perovskite solar cells is possible.

Table 2. Photovoltaic performance of bromide-based perovskite solar cells.

\begin{tabular}{cccc}
\hline Active Layer & MAPbBr $_{3}$ & $\mathbf{C s P b I}_{\mathbf{2}} \mathbf{B r}$ & $\mathbf{C s P b}_{\mathbf{0 . 9}} \mathbf{T b}_{\mathbf{0 . 0 3}} \mathbf{B r}_{\mathbf{3}}$ \\
\hline ETL/LUMO & $\mathrm{ICBA} /-3.9 \mathrm{eV}$ & $\mathrm{TiO}_{2} /-4.1 \mathrm{eV}$ & $\mathrm{TiO}_{2} /-4.1 \mathrm{eV}$ \\
$\mathrm{HTL} / \mathrm{E}_{\mathrm{F}}$ or HOMO & PEDOT:PSS/-5.1 eV & Spiro-OMe TAD/-5.2 eV & $\mathrm{NiO}_{\mathbf{x}} /-5.1 \mathrm{eV}$ \\
$\mathrm{V}_{\mathrm{OC}}(\mathrm{V})$ & 1.61 & $\sim 1.3$ & 1.57 \\
$\mathrm{~J}_{\mathrm{SC}}\left(\mathrm{mA} / \mathrm{cm}^{2}\right)$ & 6.04 & $\sim 12$ & 8.21 \\
$\mathrm{FF}(\%)$ & 77.0 & $\sim 74$ & 79.6 \\
Ref. & {$[63]$} & {$[69]$} & {$[70]$} \\
\hline
\end{tabular}

\section{Hot-Carrier Extraction at a LAM/Hole Transport Layer (HTL) Interface}

As we know that the bounded electrons are not excited from the valence band maximum ( $\left.\mathrm{E}_{\mathrm{VBM}}\right)$ when the photon energy of the incident lightwaves is higher than the absorption bandgap of materials. 
Therefore, the hot-hole relaxation process has to be considered in order to realize the hot-carrier solar cells. Figure 4 shows the hot-hole and hot-electron dynamics in the energy diagram. For example, the hot-hole and hot-electron relaxation times of a $\mathrm{MAPbI}_{3}$ thin film are 100-500 fs and 1-5 ps [71], respectively, which means that it is more difficult to collect the hot holes in perovskite thin films by using a hot-hole selective layer due to the sub-picosecond relaxation time. Fortunately, there is experimental evidence of transient absorbance spectra to show that the hot holes in a $\mathrm{CsPl}_{3}$ thin film can be efficiently extracted by the capping layer of P3HT thin film within a few $100 \mathrm{fs}$ [72]. However, the hot-hole extraction process from the perovskite thin film to the P3HT thin film is not yet completely understood. Further experiments are needed to demonstrate that the hot-hole extraction can increase the $\mathrm{V}_{\mathrm{OC}}$ of perovskite solar cells.

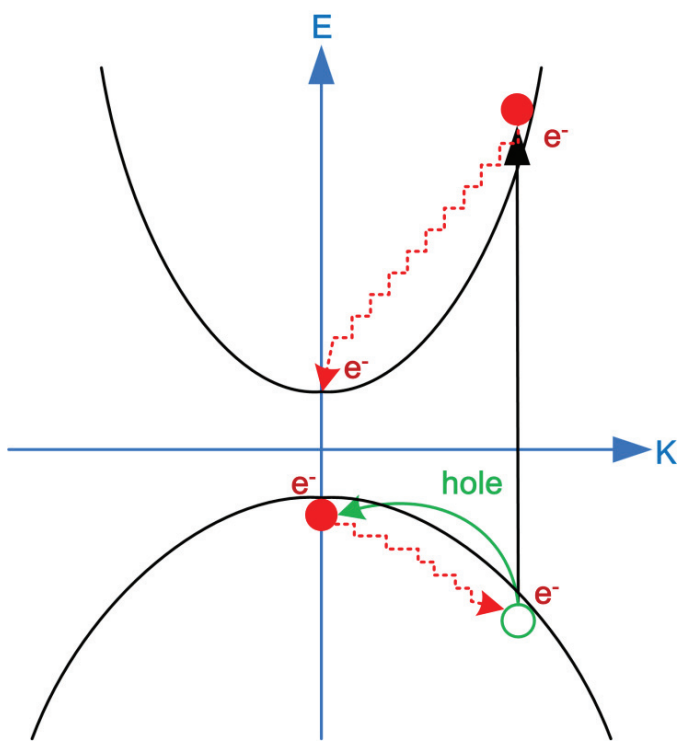

Figure 4. Energy diagram of hot-hole and hot-electron relaxations.

The extraction efficiency of hot holes is also related to the carrier diffusion coefficient of perovskite thin films because the hot holes have to diffuse into the region of the charge transfer radius at the perovskite/HTL interface. According to the Einstein relation $\left(D=\mu k_{B} T / e\right)$, the carrier diffusion coefficient $(D)$ is proportional to the carrier mobility $(\mu)$, where $k_{B} T$ is the thermal energy and $e$ is the electric charge. The carrier drift equation $\left(\mu=e \tau / m^{*}\right)$ shows that the carrier mobility is proportional (inversely proportional) to the carrier relaxation time (effective mass), where $\tau$ and $m^{*}$ are the carrier relaxation time and carrier effective mass, respectively. Therefore, the smaller hot-hole effective mass corresponds to the longer hot-hole diffusion length and thereby results in the higher extraction efficiency of hot holes. Interestingly, the hole mobility can be higher than the electron mobility when the LAM is $\mathrm{CsPbBr}_{3}$ or $\mathrm{CsPbCl}_{3}$, which is due to the lower hole effective mass [73]. However, the propagation characteristics of hot holes are not yet completely understood.

\section{Theoretical Point of View}

The highest PCE of single-junction hot-carrier solar cells was theoretically predicted to be $66 \%$ under one sun illumination [74]. Figure 5a shows the energy diagram of a single-junction hot-carrier solar cell. In the single-junction solar cell, the high-energy and low-energy incident photons are absorbed by the electrons in the deeper levels and in the shallower levels of the valence band, respectively. When the electrons in the valence band are excited to the conduction band, the hot 
electrons in the higher energy levels and in the lower energy levels both have to be directly extracted in order to avoid ultrafast potential loss. As to the hot holes, they also have to be directly extracted in order to keep the original potential.

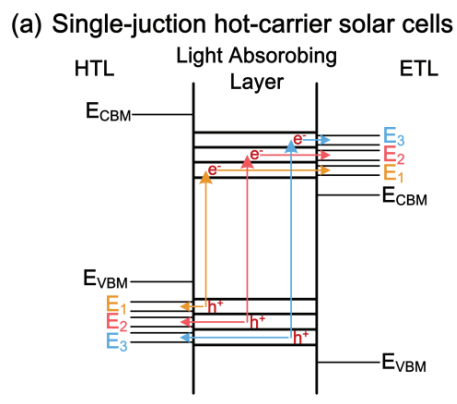

(b) Tanden (multi-junction) solar cells

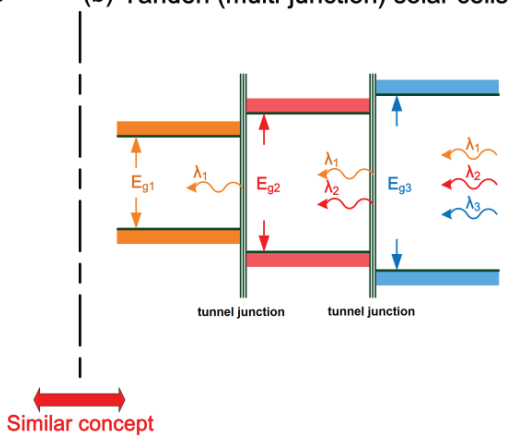

Figure 5. Energy diagrams. (a) Single-junction hot-carrier solar cell. (b) Tandem solar cell.

The concept of single-junction hot-carrier solar cells is similar to the tandem (multi-junction) solar cells which has a highly theoretical PCE of $68 \%$ under one sun illumination [75]. Up to now, the highest PCE of tandem solar cells is $39.2 \%$ under one sun illumination, which is significantly higher than the highest PCE (29.1\%) of single-junction GaAs solar cells [19]. When the different absorption ranges in a single LAM are viewed as the individual materials with the different absorption bandgaps, the energy diagram of a tandem solar cell can be plotted in Figure 5b. The PCE of tandem solar cells is strongly related to the performance of the tunnel junctions [76] with an ultrafast carrier dynamic [77]. In single-junction hot-carrier solar cells, the double-barrier resonant tunneling structure was proposed as the energy selective contact of hot carrier solar cells [78] due to the sub-picosecond carrier extraction ability [79]. Therefore, it can be believed that the highly efficient single-junction hot-carrier solar cells can be realized when the ultrafast carrier lifetimes of hot carriers in the LAM can be increased from the sub-picosecond time scale to sub-nanosecond time scale.

In order to efficiently collect the hot carriers at the different energy levels, a multi-band ETL and a multi-band HTL have to be used to extract the dispersive hot carriers under a broadband excitation. $\mathrm{T} 5$ ashows the energy diagram of an ideal hot-carrier solar cell. The $\mathrm{E}_{\mathrm{CBM}}$ of HTL (EVBM of ETL) has to be higher (lower) than the $\mathrm{E}_{3}$ in the conduction band of ETL ( $\mathrm{E}_{3}$ in the valence band of HTL) in order to block the hot electrons (hot holes), which can help the collection of hot carriers. If the high-energy hot carriers can be efficiently collected by the $\mathrm{E}_{3}$, the hot electrons (hot holes) have to freely transport within the $E_{3}$ of ETL (HTL) without the energy transitions from the $E_{3}$ to the $E_{2}$ and/or $E_{1}$. Fortunately, the photo-excited carriers can be collected and transport in the quantized energy levels of Si-doped quantum dots, which increases the $\mathrm{V}_{\mathrm{OC}}$ from $0.78 \mathrm{~V}$ to $0.91 \mathrm{~V}$ [80]. Therefore, it can be expected that the hot electrons and hot holes can freely transport in the quantized energy levels of ETL and HTL, respectively. In addition, n-type graphene quantum dots [81-83] and p-type graphene quantum dots [84-86] might have the potential as the multi-band ETL and multi-band HTL of hot-carrier solar cells, respectively.

In addition, a theoretical approach is used to calculate the J-V curves of single-junction solar cells when the selective contacts are used to collect the hot carriers [87]. Their simulation results show that the $e \times \mathrm{V}_{\mathrm{OC}}$ of hot-carrier solar cells can larger than the absorption bandgap of LAMs. For example, $e \times V_{\mathrm{OC}}$ of the GaAs solar cell is $1.85 \mathrm{eV}$ which is larger than the absorption bandgap of crystalline GaAs. 


\section{Experimental Challenges and Opportunities}

Up to now, the LAMs of highly efficient perovskite solar cells were fabricated by using solution-processed methods [26,28,88-91], which means that the defect density of LAMs remains high. Although the shallow defects of perovskite thin films do not significantly influence the photovoltaic performance [92,93], the formation of defects can increase the exciton binding energy and optical phonon energy of perovskite thin films [51,94]. Therefore, the defect-mediated phononic properties of perovskite thin films have to be investigated in order to understand how to realize hot-carrier solar cells.

The grain size of solution-processed perovskite thin films can be increased from several hundred nanometers to several micrometers by adding the small molecules [95] or with the solvent annealing process [96]. The average crystal domain size of perovskite thin films is smaller than averaged grain size, which indicates that the perovskite thin films are composed of multi-crystalline grains [97]. It means that the residual stress in a multi-crystalline perovskite thin film [98] can also influence the phononic properties, which might dominate the hot-carrier characteristics. In other words, the defect-mediated phononic properties [99] and/or crystal distortion-mediated phononic properties [100] have to be considered when the perovskite thin films are fabricated on top of amorphous substrates or poly-crystalline substrates by using solution processes or thermal evaporation methods. However, the preferred oriented perovskite thin films can be fabricated on top of the single-crystalline substrates by using the spin-coating method [101], which was observed by measuring the two-dimensional X-ray diffraction patterns.

Conceptually, the existences of defects and lattice distortions should decrease the hot-carrier lifetimes in the LAMs, which are predicted to impede the development of hot-carrier solar cells. Therefore, the development of single-crystalline perovskite bulks plays an important step for the realization of high-performance optoelectronic devices. Two years ago, the single-crystalline perovskites were grown on top of various substrates, such as indium tin oxide (ITO), quartz and silicon wafer, which were used as the X-ray detector [102]. The strategy is to modify the surface of the substrates with a $\mathrm{NH}_{3}$-Br-teminated self-assembling molecules monolayer, which provides a seeding layer to grow the single-crystalline $\mathrm{MAPbBr}_{3}$. The long carrier lifetime of the single-crystalline $\mathrm{MAPbBr}_{3}$ is $692 \mathrm{~ns}$, which indicates the low defect density. Therefore, the hot-carrier lifetimes of single-crystalline perovskites can be expected to be longer than that of poly-crystalline perovskite thin films.

When the substrate $\left(\mathrm{Au} / \mathrm{p}^{+}\right.$-type wafer) is the anode side, the single-crystalline perovskite has to be grown on top of a quantized HTL. Then, a quantized ETL has to be fabricated on top of the single-crystalline perovskite. A transparent conductive oxide has to be deposited on top of the device as the cathode electrode. Therefore, it can be imagined that the device architecture is $\mathrm{Au} / \mathrm{p}^{+}$-type wafer/quantized $\mathrm{HTL} /$ single-crystalline perovskite/quantized ETL/transparent conductive cathode. The $\mathrm{p}^{+}$-type wafer has to be a large-bandgap material in order to block the hot electrons from the single-crystalline perovskite. The quantized HTL and the quantized ETL can be a p-type quantum well (QW) structure [103] and a double-barrier resonant-tunneling structure [78], respectively. In addition, the transparent conductive cathode is used to block the hot holes from the single-crystalline perovskite. The potential candidates as the $\mathrm{p}^{+}$-type substrate, HTL, ETL and transparent conductive anode are listed in Table 3. The Au coated $\mathrm{p}^{+}$-type GaN, AlN or SiC wafer can be used as the anode electrode. The epitaxial growth process of GaN/AlN QW [104] or AlGaN QDs [105] on top of the GaN or AlN wafer is a mature technique by using metal organic chemical-vapor deposition (MOCVD) or molecular beam epitaxy (MBE). However, the barrier high and physical size of the QW or QDs has to be investigated and designed in order to be used as the quantized HTL for the collection of hot holes. P-type graphene QDs can be produced by using microwave-assisted heating method [106] or pulsed laser ablation method [107]. And, the p-type graphene QDs thin film can be deposited on top of the $\mathrm{p}^{+}$-type wafer by using the spin-coating method. Although, the single-crystalline $\mathrm{MAPbBr}_{3}$ has been demonstrated that can be grown on various substrates with a surface modification method [102]. The contact at the $\mathrm{MAPbI}_{3} / \mathrm{HTL}$ interface, which should strongly influence the collection efficiency 
of hot holes, has not yet investigated. It is predicted that the $[6,6]$-phenyl- $\mathrm{C}_{61}$-butyric acid methyl ester (PCBM)/bathocuproine (BCP) QW, ZnO QDs [108] or $\mathrm{TiO}_{2}$ QDs [109] can be used to collect the hot electrons from the single-crystalline perovskite. PCBM molecules can be dissolved in low-polarity solvents, such as chlorobenzene and toluene, which can be directly spin-coated on top of $\mathrm{MAPbI}_{3}$ thin films. BCP molecules, $\mathrm{ZnO}$ QDs and $\mathrm{TiO}_{2}$ QDs are usually dissolved in isopropanol (IPA) which is a polar solvent. Therefore, the $\mathrm{BCP}, \mathrm{ZnO}$ QDs or $\mathrm{TiO}_{2}$ QDs thin film cannot be directly spin-coated on top of $\mathrm{MAPbI}_{3}$ thin films. The contact at the hydrophobic ETL/hydrophilic $\mathrm{MAPbI}_{3}$ interface can be improved by slightly roughening the surface of $\mathrm{MAPbI}_{3}$ thin film [91]. Then, the Al-doped $\mathrm{ZnO}$, Ga-doped $\mathrm{ZnO}$ or Al-Ga co-doped $\mathrm{ZnO}$ thin film can be used as the transparent conductive cathode because of the metal-like electrical conductivity which can directly collect the hot electrons without the additional potential loss. However, the high-quality transparent conductive cathodes are usually deposited by using the radio-frequency magnetron sputtering method, which can damage the $\mathrm{MAPbI}_{3}$ thin film due to the excessive energy bombardment during the deposition process [110]. To resist the excessive energy bombardment, an inorganic thin film has to be used as the buffer layer in between the $\mathrm{MAPbI}_{3}$ thin film and transparent conductive cathode [110].

Table 3. Potential candidates as the $\mathrm{p}^{+}$-type substrate, hole transport layer (HTL), electron transport layer (ETL) and transparent conductive anode.

\begin{tabular}{cccc}
\hline $\mathbf{p}^{+}$-Type Substrate & HTL & ETL & Transparent Conductive Cathode \\
\hline GaN & GaN/AlGaN QW & PCBM/BCP QW & Al-doped ZnO \\
$\mathrm{AlN}$ & AlGaN QDs & ZnO QDs & Ga-doped ZnO \\
$\mathrm{SiC}$ & p-type graphene QDs & $\mathrm{TiO}_{2}$ QDs & Al-Ga co-doped ZnO \\
\hline
\end{tabular}

The realization of hot-carrier solar cells has to rely on the long-lived hot carriers in the active layer and the efficient collections of hot carriers by the HTL and ETL. The hot-carrier lifetime and hot-carrier diffusion length of crystalline perovskite thin films can be longer than 100 ps and $600 \mathrm{~nm}$, respectively, which indicates that the hot carriers are possibly collected without potential loss. However, the hot carriers have to be rapidly collected before the ultrafast thermalization process, which means that the collection times of hot carriers have to be faster than the hot-carrier lifetimes. For example, the hot-carrier lifetime of the LAM and the hot-carrier collection time of a double-barrier resonant tunneling structure can be 100 ps and $0.4 \mathrm{ps}$, respectively. Furthermore, the hot-carrier collection efficiency can be calculated by $h=1 / t_{1} /\left(1 / t_{1}+1 / t_{2}\right)$ [58], where $t_{1}$ and $t_{2}$ are hot-carrier collection time and hot-carrier lifetime, respectively. Therefore, the calculated hot-carrier collection efficiency equals to $99.6 \%$, which means that it is worthwhile to develop a double-barrier resonant tunneling structure as the selective contact of hot-carrier perovskite solar cells. In this review, we suggest that the quantized HTL and quantized ETL can be used to collect the dispersive hot holes and hot electrons, respectively. The collection times of hot carriers will dominate the collection efficiency. Therefore, the barrier height and physical size of the quantized HTL and quantized ETL has to be varied in order to decrease the collection times of hot carriers. Conceptually, the collection times of hot carriers are also influenced by the crystallinity (carrier mobility) of the HTL and ETL. Therefore, the formation of high-quality quantized HTL, quantized ETL and perovskite thin film is necessary in order to realize hot-carrier solar cells.

\section{Conclusions}

Recent progress in the understanding of the light-perovskite interactions shows that the realization of highly efficient hot-carrier solar cells is possible because the long-lived hot polarons can be formed and thereby delays the thermalization process. Conceptually, the extraction of hot electrons and hot holes can increase the open-circuit voltage $\left(\mathrm{V}_{\mathrm{OC}}\right)$. The hot-electron injection was firstly observed in the dye-sensitized solar cells, which significantly increased the $\mathrm{V}_{\mathrm{OC}}$ from $0.75 \mathrm{~V}$ to $0.93 \mathrm{~V}$. 
The long-lived hot electrons in the organic fused thiophene-based dyes were observed by using the femtosecond time-resolved photoluminescence technique.

The highest $\mathrm{V}_{\mathrm{OC}}$ of $\mathrm{CH}_{3} \mathrm{NH}_{3} \mathrm{PbBr}_{3}$ solar cells is $1.61 \mathrm{~V}$, which is far larger than the potential difference $(1.2 \mathrm{~V})$ between the LUMO energy level of the electron transport layer (ICBA thin film) and the Fermi level of the hole transport layer (PEDOT:PSS thin film). The abnormal high $\mathrm{V}_{\mathrm{OC}}$ of perovskite solar cells can be explained due to the efficient collection of hot electrons by the LUMO+1 and/or LUMO+2 of the ICBA thin film. In addition, the P3HT polymer thin film was used as the hot-hole selective contact layer, which was observed by using the femtosecond transient absorbance spectra.

To realize truly high-performance hot-carrier perovskite solar cells, it is necessary to simultaneously collect the hot electrons and hot holes without the additional potential loss. We have proposed a device architecture which might be used to achieve the desired power conversion efficiency. The device architecture is $\mathrm{Au} / \mathrm{p}^{+}$-type GaN wafer/quantized hole transport layer (QHTL)/crystalline perovskite/quantized electron transport layer (QETL)/transparent conductive cathode. Ideally, the hot holes and hot electrons in the crystalline perovskite have to be collected by the QHTL and QETL, respectively. Therefore, it is necessaryto investigate the ultrafast energy transfer dynamics of hot carriers from the crystalline perovskite to the QHTL and QETL by varying the barrier high and physical size of the quantum wells or quantum dots.

Author Contributions: Conceptualization was made by S.H.C., J.-S.W. and K.-C.C. References were collected by J.-R.W., D.T., S.-E.C. and A.C. Draft preparation was made by J.-R.W. and D.T. Writing-Review and Editing was made by S.H.C.

Funding: This research was funded by Ministry of Science and Technology, Taiwan. Grant number is MOST 107-2112-M-033-001-MY3.

Conflicts of Interest: The authors declare no conflict of interest.

\section{References}

1. Katayama, K.; Inagaki, Y.; Sawada, T. Ultrafast two-step thermalization processes of photoexcited electrons at a gold surface: Application of a wavelength-selective transient reflecting grating method. Phys. Rev. B 2000, 61, 7332-7335. [CrossRef]

2. Xie, Y.; Li, Y.; Xiao, L.; Qiao, Q.; Dhakal, R.; Zhang, Z.; Gong, Q.; Galipeau, D.; Yan, X. Femtosecond Time-Resolved Fluorescence Study of P3HT/PCBM Blend Films. J. Phys. Chem. C 2010, 114, 14590-14600. [CrossRef]

3. Bräm, O.; Cannizzo, A.; Chergui, M. Ultrafast fluorescence studies of dye sensitized solar cells. Phys. Chem. Chem. Phys. 2012, 14, 7934-7937. [CrossRef] [PubMed]

4. Kirton, P.; Keeling, J. Thermalization and breakdown of thermalization in photon condensates. Phys. Rev. A 2015, 91, 033826. [CrossRef]

5. Shockley, W.; Queisser, H.J. Detailed Balance Limit of Efficiency of p-n Junction Solar Cells. J. Appl. Phys. 1961, 32, 510-519. [CrossRef]

6. Blakers, A.; Zin, N.; McIntosh, K.R.; Fong, K. High Efficiency Silicon Solar Cells. Energy Procedia 2013, 33, 1-10. [CrossRef]

7. De Wolf, S.; Cuevas, A.; Battaglia, C. High-efficiency crystalline silicon solar cells: Status and perspectives. Energy Environ. Sci. 2016, 9, 1552-1576.

8. Moon, S.; Kim, K.; Kim, Y.; Heo, J.; Lee, J. Highly efficient single-junction GaAs thin-film solar cell on flexible substrate. Sci. Rep. 2016, 6, 30107. [CrossRef]

9. Liang, D.; Kang, Y.; Huo, Y.; Chen, Y.; Cui, Y.; Harris, J.S. High-Efficiency Nanostructured Window GaAs Solar Cells. Nano Lett. 2013, 13, 4850-4856. [CrossRef] [PubMed]

10. Yamamoto, A.; Yamaguchi, M.; Uemura, C. High efficiency homojunction InP solar cells. Appl. Phys. Lett. 1985, 47, 975-977. [CrossRef]

11. Yin, X.; Battaglia, C.; Lin, Y.; Chen, K.; Hettick, M.; Zheng, M.; Chen, C.-Y.; Kiriya, D.; Javey, A. 19.2\% Efficient InP Heterojunction Solar Cell with Electron-Selective $\mathrm{TiO}_{2}$ Contact. ACS Photon. 2014, 1, 1245-1250. [CrossRef] [PubMed] 
12. He, Y.; Chen, H.-Y.; Hou, J.; Li, Y. Indene-C60Bisadduct: A New Acceptor for High-Performance Polymer Solar Cells. J. Am. Chem. Soc. 2010, 132, 1377-1382. [CrossRef] [PubMed]

13. Guo, X.; Cui, C.; Zhang, M.; Huo, L.; Huang, Y.; Hou, J.; Li, Y. High efficiency polymer solar cells based on poly(3-hexylthiophene)/indene-C70 bisadduct with solvent additive. Energy Environ. Sci. 2012, 5, 7943-7949. [CrossRef]

14. Zhang, H.; Yao, H.; Hou, J.; Zhu, J.; Zhang, J.; Li, W.; Yu, R.; Gao, B.; Zhang, S.; Hou, J. Over 14\% Efficiency in Organic Solar Cells Enabled by Chlorinated Nonfullerene Small-Molecule Acceptors. Adv. Mater. 2018, 30, 1800613. [CrossRef] [PubMed]

15. Roy, P.; Kim, D.; Lee, K.; Spiecker, F.; Schmuki, P. $\mathrm{TiO}_{2}$ nanotubes and their application in dye-senstized solar cells. Nanoscale 2010, 2, 45-49. [CrossRef] [PubMed]

16. Liao, J.-Y.; He, J.-W.; Xu, H.; Kuang, D.-B.; Su, C.-Y. Effect of $\mathrm{TiO}_{2}$ morphology on photovoltaic performance of dye-sensitized solar cells: Nanoparticles, nanofibers, hierarchical spheres and ellipsoid spheres. J. Mater. Chem. 2012, 22, 7910-7918. [CrossRef]

17. Fan, Y.-H.; Ho, C.-Y.; Chang, Y.-J. Enhancement of Dye-Sensitized Solar Cells Efficiency Using Mixed-Phase $\mathrm{TiO}_{2}$ Nanoparticles as Photoanode. Scanning 2017, 2017, 9152973. [CrossRef]

18. Kojima, A.; Teshima, K.; Shirai, Y.; Miyasaka, T. Organometal Halide Perovskites as Visible-Light Sensitizers for Photovoltaic Cells. J. Am. Chem. Soc. 2009, 131, 6050-6051. [CrossRef] [PubMed]

19. NREL Efficiency Chart. This Plot is Courtesy of the National Renewable Energy Laboratory, Golden. Available online: https://www.nrel.gov/pv/assets/pdfs/best-reserch-cell-efficiencies.20190802.pdf (accessed on 5 August 2019).

20. Bi, C.; Shao, Y.; Yuan, Y.; Xiao, Z.; Wang, C.; Gao, Y.; Huang, J. Understanding the formation and evolution of interdiffusion grown organolead halide perovskite thin films by thermal annealing. J. Mater. Chem. A 2014, 2, 18508-18514. [CrossRef]

21. Barker, A.J.; Sadhanala, A.; Deschler, F.; Gandini, M.; Senanayak, S.P.; Pearce, P.M.; Mosconi, E.; Pearson, A.J.; Wu, Y.; Kandada, A.R.S.; et al. Defect-Assisted Photoinduced Halide Segregation in Mixed-Halide Perovskite Thin Films. ACS Energy Lett. 2017, 2, 1416-1424. [CrossRef]

22. Ran, C.; Xu, J.; Gao, W.; Huang, C.; Dou, S. Defects in metal triiodide perovskite materials towards high-performance solar cells: Origin, impact, characterization, and engineering. Chem. Soc. Rev. 2018, 47, 4581-4610. [CrossRef] [PubMed]

23. Chang, S.H.; Lin, K.-F.; Chiang, C.-H.; Chen, S.-H.; Wu, C.-G. Plasmonic Structure Enhanced Exciton Generation at the Interface between the Perovskite Absorber and Copper Nanoparticles. Sci. World J. 2014, 2014, 128414. [CrossRef] [PubMed]

24. De Wolf, S.; Holovsky, J.; Moon, S.-J.; Löper, P.; Niesen, B.; Ledinsky, M.; Haug, F.-J.; Yum, J.-H.; Ballif, C. Organometallic Halide Perovskites: Sharp Optical Absorption Edge and Its Relation to Photovoltaic Performance. J. Phys. Chem. Lett. 2014, 5, 1035-1039. [CrossRef] [PubMed]

25. Xie, Z.; Liu, S.; Qin, L.; Pang, S.; Wang, W.; Yan, Y.; Yao, L.; Chen, Z.; Wang, S.; Du, H.; et al. Refractive index and extinction coefficient of $\mathrm{CH} 3 \mathrm{NH} 3 \mathrm{PbI} 3$ studied by spectroscopic ellipsometry. Opt. Mater. Express 2015, 5, 29-43.

26. Chang, S.H.; Huang, W.-C.; Chen, C.-C.; Chen, S.-H.; Wu, C.-G. Effects of anti-solvent (iodobenzene) volume on the formation of $\mathrm{CH}_{3} \mathrm{NH}_{3} \mathrm{PbI}_{3}$ thin films and their application in photovoltaic cells. Appl. Surf. Sci. 2018, 445, 24-29. [CrossRef]

27. Galkowski, K.; Mitioglu, A.; Miyata, A.; Plochocka, P.; Portugall, O.; Eperon, G.E.; Wang, J.T.-W.; Stergiopoulos, T.; Stranks, S.D.; Snaith, H.J.; et al. Determination of the exciton binding energy and effective masses for methylammonium and formamidinium lead tri-halide perovskite semicroductors. Energy Environ. Sci. 2016, 9, 962-970. [CrossRef]

28. Chen, C.-C.; Chang, S.H.; Chen, L.-C.; Tsai, C.-L.; Cheng, H.-M.; Huang, W.-C.; Chen, W.-N.; Lu, Y.-C.; Tseng, Z.-L.; Chiu, K.Y.; et al. Interplay between nucleation and crystal growth during the formation of $\mathrm{CH}_{3} \mathrm{NH}_{3} \mathrm{PbI}_{3}$ thin films and their application in solar cells. Sol. Energy Mater. Sol. Cells 2017, 159, 583-589. [CrossRef]

29. Yang, Y.; Yang, M.; Li, Z.; Crisp, R.; Zhu, K.; Beard, M.C. Comparison of recombination dynamics in $\mathrm{CH}_{3} \mathrm{NH}_{3} \mathrm{PbBr}_{3}$ and $\mathrm{CH}_{3} \mathrm{NH}_{3} \mathrm{PbI}_{3}$ perovskite thin films: Influence of exciton binding energy. J. Phys. Chem. Lett. 2015, 6, 4688-4692. [CrossRef] [PubMed] 
30. Chen, C.-C.; Chang, S.H.; Chen, L.-C.; Kao, F.-S.; Cheng, H.-M.; Yeh, S.-C.; Chen, C.-T.; Wu, W.-T.; Tseng, Z.-L.; Chuang, C.L.; et al. Improving the efficiency of inverted mixed-organic-cation perovskite absorber based photovoltaics by tailing the surface roughness of PEDOT: PSS thin film. Sol. Energy 2016, 134, 445-451. [CrossRef]

31. Stranks, S.D.; Eperon, G.E.; Grancini, G.; Menelaou, C.; Alcocer, M.J.P.; Leijtens, T.; Herz, L.M.; Petrozza, A.; Snaith, H.J. Electron-Hole Diffusion Lengths Exceeding 1 Micrometer in an Organometal Trihalide Perovskite Absorber. Science 2013, 342, 341-344. [CrossRef]

32. Guo, Z.; Manser, J.S.; Wan, Y.; Kamat, P.V.; Huang, L. Spatial and temporal imaging of long-range charge transport in perovskite thin films by ultrafast microscopy. Nat. Commun. 2015, 6, 7471. [CrossRef] [PubMed]

33. Sha, W.E.I.; Ren, X.; Chen, L.; Choy, W.C.H. The efficiency limit of $\mathrm{CH}_{3} \mathrm{NH}_{3} \mathrm{PbI}_{3}$ perovskite solar cells. Appl. Phys. Lett. 2015, 106, 221104. [CrossRef]

34. Bernardi, M.; Vigil-Fowler, D.; Ong, C.S.; Neaton, J.B.; Louie, S.G. Ab initio study of hot electrons in GaAs. Proc. Natl. Acad. Sci. USA 2015, 112, 5291-5296. [CrossRef] [PubMed]

35. Cushing, S.K.; Zürch, M.; Kraus, P.M.; Carneiro, L.M.; Lee, A.; Chang, H.-T.; Kaplan, C.J.; Leone, S.R. Hot phonon and carrier relaxation in $\mathrm{Si}(100)$ determined by transient extreme ultraviolet spectroscopy. Struct. Dyn. 2018, 5, 054302. [CrossRef] [PubMed]

36. Lock, D.; Rusimova, K.R.; Pan, T.L.; Palmer, R.E.; Sloan, P.A. Atomically resolved real-space imaging of hot electron dynamics. Nat. Commun. 2015, 6, 8365. [CrossRef] [PubMed]

37. Gadret, E.G.; de Lima, M.M., Jr.; Madureira, J.R.; Chiaramonte, T.; Cotta, M.A.; Iikawa, F.; Cantarero, A. Optical phonon modes of wurtzite InP. Appl. Phys. Lett. 2013, 102, 122101. [CrossRef]

38. Wang, Y.; Jackson, H.E.; Smith, L.M.; Burgess, T.; Paiman, S.; Gao, Q.; Tan, H.H.; Jagadish, C. Carrier Thermalization Dynamics in Single Zincblende and Wurtzite InP Nanowires. Nano Lett. 2014, 14, 7153-7160. [CrossRef] [PubMed]

39. Madjet, M.E.-A.; Berdiyorov, G.R.; El-Mellouhi, F.; Alharbi, F.H.; Akimov, A.V.; Kais, S. Cation Effect on Hot Carrier Cooling in Halide Perovskite Materials. J. Phys. Chem. Lett. 2017, 8, 4439-4445. [CrossRef] [PubMed]

40. Guo, Z.; Wan, Y.; Yang, M.; Snaider, J.; Zhu, K.; Huang, L. Long-range hot-carrier transport in hybrid perovskites visualized by ultrafast microscopy. Science 2017, 356, 59-62. [CrossRef]

41. Fang, H.-H.; Adjokatse, S.; Shao, S.; Even, J.; Loi, M.A. Long-lived hot-carrier light emission and large blue shift in formamidinium tin triiodide perovskites. Nat. Commun. 2018, 9, 243. [CrossRef]

42. Murakami, H. Femtosecond time-resolved fluorescence up-conversion spectrometer corrected for wavelength-dependent conversion efficiency using continuous white light. Rev. Sci. Instrum. 2006, 77, 113105. [CrossRef]

43. Xu, J.; Knutson, J.R. Ultrafast fluorescence spectroscopy via upconversion: Applications to biophyiscs. Methods Enzymol. 2008, 450, 159-183. [PubMed]

44. Maultzsch, J.; Reich, S.; Thomsen, C.; Requardt, H.; Ordejon, P. Phonon dispersion in graphite. Phys. Rev. Lett. 2004, 92, 075501. [CrossRef] [PubMed]

45. Banerji, N.; Cowan, S.; Vauthey, E.; Heeger, A.J. Ultrafast Relaxation of the Poly(3-hexylthiophene) Emission Spectrum. J. Phys. Chem. C 2011, 115, 9726-9739. [CrossRef]

46. Kaufmann, C.; Kim, W.; Nowak-Król, A.; Hong, Y.; Kim, D.; Würthner, F. Ultrafast Exciton Delocalization, Localization, and Excimer Formation Dynamics in a Highly Defined Perylene Bisimide Quadruple $\pi$-Stack. J. Am. Chem. Soc. 2018, 140, 4253-4258. [CrossRef]

47. Knupfer, M. Exciton binding energies in organic semiconductors. Appl. Phys. A 2003, 77, 623-626. [CrossRef]

48. Nayak, P.K. Exicton binding energy in small organic conjugated molecule. Synth. Met. 2013, 174, 42-45. [CrossRef]

49. Chen, K.; Barker, A.J.; Reish, M.E.; Gordon, K.C.; Hodgkiss, J.M. Broadband Ultrafast Photoluminescence Spectroscopy Resolves Charge Photogeneration via Delocalized Hot Excitons in Polymer:Fullerene Photovoltaic Blends. J. Am. Chem. Soc. 2013, 135, 18502-18512. [CrossRef]

50. Zhou, N.; Prabakaran, K.; Lee, B.; Chang, S.H.; Harutyunyan, B.; Guo, P.; Butler, M.R.; Timalsina, A.; Bedzyk, M.J.; Ratner, M.A.; et al. Metal-Free Tetrathienoacene Sensitizers for High-Performance Dye-Sensitized Solar Cells. J. Am. Chem. Soc. 2015, 137, 4414-4423. [CrossRef] [PubMed]

51. Wu, K.; Bera, A.; Ma, C.; Du, Y.; Yang, Y.; Li, L.; Wu, T. Temperature-dependent excitonic photoluminescence of hybrid organometal halide perovskite films. Phys. Chem. Chem. Phys. 2014, 16, 22476-22481. [CrossRef] [PubMed] 
52. Wright, A.D.; Verdi, C.; Milot, R.L.; Eperon, G.E.; Pérez-Osorio, M.A.; Snaith, H.J.; Giustino, F.; Johnston, M.B.; Herz, L.M. Electron-phonon coupling in hybrid lead halide perovskites. Nat. Commun. 2016, 7, 11755. [CrossRef] [PubMed]

53. Yang, J.; Wen, X.; Xia, H.; Sheng, R.; Ma, Q.; Kim, J.; Tapping, P.; Harada, T.; Kee, T.W.; Huang, F.; et al. Acoustic-optical phonon up-conversion and hot-phonon bottleneck in lead-halide perovskites. Nat. Commun. 2017, 8, 14120. [CrossRef] [PubMed]

54. Ernst, T. Controlling the Polarity of Silicon Nanowire Transistors. Science 2013, 340, 1414-1415. [CrossRef] [PubMed]

55. Masselink, W.T.; Fischer, R.; Klem, J.; Henderson, T.; Pearah, P.; Morkoc, H. Polar semiconductor quantum wells on onopolar substrates: (Al,Ga) As/GaAs on (100)Ge. Appl. Phys. Lett. 1984, 45, 457. [CrossRef]

56. Yang, Y.; Ostrowski, D.P.; France, R.M.; Zhu, K.; van de Lagemaat, J.; Luther, J.M.; Beard, M.C. Observation of a hot-phonon bottleneck in lead-iodide perovskites. Nat. Photonics 2016, 10, 53-59. [CrossRef]

57. Frost, J.M.; Whalley, L.D.; Walsh, A. Slow Cooling of Hot Polarons in Halide Perovskite Solar Cells. ACS Energy Lett. 2017, 2, 2647-2652. [CrossRef] [PubMed]

58. Chang, S.H.; Chiang, C.-H.; Tseng, Z.-L.; Chiu, K.-Y.; Tai, C.-Y.; Wu, C.-G. Unraveling simultaneously enhanced open-circuit voltage and short-circuit current density in P3HT:ICBA:2,3-pyridinediol blended film based photovoltaics. J. Phys. D Appl. Phys. 2015, 48, 195104. [CrossRef]

59. Lee, B.; Stoumpos, C.C.; Zhou, N.; Hao, F.; Malliakas, C.; Yeh, C.-Y.; Marks, T.J.; Kanatzidis, M.G.; Chang, R.P.H. Air-stable molecular semiconductor lodosalts for solar cell applications: $\mathrm{Cs}_{2} \mathrm{SnI}_{6}$ as a hole conductor. J. Am. Chem. Soc. 2014, 136, 15379-15385. [CrossRef] [PubMed]

60. Zou, B.; Zhang, Y.; Xiao, L.; Li, T. Self-trapped state and phonon localization in $\mathrm{TiO}_{2}$ quantum dot with a dipole layer. J. Appl. Phys. 1993, 73, 4689-4690. [CrossRef]

61. Chang, S.H.; Chiang, C.-H.; Cheng, H.-M.; Tai, C.-Y.; Wu, C.-G. Broadband charge transfer dynamics in P3HT:PCBM blended film. Opt. Lett. 2013, 38, 5342-5345. [CrossRef] [PubMed]

62. Wang, H.-Y.; Gao, B.-R.; Wang, L.; Yang, Z.-Y.; Du, X.-B.; Chen, Q.-D.; Song, J.-F.; Sun, H.-B. Exciton diffusion and charge transfer dynamics in nano phase-separated P3HT/PCBM blend films. Nanoscale 2011, 3, 2280-2285. [CrossRef]

63. Wu, C.-G.; Chiang, C.-H.; Chang, S.H. A perovskite cell with a record-high-VOC of $1.61 \mathrm{~V}$ based on solvent annealed $\mathrm{CH}_{3} \mathrm{NH}_{3} \mathrm{PbBr}_{3} / \mathrm{ICBA}$ active layer. Nanoscale 2016, 8, 4077-4085. [CrossRef] [PubMed]

64. Chang, S.H.; Lin, K.-F.; Chiu, K.Y.; Tsai, C.-L.; Cheng, H.-M.; Yeh, S.-C.; Wu, W.-T.; Chen, W.-N.; Chen, C.-T.; Chen, S.-H.; et al. Improving the efficiency of $\mathrm{CH}_{3} \mathrm{NH}_{3} \mathrm{PbI}_{3}$ based photovoltaics by tuning the work function of the PEDOT:PSS hole transport layer. Sol. Energy 2015, 122, 892-899. [CrossRef]

65. Chang, S.H.; Chen, W.-N.; Chen, C.-C.; Yeh, S.-C.; Cheng, H.-M.; Tseng, Z.-L.; Chen, L.-C.; Chiu, K.Y.; Wu, W.-T.; Chen, C.-T.; et al. Manipulating the molecular structure of PEDOT chains through controlling the viscosity of PEDOT:PSS solutions to improve the photovoltaic performance of $\mathrm{CH}_{3} \mathrm{NH}_{3} \mathrm{PbI}_{3}$ solar cells. Sol. Energy Mater. Sol. Cells 2017, 161, 7-13. [CrossRef]

66. Yip, H.-L.; Jen, A.K.-Y. Recent advances in solution-processed interfacial materials for efficient and stable polymer solar cells. Energy Environ. Sci. 2012, 5, 5994-6011. [CrossRef]

67. Fang, J.; Deng, D.; Zhang, J.; Zhang, Y.; Lu, K.; Wei, Z. High open-circuit voltage ternary organic solar cells based on ICBA as acceptor and absorption-complementary donors. Mater. Chem. Front. 2017, 1, 1223-1228. [CrossRef]

68. Xia, Y.; Sun, K.; Ouyang, J. Solution-Processed Metallic Conducting Polymer Films as Transparent Electrode of Optoelectronic Devices. Adv. Mater. 2012, 24, 2436-2440. [CrossRef]

69. Zhang, L.; Li, B.; Yuan, J.; Wang, M.; Shen, T.; Huang, F.; Wen, W.; Cao, G.; Tian, J. High-Voltage-Efficiency Inorganic Perovskite Solar Cells in a Wide Solution-Processing Window. J. Phys. Chem. Lett. 2018, 9, 3646-3653. [CrossRef]

70. Yuan, H.; Zhao, Y.; Duan, J.; Wang, Y.; Yang, X.; Tang, Q. All-inorganic CsPbBr 3 perovskite solar cell with $10.26 \%$ efficiency by spectra engineering. J. Mater. Chem. A 2018, 6, 24324-24329. [CrossRef]

71. Hedley, G.J.; Quati, C.; Harwell, J.; Predhdo, O.V.; Beljonne, D.; Samuel, I.D.W. Hot-hole cooling controls the intial ultrafast relaxation in methylammonium lead iodide perovskite. Sci. Rep. 2018, 8, 8115. [CrossRef]

72. Shen, Q.; Ripolles, T.S.; Even, J.; Zhang, Y.; Ding, C.; Liu, F.; Izuishi, T.; Nakazawa, N.; Toyoda, T.; Ogomi, Y.; et al. Ultrafast selective extraction of hot holes from cesium lead iodide perovskite films. J. Energy Chem. 2018, 27, 1170-1174. [CrossRef] 
73. Kang, Y.; Han, S. Intrinsic Carrier Mobility of Cesium Lead Halide Perovskites. Phys. Rev. Appl. 2018, 10, 044013. [CrossRef]

74. Kahmann, S.; Loi, M.A. Hot carrier solar cells and the potential of perovskites for breaking the Shockley-Queisser limit. J. Mater. Chem. C 2019, 7, 2471-2486. [CrossRef]

75. De Vos, A. Detailed balance limit of the efficiency of tandem solar cells. J. Phys. D Appl. Phys. 1980, 13, 839-846. [CrossRef]

76. Wheeldon, J.F.; Valdivia, C.E.; Walker, A.W.; Kolhatar, G.; Jaouad, A.; Turala, A.; Riel, B.; Masson, D.; Puetz, N.; Fafard, S.; et al. Performance comparison of AlGaAs, GaAs and InGaP tunnel junctions for concentrated multijunction solar cells. Prog. Photovolt. 2011, 19, 442-452. [CrossRef]

77. Nagae, M. Response Time of Metal-Insulator-Metal Tunnel Junctions. Jpn. J. Appl. Phys. 1972, 11, 1611-1621. [CrossRef]

78. Bannai, R.; Kikuchi, A.; Kishino, K.; Lee, C.-M.; Chyi, J.-I. AlN/GaN double-barrier resonant tunneling diodes grown by rf-plasma-assisted molecular-beam epitaxy. Appl. Phys. Lett. 2002, 81, 1729-1731.

79. Sollner, T.C.L.G. Resonant tunneling through quantum wells at frequencies up to $2.5 \mathrm{THz}$. Appl. Phys. Lett. 1983, 43, 588. [CrossRef]

80. Lam, P.; Hatch, S.; Wu, J.; Tang, M.; Dorogan, V.G.; Mazur, Y.I.; Salamo, G.J.; Ramiro, Í.; Seeds, A.; Liu, H. Voltage recovery in charged InAs/GaAs quantum dot solar cells. Nano Energy 2014, 6, 159-166. [CrossRef]

81. Shi, X.; Dong, G.; Fang, M.; Wang, F.; Lin, H.; Yen, W.-C.; Chan, K.S.; Chueh, Y.-L.; Ho, J.C. Selective n-type doping in graphene via the aluminium nanoparticle decoration approach. J. Mater. Chem. C 2014, 2, 5417-5421. [CrossRef]

82. Rani, P.; Jindal, V.K. Designing band gap of graphene by B and N dopant atoms. RSC Adv. 2013, 3, 802-812. [CrossRef]

83. Tian, P.; Tang, L.; Teng, K.; Lau, S. Graphene quantum dots from chemistry to applications. Mater. Today Chem. 2018, 10, 221-258. [CrossRef]

84. Qian, F.; Li, X.; Tang, L.; Lai, S.K.; Lu, C.; Lau, S.P. Postassium doping: Tuning the optical properties of graphene quantum dots. AIP Adv. 2016, 6, 075116. [CrossRef]

85. Qian, J.; Shen, C.; Yan, J.; Xi, F.; Dong, X.; Liu, J. Tailoring the electronic properties of graphene quantum dots by $p$ doping and their enhanced performance in metal-free composite photocatalyst. J. Phys. Chem. C 2018, 122, 349-358. [CrossRef]

86. Lee, S.I.; Song, W.; Kim, Y.; Song, I.; Jung, D.S.; Jung, M.W.; Cha, M.-J.; Park, S.E.; An, K.-S.; Park, C.-Y. P-Type Doping of Graphene Films by Hybridization with Nickel Nanoparticles. Jpn. J. Appl. Phys. 2013, 52, 75101. [CrossRef]

87. Tsai, C.-Y. Carrier heating and its effects on the current-voltage relations of conventional and hot-carrier solar cells: A physical model incorporating energy transfer between carriers, photons, and phonons. Sol. Energy 2019, 188, 450-463. [CrossRef]

88. Liang, P.-W.; Liao, C.-Y.; Chueh, C.-C.; Zuo, F.; Williams, S.T.; Xin, X.-K.; Lin, J.-J.; Jen, A.K.-Y. Additive Enhanced Crystallization of Solution-Processed Perovskite for Highly Efficient Planar-Heterojunction Solar Cells. Adv. Mater. 2014, 26, 3748-3754. [CrossRef] [PubMed]

89. Xiao, M.; Huang, F.; Huang, W.; Dkhissi, Y.; Zhu, Y.; Etheridge, J.; Bach, U.; Cheng, Y.-B.; Spiccia, L.; Gray-Weale, A.; et al. A Fast Deposition-Crystallization Procedure for Highly Efficient Lead Iodide Perovskite Thin-Film Solar Cells. Angew. Chem. 2014, 126, 10056-10061. [CrossRef]

90. Jeon, N.J.; Noh, J.H.; Kim, Y.C.; Yang, W.S.; Ryu, S.; Seok, S.I. Solvent engineering for high-performance inorganic-organic hybrid perovskite solar cells. Nat. Mater. 2014, 13, 897-903. [CrossRef]

91. Chang, S.H.; Wong, S.-D.; Huang, H.-Y.; Yuan, C.-T.; Wu, J.-R.; Chiang, S.-E.; Tseng, Z.-L.; Chen, S.-H. Effects of the washing-enhanced nucleation process on the material properties and performance of perovskite solar cells. J. Alloys Compd. 2019, 808, 151723. [CrossRef]

92. Yin, W.-J.; Shi, T.; Yan, Y. Unique Properties of Halide Perovskites as Possible Origins of the Superior Solar Cell Performance. Adv. Mater. 2014, 26, 4653-4658. [CrossRef] [PubMed]

93. Shao, Y.; Xiao, Z.; Bi, C.; Yuan, Y.; Huang, J. Origin and elimination of photocurrent hysteresis by fullerene passivation in $\mathrm{CH}_{3} \mathrm{NH}_{3} \mathrm{PbI}_{3}$ planar heterojunction solar cells. Nat. Commun. 2014, 5, 5784. [CrossRef] [PubMed] 
94. March, S.A.; Clegg, C.; Riley, D.B.; Webber, D.; Hill, I.G.; Hall, K.C. Simultaneous observation of free and defect-bound excitons in $\mathrm{CH}_{3} \mathrm{NH}_{3} \mathrm{PbI}_{3}$ using four-wave mixing spectroscopy. Sci. Rep. 2016, 6, 39139. [CrossRef] [PubMed]

95. Hsu, H.-L.; Hsiao, H.-T.; Juang, T.-Y.; Jiang, B.-H.; Chen, S.-C.; Jeng, R.-J.; Chen, C.-P. Carbon Nanodot Additives Realize High-Performance Air-Stable p-i-n Perovskite Solar Cells Providing Efficiencies of up to $20.2 \%$. Adv. Energy Mater. 2018, 8, 1802323. [CrossRef]

96. Chiang, C.-H.; Wu, C.-G. Film Grain-Size Related Long-Term Stability of Inverted Perovskite Solar Cells. ChemSusChem 2016, 9, 2666-2672. [CrossRef] [PubMed]

97. Chen, C.-C.; Chang, S.H.; Chen, L.-C.; Cheng, H.-M.; Tseng, Z.-L.; Wu, C.-G. Manipulating multicrystalline grain size in $\mathrm{CH}_{3} \mathrm{NH}_{3} \mathrm{PbI}_{3}$ thin films for application in photovoltaics. Sol. Energy 2016, 139, 518-523. [CrossRef]

98. Chang, S.H.; Chen, C.-C.; Chen, L.-C.; Tien, C.-L.; Cheng, H.-M.; Huang, W.-C.; Lin, H.-Y.; Chen, S.-H.; $\mathrm{Wu}, \mathrm{C}$.-G. Unraveling the multifunctional capabilities of PCBM thin films in inverted-type $\mathrm{CH}_{3} \mathrm{NH}_{3} \mathrm{PbI}_{3}$ based photovoltaics. Sol. Energy Mater. Sol. Cells 2017, 169, 40-46. [CrossRef]

99. Murphy, K.F.; Piccione, B.; Zanjani, M.B.; Lukes, J.R.; Gianola, D.S. Strain- and Defect-Mediated Thermal Conductivity in Silicon Nanowires. Nano Lett. 2014, 14, 3785-3792. [CrossRef]

100. Cohn, J.L.; Neumeier, J.J.; Popoviciu, C.P.; McClellan, K.J.; Leventouri, T. Local lattic distorsions and thermal transport in perovskite maganites. Phys. Rev. B 1997, 56, R8495-R9498. [CrossRef]

101. Chen, L.-C.; Chen, C.-C.; Chang, S.H.; Lee, K.-L.; Tseng, Z.-L.; Chen, S.-H.; Kuo, H.-C. Formation and characterization of preferred oriented perovskite thin films on single-crystalline substrates. Mater. Res. Express 2018, 5, 066403. [CrossRef]

102. Wei, W.; Zhang, Y.; Xu, Q.; Wei, H.; Fang, Y.; Wang, Q.; Deng, Y.; Li, T.; Gruverman, A.; Cao, L.; et al. Monolithic integration of hybrid perovskite single crystals with heterogenous substrate for highly sensitive X-ray imaging. Nat. Photon. 2017, 11, 315-321. [CrossRef]

103. Park, S.-H.; Ahn, D.; Park, C.-Y. Intersubband absorption of p-type wurtzite GaN/AlN quantum well for fiber-optics telecommunication. J. Appl. Phys. 2017, 122, 184303. [CrossRef]

104. Fan, Z.Y.; Li, J.; Nakarmi, M.L.; Lin, J.Y.; Jiang, H.X. AlGaN/GaN/AlN quantum-well field-effect transistors with highly resistive AlN epilayers. Appl. Phys. Lett. 2006, 88, 73513. [CrossRef]

105. Hirayama, H.; Tanaka, S.; Aoyagia, Y. Fabrication of self-assembling InGaN and AlGaN quantum dots on AlGaN surfaces using anti-surfactant. Microelectron. Eng. 1999, 49, 287-290. [CrossRef]

106. Tsai, M.-K.; Hu, S.-Y.; Lee, J.-W.; Lee, Y.-C.; Lee, M.-H.; Shen, J.-L. Morphology control and characteristics of $\mathrm{ZnO} / \mathrm{ZnS}$ nanorod arrays synthesised by microwave-assistd heating. Micro Nano Lett. 2016, 11, 192-195. [CrossRef]

107. Lin, T.N.; Santiago, S.R.M.; Yuan, C.T.; Huang, H.Y.; Shen, J.L. Origin of tunable photoluminescence from graphene quantum dots synthesized via pulsed laser ablation. Phys. Chem. Chem. Phys. 2016, 18, 22599-22605.

108. Patra, M.; Manoth, M.; Singh, V.; Gowd, G.S.; Choudhry, V.; Vadera, S.; Kumar, N. Synthesis of stable dispersion of $\mathrm{ZnO}$ quantum dots in aqueous medium showing visible emission from bluish green to yellow. J. Lumin. 2009, 129, 320-324. [CrossRef]

109. Wang, X.; Jiang, S.; Huo, X.; Xia, R.; Muhire, E.; Gao, M. Facile preparation of a $\mathrm{TiO}_{2}$ quantum dot/graphitic carbon nitride heterojunction with highly efficient photocatalytic activity. Nanotechnology 2018, 29, 205702. [CrossRef] [PubMed]

110. Lee, K.-M.; Chen, K.-S.; Wu, J.-R.; Lin, Y.-D.; Yu, S.-M.; Chang, S.H. Hihgly efficient and stable semi-transparent perovskite solar modules with a trilayer anode electrode. Nanoscale 2018, 10, 17699-17704. [CrossRef] 

Article

\title{
Efficient CdTe Nanocrystal/ $/ \mathrm{TiO}_{2}$ Hetero-Junction Solar Cells with Open Circuit Voltage Breaking $0.8 \mathrm{~V}$ by Incorporating A Thin Layer of CdS Nanocrystal
}

\author{
Xianglin Mei ${ }^{1}$, Bin $\mathrm{Wu}^{1}{ }^{1}$, Xiuzhen Guo ${ }^{1}$, Xiaolin Liu ${ }^{1}$, Zhitao Rong ${ }^{1}$, Songwei Liu ${ }^{1}$, \\ Yanru Chen ${ }^{1}$, Donghuan Qin ${ }^{1,2, *}$, Wei Xu ${ }^{1,2, *}$, Lintao Hou ${ }^{3, *}$ and Bingchang Chen ${ }^{1}$ \\ 1 School of Materials Science and Engineering, South China University of Technology, Guangzhou 510640, China; \\ mxianglin@sina.com (X.M.); damien_wu@foxmail.com (B.W.); XzGuo_19@163.com (X.G.); \\ LiuLin9708@163.com (X.L.); rzt1512388848@163.com (Z.R.); majestyv@sina.com (S.L.); \\ caro_ccyr@163.com (Y.C.); $17728100969 @ 163 . c o m$ (B.C.) \\ 2 Institute of Polymer Optoelectronic Materials \& Devices, State Key Laboratory of Luminescent Materials \& \\ Devices, South China University of Technology, Guangzhou 510640, China \\ 3 Guangdong Provincial Key Laboratory of Optical Fiber Sensing and Communications, Guangzhou Key \\ Laboratory of Vacuum Coating Technologies and New Energy Materials, Siyuan Laboratory, \\ Department of Physics, Jinan University, Guangzhou 510632, China \\ * Correspondence: qindh@scut.edu.cn (D.Q.); xuwei@scut.edu.cn (W.X.); thlt@jnu.edu.cn (L.H.)
}

Received: 22 July 2018; Accepted: 10 August 2018; Published: 13 August 2018

\begin{abstract}
Nanocrystal solar cells (NCs) allow for large scale solution processing under ambient conditions, permitting a promising approach for low-cost photovoltaic products. Although an up to $10 \%$ power conversion efficiency (PCE) has been realized with the development of device fabrication technologies, the open circuit voltage $\left(V_{o c}\right)$ of CdTe NC solar cells has stagnated below $0.7 \mathrm{~V}$, which is significantly lower than most CdTe thin film solar cells fabricated by vacuum technology (around $0.8 \mathrm{~V} \sim 0.9 \mathrm{~V}$ ). To further improve the NC solar cells' performance, an enhancement in the $V_{o c}$ towards $0.8-1.0 \mathrm{~V}$ is urgently required. Given the unique processing technologies and physical properties in CdTe NC, the design of an optimized band alignment and improved junction quality are important issues to obtain efficient solar cells coupled with high $V_{o c}$. In this work, an efficient method was developed to improve the performance and $V_{o c}$ of solution-processed $\mathrm{CdTe}$ nanocrystal/ $\mathrm{TiO}_{2}$ hetero-junction solar cells. A thin layer of solution-processed CdS NC film $(\sim 5 \mathrm{~nm})$ as introduced into CdTe NC/ $\mathrm{TiO}_{2}$ to construct hetero-junction solar cells with an optimized band alignment and $p-n$ junction quality, which resulted in a low dark current density and reduced carrier recombination. As a result, devices with improved performance (5.16\% compared to $2.63 \%$ for the control device) and a $V_{o c}$ as high as $0.83 \mathrm{~V}$ were obtained; this $V_{o c}$ value is a record for a solution-processed CdTe NC solar cell.
\end{abstract}

Keywords: nanocrystal; $\mathrm{CdTe} ; \mathrm{TiO}_{2} ; \mathrm{CdS}$; solar cells; solution processed

\section{Introduction}

Since the first reported solution-processed CdTe nanocrystal solar cells (NCs) in 2005, they have been rapidly developed due to their potential for next-generation photovoltaic products (including NCs, quantum dots, polymers, $\mathrm{Sb}_{2} \mathrm{Se}_{3}$, and perovskite solar cells) at low cost, low material consumption, and simple fabricating techniques [1-8]. During the past decade, intensive research has been focused on preparing high-quality CdTe NC films to improve the performance of NC solar cells [9-11]. Advances in CdTe NC thin film treatment and device architecture have led to a significant increase in the performance of solar cells from $2.9 \%$ in 2005 to 7\% in 2011 [12]. Efficient CdTe NC solar cells are prepared by using a planar $p-n$ hetero-junction configuration. In this device structure, carriers are mainly generated in the CdTe NC film and electrons are injected from the conducting band 
of the $\mathrm{CdTe} \mathrm{NC}$ to an $\mathrm{n}$ type partner (such as $\mathrm{CdSe}, \mathrm{CdS}, \mathrm{ZnO}$, or $\mathrm{TiO}_{2}$ et al.), while the hole travels to the back contact of the device. Nowadays, solution-processed CdTe NC solar cells mainly suffer from a low open circuit voltage $\left(V_{o c}\right)$ : most $\mathrm{CdTe} \mathrm{NC}$ solar cells have a $V_{o c}$ between $0.5 \mathrm{~V}$ and $0.7 \mathrm{~V}$ [13], while these values are $0.8 \mathrm{~V} \sim 0.9 \mathrm{~V}$ for CdTe thin film solar cells that have been prepared by the close space sublimation (CSS) method [14], which limits further improvement in performance. The loss in potential for CdTe NC solar cells is defined as $E_{l o s s}=E_{g}-\mathrm{e} V_{o c}$, where $E_{g}$ is the bandgap of the CdTe $\mathrm{NC}$ thin film $(\sim 1.45 \mathrm{eV})$. The value of $E_{\text {loss }}$ is greater than $0.7 \mathrm{eV}$ for the CdTe NC solar cells, while this value is below $0.4 \mathrm{eV}$ for most perovskite or III-V group semiconductor solar cells [15,16]. According to the Shockley-Queisser constraint, the minimum $E_{\text {loss }}$ is about $0.3 \mathrm{eV}$ for CdTe NC solar cells and the maximum theoretical $V_{o c}$ with a bandgap of $1.45 \mathrm{eV}$ is $1.15 \mathrm{eV}$ [17]. The $E_{\text {loss }}$ for CdTe NC solar cells can be mainly attributed to the recombination existing in the $p$ - $n$ junction and the back contact, given that the CdTe NC film has been prepared at optimized conditions. To obtain low resistance ohmic contacts to CdTe thin films, a heavily doped region at the surface of the CdTe should be formed before back contact formation via wet etching (using a bromine/methanol or phosphoric/nitric treatment) [18-20]. Unfortunately, the wet etching will result in the NC thin film being removed from the substrate or device shunt, which was confirmed by Panthani et al. [21].

Another way to make good ohmic contacts to the CdTe NC film is by using metal/ $\mathrm{p}^{+}$ semiconductor/metal oxide/organic hole transport materials with a high work function as a back contact. Occasionally, Au is selected as the back contact for CdTe NC solar cells, and a $V_{o c}$ of $0.65 \mathrm{~V}$ can be obtained [22] due to the low work function (5.1 eV for $\mathrm{Au} \sim 5.5 \mathrm{eV}$ for CdTe). Recently, Kurley et al. demonstrated ohmic contacts could be realized by inserting transparent $\mathrm{ZnTe}: \mathrm{Cu}$, etched $\mathrm{CdTe}: \mathrm{Cu}$, or a Te buffer layer between the CdTe and ITO (Indium Tin Oxide) [23]. Unfortunately, although as high as $8.6 \%$ (without light soaking/current treatment) of the PCE coupled with a high fill factor $(\sim 60 \%)$ and $J_{s c}$ were attained in this case, the $V_{o c}$ was below $0.7 \mathrm{~V}$, which limits the device's performance for further improvement. $p$-doping spiro-OMeTAD [24] or P3KT [25] have also been employed as hole transport materials for the CdTe NC thin film's back contact, and a high efficiency $(\sim 6 \%)$ was obtained in optimized NC solar cells. Most recently, a novel crosslinkable conjugated polymer poly(diphenylsilane-co-4-vinyl-triphenylamine) (Si-TPA) with high work function (5.38 eV) was introduced successfully into solution-processed CdTe/CdSe (or CdS) NC solar cells with an inverted structure of (ITO/ZnO/CdSe/CdTe/Si-TPA/Au); a PCE as high as $8.34 \%$ was obtained due to the decreased carrier recombination and dipole effects [26]. Another important issue for increasing the $V_{o c}$ of CdTe NC solar cells is preparing a high-quality $p-n$ junction and optimizing the band alignment of the whole device. As the size of a CdTe NC is in the range of $1 \sim 0 \mathrm{~nm}$, the $n$-type partner is expected to have a similar size to obtain a homogeneous interface. In our previous work, we found that using solution-processed CdS NC or CdSe NC to replace the widely used CBD-CdS (chemical bath deposition (dS) as an $n$-type partner for CdTe NC solar cells improved $V_{o c}$ and performance due to the high junction quality and reduced carrier recombination in the $p / n$ junction $[27,28]$. Most recently, we found that a higher $V_{o c}(0.66-0.74 \mathrm{~V})$ could be obtained in $\mathrm{CdTe} \mathrm{NC} / \mathrm{TiO}_{2}$ heterojunction solar cells by using $\mathrm{Sb}$ doped $\mathrm{TiO}_{2}$ as the buffer layer due to the improved band alignment. However, the large differences in crystal type (solution-processed $\mathrm{TiO}_{2}$ has an anatase structure [29] while CdTe NC has a zinc blende structure [30]) and lattice constant $\left(0.948 \mathrm{~nm}\right.$ for $\mathrm{TiO}_{2}$ and $0.648 \mathrm{~nm}$ for CdTe) resulted in low junction quality. On the contrary, when compared to $\mathrm{TiO}_{2}, \mathrm{CdS}$ had a lower lattice mismatch with CdTe and a high-quality hetero-junction is expected by incorporating a CdS thin film, which suppresses the leakage current due to the reduced defect density. In this paper, we developed an efficient method to simultaneously enhance the $V_{o c}$ and PCE of solution-processed CdTe NC/ $\mathrm{TiO}_{2}$ solar cells by inserting a thin layer of CdS NC between the $\mathrm{CdTe}$ and $\mathrm{TiO}_{2}$ film. The CdS NC possesses a similar size and structure as that of $\mathrm{CdTe} \mathrm{NC}$, which can efficiently decrease the lattice mismatch between $\mathrm{CdTe}$ and $\mathrm{TiO}_{2}$; in addition, $\mathrm{CdS}$ has suitable energy levels, which are well matched with $\mathrm{CdTe}$, therefore decreasing the energy loss and improving the $V_{o c}$ of the device. The incorporation of a CdS NC thin film optimizes the band alignment of the $\mathrm{CdTe} / \mathrm{TiO}_{2}$ junction and reduces the interface 
recombination. Compared to the control device (with the structure $\mathrm{FTO}\left(\mathrm{SnO}_{2}: \mathrm{F}\right) / \mathrm{TiO}_{2} / \mathrm{CdTe} / \mathrm{Au}$ ), all of the devices with a CdS interlayer showed a significantly higher $V_{o c}(0.72-0.83 \mathrm{~V})$. A $V_{o c}$ as high as $0.83 \mathrm{~V}$ was obtained with an optimal thickness of the CdS NC film $(3.74 \mathrm{~nm})$, which is a record for a solution-processed CdTe NC solar cell. When further optimizing the device fabrication conditions, we achieved $\mathrm{CdTe} / \mathrm{TiO}_{2} \mathrm{NC}$ solar cells that exhibited a $J_{s c}$ of $17.38 \mathrm{~mA} / \mathrm{cm}^{2}$, a $V_{o c}$ of $0.73 \mathrm{~V}$, an FF (fill factor) of $40.67 \%$, and a high PCE of $5.16 \%$. This PCE value was almost two times higher than the control device (with a PCE of $2.65 \%$ ). As a simple fabrication process, we believe that this design holds potential for efficient CdTe NC solar cells with a PCE of up to $10 \%$.

\section{Experiment Procedure}

A $\mathrm{TiO}_{2}$ sol-gel precursor was synthesized via a convenient method according to our previous work [31]. In a typical process, $4.25 \mathrm{~mL}$ titanium $n$-butoxide, $3.75 \mathrm{~mL}$ ethanolamine, and $25 \mathrm{~mL}$ ethyl alcohol were mixed and gently stirred in a $50 \mathrm{~mL}$ beaker for $2 \mathrm{~h}$ to form a transparent sol-gel. Next, $5 \mathrm{~mL}$ of acetic acid in $5 \mathrm{~mL}$ of deionized water was gradually dropped into the mixture and continuously stirred for $24 \mathrm{~h}$. Finally, the mixture was transferred to the fume hood to accelerate the condensation procedure. When the total volume of the mixture decreased to $15 \mathrm{~mL}$, it was taken out for the fabrication of $\mathrm{TiO}_{2}$ thin film. The synthesis of the CdS NC and CdTe NC solutions was conducted following methods published previously $[23,28]$. Transmission electron microscope (TEM) images of the CdS and CdTe NC are presented in Figure S1a,b. The CdS NC showed a spherical morphology while the CdTe NC showed a rod-shaped structure. The transmission spectrum of $\mathrm{FTO} / \mathrm{TiO}_{2} / \mathrm{CdS}$ with different thicknesses of CdS is shown in Figure S2. It is evident that the introduction of a thin layer CdS NC film had little impact on the transmission of $\mathrm{FTO} / \mathrm{TiO}_{2}$ (less than $10 \%$ decrease when compared to the $\mathrm{NC}$ device without $\mathrm{CdS} \mathrm{NC}$ film), which is prospective for increasing the spectrum response in short wavelengths.

Solar cells with the configuration of $\mathrm{FTO} / \mathrm{TiO}_{2} / \mathrm{CdS} / \mathrm{CdTe} / \mathrm{Au}$ were prepared by a simple solution process under ambient conditions, as shown in Figure 1. A TiO film with a thickness of $40 \mathrm{~nm}$ was prepared by depositing a $\mathrm{Ti}^{2+}$ precursor onto the FTO substrate and spin-casted at $2500 \mathrm{rpm}$ for $15 \mathrm{~s}$, then the substrate was annealed at $500^{\circ} \mathrm{C}$ for $1 \mathrm{~h}$ to eliminate any organic solvent and form a compact $\mathrm{TiO}_{2}$ thin film. Several drops of the CdS NC solution with different concentrations $(5 \mathrm{mg} / \mathrm{mL}$, $10 \mathrm{mg} / \mathrm{mL}, 15 \mathrm{mg} / \mathrm{mL}$, and $20 \mathrm{mg} / \mathrm{mL}$ ) were then deposited onto the $\mathrm{FTO} / \mathrm{TiO}_{2}$ and spin-casted at $3000 \mathrm{rpm}$ for $20 \mathrm{~s}$. Following this, the substrate was transferred to a hot plate and annealed at $150{ }^{\circ} \mathrm{C}$ for 10 minutes, then transferred to another hot plate and annealed at $380{ }^{\circ} \mathrm{C}$ for $30 \mathrm{~min}$. One wash with isopropanol was used to remove any impurities. The CdTe NCs were then deposited layer by layer onto the $\mathrm{FTO} / \mathrm{TiO}_{2} / \mathrm{CdS}$ substrate with a process described previously in [23]. Finally, several drops of saturated $\mathrm{CdCl}_{2} /$ methanol were put onto the $\mathrm{FTO} / \mathrm{TiO}_{2} / \mathrm{CdS} / \mathrm{CdTe}$ substrate and spin-casted at $1100 \mathrm{rpm}$ for $20 \mathrm{~s}$, then transferred onto a hot plate at $330-420^{\circ} \mathrm{C}$ for $15 \mathrm{~min}$. Sixty nanometers of $\mathrm{Au}$ was deposited via thermal evaporation through a shadow mask with an active area of $0.16 \mathrm{~cm}^{2}$ to make the electrode contact. 


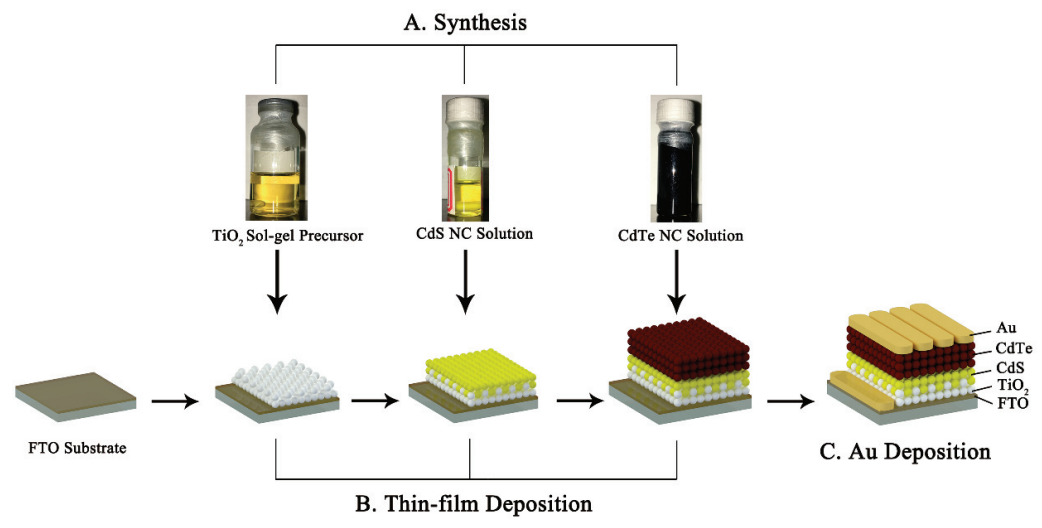

Figure 1. A schematic of the fabrication process of the NC solar cells.

The PCE of the NC solar cells were investigated under an illumination of $100 \mathrm{~mW} \mathrm{~cm}{ }^{-2}$ with an air mass 1.5 (AM 1.5) solar simulator (Oriel model 91192), while the $J-V$ characteristics were measured with a Keithley 2400. The $C-V$ (Capacity-Voltage) measurements were taken with an Autolab PGSTAT-30 equipped with an impedance analyzer module. The external quantum efficiency (EQE) of the NC solar cell was measured using Solar Cell Scan 100 (Zolix, Beijing, China). Atomic force microscopy (AFM) images were obtained using a NanoScope NS3A system (Veeko, CA, USA). Transient photovoltage measurements (TPV) were taken by using the OmniFluo system (Zolix, Beijing, China).

\section{Results and Discussion}

The cross-section scanning electron microscope (SEM) image of the optimal $\mathrm{CdTe} / \mathrm{TiO}_{2} \mathrm{NC}$ heterojunction solar cells is shown in Figure 2a. A high-temperature prepared $\mathrm{TiO}_{2}$ thin film that was compatible with the FTO substrate was selected as a buffer layer for electron collecting. Zinc-blende CdS NC has a similar structure and size as CdTe NC and was deposited on the $\mathrm{TiO}_{2}$ film. A gold electrode was deposited onto the CdTe NC film to collect photo-generated holes. The introduction of the CdS NC film was anticipated to decrease the lattice mismatch and interface defects between the $\mathrm{CdTe}$ and $\mathrm{TiO}_{2}$. From the energy dispersive spectrum (EDS, Figure S3, supporting information), the emergence of an $\mathrm{S}$ element implied that the CdS had been introduced into the NC solar cells. The XRD pattern of the $\mathrm{FTO} / \mathrm{TiO}_{2} / \mathrm{CdTe}$ and $\mathrm{FTO} / \mathrm{TiO}_{2} / \mathrm{CdS} / \mathrm{CdTe}$ thin films is presented in Figure S4; peaks for the zinc blende CdS were found when the CdS NC film was introduced. The band alignment of the $\mathrm{FTO}, \mathrm{TiO}_{2}, \mathrm{CdS}, \mathrm{CdTe}$, and $\mathrm{Au}$ is presented in Figure 2b. In this device architecture, light passes through the $\mathrm{FTO}, \mathrm{TiO}_{2}$, then $\mathrm{CdS}$, and is absorbed by the $\mathrm{CdTe} \mathrm{NC}$ active layer. The photon-generated carriers are separated by the built-in field of $\mathrm{CdTe} / \mathrm{TiO}_{2}$. Electrons are injected from the conducting band of $\mathrm{CdTe}$ to $\mathrm{CdS}$ then $\mathrm{TiO}_{2}$, and collected by the FTO electrode, while the hole transfers from the valence band of CdTe to the gold electrode. To investigate the morphology changes of the $\mathrm{TiO}_{2}$ thin film after the deposition of the CdS thin layer, atomic force microscopy (AFM) was used to characterize the surface images of $\mathrm{FTO} / \mathrm{TiO}_{2} / \mathrm{CdS}$ with different thicknesses of CdS NC. As shown in Figure 2c-f, a smooth surface was observed in the case of $\mathrm{FTO} / \mathrm{TiO}_{2} / \mathrm{CdS}$ with the thin CdS NC film $\left(0.78 \mathrm{~nm}\right.$, Figure 2d). The $\mathrm{TiO}_{2}$ film was totally covered with the CdS NC film when the CdS NC thickness was increased to $3.74 \mathrm{~nm}$ (Figure 2e). When the thickness of the CdS NC film reached $9.51 \mathrm{~nm}$, although the $\mathrm{TiO}_{2}$ was totally covered by the CdS NC film, the surface was very undulating. It was noted that the root mean squares were $3.01 \mathrm{~nm}, 4.00 \mathrm{~nm}, 13.80 \mathrm{~nm}$, and $13.90 \mathrm{~nm}$ for a CdS NC thickness increase from 0 to $9.51 \mathrm{~nm}$, respectively. A smooth CdS NC surface is essential to enhance the physical contact between CdS and CdTe and decrease interfacial recombination, leading to improved device performance. 
(a)
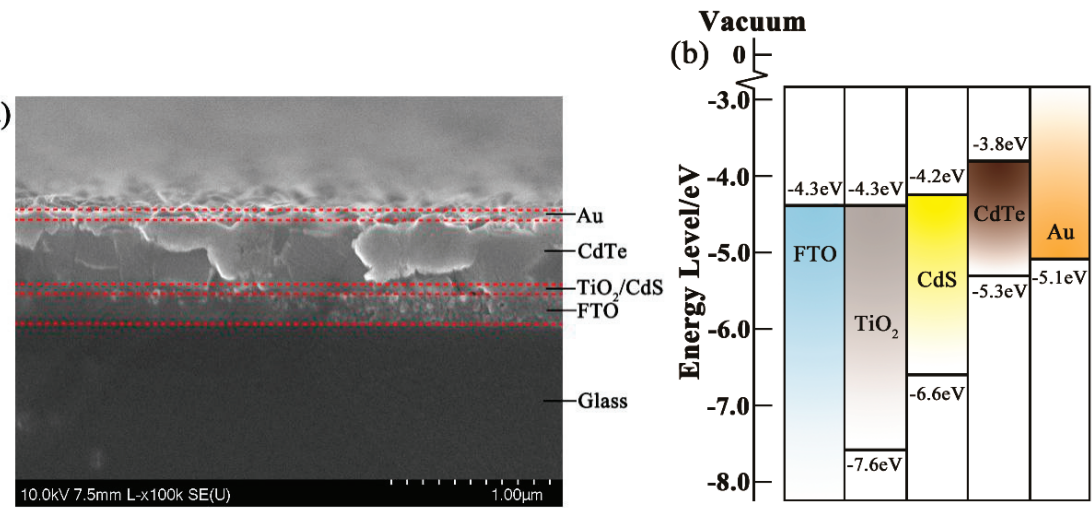

(c)

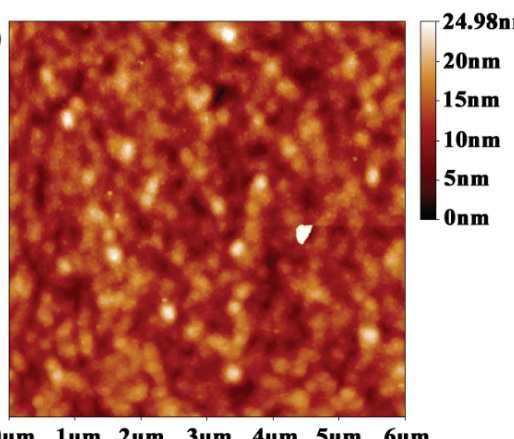

(d)

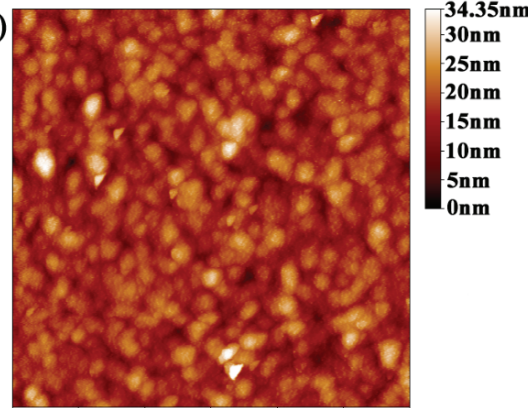

$0 \mu \mathrm{m} \quad 1 \mu \mathrm{m} \quad 2 \mu \mathrm{m} \quad 3 \mu \mathrm{m} \quad 4 \mu \mathrm{m} \quad 5 \mu \mathrm{m} \quad 6 \mu \mathrm{m}$

$0 \mu \mathrm{m} 1 \mu \mathrm{m} 2 \mu \mathrm{m} 3 \mu \mathrm{m} 4 \mu \mathrm{m} 5 \mu \mathrm{m} 6 \mu \mathrm{m}$

(e)

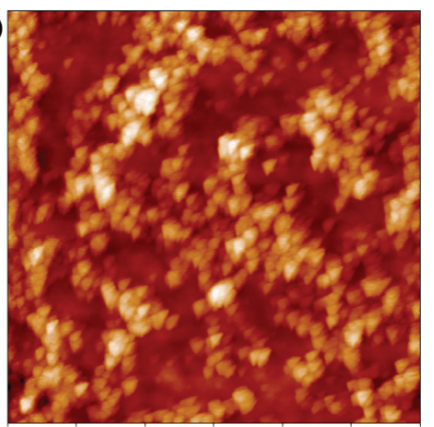

$0 \mu \mathrm{m} \quad 1 \mu \mathrm{m} \quad 2 \mu \mathrm{m} \quad 3 \mu \mathrm{m} \quad 4 \mu \mathrm{m} \quad 5 \mu \mathrm{m} \quad 6 \mu \mathrm{m}$

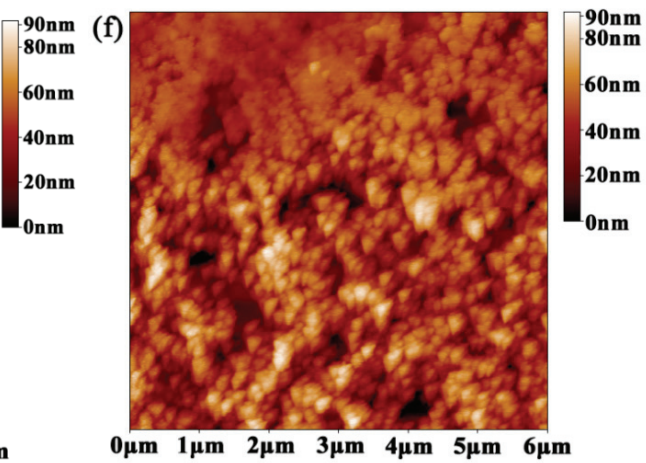

$0 \mu \mathrm{m} \quad 1 \mu \mathrm{m} \quad 2 \mu \mathrm{m} \quad 3 \mu \mathrm{m} \quad 4 \mu \mathrm{m} \quad 5 \mu \mathrm{m} \quad 6 \mu \mathrm{m}$

Figure 2. (a) Cross-section SEM image of the NC solar cells; (b) Energy levels of $\mathrm{FTO}, \mathrm{TiO}_{2}, \mathrm{CdS}, \mathrm{CdTe}$, and $\mathrm{Au}$; (c) AFM images of $\mathrm{FTO} / \mathrm{TiO}_{2}$ without $\mathrm{CdS}$; $\mathrm{AFM}$ images of $\mathrm{FTO} / \mathrm{TiO}_{2}$ with $\mathrm{CdS}$; (d) $0.78 \mathrm{~nm}$ CdS NC; (e) $3.74 \mathrm{~nm} \mathrm{CdS} \mathrm{NC;} \mathrm{and} \mathrm{(f)} 9.51 \mathrm{~nm} \mathrm{CdS} \mathrm{NC.}$

To decrease the interface defects between $\mathrm{CdTe}$ and $\mathrm{TiO}_{2}$, a thin layer of $\mathrm{CdS} \mathrm{NC}$ was deposited onto the $\mathrm{TiO}_{2}$ film with different thicknesses via a solution process. It was reported in our previous works that an optimal annealing temperature for the $\mathrm{CdTe} \mathrm{NC} / \mathrm{TiO}_{2}$ heterojunction was around $400{ }^{\circ} \mathrm{C}$ [32]. Figure 3 a presents the current density vs. voltage $(J-V)$ curves of the devices with $\mathrm{CdS}$ $(3.74 \mathrm{~nm})$ under air mass $1.5 \mathrm{G}$ (AM $1.5 \mathrm{G})$ illumination, and the detailed parameters are summarized in Table 1. The NC solar cell with a CdS NC interlayer showed a $V_{o c}$ of $0.83 \mathrm{~V}$, a $J_{s c}$ of $16.02 \mathrm{~mA} / \mathrm{cm}^{2}$, and a fill factor (FF) of $30.46 \%$, resulting in a PCE of $4.05 \%$; NC solar cells without the CdS NC 
interlayer only showed a $V_{o c}$ of $0.69 \mathrm{~V}$, a $J_{s c}$ of $12.32 \mathrm{~mA} / \mathrm{cm}^{2}$, and an FF of $31.17 \%$, leading to a PCE of $2.65 \%$. Therefore, the PCE observed from the NC solar cells with a CdS NC interlayer showed a $52.8 \%$ improvement when compared to devices without the CdS NC interlayer. The parallel resistance $\left(R_{\mathrm{sh}}\right)$ of the NC solar cells was found to be slightly improved after inserting the CdS NC film, which implies a decreasing carrier recombination for CdS NC devices (Table 1). From the external quantum efficiency (EQE) spectrum (Figure 3b), one can see that the CdS NC interlayer device had a higher photon-to-electron conversion efficiency over the whole wavelength; when they were integrated, current densities of $15.99 \mathrm{~mA} / \mathrm{cm}^{2}$ and $12.30 \mathrm{~mA} / \mathrm{cm}^{2}$ were predicted, respectively, which were consistent with our $J-V$ curves (Figure $3 a$ ). It is interesting that the NC devices with a CdS NC interlayer had a drastically improved $V_{o c}(0.83 \mathrm{~V}$ for the CdS NC device, $0.69 \mathrm{~V}$ for the control device), demonstrating the advantage of the CdS NC interlayer. Figure $3 c$ shows the $V_{o c}$ of efficient CdTe NC solar cells with the different device structures (the device parameters are summarized in Table 2) that have been reported in recent years. Most devices showed a $V_{o c}$ below $0.7 \mathrm{~V}$, which was significantly lower than the devices fabricated in this work. This high $V_{o c}$ value, to the best of our knowledge, is the highest $V_{o c}$ reported for solution-processed CdTe NC solar cells with different structures. The $V_{o c}$ obtained in this work was $13-40 \%$ higher than that of the conventional CdTe- $\mathrm{ZnO}$ $\mathrm{NCs}$ solar cells and $\sim 18 \%$ higher than that of the inverted $\mathrm{CdTe}-\mathrm{TiO}_{2} \mathrm{NCs}$ solar cells previously reported. The annealing temperature and thickness of the CdS NC film evidently has an influence on the junction quality of the NC solar cells. To investigate the annealing temperature on the performance of the devices, all devices with a $3.74 \mathrm{~nm}$ CdS NC interlayer were fabricated at the same conditions except for the final annealing procedure. As shown in Figure $3 \mathrm{~d}$ (the $J-V$ curves are presented in Supporting Information Figure S2, while the parameters are summarized in Table 1), the PCE increased linearly with an annealing temperature from $330^{\circ} \mathrm{C}$ to $400{ }^{\circ} \mathrm{C}$, then dropped when the annealing temperature was further increased to $420^{\circ} \mathrm{C}$. It was noted that all the devices showed a $V_{o c}$ up to $0.7 \mathrm{~V}$, and devices annealed at $390{ }^{\circ} \mathrm{C} / 400{ }^{\circ} \mathrm{C}$ showed the highest $V_{o c}$, surpassing $0.8 \mathrm{~V}(0.82 \mathrm{~V} / 0.83 \mathrm{~V})$. It is well known that a $\mathrm{TiO}_{2}$ thin film prepared by the decomposition of a $\mathrm{Ti}^{2+}$ precursor shows a porous structure, which is of benefit for separating the hole/electron pair in the case of dye sensitization solar cells [33]. However, a planar heterojunction is expected for thin film solar cells as a reduced interface area. We anticipated that the incorporation of CdS NC on top of a $\mathrm{TiO}_{2}$ thin film would fill the hole of the $\mathrm{TiO}_{2}$ film and permit the formation of a smooth and compact CdTe NC film on top of it. Furthermore, when compared to $\mathrm{TiO}_{2}$, the CdS NC had a similar size and structure to that of CdTe NC, and therefore a high junction quality was attained in this case due to decreased defects and reduced nonradiative recombination in the interface. On the other hand, due to the low band offset between CdTe and CdS, a high $V_{o c}$ was expected once the junction quality was improved (improving annealing temperature resulted in a higher junction quality). Further increases of the annealing temperature up to $400{ }^{\circ} \mathrm{C}$ may result in the oxidation of CdTe or pin-holes in the CdTe NC thin film, and therefore low device performances will be obtained in this case. It was also found that with increases in annealing temperature from $330{ }^{\circ} \mathrm{C}$ to $400{ }^{\circ} \mathrm{C}$, the $R_{\mathrm{S}}$ decreased from $142.7 \Omega \cdot \mathrm{cm}^{-2}$ to $\sim 100 \Omega \cdot \mathrm{cm}^{-2}$, while $R_{\mathrm{sh}}$ decreased from $400 \Omega \cdot \mathrm{cm}^{-2}$ to $\sim 150 \Omega \cdot \mathrm{cm}^{-2}$. We speculated that with the increase in annealing temperature, the NC may grow larger, therefore resulting in a low $R_{\mathrm{s}}$. However, as the annealing is conducted under ambient conditions, the surface of $\mathrm{CdTe}$ may oxidize, forming $\mathrm{CdO}$ at high temperatures, which could increase the series resistance $\left(R_{\mathrm{S}}\right)$ of the NC solar cells. On the other hand, aggressive $\mathrm{CdCl}_{2}$ treatment at higher temperatures may lead to the formation of some pinholes, which will decrease the $R_{\mathrm{sh}}$ of the NC solar cells. In CdS thickness experiments, the thickness varied from 0.78 to $9.51 \mathrm{~nm}$, whereas for $\mathrm{TiO}_{2}$, the $\mathrm{CdTe}$ was fixed at $40 \mathrm{~nm}$ and $400 \mathrm{~nm}$ with the same structure $\left(\mathrm{FTO} / \mathrm{TiO}_{2} / \mathrm{CdS} / \mathrm{CdTe} / \mathrm{Au}\right)$. The PCEs with different $\mathrm{CdS}$ NC thicknesses are presented in Figure 3e (the $J-V$ curves for different $C d S$ NC thicknesses under light are provided in Supporting Information Figure S5, while the detailed photovoltaic parameters are summarized in Table 1). It was evident that the PCEs of the NC solar cells with different thicknesses of CdS were higher than those without a CdS NC interlayer. The PCEs of the NC solar cells increased with a CdS NC from 0 to $2.23 \mathrm{~nm}$, then 
degraded when the CdS NC thickness exceeded $2.23 \mathrm{~nm}$. The best device was obtained in the case of a $2.23 \mathrm{~nm}$ CdS NC interlayer, which showed the following of merits: a $J_{s c}$ of $17.38 \mathrm{~mA} / \mathrm{cm}^{2}$, a $V_{o c}$ of $0.73 \mathrm{~V}$, an FF of $40.67 \%$, and a PCE of $5.16 \%$. The best PCE value was almost one time higher than the control device. It was noted that, although a high PCE was obtained in the $2.23 \mathrm{~nm}$ CdS NC device, the $V_{o c}$ was significantly lower than that of the $3.74 \mathrm{~nm} \mathrm{CdS} \mathrm{NC} \mathrm{device.} \mathrm{We} \mathrm{anticipated} \mathrm{that} \mathrm{the} \mathrm{built-in}$ field was weak for devices with a too-thin CdS thickness due to the inadequate coverage of the $\mathrm{TiO}_{2}$ film. The $V_{o c}$ value was proportional to the built-in field in the NC solar cells. With an increase in the CdS NC thickness, the built-in field of the NC solar cells increased and a high $V_{o c}$ was expected in this case, which conformed to our experiment results. However, with the increase in the CdS NC film thickness, the $R_{\mathrm{S}}$ of the NC solar cells increased, which may affect the $J_{s C}$ and FF of the NC solar cells. Furthermore, the junction quality of $\mathrm{CdTe} / \mathrm{CdS} / \mathrm{TiO}_{2}$ also had significant effects on the FF and the efficiency of the NC solar cells. One of the major issues for solution-processed NC solar cells is device stability. We examined the stability of NC solar cells without a CdS NC interlayer under ambient operating conditions. In this device configuration, the stability of the NC solar cells is mainly related to the $\mathrm{CdTe} / \mathrm{TiO}_{2}$ interface, the $\mathrm{CdTe} \mathrm{NC}$ active layer, and the back contact. A device with a CdS NC interlayer maintained $96.7 \%$ of its PCE after being placed at ambient conditions (Figure $3 f$ ) for 30 days. In contrast, the control device only maintained $79.2 \%$ of its initial efficiency. We speculated that the introduction of a CdS NC interlayer restrains the diffusion of defects on the surface of the CdTe NC, therefore improving the stability of the NC solar cells.

Table 1. Summary of the photovoltaic parameters of the NC solar cells prepared under different conditions.

\begin{tabular}{|c|c|c|c|c|c|c|c|}
\hline Annealing Temperature $\left({ }^{\circ} \mathrm{C}\right)$ & CdS Layer Thickness (nm) & $V_{o c}(\mathrm{~V})$ & $J_{s c}\left(\mathrm{~mA} / \mathrm{cm}^{2}\right)$ & FF (\%) & PCE (\%) & $R_{S}\left(\Omega \cdot \mathrm{cm}^{-2}\right)$ & $R_{s h}\left(\Omega \cdot \mathrm{cm}^{-2}\right)$ \\
\hline 400 & 0 & 0.69 & 12.32 & 31.17 & 2.65 & 96.7 & 149.1 \\
\hline 330 & 3.74 & 0.71 & 6.88 & 29.07 & 1.42 & 142.7 & 408.0 \\
\hline 350 & 3.74 & 0.71 & 12.67 & 26.01 & 2.34 & 96.1 & 101.4 \\
\hline 380 & 3.74 & 0.75 & 14.66 & 30.56 & 3.36 & 101.7 & 228.4 \\
\hline 390 & 3.74 & 0.82 & 15.61 & 30.62 & 3.92 & 103.0 & 135.8 \\
\hline 400 & 3.74 & 0.83 & 16.02 & 30.46 & 4.05 & 108.8 & 163.4 \\
\hline 420 & 3.74 & 0.71 & 9.11 & 24.89 & 1.61 & 148.4 & 157.8 \\
\hline 400 & 0.78 & 0.73 & 14.56 & 31.24 & 3.32 & 93.0 & 103.9 \\
\hline 400 & 2.23 & 0.73 & 17.38 & 40.67 & 5.16 & 51.9 & 268.3 \\
\hline 400 & 9.51 & 0.72 & 11.78 & 20.28 & 1.72 & 126.8 & 54.4 \\
\hline
\end{tabular}

Table 2. Summary of the $V_{o c}$ obtained in efficient CdTe NC solar cells in the literature.

\begin{tabular}{|c|c|c|c|c|c|}
\hline Device Architecture & $V_{o c}(\mathrm{~V})$ & $J_{s c}\left(\mathrm{~mA} / \mathrm{cm}^{2}\right)$ & FF $(\%)$ & AM 1.5G Efficiency (\%) & Ref. \\
\hline $\mathrm{ITO} / \mathrm{CdTe} / \mathrm{CdSe} / \mathrm{Ca} / \mathrm{Al}$ & 0.45 & 13.2 & 49 & 2.9 & [1] \\
\hline $\mathrm{ITO} / \mathrm{CdTe} / \mathrm{Al}$ & 0.50 & 4.1 & 51 & 1.1 & [9] \\
\hline $\mathrm{ITO} / \mathrm{CdTe} / \mathrm{ZnO} / \mathrm{Al}$ & 0.59 & 20.7 & 56 & 6.9 & {$[12]$} \\
\hline $\mathrm{ITO} / \mathrm{CdTe} / \mathrm{In}: \mathrm{ZnO} / \mathrm{Al}$ & 0.68 & 25.8 & 71 & 12.3 & {$[21]$} \\
\hline $\mathrm{ITO} / \mathrm{CdTe} / \mathrm{ZnO} / \mathrm{Al}$ & 0.69 & 25.5 & 64.7 & 11.3 & [5] \\
\hline $\mathrm{ITO} / \mathrm{ZnO} / \mathrm{CdSe} / \mathrm{CdTe} / \mathrm{Au}$ & 0.65 & 15.28 & 58.5 & 5.81 & {$[22]$} \\
\hline $\mathrm{ITO} / \mathrm{TiO}_{2} / \mathrm{CdTe} /$ spiro-OMeTAD/Au & 0.71 & 15.82 & 45.2 & 5.16 & [25] \\
\hline $\mathrm{ITO} / \mathrm{ZnO} / \mathrm{CdSe} / \mathrm{CdSe}: \mathrm{CdTe} / \mathrm{CdTe} / \mathrm{Au}$ & 0.60 & 21.06 & 49.5 & 6.25 & {$[23]$} \\
\hline $\mathrm{ITO} /\left(\mathrm{N}_{2} \mathrm{H}_{5}\right)_{2} \mathrm{CdTe}_{2} / \mathrm{CdTe} / \mathrm{ZnO}: \mathrm{In} / \mathrm{Al}$ & 0.73 & 24.6 & 71 & 12.7 & [24] \\
\hline $\mathrm{FTO} / \mathrm{ZnO} / \mathrm{Sb}: \mathrm{TiO}_{2} / \mathrm{CdTe} / \mathrm{Au}$ & 0.74 & 11.16 & 30.13 & 2.49 & [32] \\
\hline $\mathrm{ITO} / \mathrm{ZnO} / \mathrm{CdS} / \mathrm{CdTe} / \mathrm{Si}-\mathrm{TPA} / \mathrm{Au}$ & 0.67 & 20.58 & 52.76 & 7.27 & [27] \\
\hline $\mathrm{FTO} / \mathrm{TiO}_{2} / \mathrm{CdS} / \mathrm{CdTe} / \mathrm{Au}$ & 0.83 & 16.02 & 30.5 & 4.05 & This Work \\
\hline
\end{tabular}



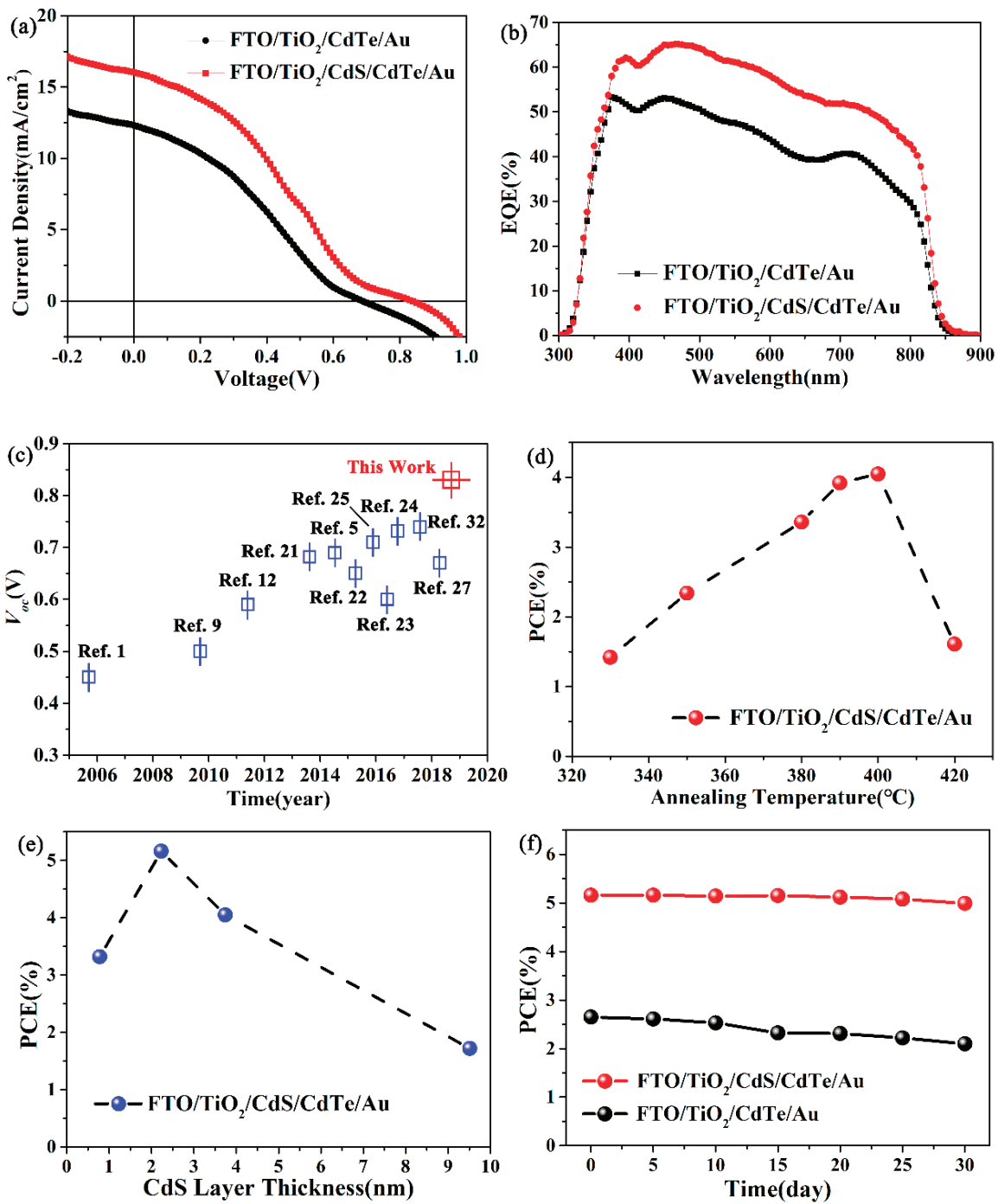

Figure 3. (a) $J-V$ characteristics of the $\mathrm{NC}$ solar cells with/without a CdS (3.74 nm) NC interlayer in a structure of $\mathrm{FTO} / \mathrm{TiO}_{2} / \mathrm{CdS}$ (with/without)/CdTe/Au. The $J-V$ curves were measured under $100 \mathrm{~mW} \cdot \mathrm{cm}^{-2} \mathrm{AM} 1.5 \mathrm{G}$ illumination, which were corrected by a calibrated Si solar cell. Corresponding (b) external quantum efficiency (EQE) spectrum; (c) Summary of the $V_{o c}$ of efficient CdTe NC solar cells reported in the literature; NC solar cells with (d) different annealing temperatures and (e) different thicknesses of CdS NC film; and (f) The stabilized PCEs of NC solar cells with/without a CdS NC interlayer.

To gain more insight into the performance improvement in NC solar cells with a CdS NC interlayer, we characterized the $J-V$ curves under dark. As shown in Figure 4a, the current at the reversed bias from a device with a CdS NC interlayer was almost one order lower than that from a device without a CdS NC interlayer. The low leakage current implied that the CdS NC interlayer could decrease the $\mathrm{CdTe} / \mathrm{TiO}_{2}$ interface defects and carrier recombination, resulting in a significant improvement in device performance. The built-in potential $\left(V_{b i}\right)$ of the NC solar cells was mainly determined by 
the $p$ - $n$ junction between the $\mathrm{CdTe}$ and $n$-type partner. Compared to $\mathrm{TiO}_{2}, \mathrm{CdS}$ had a lower lattice mismatch with CdTe and a lower band offset; therefore, a higher $V_{o c}$ was expected in devices with a CdS NC interlayer, which agreed well to our experimental results. Capacitance-voltage curves (measured at a constant frequency of $1000 \mathrm{~Hz}$ ) were carried out to investigate the built-in field of NC solar cells with/without a CdS NC interlayer. The $C^{-2}$ with voltage $(V)$ plotted is shown in Figure $4 \mathrm{~b}$. According to the Mott-Schottky equation [34],

$$
C^{-2}=\frac{2}{A^{2} \mathrm{q} \varepsilon_{0} \varepsilon N_{A}}\left(V_{b i}-V\right)
$$

where $A$ is the active area $\left(0.16 \mathrm{~cm}^{2}\right) ; \varepsilon$ is the relative dielectric constant of $\mathrm{CdTe}(10.6) ; \varepsilon_{0}$ is the vacuum permittivity; and $N_{A}$ is the net acceptor concentration. The $V_{b i}$ was extracted at a forward bias from the interception of the fitted line with the $x$ axis. A higher $V_{b i}(0.82 \mathrm{~V})$ for devices with a CdS NC interlayer was observed, while this value was $0.72 \mathrm{~V}$ for devices without a CdS NC interlayer, which agreed well with their $J-V$ curves, as shown in Figure 3a. The $N_{A}$ of NC solar cells calculated from the above formula was $\sim 10^{16} / \mathrm{cm}^{3}$. Altering the annealing temperature or using a different structure did not have a significant effect on the $N_{\mathrm{a}}$ value. To further investigate the effects of the CdS NC interlayer on the recombination process of the NC solar cells, the transient photovoltage (TPV) was used to measure the charge recombination in the NC solar cells with/without a CdS NC interlayer. In the case of TPV measurement, a steady state equilibrium was obtained when the NC solar cells were placed under a white light bias and an additional number of charges were generated by applying another weak laser pulse. As shown in Figure 4c, the charge recombination was characterized by tracking the transient voltage associated with the perturbations in charge population. The charge recombination times for NC devices with/without a CdS NC interlayer were $2.96 \mu$ s and $1.26 \mu \mathrm{s}$, respectively, which implied a lower charge recombination rate in the CdS NC interlayer device when compared to devices without a CdS NC interlayer. The roll-over of $J-V$ at high annealing temperatures $\left(400{ }^{\circ} \mathrm{C}\right.$ or above, Figure 3a, Figures S4 and S6), which was also found in our previous work, was also noteworthy [32]. The roll-over mainly originated from the non-ohmic contact between the CdTe and $\mathrm{Au}$, which can be mainly attributed to the large resistance present in the surface of the CdTe NC thin film. We speculated that CdO formed on the surface of the CdTe NC film at high annealing temperatures under ambient conditions. As $\mathrm{CdO}$ is an n-type semiconductor material, the device showed a $n\left(\mathrm{TiO}_{2}\right)-p(\mathrm{CdTe})-n(\mathrm{CdO})$ structure, so a $J-V$ curve with roll-over was very likely to be obtained in this case. Pin-holes that formed in some parts of the NC thin film (due to the large inner stress in NC thin film at high temperature) or the diffusion of $\mathrm{CdCl}_{2}$ across the whole NC thin film may also result in device shunt at high annealing temperatures. In this case, a low FF is likely to be obtained. In order to improve the contact quality, we also fabricated an $\mathrm{NC}$ device with a $\mathrm{MoO}_{\mathrm{x}} / \mathrm{Au}$ back contact or devices that were ozone etched before the Au electrode was deposited. The J-V curves for the devices with the structure $\mathrm{FTO} / \mathrm{TiO}_{2} / \mathrm{CdS} / \mathrm{CdTe} / \mathrm{MoO}_{\mathrm{x}}(5 \mathrm{~nm}) / \mathrm{Au}$ and the devices with different ozone etching times are presented in the Supporting Information Figure S7a,b, while the photovoltaic parameters are summarized in Table S1. Unfortunately, all of these attempts may result in devices shunting, or the degradation of the device performance. Further work should be carried out to eliminate the roll over to improve the performance of the NC solar cells. 

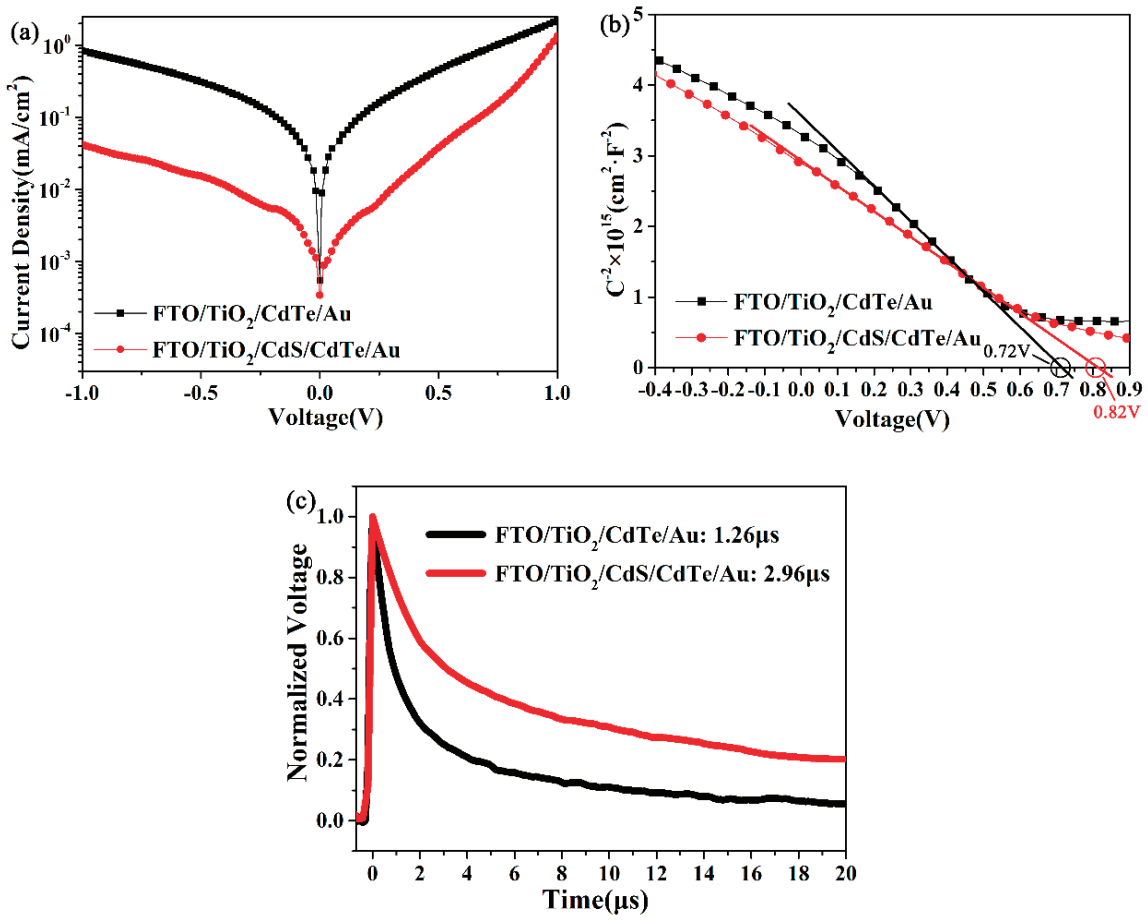

Figure 4. (a) $J-V$ curves of the NC solar cells with/without a CdS thin film under dark; (b) Mott-Schottky curves in dark conditions measured at a constant frequency of $1000 \mathrm{~Hz}$ for the NC solar cell device with/without a CdS interlayer; and (c) Transient photovoltage measurements of the NC solar cells with/without a CdS interlayer.

\section{Conclusions}

In conclusion, we fabricated efficient $\mathrm{CdTe} \mathrm{NC} / \mathrm{TiO}_{2}$ heterojunction solar cells through a simple layer by layer sintering solution process. The introduction of a thin layer of CdS NC between the $\mathrm{CdTe}$ and $\mathrm{TiO}_{2}$ resulted in optimized band alignment and reduced the interface defects. Compared to the control devices, drastic improvements in $V_{o c}$ and PCE were observed for the devices with a CdS $\mathrm{NC}$ interlayer. A $V_{o c}$ as high as $0.83 \mathrm{~V}$ was attained by optimizing the thickness of the CdS NC, which was the highest record for solution-processed CdTe NC solar cells. After carefully optimizing the fabrication parameters, we obtained a device with a PCE of $5.16 \%$, showing a $94.7 \%$ increase when compared to the control device. Our work here provides a new way to improve the $V_{o c}$ and performance of CdTe NC solar cells.

Supplementary Materials: The following are available online at http:/ /www.mdpi.com/2079-4991/8/8/614/s1, Figure S1: TEM images of as prepared (a) CdS and (b) CdTe nanocrystal, Figure S2: Transmission spectrum of $\mathrm{FTO} / \mathrm{TiO}_{2} / \mathrm{CdS}$ with different thickness of CdS NC film, Figure S3: EDS obtained on the cross-section of CdTe $\mathrm{NC}$ solar cells with configuration of $\mathrm{FTO} / \mathrm{TiO}_{2} / \mathrm{CdS} / \mathrm{CdTe} / \mathrm{Au}$, Figure S4: $J-V$ characteristic of NC solar cells with different annealing temperatures (all devices with $3.74 \mathrm{~nm}$ CdS interlayer), Figure S5: XRD pattern of FTO/ $\mathrm{TiO}_{2}$ and $\mathrm{FTO} / \mathrm{TiO}_{2} / \mathrm{CdS}$, Figure S6: $J-V$ characteristic of NC solar cells with different thicknesses of CdS NC film (all devices annealing at $400^{\circ} \mathrm{C}$ ), Figure S7: (a) $J-V$ curves for NC solar cells with/without MoOx buffer layer (b) $J-V$ curves for NCs solar cells with different ozone etching times, Table S1: Summarized photovoltaic parameters from Figure S4.

Author Contributions: D.Q. and X.M. conceived and designed the experiments; X.M., B.W., and X.L. performed the experiments; X.M. and B.C. analyzed the data; X.G., Z.R., S.L., and Y.C. contributed reagents/materials/analysis tools; and X.M., D.Q., W.X. and L.H. wrote the paper. 
Funding: This research received no external funding.

Acknowledgments: We thank the financial support of the National Natural Science Foundation of China (Nos. 91333206, 61274062, and 61774077), the Guangzhou Science and Technology Planning Project (No. 201804010295), the National Undergraduate Innovative and Entrepreneurial Training Program (No. 201810561016), and the Fundamental Research Funds for the Central Universities.

Conflicts of Interest: The authors declare no conflict of interest.

\section{References}

1. Gur, I.; Fromer, N.A.; Geier, M.L.; Alivisators, A.P. Air-Stable All-Inorganic Nanocrystal Solar Cells Processed from Solution. Science 2005, 310, 462-465. [CrossRef] [PubMed]

2. Kim, T.; Firdaus, Y.; Kirmani, A.R.; Liang, R.Z.; Hu, H.; Liu, M.; Labban, A.E.; Hoogland, S.; Beaujuge, P.M.; Sargent, E.H.; et al. Hybrid Tandem Quantum Dot/Organic Solar Cells with Enhanced Photocurrent and Efficiency via Ink and Interlayer Engineering. ACS Energy Lett. 2018, 3, 1307-1314. [CrossRef]

3. Wen, X.; Chen, C.; Lu, S.; Li, K.; Kondrotas, R.; Zhao, Y.; Chen, W.; Gao, L.; Wang, C.; Zhang, J.; et al. Vapor transport deposition of antimony selenide thin film solar cells with $7.6 \%$ efficiency. Nat. Commun. 2018, 9, 2179. [CrossRef] [PubMed]

4. Li, D.B.; Yin, X.; Grice, C.R.; Guan, L.; Song, Z.; Wang, C.; Chen, C.; Li, K.; Cimaroli, A.J.; Awni, R.A.; et al. Stable and efficient $\mathrm{CdS} / \mathrm{Sb}_{2} \mathrm{Se}_{3}$ solar cells prepared by scalable close space sublimation. Nano Energy 2018, 49, 346-353. [CrossRef]

5. Crisp, R.W.; Panthani, M.G.; Rance, W.L.; Duenow, J.N.; Parilla, P.A.; Callahan, R.; Dabney, M.S.; Berry, J.J.; Talapin, D.V.; Luther, J.M. Nanocrystal Grain Growth and Device Architectures for High-Efficiency CdTe Ink-Based Photovoltaics. ACS NANO 2014, 8, 9063-9072. [CrossRef] [PubMed]

6. Chen, Z.; Du, X.; Zeng, Q.; Yang, B. Recent development and understanding of polymer-nanocrystal hybrid solar cells. Mater. Chem. Front. 2017, 1, 1502-1513. [CrossRef]

7. Zhao, Y.; Tan, H.; Yuan, H.; Yang, Z.; Fan, J.Z.; Kim, J.; Voznyy, O.; Gong, X.; Quan, L.N.; Tan, C.S.; et al. Perovskite seeding growth of formamidinium-leadiodide-based perovskites for efficient and stable solar cells. Nat. Commun. 2018, 9, 1607. [CrossRef] [PubMed]

8. He, Z.; Zhong, C.; Su, S.; Xu, M.; Wu, H.; Cao, Y. Enhanced power-conversion efficiency in polymer solar cells using an inverted device structure. Nat. Photon. 2012, 6, 591-595. [CrossRef]

9. Anderson, I.E.; Breeze, A.J.; Olson, J.D.; Yang, L.; Sahoo, Y.; Carter, S.A. All-inorganic spin-cast nanoparticle solar cells with nonselective electrodes. Appl. Phys. Lett. 2009, 94, 063101. [CrossRef]

10. Townsend, T.K.; Foos, E.E. Fully solution processed all inorganic nanocrystal solar cells. Phys. Chem. Chem. Phys. 2014, 16, 16458. [CrossRef] [PubMed]

11. Tian, Y.; Zhang, Y.; Lin, Y.; Gao, K.; Zhang, Y.; Liu, K.; Yang, Q.; Zhou, X.; Qin, D.; Wu, H.; et al. Solution-processed efficient CdTe nanocrystal/CBD-CdS hetero-junction solar cells with ZnO interlayer. J. Nanopart. Res. 2013, 15, 2053. [CrossRef]

12. Jasieniak, J.; MacDonald, B.I.; Watkins, S.E.; Mulvaney, P. Solution-Processed Sintered Nanocrystal Solar Cells via Layer-by-Layer Assembly. Nano Lett. 2011, 11, 2856-2864. [CrossRef] [PubMed]

13. Xue, H.; Wu, R.; Xie, Y.; Tan, Q.; Qin, D.; Wu, H.; Huang, W. Recent Progress on Solution-Processed CdTe Nanocrystals Solar Cells. Appl. Sci. 2016, 6, 197. [CrossRef]

14. Kumar, S.G.; Rao, K.S.R.K. Physics and chemistry of CdTe/CdS thin film heterojunction photovoltaic devices: fundamental and critical aspects. Energy Environ. Sci. 2014, 7, 45. [CrossRef]

15. Tan, H.; Jain, A.; Voznyy, O.; Lan, X.; Arquer, F.P.G.D.; Fan, J.Z.; Quintero-Bermudez, R.; Yuan, M.; Zhang, B.; Zhao, Y.; et al. Efficient and stable solution-processed planar perovskite solar cells via contact passivation. Science 2017, 355, 722-726. [CrossRef] [PubMed]

16. Green, M.A.; Hishikawa, Y.; Dunlop, E.D.; Levi, D.H.; Hohl-Ebinger, J.; Ho-Baillie, A.W.Y. Solar cell efficiency tables (version 51). Prog. Photovolt. Res. Appl. 2018, 26, 3-12. [CrossRef]

17. Grätzel, M. The light and shade of perovskite solar cells. Nat. Mater. 2014, 13, 838-842. [CrossRef] [PubMed]

18. Kotina, I.M.; Tukhkonen, L.M.; Patsekina, G.V.; Shchukarev, A.V.; Gusinskii, G.M. Study of CdTe etching process in alcoholic solutions of bromine. Semicond. Sci. Technol. 1998, 13, 890-894. [CrossRef]

19. Seymour, F.H.; Kaydanov, V.; Ohno, T.R. $\mathrm{Cu}$ and $\mathrm{CdCl}_{2}$ influence on defects detected in CdTe solar cells with admittance spectroscopy. Appl. Phys. Lett. 2005, 87, 153507. [CrossRef] 
20. Rose, D.H.; Hasoon, F.S.; Dhere, R.G.; Albin, D.S.; Ribelin, R.M.; Li, X.S.; Mahathongdy, Y.; Gessert, T.A.; Sheldon, P. Fabrication Procedures and Process Sensitivities for CdS/CdTe Solar Cells. Prog. Photovolt. Res. Appl. 1999, 7, 331-340. [CrossRef]

21. Panthani, M.G.; Kurley, J.M.; Crisp, R.W.; Dietz, T.C.; Ezzyat, T.; Luther, J.M.; Talapin, D.V. High Efficiency Solution Processed Sintered CdTe Nanocrystal Solar Cells: The Role of Interfaces. Nano Lett. 2014, 14, 670-675. [CrossRef] [PubMed]

22. Liu, H.; Tian, Y.; Zhang, Y.; Gao, K.; Lu, K.; Wu, R.; Qin, D.; Wu, H.; Peng, Z.; Hou, L.; et al. Solution processed $\mathrm{CdTe} / \mathrm{CdSe}$ nanocrystal solar cells with more than $5.5 \%$ efficiency by using an inverted device structure. J. Mater. Chem. C. 2015, 3, 4227-4234. [CrossRef]

23. Xie, Y.; Tan, Q.; Zhang, Z.; Lu, K.; Li, M.; Xu, W.; Qin, D.; Zhang, Y.; Hou, L.; Wu, H. Improving performance in CdTe/CdSe nanocrystals solar cells by using bulk nano-heterojunctions. J. Mater. Chem. C. 2016, 4, 6483. [CrossRef]

24. Kurley, J.M.; Panthani, M.G.; Crisp, R.W.; Nanayakkara, S.U.; Pach, G.F.; Reese, M.O.; Hudson, M.H.; Dolzhnikov, D.S.; Tanygin, V.; Luther, J.M.; et al. Transparent Ohmic Contacts for Solution-Processed, Ultrathin CdTe Solar Cells. ACS Energy Lett. 2017, 2, 270-278. [CrossRef]

25. Du, X.; Chen, Z.; Liu, F.; Zeng, Q.; Jin, G.; Li, F.; Yao, D.; Yang, B. Improvement in Open-Circuit Voltage of Thin Film Solar Cells from Aqueous Nanocrystals by Interface Engineering. ACS Appl. Mater. Interfaces 2016, 8, 900-907. [CrossRef] [PubMed]

26. Zeng, Q.; Hu, L.; Cui, J.; Feng, T.; Du, X.; Jin, G.; Liu, F.; Ji, T.; Li, F.; Zhang, H.; et al. High-Efficiency Aqueous-Processed Polymer/CdTe Nanocrystals Planar Heterojunction Solar Cells with Optimized Band Alignment and Reduced Interfacial Charge Recombination. ACS Appl. Mater. Interfaces 2017, 9, 31345-31351. [CrossRef] [PubMed]

27. Guo, X.; Tan, Q.; Liu, S.; Qin, D.; Mo, Y.; Hou, L.; Liu, A.; Wu, H.; Ma, Y. High-efficiency solution-processed CdTe nanocrystal solar cells incorporating a novel crosslinkable conjugated polymer as the hole transport layer. Nano Energy 2018, 46, 150-157. [CrossRef]

28. Liu, S.; Liu, W.; Heng, J.; Zhou, W.; Chen, Y.; Wen, S.; Qin, D.; Hou, L.; Wang, D.; Xu, H. Solution-Processed Efficient Nanocrystal Solar Cells Based on CdTe and CdS Nanocrystals. Coatings 2018, 8, 26. [CrossRef]

29. Wen, S.; Li, M.; Yang, J.; Mei, X.; Wu, B.; Liu, X.; Heng, J.; Qin, D.; Hou, L.; Xu, W.; et al. Rationally Controlled Synthesis of $\mathrm{CdSe}_{\mathrm{x}} \mathrm{Te}_{1-\mathrm{x}}$ Alloy Nanocrystals and Their Application in Efficient Graded Bandgap Solar Cells. Nanomaterials 2017, 7, 380. [CrossRef] [PubMed]

30. Liu, H.; Tang, J.; Kramer, I.J.; Debnath, R.; Koleilat, G.I.; Wang, X.; Fisher, A.; Li, R.; Brzozowski, L.; Levina, L.; et al. Electron Acceptor Materials Engineering in Colloidal Quantum Dot Solar Cells. Adv. Mater. 2011, 23, 3832-3837. [CrossRef] [PubMed]

31. Yang, Y.; Zhao, B.; Gao, Y.; Liu, H.; Tian, Y.; Qin, D.; Wu, H.; Huang, W.; Hou, L. Novel Hybrid Ligands for Passivating PbS Colloidal Quantum Dots to Enhance the Performance of Solar Cells. Nano-Micro Lett. 2015, 7, 325-331. [CrossRef]

32. Li, M.; Liu, X.; Wen, S.; Liu, S.; Heng, J.; Qin, D.; Hou, L.; Wu, H.; Xu, W.; Huang, W. CdTe Nanocrystal Hetero-Junction Solar Cells with High Open Circuit Voltage Based on Sb-doped $\mathrm{TiO}_{2}$ Electron Acceptor Materials. Nanomaterials 2017, 7, 101. [CrossRef] [PubMed]

33. Galliano, S.; Bella, F.; Gerbaldi, C.; Falco, M.; Viscardi, G.; Grätzel, M.; Barolo, C. Photoanode/Electrolyte Interface Stability in Aqueous Dye-Sensitized Solar Cells. Energy Technol. 2017, 5, 300-311. [CrossRef]

34. Zhu, J.; Yang, Y.; Gao, Y.; Qin, D.; Wu, H.; Hou, L.; Huang, W. Enhancement of open-circuit voltage and fill factor in CdTe nanocrystals solar cells by using interface materials. Nanotechnology 2014, 25, 365203. [CrossRef] [PubMed]

(C) 2018 by the authors. Licensee MDPI, Basel, Switzerland. This article is an open access article distributed under the terms and conditions of the Creative Commons Attribution (CC BY) license (http:/ / creativecommons.org/licenses/by/4.0/). 
Article

\title{
Improving Electron Extraction Ability and Device Stability of Perovskite Solar Cells Using a Compatible PCBM/AZO Electron Transporting Bilayer
}

\author{
Hang Dong, Shangzheng Pang, Yi Zhang *, Dazheng Chen, Weidong Zhu, He Xi, Jingjing Chang, \\ Jincheng Zhang, Chunfu Zhang * and Yue Hao \\ State Key Discipline Laboratory of Wide Band Gap Semiconductor Technology, School of Microelectronics, \\ Xidian University, 2 South Taibai Road, Xi'an 710071, China; donghangxd@163.com (H.D.); \\ 18717344558@163.com (S.P.); dzchen@xidian.edu.cn (D.C.); wdzhu@xidian.edu.cn (W.Z.); \\ hxi@xidian.edu.cn (H.X.); jjingchang@xidian.edu.cn (J.C.); jchzhang@xidian.edu.cn (J.Z.); \\ yhao@xidian.edu.cn (Y.H.) \\ * Correspondence: hyper_sys@163.com (Y.Z.); cfzhang@xidian.edu.cn (C.Z.)
}

Received: 2 August 2018; Accepted: 6 September 2018; Published: 12 September 2018

\begin{abstract}
Due to the low temperature fabrication process and reduced hysteresis effect, inverted p-i-n structured perovskite solar cells (PSCs) with the PEDOT:PSS as the hole transporting layer and PCBM as the electron transporting layer have attracted considerable attention. However, the energy barrier at the interface between the PCBM layer and the metal electrode, which is due to an energy level mismatch, limits the electron extraction ability. In this work, an inorganic aluminum-doped zinc oxide (AZO) interlayer is inserted between the PCBM layer and the metal electrode so that electrons can be collected efficiently by the electrode. It is shown that with the help of the PCBM/AZO bilayer, the power conversion efficiency of PSCs is significantly improved, with negligible hysteresis and improved device stability. The UPS measurement shows that the AZO interlayer can effectively decrease the energy offset between PCBM and the metal electrode. The steady state photoluminescence, time-resolved photoluminescence, transient photocurrent, and transient photovoltage measurements show that the PSCs with the AZO interlayer have a longer radiative carrier recombination lifetime and more efficient charge extraction efficiency. Moreover, the introduction of the AZO interlayer could protect the underlying perovskite, and thus, greatly improve device stability.
\end{abstract}

Keywords: perovskite solar cells; aluminum-doped zinc oxide (AZO); electron transporting bilayer; stability

\section{Introduction}

Despite uncertainties regarding device stability and the usage of lead, metal halide perovskite solar cells (PSCs) have attracted increasing attention from both academia and industry due to their unprecedented properties, such as high absorption coefficients, long charge carrier diffusion lengths, and solution processing approach, since their first use as the active layer for photoelectron chemical cells in 2009 [1,2]. In the past few years, the power conversion efficiency (PCE) of PSCs has been rising dramatically, from $3.8 \%$ [3] to present values which are higher than $23 \%$ [4]. So far, two main device architectures have been used to fabricate PSCs. One is named the n-i-p structure, which usually involves depositing the perovskite material onto transparent substrates covered with a compact $\mathrm{TiO}_{2}$ electron transport layer (ETL) and an optional mesoporous $\mathrm{TiO}_{2}\left(\mathrm{or}_{\mathrm{Al}_{2} \mathrm{O}_{3}}\right)$ scaffold layer $[5,6]$. The other is named the $\mathrm{p}-\mathrm{i}-\mathrm{n}$ structure, which involves depositing the perovskite material onto transparent substrates which are covered with a hole transport layer (HTL), such as 
the poly(3,4-ethylenedioxythiophene):polystyrene sulfonic acid (PEDOT:PSS) [7,8]. High temperature annealing is usually necessary for the n-i-p structure to attaim high quality $\mathrm{TiO}_{2}$ layers compared to the p-i-n structure, which could increase the production cost, and prevent its use in flexible substrates and multi-junction device architectures. As an alternative approach, the $\mathrm{p}$-i-n structure is being used in this paper with PEDOT:PSS as the HTL and [6,6]-phenyl-C61-butyric acid methyl ester (PCBM) as the ETL, due to the low temperature fabrication process and reduced hysteresis effects $[7,8]$.

In order to improve the PCE of p-i-n PSCs, many film growth methods such as the one step method [8], two step sequential deposition method [9-11], and the mixed-solvent-vapor annealing method [7] have been developed to achieve a highly uniform, dense, and pin-hole free perovskite films, which can yield more electron-hole pairs upon illumination with light, and thereby reduce the energy loss induced by recombination. With the continuous quality improvement of perovskite films, another issue in regard to interfaces in the PSCs is becoming more and more important, i.e., the p-i-n structure requires that the ETL be deposited on top of the perovskite layer. PCBM as a typical ETL is usually used in this structure. However, if the cathode electrode $(\mathrm{Ag}, \mathrm{Al})$ is evaporated onto the PCBM layer directly, there is always an energy barrier at the interface between the PCBM layer and the metal electrode due to the energy level mismatch [12]. Such a PCBM/metal electrode is not optimized for the electron extraction [12]. Therefore, in order to improve the device performance, a method of interface engineering between the PCBM layer and the metal electrode whereby additional layers are inserted has been proposed. In the past few years, some attempts have been proposed to improve the electron extraction properties between the PCBM layer and the metal electrode. For example, by inserting the interlayer of LiF between PCBM and electrode, Seo et al. achieved a PSC with a PCE of $14.1 \%$ for a unit cell and $8.7 \%$ for the module [13]. By using the polyethylenimine ethoxylated (PEIE) interlayer between the PCBM and electrode, Yang et al. demonstrated a high performance planar heterojunction PSC with a PCE of 14.82\% [12]. By inserting the Ca between the PCBM and electrode, Chiang et al. achieved the best PCE, 16.31\% [14]. By using the $\mathrm{C}_{60}$ and bathocuproine (BCP) interface modified layer, an optimal PCE of $17.9 \%$ was obtained [15]. By inserting PFN (poly [(9,9-bis(30-(N,N-dimethylamino)propyl)-2,7-fluorence)-alt-2,7-(9,9-dioct ylfluorene)]) interlayer between the PCBM and electrode, You et al. got an improved PCE of 17.1\% [16]. All of these have shown that inserting the interlayer between the PCBM and electrode is an effective way to improve device performance. However, the interlayer materials such as the low workfunction metal (Ca) or organic materials are usually not stable enough. Thus, other interface materials are required. There are many n-type metal oxides such as zinc oxide $(\mathrm{ZnO})[17,18]$, titanium oxide $\left(\mathrm{TiO}_{\mathrm{x}}\right)[19,20]$, and tin oxide $\left(\mathrm{SnO}_{2}\right)$ [21-23], which has a low work function, and improves the electron extraction ability when used as the interlayer. However, in order to achieve good material quality, these metal oxides usually require a high temperature process, which is not suitable for the $\mathrm{p}-\mathrm{i}-\mathrm{n}$ structure in PSCs because the high process temperature will destroy the underlying perovskite materials. Thus, the means by which a high quality metal oxide may be obtained at a low temperature becomes important for the $\mathrm{p}$-i-n structure in PSCs.

In this work, we adopt a room temperature solution processed Al-doped $\mathrm{ZnO}(\mathrm{AZO})$ as the interlayer between the PCBM and Ag electrode to improve device performance. AZO is a wide bandgap material with beneficial properties such as low workfunciton, high electron mobility, high optical transparency, and low-cost [24]. By using the AZO interlayer, the fabricated PSC shows an improved performance with low hysteresis and enhanced device stability. By comparing to devices without the AZO interlayer, it was found that the PSC with the AZO interlayer has a longer radiative carrier recombination lifetime. This may be attributed to the reduction of the energy mismatch between the PCBM layer and Ag electrode by introducing the AZO interlayer, which improved the electron extraction ability. By using the PCBM/AZO bilayer, a PSC with a short current density (Jsc) of $22.82 \mathrm{~mA} / \mathrm{cm}^{2}$, an open circuit voltage (Voc) of $0.99 \mathrm{~V}$, a fill factor $(\mathrm{FF})$ of $71.68 \%$, and PCE of $16.18 \%$ was achieved. Moreover, the AZO interlayer can improve the stability of the device, with the PCE of the best device remaining $86.41 \%$ of its initial value after storing the device for over $720 \mathrm{~h}$. 


\section{Materials and Methods}

\subsection{Materials}

All solvents and reagents, Aluminum-doped zinc oxide nanoparticle ink (AZO, 2.5 wt.\%, Sigma-Aldrich, Saint Louis, MI, USA), Methylammonium iodide (MAI, 99.8\%, Dyesol, Queanbeyan, Australia), Formamidinium iodide (FAI, 99.8\%, Dyesol, Queanbeyan, Australia), Lead iodide $\left(\mathrm{PbI}_{2}\right.$, 99.999\%, Sigma-Aldrich, Saint Louis, MI, USA), Lead chloride $\left(\mathrm{PbCl}_{2}, 99.999 \%\right.$, Sigma-Aldrich, Saint Louis, MI, USA), Phenyl-C61-butyric acid methyl ester (PCBM, 98\%, Nano-c, Westwood, MA, USA), Poly(3,4-ethy-lenedioxythiophene) Poly(styrenesulfonate) (PEDOT: PSS, Clevios PVP Al 4083, Hanau, Germany), N,N'-Dimethylformamide (DMF, 99.8\%, Aladdin, Beijing, China), Chlorobenzene (CB, 99.8\%, Sigma-Aldrich, Saint Louis, MI, USA), and Isopropanol (IPA, 99.5\%, Sigma-Aldrich, Saint Louis, MI, USA), unless stated otherwise, are used as received without further purification.

\subsection{Film Formation and Device Fabrication}

The planer PSCs were fabricated on pre-patterned ITO glass substrates ( $10 \Omega$ per square, around $2 \times 2.5 \mathrm{~cm}^{2}$ in size, Zhuhai Kaivo, Zhuhai, China). The patterned ITO glass substrates were sequentially ultrasonic cleaned with 5\% decon-90 solution, de-ionized water, acetone, de-ionized water, alcohol at $50{ }^{\circ} \mathrm{C}$ for $20 \mathrm{~min}$, respectively. Then the ITO substrates were dried with nitrogen and cleaned in a UV ozone oven for $30 \mathrm{~min}$. A thin layer of PEDOT:PSS was spin-coated on the substrates at $7000 \mathrm{rpm}$ for $45 \mathrm{~s}$, and annealed at $150^{\circ} \mathrm{C}$ for $15 \mathrm{~min}$. After that, the substrates were transferred into a nitrogen-filled glovebox. To make a uniform perovskite layer, a perovskite precursor solution consisting of $1.36 \mathrm{M} \mathrm{PbI}_{2}$ and $0.24 \mathrm{M} \mathrm{PbCl}_{2}$ in the solvent of DMF (named $\mathrm{PbX}_{2}$ solution) was stirred for $2 \mathrm{~h}$ at $75^{\circ} \mathrm{C}$, and $70 \mathrm{mg}$ $\mathrm{MAI}$ and $30 \mathrm{mg}$ FAI were dissolved in the solvent of IPA for the late use. Around $60 \mu \mathrm{L} \mathrm{PbX} 2$ precursor solution pre-heated to $75^{\circ} \mathrm{C}$ was transferred by pipettes to the PEDOT:PSS covered ITO substrates. Briefly, the spin coating process was programmed to run at $3000 \mathrm{rpm}$ for $45 \mathrm{~s}$. Then MAI and FAI mixed solution was spin-coated on top of the dried $\mathrm{PbX}_{2}$ layer at room temperature at $3000 \mathrm{rpm}$ for $45 \mathrm{~s}$. All of the films were thermally annealed on the hotplate at $100{ }^{\circ} \mathrm{C}$ for $10 \mathrm{~min}$. Next, a layer of PCBM (20 mg/mL in chlorobenzene) was spin-coated on the top of the perovskite layer at $2000 \mathrm{rpm}$ for $45 \mathrm{~s}$. After that, the AZO solution ( $8 \mathrm{mg} / \mathrm{mL}$ in IPA) was spin-coated on the top of the PCBM layer at $6000 \mathrm{rpm}$ for $45 \mathrm{~s}$, and the thickness of AZO film is about $90 \mathrm{~nm}$ measured by Stylus Profiler (Bruker Dektak XT, Bremen, Germany). The devices were finished by thermally evaporated $100 \mathrm{~nm} \mathrm{Ag}$. All the devices had an effective area of $7 \mathrm{~mm}^{2}$.

\subsection{Device Characterization}

The morphologies of the perovskite layers were measured by scanning electron microscopy (SEM) (JSM-7800F, JEOL Ltd., Tokyo, Japan) and atomic force microscopy (AFM) (Agilent 5500, Santa Clara, CA, USA). X-ray diffraction (XRD) test was conducted on $X^{\prime}$ Pert Pro XRD (Bruker Optics, Ettlingen, Germany) and the samples were prepared as the same process of device fabrication. UPS measurements were acquired with a VG ESCA 220i-XL system (VG Instruments, Manchester, UK). The UV source was a He discharge lamp with a photon energy of $21.2 \mathrm{eV}$. The UV-visible absorption spectra were recorded with an UV-visible spectrophotometer (Perkin-Elmer Lambda 950, Waltham, MA, USA). Photovoltaic performances were measured by using a Keithley 2400 source meter (Tektronix, Inc., Beaverton, OR, USA) under simulated sunlight from XES-70S1 solar simulator (SEN-EI Electric. Co. Ltd, Osaka, Japan) matching the AM $1.5 \mathrm{G}$ standard with an intensity of $100 \mathrm{~mW} / \mathrm{cm}^{2}$. The system was calibrated against a NREL certified reference solar cell. Incident photo-to-current conversion efficiencies (IPCEs) of PSCs were measured by the solar cell quantum efficiency measurement system (SCS10-X150, Zolix instrument. Co. Ltd, Beijing, China). Transient photocurrent measurement was performed with a system excited by a $532 \mathrm{~nm}(1000 \mathrm{~Hz}, 3.2 \mathrm{~ns})$ pulse laser. Transient photovoltage measurement was performed with the same system excited by a $405 \mathrm{~nm}(50 \mathrm{~Hz}, 20 \mathrm{~ms})$ pulse laser. A digital oscilloscope (Tektronix, D4105, Beaverton, OR, USA) was used to record the photocurrent or photovoltage decay 
process with a sampling resistor of $50 \Omega$ or $1 \mathrm{M} \Omega$, respectively. The thickness of AZO film was measured by Stylus Profiler (Bruker Dektak XT, Bremen, Germany). All measurements of the solar cells were performed under ambient atmosphere at room temperature without encapsulation.

\section{Results and Discussion}

The device structure in this work is shown in Figure 1a, where the PEDOT:PSS and PCBM act as the HTL and ETL, respectively. Here an inverted planar heterojunction structure is used instead of the conventional structure due to its advantages as mentioned earlier. AZO is inserted between the PCBM layer and Ag electrode to decrease the energy mismatch between them, so that the carrier collection may be efficiently improved. Figure $1 \mathrm{~b}$ shows the schematic band diagram of this work with/without AZO. The energy level mismatch between PCBM and Ag electrode could lead to inefficient carrier transport. One of the methods to enhance the performance of the p-i-n PSCs is interface engineering. It is expected that the AZO interlayer with excellent photoelectric properties can reduce the work function of metal electrode $[25,26]$, so that the carriers can be efficiently collected by the Ag electrode, as shown in Figure 1b.

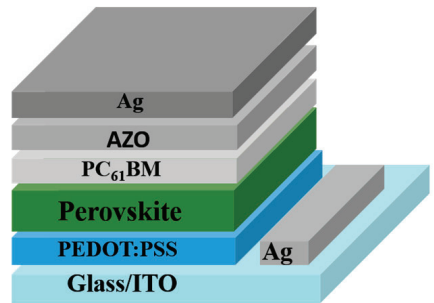

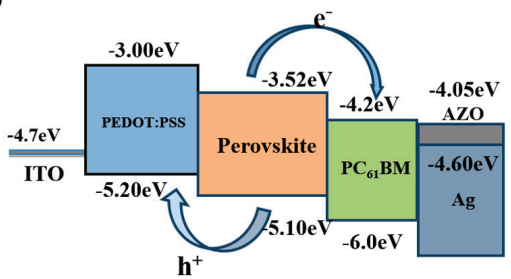

Figure 1. (a) Schematic structure of the $\mathrm{MA}_{0.7} \mathrm{FA}_{0.3} \mathrm{PbI}_{3-\mathrm{x}} \mathrm{Cl}_{\mathrm{x}}$ devices in this study: ITO/PEDOT:PSS/ $\mathrm{MA}_{0.7} \mathrm{FA}_{0.3} \mathrm{PbI}_{3-\mathrm{x}} \mathrm{Cl}_{\mathrm{x}} / \mathrm{PCBM} / \mathrm{AZO} / \mathrm{Ag}$. (b) The energy level diagram of the $\mathrm{p}-\mathrm{i}-\mathrm{n}$ solar cell. The energy levels of ITO, the bandgap of PEDOT:PSS, and the bandgap of PCBM were referenced from the previous report [12]. The workfunction of AZO was measured by UPS as stated in the following.

High quality perovskite material is the key to achieving a high performance PSC. In order to create a uniform and smooth perovskite film, a mixed-solvent-vapor annealing technique is used here, as in the previous report [7]. After spin-coated the MAI and FAI mixed solution, the perovskite films were put on top of a hot plate and covered by a glass petri dish. $40 \mu \mathrm{L}$ of IPA:DMF $(100: 1 v / v)$ solvent was added in the petri dish around the substrates during the thermal annealing process so that the solvent vapor could react with the perovskite film. Figure S1 reveals the surface morphology of the fabricated perovskite film on the top of the ITO/PEDOT:PSS layer. It is obvious that the perovskite film is uniform and smooth with the grain size approximately $300-500 \mathrm{~nm}$.

Figure 2a presents the champion current density-voltage $(\mathrm{J}-\mathrm{V})$ curves of devices with/without the AZO interlayer, and Table 1 shows the corresponding device parameters. The champion device with the AZO interlayer achieves a PCE of $16.19 \%$, with a Jsc of $22.82 \mathrm{~mA} / \mathrm{cm}^{2}$, a Voc of $0.99 \mathrm{~V}$ and a FF of $71.68 \%$. Compared with this device, the device without the AZO interlayer gives a PCE of $14.80 \%$, with a Jsc of $22.18 \mathrm{~mA} / \mathrm{cm}^{2}$, a Voc of $0.94 \mathrm{~V}$ and a FF of $71.02 \%$. The device performance with the AZO interlayer is much higher than that without the AZO layer. The higher Jsc, Voc and FF values for the device with the AZO interlayer are supposed to be mainly caused by the suitable work function and efficient charge extraction with the insertion of the AZO layer. Jsc of the devices is also checked by the IPCE spectra, as shown in Figure $2 b$. It can be seen that the Jsc of the devices integrated from the IPCE spectra matches well with those obtained from J-V measurements. The high IPCE value for the device with the AZO interlayer should be related with the excellent charge transport in the interface of PCBM/AZO bilayer. Figure S2 reveals the J-V curves of PSCs with/without the AZO interlayer measured via both forward and reverse bias sweeps. (Forward scan: from a negative bias $-0.2 \mathrm{~V}$ to 
a positive bias $1.1 \mathrm{~V}$, and reverse scan: from a positive bias $1.1 \mathrm{~V}$ to a negative bias $-0.2 \mathrm{~V}$ ). It was observed that the PSC with the AZO interlayer shows the neglect photocurrent hysteresis. On the other hand, the PSC without the AZO interlayer shows an obvious photocurrent hysteresis. The hysteresis effect in J-V measurements is one of the most challenging issues for PSCs. It has been shown that it is related to the accumulation of the interface [27]. The neglect photocurrent hysteresis for the device with the AZO interlayer means that there is negligible accumulation at the interface, and thus, better carrier extraction ability. Furthermore, the stabilized PCEs at the maximum power output point were examined, as shown in Figure 2c. The steady-state PCEs are measured to be $15.65 \%$ and $13.85 \%$ for the devices with/without the AZO interlayer, respectively. They are close to the values obtained from light $\mathrm{J}-\mathrm{V}$ curves, indicating the reliability of the $\mathrm{J}-\mathrm{V}$ curve measurement. Both the hysteresis measurement and the stead-state measurement show that the device with the AZO interlayer has the best performance, which is consistent with the PCE measurement shown in Figure 2a. This may be attributed to the fact that with the insertion of the AZO interlayer between the PCBM layer and Ag electrode, a bilayer with excellent charge transport efficiency will be formed.
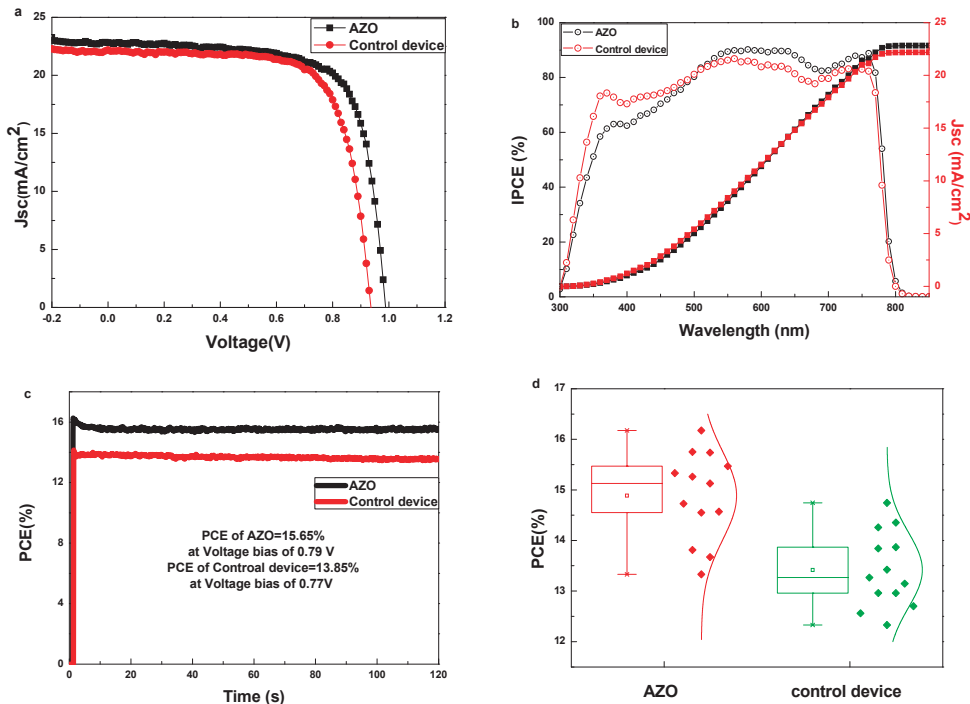

Figure 2. (a) Best performed J-V characteristics of PSCs with/without the AZO interlayer measured under $100 \mathrm{~mW} / \mathrm{cm}^{2}$ AM 1.5G illumination. (b) IPCE curves and integrated current density of PSCs with/without the AZO interlayer. (c) Steady output characteristics of PSCs with/without the AZO interlayer. (d) Statistics result of PCE for PSCs with/without the AZO interlayer.

Table 1. Photovoltaic performances of PSCs under AM 1.5G illumination $\left(100 \mathrm{~mW} / \mathrm{cm}^{2}\right)$.

\begin{tabular}{ccccc}
\hline & Jsc $\left(\mathbf{m A} / \mathbf{c m}^{\mathbf{2}}\right)$ & Voc $(\mathbf{V})$ & FF (\%) & PCE (\%) \\
\hline AZO & 22.82 & 0.99 & 71.68 & 16.19 \\
Control device & 22.18 & 0.94 & 71.02 & 14.75 \\
\hline
\end{tabular}

To confirm the above, the statistic results for the device parameters are summarized in Table S1, Figure $2 \mathrm{~d}$ and Figure S3a-c. PSCs with the AZO interlayer exhibit a promising average PCE of $14.89 \%$ with an average Jsc of $20.99 \mathrm{~mA} / \mathrm{cm}^{2}$, an average Voc of $0.97 \mathrm{~V}$ and an average $\mathrm{FF}$ of $73.34 \%$, outperforming the devices without the AZO interlayer, where an average PCE of $13.42 \%$ is achieved (the average Jsc, Voc and FF were $22.35 \mathrm{~mA} / \mathrm{cm}^{2}, 0.95 \mathrm{~V}$ and $63.60 \%$ respectively). The parameters of 
Voc and FF display significant enhancement, indicating the beneficial role of the AZO interlayer with enhanced charge extraction ability.

It is supposed that the PCBM/AZO bilayer could lower the energy barrier between the Ag electrode and the active layer; then, the electron extraction from the active layer to Ag electrode is facilitated. To verify this supposition, UPS measurement was carried out. Figure 3 a shows the UPS spectra of Ag electrode, Ag/AZO and ITO/PEDOT:PSS/perovskite to investigate how the energy levels shift. The UPS measurement shows that the work function of Ag is $4.6 \mathrm{eV}$. After depositing $\mathrm{AZO}$ on $\mathrm{Ag}$, there is an obvious shift toward lower work function of 4.05. Figure 3 a reveals that the Fermi level $\left(\mathrm{E}_{\mathrm{F}}\right)$ of the perovskite film on the ITO/PEDOT:PSS substrate is $3.2 \mathrm{eV}$, and the energy difference between the valance band maximum and $\mathrm{E}_{\mathrm{F}}$ is $1.9 \mathrm{eV}$. We also measured the absorption of ITO/PEDOT:PSS/perovskite/PCBM (as shown in Figure 3b); this indicated that the energy gap of the perovskite is $1.58 \mathrm{eV}$. Therefore, we can obtain that the conduction band minimum of perovskite film in this work is $3.52 \mathrm{eV}$. The energy band of PCBM is referenced from the previous report [7] with the conduction band minimum of $4.20 \mathrm{eV}$ and valance band maximum of $6.0 \mathrm{eV}$. It is obvious that the introduction of the AZO interface layer could decrease the energy level mismatch between PCBM layer and Ag electrode. Thus, electrons produced in the perovskite film could be collected by the Ag electrode more efficiently, which is consistent with the better performance of the device with the AZO interface layer.
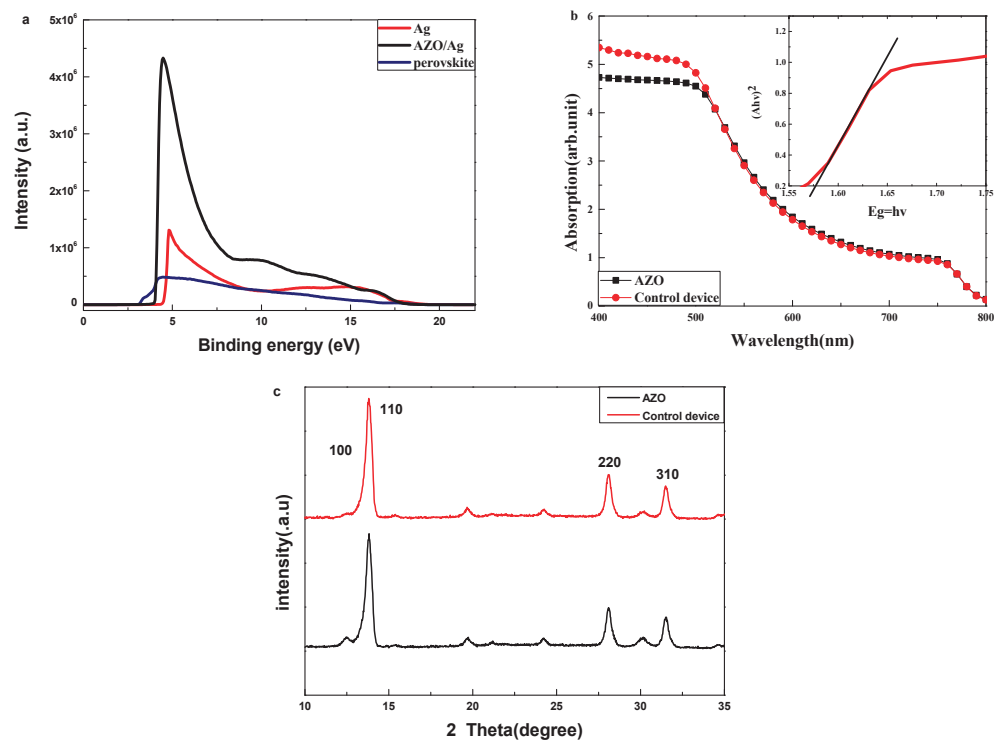

Figure 3. (a) UPS measurements of Ag electrode, Ag/AZO and ITO/PEDOT:PSS/perovskite. (b) The optical absorption spectra of ITO/PEDOT:PSS/perovskite/PCBM and ITO/PEDOT:PSS/perovskite/ $\mathrm{PCBM} / \mathrm{AZO}$. inset: the corresponding bandgap of perovskite film. It is noted that the corresponding optical bandgap is about $1.58 \mathrm{eV}$. (c) XRD patterns of ITO/PEDOT:PSS/perovskite/PCBM and ITO/PEDOT:PSS/perovskite/PCBM/AZO.

Figure $3 \mathrm{~b}$ shows the UV-vis spectra of ITO/PEDOT:PSS/perovskite/PCBM and ITO/PEDOT:PSS/ perovskite/PCBM/AZO. It is obvious that at between 400 and $500 \mathrm{~nm}$ wavelengths, the absorbance of the device with $A Z O$ is lower than the device without AZO, which matches with the result of IPCE. The result of UV-vis measurement also indicates that the layers of AZO have minimal influence on the light absorption of the perovskite layer between 500 and $800 \mathrm{~nm}$ wavelengths. Because the absorbance of AZO layer is very weak and that of ITO/PEDOT:PSS/perovskite/PCBM is very strong, the absorbance 
of AZO has a little effect on the whole device. The XRD of ITO/PEDOT:PSS/perovskite/PCBM and ITO/PEDOT:PSS/perovskite/PCBM/AZO were also be measured, in order to observe the influence of AZO layer on the perovskite film. As shown in Figure 3c, diffraction peaks at the XRD patterns around $14.17^{\circ}, 28.52^{\circ}$, and $31.98^{\circ}$ are assigned to the (110), (220), and (310) lattice planes of the tetragonal perovskite structure, respectively. The peak at $12.70^{\circ}$ is associated with the (100) crystal plane of $\mathrm{PbI}_{2}$. The XRD patterns with/without AZO are similar; this demonstrates that the influence of AZO layer to perovskite layer is negligible. Thus, we can conclude that the improved performance of the device with the AZO interlayer is mainly induced by the improved electron extraction ability instead of the improved absorption or crystal quality.

The ITO/PEDOT:PSS/perovskite, ITO/PEDOT:PSS/perovskite/PCBM and ITO/PEDOT:PSS/ perovskite/PCBM/AZO film morphologies and surface textures were also investigated by SEM. It is shown that with the method of mix-solvent-vapor annealing, a high uniform and smooth perovskite film was achieved as shown in Figure S1. Figure S4 shows the top-view SEM images of ITO/PEDOT:PSS/perovskite/PCBM and ITO/PEDOT:PSS/perovskite/PCBM/AZO. It is observed that with the PCBM or PCBM/AZO bilayer deposited on perovskite film their SEM images are breezing. However, the grain size and surface textures are unchanged. This demonstrates that the influence of AZO layer to perovskite layer is negligible, which is consistent with the result of the UV-vis and XRD which we measured above.

Figure 4a shows the steady-state photoluminescence (PL) spectra of the ITO/PEDOT:PSS/ perovskite/PCBM layer with/without the AZO interlayer. The perovskite films were deposited on the glass/ITO/PEDOT:PSS substrates under the same experimental conditions. The excitation light wavelength is $700 \mathrm{~nm}$ and the PL emission is collected from the PCBM or PCBM/AZO side. To protect the samples during the measurement, the device was sealed by spin-coating a layer of insulating polymer (PMMA). When the sample has the AZO layer, it could be clearly observed that the peak intensity at $783 \mathrm{~nm}$ decreased, which demonstrates that the charge transfer from the perovskite to the ETL is more efficient. This indicates a suppressed non-radiative recombination with the optimized PCBM/AZO bilayer; this is consistent with the obtained UPS results and J-V characteristics discussed above. Figure $4 \mathrm{~b}$ shows the TRPL behaviors for the sample with/without AZO layer. It is obvious that the sample with the AZO interlayer has a shorter lifespan, and that the sample without the AZO interlayer has a longer one. The lifespan for the sample without the AZO interlayer is around $239.08 \mathrm{~ns}$; this is reduced to $201.84 \mathrm{~ns}$ when the AZO interlayer is inserted between the PCBM layer and the Ag electrode. This shows that the photogenerated charge carriers could be efficiently transported to the AZO layer and collected by the Ag electrode. All of these results indicate that efficient electron transfer occurs with the PCBM/AZO bilayer, which is necessary for efficient charge extraction and collection in PSCs, and corresponds with the higher performance and neglect photocurrent hysteresis for devices with the PCBM/AZO bilayer.
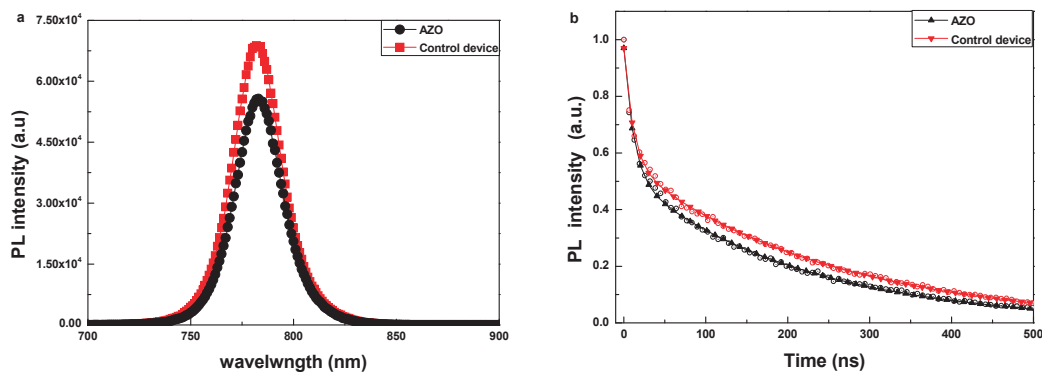

Figure 4. Cont. 

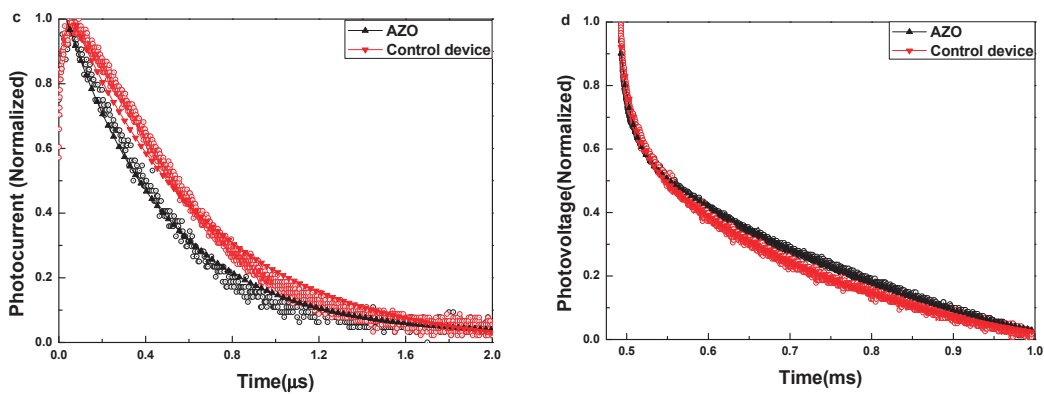

Figure 4. (a) Steady-state PL spectra and (b) Time-resolved PL spectra of perovskite/PCBM with/without the AZO layer. (c) Transient photocurrent and (d) transient photovoltage measurements of solar cells with/without the AZO interlayer.

The transient photocurrent and photovoltage measurements of PSCs were further performed to verify these results. Figure $4 \mathrm{c}$ shows the transient photocurrent of PSCs prepared with/without the AZO interlayer, measured at the short circuit condition. It was found that the device with the AZO interlayer has faster extraction (467.58 ns) than the device without the AZO interlayer (648.25 ns), indicating that the device former possesses much more efficient charge extraction and charge transport properties. Hence, the Voc and FF are enhanced. The transient photovoltage is used to determine the charge recombination lifetime, as shown in Figure $4 \mathrm{~d}$. The charge recombination lifetime of the device with the AZO interlayer increases to $0.41 \mathrm{~ms}$, compared to that without the AZO interlayer $(0.27 \mathrm{~ms})$, indicating that the charge recombination is efficiently suppressed with the introduction of the AZO interlayer. These transient photocurrent and photovoltage measurement results are consistent with the PL measurement results.

Finally, we studied the stability of the device by storing it for $720 \mathrm{~h}$. As shown in Figure 5 and Figure S5a-c, the device with the AZO interlayer exhibits remarkable PCE stability, retaining $86.41 \%$ of its initial value even after storing for over $720 \mathrm{~h}$. The Jsc remained almost unchanged, with a slightly decreased FF value. The Voc has a small increase in the first $100 \mathrm{~h}$, and stays around $1.00 \mathrm{~V}$ in the following measurement, while for the device without the AZO interlayer, the PCE decreases quickly to $60.14 \%$ of its initial value for the same storage condition and duration, which is mainly caused by the decreased FF and Jsc. These results suggest that the PSC with the PCBM/AZO bilayer exhibits better stability.

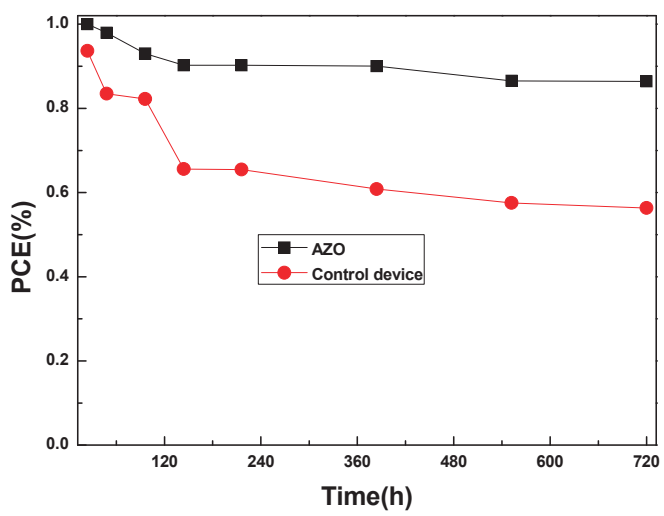

Figure 5. Stability of unencapsulated PSCs with/without the AZO interlayer. 


\section{Conclusions}

In conclusion, we have demonstrated a stable and efficient $\mathrm{p}-\mathrm{i}-\mathrm{n}$ structure PSC with a PCBM/AZO electron transporting bilayer. The insertion of the AZO interlayer could greatly improve the performance of PSCs; the best-performing device exhibits a PCE of $16.18 \%$ with a Jsc of $22.82 \mathrm{~mA} / \mathrm{cm}^{2}$, a Voc of $0.99 \mathrm{~V}$, and a FF $71.68 \%$. The UPS measurement shows that the AZO interlayer can decrease the energy offset between PCBM and metal electrode. The measurements of PL, TRPL, transient photocurrent, and transient photovoltage show that the PSC with the AZO interlayer has a longer radiative carrier recombination lifetime, and more efficient charge extraction efficiency. In addition, the PSC with the AZO interlayer shows an improved stability.

Supplementary Materials: The following are available online at http://www.mdpi.com/2079-4991/8/9/720/s1, Figure S1: Top-view SEM image of the surface morphology of perovskite, Figure S2: (a) J-V curves in forward and reverse scans of PSCs with AZO, (b) J-V curves in forward and reverse scans of PSCs without AZO, Figure S3: Statistics results of Jsc (a) Voc (b) and FF (c) for PSCs with/without AZO, Figure S4: SEM graphs of (a) ITO/PEDOT:PSS/perovskite/PCBM and (b) ITO/PEDOT:PSS/perovskite/PCBM/AZO, Figure S5: Stability of (a) Jsc (b) Voc and (c) FF for unencapsulated devices with/without AZO, Table S1: Statistical results of perovskite solar cells under AM 1.5G illumination $\left(100 \mathrm{~mW} / \mathrm{cm}^{2}\right)$. The standard deviation results are derived from 12 perovskite solar cells.

Author Contributions: C.Z. conceived the idea. C.Z. and Y.Z. designed the experiment and guided the experiment. H.D. conducted most of the device fabrication and data collection and wrote the manuscript; C.Z. and J.Z. revised the manuscript; S.P., D.C., W.Z., H.X. helped the device measurement, J.C. helped the data analysis. Y.H. supervised the group. All authors read and approved the manuscript.

Funding: This work is supported by the Fundamental Research Funds for the National 111 Center (Grant No. B12026), Natural Science Foundation of Shaanxi Province (Grant No. 2017JM6049), the Central Universities (Grant no. JBX171103), Natural Science Foundation of China (61604119), and Class General Financial Grant from the China Postdoctoral Science Foundation (Grant No. 2016M602771).

Acknowledgments: In this section you can acknowledge any support given which is not covered by the author contribution or funding sections. This may include administrative and technical support, or donations in kind (e.g. materials used for experiments).

Conflicts of Interest: The authors declare no conflicts of interest.

\section{References}

1. Jeon, N.J.; Noh, J.H.; Yang, W.S.; Kim, Y.C.; Ryu, S.; Seo, J.; Seok, S. Compositional engineering of perovskite materials for high-performance solar cells. Nature 2015, 517, 476-480. [CrossRef] [PubMed]

2. Adnan, M.; Lee, J.K. All Sequential Dip-Coating Processed Perovskite Layers from an Aqueous Lead Precursor for High Efficiency Perovskite Solar Cells. Sci. Rep. 2018, 8, 1-10. [CrossRef] [PubMed]

3. Kojima, A.; Teshima, K.; Shirai, Y.; Miyasaka, T. Organometal halide perovskites as visible-light sensitizers for photovoltaic cells. J. Am. Chem. Soc. 2009, 131, 6050-6051. [CrossRef] [PubMed]

4. Best Research-Cell Efficiencies. Available online: https://www.nrel.gov/pv/assets/images/efficiencychart-20180716.jpg (accessed on 16 July 2018).

5. Ma, J.; Chang, J.; Lin, Z.H.; Guo, X.; Zhou, L.; Liu, Z.; Xi, H.; Chen, D.; Zhang, C.; Hao, Y. Elucidating the Roles of $\mathrm{TiCl}_{4}$ and PCBM Fullerene Treatment on $\mathrm{TiO}_{2}$ Electron Transporting Layer for Highly Efficient Planar Perovskite Solar Cells. J. Phys. Chem. C 2017, 122, 1044-1053. [CrossRef]

6. Kim, J. The Stability Effect of Atomic Layer Deposition (ALD) of $\mathrm{Al}_{2} \mathrm{O}_{3}$ on $\mathrm{CH}_{3} \mathrm{NH}_{3} \mathrm{PbI}_{3}$ Perovskite Solar Cell Fabricated by Vapor Deposition. Key Eng. Mat. 2017, 753, 156-162. [CrossRef]

7. Sun, X.; Zhang, C.; Chang, J.; Yang, H.; Xi, H.; Lu, G.; Chen, D.; Lin, Z.; Lu, X.; Zhang, J.; et al. Mixed-solvent-vapor annealing of perovskite for photovoltaic device efficiency enhancement. Nano Energy 2016, 28, 417-425. [CrossRef]

8. Pang, S.; Li, X.; Dong, H.; Chen, D.; Zhu, W.; Chang, J.; Lin, Z.; Xi, H.; Zhang, J.; Zhang, C.; et al. Efficient bifacial semitransparent perovskite solar cells using $\mathrm{Ag} / \mathrm{V}_{2} \mathrm{O}_{5}$ as transparent anodes. ACS Appl. Mater. Interfaces 2018, 10, 12731-12739. [CrossRef] [PubMed]

9. Liu, Z.; Chang, J.; Lin, Z.; Zhou, L.; Yang, Z.; Chen, D.; Zhang, C.; Liu, S.; Hao, Y. High-Performance Planar Perovskite Solar Cells Using Low Temperature, Solution-Combustion-Based Nickel Oxide Hole Transporting Layer with Efficiency Exceeding 20\%. Adv. Energy Mater. 2018, 1703432, 1-9. [CrossRef] 
10. Mo, J.; Zhang, C.; Chang, J.; Yang, H.; Xi, H.; Chen, D.; Lin, Z.; Lu, G.; Zhang, J.; Hao, Y. Enhanced efficiency of planar perovskite solar cells via a two-step deposition using DMF as an additive to optimize the crystal growth behavior. J. Mater. Chem. A 2017, 5, 13032-13038. [CrossRef]

11. Shi, Z.; Ahalapitiya, H.J. Perovskites-Based Solar Cells: A Review of Recent Progress, Materials and Processing Methods. Materials 2018, 11, 729. [CrossRef] [PubMed]

12. Yang, H.; Zhang, J.; Zhang, C.; Chang, J.; Lin, Z.; Chen, D.; Sun, X.; Xi, H.; Han, G.; Hao, Y. Effect of polyelectrolyte interlayer on efficiency and stability of p-i-n perovskite solar cells. Sol. Energy 2016, 139, 190-198. [CrossRef]

13. Seo, J.; Park, S.; Kim, Y.C.; Jeon, N.J.; Noh, J.H.; Yoon, S.C.; Seok, S. Benefits of very thin PCBM and LiF layers for solution-processed p-i-n perovskite solar cells. Energy Environ. Sci. 2014, 7, 2642-2646. [CrossRef]

14. Chiang, C.H.; Tseng, Z.L.; Wu, C.G. Planar heterojunction perovskite/PC71BM solar cells with enhanced open-circuit voltage via a (2/1)-step spin-coating process. J. Mater. Chem. A 2014, 2, 15897-15903. [CrossRef]

15. Chen, C.; Zhang, S.; Wu, S.; Zhang, W.; Zhu, H.; Xiong, Z.; Zhang, Y.; Chen, W. Effect of BCP buffer layer on eliminating charge accumulation for high performance of inverted perovskite solar cells. RSC Adv. 2017, 7, 35819-35826. [CrossRef]

16. You, J.; Yang, Y.; Hong, Z.; Song, T.B.; Meng, L.; Liu, Y.; Jiang, C.; Zhou, H.; Chang, W.H.; Li, G.; et al. Moisture assisted perovskite film growth for high performance solar cells. Appl. Phys. Lett. 2014, 105, 945. [CrossRef]

17. Su, T.; Zheng, Y.; Ma, Z.; Cheng, L.; Xu, X.; Zhang, F.; Yu, G.; Sheng, Z. Band Engineering via Sn-doping of Zinc Oxide Electron Transport Materials for Perovskite Solar Cells. ChemistrySelect 2018, 3, 363-367. [CrossRef]

18. AitDads, H.; Bouzit, S.; Nkhaili, L.; Elkissani, A.; Outzourhit, A. Structural, optical and electrical properties of planar mixed perovskite halides/Al-doped Zinc oxide solar cells. Sol. Energy Mater. Sol. Cells 2016, 148, 30-33. [CrossRef]

19. Pérez-del-Rey, D.; Boix, P.P.; Sessolo, M.; Hadipour, A.; Bolink, H.J. Interfacial Modification for High-Efficiency Vapor-Phase-Deposited Perovskite Solar Cells Based on a Metal Oxide Buffer Layer. J. Phys. Chem. Lett. 2018, 1041-1046. [CrossRef] [PubMed]

20. Li, Y.; Guo, Y.; Li, Y.; Zhou, X. Fabrication of Cd-Doped $\mathrm{TiO}_{2}$ Nanorod Arrays and Photovoltaic Property in Perovskite Solar Cell. Electrochim. Acta 2016, 200, 29-36. [CrossRef]

21. Song, J.; Zheng, E.; Wang, X.F.; Tian, W.; Miyasaka, T. Low-temperature-processed ZnO-SnO 2 nanocomposite for efficient planar perovskite solar cells. Sol. Energy Mater. Sol. Cells 2016, 144, 623-630. [CrossRef]

22. Ren, X.; Yang, D.; Yang, Z.; Feng, J.; Zhu, X.; Niu, J.; Liu, Y.; Zhao, Y.; Liu, S. Solution-processed Nb:SnO 2 electron transport layer for efficient planar perovskite solar cells. ACS Appl. Mater. Inter. 2017, 9, 2421-2429. [CrossRef] [PubMed]

23. Li, W.; Jiang, Q.; Yang, J.; Luo, Y.; Li, X.; Hou, Y.; Zhou, S. Improvement of photovoltaic performance of perovskite solar cells with a $\mathrm{ZnO} / \mathrm{Zn}_{2} \mathrm{SnO}_{4}$, composite compact layer. Sol. Energy Mater. Sol. Cells 2017, 159, 143-150. [CrossRef]

24. Zhang, Q.; Peng, R.; Zhang, C.; Chen, D.; Lin, Z.; Chang, J.; Zhang, J.; Hao, Y. Inverted Organic Solar Cells with Low-Temperature Al-Doped-ZnO Electron Transport Layer Processed from Aqueous Solution. Polymers 2018, 10, 127. [CrossRef]

25. Hwang, K.; Jung, Y.; Heo, Y.; Scholes, F.H.; Watkins, S.E.; Subbiah, J.; Jones, D.J.; Kim, D.Y.; Vak, D. Toward large scale roll-to-roll production of fully printed perovskite solar cells. Adv. Mater. 2015, 27, 1241-1247. [CrossRef] [PubMed]

26. Subbiah, J.; Mitchell, V.D.; Hui, N.K.C.; Jones, D.J.; Wong, W.W.H. A Green Route to Conjugated Polyelectrolyte Interlayers for High-Performance Solar Cells. Angew. Chem. Int. Ed. 2017, 56, 8431-8434. [CrossRef] [PubMed]

27. Zhou, L.; Chang, J.; Liu, Z.; Sun, X.; Lin, Z.; Chen, D.; Zhang, C.; Zhang, J.; Hao, Y. Enhanced planar perovskite solar cell efficiency and stability using a perovskite/PCBM heterojunction formed in one step. Nanoscale 2018, 10, 3053-3059. [CrossRef] [PubMed]

(C) 2018 by the authors. Licensee MDPI, Basel, Switzerland. This article is an open access article distributed under the terms and conditions of the Creative Commons Attribution (CC BY) license (http:/ / creativecommons.org/licenses/by/4.0/). 
Article

\title{
Enhanced Silver Nanowire Composite Window Electrode Protected by Large Size Graphene Oxide Sheets for Perovskite Solar Cells
}

\author{
Hongye Chen ${ }^{1}$, Min Li ${ }^{1}$, Xiaoyan Wen ${ }^{1}$, Yingping Yang ${ }^{1}$, Daping He ${ }^{1}$, Wallace C. H. Choy ${ }^{2}$ and \\ Haifei Lu ${ }^{1, *}$ \\ 1 School of Science, Wuhan University of Technology, Wuhan 430070, China; hongyechen@whut.edu.cn (H.C.); \\ minli@whut.edu.cn (M.L.); wenxy@whut.edu.cn (X.W.); ypyang@whut.edu.cn (Y.Y.); \\ hedaping@whut.edu.cn (D.H.) \\ 2 Department of Electrical and Electronic Engineering, The University of Hong Kong, Pok Fu Lam Road, \\ Hong Kong SAR, China; chchoy@eee.hku.hk \\ * Correspondence: haifeilv@whut.edu.cn; Tel.: +86-27-8765-1907
}

Received: 12 January 2019; Accepted: 31 January 2019; Published: 2 February 2019

\begin{abstract}
Despite the outstanding features of high transmittance and low sheet resistance from silver nanowire (Ag NW) based transparent electrodes, their applications in perovskite solar cells (PVSCs) as window electrodes encounter significant obstacles due to the stability issue brought by the corrosion of halogen species from perovskite layer. In this study, we used large size graphene oxide (LGO) sheets as the protective barrier for bottom Ag NW nano-network. Contributed by the LGO with average size of $60 \mu \mathrm{m}$, less GO sheet was necessary for forming the fully covered protective barrier with fewer cracks, which consequently improved the optical transparency and anticorrosive ability of the composite electrode compared to the one from relatively small size GO. Our experiments demonstrated the composite electrode of Ag NW/LGO. The glass substrate exhibited transmittance of $83.8 \%$ and $81.8 \%$ at $550 \mathrm{~nm}$ before and after partial reduction, which maintained $98.4 \%$ and $95.1 \%$ average transmittance (AVT) of the pristine Ag NW electrode. Meanwhile, we utilized the steady hot airflow to assist the fast solvent evaporation and the uniform GO film formation on Ag NW electrode. Before the application of composite electrode in organic-inorganic hybrid perovskite solar cells, the operational stability of composite electrodes from different sizes of GO with perovskite film fabricated on top were characterized under continuing external bias and light irradiation. Experimental results indicate that the Ag NW electrode protected by LGO could maintain original resistance for more than 45 h. Finally, the PVSC fabricated on Ag NW/LGO based composite electrode yielded a power conversion efficiency (PCE) of $9.62 \%$, i.e., nearly $85 \%$ of that of the reference device fabricated on the commercial indium-tin oxide (ITO) glass. Our proposed low temperature and solution processed bottom electrode with improved optical transparency and operational stability can serve as the very beginning layer of optoelectronic devices, to promote the development of low cost and large area fabrication perovskite solar cells.
\end{abstract}

Keywords: Ag nanowires; graphene oxide; perovskite solar cell; transparent bottom electrode

\section{Introduction}

Organic-inorganic hybrid perovskite has been demonstrated as a promising candidate of light absorber because of its excellent properties for photovoltaic devices. The power conversion efficiency (PCE) has achieved over $23 \%$ since it was first introduced in 2009 with PCE of 3.8\% [1-7]. With the increase in efficiency and potential commercial value, researchers have paid more attention to controlling the cost of preparation, by avoiding the use of high energy consuming instruments and 
adopting low temperature and solution processed methods for each layer. For example, the low temperature and solution processed interfacial layers, including electron [8-14] and hole [15-19] transporting layers, have been intensively studied to improve the efficiency of PVSCs. Carbon based materials, such as carbon paste [20,21], carbon nanotubes [22-25] and graphene [26], have also been used as top electrodes in PVSCs to replace conventional top metal electrodes formed by thermal evaporation, to reduce the cost of device fabrication and improve the stability of device simultaneously. Besides, metal nanowire electrode through spray-coating or spin-coating method is another favored candidate of top electrode for semi-transparent PVSCs $[27,28]$.

For the bottom electrode of PVSCs, the most commonly used transparent conductive electrodes at present are indium-tin oxide (ITO) and fluorine-doped tin oxide (FTO) films fabricated by evaporation or sputtering in high vacuum environment, which however have the following problems. First, due to the large amount of electrical energy consumption and machine loss during the preparation process, the fabrication cost of ITO and FTO is relatively high. Second, the indium element required for ITO is a rare element. The rising of its price could be predicted in the long-term. Third, the metal oxide electrode has natural brittleness. The optoelectronic device based on this type of electrode will be greatly limited in flexibility and folding characteristics. As a result, several candidate materials have been investigated as bottom electrode to replace ITO or FTO, such as carbon nanotubes [29], graphene [30,31], conductive polymers [32] and metal nanowires [33-36]. Among these materials, silver nanowire ( $\mathrm{Ag} \mathrm{NW}$ ) network is regarded as the most promising candidate because of the low sheet resistance and high transmittance. Moreover, silver nanowires have excellent flexibility, making them suitable for flexible optoelectronic device. However, the application of silver nanowire as bottom electrode to perovskite solar cells has encountered various obstacles, especially the chemical stability upon the perovskite materials because the halide species released from the perovskite layer will easily penetrate through the conventional interfacial layer, corrode the bottom silver nanowires, and thus lead to degradation of the electrical conduction [37-39].

To address the chemical stability issue, various attempts have been made to protect the bottom silver nanowire electrode. For instance, Han et al. [38] proposed a dense fluorine-doped ZnO (FZO) layer deposited on the surface of Ag NWs by pulsed laser deposition (PLD) to enhance the corrosion resistance of the electrode and ensure the conductivity of the electrode, achieving a PCE of 3.29\% from perovskite device. Kim et al. [39] demonstrated a sandwich protection structure of ITO/Ag $\mathrm{NW} / \mathrm{ITO}$ by successive-spin-coating method and annealing at $250{ }^{\circ} \mathrm{C}$ to enhance the conductivity of the composite electrode, resulting in a PCE of $8.44 \%$ from PVSC. Based on the sandwich protection structure, Lee et al. [37] proposed using amorphous Al-doped zinc oxide (AZO) instead of ITO as a protective layer for the purpose of reducing the use of indium and achieved a PCE of 13.93\% from PVSC. In addition, our previous research [40] reported an anti-corrosive film composed of self-assembled graphene oxide (GO) flakes on a silver nano-network under ambient conditions, which can effectively prevent halide corrosion against the Ag NWs, and finally revealed a PCE of $9.23 \%$ by optimizing the amount of graphene oxide and reducing agent.

We demonstrated the formation of fully covered film composed of large size graphene oxide sheets (LGO) as the protective barrier for bottom Ag NW nano-network through utilizing a time-saving strategy of steady hot airflow, which is beneficial for the film formation with good uniformity. We found that the anti-corrosive abilities of the composite Ag NW electrodes from large size GO sheets were significantly enhanced compared to those composited from small size GO sheets. They were experimentally demonstrated by characterizing the resistance of composite electrode under continuing external bias and light irradiation. Importantly, the composite electrode of Ag NW/LGO after partially reduction showed an excellent optical transmittance, reaching $81.8 \%$ at $550 \mathrm{~nm}$ and maintaining $95.1 \%$ average transmittance (AVT) of the pristine Ag NW electrode. Finally, the PVSC fabricated with Ag NW/LGO based composite electrode demonstrated a power conversion efficiency (PCE) of 9.62\%, corresponding to nearly $85 \%$ of the efficiency from reference device on commercial ITO glass. 


\section{Materials and Methods}

\subsection{Materials}

Graphene oxide powder was purchased from Anhui Lianruan Education Technology Co., Ltd. (Hefei, China). ITO glasses were purchased from YINGKOU OPV TECH NEW ENERGY Co., Ltd. (Yingkou, China). Poly(3,4-ethylenedioxythiophene):poly(styrene sulfonate) PEDOT:PSS (Heraeus Clevios PVP AI 4083), Lead (II) iodide( $\left.\mathrm{PbI}_{2},>99.99 \%\right)$ and 2,9-dimethyl-4,7-diphenyl-1,10-Phenanthroline (BCP, >99\%) were purchased from Xi'an Polymer Light Technology Corp. (Xian, China). Methylammonium iodide (MAI, 99\%) was purchased from Greatcell Solar PTY Ltd. (Queanbeyan, Australia). [6,6]-Phenyl-C61butyric acid methyl ester (PCBM, >99.5\%) was purchased from Luminescence Technology Corp. (Shanghai, China). Dimethyl sulfoxide (DMSO, anhydrous, $\geq 99.9 \%$ ), chlorobenzene (anhydrous, 99.8\%) and 2-Propanol (anhydrous, 99.5\%) were purchased from Sigma-Aldrich Co. LLC. (Shanghai, China). $\gamma$-Butyrolactone (GBL, anhydrous, 99.9\%) was purchased from Shanghai Aladdin Biochemical Technology Co., Ltd. (Shanghai, China). Ethanol, acetone and sodium borohydride were purchased from Sinopharm Chemical Reagent Co., Ltd. (Shanghai, China). All chemicals were used without further purification.

\subsection{Preparation of Large Size GO}

Large size GO sheets were prepared using a centrifugal classification method according to previous report [41]. Briefly, appropriate amount of GO powder was taken for preparing an aqueous dispersion with a concentration of $2 \mathrm{mg} / \mathrm{mL}$, which was stirred for $24 \mathrm{~h}$. After centrifugation at $5000 \mathrm{rpm}$ for $30 \mathrm{~min}$, the bottom solution (about 30\% in volume) was kept and diluted to $2 \mathrm{mg} / \mathrm{mL} \mathrm{for}$ the next cycle of centrifugation. After repeating the above process seven times, the gel at bottom was collected and used for investigations in this study.

\subsection{Preparation of Ag NW/RLGO Composite Electrodes}

The glass substrates were cleaned ultrasonically with acetone, deionized water and ethanol for $15 \mathrm{~min}$ in sequence, and then dried with $\mathrm{N}_{2}$, followed by UV/ozone treatment for $15 \mathrm{~min}$. The pristine Ag NW dispersion was diluted to $1.3 \mathrm{mg} / \mathrm{mL}$ before use. Highly conductive Ag NW transparent electrodes were fabricated by spin-coating the Ag NW dispersion at $2500 \mathrm{rpm}$ for $30 \mathrm{~s}$ and annealing at $150{ }^{\circ} \mathrm{C}$ for $10 \mathrm{~min}$ in air. According to our previous research [40], $32 \mu \mathrm{mol} \mathrm{NaBH} 4$ were added to $2.5 \mathrm{~mL}$ LGO aqueous dispersion $(0.25 \mathrm{mg} / \mathrm{mL})$. Then, the dispersion was kept for $12 \mathrm{~h}$ for the partial reduction of LGO. Fifty microliters of partially-reduced LGO dispersion (RLGO) were dropped onto the Ag NW transparent electrode with area of $2.89 \mathrm{~cm}^{2}$, allowing the liquid to disperse onto the entire substrate uniformly. Finally, the substrate was dried under a steady hot airflow, which could greatly speed up the evaporation of the solution. The "steady hot air flow" was achieved by a commercial adjustable electric hair dryer (FH6618, FLYCO, Shanghai, China) through carefully controlling wind and power.

\subsection{Preparation of Perovskite Solar Cells on Ag NW/RLGO Composite Electrodes}

For the fabrication of perovskite solar cells, the transparent electrodes of Ag NW/RLGO and commercial ITO glass were used. The Ag NW/RLGO composite transparent electrodes were prepared as described above. The control ITO substrates were ultrasonically cleaned with detergent, deionized water, acetone, and ethanol for $15 \mathrm{~min}$ in sequence. To prepare hole transport layer, the as-received PEDOT:PSS solution was spin-coated on the transparent electrodes at a speed of $2000 \mathrm{rpm}$ for $30 \mathrm{~s}$ and annealed on a hotplate at $125^{\circ} \mathrm{C}$ for $10 \mathrm{~min}$. The samples were then transferred to a glove-box after cooling to room temperature. The perovskite $\mathrm{MAPbI}_{3}$ films were fabricated on the substrates according to a previously reported method [42]. Generally, $\mathrm{PbI}_{2}$ and $\mathrm{MAI}$ with 1:1 ratio were mixed in the mixing solvent of GBL and DMSO (volume ratio $=7: 3$ ) to form the precursor with a concentration of $1.2 \mathrm{M}$. The mixture solution was stirred at $60^{\circ} \mathrm{C}$ overnight before use. The perovskite films were 
fabricated by a successive two step spin-coating process of $1000 \mathrm{rpm}$ for $10 \mathrm{~s}$ and $4000 \mathrm{rpm}$ for $30 \mathrm{~s}$. During the second step of spin-coating, $150 \mu \mathrm{L}$ of toluene were quickly dropped on the substrate, which was then annealed on a hotplate at $100{ }^{\circ} \mathrm{C}$ for $10 \mathrm{~min}$. The PCBM layer was deposited on the as-formed perovskite film by spin-coating its chlorobenzene solution $(17 \mathrm{mg} / \mathrm{mL})$ at $2000 \mathrm{rpm}$ for $30 \mathrm{~s}$, followed by annealing at $100{ }^{\circ} \mathrm{C}$ for $10 \mathrm{~min}$. Subsequently, a thin BCP film, used as buffer layer, was deposited by spin-coating its saturated solution at $3000 \mathrm{rpm}$ for $60 \mathrm{~s}$. Finally, the device was completed by thermal evaporation of $150 \mathrm{~nm}$ thick $\mathrm{Ag}$ cathode under $3.0 \times 10^{-4} \mathrm{~Pa}$.

\subsection{Characterizations}

The surface morphology and cross section of the as-prepared samples were examined by field-emission scanning electron microscope (FE-SEM, Zeiss Ultra Plus, Oberkochen, German). GO sheets were measured by optical microscope (XJP-107JX, Pudan Optical Instrument Co., Ltd., Shanghai, China). The diffused transmission spectra of the transparent electrodes were obtained from a UV-vis spectrophotometer (UV2600, Shimadzu, Tokyo, Japan) with an integrating sphere. The sheet resistances of the electrodes were measured using a four-point probe system with a current source-meter (Keithley 2400, Tektronix, Beaverton, OR, USA). To characterize the resistance variation of composite electrode before and after device fabrication, two electrical contacts were formed on the two sides of the electrode using silver paste and a digital multimeter (DT9206, FLUKE Corporation, Elite, WA USA) was used for resistance measurement. The photocurrent density-voltage $(\mathrm{J}-\mathrm{V})$ characteristics of all devices were analyzed using an AM1.5G solar simulator (Oriel Sol3A, Newport Corporation, Irvine, CA, USA) and Keithley 2400 sourcemeter (Beaverton, OR, USA), scanning from -0.1 to $1.2 \mathrm{~V}$ at a scan rate of $0.1 \mathrm{~V} \mathrm{~s}^{-1}$. The IPCE (Newport Corporation, Irvine, CA, USA) system was employed to study the quantum efficiency of the solar cells.

\section{Results and Discussion}

In our previous research [40], we demonstrated that Ag NWs underneath perovskite layer was severely corroded after the formation of perovskite film, which is the most critical issue that hinders their application in PVSCs as bottom electrode. To solve the chemical instability and improve the optical transparency, we used a fully-covered film composed of LGO sheets on silver nanowire electrode as an anti-corrosive barrier. As depicted in Figure 1, three different GO sheets with average sizes of $60 \mu \mathrm{m}, 30 \mu \mathrm{m}$ and $3 \mu \mathrm{m}$ were successfully separated by a centrifugal classification method. The obtained GO sheets were diluted to an appropriate concentration, dropped on clean silicon wafer with a $300 \mathrm{~nm} \mathrm{SiO}{ }_{2}$ layer, and then characterized by optical microscope. In Figure 1, we can clearly observe that most GO sheets were thin and well classified, which was beneficial to the transmittance of Ag NW/GO composite electrodes and our later research. Figure $1 \mathrm{~b}, \mathrm{~d}$, $\mathrm{f}$ shows the size distributions of the three different GO sheets. 


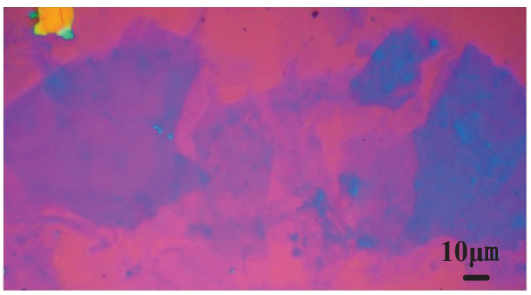

c

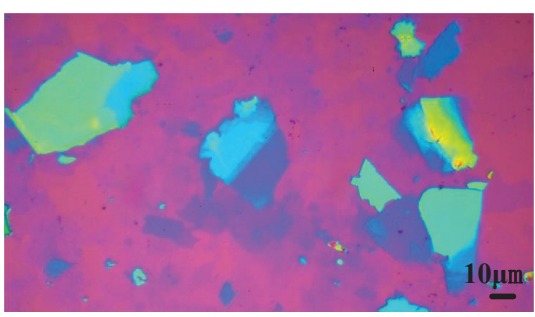

b

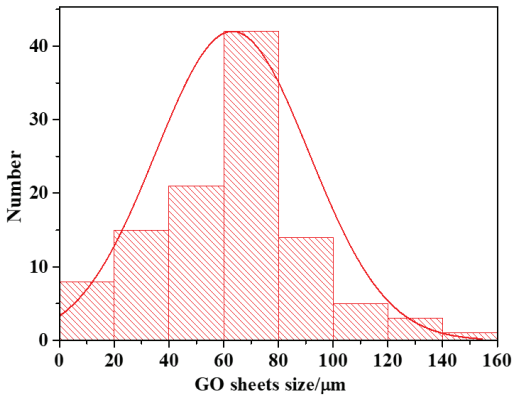

d

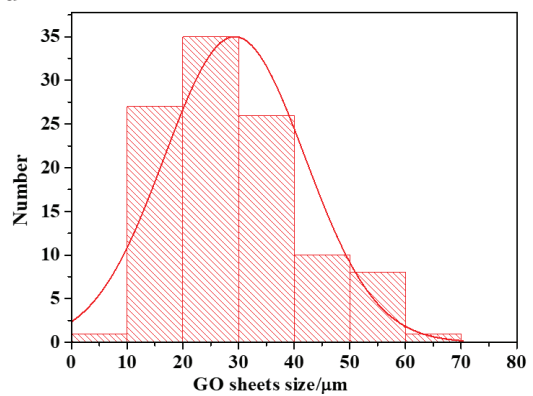

e

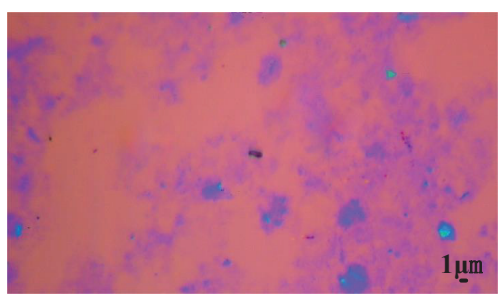

f

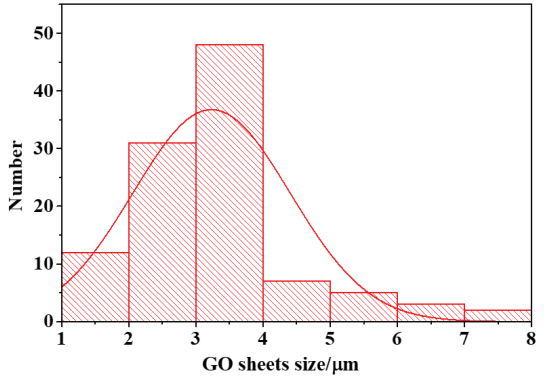

Figure 1. (a,c,e) The optical microscope images of $60 \mu \mathrm{m}, 30 \mu \mathrm{m}$ and $3 \mu \mathrm{m}$ GO sheets, respectively;and $(\mathbf{b}, \mathbf{d}, \mathbf{f})$ the size distributions of $60 \mu \mathrm{m}, 30 \mu \mathrm{m}$ and $3 \mu \mathrm{m}$ GO sheets, respectively.

It is also worth mentioning our strategy of forming fully-covered GO film on Ag NW substrate. Our previous method of forming the GO film was obtained through self-assembly and the solvent was dried naturally under ambient condition, which was very time consuming and not suitable for large area film fabrication. Here, a rapid GO film formation approach was tested by using the steady hot airflow for the drying of the solvent. We believe this strategy is compatible with roll-to-roll technology. The preparation procedure of the composite electrode is shown in Figure 2a. To illuminate the difference from two approaches for the formation of composite electrode, a relatively high concentration of GO solution $(0.5 \mathrm{mg} / \mathrm{mL})$ was used. Figure $2 \mathrm{~b}$ shows the photo of $\mathrm{Ag} \mathrm{NW} / \mathrm{LGO}$ composite electrodes that were prepared by the two methods with the large area of $6.25 \mathrm{~cm}^{2}$. Sample 1 was prepared by a conventional method, in which water was evaporated naturally. Sample 2 was prepared with the assistance of a steady hot airflow, as indicated in Figure 2a. The preparation of Sample 1 was time 
consuming and resulted in non-uniform film formation, as indicated in Figure $2 \mathrm{~b}$. However, with the assistance of steady hot airflow, a flat and uniform GO film could be rapidly fabricated, and the preparation process of the Ag NW/LGO composite was efficient and suitable for large-scale fabrication.

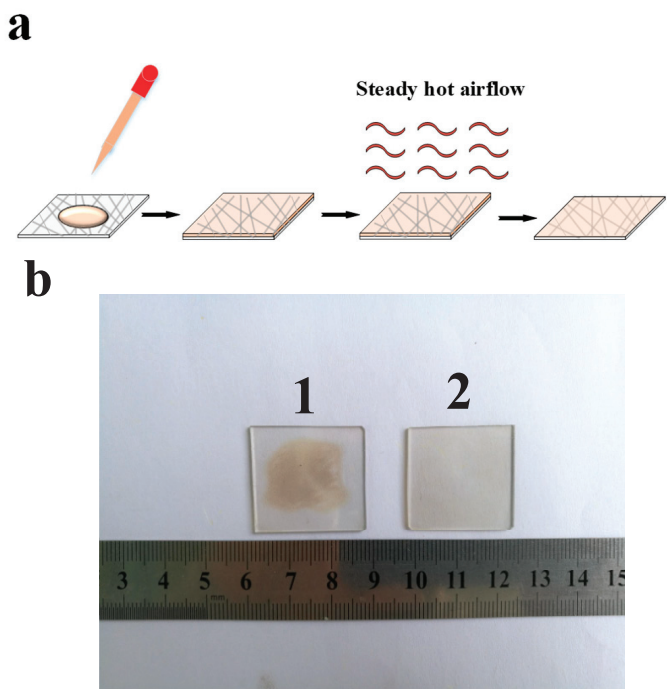

Figure 2. (a) Schematic representation of the Ag NW/LGO composite electrode fabrication process; and (b) photos of Ag NW/LGO composite electrodes fabricated from relatively high concentration of LGO solution $(0.5 \mathrm{mg} / \mathrm{mL})$ on the area of $6.25 \mathrm{~cm}^{2}$ using two different methods.

To evaluate the anticorrosive effect of the film made of different size of GO sheets, the same volumes of GO aqueous solution with a constant concentration of $0.25 \mathrm{mg} / \mathrm{mL}$ were dropped on three identical Ag NW electrodes and allowed to dry under a steady hot airflow, as discussed above. Two electrical contacts using silver paste were formed on the two sides of the electrode to measure its resistance variation before and after device fabrication. PEDOT:PSS layer, perovskite $\left(\mathrm{MAPbI}_{3}\right)$ layer and PCBM layer were fabricated on the composite electrodes in sequence. The control sample of Ag NW electrode without GO was also prepared following the same procedure. The resistance variations of the Ag NW/GO composite electrodes were measured in a glove-box filled with $\mathrm{N}_{2}\left(\mathrm{O}_{2}<0.1 \mathrm{ppm}\right.$, $\mathrm{H}_{2} \mathrm{O}<0.1 \mathrm{ppm}$ ) after device fabrication. As illustrated in Figure 3a, the resistances of all composite electrodes remained stable for the first $10 \mathrm{~h}$, including the control sample. This was because of the glove-box, in which water and oxygen content were low. The process of decomposition of perovskite layer was relatively slow. Meanwhile, the corrosion of halide species against silver nanowires was also a gradual process in such condition. Over time, the resistance of the control electrode changed dramatically, by exhibiting more than 100 times the original resistance during $8 \mathrm{~h}$. This result directly reflected the severe corrosion of the silver nano-network underneath the perovskite film. In contrast, the resistances of the electrodes protected by GO sheets increased slowly, and the resistance increasing rates decreased as the sizes of GO sheets increased. The inset in Figure 3a clearly indicates that the Ag NW electrode protected by $60 \mu \mathrm{m}$ GO sheets showed an excellent chemical stability, which can keep stable with negligible variation for $24 \mathrm{~h}$. In addition, we also measured the resistance of the Ag NW electrode protected by $60 \mu \mathrm{m}$ GO sheets under continuous $0.8 \mathrm{~V}$ bias and light irradiation ( 0.5 sun), as shown in Figure $3 \mathrm{~b}$. The result clearly demonstrates that, even under continuous electricity and irradiation, the composite electrode was almost unaffected and maintained a stable resistance, proving the outstanding protective effect of large size GO sheets. 
a

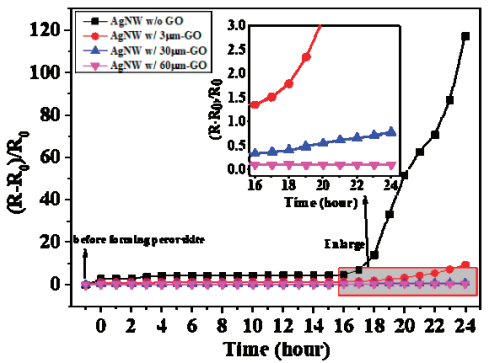

b

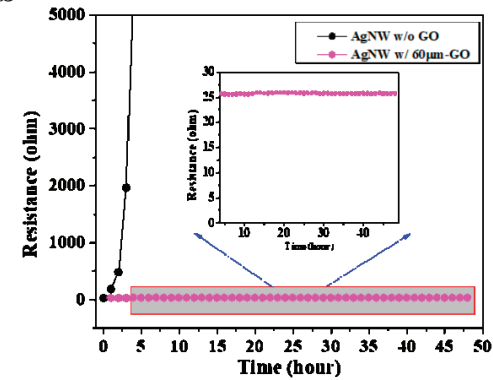

Figure 3. (a) The resistance variation of the Ag NW electrodes protected by different sizes of GO sheets $(40 \mu \mathrm{L}, 0.25 \mathrm{mg} / \mathrm{mL})$ before and after the fabrication of perovskite devices: and (b) the resistance of the Ag NW electrode protected by $60 \mu \mathrm{m}$ GO sheets under continuous $0.8 \mathrm{~V}$ bias and light irradiation (0.5 sun).

To illuminate the enhanced stability of the composite electrode of Ag NW/LGO against perovskite layer, the electrode was characterized by SEM. As evidenced by the SEM images from the silver nano-network coated with $60 \mu \mathrm{m}$ GO sheets (Figure 4), the silver nanowires were widely covered by single graphene oxide sheet, which acted as anti-corrosive barrier against halide ions from perovskite. Since the average length of the silver nanowires was about $30 \mu \mathrm{m}$, it is easy to understand that a larger area of GO sheet can protect more silver nanowires from corrosion. In other words, less GO would be necessary to fully cover the same area of Ag NW electrode than one composed of small-sized GO sheets, as schematically depicted in Figure 5. Due to the physical stacking of the GO sheets, it is also reasonable to believe that the penetration of halide species through the cracks indicated by the dotted lines formed between GO sheets could still happen and caused the deterioration of the electrode. Therefore, the gradual increase of the resistance of electrode composited by $30 \mu \mathrm{m}$ and $3 \mu \mathrm{m}$ GO sheets after the fabrication of perovskite layer could be attributed to the formation of more cracks or defects in the anticorrosive film. Stacking more GO sheets on the electrode to block the cracks with additional GO layers might be an efficient method to prevent such penetration; however, this would be harmful to the optical transparency and electrical conductivity of transparent electrode. Solar cells fabricated on the composite electrode based on that strategy would be difficult to optimize to achieve good performance. It should also be noted that, even though the combination of metal nanowire electrode and single- or double-layer graphene in CVD method being able to obtain the best optical, electrical and stability properties, the hydrophobic feature of the film would add difficulty to the fabrication of the charge transporting layer and perovskite film. Therefore, relatively large GO sheets with average size of $60 \mu \mathrm{m}$ were used for demonstration.
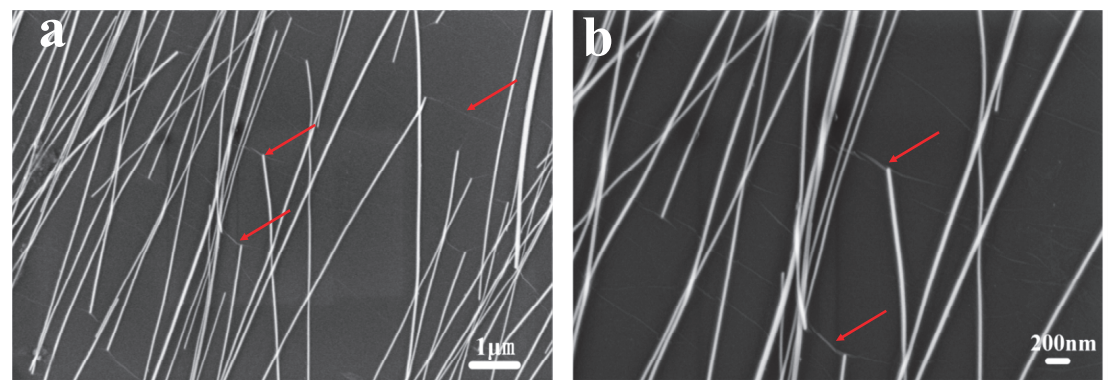

Figure 4. (a) Large-scale; and (b) enlarged SEM images of silver nano-network under the protection of $60 \mu \mathrm{m}$ GO sheets. The red arrows inside indicate the crinkles of GO. 


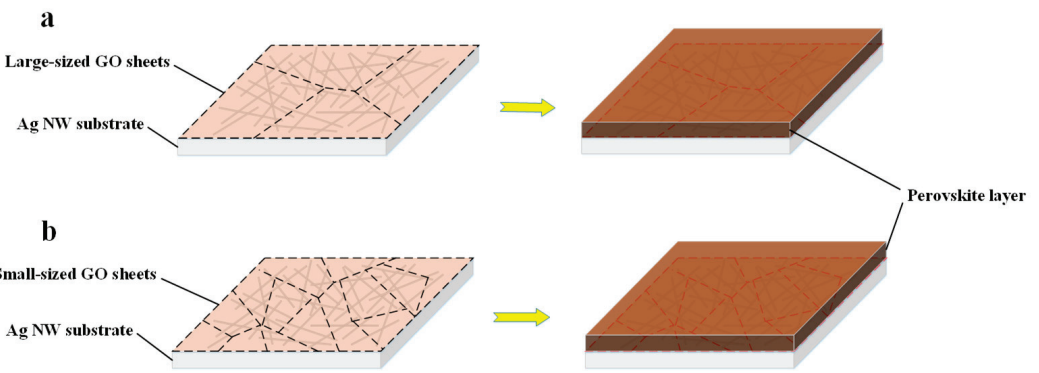

Figure 5. Schematic of Ag NW electrodes protected by: (a) large GO sheets; and (b) small GO sheets.

Even though the reduced stacking layer from large size GO sheets helped decrease the vertical resistance between bottom Ag NW electrode and charge transporting layer fabricated above, the lateral resistance of GO was poor due to the high degree of oxidation. Partially-reduced LGO was still essential to improve the lateral conductivity, which could help the efficient collection of photo-induced carriers generated at the position away from the metal nanowires. Hence, an appropriate amount of $\mathrm{NaBH}_{4}$ was added into the pristine LGO solution as a reducing agent to enhance the electrical conductivity of LGO film. More details are shown in Experimental Section 2.3. To characterize the optical property of the composite transparent electrodes, diffused transmission spectra of the silver nano-network electrodes coated with $40 \mu \mathrm{L}$ of LGO (average size of $60 \mu \mathrm{m}$ ) solution with and without partial reduction by optimal amounts of $\mathrm{NaBH}_{4}$ are shown in Figure 6. The spectra indicated the composite electrodes of Ag NW/LGO and Ag NW/RLGO including the glass substrate exhibited transmittances of $83.8 \%$ and $81.8 \%$, respectively, at the wavelength of $550 \mathrm{~nm}$. Contributed by the size effect of GO sheet, as discussed above, the quantity of GO sheets forming the anticorrosive film on the electrode surface could be reduced. The optical loss of bare silver nanowire electrode brought by the addition of $60 \mu \mathrm{m}$ LGO and $60 \mu \mathrm{m}$ RLGO were minimized to $1.6 \%$ and $4.6 \%$ of average transmittance (AVT), respectively, at the spectral range of $400-800 \mathrm{~nm}$.

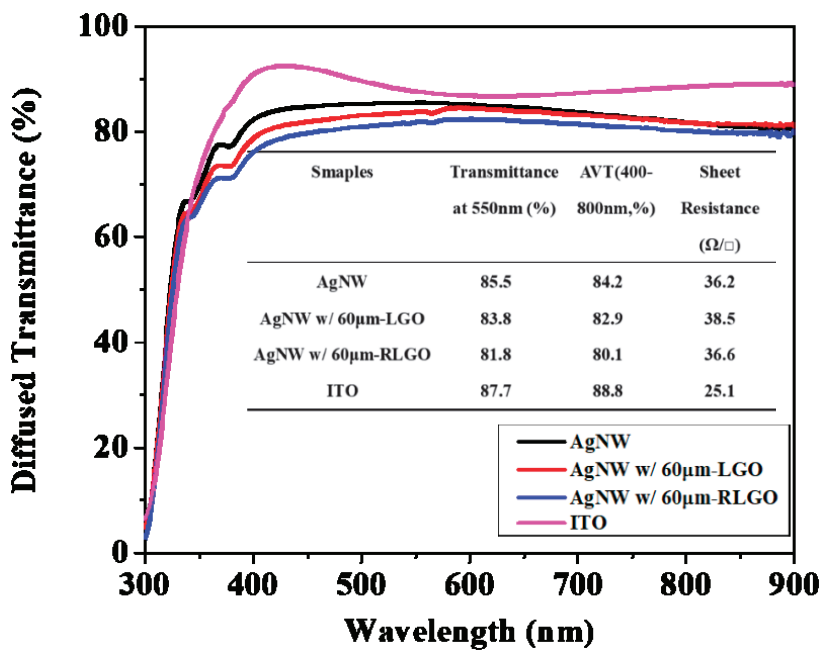

Figure 6. Diffused transmission spectra of silver nano-network electrodes and the network electrode coated by the same amount of $60 \mu \mathrm{m}$ LGO sheets with and without chemical reduction, and the commercial ITO substrate. The inset is the performance parameters of these samples. 
Based on the excellent chemical stability and transmittance of the Ag NW/LGO composite electrodes, we further evaluated the transparent electrodes for perovskite solar cell applications. To fabricate PVSCs based on the Ag NW nano-network transparent electrodes protected by anti-corrosive LGO film, PEDOT:PSS, $\mathrm{MAPBI}_{3}, \mathrm{PCBM}$ and BCP were deposited as hole transport layer (HTL), absorber layer, electron transport layer (ETL) and buffer layer, respectively. The devices were finally finished after thermal evaporation of the silver counter electrode. The schematic diagram and cross section SEM image are shown in Figure 7a,b. The control devices of perovskite solar cells on commercial ITO electrode were also fabricated for reference. More details on device fabrication can be found in Experiment Section 2.4.
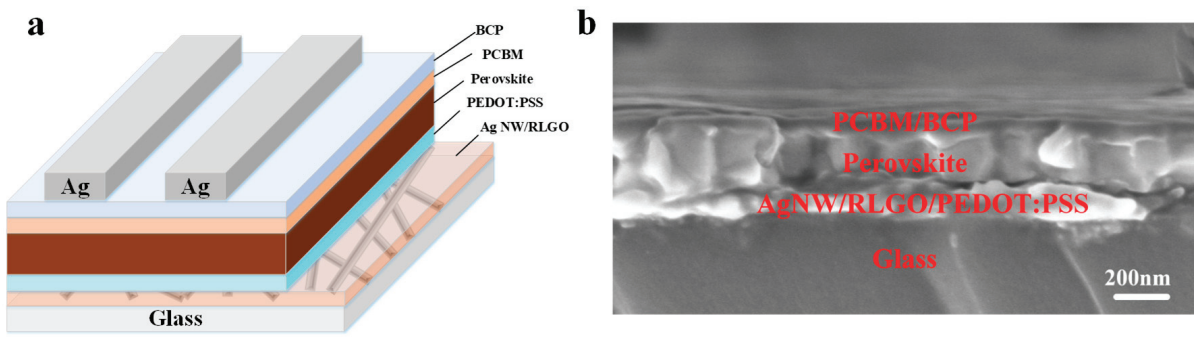

Figure 7. (a) Schematic illustration of the perovskite solar cell structure on an Ag NW/LGO composite electrode; and (b) cross-sectional SEM image of the perovskite solar cell fabricated on Ag NW/LGO composite electrode.

The current density-voltage (J-V) curves of PVSCs fabricated on ITO glass, the pristine Ag NW electrode without GO and the composite electrode of Ag NW nano-network with $60 \mu \mathrm{m}$ LGO sheets are shown in Figure $8 \mathrm{a}$, and the performance parameters are summarized in Table 1 . The performance of PVSCs was obtained under 1 sun illumination (AM 1.5G, $100 \mathrm{~mW} / \mathrm{cm}^{2}$ ) irradiated from the bottom electrode side covered with a black shadow mask. The perovskite solar cell using the Ag NW/RLGO electrode showed an open circuit voltage ( $\mathrm{V}_{\mathrm{OC}}$ ) of $0.87 \mathrm{~V}$, short-circuit current $\left(\mathrm{J}_{\mathrm{SC}}\right)$ of $15.43 \mathrm{~mA} / \mathrm{cm}^{2}$, fill factor (FF) of 70.9\%, and PCE of 9.62\%. The incident photon-to-electron conversion efficiency (IPCE) of the device based on the composite electrode is shown in Figure $8 \mathrm{~b}$. The calculated JSC from the IPCE spectrum is $15.23 \mathrm{~mA} / \mathrm{cm}^{2}$, which is consistent with the value of $15.43 \mathrm{~mA} / \mathrm{cm}^{2}$ from the $\mathrm{J}-\mathrm{V}$ curve. Figure $8 c$ exhibits the J-V hysteresis characteristics of the cells based on the optimized Ag NW/RLGO composite electrode using a dwell time of $10 \mathrm{~ms}$ for both forward ( $\mathrm{JSC}_{\mathrm{SC}}$ to $\mathrm{V}_{\mathrm{OC}}$ ) and backward ( $\mathrm{V}_{\mathrm{OC}}$ to $\mathrm{JSC}_{\mathrm{SC}}$ ) scan directions. The detailed hysteresis performance parameters are summarized in Table 2. As shown in Table 2, a PCE of 9.62\% was achieved in the backward scan, whereas the PCE value was $9.08 \%$ in the forward scan. The little hysteresis phenomenon might be due to the coating of the PCBM layer [43,44]. The stabilized photocurrent and PCE at the maximum power output point (MPP) under AM1.5 sun illumination are shown in Figure 8d, which exhibited stabilized photocurrent of $12.72 \mathrm{~mA} / \mathrm{cm}^{2}$ and PCE of $9.35 \%$ at $0.76 \mathrm{~V}$ under $400 \mathrm{~s}$ continuing light irradiation, agreeing well with the value measured from J-V curves (Figure 8c). As illustrated in Table 1, the JSC value from Ag NW/RLGO composite electrode accounted for $95 \%$ of the value of reference device, which was consistent with the optical transparency ratio of the composite electrode and ITO glass, indicating their qualification of optical transparency and electrical conductivity for transparent bottom electrode. The slight decrease of the FF value from the Ag NW/RLGO composite electrode-based device could be attributed to relative larger surface roughness of the composite electrode. Even though the coating of GO and PEDOT:PSS layers could improve the smoothness of bare silver nanowire electrode, the surface of composite electrode in large scale was still worse than the ITO film possessing nanometer surface roughness. The additional GO layer and thick PEDOT:PSS layer slightly affected the charge transferring between the composite electrode and perovskite layer, as evidenced by the slight increase of the serial resistance in Table 1. Nevertheless, a PCE of 9.62\% was achieved, which corresponded to 
nearly $85 \%$ of that of the reference device with an ITO electrode, indicating that it is suitable to use our Ag NW/RLGO based electrode for PVSCs. More importantly, our Ag NW composite electrode protected by large size GO sheets exhibited superior chemical stability over those that are pristine or protected by small size GO sheets, and maintained $95.1 \%$ average transmittance of pristine Ag NW electrode. Furthermore, the fast GO film formation method, which was assisted by steady hot airflow, was beneficial to large scale fabrication technology. Future optimization on the surface of composite electrode and perovskite film quality on the composite electrode would undoubtedly boost the efficiency of the devices.

a

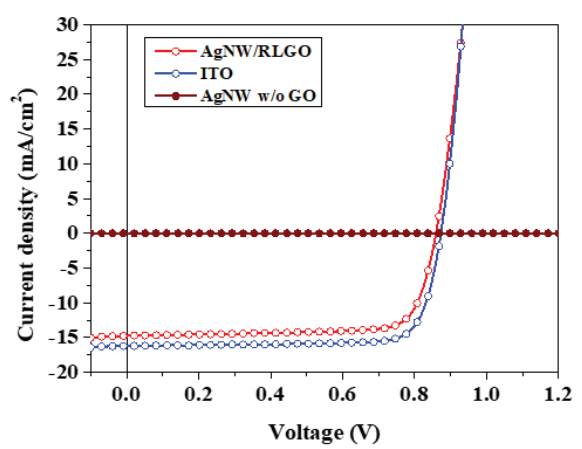

c

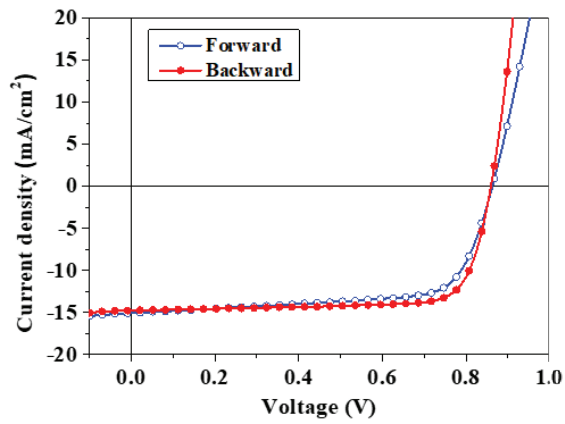

b

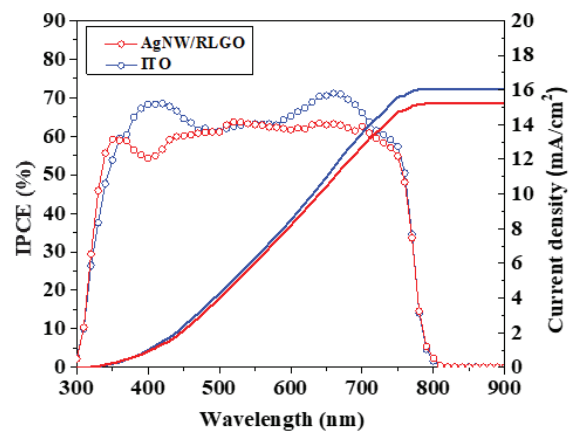

d

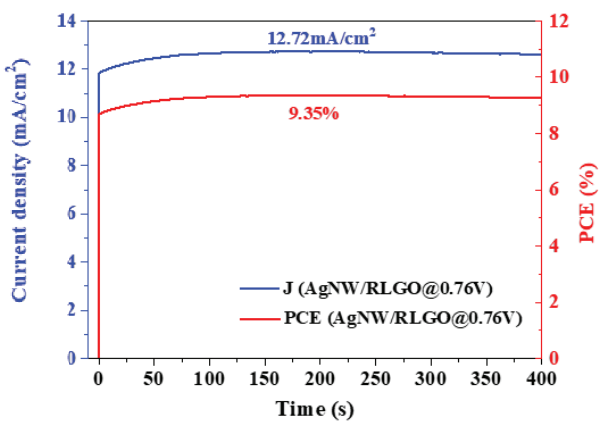

Figure 8. (a) J-V curves of the PVSC fabricated on the Ag NW nano-network electrode protected by $60 \mu \mathrm{m}$ LGO sheets. Data from commercial ITO glass and Ag NW electrode without GO are also presented. (b) IPCE performances of the devices fabricated on the nano-composite electrode and ITO substrate. The blue and red solid lines indicate the integrated current of the ITO-based and composite electrode based devices, respectively. (c) J-V curves of the PVSC fabricated on the Ag NW nano-network electrode protected by $60 \mu \mathrm{m}$ LGO sheets measured under forward and backward bias scanning. (d) Steady photocurrent (blue) and PCE (red) under 1 sun illumination of the Ag NW/RLGO based PVSC. 
Table 1. Summarized photovoltaic parameters of PVSC devices based on Ag NW/RLGO composite electrodes, control ITO substrates and pristine Ag NW electrodes without GO.

\begin{tabular}{cccccc}
\hline Samples & $\mathbf{V}_{\mathbf{~ o c}}(\mathbf{V})$ & $\mathbf{J}_{\mathbf{s c}}\left(\mathbf{m A} / \mathbf{c m}^{2}\right)$ & FF (\%) & PCE (\%) & Rs $\left(\mathbf{\Omega} \mathbf{c m}^{2}\right)$ \\
\hline Ag NW/RLGO & 0.87 & 15.43 & 70.9 & 9.62 & 98.85 \\
Average & $0.86 \pm 0.01$ & $14.82 \pm 0.59$ & $69.7 \pm 4.2$ & $8.89 \pm 0.67$ & $96.79 \pm 24.61$ \\
ITO & 0.87 & 16.23 & 80 & 11.34 & 54.49 \\
Average & $0.87 \pm 0.02$ & $15.98 \pm 0.62$ & $78.1 \pm 1.5$ & $10.87 \pm 0.35$ & $61.54 \pm 11.42$ \\
Ag NW without GO & 0.04185 & 0.000026 & 30.66 & $5.12 \times 10^{-9}$ & $1.38 \times 10^{8}$ \\
Average & $0.037 \pm 0.009$ & $(21.2 \pm 5.4) \times 10^{-6}$ & $27.41 \pm 2.1$ & $(3.48 \pm 1.27) \times 10^{-9}$ & $(1.58 \pm 0.19) \times 10^{8}$ \\
\hline
\end{tabular}

Table 2. Photovoltaic parameters of PVSC devices based on Ag NW/RLGO composite electrodes scanned forward and scanned backward.

\begin{tabular}{ccccc}
\hline Samples & $\mathbf{V}_{\text {oc }}(\mathbf{V})$ & $\mathbf{J}_{\text {sc }}\left(\mathbf{m A} / \mathbf{c m}^{2}\right)$ & FF (\%) & PCE (\%) \\
\hline Forward & 0.86 & 15.08 & 69.8 & 9.08 \\
Backward & 0.87 & 15.43 & 70.9 & 9.62 \\
\hline
\end{tabular}

\section{Conclusions}

In summary, different sizes of GO sheets from a centrifugal classification method were used and compared for the formation of fully-covered barrier on silver nanowire electrode with the assistance of steady hot airflow. Experimental results show that the size of GO sheet played an important role in preventing the corrosion of halogen species. By employing large size GO sheets, the anti-corrosive ability of Ag NW/LGO composite electrodes were significantly improved compared to those with small size GO sheets, as proven by monitoring the resistance variation under external bias and light illumination. Moreover, the Ag NW/RLGO composite electrode exhibited excellent transmittance of $81.8 \%$ at $550 \mathrm{~nm}$ and maintained $95.1 \%$ average transmittance (AVT) of the pristine Ag NW electrode. Consequently, the PVSCs fabricated on the Ag NW/RLGO based composite electrodes achieved a power conversion efficiency (PCE) of $9.62 \%$, i.e., nearly $85 \%$ of the PCE from the solar cell on commercial ITO. These results clearly demonstrate the potential of Ag NW/RLGO composite as window electrode for PVSCs, which would be beneficial to large-scale low-temperature fabrication and future commercialization of PVSCs.

Author Contributions: H.C. and H.L. conceived the idea. H.C. and H.L. designed the experiment and guided the experiment. M.L., X.W. and W.C.H.C. helped the data analysis. Y.Y. and D.H. helped the device fabrication. H.C. conducted data collection and wrote the manuscript. H.C. and H.L. revised the manuscript.

Acknowledgments: This work was supported by the National Natural Science Foundation of China (Grant No. 11704293), Hubei Provincial Natural Science Foundation of China (Grant No. 2017CFB286) and the Fundamental Research Funds for the Central Universities (WUT: 2018IB008, 2018IVB016).

Conflicts of Interest: There are no conflicts to declare.

\section{References}

1. Kojima, A.; Teshima, K.; Shirai, Y.; Miyasaka, T. Organometal Halide Perovskites as Visible-Light Sensitizers for Photovoltaic Cells. J. Am. Chem. Soc. 2009, 131, 6050-6051. [CrossRef] [PubMed]

2. Im, J.H.; Lee, C.R.; Lee, J.W.; Park, S.W.; Park, N.G. 6.5\% efficient perovskite quantum-dot-sensitized solar cell. Nanoscale 2011, 3, 4088. [CrossRef] [PubMed]

3. Lee, M.M.; Teuscher, J.; Miyasaka, T.; Murakami, T.N.; Snaith, H.J. Efficient Hybrid Solar Cells Based on Meso-Superstructured Organometal Halide Perovskites. Science 2012, 338, 643-647. [CrossRef] [PubMed]

4. Liu, M.; Johnston, M.B.; Snaith, H.J. Efficient planar heterojunction perovskite solar cells by vapour deposition. Nature 2013, 501, 395-398. [CrossRef]

5. Jeon, N.J.; Lee, J.; Noh, J.H.; Nazeeruddin, M.K.; Grätzel, M.; Seok, S.I. Efficient Inorganic-Organic Hybrid Perovskite Solar Cells Based on Pyrene Arylamine Derivatives as Hole-Transporting Materials. J. Am. Chem. Soc. 2013, 135, 19087-19090. [CrossRef] 
6. Jeon, N.J.; Noh, J.H.; Yang, W.S.; Kim, Y.C.; Ryu, S.; Seo, J.; Seok, S.I. Compositional engineering of perovskite materials for high-performance solar cells. Nature 2015, 517, 476-480. [CrossRef]

7. Yang, W.S.; Park, B.W.; Jung, E.H.; Jeon, N.J.; Kim, Y.C.; Lee, D.U.; Shin, S.S.; Seo, J.; Kim, E.K.; Noh, J.H.; et al. Iodide management in formamidinium-lead-halide-based perovskite layers for efficient solar cells. Science 2017, 356, 1376-1379. [CrossRef]

8. Chen, J.Y.; Chueh, C.C.; Zhu, Z.; Chen, W.C.; Jen, A.K.Y. Low-temperature electrodeposited crystalline $\mathrm{SnO}_{2}$ as an efficient electron-transporting layer for conventional perovskite solar cells. Sol. Energy Mater. Sol. Cells 2017, 164, 47-55. [CrossRef]

9. Ke, W.; Fang, G.; Liu, Q.; Xiong, L.; Qin, P.; Tao, H.; Wang, J.; Lei, H.; Li, B.; Wan, J.; et al. Low-Temperature Solution-Processed Tin Oxide as an Alternative Electron Transporting Layer for Efficient Perovskite Solar Cells. J. Am. Chem. Soc. 2015, 137, 6730-6733. [CrossRef]

10. Cai, F.; Yang, L.; Yan, Y.; Zhang, J.; Qin, F.; Liu, D.; Cheng, Y.B.; Zhou, Y.; Wang, T. Eliminated hysteresis and stabilized power output over $20 \%$ in planar heterojunction perovskite solar cells by compositional and surface modifications to the low-temperature-processed $\mathrm{TiO}_{2}$ layer. J. Mater. Chem. A 2017, 5, 9402-9411. [CrossRef]

11. Kim, J.; Kim, G.; Kim, T.K.; Kwon, S.; Back, H.; Lee, J.; Lee, S.H.; Kang, H.; Lee, K. Efficient planar-heterojunction perovskite solar cells achieved via interfacial modification of a sol-gel $\mathrm{ZnO}$ electron collection layer. J. Mater. Chem. A 2014, 2, 17291-17296. [CrossRef]

12. Konrad, W.; Michael, S.; Tomas, L.; Abate, A.; Snaith, H.J. Sub-150 ${ }^{\circ} \mathrm{C}$ processed meso-superstructured perovskite solar cells with enhanced efficiency. Energy Environ. Sci. 2014, 7, 1142-1147.

13. Batmunkh, M.; Macdonald, T.J.; Peveler, W.J.; Bati, A.S.R.; Carmalt, C.J.; Parkin, I.P.; Shapter, J.G. Plasmonic Gold Nanostars Incorporated into High-Efficiency Perovskite Solar Cells. ChemSusChem 2017, 10, 3750-3753. [CrossRef] [PubMed]

14. Song, J.; Zheng, E.; Wang, X.F.; Tian, W.; Miyasaka, T. Low-temperature-processed ZnO-SnO 2 nanocomposite for efficient planar perovskite solar cells. Sol. Energy Mater. Sol. 2016, 144, 623-630. [CrossRef]

15. Arora, N.; Dar, M.I.; Hinderhofer, A.; Pellet, N.; Schreiber, F.; Zakeeruddi, S.M.; Grätzel, M. Perovskite solar cells with CuSCN hole extraction layers yield stabilized efficiencies greater than 20\%. Science 2017, 358, 768-771. [CrossRef] [PubMed]

16. Zhang, H.; Cheng, J.; Lin, F.; He, H.; Mao, J.; Wong, K.S.; Jen, A.K.Y.; Choy, W.C.H. Pinhole-Free and Surface-Nanostructured NiOx Film by Room-Temperature Solution Process for High-Performance Flexible Perovskite Solar Cells with Good Stability and Reproducibility. ACS Nano 2016, 10, 1503-1511. [CrossRef] [PubMed]

17. Ouyang, D.; Xiao, J.; Ye, F.; Huang, Z.; Zhang, H.; Zhu, L.; Cheng, J. Strategic Synthesis of Ultrasmall NiCo2O4 NPs as Hole Transport Layer for Highly Efficient Perovskite Solar Cells. Adv. Funct. Mater. 2018, 1702722.

18. Zhang, H.; Wang, H.; Zhu, H.; Chueh, C.C.; Chen, W.; Yang, S.; Jen, A.K.Y. Low-Temperature Solution-Processed $\mathrm{CuCrO}_{2}$ Hole-Transporting Layer for Efficient and Photostable Perovskite Solar Cells. Adv. Energy Mater. 2018, 8, 1702762. [CrossRef]

19. Sun, W.; Ye, S.; Rao, H.; Li, Y.; Liu, Z.; Xiao, L.; Chen, Z.; Bian, Z.; Huang, C. Room-temperature and solution-processed copper iodide as the hole transport layer for inverted planar perovskite solar cells. Nanoscale 2016, 8, 15954-15960. [CrossRef] [PubMed]

20. Xu, L.; Wan, F.; Rong, Y.; Chen, H.; He, S.; Xu, X.; Liu, G.; Han, H.; Yuan, Y.; Yang, J.; et al. Stable monolithic hole-conductor-free perovskite solar cells using $\mathrm{TiO}_{2}$ nanoparticle binding carbon films. Org. Electron. 2017, 45, 131-138. [CrossRef]

21. Xiong, Y.; Zhu, X.; Mei, A.; Fei, Q.; Liu, S.; Zhang, S.; Jiang, Y.; Zhou, Y.; Han, H. Bifunctional $\mathrm{Al}_{2} \mathrm{O}_{3}$ Interlayer Leads to Enhanced Open-Circuit Voltage for Hole-Conductor-Free Carbon-Based Perovskite Solar Cells. Sol. RRL 2018, 2, 1800002. [CrossRef]

22. Tran, V.; Pammi, S.V.N.; Dao, V.D.; Choi, H.S.; Yoon, S.G. Chemical vapor deposition in fabrication of robust and highly efficient perovskite solar cells based on single-walled carbon nanotubes counter electrodes. J. Alloys Compd. 2018, 747, 703-711. [CrossRef]

23. Zhen, L.; Kulkarni, S.A.; Boix, P.P.; Shi, E.; Cao, A.; Fu, K.; Batabyal, S.K.; Zhang, J.; Xiong, Q.; Wong, L.H.; et al. Laminated Carbon Nanotube Networks for Metal Electrode-Free Efficient Perovskite Solar Cells. ACS Nano 2014, 8, 6797-6804. 
24. Habisreutinger, S.N.; Wenger, B.; Snaith, H.J.; Nicholas, R.J. Dopant-Free Planar n-i-p Perovskite Solar Cells with Steady-State Efficiencies Exceeding 18\%. ACS Energy Lett. 2017, 2, 622-628. [CrossRef]

25. Batmunkh, M.; Macdonald, T.J.; Shearer, C.J.; Bat-Erdene, M.; Wang, Y.; Biggs, M.J.; Parkin, I.P.; Nann, T.; Shapter, J.G. Carbon Nanotubes in $\mathrm{TiO}_{2}$ Nanofber Photoelectrodes for High-Performance Perovskite Solar Cells. Adv. Sci. 2017, 2017, 1600504. [CrossRef] [PubMed]

26. Zhou, J.; Ren, Z.; Li, S.; Liang, Z.; Surya, C.; Shen, H. Semi-transparent Cl-doped perovskite solar cells with graphene electrodes for tandem application. Mater. Lett. 2018, 220, 82-85. [CrossRef]

27. Liu, T.; Liu, W.; Zhu, Y.; Wang, S.; Wu, G.; Chen, H. All solution processed perovskite solar cells with Ag@Au nanowires as top electrode. Sol. Energy Mater. Sol. Cells 2017, 171, 43-49. [CrossRef]

28. Guo, F.; Azimi, H.; Hou, Y.; Przybilla, T.; Hu, M.; Bronnbauer, C.; Langner, S.; Spiecker, E.; Forberich, K.; Brabec, C.J. High-performance semitransparent perovskite solar cells with solution-processed silver nanowires as top electrodes. Nanoscale 2015, 7, 1642-1649. [CrossRef] [PubMed]

29. Jeon, I.; Yoon, J.; Ahn, N.; Atwa, M.; Delacou, C.; Anisimov, A.; Kauppinen, E.I.; Choi, M.; Maruyama, S.; Matsuo, Y. Carbon Nanotubes versus Graphene as Flexible Transparent Electrodes in Inverted Perovskite Solar Cells. J. Phys. Chem. Lett. 2017, 8, 5395-5401. [CrossRef] [PubMed]

30. Heo, J.H.; Shin, D.H.; Song, D.H.; Kim, D.H.; Lee, S.J.; Im, S.H. Super-flexible bis(trifluoromethanesulfonyl)-amide doped graphene transparent conductive electrodes for photo-stable perovskite solar cells. J. Mater. Chem. A 2018, 6, 8251-8258. [CrossRef]

31. Sung, H.; Ahn, N.; Jang, M.S.; Lee, J.K.; Yoon, H.; Park, N.G.; Choi, M. Transparent Conductive Oxide-Free Graphene-Based Perovskite Solar Cells with over 17\% Efficiency. Adv. Energy Mater. 2016, 6, 1501873. [CrossRef]

32. Sun, K.; Li, P.; Xia, Y.; Chang, J.; Ouyang, J. Transparent Conductive Oxide-Free Perovskite Solar Cells with PEDOT:PSS as Transparent Electrode. ACS Appl. Mater. Interface 2015, 7, 15314-15320. [CrossRef] [PubMed]

33. Kim, K.; Kwon, H.C.; Ma, S.; Lee, E.; Yun, S.C.; Jang, G.; Yang, H.; Moon, J. All-Solution-Processed Thermally and Chemically Stable Copper-Nickel Core-Shell Nanowire-Based Composite Window Electrodes for Perovskite Solar Cells. ACS Appl. Mater. Interface 2018, 10, 30337-30347. [CrossRef] [PubMed]

34. Hwang, H.; Ahn, J.; Lee, E.; Kim, K.; Kwon, H.C.; Moon, J. Enhanced compatibility between a copper nanowire-based transparent electrode and a hybrid perovskite absorber by poly(ethylenimine). Nanoscale 2017, 9, 17207-17211. [CrossRef] [PubMed]

35. Lu, H.; Zhang, D.; Cheng, J.; Liu, J.; Mao, J.; Choy, W.C.H. Locally Welded Silver Nano-Network Transparent Electrodes with High Operational Stability by a Simple Alcohol-Based Chemical Approach. Adv. Funct. Mater. 2015, 25, 4211-4218. [CrossRef]

36. Lu, H.; Zhang, D.; Ren, X.; Liu, J.; Choy, W.C.H. Selective Growth and Integration of Silver Nanoparticles on Silver Nanowires at Room Conditions for Transparent Nano-Network Electrode. ACS Nano 2014, 8, 10980-10987. [CrossRef] [PubMed]

37. Lee, E.; Ahn, J.; Kwon, H.C.; Ma, S.; Kim, K.; Yun, S.; Moon, J. All-Solution-Processed Silver Nanowire Window Electrode-Based Flexible Perovskite Solar Cells Enabled with Amorphous Metal Oxide Protection. Adv. Energy Mater. 2018, 8, 1702182. [CrossRef]

38. Han, J.; Yuan, S.; Liu, L.; Qiu, X.; Gong, H.; Yang, X.; Li, C.; Hao, Y.; Cao, B. Fully indium-free flexible Ag nanowires/ZnO:F composite transparent conductive electrodes with high haze. J. Mater. Chem. A 2015, 3, 5375-5384. [CrossRef]

39. Kim, A.; Lee, H.; Kwon, H.C.; Jung, H.S.; Park, N.G.; Jeong, S.; Moon, J. Fully solution-processed transparent electrodes based on silver nanowire composites for perovskite solar cells. Nanoscale 2016, 8, 6308-6316. [CrossRef]

40. Lu, H.; Sun, J.; Zhang, H.; Lu, S.; Choy, W.C.H. Room-temperature solution-processed and metal oxide-free nano-composite for the flexible transparent bottom electrode of perovskite solar cells. Nanoscale 2016, 8 , 5946-5953. [CrossRef]

41. Peng, L.; Xu, Z.; Liu, Z.; Guo, Y.; Li, P.; Gao, C. Ultrahigh Thermal Conductive yet Superflexible Graphene Films. Adv. Mater. 2017, 29, 1700589. [CrossRef] [PubMed]

42. Seo, J.W.; Park, S.; Kim, Y.C.; Jeon, N.J.; Noh, J.H.; Yoon, S.C.; Seok, S.I. Benefits of very thin PCBM and LiF layers for solution-processed p-i-n perovskite solar cells. Energy Environ. Sci. 2014, 7, 2642-2646. [CrossRef] 
43. Namkoong, G.; Mamun, A.A.; Ava, T.T. Impact of PCBM/C60 electron transfer layer on charge transports on ordered and disordered perovskite phases and hysteresis-free perovskite solar cells. Org. Electron. 2018, 56, 163-169. [CrossRef]

44. Wei, J.; Li, H.; Zhao, Y.; Zhou, W.; Fu, R.; Leprince-Wang, Y.; Yu, D.; Zhao, Q. Suppressed hysteresis and improved stability in perovskite solar cells with conductive organic network. Nano Energy 2016, 26, 139-147. [CrossRef]

(c) 2019 by the authors. Licensee MDPI, Basel, Switzerland. This article is an open access article distributed under the terms and conditions of the Creative Commons Attribution (CC BY) license (http:/ / creativecommons.org/licenses/by/4.0/). 
Article

\title{
High-Dose Electron Radiation and Unexpected Room-Temperature Self-Healing of Epitaxial SiC Schottky Barrier Diodes
}

\author{
Guixia Yang ${ }^{1}$, Yuanlong Pang ${ }^{1}$, Yuqing Yang ${ }^{1}$, Jianyong Liu ${ }^{1}$, Shuming Peng ${ }^{1}$, Gang Chen ${ }^{2}$, \\ Ming Jiang ${ }^{3}$, Xiaotao $\mathrm{Zu}^{3}$, Xuan Fang ${ }^{4}$, Hongbin Zhao ${ }^{5}$, Liang Qiao ${ }^{3, *}$ and Haiyan Xiao ${ }^{3, *}$ \\ 1 Institute of Nuclear Physics and Chemistry, China Academy of Engineering Physics, P.O. Box 919-220, \\ Mianyang 621900, China; biansechong@163.com (G.Y.); pyl641122@163.com (Y.P.); \\ yangsapphire@aliyun.com (Y.Y.); m13568266352@163.com (J.L.); pengshuming@caep.cn (S.P.) \\ 2 State Key Laboratory of Wide-Bandgap Semiconductor Power Electronics, Nanjing 210000, China; \\ steelchg@163.com \\ 3 School of Physical, University of Electronic Science and Technology of China, Chengdu 610054, China; \\ mjianglw@gmail.com (M.J.); xtzu@uestc.edu.cn (X.Z.) \\ 4 School of Science, Changchun University of Science and Technology, 7089 Wei-Xing Road, \\ Changchun 130022, China; fangxuan110@126.com \\ 5 State Key Laboratory of Advanced Materials for Smart Sensing, General Research Institute for Nonferrous \\ Metals, Beijing 100088, China; zhaohongbin@grinm.com \\ * Correspondence: liang.qiao@uestc.edu.cn (L.Q.); hyxiao@uestc.edu.cn (H.X.); \\ Tel.: +86-135-5139-2292 (L.Q.); +86-151-9800-6082 (H.X.)
}

Received: 31 December 2018; Accepted: 28 January 2019; Published: 2 February 2019

\begin{abstract}
Silicon carbide ( $\mathrm{SiC}$ ) has been widely used for electronic radiation detectors and atomic battery sensors. However, the physical properties of $\mathrm{SiC}$ exposure to high-dose irradiation as well as its related electrical responses are not yet well understood. Meanwhile, the current research in this field are generally focused on electrical properties and defects formation, which are not suitable to explain the intrinsic response of irradiation effect since defect itself is not easy to characterize, and it is complex to determine whether it comes from the raw material or exists only upon irradiation. Therefore, a more straightforward quantification of irradiation effect is needed to establish the direct correlation between irradiation-induced current and the radiation fluence. This work reports the on-line electrical properties of $4 \mathrm{H}-\mathrm{SiC}$ Schottky barrier diodes (SBDs) under high-dose electron irradiation and employs in situ noise diagnostic analysis to demonstrate the correlation of irradiation-induced defects and microscopic electronic properties. It is found that the electron beam has a strong radiation destructive effect on $4 \mathrm{H}-\mathrm{SiC}$ SBDs. The on-line electron-induced current and noise information reveal a self-healing like procedure, in which the internal defects of the devices are likely to be annealed at room temperature and devices' performance is restored to some extent.
\end{abstract}

Keywords: electron irradiation; room temperature self-healing; noise; electron-induced current; I-V curve

\section{Introduction}

Silicon carbide $(\mathrm{SiC})$ is an ideal material for high-frequency, high-power, and high-temperature devices due to its strong hardness, excellent thermal/mechanical stability, high-thermal conductivity, and controlled electrical properties [1,2]. With the advance of state-of-the-art growth and epitaxy techniques in the past decade, a variety of high-quality SiC-based structures and devices have been fabricated [1], making them very competitive toward third-generation wide-gap semiconductors. Thus, 
SiC-based structures have recently regained significant attention in advanced device applications. Furthermore, owing to its large intrinsic fundamental band gap (up to $3.26 \mathrm{eV} \mathrm{[3]),} \mathrm{SiC}$ is not suitable to visible and infrared light stimulation or irradiation, and their radiation resistance is stronger than that of the conventional semiconductors (such as Si-based materials); therefore, SiC-based diodes are very promising candidates to replace silicon devices for atomic battery light sensors, nuclear cell photosensors [4,5], or particle detectors [6,7].

Required by long-term exposure applications, the radiation resistance and durability of $\mathrm{SiC}$ diodes (as radiation detectors and atomic battery light sensors) are very critical and have been subjected to extensive research. For particle detector applications, the detectivity and radiation resistance of $\mathrm{SiC}$ diodes were studied under gamma ray $[7,8]$, proton $[7,8]$, neutron [9], electron $[8,10]$, and X-ray [6] irradiations. The results indicated that the electrical properties of radiated SiC diodes and their radiation resistance depended on types, energies, flux, fluence, and the absorbed dose of irradiated particles. It was found that when the total dose of $32-\mathrm{MeV}$ proton was $8.5 \times 10^{12} \mathrm{~cm}^{-2}$ and the total absorbed dose of $1.25-\mathrm{MeV} \gamma$-ray was $1000 \mathrm{kGy}$ (Air), the electrical properties of $6 \mathrm{H}-\mathrm{SiC}$ diodes were basically unchanged [7]. Within the range of 1-10 Gy absorbed dose, the radiation damage to $4 \mathrm{H}-\mathrm{SiC}$ diodes caused by $22-\mathrm{MeV}$ electron and 6-MeV X-ray photon beams hardly affected the radiation-induced current [6]. When the neutron fluence exceeded $5.7 \times 10^{16} \mathrm{~cm}^{-2}$, the charge collection efficiency of the $4 \mathrm{H}-\mathrm{SiC}$ diode started to drop [9]. For atomic battery light sensor applications, electrons were an important radiation source [4]; thus, many studies had focused on the ability of $4 \mathrm{H}-\mathrm{SiC}$ diodes' resistance to electron irradiation. For example, Eiting et al. studied the radiation resistance of $4 \mathrm{H}-\mathrm{SiC} \mathrm{p}-\mathrm{i}-\mathrm{n}$ junction betavoltaic irradiated with $8.5 \mathrm{GBq}{ }^{33} \mathrm{P}$ source with an average beta decay energy of $77 \mathrm{keV}$, and found that the devices did not experience degradation under the irradiation of ${ }^{33} \mathrm{P}$ source for four half-lives of ${ }^{33} \mathrm{P}$ source, thus demonstrating a good electron radiation resistance [4]. Chandrashekhar et al. experimentally studied the devices' radiation resistance performance under the $1 \mathrm{mCi}{ }^{63} \mathrm{Ni} \beta$-radiation source for ten days, and the results suggested such irradiation conditions did not cause the degradation of $4 \mathrm{H}-\mathrm{SiC}$ diodes [5].

In practical applications for both radiation detectors and atomic battery light sensors in many extreme conditions, such as nuclear, aerospace, military, and astrophysics, the total expected irradiation dose is normally enormous. However, the most common research of experimental or theoretical study on $\mathrm{SiC}$ electron radiation resistance is still relatively low; for example, the largest total $8.2-\mathrm{MeV}$ electron fluence ever reported is $9.48 \times 10^{14} \mathrm{~cm}^{-2}[8,10]$. Large fluence of electron irradiation is not only common in the radiation detection experiments, but also critical in the integrated design of the next-generation atomic battery, and thus deserves further study.

Moreover, the general principle of particle detector and atomic battery light sensor is based on induced-current generation (by radiation of electrons, neutrons, photons, and heavy ions) and detection (of the induced-voltage signals in diodes). The previous research were mostly focused on the correlation between the internal defects of $\mathrm{SiC}$ materials (or devices) and their electrical parameters under electron irradiation, such as relationship between defect levels and I-V as well as $\mathrm{C}-\mathrm{V}$ characteristic curves $[5,8]$. However, this apparent relationship is not suitable to explain the intrinsic response of irradiation effect, since defects are not easy to characterize and it is complex to distinguish whether the defects come from the raw material or exists only upon irradiation. Therefore, a more straightforward quantification of irradiation effect is greatly needed to establish the direct correlation between irradiation-induced current and the radiation fluence.

For this purpose, low-frequency noise information, especially $1 / \mathrm{f}$ noise, can be used as a characterization means for the sensitive detection of internal defects in electronic materials [11] and devices [12,13]. This method in principle can also be utilized to characterize radiation damage to electronic devices [12]. Under the beam radiation, the internal defects and the structural damage will lead to the increase of low-frequency noise power spectral density $S_{V}[14,15]$. For example, Babcock et al. [16] studied the radiation resistance of Ultra High Vacuum/Chemical Vapor Deposition SiGe heterojunction bipolar transistor (HBT) irradiated by ${ }^{60} \mathrm{Co} \gamma$-ray and found that the increase of the 
total absorbed dose resulted in the performance degradation of the SiGe HBT. The current gain $\beta$ was decreased with the increase of absorbed dose, and the internal defects were increased, while the noise information $S_{V}$ increased in the low-frequency range, as compared with that before irradiation. Therefore, the 1 / $\mathrm{f}$ noise can be used as a tool to characterize the defects in materials and devices, and correlate the defects with devices performance.

Here, we reported the study of electron-induced current and radiation resistance of SiC Schottky barrier diodes (SBDs) under high-fluence electron irradiation as well as an in situ noise diagnostics for defect-electrical property analysis. Through on-line electron-induced current, I-V curve, noise information, and SBDs' radiation resistance to the environment of electron irradiation had been analyzed, and a self-driven healing process was observed at room temperature, which led to some extent of electrical performance recovery.

\section{Materials and Methods}

\subsection{H-SiC SBDs Samples and Irradiation Experimental Conditions}

The epitaxial 4H-SiC SBDs used in this experiment were provided by State Key Laboratory of Wide-Band Gap Semiconductor Power Electronics located at Nanjing, China. Its structure is shown in Figure 1a, where the photosensitive area of SBDs is $3 \mathrm{~mm} \times 3 \mathrm{~mm}$ and the voltage-withstand range is -100 to $100 \mathrm{~V}$. The $4 \mathrm{H}-\mathrm{SiC}$ SBDs were $4 \mathrm{H}-\mathrm{SiC}$ epilayers grown by chemical vapor deposition on $\mathrm{SiC}$ substrates of $360 \mathrm{~mm}$ thickness, with nitrogen doped with a net doping density of $1 \times 10^{18} \mathrm{~cm}^{-3}$ and micropipe density of 1 micropipe $\mathrm{cm}^{-2}$. The buffer was n-type, $1 \mu \mathrm{m}$ thick, with a net free carrier concentration of $1 \times 10^{18} \mathrm{~cm}^{-3}$. The epilayer was n-type, $12 \mu \mathrm{m}$ thick, with a net free carrier concentration of $3 \times 10^{15} \mathrm{~cm}^{-3}$. The ohmic contact was obtained by deposition of a 1000- $\AA$-thick layer of $\mathrm{Ni}$ and a 3- $\mu \mathrm{m}$-thick layer of $\mathrm{Au}$. The Schottky contact was obtained by radio frequency magneton sputtering of a 1000- $\AA$-thick layer of $\mathrm{Ni}$ at room temperature. In order to reduce the influence of environment on the device, $\mathrm{SiO}_{2}$ of $1000 \AA$ thickness and $\mathrm{Si}_{3} \mathrm{~N}_{4}$ of $1000 \AA$ thickness were grown on $\mathrm{Ni}$ by sputtering method.

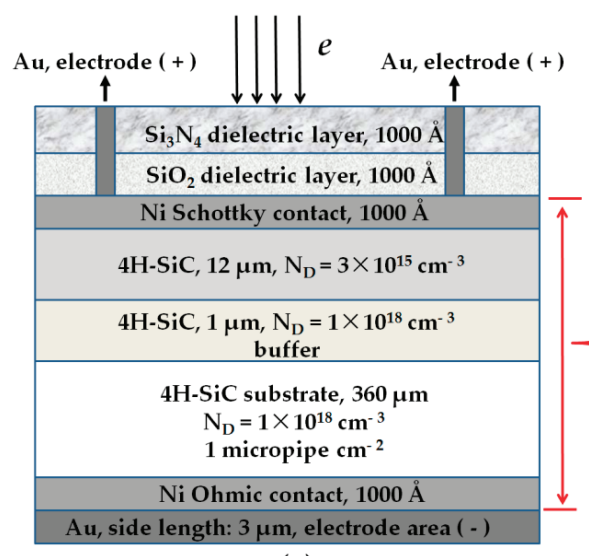

(a)

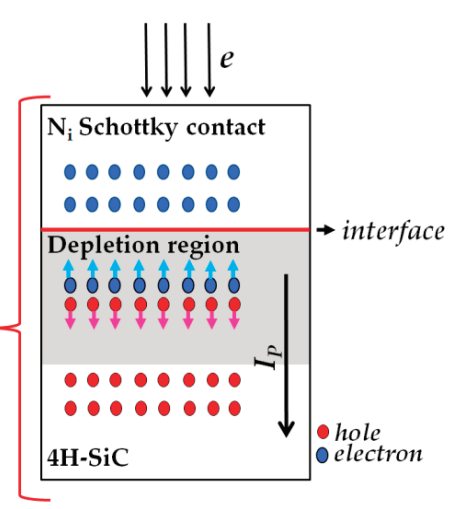

(b)

Figure 1. (a) The schematic diagram of Silicon carbide (SiC) Schottky barrier diodes (SBDs) and (b) the principle of electron-induced current generation under irradiation.

Electron beam irradiation experiments were performed on the electron accelerator of Sichuan Forever Holding Co., Ltd, located at Mianyang, China. The electron energy was $1.8 \mathrm{MeV}$, the electron flux was $9.62 \times 10^{12} \mathrm{~cm}^{-2} \mathrm{~s}^{-1}$, and the total electron fluence was $9.05 \times 10^{17} \mathrm{~cm}^{-2}$. In order to avoid overheating of SiC SBDs during electron beam irradiation, the bottom of the irradiated metal platform 
was continuously cooled with water, and meanwhile, the temperature of the SiC SBDs was monitored by a thermocouple and controlled at a constant temperature of $25^{\circ} \mathrm{C}$. The home-made real-time on-line current test system was used to monitor and record the changes of the electron-induced current of $\mathrm{SiC}$ SBDs during irradiation and $30 \mathrm{~min}$ after electron irradiation. Then the devices were kept at room temperature $\left(25^{\circ} \mathrm{C}\right)$ for $72 \mathrm{~h}$ without heating. The devices performance tended to decrease with the increasing electron fluence, but it was not certain whether the devices were disabled or not. In the case of reverse breakdown, the devices would be disabled completely, and the reverse breakdown state can be regarded as the worst-case state of devices performance. The devices were reverse biased to breakdown at $200 \mathrm{~V}$ voltage by Keithley 6517B high impedance/electrometer located at Mianyang, China toward the end of the experiment, and the damage of the device after irradiation was evaluated when the devices performance at reverse breakdown state was considered as the worst-case state. The I-V curves and noise information of SiC SBDs before and after electron beam irradiation, room-temperature self-healing, and reverse breakdown were measured by Keithley 2635 sourcemeter and the self-developed noise parameter test system located at Mianyang, China.

\subsection{The Electron-Induced Current Test}

When subjected to radiations of electron beam, $\gamma$-ray, and neutron, current can be induced in SBDs due to the ionization effect within Schottky barrier junctions, which is shown in Figure $1 \mathrm{~b}$. The principle of the electron-induced current can be understood by taking the electrons as an example-1.8 MeV electrons penetrate the SBDs completely. The n-type $4 \mathrm{H}-\mathrm{SiC}$ material of the Schottky barrier junction was irradiated by incident electrons with an energy larger than the material's fundamental electronic band gap; thus electron-hole pairs would be generated in n-type $4 \mathrm{H}-\mathrm{SiC}$ material. The Fermi lever in the Ni Schottky contact was less than the Fermi lever in the n-type 4H-SiC material; therefore, the average energy of electrons in the n-type $4 \mathrm{H}-\mathrm{SiC}$ material was greater than the average energy of those in the Ni Schottky contact. The difference in the average electron energy can be expected to transfer electrons from the n-type $4 \mathrm{H}-\mathrm{SiC}$ material to the Ni Schottky contact until the average electron energies were equal. While the holes can only stay in n-type $4 \mathrm{H}-\mathrm{SiC}$ material, the electrons were pulled toward the Ni Schottky contact. As a result, the width of the depletion region became narrower, and the contact potential difference decreased. The incident electron energy was converted into electrical energy. Once the external circuit was short-circuited, current could flow through the Schottky barrier junction. In this way, the separation of the electron-hole pairs can be achieved, and the induced current $I_{P}$, whose direction was from the Ni Schottky contact to the n-type $4 \mathrm{H}-\mathrm{SiC}$ material through the Schottky barrier junction, can be produced. The current equation of Schottky barrier junction under electron beam irradiation is

$$
I=I_{0}\left(e^{e U / k T}-1\right)-I_{P}
$$

where $I$ and $I_{0}$ are the current flowing through the Schottky barrier junction and the reverse saturation current, respectively; e, $U$, and $T$ stand for the electron charge, the applied voltage, and temperature, respectively; and $k$ is Boltzmann constant $\left(k=1.38 \times 10^{-23} \mathrm{~J} \mathrm{~K}^{-1}\right)$.

When the applied voltage $U$ is $0 \mathrm{~V}$, the Formula (1) becomes

$$
I=-I_{P} .
$$

In this study, the open-circuit induced current of SiC SBDs has been tested by a real-time on-line current test system, as shown in Figure 2a. This test system consisted of the fixtures, low-loss cables, 10-channel scanning card, data interface, Keithley 6517B high impedance/electrometer, and self-compiled control software (installed in the control computer). The fixtures were used to fix SiC SBDs and transmit current signals to low-loss cables. The 10-channel scanning card was installed at the rear panel of Keithley 6517B high impedance/electrometer and they were used to capture multiple electron-induced currents. The self-compiled control software was used to control and record current data detected by Keithley 6517B high impedance/electrometer in real time. The system can 
achieve a 10-channel real-time signal acquisition with the current and voltage accuracies of each signal acquisition reaching way up to $1 \mathrm{fA}$ and $1 \mathrm{nV}$, respectively.

(a)

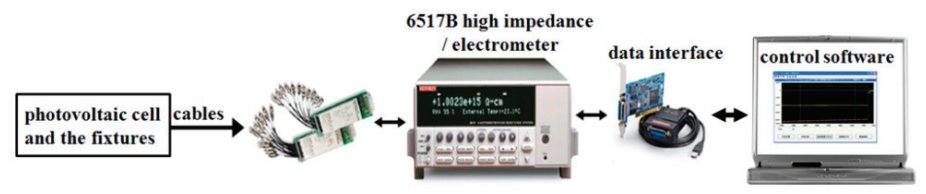

(b)

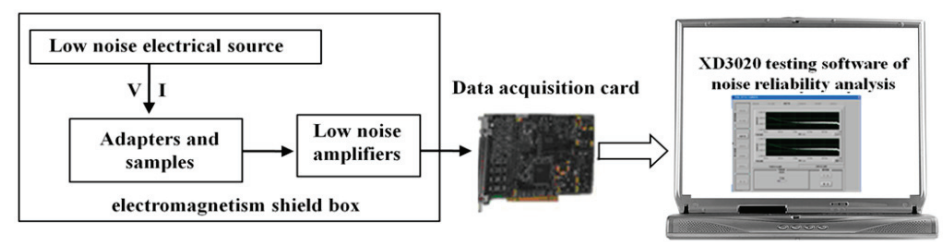

Figure 2. The illustration for (a) real-time on-line current test system and (b) test system for noise parameters.

\subsection{Noise Information Test}

In this study, the changes of noise information before and after irradiation of SiC SBDs have been tested by using the noise parameter test system. The noise parameter test system consists of low-noise bias, adapter, Stanford Research Systems SR560 voltage amplifier, acquisition card, and XD3020 [17] noise analysis software with the system bandwidth being $0-10^{6} \mathrm{~Hz}$, the background noise being $<4 \mathrm{nV} / \sqrt{ } \mathrm{Hz}(@ 1 \mathrm{kHz})$, and the signal magnification capability being $10^{0}-10^{5}$, as shown in Figure $2 b$.

The noise of the diode was typically composed of two or three components of shot noise, $1 / \mathrm{f}$ noise, and generation-recombination noise (G-R noise). The noise power spectral density $(S)$ can be written as:

$$
S(f)=A+\frac{B}{f^{\gamma}}
$$

where $A$ is the shot noise amplitude, $B$, the $1 / \mathrm{f}$ noise amplitude, and the exponents of $\gamma$ is usually taken to be unity.

In this work, based on the noise spectrum information of SiC SBDs, the electron irradiation effects of SiC SBDs were studied by using the parameter information in Equation (3). The damage degree of the device had been determined according to the change of noise power spectral density before and after irradiation and room-temperature self-healing.

\subsection{I-V Curve Test}

The current-voltage (I-V) curve of a semiconductor device contained the electrical information of dark current as well as break-over voltage. The real-time on-line electron-induced current and I-V characteristics can characterize the device to some extent. The I-V curve with voltage range of -100 to $2.5 \mathrm{~V}$ before and after irradiation of SiC SBDs had been measured with Keithley 2635 sourcemeter in this work. The damage degree of the device had been determined according to the change of I-V curve before and after irradiation and room-temperature self-healing.

\section{Results and Discussion}

\subsection{High-Dose Electron Irradiation}

Figure 3 shows the real-time curves of the open-circuit electron-induced current in SiC SBDs. It can be seen that when the energy of electrons was $1.8 \mathrm{MeV}$, and the electron flux was $9.62 \times 10^{12} \mathrm{~cm}^{-2} \mathrm{~s}^{-1}$, a current of $1.27 \times 10^{-5} \mathrm{~A}$ was induced due to the ionization effect. However, as the electron fluence 
further increased, the electron-induced current of the device decreased continuously. When the electron fluence reached $1 \times 10^{15} \mathrm{~cm}^{-2}$, the current decreased to $1.24 \times 10^{-5} \mathrm{~A}$, accounting for only a decrease of $2.36 \%$, which was consistent with the results reported by Nava et al. with the total electron fluence being $9.48 \times 10^{14} \mathrm{~cm}^{-2}[8,10]$. SiC SBDs can be considered as sufficient to resist the irradiation of electrons with a fluence under $1 \times 10^{15} \mathrm{~cm}^{-2}$. However, with a further increase of electron fluence, the electron-induced current of SiC SBDs began to decrease sharply, particularly when the electron fluence was $\leq 3 \times 10^{17} \mathrm{~cm}^{-2}$. When the electron fluence was $1 \times 10^{16} \mathrm{~cm}^{-2}$, the current decreased to $1.03 \times 10^{-5} \mathrm{~A}$, showing a decrease of $18.90 \%$. When the electron fluence was $1 \times 10^{17} \mathrm{~cm}^{-2}$, the current decreased to $5.00 \times 10^{-6} \mathrm{~A}$, accounting for a decrease of $60.63 \%$. At the end of irradiation, the total electron fluence reached $9.05 \times 10^{17} \mathrm{~cm}^{-2}$ and the current became $1.82 \times 10^{-6} \mathrm{~A}$, showing a decrease of $85.70 \%$. It was noteworthy that when the electron fluence was $>3.87 \times 10^{17} \mathrm{~cm}^{-2}$, the electron-induced current fluctuation of SiC SBDs increased sharply and the current fluctuation could reach up to $86 \%$.

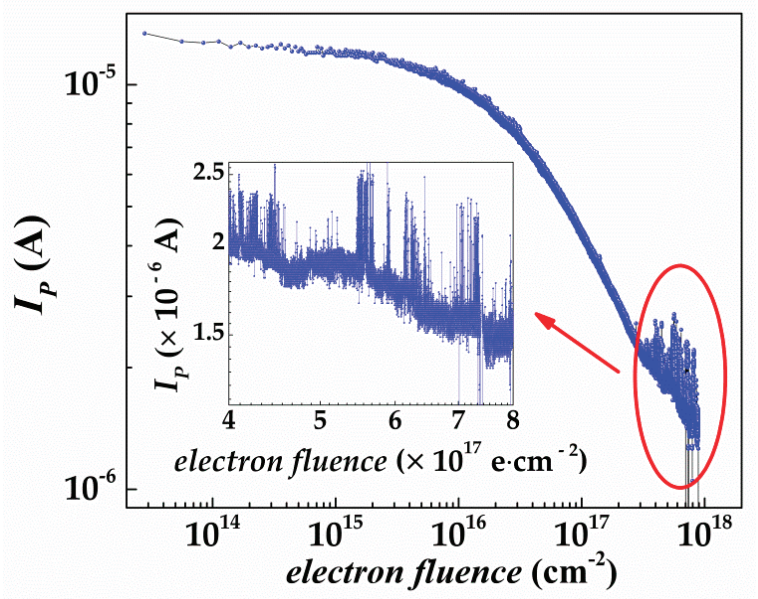

Figure 3. The real-time changing profiles of the induced current with electron fluence.

When SiC SBDs were irradiated by high dose of electrons, a large number of defects would be generated inside the silica layer [18], silicon carbid layer [19-22], and the interfaces [23,24] between the metal and silicon carbide. These defects would produce a removal effect $[25,26]$ on charge carriers at $1.8 \mathrm{MeV}$ electron irradiation, leading to the decrease of current.

Hemmingsson et al. studied the deep level defects in electron-irradiated $4 \mathrm{H}-\mathrm{SiC}$ epitaxial layers grown by chemical vapor deposition using deep level transient spectroscopy (DLTS). The measurements performed on electron-irradiated p-n junctions in the temperature range 100-750 K revealed both electron and hole traps with thermal ionization energies ranging from 0.35 to $1.65 \mathrm{eV}$ [27], which led to the deterioration of device performance. Iwamoto et al. investigated the formation and evolution of defects in 4H-SiC Schottky barrier diodes and correlated with the SBDs' performances [28]. The SBDs were irradiated with $1 \mathrm{MeV}$ electrons to a fluence of $1.00 \times 10^{15} \mathrm{~cm}^{-2}$. Current-voltage, capacitance-voltage, and DLTS measurements were used to study the effect of defects on the SBDs performance. It was found that the DLTS defect levels $\left(\mathrm{EH}_{1}, \mathrm{EH}_{3}\right.$, and $\left.\mathrm{Z}_{1 / 2}\right)$ were very likely to be partly responsible for the charge collection efficiency reduction after electron irradiation. $\mathrm{EH}_{1}$ and $\mathrm{EH}_{3}$ were related to carbon interstitials and $Z_{1 / 2}$ was related to carbon vacancies. DLTS study on $n$-type $4 \mathrm{H}-\mathrm{SiC}$ (0001) epilayers also showed that the carrier lifetime in an n-type 4H-SiC epilayer, measured by differential microwave photoconductance decay, had been significantly improved from $0.73 \mu \mathrm{s}$ (as-grown) to $1.62 \mu$ s (after oxidation, $1300{ }^{\circ} \mathrm{C}$ ) as the $\mathrm{Z}_{1 / 2}$ and $\mathrm{EH}_{6 / 7}$ centers had been reduced from $(0.3-2) \times 10^{13} \mathrm{~cm}^{-3}$ to below the detection limit $\left(1 \times 10^{11} \mathrm{~cm}^{-3}\right)$ by thermal oxidation of epilayers at 
$1150-1300{ }^{\circ} \mathrm{C}$ [29]. Based on the above results, we suggested that the current fluctuation might due to the increasing defects in the devices, such as interstitials and vacancies. These defects led to a slower and less stable carrier motion, which resulted in current fluctuation.

Figure 4 shows the I-V curves (including reverse breakdown region) of SiC SBDs before and after irradiation. From Figure $4 b$, it can be seen that the reserve current of SiC SBDs before irradiation increases with the increase of reserve bias, showing typical diode characteristics. For the 2-h irradiation sample, the forward current of the device dropped sharply from $2.39 \times 10^{-5}$ A (before irradiation) to $2.06 \times 10^{-8} \mathrm{~A}$ at a voltage of $2.5 \mathrm{~V}$, while the absolute value of the reverse dark current further increased (Figure $2 \mathrm{~b}$ ). When the voltage became $-100 \mathrm{~V}$, the current was $-8.76 \times 10^{-7} \mathrm{~A}$, showing a serious degradation of the device characteristics. At the reverse breakdown of the device, the I-V curve of the device had been tested. It was found that the forward current was further reduced compared to the case of $2 \mathrm{~h}$ after irradiation. When the voltage became $2.5 \mathrm{~V}$, the current dropped to $1.42 \times 10^{-9} \mathrm{~A}$, while the voltage became $-100 \mathrm{~V}$, the current was $-1.3 \times 10^{-9} \mathrm{~A}$, which was similar to the I-V characteristics of the resistance. The electron capture levels had been proved to be induced by the electron irradiation, and it would drastically influence the resistance in the bulk crystal and the Schottky barrier of SiC SBDs [30]. Under $2 \mathrm{MeV}$ electron irradiation, the Schottky barrier was found to decrease and the resistance of the bulk crystal was found to increase with the electron fluence, leading to the decrease of the forward current. The Schottky barrier of SiC SBDs decreased from $1.25 \mathrm{eV}$ (pre-irradiation) to $1.17 \mathrm{eV}$ (post-irradiation, $1.00 \times 10^{17} \mathrm{~cm}^{-2}$ ). The decrease of the barrier height was thus responsible for the increase of the reverse current. On the other hand, the increase of electron-induced defects in passivation layers was expected to result in the increase of the reverse leakage [31,32]. In this work, the I-V curves ( $2 \mathrm{~h}$ after electron irradiation) exhibited similar behavior. The SiC SBDs could be considered as the resistance since the barrier height disappeared and the bulk crystal resistance increased further after the SiC SBDs were reverse biased to breakdown. The I-V curves (reverse breakdown) of SiC SBDs were similar to the I-V characteristics of the resistance.

(a)

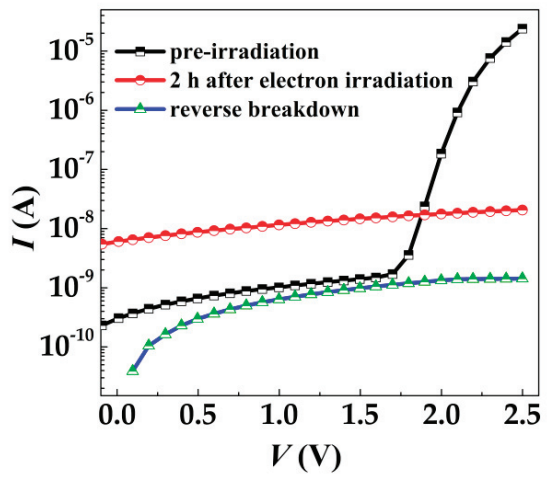

(b)

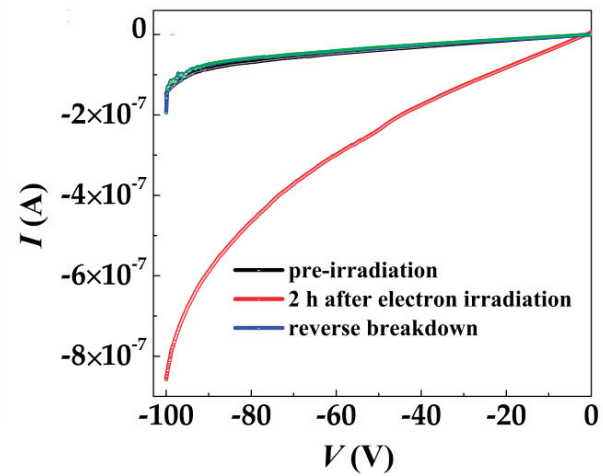

Figure 4. The I-V curves for SiC SBDs before and after electron beam irradiation. (a) The foward bias region and (b) the reverse bias region.

Besides the electrical properties (electron-induced current and I-V curves), the noise information of SiC SBDs also reflects the internal defect states before and after irradiation and the reverse breakdown, as shown in Figure $5 \mathrm{a}$. It can be seen that in the frequency range of $10^{2} \mathrm{~Hz}$ to $10^{5} \mathrm{~Hz}$, the noise power spectral density, $S_{V}$, exhibited a clear dependence on the electron irridation, with $S_{V}$ (reverse breakdown) $>S_{V}$ (2 h after irradiation) $>S_{V}$ (pre-irradiation). Ziel et al. [33] proposed that under small fluence irradiation, induced current was mainly contributed by two components: (1) the current $I_{0} e^{q U / k T}$ due to the injection of electrons from the semiconductor into the metal and (2) $-I_{0}$ due 
to the injection of electrons from the metal into the semiconductor. Both currents contained carriers that pass independently and randomly through the junction barrier, thereby showing as pure intermediate frequency shot noise. In this work, the shot noise of current SiC SBDs was in the frequency range of $10^{2}$ to $10^{5} \mathrm{~Hz}$.
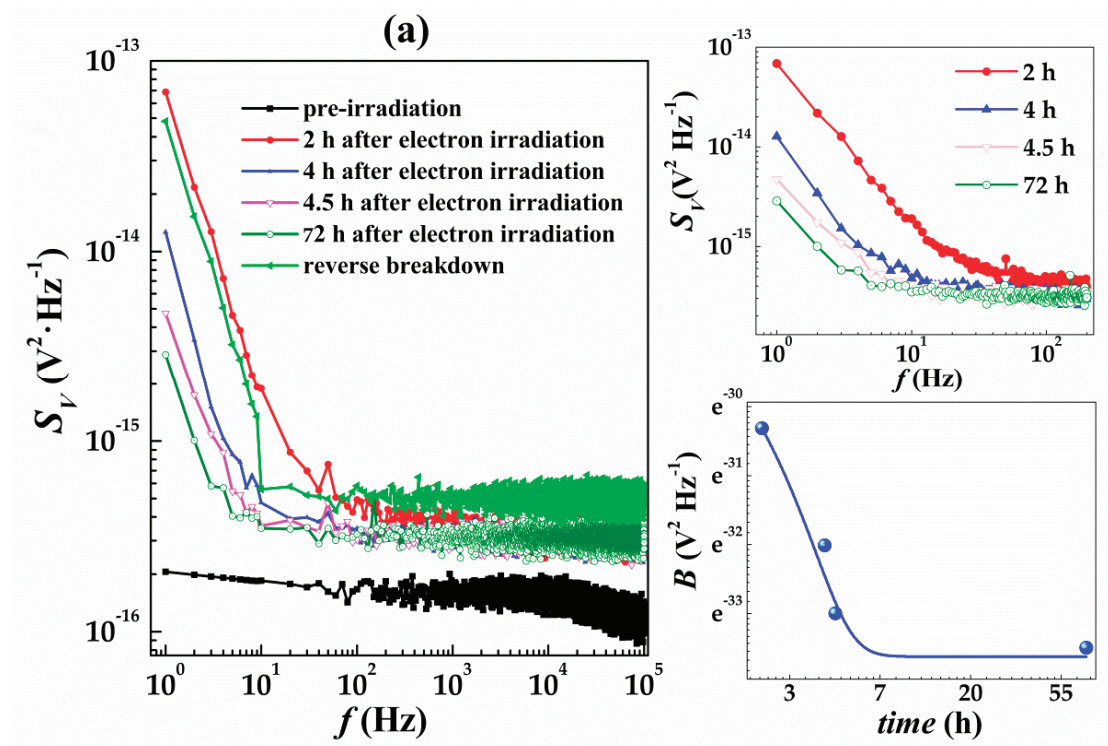

(b)

Figure 5. The noise power spectral densities of SiC SBDs. (a) Before and after electron beam irradiation and in a reverse breakdown state; (b) the low-frequency noise curve within $72 \mathrm{~h}$ after electron irradiation; and (c) the changing profiles of the low-frequency noise amplitude within $72 \mathrm{~h}$ after electron irradiation.

The current noise power spectral density $\left(S_{I}\right)$ of SBDs' shot noise is [34]

$$
S_{I}=2 e\left(I+2 I_{0}\right)
$$

The SBDs resistance can be obtained by Equation (1)

$$
R=\frac{d U}{d I} \approx \frac{k T}{e\left(I+I_{0}\right)}
$$

The voltage noise power spectral density $S_{V}$ is

$$
A=S_{V}=S_{I} \times R^{2}=\frac{2(k T)^{2}\left(I+2 I_{0}\right)}{e\left(I+I_{0}\right)^{2}}
$$

The current $I$ is

$$
I=\frac{2 n e}{t}
$$

where $R$ stands for the diode resistance, $n$ and $t$ are the carrier concentration and time for drifting through the barrier, respectively.

When $I \gg I_{0}$, Equation (6) can be simplified as

$$
S_{V} \approx \frac{2(k T)^{2}}{e I}=\frac{t(k T)^{2}}{e^{2} n}
$$


As the current decreased, $n$ decreased, which made $S_{V}$ to increase according to Equation (8), thus leading to $S_{V}(2 \mathrm{~h}$ after irradiation $)>S_{V}$ (pre-irradiation). When SiC SBDs first experienced the electron beam irradiation and then subjected to reverse breakdown, a large number of defects would be produced inside SiC SBDs, which made the noise power spectral density of SiC SBDs to further increase compared with SBDs that only irradiated by electrons, therefore showing $S_{V}$ (reverse breakdown $)>S_{V}(2 \mathrm{~h}$ after irradiation).

\subsection{Room-Temperature Self-Healing}

As shown in Figure 5a, the noise spectra of SiC SBDs before and after irradiation as well as in reverse breakdown state are $1 / \mathrm{f}$ noise in the frequency range of $10^{0}$ to $10^{2} \mathrm{~Hz} .1 / \mathrm{f}$ noise had an extrinsic origin that arose from defects [35]. The defects of electronic origin lying in the gap acted as electron traps leading to both mobility and carrier density fluctuations. In the frequency range of $10^{0}$ to $10^{2} \mathrm{~Hz}, S_{V}$ reached the minimum before irradiation, while reached the maximum at $2 \mathrm{~h}$ after electron irradiation, and $S_{V}$ even was greater than that of the reverse breakdown. However, if the $\mathrm{SiC}$ SBDs were left alone for $72 \mathrm{~h}$ after electron irradiation at room temperature, their $S_{V}$ could become lower than that of $S_{V}$ at reverse breakdown state, showing a significant decrease. The observed $S_{V}(2 \mathrm{~h}$ after irradiation) $>S_{V}$ (72 h after irradiation) was partially due to the fact that part of the defects were rapidly annealed at room temperature; thus, the effect of carrier removal was weakened, leading to the increase of carrier concentration. According to Hooge's equation [36], the relationship between $S_{V}$ and carrier concentration $n$ are given by Equation (9).

$$
S_{V}(f)=\frac{B}{f^{\gamma}} \propto \frac{\alpha_{H}}{n}
$$

where $\alpha_{H}$ stands for the Hooge parameter. The $S_{V}$ corresponding to $1 / \mathrm{f}$ noise was inversely proportional to the carrier concentration inside the device. As carrier concentration increased, $S_{V}$ decreased.

The noise power spectra at $2 \mathrm{~h}$ and $72 \mathrm{~h}$ after irradiation (shown in Figure 5a) cannot clearly reflect the annealing effect of the internal defects in SiC SBDs at room temperature. Therefore, at $72 \mathrm{~h}$ after irradiation exposure, we have carried out the tracking measurement on the low-frequency noise of $\mathrm{SiC}$ SBDs irradiated by electron beam at room temperature, which is shown in Figure $5 \mathrm{~b}$. It can be clearly seen that in the frequency range of $10^{0} \sim 10^{2} \mathrm{~Hz}$, the noise power spectral density of SiC SBDs decreased with time, and the observable frequency range of $1 / \mathrm{f}$ noise gradually decreased. At $2 \mathrm{~h}$ after irradiation, $1 / \mathrm{f}$ noise can be observed in the frequency range of $1-100 \mathrm{~Hz}$; at $4 \mathrm{~h}$ after irradiation exposure, $1 / \mathrm{f}$ noise can be observed in the frequency range of $1-30 \mathrm{~Hz}$; and at $72 \mathrm{~h}$ after irradiation exposure, 1 /f noise frequency further decreased into $1-6 \mathrm{~Hz}$, while 1 / f noise will be annihilated by shot noise above these frequency ranges.

The temporal variation of $1 / \mathrm{f}$ noise amplitude of the SiC SBDs irradiated by electrons can be calculated by Equation (9), and the results are shown in Figure $5 c$, where the $1 / \mathrm{f}$ noise amplitude $B$ decreases exponentially with time $t$, and this relationship is further well fitted by Equation (10).

$$
B=7.81 \times 10^{-13} e^{-t / 0.81}+2.50 \times 10^{-15}
$$

where the unit of $B$ is $\mathrm{V}^{2} \cdot \mathrm{Hz}^{-1}$, the unit of $t$ is $\mathrm{s}$.

Then the declining rate is

$$
\frac{d B}{d t}=-9.64 \times 10^{-13} e^{-t / 0.81}
$$

At $4.5 \mathrm{~h}$ after irradiation, $B$ declined sharply, while the declining rate decreased with the increase of time, and the declining rate followed Equation (11). At $72 \mathrm{~h}$ after irradiation, the declining rate tended to be constant. The value of $B$ decreased from $6.75 \times 10^{-14} \mathrm{~V}^{2} \cdot \mathrm{Hz}^{-1}$ (2 h after irradiation) to $2.05 \times 10^{-15} \mathrm{~V}^{2} \cdot \mathrm{Hz}^{-1}$ (72 $\mathrm{h}$ after irradiation), accounting for $96.96 \%$ decrease. 
Figure $5 b, c$ shows that the internal defects of the SiC SBDs continuously decrease at room temperature, weakening the removal effects of the defects on carriers. Back in 1966, Fischerrr et al. [37] had systematically investigated the temperature annealing of traps produced by 6- $88 \mathrm{MeV}$ electron irradiation in n-type Ge. In their experiment, the electron irradiation temperature was $85 \mathrm{~K}$, and it was found that some traps disappeared when the temperature increased to near $200 \mathrm{~K}$, thereby, leading to an increase of the carrier concentration. In 2009, Messina et al. [38] found that a significant portion of $E_{\gamma}^{\prime}$ centers, which induced in amorphous silica at room temperature by $\gamma$-irradiation up to $79 \mathrm{kGy}$, spontaneously decayed after the end of irradiation. In 1984, Yamaguchi et al. [39] found that effective room-temperature self-healing of radiation-induced defects in both p-type and n-type InP after electron irradiation leading to the recovery of $\mathrm{InP}$ solar cell properties. Besides $\mathrm{Ge}$, amorphous silica, and InP solar cell, room-temperature self-healing of radiation-induced defects were also shown in Si-based devices [25,40-43], as reported by Pease et al. Pease et al. [25] found the normalized change in reciprocal resistivity in the drain to source $\left(\overline{\Delta 1 / R_{D S}}\right)$ of Si-based power Metal-Oxide-Semiconductor Field-Effect Transistors degraded between 2 and 10\% (most less than 5\%) over a period of $24 \mathrm{~h}$ after room-temperature proton and neutron irradiation. These phenomena suggested that the internal defects generated inside the semiconductor material under irradiation can be annealed and annihilated below room temperature. However, as far as the room-temperature annealing of $\mathrm{SiC}$ materials is concerned, currently there is still not enough experimental evidences to demonstrate that some defects of $\mathrm{SiC}$ materials can be annealed after electron irradiation at room temperature. In this work, we used low-frequency noise to show that electron irradiation can produce the defects in $\mathrm{SiC}$ devices and these induced defects can be further annealed at room temperature. Assuming only electron irradiation and $\alpha_{H}$ remained constant, regardless of the amount of electron irradiation, part of internal defects in $\mathrm{SiC}$ material at $72 \mathrm{~h}$ after irradiation can be calculated to decrease by $3.04 \%$ as compared with the same internal defects at $2 \mathrm{~h}$ after irradiation. Since $1 / \mathrm{f}$ noise cannot be directly used to differentiate the types of defects, it is impossible to know what kinds of defects are annealed at room temperature. However, this property can still be used to characterize the declining trend of internal defects with time after electron irradiation via the noise information, and this method is also applicable for the defects characterization in other semiconductor materials and devices.

Furthermore, noise characterization were used to demonstrate that the SiC SBDs after electron irradiation have undergone an unexpected self-annealing or relaxation process at room temperature, thereby, reducing the induced defects while increasing the carrier concentration. Such room-temperature annealing was consistent with the on-line electron-induced current curve after irradiation and vice versa. As shown in Figure 6, the data collected by the on-line current-voltage test system shows that the electron-induced current of the device does not decrease to the background level within 19 min after the exposure to electron irradiation, but instead presents a linear increasing profile with the current rising from $10^{-10}$ to $10^{-7} \mathrm{~A}$. This phenomenon suggested that within $19 \mathrm{~min}$ after the irradiation, the device was subjected to a room-temperature annealing or relaxation, curing some of the internal defects, and recovering the electrical performance to a certain level. This phenomenon was also consistent with the I-V characteristics of the SiC SBDs, demonstrating that although the performance of the SiC SBDs was greatly lowered after the exposure to $9.05 \times 10^{17} \mathrm{~cm}^{-2}$ electron irradiation, this type of semiconductor device can still recover its electrical properties to some extent under this unexpected self-annealing mechanism. 


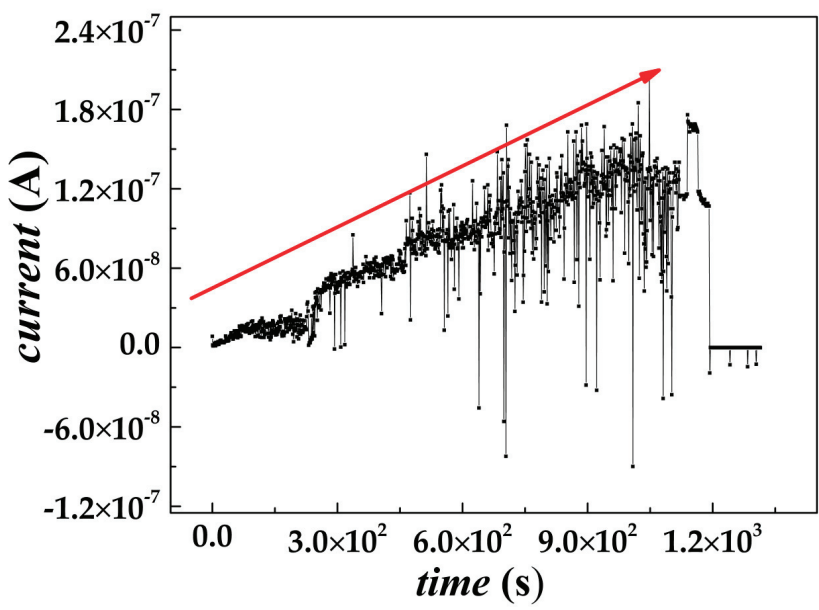

Figure 6. The real-time electron-induced current curve of SiC SBDs after the end of exposure to electron beam irradiation.

\section{Conclusions}

The electrical performance of SiC SBDs irradiated by high-dose, high-energy (1.8 MeV) electron beam had been investigated in this work. It was found that electron beam had a strong radiation destructive effect on $4 \mathrm{H}-\mathrm{SiC}$ SBDs. Their electrical performance was greatly reduced when exposed to high-energy electron beam with a fluence as high as $9.05 \times 10^{17} \mathrm{~cm}^{-2}$, the electron-induced current reduced by $85.70 \%$, and the device characteristics degraded seriously. The on-line electron-induced current and noise information revealed a self-healing like procedure, in which the internal defects of the devices were likely to be annealed at room temperature and devices performance was restored to some extent. Although the mechanism of this self-healing is under investigation, the high-dose irradiation and noise diagnostics study reported here can provide useful information for designing next-generation atomic battery and detectors for extreme environment applications.

\section{Patents}

Guixia Yang, Yuanlong Pang, Fansong Zeng, et al. Low-noise bias device, the Chinese patent of invention, patent number: ZL 201510729381.1.

Author Contributions: All the authors contributed to the conception, design, and performance of the experiment, the analysis of the data, and the writing of the paper. G.Y., H.X., and L.Q. initiated and discussed the research problem; Y.P., Y.Y., and M.J. performed the irradiation and on-line current experiments; G.Y., S.P., and J.L. performed the I-V and noise experiments; X.F. and H.Z. performed defect analysis; L.Q., X.Z., and G.Y. made the figures and analyzed the data; and G.Y., H.X., and L.Q. wrote the paper.

Acknowledgments: This research was funded by NSAF Joint Foundation of China (Grant No. U1530129), the Institution of Nuclear Physics and Chemistry (INPC), China. Project (Grant No. 2015CX03), National key laboratory of Materials Behavior and Evaluation Technology in Space Environment (Grant No. 6142910010403).

Conflicts of Interest: The authors declare no conflict of interest.

\section{References}

1. Morkoç, H.; Strite, S.; Gao, G.B.; Lin, M.E.; Sverdlov, B.; Burns, M. Large-band-gap sic, iii-v nitride, and ii-vi znse-based semiconductor device technologies. J. Appl. Phys. 1994, 76, 1363-1398. [CrossRef]

2. Spiazzi, G.; Buso, S.; Citron, M.; Corradin, M. Performance evaluation of a schottky sic power diode in a boost pfc application. IEEE Trans. Power Electron. 2003, 18, 1249-1253. [CrossRef] 
3. Persson, C.; Lindefelt, U. Detailed band structure for 3c-, 2h-, 4h-, 6h-sic, and si around the fundamental band gap. Phys. Rev. B 1996, 54, 10257-10260. [CrossRef]

4. Eiting, C.J.; Krishnamoorthy, V.; Rodgers, S.; George, T. Demonstration of a radiation resistant, high efficiency sic betavoltaic. Appl. Phys. Lett. 2006, 88, 064101. [CrossRef]

5. Chandrashekhar, M.V.S.; Thomas, C.I.; Li, H.; Spencer, M.G.; Lal, A. Demonstration of a 4 h sic betavoltaic cell. Appl. Phys. Lett. 2006, 88, 1009. [CrossRef]

6. Bruzzi, M.; Nava, F.; Russo, S.; Sciortino, S.; Vanni, P. Characterisation of silicon carbide detectors response to electron and photon irradiation. Diam. Relat. Mat. 2001, 10, 657-661. [CrossRef]

7. Metzger, S.; Henschel, H.; Kohn, O.; Lennartz, W. Silicon carbide radiation detector for harsh environments. IEEE Trans. Nucl. Sci. 2002, 49, 1351-1355. [CrossRef]

8. Nava, F.; Vittone, E.; Vanni, P.; Verzellesi, G.; Fuochi, P.G.; Lanzieri, C.; Glaser, M. Radiation tolerance of epitaxial silicon carbide detectors for electrons, protons and gamma-rays. Nucl. Instrum. Methods Phys. Res. Sect. A 2003, 505, 645-655. [CrossRef]

9. Seshadri, S.; Dulloo, A.R.; Ruddy, F.H.; Seidel, J.G.; Rowland, L.B. Demonstration of an sic neutron detector for high-radiation environments. IEEE Trans. Electron Devices 1999, 46, 567-571. [CrossRef]

10. Castaldini, A.; Cavallini, A.; Rigutti, L.; Nava, F. Low temperature annealing of electron irradiation induced defects in 4h-sic. Appl. Phys. Lett. 2004, 85, 3780-3782. [CrossRef]

11. Celik-Butler, Z.; Hsiang, T.Y. Determination of si-sio 2 interface trap density by $1 / \mathrm{f}$ noise measurements. IEEE Trans. Electron. Dev. 2015, 35, 1651-1655. [CrossRef]

12. Adak, O.; Rosenthal, E.; Meisner, J.; Andrade, E.F.; Pasupathy, A.N.; Nuckolls, C.; Hybertsen, M.S.; Venkataraman, L. Flicker noise as a probe of electronic interaction at metal-single molecule interfaces. Nano Lett. 2015, 15, 4143-4149. [CrossRef] [PubMed]

13. Folkes, P.A. Fluctuating deep-level trap occupancy model for hooge's $1 / \mathrm{f}$ noise parameter for semiconductor resistors. J. Appl. Phys. 1994, 64, 487-489.

14. Fleetwood, D.M.; Meisenheimer, T.L.; Scofield, J.H. 1/f noise and radiation effects in mos devices. IEEE Trans. Electron. Dev. 1994, 41, 1953-1964. [CrossRef]

15. Arora, S.K.; Singh, R.; Kumar, R.; Kanjilal, D.; Mehta, G.K. In situ 1/f noise studies on swift heavy ion irradiated p-type silicon. Nucl. Instrum. Methods Phys. Res. Sect. B 1999, 156, 265-269. [CrossRef]

16. Babcock, J.A.; Cressler, J.D.; Vempati, L.S.; Clark, S.D.; Jaeger, R.C.; Harame, D.L. Ionizing radiation tolerance of high-performance sige hbt's grown by uhv/cvd. IEEE Trans. Nucl. Sci. 1995, 42, 1558-1566. [CrossRef]

17. Li, Y.; Zhou, Q. The Noise Measurement and Analysis System of Optoelectronic Coupled Devices Based on Virtual Instrument. In Proceedings of the SPIE 2008 International Conference on Optical Instruments and Technology, Beijing, China, 16-19 November 2008.

18. Aitken, J.M.; Young, D.R.; Pan, K. Electron trapping in electron-beam irradiated $\mathrm{SiO}_{2}$. J. Appl. Phys. 1978, 49, 3386-3391. [CrossRef]

19. David, M.L.; Alfieri, G.; Monakhov, E.M.; Hallén, A.; Blanchard, C.; Svensson, B.G.; Barbot, J.F. Electrically active defects in irradiated 4h-sic. J. Appl. Phys. 2004, 95, 4728-4733. [CrossRef]

20. Barry, A.L.; Lehmann, B.; Fritsch, D.; Bräunig, D. Energy dependence of electron damage and displacement threshold energy in 6h silicon carbide. IEEE Trans. Nucl. Sci. 1991, 38, 1111-1115. [CrossRef]

21. Storasta, L.; Bergman, J.P.; Janzén, E.; Henry, A.; Lu, J. Deep levels created by low energy electron irradiation in 4h-sic. J. Appl. Phys. 2004, 96, 4909-4915. [CrossRef]

22. Bardeleben, H.J.V.; Cantin, J.L.; Henry, L.; Barthe, M.F. Vacancy defects in p-type $6 \mathrm{~h}$-sic created by low-energy electron irradiation. Phys. Rev. B 2000, 62, 10841-10846. [CrossRef]

23. Sheridan, D.C.; Chung, G.; Clark, S.; Cressler, J.D. The effects of high-dose gamma irradiation on high-voltage 4h-sic schottky diodes and the sic-SiO 2 interface. IEEE Trans. Nucl. Sci. 2001, 48, 2229-2232. [CrossRef]

24. Çınar, K.; Coşkun, C.; Aydoğan, Ş.; Asıl, H.; Gür, E. The effect of the electron irradiation on the series resistance of au/ni/6h-sic and au/ni/4h-sic schottky contacts. Nucl. Instrum. Methods Phys. Res. Sect. B 2010, 268, 616-621. [CrossRef]

25. Pease, R.L.; Enlow, E.W.; Dinger, G.L.; Marshall, P. Comparison of proton and neutron carrier removal rates. IEEE Trans. Nucl. Sci. 1987, 34, 1140-1146. [CrossRef]

26. McGarrity, J.M.; McLean, F.B.; DeLancey, W.M.; Palmour, J.; Carter, C.; Edmond, J.; Oakley, R.E. Silicon carbide jfet radiation response. IEEE Trans. Nucl. Sci. 1992, 39, 1974-1981. [CrossRef] 
27. Hemmingsson, C.; Son, N.T.; Kordina, O.; Bergman, J.P.; Janzén, E.; Lindström, J.L.; Savage, S.; Nordell, N. Deep level defects in electron-irradiated 4h sic epitaxial layers. J. Appl. Phys. 1997, 81, 6155-6159. [CrossRef]

28. Iwamoto, N.; Johnson, B.C.; Hoshino, N.; Ito, M.; Tsuchida, H.; Kojima, K.; Ohshima, T. Defect-induced performance degradation of 4h-sic schottky barrier diode particle detectors. J. Appl. Phys. 2013, 113, 1065. [CrossRef]

29. Toru, H.; Tsunenobu, K. Reduction of deep levels and improvement of carrier lifetime in n-type 4h-sic by thermal oxidation. Appl. Phys. Express 2009, 2, 041101.

30. Ohyama, H.; Takakura, K.; Watanabe, T.; Nishiyama, K.; Shigaki, K.; Kudou, T.; Nakabayashi, M.; Kuboyama, S.; Matsuda, S.; Kamezawa, C.; et al. Radiation damage of sic schottky diodes by electron irradiation. J. Mater. Sci. Mater. Electron. 2005, 16, 455-458. [CrossRef]

31. Muzykov, P.G.; Bolotnikov, A.V.; Sudarshan, T.S. Study of leakage current and breakdown issues in 4 h-sic unterminated schottky diodes. Solid-State Electron. 2009, 53, 14-17. [CrossRef]

32. Luo, Z.; Chen, T.; Ahyi, A.C.; Sutton, A.K.; Haugerud, B.M.; Cressler, J.D.; Sheridan, D.C.; Williams, J.R.; Marshall, P.W.; Reed, R.A. Proton radiation effects in 4 h-sic diodes and mos capacitors. IEEE Trans. Nucl. Sci. 2004, 51, 3748-3752.

33. Van Der Ziel, A. Theory of shot noise in junction diodes and junction transistors. Proc. IRE 1955, 43, 1639-1646. [CrossRef]

34. Van Der Ziel, A. Noise in solid-state devices and lasers. Proc. IEEE 1970, 58, 1178-1206. [CrossRef]

35. Kar, S.; Raychaudhuri, A.K. Temperature and frequency dependence of flicker noise in degenerately doped si single crystals. J. Phys. D Appl. Phys. 2001, 34, 3197-3202. [CrossRef]

36. Hooge, F.N. The relation between $1 / f$ noise and number of electrons. Physica B 1990, 162, 344-352. [CrossRef]

37. Fischer, J.; Corelli, J. Production and annealing of defects in 6-88 mev electron-irradiated n-type germanium. J. Appl. Phys. 1966, 37, 3287-3297. [CrossRef]

38. Messina, F.; Agnello, S.; Cannas, M.; Parlato, A. Room temperature instability of $\mathrm{e}^{\prime} \gamma$ centers induced by $\gamma$ irradiation in amorphous $\mathrm{SiO}_{2}$. J. Phys. Chem. A 2009, 113, 1026-1032. [CrossRef]

39. Yamaguchi, M.; Itoh, Y.; Ando, K. Room-temperature annealing of radiation-induced defects in inp solar cells. Appl. Phys. Lett. 1984, 45, 1206-1208. [CrossRef]

40. Zhou, X.J.; Fleetwood, D.M.; Schrimpf, R.D.; Faccio, F.; Gonella, L. Radiation effects on the 1/f noise of field-oxide field effect transistors. IEEE Trans. Nucl. Sci. 2008, 55, 2975-2980. [CrossRef]

41. Haohao, Z.; Jinshun, B.; Yuan, D.; Yannan, X.; Ming, L. Proton irradiation effects and annealing behaviors of $16 \mathrm{mb}$ magneto-resistive random access memory(mram). In Proceedings of the 2016 13th IEEE International Conference on Solid-State and Integrated Circuit Technology (ICSICT), Hangzhou, China, 25-28 October 2016; pp. 1194-1196.

42. Sato, S.i.; Beernink, K.; Ohshima, T. Charged particle radiation effects on flexible a-si/a-sige/a-sige triple junction solar cells for space use. In Proceedings of the 2013 IEEE 39th Photovoltaic Specialists Conference (PVSC) PART 2, Tampa, FL, USA, 16-21 June 2013; pp. 76-82.

43. Simons, M.; Monteith, L.K.; Hauser, J.R. Some observations on charge buildup and release in silicon dioxide irradiated with low energy electrons. IEEE Trans. Electron. Dev. 1968, 15, 966-973. [CrossRef]

(C) 2019 by the authors. Licensee MDPI, Basel, Switzerland. This article is an open access article distributed under the terms and conditions of the Creative Commons Attribution (CC BY) license (http:/ / creativecommons.org/licenses/by/4.0/). 

Article

\title{
Improving Two-Step Prepared $\mathrm{CH}_{3} \mathrm{NH}_{3} \mathrm{PbI}_{3}$ Perovskite Solar Cells by Co-Doping Potassium Halide and Water in $\mathrm{PbI}_{2}$ Layer
}

\author{
Hsuan-Ta Wu ${ }^{1}$, Yu-Ting Cheng ${ }^{1}$, Ching-Chich Leu ${ }^{2, *}$, Shih-Hsiung $\mathrm{Wu}^{3}$ and \\ Chuan-Feng Shih ${ }^{1,4, *}$ \\ 1 Department of Electrical Engineering, National Cheng Kung University, Tainan 70101, Taiwan; \\ n28004012@mail.ncku.edu.tw (H.-T.W.); n26041068@mail.ncku.edu.tw (Y.-T.C.) \\ 2 Department of Chemical and Materials Engineering, National University of Kaohsiung, \\ Kaohsiung 81148, Taiwan \\ 3 Green Energy and Environment Research Laboratories, Industrial Technology Research Institute, \\ Hsinchu 31040, Taiwan; shihhsiung@itri.org.tw \\ 4 Hierarchical Green-Energy Materials (Hi-GEM) Research Center, National Cheng Kung University, \\ Tainan 70101, Taiwan \\ * Correspondence: ccleu@nuk.edu.tw (C.-C.L.); cfshih@mail.ncku.edu.tw (C.-F.S.); \\ Tel.: +886-7-5919456 (ext. 7456) (C.-C.L.); +886-6-2757575 (ext. 62398) (C.-F.S.)
}

Received: 25 March 2019; Accepted: 23 April 2019; Published: 27 April 2019

\begin{abstract}
Incorporating additives into organic halide perovskite solar cells is the typical approach to improve power conversion efficiency. In this paper, a methyl-ammonium lead iodide $\left(\mathrm{CH}_{3} \mathrm{NH}_{3} \mathrm{PbI}_{3}\right.$, $\mathrm{MAPbI}_{3}$ ) organic perovskite film was fabricated using a two-step sequential process on top of the poly(3,4-ethylenedioxythiophene) polystyrene sulfonate (PEDOT:PSS) hole-transporting layer. Experimentally, water and potassium halides $(\mathrm{KCl}, \mathrm{KBr}$, and $\mathrm{KI})$ were incorporated into the $\mathrm{PbI}_{2}$ precursor solution. With only $2 \mathrm{vol} \%$ water, the cell efficiency was effectively improved. Without water, the addition of all of the three potassium halides unanimously degraded the performance of the solar cells, although the crystallinity was improved. Co-doping with KI and water showed a pronounced improvement in crystallinity and the elimination of carrier traps, yielding a power conversion efficiency (PCE) of $13.9 \%$, which was approximately $60 \%$ higher than the pristine reference cell. The effect of metal halide and water co-doping in the $\mathrm{PbI}_{2}$ layer on the performance of organic perovskite solar cells was studied. Raman and Fourier transform infrared spectroscopies indicated that a $\mathrm{PbI}_{2}$-dimethylformamide-water related adduct was formed upon co-doping. Photoluminescence enhancement was observed due to the co-doping of KI and water, indicating the defect density was reduced. Finally, the co-doping process was recommended for developing high-performance organic halide perovskite solar cells.
\end{abstract}

Keywords: perovskite solar cells; water doping; potassium halide doping

\section{Introduction}

The first report on lead halide organic perovskites for photovoltaic applications was published in 2009 [1]. Kojima et al. used methylammonium lead iodide $\left(\mathrm{CH}_{3} \mathrm{NH}_{3} \mathrm{PbI}_{3}, \mathrm{MAPbI}_{3}\right)$ to replace organic dyes in dye-sensitized solar cells (DSSCs), where mesoporous titanium oxide $\left(\mathrm{TiO}_{2}\right)$ and a liquid electrolyte were used, achieving a power conversion efficiency (PCE) of $3.8 \%$. Recently, the best solar cell efficiency achieved was $22 \%$, giving perovskites a reasonable chance to reach commercial competiveness [2]. PCE of the $\mathrm{MAPbI}_{3}$-based solar cell has been close to $20 \%$ in both mesoporous structure devices [3] as well as in planar heterojunction architectures [4]. High temperature annealing $\left(>400{ }^{\circ} \mathrm{C}\right)$ is required to crystallize the $\mathrm{TiO}_{2}$ layers used in mesoporous-type solar cells. Compared 
to the high-temperature processing of mesoporous solar cells, the planar heterojunction perovskite photovoltaics has the advantage of a low-temperature $\left(100^{\circ} \mathrm{C}\right)$ solution process, and, therefore, can be adopted in the roll-to-roll production of flexible devices [5].

One key aspect that affects the performance of planar heterojunction perovskite solar cells is the quality of the organic perovskite film, which is determined by the thermodynamics and the growth kinetics of the film [6-8]. Solution-processed perovskite films usually have abundant defects when compared to single-crystal samples. The introduction of additives into the perovskite precursor solution was reported to be an effective way to prepare a high quality perovskite film with fewer defects, leading to enhanced device performance [4,9-11]. Potassium halides were wildly used as additives in the perovskite precursor solutions adopted for solar cell research [12-14]. Potassium halide-doped perovskite solar cells that have a record PCE of more than $20 \%$, without I-V hysteresis, have been constructed $[13,15]$. Potassium halides were found to significantly facilitate the crystal growth of perovskite films and ameliorate the perovskite morphology, resulting in a reduced density in trap states and enhanced device performance $[13,16]$. However, it is not easy to form a homogeneous organic precursor by adding considerable amounts of potassium halide salts due to its restricted solubility in some organic solvent used for organic perovskite processing, which limits the application of potassium halides as additives. Water is a good solvent for potassium halide salts. Additionally, water additives have been reported to enhance the property of a two-step processed $\mathrm{MAPbI}_{3}[17,18]$. Water additives changed the characteristics of dimethylformamide (DMF), which is a general solvent for $\mathrm{PbI}_{2}$, thus helping to make a homogeneous $\mathrm{PbI}_{2}$ solution. A smooth and dense $\mathrm{PbI}_{2}$ film was fabricated by adding a small amount of water into the $\mathrm{PbI}_{2}$ precursor with $\mathrm{DMF}$, and then a high-quality $\mathrm{MAPbI}_{3}$ was obtained after the methylammonium iodide (MAI) conversion. Therefore, water was considered to be a suitable candidate for a co-doping additive for potassium halides during the $\mathrm{MAPbI}_{3}$ solution process.

However, it is challenging to deposit high-quality organic perovskite films on PEDOT:PSS, which is wildly used as the hole-transporting material in planar heterojunction perovskite solar cells. To obtain a homogeneous film structure on top of an organic surface, such as the PEDOT:PSS film, through a simple-solution process is not easy for an ionic material (such as $\mathrm{MAPbI}_{3}$ ) [17]. Compared to $\mathrm{MAPbI}_{3}$, $\mathrm{PbI}_{2}$ is less polar and, therefore, can easily form a continuous film on the PEDOT:PSS surface. Therefore, the two-step sequential process $\left(\mathrm{PbI}_{2}\right.$ layer $+\mathrm{MAI}$ conversion) is an appropriate way to fabricate a perovskite film when PEDOT:PSS is used as the hole-transporting layer [17]. However, very few studies have reported the effects of water or potassium halide additives on two-step processed perovskite solar cells [19]. According to this report, the alkali metal halides $(\mathrm{KCl}, \mathrm{NaCl}$, and $\mathrm{LiCl})$ were incorporated with the $\mathrm{PbI}_{2}$ layer and chelated with $\mathrm{Pb}^{2+}$ ions, enhancing the crystal growth of $\mathrm{PbI}_{2}$ films that, in turn, improved the crystallinity of the perovskite films and their photovoltaic properties. However, to the best of our knowledge, no report has investigated the performance of a planar heterojunction perovskite device by considering their interactive effects by using both water and potassium halides.

In this work, we proposed an effective way to enhance the efficiency of the $\mathrm{MAPbI}_{3}$-based perovskite device through the co-doping of water and potassium halides ( $\mathrm{KI}, \mathrm{KBr}$, and $\mathrm{KCl}$ ) during the $\mathrm{PbI}_{2}$ deposition process. Systematic studies of the effects of water and potassium halides co-doping on the thin film and device were investigated and discussed. To construct a planar heterojunction perovskite solar cell, a two-step process was employed to fabricate the $\mathrm{MAPbI}_{3}$ film. $\mathrm{PbI}_{2}$ was first deposited on PEDOT:PSS film, then the MAI was spin-coated on the $\mathrm{PbI}_{2}$ layer, followed by thermal annealing. Water and potassium halides were added into the $\mathrm{PbI}_{2}$ precursor solution to elucidate their influence on the performance of perovskite solar cells. As a result, the PCE of devices made from these additive-enhanced perovskites increased from $8.8 \%$ (based on pristine perovskite) to $13.9 \%$. 


\section{Materials and Methods}

\subsection{Chemicals}

Lead (II) iodide $\left(\mathrm{PbI}_{2}, 99.9985 \%\right)$, potassium iodide (KI, 99.995\%), and potassium chloride $(\mathrm{KCl}, 99.997 \%)$ were purchased from Alfa Aesar. Anhydrous N,N-dimethylformide (DMF, 99.8\%), 2-propanol (IPA, 99.5\%), and chlorobenzene (CB, 99.8\%) were purchased from Sigma-Aldrich (Saint Louis, MO, USA). Potassium bromide (KBr, IR spectroscopic) was purchased from Honeywell (Morristown, NJ, USA). Ultra-pure wa ter (Resistivity $>18.2 \mathrm{M} \Omega \cdot \mathrm{cm}$ at $25{ }^{\circ} \mathrm{C}$, Baker Analyzed LC/MS Reagent) was purchased from J.T. Baker (Radnor, PA, USA). Poly(3,4-ethylenedioxythiophene) polystyrene sulfonate (PEDOT:PSS), methylammonium iodide (MAI, >98\%), bathocuproine (BCP, $>99.5 \%$ ), and phenyl-C61-butyric acid methyl ester $\left(\mathrm{PC}_{61} \mathrm{BM},>99.5 \%\right.$ ) were purchased from Uni-onward (New Taipei City, Taiwan). All materials were used as received.

\subsection{Device Fabrication}

The fabrication process of the referenced standard perovskite solar cell (Ref) was as follows: patterned ITO-coated (indium tin oxide) glass substrates were cleaned ultrasonically in acetone and isopropanol for $10 \mathrm{~min}$, and then dried in an oven for $15 \mathrm{~min}$ at $110^{\circ} \mathrm{C}$. After a UV-ozone treatment of $30 \mathrm{~min}$, the substrates were transferred into a $\mathrm{N}_{2}$-filled glovebox. Filtered PEDOT:PSS was spin-coated at $2000 \mathrm{rpm}$ onto the ITO substrate and baked on a hot plate at $110{ }^{\circ} \mathrm{C}$ for $10 \mathrm{~min}$. The $\mathrm{PbI}_{2}$ precursor was prepared by dissolving $\mathrm{PbI}_{2}$ in the DMF solvent $(370 \mathrm{mg} / \mathrm{mL})$ and heated to $70{ }^{\circ} \mathrm{C}$ on a hot plate. Following this, the hot $\mathrm{PbI}_{2}$-DMF precursor was spin-coated on top of the PEDOT:PSS layer and baked on a hot plate at $90{ }^{\circ} \mathrm{C}$ for $10 \mathrm{~min}$. The MAI (45 mg/mL in IPA) precursor was spin-coated on the crystalline $\mathrm{PbI}_{2}$ layer and annealed at $110{ }^{\circ} \mathrm{C}$ for $1 \mathrm{~h}$ to form the $\mathrm{MAPbI}_{3}$ perovskite. After annealing for $20 \mathrm{~min}$, the pure IPA solution was spun on the $\mathrm{MAPbI}_{3}$ layer to wash out redundant $\mathrm{MAI}$, and then the annealing process continued for $40 \mathrm{~min}$. The $\mathrm{PC}_{61} \mathrm{BM}(20 \mathrm{mg} / \mathrm{mL}$ in $\mathrm{CB})$ was spin-coated on the perovskite. $\mathrm{BCP}$ of $10 \mathrm{~nm}$ and $\mathrm{Al}$ of $150 \mathrm{~nm}$ were sequentially evaporated on the top with a deposition rate of $0.4 \AA / s$ and $3-5 \AA / s$, respectively. For the co-doping samples, $\mathrm{H}_{2} \mathrm{O}$ with a 1,2 , or 3 volume percent, and potassium halide of various concentrations were added into the $\mathrm{PbI}_{2}-\mathrm{DMF}$ solution. The water added into the precursor was ultra-pure water.

\subsection{Characterizations}

The crystallinity of the $\mathrm{MAPbI}_{3}$ film was examined by X-ray Diffraction (XRD) with ultraX 18 (Tokyo, Japan). The microstructure of the films was characterized by high resolution scanning electron microscope (HR-SEM) SU8000 (HITACHI, Tokyo, Japan). The electrical analysis was performed by E5270B Precision IV Analyzer (Keysight, Santa Rosa, CA, USA) under AM 1.5 G illumination. The absorption analysis was performed by UV-vis-NIR spectrophotometer U-4100 (HITACHI, Tokyo, Japan). The photoluminescence (PL) was performed by Jobin Yvon LabRAM HR micro-Raman system (HORIBA, Kyoto, Japan) and the excitation laser wavelength was set to $532 \mathrm{~nm}$. The Fourier transform infrared spectroscopies (FTIRs) were performed by Nicolet FTIR instrument (Thermo Fisher Scientific, Waltham, MA, USA). The Raman spectroscopy was performed by Raman microscope (Renishaw, Wotton-under-Edge, UK). The depth profiles were performed by Auger Electron Spectroscopy MICROLAB 350 (Thermo Fisher Scientific, Waltham, MA, USA).

\section{Results and Discussion}

The photovoltaic properties of the devices (structure: glass/ITO/PEDOT:PSS/MAPbI $3 / \mathrm{PC}_{61} \mathrm{BM} /$ $\mathrm{BCP} / \mathrm{Al})$ were investigated. Figure 1 displays the photocurrent density-voltage $(\mathrm{J}-\mathrm{V})$ curves of the perovskite solar cells prepared with and without the incorporation of water and potassium halide additives in the $\mathrm{PbI}_{2}$-DMF precursor. The concentration of each cell was at the optimal conditions for cell properties. Table 1 lists the corresponding cell parameters. The cell performance was measured using an aperture metal mask of $2.2 \mathrm{~mm} \times 3.2 \mathrm{~mm}$ to a device active area of $2 \mathrm{~mm} \times 3 \mathrm{~mm}$. The PCE of 
device that was prepared using the 2 vol\% water-doped $\mathrm{PbI}_{2}$ precursor increased from $8.8 \%$ (without water) to $12.0 \%$ with a short-circuit current density (JSC) of $22.5 \mathrm{~mA} \cdot \mathrm{cm}^{-2}$, an open-circuit voltage ( $\left.\mathrm{V}_{\mathrm{OC}}\right)$ of $0.9 \mathrm{~V}$, and a fill factor (FF) of $59.2 \%$. The photovoltaic performance, as a function of the water content, is illustrated in Figure S1, and the corresponding photovoltaic parameters are listed in Table S1. It was found that the PCE of devices that were prepared using a water content below 3 vol\% were improved, and that the best performance was achieved by adding 2 vol\% water in $\mathrm{PbI}_{2}$. The $\mathrm{V}_{\mathrm{OC}}$ and FF increased slightly, and the JSC increased markedly by increasing the water content to $2 \mathrm{vol} \%$, resulting in the best PCE. Further increasing the water content to $3 \mathrm{vol} \%$ degraded the cell property. It has been reported that a planar heterojunction solar cell based on a high-quality perovskite film has a power conversion efficiency of $18 \%$ with a remarkably high FF value of 0.85 [17]. The study indicated that adding small amounts of water into the $\mathrm{PbI}_{2}-\mathrm{DMF}$ precursor made the solution more uniform, forming a smooth $\mathrm{PbI}_{2}$ film on top of the PEDOT:PSS, with high crystallinity and large crystalline domains. The perovskite film fabricated from the high-quality $\mathrm{PbI}_{2}$ film was highly pure and dense, without any pinhole. Our research showed similar observations. Water addition improved the morphology and crystallinity of the $\mathrm{PbI}_{2}$ films, as revealed in the SEM images (Figure S2). Moreover, the thickness of the $\mathrm{PbI}_{2}$ films increased with the content of water. The thickness was 156, 192, 189, and $194 \mathrm{~nm}$ for $0,1,2$, and 3 vol\% water incorporated $\mathrm{PbI}_{2}$ films, respectively. Figure $\mathrm{S} 3$ shows the $\mathrm{MAPbI}_{3}$ films fabricated from the water-doped $\mathrm{PbI}_{2}$ films. The grain size of all of the three water-incorporated films, Figure S3b-d, was larger than the film without water (Figure S3a). It has been observed that a rapid crystallization of organo-halide perovskites into the expected tetragonal cell for $\mathrm{MAPbI}_{3}$ occurred on exposure to small amounts of moisture [20]. You et al. have proposed a growth mode via thermal annealing of the perovskite precursor film in a humid environment (e.g., ambient air) to greatly improve the film quality, grain size, carrier mobility, and lifetime [21]. They indicated that, due to the strong hydroscopic nature of MAI, exposing the perovskite precursor to moisture during film formation could result in the accumulation of moisture within grain boundaries, inducing grain boundary creep and, subsequently, merging adjacent grains together. In addition, moisture could also provide an aqueous environment to enhance the diffusion length of the precursor ions, further promoting perovskite grain growth. The $\mathrm{PbI}_{2}$ films fabricated by the water-containing precursor possibly retained residual water or a water-related function group, which helped perovskite grain growth, until the deposition of MAI.

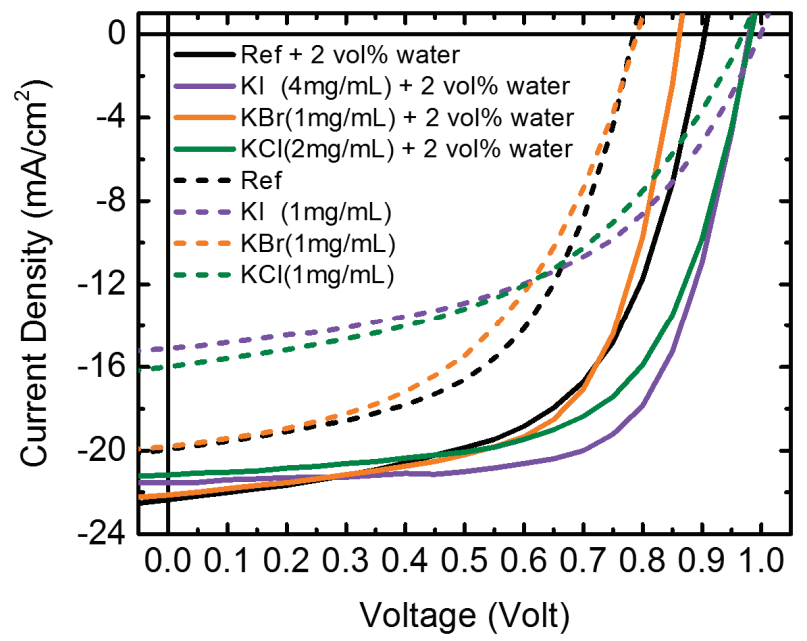

Figure 1. Photocurrent density-voltage (J-V) curves of perovskite solar cells prepared without and with water and/or potassium halide additives under their optimized concentrations. 
Table 1. The corresponding photovoltaic parameters of devices in Figure 1.

\begin{tabular}{lcccccc}
\hline \multicolumn{1}{c}{ Samples } & $V_{\text {OC }}(\mathbf{V})$ & $J_{\text {SC }}\left(\mathbf{m A} / \mathbf{c m}^{2}\right)$ & FF & PCE $(\%)$ & $R_{\text {SH }}\left(\boldsymbol{\Omega} \cdot \mathbf{c m}^{2}\right)$ & $R_{\mathbf{S}}\left(\boldsymbol{\Omega} \cdot \mathrm{cm}^{2}\right)$ \\
\hline Ref & $0.79 \pm 0.03$ & $19.7 \pm 1.4$ & $56.3 \pm 1.6$ & $8.8 \pm 1.1$ & $340 \pm 99$ & $7.2 \pm 0.7$ \\
KI $(1 \mathrm{mg} / \mathrm{mL})$ & $0.99 \pm 0.02$ & $15.1 \pm 0.8$ & $50.1 \pm 1.5$ & $7.5 \pm 0.6$ & $262 \pm 40$ & $8.8 \pm 1.6$ \\
$\mathrm{KBr}(1 \mathrm{mg} / \mathrm{mL})$ & $0.79 \pm 0.05$ & $19.8 \pm 3.9$ & $52.2 \pm 4.8$ & $8.2 \pm 2.5$ & $220 \pm 70$ & $11.7 \pm 3.3$ \\
$\mathrm{KCl}(1 \mathrm{mg} / \mathrm{mL})$ & $0.96 \pm 0.03$ & $16.0 \pm 1.0$ & $52.4 \pm 2.1$ & $8.0 \pm 0.6$ & $337 \pm 137$ & $12.5 \pm 1.8$ \\
Ref + water & $0.90 \pm 0.01$ & $22.5 \pm 1.3$ & $59.2 \pm 0.6$ & $12.0 \pm 0.6$ & $168 \pm 40$ & $3.6 \pm 0.1$ \\
$\mathrm{KI}(4 \mathrm{mg} / \mathrm{mL})+$ water & $0.97 \pm 0.01$ & $21.3 \pm 1.2$ & $67.0 \pm 2.2$ & $13.9 \pm 0.7$ & $555 \pm 39$ & $5.5 \pm 0.7$ \\
$\mathrm{KBr}(1 \mathrm{mg} / \mathrm{mL})+$ water & $0.85 \pm 0.04$ & $22.1 \pm 1.0$ & $63.4 \pm 1.9$ & $11.9 \pm 1.2$ & $264 \pm 46$ & $3.8 \pm 0.3$ \\
$\mathrm{KCl}(2 \mathrm{mg} / \mathrm{mL})+$ water & $0.97 \pm 0.01$ & $21.0 \pm 1.6$ & $62.8 \pm 0.8$ & $12.8 \pm 1.2$ & $1217 \pm 106$ & $4.7 \pm 0.3$ \\
\hline
\end{tabular}

Conversely, the PCE of photovoltaic devices fabricated by the $\mathrm{PbI}_{2}$-DMF precursor with potassium halides $(\mathrm{KI}, \mathrm{KBr}$, and $\mathrm{KCl})$ as the only additives became worse. As displayed in Figure 1, the PCE deteriorated from $8.8 \%$ for pristine $\mathrm{MAPbI}_{3}$ to $7.5 \%, 8.2 \%$, and $8.0 \%$, by adding $1 \mathrm{mg} / \mathrm{mL} \mathrm{KI}, \mathrm{KBr}$, and $\mathrm{KCl}$, respectively. For $\mathrm{KCl}$ - and $\mathrm{KI}$-doped samples, the degradation of PCE was caused by the decrease in the JSC and the fill factor, while for KBr-doped samples, only the fill factor decreased. Figure S4 illustrates the changes in photovoltaic performance of the potassium halide-doped devices as a function of the amount of potassium halide added. Notably, the devices were further improved by incorporating potassium halide into the water- $\mathrm{PbI}_{2}-\mathrm{DMF}$ precursor. By co-doping with 2 vol\% water and potassium halides, the PCE was improved from $8.8 \%$ (pristine perovskite) to $13.9 \%$ ( $4 \mathrm{mg} / \mathrm{mL}$ $\mathrm{KI}), 11.9 \%(1 \mathrm{mg} / \mathrm{mL} \mathrm{KBr})$ and $12.8 \%(2 \mathrm{mg} / \mathrm{mL} \mathrm{KCl})$. The changes in the photovoltaic performance of the water and potassium halide co-doped devices as a function of the potassium halide additives is also illustrated in Figure 2. The performance of devices was enhanced by adding $\mathrm{KI}$ or $\mathrm{KCl}$ into the 2 vol\% water-doped $\mathrm{PbI}_{2}$-DMF precursor, while $\mathrm{KBr}$-doped devices had inferior properties than those without $\mathrm{KBr}$. Using $4 \mathrm{mg} / \mathrm{mL} \mathrm{KI}$ as the additive provided the best performance of the device. Figure S4 further plots the cell parameters as functions of the content of the potassium halides for devices prepared by $\mathrm{PbI}_{2}$ without water; all of the cell parameters degraded and Table S2 lists the corresponding photovoltaic parameters of the devices.
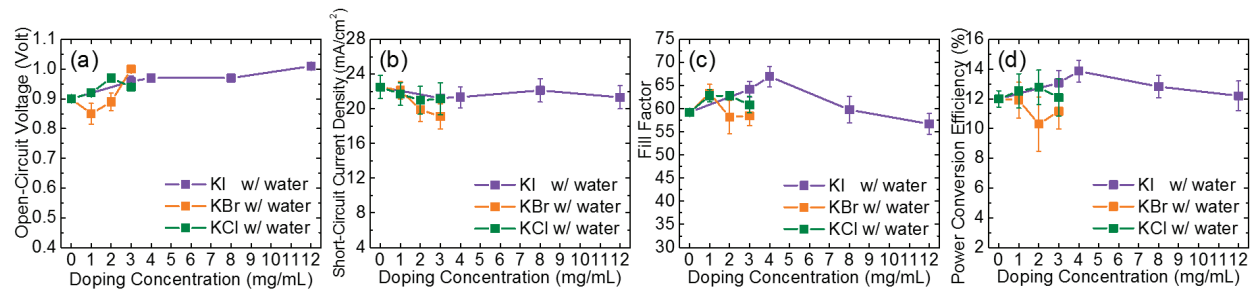

Figure 2. The changes in (a) $V_{\mathrm{OC}}$; (b) $J_{\mathrm{SC}}$; (c) FF (fill factor); (d) power conversion efficiency (PCE) of the potassium halide-doped devices with $2 \mathrm{vol} \%$ water co-doping as a function of doping amounts of $\mathrm{KI}, \mathrm{KBr}$, and $\mathrm{KCl}$.

Figure 3 shows comprehensive XRD analyses of the potassium halides-doped $\mathrm{PbI}_{2}$ and $\mathrm{MAPbI}_{3}$ films with and without water incorporated with $\mathrm{PbI}_{2}$. The $\mathrm{PbI}_{2}$ and $\mathrm{MAPbI}_{3}$ films were deposited on ITO/PEDOT:PSS. Without water, the XRD intensity increased markedly for all the $\mathrm{KCl}-$, $\mathrm{KBr}-$, and $\mathrm{KI}$-doped $\mathrm{PbI}_{2}$ films (Figure 3a). However, the XRD of the $\mathrm{MAPbI}_{3}$ films prepared on the potassium-doped $\mathrm{PbI}_{2}$ were similar to that without doping (Figure 3c). Water incorporation increased the XRD intensity of $\mathrm{PbI}_{2}$, but did not affect the XRD intensity of the perovskite film (Figure 3a,c). Co-doping of water and potassium halide increased the XRD intensity of both the $\mathrm{PbI}_{2}$ and $\mathrm{MAPbI}_{3}$ significantly (Figure 3b,d). The increase in the XRD intensity was also accompanied by an increase in the grain size. 


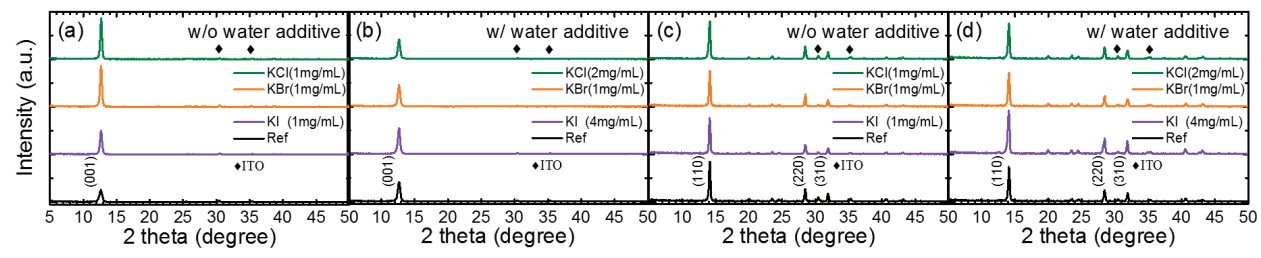

Figure 3. X-ray Diffraction (XRD) of $\mathrm{PbI}_{2}$ prepared by incorporating (a) $\mathrm{KCl}, \mathrm{KBr}$, and $\mathrm{KI}$ (without water) and (b) $\mathrm{KCl}, \mathrm{KBr}$, and $\mathrm{KI}$ with water additives. $\mathrm{XRD}$ of $\mathrm{MAPbI}_{3}$ on $\mathrm{PbI}_{2}$ prepared using the same conditions as (a) and (b) are shown in (c) and (d), respectively.

Figure 4 shows the top-view and cross-section SEM images of the $\mathrm{PbI}_{2}$ films that were co-doped with $2 \mathrm{vol} \%$ water and potassium halides (KI: $4 \mathrm{mg} / \mathrm{mL}, \mathrm{KBr}: 1 \mathrm{mg} / \mathrm{mL}$, and $\mathrm{KCl}: 2 \mathrm{mg} / \mathrm{mL}$ ). The film thickness was unchanged by the potassium halides, but the surface coverage was improved and the grain size was enlarged, which agreed with the XRD observation. Figure 5 displays the SEM images of the co-doped films. Adding potassium halides (especially $\mathrm{KI}$ and $\mathrm{KBr}$ ) to the $2 \mathrm{vol} \%$ water-incorporated $\mathrm{PbI}_{2}$ precursor enhanced $\mathrm{MAPbI}_{3}$ grain growth, which was denser with higher continuity, allowing for effective charge generation and dissociation in perovskite films. Such a highly continuous and large grain structure was also beneficial for carriers to transport through the film.

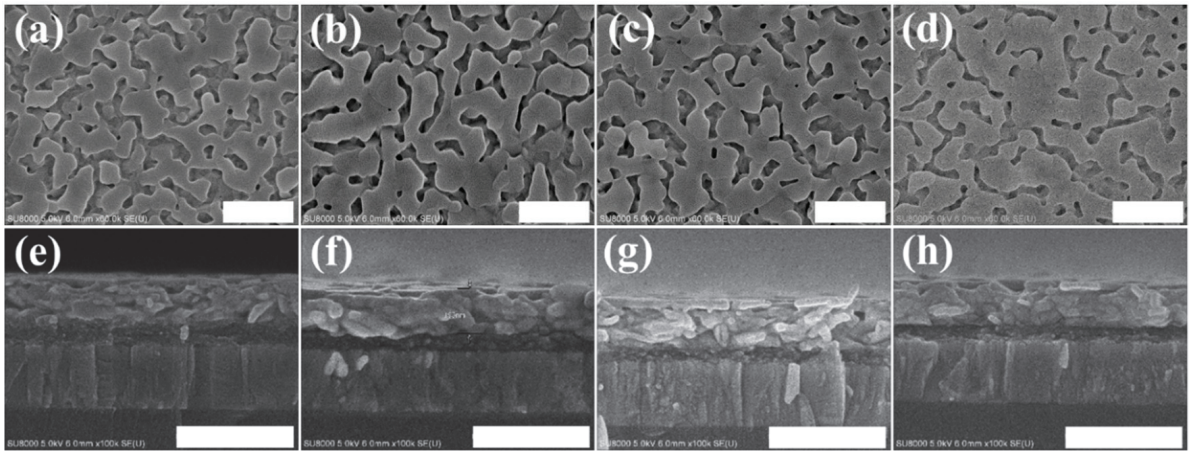

Figure 4. Plane and cross-section scanning electron microscope (SEM) images, respectively, of $\mathrm{PbI}_{2}$ prepared with (a,e) $2 \%$ water, $(\mathbf{b}, \mathbf{f}) 2 \%$ water $+\mathrm{KI}(4 \mathrm{mg} / \mathrm{mL})(\mathbf{c}, \mathbf{g}) 2 \%$ water $+\mathrm{KBr}(1 \mathrm{mg} / \mathrm{mL})$, and $(\mathbf{d}, \mathbf{h})$ $2 \%$ water $+\mathrm{KCl}(2 \mathrm{mg} / \mathrm{mL})$. (Scale bar $=500 \mathrm{~nm})$.
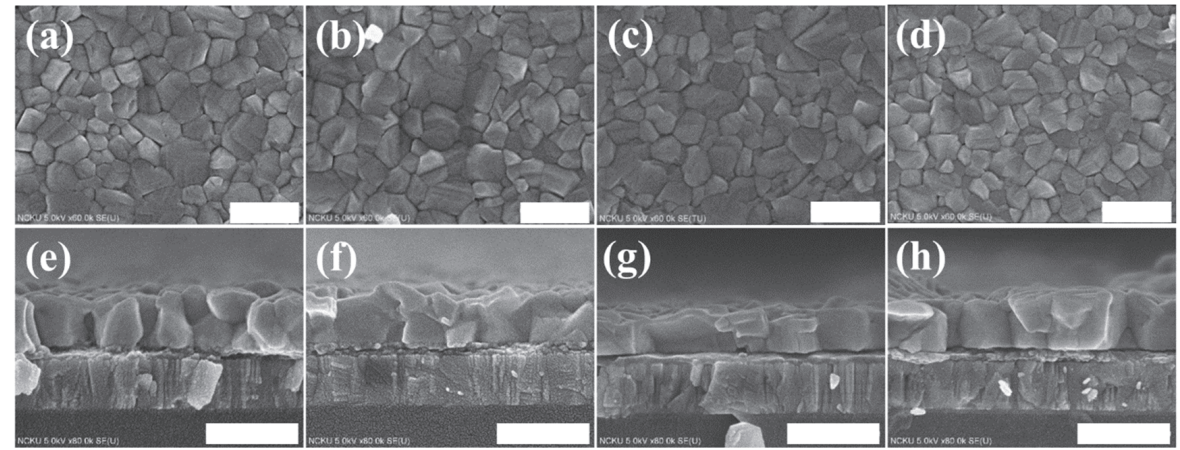

Figure 5. Plane and cross-section SEM images, respectively, of $\mathrm{MAPbI}_{3}$ on $\mathrm{PbI}_{2}$ with $(\mathrm{a}, \mathrm{e}) 2 \%$ water, $(\mathbf{b}, \mathbf{f}) 2 \%$ water $+\mathrm{KI}(4 \mathrm{mg} / \mathrm{mL})(\mathbf{c}, \mathbf{g}) 2 \%$ water $+\mathrm{KBr}(1 \mathrm{mg} / \mathrm{mL})$, and $(\mathbf{d}, \mathbf{h}) 2 \%$ water $+\mathrm{KCl}(2 \mathrm{mg} / \mathrm{mL})$. $($ Scale bar $=500 \mathrm{~nm})$. 
To exploit the effect of co-doping water and potassium halides in the $\mathrm{PbI}_{2}$ layer, the Fourier transform infrared spectroscopy and Raman spectroscopy were adopted, as shown in Figure 6 . The $\mathrm{PbI}_{2}$ films were prepared on Si/PEDOT:PSS because glass absorbs the IR light. In Figure 6a, characteristic peaks related to the $\mathrm{C}=\mathrm{O}$ stretching were found around $1715 \mathrm{~cm}^{-1}$ [22]. According to the literature, the $\mathrm{C}=\mathrm{O}$ vibration shifts to lower frequency around $1650 \mathrm{~cm}^{-1}$ for $\mathrm{DMF}$, which forms Lewis adducts due to the reaction of the $\mathrm{PbI}_{2}$ layer $[23,24]$. In our sample, the $\mathrm{C}=\mathrm{O}$ stretching was found to be blue-shifted, which might be caused by the formation of a $\mathrm{PbI}_{2}-\mathrm{DMF}-\mathrm{H}_{2} \mathrm{O}$ adduct by incorporating water through a Lewis acid-base reaction. The other possibility was that the $\mathrm{PbI}_{2}-\mathrm{DMF}$ precursor reacted with the PEDOT:PSS under-layer because of the incorporation of water by partially dissolving the PEDOT:PSS near the $\mathrm{PbI}_{2} / \mathrm{PEDOT}$ :PSS interface. A similar observation has been reported by Winther et al. [25]. Figure $6 \mathrm{~b}$ shows the Raman spectra of the $\mathrm{PbI}_{2}$ layer with or without potassium halides and water. Si-related signals were found at $521 \mathrm{~cm}^{-1}(\mathrm{Si}-\mathrm{Si} \mathrm{LO}), 940$, and $987 \mathrm{~cm}^{-1}(\mathrm{Si}-\mathrm{OH})$ [26]. Notably, the O-H and C-H stretching of PEDOT split into two peaks at 2865 and $2945 \mathrm{~cm}^{-1}$, owing to the incorporation of metal halides and water, particularly for $\mathrm{KBr}$ - and $\mathrm{KCl}$-doping [27]. Evidence from FTIR and Raman spectroscopies indicated that the doping of water and potassium halides could form some new adducts and change the interfacial chemistry near the $\mathrm{PbI}_{2} / \mathrm{PEDOT}$ PSS.
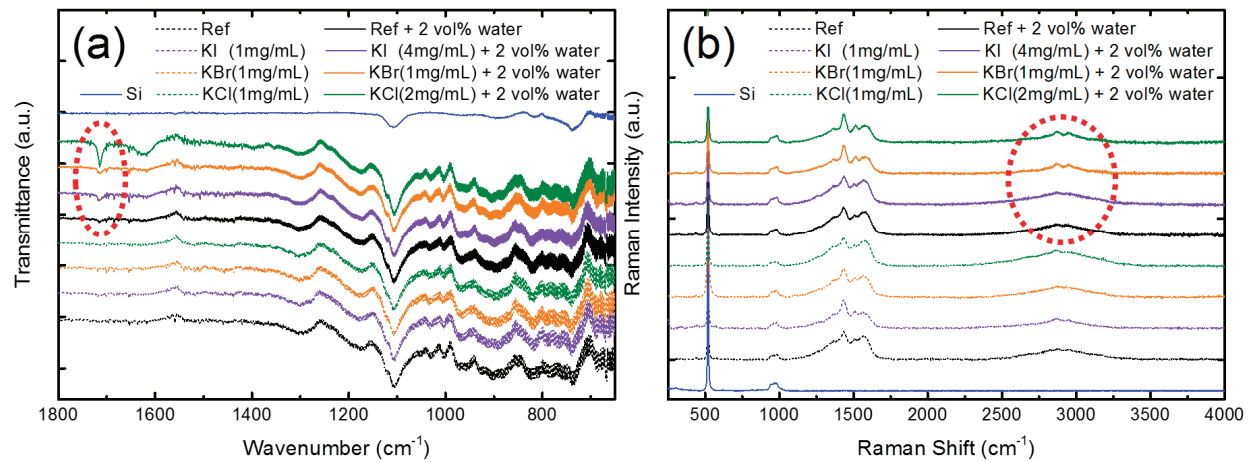

Figure 6. (a) Fourier transform infrared (FTIR) and (b) Raman spectroscopies of $\mathrm{PbI}_{2}$ films doped using potassium halides with and without water.

Figure 7 displays the absorption spectra (Figure 7a) and PL spectra (Figure $7 \mathrm{~b}, \mathrm{c}$ ) of the perovskiteglass structures prepared on the $\mathrm{PbI}_{2}$ layers that were doped with water, potassium halides, and potassium halides and water co-dopants. In the visible region (470-800 $\mathrm{nm})$, the absorbance of the $\mathrm{MAPbI}_{3}$ on $\mathrm{PbI}_{2}$, prepared with the co-doped potassium halides and water, increased, indicating improved crystallinity. With potassium-only additives, the absorbance of $\mathrm{MAPbI}_{3}$ decreased. The PL-quenching effect of KBr-doping was observed (Figure $7 \mathrm{~b}$ ), while PL enhancement was found in the KI- and KCl-doped films. The steady-state photoluminescence (PL) was an effective way to detect the trap states within the perovskite layer. The higher PL intensity indicated fewer traps or defects within the films and improved crystallinity. Figure 7c shows the PL spectra of the co-doped water and potassium halides for $\mathrm{MAPbI}_{3}$ films. The PL intensity of the perovskite films obviously increased by co-doping, except for the KBr-doped film. In particular, the PL intensity of the co-doped KI and water increased by five times. Therefore, it was concluded that the co-doping of water and potassium halides increased the grain size of $\mathrm{MAPbI}_{3}$ and eliminated radiative defects that contributed to the strong PL response. 

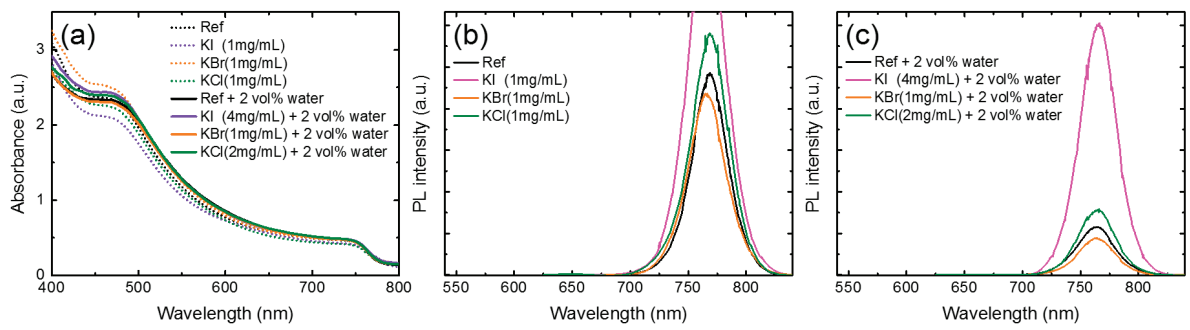

Figure 7. (a) Absorption spectra and (b,c) photoluminescence (PL) spectra of perovskite films prepared using $\mathrm{PbI}_{2}$ with different potassium halide and water additives. The samples were measured with this structure: glass/ITO/PEDOT:PSS/MAPbI$/ \mathrm{PC}_{61} \mathrm{BM}$.

Auger electron spectroscopy (AES) was used to investigate the elementary depth distribution of the full device structure using KI and 2 vol\% water co-doping, as shown in Figure 8 . The potassium signal was found to be uniformly distributed across the perovskite and penetrated into the PEDOT:PSS. It has been reported that $\mathrm{KI}$ can provide an extra I-ion source that affects the coordination with $\mathrm{Pb}^{2+}$ and compensates for the I vacancy [15]. Therefore, in addition to the positive effect due to water- and potassium halides-induced grain growth, the enhancement of PL intensity can be associated with the passivation of the $\mathrm{K}^{+}$cation and halide anions on the grain boundaries of perovskite film $[15,16]$ and the perovskite interface, thus, reducing the trapped states. In other words, the addition of potassium halides and water improved the quality of the perovskite by reducing the traps and interfacial radiative recombination centers, allowing for effective charge generation and collection. Such a highly continuous and large grain structure was also beneficial for carriers to transport through the film. This improvement reduced series resistance $\left(R_{S}\right)$ and increased shunt resistance $\left(R_{\mathrm{SH}}\right)$, improving the $J_{\mathrm{SC}}, \mathrm{FF}$, and $V_{\mathrm{OC}}$ as observed in Table 1 . Some studies partially attributed good photovoltaic performance to a significant absorption improvement because the use of additives led to a denser perovskite film with less pinholes [14,28]. However, our research results showed water and/or potassium halide additives only slightly enhanced the absorption of perovskite. The pristine $\mathrm{MAPbI}_{3}$, prepared by our process, exhibited a compact microstructure with pure tetragonal structure phases, and the absorption effect was considered to be minor. It is worth noting that the $\mathrm{KBr}$ additive was harmful to the device, where even its physical properties, shown in Figures 3-5, seemed as good as KI. We attributed this to the possible formation of a small amount of $\mathrm{MAPbBr}_{3}$, through the incorporation of $\mathrm{Br}$ even though no secondary phase was found in the XRD spectra. The existence of $\mathrm{MAPbBr}_{3}$ within the $\mathrm{MAPbI}_{3}$ film may cause an energy barrier and inhibit charge transport from the perovskite layer to the ITO [12].

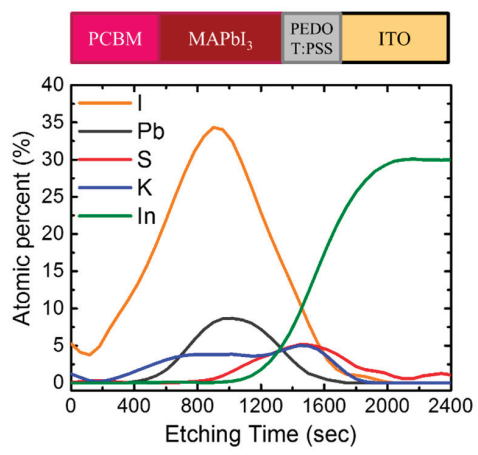

Figure 8. Auger electron spectroscopy (AES) depth profile of $\mathrm{MAPbI}_{3}$ prepared on PEDOT:PSS coated ITO (indium tin oxide) glass. 
However, incorporation of potassium halides had little influence on the microstructure of the perovskite without any water additive. As shown in Figure S5, the surface morphology and the cross-section images of the films were similar, regardless of the types of potassium halides. The grain size was unchanged by the potassium halide additives, which is in agreement with the unchanged XRD FWHM (full width at half maximum) observation shown in Figure 3. The additive effect of each potassium halide can be clearly observed in Figures S6-S8. To conclude, the potassium halides had positive influences on the film quality and the device, only if they were co-doped with the water additive. Without water, the potassium halide additive made the solution more inhomogeneous, worsening the film properties. Because the solubility of potassium halides in $\mathrm{PbI}_{2}-\mathrm{DMF}$ was low, they were unevenly dispersed within the solution without water, forming an inhomogeneous film. The different optimal concentration of each potassium halide for the photovoltaic properties was influenced by their solubility.

\section{Conclusions}

In conclusion, a way to improve the perovskite solar cells (structure: glass/ITO/PEDOT:PSS/ $\mathrm{MAPbI}_{3} / \mathrm{PC}_{61} \mathrm{BM} / \mathrm{BCP} / \mathrm{Al}$ ) was proposed by co-doping water and potassium halides in the $\mathrm{PbI}_{2}$ layer, which was coated on the PEDOT:PSS layer based in a two-step sequential process. When only potassium halides were added to $\mathrm{PbI}_{2}$, the PCE of the devices became worse, while the PCE of the devices prepared using the $2 \mathrm{vol} \%$ water-doped $\mathrm{PbI}_{2}$ precursor increased from $8.8 \%$ (without water) to $12.0 \%$. By co-doping with the $2 \mathrm{vol} \%$ water and a potassium halide, the PCE was improved from $8.8 \%$ (pristine perovskite) to $13.9 \%$ ( $4 \mathrm{mg} / \mathrm{mL} \mathrm{KI}), 11.9 \%(1 \mathrm{mg} / \mathrm{mL} \mathrm{KBr})$, and $12.8 \%(2 \mathrm{mg} / \mathrm{mL}$ $\mathrm{KCl})$. XRD results showed that the incorporation of water and a potassium halide improved the crystallinity and enlarged the grain size. SEM images showed that the grain of $\mathrm{PbI}_{2}$ became coarse and continuous upon co-doping. FTIR spectra showed characteristic peaks, related to $\mathrm{C}=\mathrm{O}$ stretching, around $1715 \mathrm{~cm}^{-1}$, which was probably caused by the formation of a $\mathrm{PbI}_{2}-\mathrm{DMF}-\mathrm{H}_{2} \mathrm{O}$ adduct or an interfacial reaction near the $\mathrm{PbI}_{2} / \mathrm{PEDOT}$ :PSS interface. Raman spectra revealed that $\mathrm{O}-\mathrm{H}$ and $\mathrm{C}-\mathrm{H}$ stretching of PEDOT split into two peaks at 2865 and $2945 \mathrm{~cm}^{-1}$, owing to metal halides and water incorporation. Obvious PL enhancement was caused by the co-doping of water and KI, reducing the defect density. Together with the AES observations, it was found that KI distributed uniformly within the perovskite layer and penetrated into the PEDOT:PSS layer, which suggested that the elimination of the defects in the film and interface upon KI doping was one of the reasons to improve the KI-water co-doped solar cell.

Supplementary Materials: The following are available online at http://www.mdpi.com/2079-4991/9/5/666/s1: Figure S1: The tendency of photovoltaic performance of the water-doped devices as a function of water amount; Table S1: The corresponding photovoltaic parameters of devices in Figure S1; Figure S2: SEM morphology and cross-section of $\mathrm{PbI}_{2}$ films with $(\mathrm{a}, \mathrm{e}) \mathrm{\%}$, (b,f) $1 \%,(\mathrm{c}, \mathrm{g}) 2 \%$, and $(\mathrm{d}, \mathrm{h}) 3 \%$ water; Figure S3: SEM morphology of perovskite films prepared by $\mathrm{PbI}_{2}$ with (a) $0 \%$, (b) $1 \%$, (c) $2 \%$, and (d) $3 \%$ water; Figure $S 4$ : The (a) $V_{\mathrm{OC}}$; (b) $J_{\mathrm{SC}}$; (c) FF; (d) PCE of the potassium halide-doped devices as a function of doping amounts of $\mathrm{KI}, \mathrm{KBr}$ and $\mathrm{KCl}$; Table S2: The corresponding photovoltaic parameters of devices in Figure S4 and Figure 2; Figure S5: The SEM cross-sectional images of the potassium halide-doped $\mathrm{MAPbI}_{3}$ films (without water additive), (a) ref, (b) $1 \mathrm{mg} / \mathrm{mL}$ $\mathrm{KI}$, (c) $1 \mathrm{mg} / \mathrm{mL} \mathrm{KBr}$, and (d) $1 \mathrm{mg} / \mathrm{mL} \mathrm{KCl}$; Figure S6: SEM surface morphology of the perovskite films with different $\mathrm{KI}$ and water additives in the $\mathrm{PbI}_{2}$ layer; Figure S7: SEM surface morphology of the perovskite films with different $\mathrm{KBr}$ and water additives in the $\mathrm{PbI}_{2}$ layer; and Figure S8: SEM surface morphology of the perovskite films with different $\mathrm{KCl}$ and water additives in the $\mathrm{PbI}_{2}$ layer.

Author Contributions: Conceptualization, Y.-T.C. and C.-F.S.; Data curation, H.-T.W. and C.-C.L.; Formal analysis, H.-T.W. and Y.-T.C.; Investigation, H.-T.W. and S.-H.W.; Methodology, Y.-T.C.; Project administration, H.-T.W. and C.-F.S.; Resources, C.-C.L., S.-H.W. and C.-F.S.; Supervision, C.-C.L. and C.-F.S.; Validation, H.-T.W. and Y.-T.C.; Writing—original draft, H.-T.W. and C.-C.L.; Writing—review \& editing, H.-T.W., S.-H.W. and C.-F.S.

Funding: This research received no external funding. 
Acknowledgments: The authors are grateful for the support of the Ministry of Science and Technology of the Republic of China under Contract No. MOST 106-2221-E-006-225- and MOST 107-2221-E-006-160-, Taiwan. This work was also financially supported by the Hierarchical Green-Energy Materials (Hi-GEM) Research Center, from The Featured Areas Research Center Program within the framework of the Higher Education Sprout Project by the Ministry of Education (MOE) and the Ministry of Science and Technology (MOST 107-3017-F-006-003) in Tainan. The authors are also grateful for the support of the Department of Industrial Technology, Ministry of Economic Affairs, Taiwan.

Conflicts of Interest: The authors declare no conflict of interest.

\section{References}

1. Kojima, A.; Teshima, K.; Shirai, Y.; Miyasaka, T. Organometal Halide Perovskites as Visible-Light Sensitizers for Photovoltaic Cells. J. Am. Chem. Soc. 2009, 131, 6050-6051. [CrossRef]

2. Shin, S.S.; Yeom, E.J.; Yang, W.S.; Hur, S.; Kim, M.G.; Im, J.; Seo, J.; Noh, J.H.; Seok, S.I. Colloidally prepared La-doped $\mathrm{BaSnO}_{3}$ electrodes for efficient, photostable perovskite solar cells. Science 2017, 356, 167-171. [CrossRef]

3. Saliba, M.; Matsui, T.; Seo, J.-Y.; Domanski, K.; Correa-Baena, J.-P.; Nazeeruddin, M.K.; Zakeeruddin, S.M.; Tress, W.; Abate, A.; Hagfeldt, A.; et al. Cesium-containing triple cation perovskite solar cells: Improved stability, reproducibility and high efficiency. Energy Environ. Sci. 2016, 9, 1989-1997. [CrossRef] [PubMed]

4. Chiang, C.-H.; Nazeeruddin, M.K.; Grätzel, M.; Wu, C.-G. The synergistic effect of $\mathrm{H}_{2} \mathrm{O}$ and DMF towards stable and 20\% efficiency inverted perovskite solar cells. Energy Environ. Sci. 2017, 10, 808-817. [CrossRef]

5. Zuo, C.; Vak, D.; Angmo, D.; Ding, L.; Gao, M. One-step roll-to-roll air processed high efficiency perovskite solar cells. Nano Energy 2018, 46, 185-192. [CrossRef]

6. Bi, C.; Wang, Q.; Shao, Y.; Yuan, Y.; Xiao, Z.; Huang, J. Non-wetting surface-driven high-aspect-ratio crystalline grain growth for efficient hybrid perovskite solar cells. Nat. Commun. 2015, 6, 7747. [CrossRef] [PubMed]

7. Moore, D.T.; Sai, H.; Tan, K.W.; Smilgies, D.-M.; Zhang, W.; Snaith, H.J.; Wiesner, U.; Estroff, L.A. Crystallization Kinetics of Organic-Inorganic Trihalide Perovskites and the Role of the Lead Anion in Crystal Growth. J. Am. Chem. Soc. 2015, 137, 2350-2358. [CrossRef]

8. Fei, C.; Guo, L.; Li, B.; Zhang, R.; Fu, H.; Tian, J.; Cao, G. Controlled growth of textured perovskite films towards high performance solar cells. Nano Energy 2016, 27, 17-26. [CrossRef]

9. Song, X.; Wang, W.; Sun, P.; Ma, W.; Chen, Z.-K. Additive to regulate the perovskite crystal film growth in planar heterojunction solar cells. Appl. Phys. Lett. 2015, 106, 033901. [CrossRef]

10. Wu, Y.; Xie, F.; Chen, H.; Yang, X.; Su, H.; Cai, M.; Zhou, Z.; Noda, T.; Han, L. Thermally Stable $\mathrm{MAPbI}_{3}$ Perovskite Solar Cells with Efficiency of $19.19 \%$ and Area over $1 \mathrm{~cm}^{2}$ achieved by Additive Engineering. Adv. Mater. 2017, 29, 1701073. [CrossRef]

11. Ke, W.; Xiao, C.; Wang, C.; Saparov, B.; Duan, H.-S.; Zhao, D.; Xiao, Z.; Schulz, P.; Harvey, S.P.; Liao, W.; et al. Employing Lead Thiocyanate Additive to Reduce the Hysteresis and Boost the Fill Factor of Planar Perovskite Solar Cells. Adv. Mater. 2016, 28, 5214-5221. [CrossRef] [PubMed]

12. Wang, P.; Wang, J.; Zhang, X.; Wang, H.; Cui, X.; Yuan, S.; Lu, H.; Tu, L.; Zhan, Y.; Zheng, L. Boosting the performance of perovskite solar cells through a novel active passivation method. J. Mater. Chem. A 2018, 6, 15853-15858. [CrossRef]

13. Tang, Z.; Bessho, T.; Awai, F.; Kinoshita, T.; Maitani, M.M.; Jono, R.; Murakami, T.N.; Wang, H.; Kubo, T.; Uchida, S.; et al. Hysteresis-free perovskite solar cells made of potassium-doped organometal halide perovskite. Sci. Rep. 2017, 7, 12183. [CrossRef] [PubMed]

14. Nam, J.K.; Chai, S.U.; Cha, W.; Choi, Y.J.; Kim, W.; Jung, M.S.; Kwon, J.; Kim, D.; Park, J.H. Potassium Incorporation for Enhanced Performance and Stability of Fully Inorganic Cesium Lead Halide Perovskite Solar Cells. Nano Lett. 2017, 17, 2028-2033. [CrossRef]

15. Abdi-Jalebi, M.; Andaji-Garmaroudi, Z.; Cacovich, S.; Stavrakas, C.; Philippe, B.; Richter, J.M.; Alsari, M.; Booker, E.P.; Hutter, E.M.; Pearson, A.J.; et al. Maximizing and stabilizing luminescence from halide perovskites with potassium passivation. Nature 2018, 555, 497. [CrossRef]

16. Son, D.-Y.; Kim, S.-G.; Seo, J.-Y.; Lee, S.-H.; Shin, H.; Lee, D.; Park, N.-G. Universal Approach toward Hysteresis-Free Perovskite Solar Cell via Defect Engineering. J. Am. Chem. Soc. 2018, 140, 1358-1364. [CrossRef] 
17. Wu, C.-G.; Chiang, C.-H.; Tseng, Z.-L.; Nazeeruddin, M.K.; Hagfeldt, A.; Gratzel, M. High efficiency stable inverted perovskite solar cells without current hysteresis. Energy Environ. Sci. 2015, 8, 2725-2733. [CrossRef]

18. Xiu, G.; Meng, L.; Xiao-Bo, S.; Heng, M.; Zhao-Kui, W.; Liang-Sheng, L. Controllable Perovskite Crystallization by Water Additive for High-Performance Solar Cells. Adv. Funct. Mater. 2015, 25, 6671-6678. [CrossRef]

19. Boopathi, K.M.; Mohan, R.; Huang, T.-Y.; Budiawan, W.; Lin, M.-Y.; Lee, C.-H.; Ho, K.-C.; Chu, C.-W. Synergistic improvements in stability and performance of lead iodide perovskite solar cells incorporating salt additives. J. Mater. Chem. A 2016, 4, 1591-1597. [CrossRef]

20. Bass, K.K.; McAnally, R.E.; Zhou, S.; Djurovich, P.I.; Thompson, M.E.; Melot, B.C. Influence of moisture on the preparation, crystal structure, and photophysical properties of organohalide perovskites. Chem. Commun. 2014, 50, 15819-15822. [CrossRef] [PubMed]

21. You, J.; Yang, Y.; Hong, Z.; Song, T.-B.; Meng, L.; Liu, Y.; Jiang, C.; Zhou, H.; Chang, W.-H.; Li, G.; et al. Moisture assisted perovskite film growth for high performance solar cells. Appl. Phys. Lett. 2014, 105, 183902. [CrossRef]

22. Sison, E.S.; Rahman, M.D.; Durham, D.L.; Hermanowski, J.; Ross, M.F.; Jennison, M.J. Dielectric and chemical characteristics of electron-beam-cured photoresist. In Proceedings of the SPIE's 1995 Symposium on Microlithography, Santa Clara, CA, USA, 9 June 1995; p. 14.

23. Cao, X.; Li, C.; Li, Y.; Fang, F.; Cui, X.; Yao, Y.; Wei, J. Enhanced performance of perovskite solar cells by modulating the Lewis acid-base reaction. Nanoscale 2016, 8, 19804-19810. [CrossRef] [PubMed]

24. Cao, X.B.; Li, Y.H.; Fang, F.; Cui, X.; Yao, Y.W.; Wei, J.Q. High quality perovskite films fabricated from Lewis acid-base adduct through molecular exchange. RSC Adv. 2016, 6, 70925-70931. [CrossRef]

25. Winther-Jensen, B.; West, K. Vapor-Phase Polymerization of 3,4-Ethylenedioxythiophene: A Route to Highly Conducting Polymer Surface Layers. Macromolecules 2004, 37, 4538-4543. [CrossRef]

26. Xu, J.; Wang, C.; Wang, T.; Wang, Y.; Kang, Q.; Liu, Y.; Tian, Y. Mechanisms for low-temperature direct bonding of $\mathrm{Si} / \mathrm{Si}$ and quartz/quartz via VUV/O 3 activation. RSC Adv. 2018, 8, 11528-11535. [CrossRef]

27. Wilamowska, M.; Kujawa, M.; Michalska, M.; Lipińska, L.; Lisowska-Oleksiak, A. Electroactive polymer/graphene oxide nanostructured composites; evidence for direct chemical interactions between PEDOT and GOx. Synth. Met. 2016, 220, 334-346. [CrossRef]

28. Chang, J.; Lin, Z.; Zhu, H.; Isikgor, F.H.; Xu, Q.-H.; Zhang, C.; Hao, Y.; Ouyang, J. Enhancing the photovoltaic performance of planar heterojunction perovskite solar cells by doping the perovskite layer with alkali metal ions. J. Mater. Chem. A 2016, 4, 16546-16552. [CrossRef]

(C) 2019 by the authors. Licensee MDPI, Basel, Switzerland. This article is an open access article distributed under the terms and conditions of the Creative Commons Attribution (CC BY) license (http://creativecommons.org/licenses/by/4.0/). 

Article

\title{
Efficient Ni/Au Mesh Transparent Electrodes for ITO-Free Planar Perovskite Solar Cells
}

\author{
Dazheng Chen ${ }^{1,2, *}$, Gang Fan ${ }^{1}$, Hongxiao Zhang ${ }^{2}$, Long Zhou ${ }^{2}$, Weidong Zhu ${ }^{1}$, He Xi ${ }^{1,3}$, \\ Hang Dong ${ }^{1}$, Shangzheng Pang ${ }^{1}$, Xiaoning He ${ }^{1}$, Zhenhua Lin ${ }^{1}$, Jincheng Zhang ${ }^{1,2}$, \\ Chunfu Zhang ${ }^{1,2, *}$ and Yue Hao ${ }^{1}$ \\ 1 Wide Bandgap Semiconductor Technology Disciplines State Key Laboratory, School of Microelectronics, \\ Xidian University, Xi'an 710071, China \\ 2 Shaanxi Joint Key Laboratory of Graphene, Xidian University, Xi'an 710071, China \\ 3 School of Advanced Materials and Nanotechnology, Xidian University, Xi'an 710071, China \\ * Correspondence: dzchen@xidian.edu.cn (D.C.); cfzhang@xidian.edu.cn (C.Z.)
}

Received: 4 May 2019; Accepted: 17 June 2019; Published: 28 June 2019

\begin{abstract}
Indium thin oxide (ITO)-free planar perovskite solar cells (PSCs) were fabricated at a low temperature $\left(150^{\circ} \mathrm{C}\right)$ in this work based on the transparent electrode of photolithography processed nickel/gold $(\mathrm{Ni} / \mathrm{Au})$ mesh and the high conductivity polymer, PH1000. Ultrathin Au was introduced to increase the conductivity of metal mesh, and the optimal hexagonal $\mathrm{Ni}(30 \mathrm{~nm}) / \mathrm{Au}(10 \mathrm{~nm})$ mesh (line width of $5 \mu \mathrm{m}$ ) shows a transmittance close to $80 \%$ in the visible light region and a sheet resistance lower than $16.9 \Omega$ /sq. The conductive polymer PH1000 not only smooths the raised surface of the metal mesh but also enhances the charge collection ability of metal mesh. The fabricated PSCs have the typical planar structure (glass/Ni-Au mesh/PH1000/PEDOT:PSS/MA $\mathrm{FA}_{1-\mathrm{y}} \mathrm{PbI}_{\mathrm{x}} \mathrm{Cl}_{3-\mathrm{x}} / \mathrm{PCBM} / \mathrm{BCP} / \mathrm{Ag}$ ) and the champion PSC $\left(0.09 \mathrm{~cm}^{2}\right.$ ) obtains a power conversion efficiency (PCE) of $13.88 \%$, negligible current hysteresis, steady current density and PCE outputs, and good process repeatability. Its photovoltaic performance and stability are comparable to the reference PSC based on the ITO electrodes $(\mathrm{PCE}=15.70 \%$, which demonstrates that the $\mathrm{Ni} / \mathrm{Au}$ mesh transparent electrodes are a promising ITO alternative to fabricate efficient PSCs. The relatively lower performance of Ni/Au based PSC results from the relatively slower charge extraction and stronger charge recombination than the ITO based PSC. Further, we tried to fabricate the large area $\left(1 \mathrm{~cm}^{2}\right)$ device and achieve a PCE over $6 \%$ with negligible hysteresis and steady current density and PCE outputs. The improvements of perovskite film quality and interface modification should be an effective approach to further enhance the device performance of Ni/Au based PSCs, and the Ni/Au mesh electrode may find wider applications in PSCs and flexible devices.
\end{abstract}

Keywords: metal mesh; transparent electrode; photolithography; perovskite solar cell; large-area solar cell

\section{Introduction}

Organic-inorganic hybrid perovskites solar cells (PSCs) have attracted more and more attention due to their advantages of low fabrication cost, light weight, solution processability, tunable light absorption range, bipolar transport properties, large-area manufacturing, and compatibility to both rigid and flexible substrates. Their rapid progress of increased power conversion efficiency (PCEs) from $3.8 \%$ to $23.32 \%$ and improved stability indicate many potential applications, including in photovoltaic plants, photovoltaic curtains, building integrated photovoltaic materials, wearable electronics devices, and even space power systems [1-10]. And the efficient bottom transparent electrode is primary and crucial to meeting these versatile applications. Nowadays, transparent conductive oxides, such as the indium thin oxide (ITO) is the most commonly used transparent electrode in PSCs. However, ITO 
prices are becoming more and more expensive because of the rising cost of indium. On the other hand, the ITO shows a relatively large sheet resistance, brittleness, and poor mechanical robustness [11,12]. There will be cracks on ITO surface at a bending radius $(<10 \mathrm{~mm})$ against repeated bending, which will further decrease its conductivity and degrade the device performance, making it incompatible with low-cost technology, such as roll-to-roll printing [13].

To overcome the drawbacks of ITO, many alternatives have been developed with good electrical and optical properties, such as graphene [14,15], carbon nanotubes [16], metal nanowires [17,18], transparent conducting oxide nanocrystal [19], conducting polymer [20,21] ultrathin metal films [21-24], and metal-mesh transparent conductive electrodes (TCEs) $[25,26]$. Among the alternatives, metal meshes have excellent ductility and can be easily fabricated by mature evaporation process, which is more suitable for large-area device production. Metal-mesh TCEs are highly bendable as well, and silver metal-mesh TCEs have been successfully used to fabricate organic solar cells, PSCs, and flexible devices $[5,27]$. More importantly, the conductivity and transmittance of metal mesh can be adjusted by structure parameters such as the metal-grid pitch, line width, and film thickness. And there are many ways to achieve size-tunable metal-mesh TCEs, such as laser sintering of nanoparticle ink, lithographic patterning, grain boundary lithography, nanoimprint lithography, and photolithography [28-31]. Photolithography is a standard fabrication process in semiconductor devices and integrated circuits, which determines their feature size $(\leq 7 \mathrm{~nm})$ and operation performance. It is believed that the photolithography process provides more precise control of the shape and size of the objects it creates and can create patterns over an entire surface cost-effectively [32]. In addition, the photolithography related processes are low-temperature technology and compatible to large area substrate (18 inches) or flexible substrates. Therefore, photolithography is a promising process to prepare highly consistent metal mesh for transparent electrode and solar cell applications [33-35].

We have proved in our previous work [36] that the adhesion of Ag on a glass substrate is relatively poorer than that of $\mathrm{Ni}$, and $\mathrm{Ni}$ mesh processed by photolithography has been successfully used to fabricate PSCs, but the device performance (PCE $=5.74 \%$ ) should be further improved. In this work, we optimize the thickness and shape of Ni meshes, Au is used to increase the conductivity of metal mesh, the high conductivity polymer $\mathrm{PH} 1000$ is employed to smooth the raised surface of metal mesh and enhance the charge collection ability of metal mesh, the optimized two-step $\mathrm{MA}_{\mathrm{y}} \mathrm{FA}_{1-\mathrm{y}} \mathrm{PbI}_{\mathrm{x}} \mathrm{Cl}_{3-\mathrm{x}}$ perovskite is used as the light absorber, and the fabricated ITO free PSCs have a structure of Glass/hexagonal Ni $(30 \mathrm{~nm})-\mathrm{Au}(10 \mathrm{~nm})$ mesh/PH1000/PEDOT:PSS/MA $\mathrm{FA}_{1-\mathrm{y}} \mathrm{PbI}_{\mathrm{x}} \mathrm{Cl}_{3-\mathrm{x}} / \mathrm{PCBM} / \mathrm{BCP} / \mathrm{Ag}$. The champion PSC $\left(0.09 \mathrm{~cm}^{2}\right)$ obtains a PCE of $13.88 \%$, negligible current hysteresis, steady current density and PCE outputs, good repeatability and storing stability. Further, we tried to fabricate the large area $\left(1 \mathrm{~cm}^{2}\right)$ devices under the same process, and achieve a PCE over $6 \%$ with negligible hysteresis and stable steady-state outputs. The comparable performance to the ITO based reference PSC demonstrates that the $\mathrm{Ni} / \mathrm{Au}$ mesh transparent electrodes are a promising ITO alternative to fabricate efficient PSCs.

\section{Materials and Methods}

\subsection{Materials}

All materials and reagents, Methylammonium iodide (MAI, 99.8\%, Dyesol, Queanbeyan, Australia), Formamidinium iodide (FAI, 99.8\%, Dyesol, Queanbeyan, Australia), Lead iodide $\left(\mathrm{PbI}_{2}\right.$, 99.999\%, Sigma-Aldrich, Saint Louis, MI, USA), Lead chloride $\left(\mathrm{PbCl}_{2}, 99.999 \%\right.$, Sigma-Aldrich, Saint Louis, MI, USA), Phenyl-C 61 -butyric acid methyl ester (PCBM, 98\%, Nano-C, Westwood, MA, USA), Poly(3,4-ethy-lenedioxythiophene) poly(styrenesulfonate) (PEDOT:PSS, Clevios PVP Al 4083, Heraeus, Hanau, Germany), high conductivity polymer PH1000 (Clevios PH1000, Heraeus, Hanau, Germany), N,N'-Dimethylformamide (DMF, 99.8\%, Aladdin, Beijing, China), Chlorobenzene (CB, 99.8\%, Sigma-Aldrich, Saint Louis, MI, USA), Bathocuproine (BCP, 96\%, Sigma-Aldrich, Saint Louis, MI, USA) Isopropanol (IPA, 99.5\%, Sigma-Aldrich, Saint Louis, MI, USA), photoresist (AZ6112, 
Ruicai, Suzhou, China), and developing solution (2.38\%, NMD-3, Ruicai, Suzhou, China), were used as received without further purification.

\subsection{Metal Mesh Preparation}

Firstly, glass substrates $\left(2 \times 2.5 \mathrm{~cm}^{2}\right)$ were ultrasonically cleaned in deionized (DI) water, acetone, ethyl alcohol, and DI water for $20 \mathrm{~min}$, respectively. Secondly, the nitrogen gun was used to dry the substrates, and spin-coat the positive photoresist on substrates by two-steps of $500 \mathrm{rpm}$ for $5 \mathrm{~s}$ and $4000 \mathrm{rpm}$ for $30 \mathrm{~s}$ with the acceleration of $4000 \mathrm{rpm} / \mathrm{s}$, followed by baking on a hot plate at $100{ }^{\circ} \mathrm{C}$ for $90 \mathrm{~s}$ to cure the photoresist. Thirdly, the substrates were naturally cooled and exposed for $2.3 \mathrm{~s}$ under a shadow mask and then developed for $60 \mathrm{~s}$ in the developing solution. Then, the samples were rinsed in flowing DI water and dried by nitrogen gun. Fourthly, an optical microscope was employed to check the defined patterns and the samples were transferred into the E-beam evaporation system and nickel/gold (Ni/Au) mesh of $x \mathrm{~nm} / 10 \mathrm{~nm}$ were deposited under a pressure below $5 \times 10^{-4} \mathrm{~Pa}$. After the metal mesh deposition, the samples were immersed in the acetone solution and lifted off by a low power ultrasonic bath for several ten seconds. The completed metal-mesh show a line width of $5 \mu \mathrm{m}$, and the active areas of $0.09 \mathrm{~mm}^{2}$ and $1 \mathrm{~cm}^{2}$.

\subsection{PSCs Preparation and Characterization}

At first, the prepared metal-mesh substrates were UV-ozone treated by $15 \mathrm{~min}$, and the high conductive polymer PH 1000 were spin-coated on the metal mesh at $1000 \mathrm{rpm}$ for $60 \mathrm{~s}$ and annealed on a hotplate at $150{ }^{\circ} \mathrm{C}$ for $15 \mathrm{~min}$. Secondly, the PEDOT:PSS was spin-coated at $6000 \mathrm{rpm}$ for $45 \mathrm{~s}$ and $150{ }^{\circ} \mathrm{C}$ annealing for $15 \mathrm{~min}$. Thirdly, the $\mathrm{MA}_{y} \mathrm{FA}_{1-\mathrm{y}} \mathrm{PbI}_{\mathrm{x}} \mathrm{Cl}_{3-\mathrm{x}}$ precursor solution was prepared by mixing $\mathrm{PbI}_{2}, \mathrm{PbCl}_{2}$ that was dissolved in DMF solution, and stirred for $2 \mathrm{~h}$ at $75^{\circ} \mathrm{C}$, the solution was then spin coated onto the PEDOT/PSS layer at $3000 \mathrm{rpm}$ for $45 \mathrm{~s}$; Mixing FAI, MAI in the solvent of $\mathrm{DMF}$, stirring at room temperature until completely dissolved, then spin coated it onto the $\mathrm{PbI}_{2} / \mathrm{PbCl}_{2}$ layer at $3000 \mathrm{rpm}$ for $45 \mathrm{~s}$; after thermally annealing at $100{ }^{\circ} \mathrm{C}$ for $10 \mathrm{~min}$ the perovskite layer was formed. Fourthly, the PCBM $(20 \mathrm{mg} / \mathrm{mL}$ in CB) was spin-coated on the perovskite layer at $2000 \mathrm{rpm}$ for $40 \mathrm{~s}$, and the BCP $(0.5 \mathrm{mg} / \mathrm{mL}$ in IPA) was spin-coated on the PCBM at $6000 \mathrm{rpm}$ for $45 \mathrm{~s}$. Finally, the $\mathrm{Ag}(100 \mathrm{~nm})$ electrode was thermally evaporated under a shadow mask and the fabricated devices (seeing Figures S1 and S2 in Supporting Information) have an active area of $0.09 \mathrm{~cm}^{2}$ and $1 \mathrm{~cm}^{2}$. As a reference, the ITO based PSCs, ITO/PEDOT:PSS/Perovskite/PCBM/BCP/Ag, were also fabricated under the same process conditions.

The current density-voltage (J-V) characteristics were measured with a source measurement unit of Keithley 2400 and simulated AM1.5 G sun light $\left(100 \mathrm{~mW} / \mathrm{cm}^{2}\right.$, SEN-EI Electric. Co. Ltd, XES-300T1, Osaka, Japan). The incident photo-to-current conversion efficiency (IPCE) was measured by the quantum efficiency measurement system (SCS10-X150, Zolix instrument. Co. Ltd, Beijing, ChinaZolix Instrument. Co. Ltd). The four-point-probe system was utilized to measure the sheet resistance of electrodes. The UV-visible spectrophotometer (Perkin-Elmer Lambda 950, Waltham, MA, USA) was used to characterize the transmittance spectra of different samples. The film morphology was characterized by a JSM-7800F extreme-resolution analytical field emission scanning electron microscope (SEM) (JEOL Ltd., Tokyo, Japan) and atomic force microscopy (AFM) (Agilent 5500, Santa Clara, CA, USA). Electrochemical impedance spectroscopy (EIS) measurements were performed on an electrochemical workstation (CHI600E, Shanghai Chenhua, Shanghai, China) with a $10 \mathrm{mV}$ amplitude perturbation and frequencies between $100 \mathrm{~Hz}$ and $1 \mathrm{MHz}$. M-S plots were recorded on the same system under AC excitation amplitude of $30 \mathrm{mV}$ at a frequency of $5 \mathrm{kHz}$. Transient photocurrent (TPC) measurement was performed with a system excited by a $532 \mathrm{~nm}(1000 \mathrm{~Hz}, 3.2 \mathrm{~ns})$ pulse laser. Transient photovoltage (TPV) measurement was performed with the same system excited by a $405 \mathrm{~nm}(50 \mathrm{~Hz}$, $20 \mathrm{~ms}$ ) pulse laser. A digital oscilloscope (Tektronix, D4105, Beaverton, OR, USA) was used to record the photocurrent or photovoltage decay process with a sampling resistor of $50 \Omega$ or $1 \mathrm{M} \Omega$, respectively. All the measurements were performed under ambient atmosphere at room temperature. 


\section{Results and Discussion}

The geometry of ITO-free planar PSCs with an inverted structure based on a metal mesh transparent electrode is shown in Figure 1. Here, the two-step solution processed $\mathrm{MA}_{y} \mathrm{FA}_{1-y} \mathrm{PbI}_{\mathrm{x}} \mathrm{Cl}_{3-\mathrm{x}}$ perovskite layer is chosen as the light absorber; the PEDOT:PSS and PCBM act as the hole and electron transport layers (HTL and ETL), respectively; the BCP is further used to modify the electron collection at the PCBM/Ag interface. In particular, to obtain optimal metal mesh with high transmittance and low resistance, the photolithography process was chosen to precisely define the line width and space between metal lines. Two curial interfaces related to the metal mesh were designed to improve the properties of Ni/Au transparent electrode, then the corresponding performance of ITO-free PSCs with small and large active areas are discussed as follows.

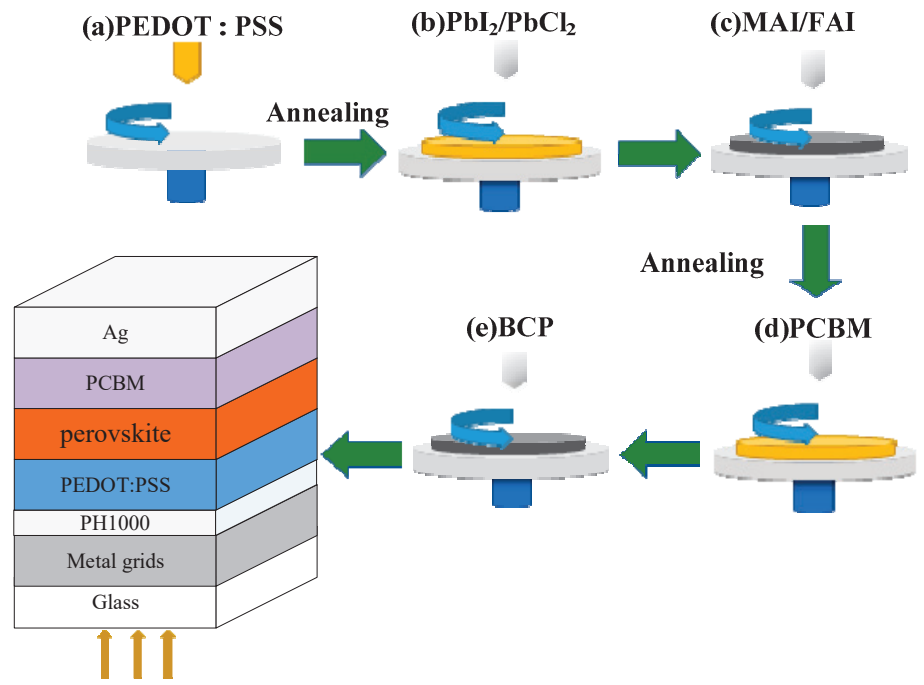

Figure 1. Process of indium thin oxide (ITO)-free perovskite solar cells (PSCs) based on a metal mesh transparent electrode.

\subsection{Optimization of Ni/Au Mesh Transparent Electrode}

There are two curial interfaces introduced by the metal mesh, including the metal/substrate and metal/HTL interfaces. First, the good adhesion of metal mesh on substrate is necessary to fabricate the PSCs. Although the silver material possesses the lowest resistivity, it has been found in our previous work [36] that the adhesion of Ag mesh on glass substrates is relatively weak, and the mesh is easily damaged in the lift-off process, thus the Ni mesh is chosen to fabricate PSCs. However, the relatively low conductivity of $\mathrm{Ni}$ limits the improvement of device performance. In this work, an ultrathin Au is introduced to enhance the conductivity of $\mathrm{Ni}$, and the shape and thickness of Ni/Au mesh has been further optimized. On the other hand, as the PEDOT:PSS HTLs (about $10 \mathrm{~nm}$ ) is prepared by solution coating, the film quality is highly related to the smoothness of the underlying layer. Considering the thickness of the Ni/Au metal mesh has exceeded $50 \mathrm{~nm}$, the high conductivity PHI000 (about $100 \mathrm{~nm}$ ) is deposited to smooth the raised surface of the metal mesh, and simultaneously enhance the hole collection ability of Ni/Au electrode. It is noted that the PH1000 only causes a little loss of transmittance in the visible region [5], therefore the Ni/Au/PH1000 electrode is selected in the ITO-free PSCs.

Figure 2a provides the transmittance of spectra of Ni/Au mesh (square, hexagon) and ITO on glass, and the glass substrate. It can be seen that the glass shows the highest transmittance at over $90 \%$ in $300 \mathrm{~nm}$ to $850 \mathrm{~nm}$, the commercial ITO coated glass substrate possesses an average transmittance over 
$80 \%$, with the oscillation behavior related to the optical interference at the ITO/glass interface. For the $\mathrm{Ni} / \mathrm{Au}$ meshes, although the highest transmittance is lower than the ITO sample, a relatively higher transmittance is obtained in the $300-370 \mathrm{~nm}$ and $420-500 \mathrm{~nm}$ regions. Their average transmittance has also exceeded $80 \%$ and the hexagon mesh shows a slightly low transmittance compared to the square mesh. Consequently, the optical performance of the Ni/Au mesh can meet the requirement of the transparent electrode. For the electrical property, the four-point-probe method is used to measure their sheet resistances. The corresponding values are also in Figure 2, showing that the hexagon mesh $(22.6 \Omega / \mathrm{sq})$ has lower resistance than the square mesh $(30.7 \Omega / \mathrm{sq})$, but larger resistance than that of the ITO $(10 \Omega / \mathrm{sq})$. From Figure S3, it is clear that the PSC with the Ni/Au square mesh electrode shows better performance compared to the device with a pure Ni electrode ( $58 \Omega / \mathrm{sq})$; and the PSC with a hexagon $\mathrm{Ni} / \mathrm{Au}$ electrode performs better than the device with a square $\mathrm{Ni} / \mathrm{Au}$ electrode. Their improved PCEs mainly come from the increased JSC values, which is in line with the results of sheet resistance. Thus, the hexagon Ni/Au mesh should be more suitable for fabricating ITO-free PSCs, and its thickness is further optimized. Here, the thickness of $\mathrm{Au}$ is fixed on $10 \mathrm{~nm}$, and the thicknesses of Ni vary by $10 \mathrm{~nm}, 20 \mathrm{~nm}, 30 \mathrm{~nm}$, and $40 \mathrm{~nm}$. Table 1 shows the corresponding sheet resistances of the $\mathrm{Ni} / \mathrm{Au}$ meshes. When the thickness of $\mathrm{Ni}$ increases from 10 to $40 \mathrm{~nm}$, the sheet resistance values are $33.8 \Omega / \mathrm{sq}, 22.6 \Omega / \mathrm{sq}, 16.9 \Omega / \mathrm{sq}$ and $13.6 \Omega / \mathrm{sq}$, respectively. It is clear that the thicker the metal is, the lower the sheet resistance is. However, too thick a metal will lead to a worse lift-off effect, such as uneven edges of the metal wire and partial fracturing of the grid, which will induce a weak conductivity in the electrode. Meanwhile, if the thickness is less than $10 \mathrm{~nm}$, the adhesion between Ni and glass substrate becomes very poor. Also, with metal deposited by electron beam evaporation it is difficult to form a homogeneous film at a thickness lower than $10 \mathrm{~nm}$, as that will lead to a weaker conductivity [37]. Therefore, the thickness of Ni is a trade-off, which should be further determined by the device performance. As shown in Figure $2 \mathrm{~b}$ and Table 1, all the devices show similar $\mathrm{V}_{\mathrm{OC}}$ and FF values, and the JSC dominants the overall PCEs. When the thickness of Ni is $10 \mathrm{~nm}$ or $40 \mathrm{~nm}$, a lower PCE of about $10 \%$ is limited by the relatively poor JSC values of $15.43 \mathrm{~mA} / \mathrm{cm}^{2}$ and $16.16 \mathrm{~mA} / \mathrm{cm}^{2}$. While if the $20 \mathrm{~nm}$ or $30 \mathrm{~nm} \mathrm{Ni}$ is used, a JSC exceeding $20 \mathrm{~mA} / \mathrm{cm}^{2}$ can be achieved for PSCs, and the PSCs with30 nm Ni obtain superior PCE of $13.72 \%$. As a result, the optimal metal mesh transparent electrode should be the hexagon $\mathrm{Ni}(30 \mathrm{~nm}) / \mathrm{Au}(10 \mathrm{~nm})$ mesh electrode, and the corresponding device performance is further investigated.

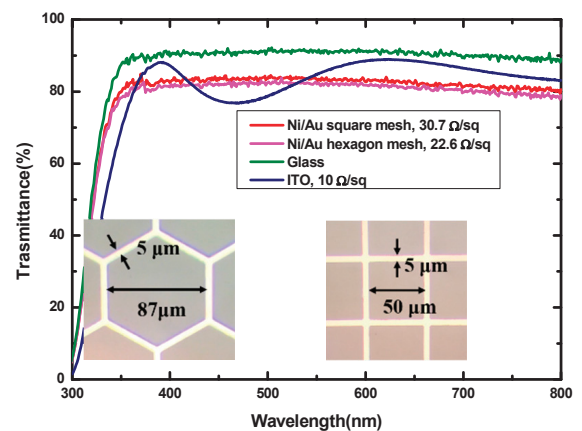

(a)

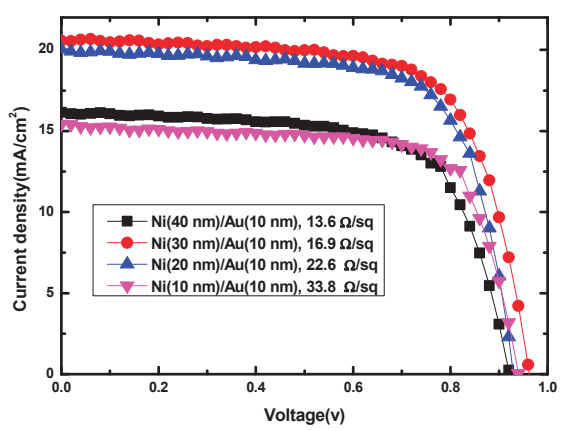

(b)

Figure 2. (a) Transmittance spectra of $\mathrm{Ni}(20 \mathrm{~nm}) / \mathrm{Au}(10 \mathrm{~nm})$ mesh (square, hexagon) and ITO on glass, and the glass substrate; (b) density-voltage (J-V) curves for PSCs with hexagon $\mathrm{Ni}(\mathrm{x} \mathrm{nm}) / \mathrm{Au}(10 \mathrm{~nm})$ $(x=10,20,30,40 \mathrm{~nm})$ metal mesh electrodes. The sheet resistances of Ni/Au and ITO electrode are also displayed in Figure 2. 
Table 1. Photovoltaic parameters of PSCs with various $\mathrm{Ni}(\mathrm{x} \mathrm{nm}) / \mathrm{Au}(10 \mathrm{~nm})$ meshes.

\begin{tabular}{cccccc}
\hline Ni Thickness $(\mathbf{n m})$ & Ni/Au Resistance $(\boldsymbol{\Omega} / \mathbf{s q})$ & $\mathrm{JSC}_{\text {SC }}\left(\mathbf{m A} / \mathbf{c m}^{\mathbf{2}}\right)$ & $\mathrm{V}_{\text {OC }}(\mathrm{V})$ & FF $(\%)$ & PCE $(\%)$ \\
\hline 40 & 13.6 & 16.16 & 0.90 & 68.76 & 10.13 \\
30 & 16.9 & 20.67 & 0.96 & 69.09 & 13.72 \\
20 & 22.6 & 20.04 & 0.92 & 71.22 & 13.14 \\
10 & 33.8 & 15.43 & 0.94 & 71.68 & 10.43 \\
\hline
\end{tabular}

\subsection{Performance of PSCs with Optimal Ni/Au Metal Mesh}

Figure 3a presents the J-V curves of the champion PSC with the electrode and reference PSC with an ITO electrode. It can be seen that the PSC based on Ni/Au mesh obtains a champion PCE of $13.88 \%, \mathrm{~V}_{\mathrm{OC}}$ of $0.94 \mathrm{~V}$, JSC of $21.14 \mathrm{~mA} / \mathrm{cm}^{2}$, and $\mathrm{FF}$ of $69.75 \%$ at reverse voltage scan direction; while the forward scanned PCE is $13.39 \%$ with $\mathrm{V}_{\mathrm{OC}}=0.93 \mathrm{~V}, \mathrm{~J}_{\mathrm{SC}}=21.04 \mathrm{~mA} / \mathrm{cm}^{2}$, and FF $=68.42 \%$ (Figure 3c). This negligible current hysteresis in the PSC based on Ni/Au mesh electrode is strongly related to the effects of PCBM passivation and BCP interface medication, which has been proved in our previous works [3,4]. Further, the steady-state outputs of current density and PCE at the maximum power point voltage of PSC based on Ni/Au mesh are shown in Figure 3d, the nearly unchanged current density and PCE outputs during $160 \mathrm{~s}$ illustrate the good operation stability of PSC. At the same time, the reference ITO based PSC shows a PCE of $15.70 \%, \mathrm{~V}_{\mathrm{OC}}$ of $0.96 \mathrm{~V}$, JSC of $21.60 \mathrm{~mA} / \mathrm{cm}^{2}$, and FF of $75.80 \%$. Meanwhile, as shown in Figure S4, the lower leakage current and better rectification characteristics are in line with the relatively higher performance of PSC based on the ITO electrode. It is clear that the PSC based on Ni/Au mesh can obtain comparable PCE to that of the ITO based PSC, which demonstrates that the hexagon $\mathrm{Ni} / \mathrm{Au}$ mesh is a promising ITO alternative. On the other hand, compared to ITO based PSC, the low $\mathrm{V}_{\mathrm{OC}}$ and FF of Ni/Au based PSC may be explained by the relatively weak charge transport and collections ability. As J-V curves under AM $1.5 \mathrm{G}$ illumination reveal the photovoltaic performance of PSC in the entire absorption range, to further study the photovoltaic conversion at single incident light wavelengths, the IPCE spectra are measured and the results are shown in Figure $3 \mathrm{~b}$. The integrated JSC values of $19.29 \mathrm{~mA} / \mathrm{cm}^{2}$ (Ni/Au-PSC) and $19.95 \mathrm{~mA} / \mathrm{cm}^{2}$ (ITO-PSC) agree well with the measured JSC in J-V measurements, which manifest the dependability of the J-V curve measurement. However, it should be noted that the IPCEs of ITO based PSC are higher than that of Ni/Au based PSC at each single wavelength from $300 \mathrm{~nm}$ to $800 \mathrm{~nm}$. As the overall optical transmittance of Ni/Au and ITO are close, the perovskite film quality and the charge transport properties may account for the relatively low performance of the $\mathrm{Ni} / \mathrm{Au}$ based PSC.

First, as the same preparation method of perovskite film has been evaluated in our previous work [3], in the present work the primary concern is the morphology of perovskite films. Figure $4 \mathrm{a}, \mathrm{c}$ and Figure $4 b$, d show the SEM and AFM images of perovskite film based on Ni/Au mesh and ITO electrodes. It has been observed that both the perovskite films are compact and smooth, there is no significant difference in the grain sizes and root-mean-square roughness (RMS) values. From this it can be understood that the PH1000 buffer layer has smoothened the raised surface of Ni/Au mesh, which ensures a similar film morphology of perovskite on PEDOT:PSS/PH1000/Ni/Au/Glass and PEDOT:PSS/ITO/Glass samples. Here, we extracted the series resistance $\left(R_{s}\right)$ and shunt resistance $\left(R_{s h}\right)$ from the J-V curves by the parameter extraction method in our previous work [38]. As show in Figure $S 5$, the experimental data are well reproduced by the fitting curves and the corresponding $R_{S}, R_{s h}$, ideality factor, saturation current are listed in Table S1. It is clear that the PSC based on Ni/Au mesh show a $R_{\mathrm{S}}$ of $1.2 \Omega \cdot \mathrm{cm}^{2}$ and $\mathrm{R}_{\mathrm{SH}}$ of $5.548 \mathrm{k} \Omega \cdot \mathrm{cm}^{2}$, while that of the ITO based PSC are $1.0 \Omega \cdot \mathrm{cm}^{2}$ and $6.398 \mathrm{k} \Omega \cdot \mathrm{cm}^{2}$, combining the larger ideality factor and saturation current values, thus the more efficient carrier transport contributes to the better performance of ITO based PSC. To further study the charge transport properties, transient photocurrent (TPC) and transient photovoltage (TPV) measurements are carried out. The TPC can reflect extraction and transport property of carriers, and the TPV provides insight to carrier recombination property in a solar cell. As shown in Figure 5a, the ITO based PSC has a relatively faster photocurrent decay $(0.46 \mu \mathrm{s})$ compared with the Ni/Au based PSC $(1.96 \mu \mathrm{s})$, 
suggesting that the extraction and transport of carriers are more efficient in ITO based PSC. Meanwhile, the photovoltage decay processes are displayed in Figure $5 b$, the fitted charge recombination lifetimes are $1389.04 \mu$ s and $1183.34 \mu$ s for PSC based on ITO and the Ni/Au mesh, respectively. What is more, EIS measurements were carried out to evaluate the carriers' recombination in the corresponding PSCs. The corresponding Nyquist plots, the equivalent circuit diagram, and fitted results are shown in Figure S6 and Table S2. It can be found that, the PSC based on Ni/Au mesh achieved a relatively smaller $\mathrm{R}_{\text {rec }}$ (carrier recombination resistance) and shorter electron lifetime. Simultaneously, the sheet resistance of $\mathrm{Ni}(30 \mathrm{~nm}) / \mathrm{Au}(10 \mathrm{~nm})$ mesh $(16.9 \Omega / \mathrm{sq})$ is higher than that of ITO. Combining the results of AFM, SEM, TPC, TPV, and conductivity, the relatively low performance of PSC based on Ni/Au mesh can be understood.
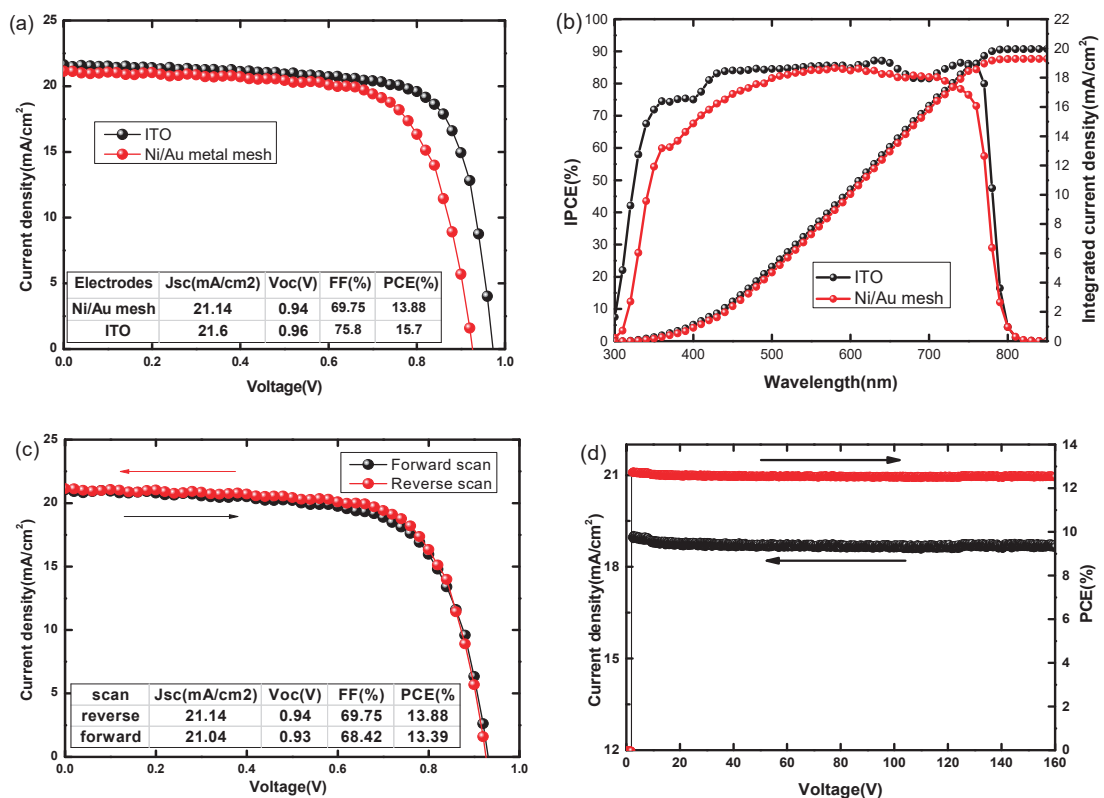

Figure 3. (a) J-V curves and (b) incident photo-to-current conversion efficiency (IPCE) spectra of PSCs based on Ni/Au mesh and PSCs based ITO measured under $100 \mathrm{~mW} / \mathrm{cm}^{2}$ AM $1.5 \mathrm{G}$ illumination; (c) $\mathrm{J}-\mathrm{V}$ curves in forward and reverse scans and (d) steady output current density and PCE of PSCs based on $\mathrm{Ni} / \mathrm{Au}$ mesh and the maximum power point $(\mathrm{Vmax}=0.67 \mathrm{~V})$.

In addition, the statistical results of photovoltaic parameters and the store stability of $\mathrm{Ni} / \mathrm{Au}$ based PSCs are shown in Figures 6 and 7, the device number in the statistical analysis is 15. From Figure 6, it can be seen that most of the $\mathrm{V}_{\mathrm{OC}}$ values concentrate in the range from $0.84 \mathrm{~V}$ to $0.98 \mathrm{~V}$ and eight of them exceed $0.92 \mathrm{~V}$; the $\mathrm{J}_{\mathrm{SC}}$ ranges from $14 \mathrm{~mA} / \mathrm{cm}^{2}$ to $24 \mathrm{~mA} / \mathrm{cm}^{2}$, with eight of them higher than $19 \mathrm{~mA} / \mathrm{cm}^{2}$; the FF from $62 \%$ to $76 \%$, with nine of them larger than $69 \%$; the PCE from $9 \%$ to $14 \%$ with eight of them exceeding $12 \%$. All the photovoltaic parameters exhibit Gaussian distribution, which suggests the good reproducibility of Ni/Au based PSCs. Here, their FF and Voc values should be further improved to obtain high performance PSCs. Besides the optimization of Ni/Au mesh electrode, more efficient charge transport layers [3,39], and interface passivation [1,40] are feasible approaches to achieve this goal. Furthermore, from Figure 7, the PSCs based on Ni/Au mesh and ITO present a similar trend of PCE degradation. After being stored in $\mathrm{N}_{2}$ for $240 \mathrm{~h}$, the Ni/Au based PSCs keep $58 \%$ of their initial PCE values, and the ITO based devices maintain $60 \%$ of their initial PCE values. Therefore, the PSCs based on Ni/Au mesh possess comparable photovoltaic performance and stability 
to the reference ITO based PSCs, and the Ni/Au mesh is one of the promising ITO alternatives to fabricate PSCs. Nowadays, owing to the improvement of perovskite quality and interface modification, the PCE of planar ITO based PSCs has exceeded 23\% [1]. It is believed that there is plenty of room for performance improvement of PSCs based on metal mesh transparent electrodes, which will be further investigated in our future works.

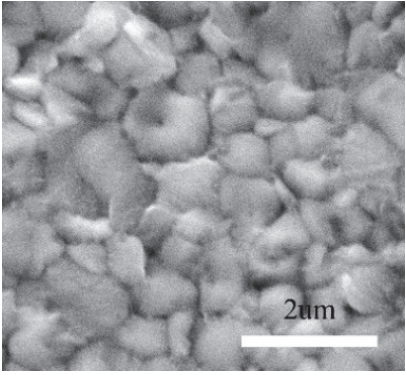

(a)

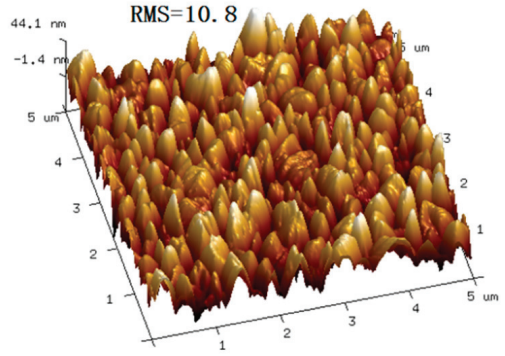

(c)

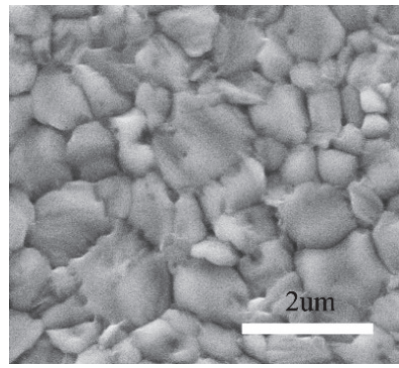

(b)

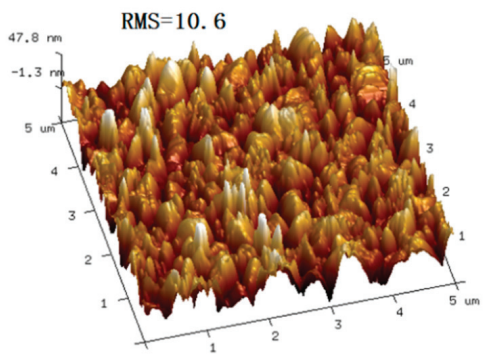

(d)

Figure 4. SEM and AFM images of perovskite film based on $(\mathbf{a}, \mathbf{c}) \mathrm{Ni} / \mathrm{Au}$ mesh and $(\mathbf{b}, \mathbf{d})$ ITO electrodes. The unit of RMS values are nm.

(a)

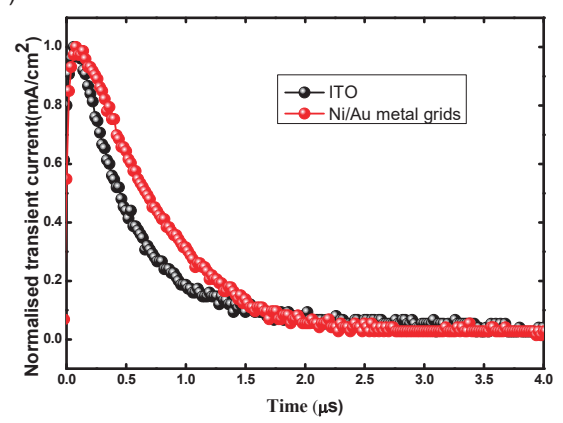

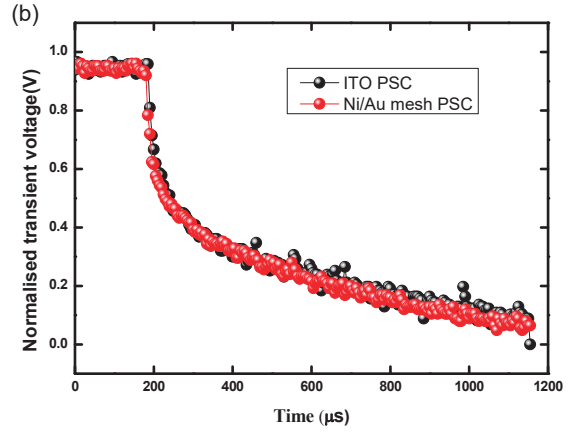

Figure 5. (a) Transient photocurrent (TPC) and (b) transient photovoltage (TPV) decay curves of the PSCs based on Ni/Au mesh and ITO electrodes. 


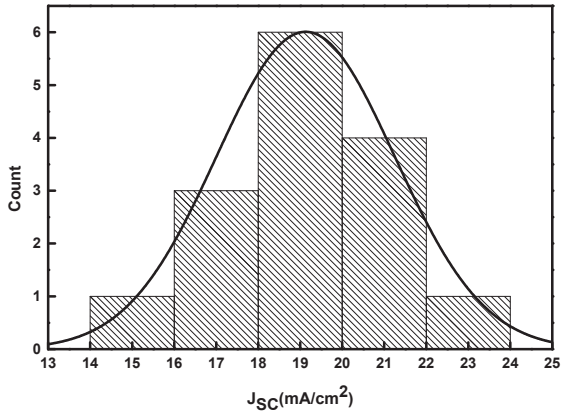

(a)

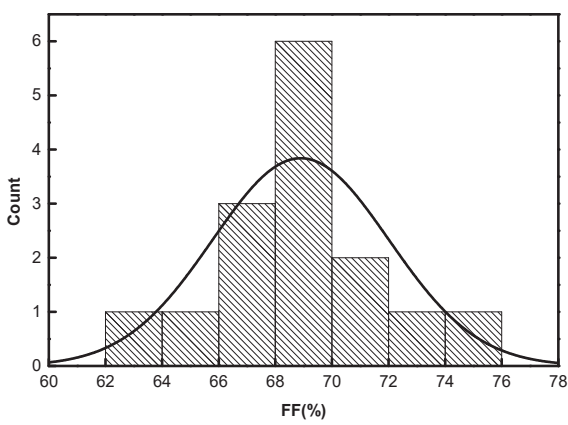

(c)

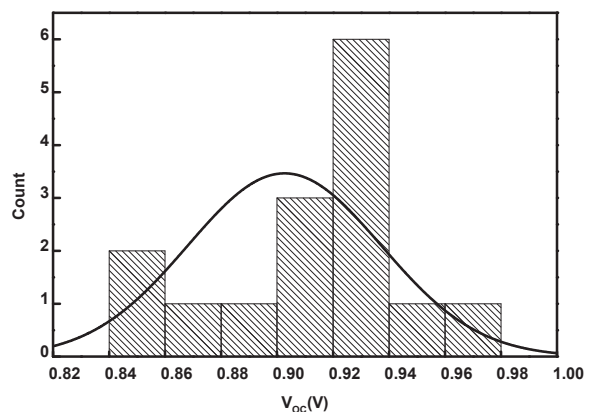

(b)

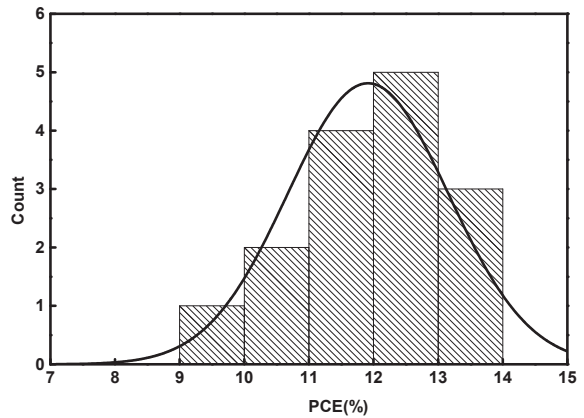

(d)

Figure 6. Histograms of photovoltaic parameters. (a) $\mathrm{JSC}_{S \mathrm{r}}$ (b) $\mathrm{V}_{\mathrm{OC}}$, (c) FF, and (d) PCE for PSC based on $\mathrm{Ni} / \mathrm{Au}$ mesh electrode. The histograms shown are the photovoltaic parameters for 15 devices.

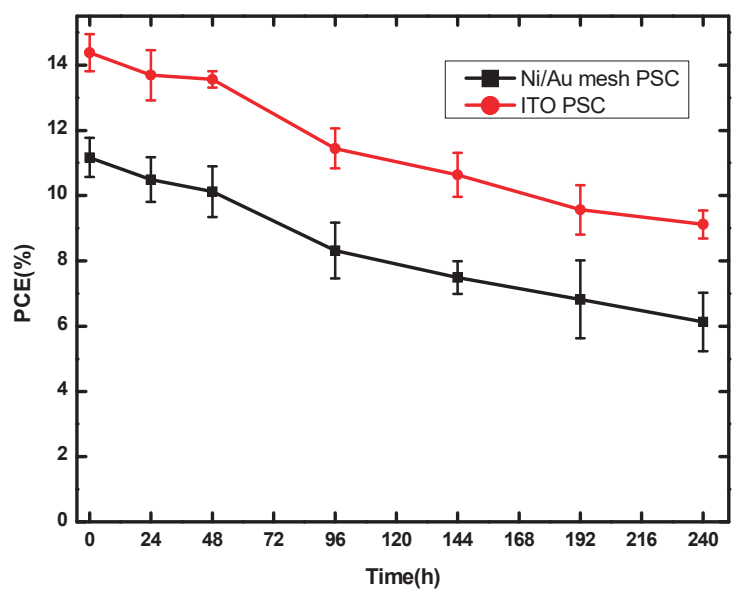

Figure 7. Storing stability of Ni/Au mesh and ITO based PSCs without encapsulation in $\mathrm{N}_{2}$ for $240 \mathrm{~h}$.

What is more, the large-area $\left(1 \mathrm{~cm}^{2}\right) \mathrm{Ni} / \mathrm{Au}$ mesh-based PSCs are fabricated under the same process conditions as the small-area $\left(0.09 \mathrm{~cm}^{2}\right)$ PSCs. Figure $8 \mathrm{a}, \mathrm{b}$ shows the J-V curve, photovoltaic parameters, and steady outputs of large-area Ni/Au based PSCs and ITO based reference PSCs. The Ni/Au based PSC obtains a PCE of $6.01 \%$, with $\mathrm{V}_{\mathrm{OC}}=1.04 \mathrm{~V}, \mathrm{~J}_{\mathrm{SC}}=11.28 \mathrm{~mA} / \mathrm{cm}^{2}$, and $\mathrm{FF}=51.28 \%$ at the reverse 
voltage scan direction, as well the steady PCE and current density outputs under continuous AM 1.5 G illumination during $160 \mathrm{~s}$. The forward scanned PCE $=5.93 \%, \mathrm{~V}_{\mathrm{OC}}=1.05 \mathrm{~V}, \mathrm{JSC}=10.81 \mathrm{~mA} / \mathrm{cm}^{2}$, and $\mathrm{FF}=52.27 \%$, thus the current hysteresis effect is negligible. While the ITO based PSC shows a higher PCE of $9.01 \%$ with $\mathrm{V}_{\mathrm{OC}}=1.02 \mathrm{~V}$, JSC $=16.24 \mathrm{~mA} / \mathrm{cm}^{2}$, and FF $=55.59 \%$, it should be noted that the JSC and FF of large area PSCs are obviously lower than the small area PSCs (Figure 3), which is due to relatively poor charge extraction and strong charge recombination related to the more defects and traps in the larger-area perovskite layer. This can be partly proved by the TPC and TPV results. As shown in Figure 8c,d, the large-area PSC displays a slower photocurrent decay (3.59 $\mu$ s) compared to the small-area cell $(1.96 \mu \mathrm{s})$, suggesting inefficient charge transport and extraction in the large-area cell. Meanwhile, a faster photovoltage decay $(644.49 \mu \mathrm{s})$ than the small-area one $(1183.34 \mu \mathrm{s})$ reveals the relatively strong charge recombination in the large-area cell. Therefore, the perovskite film quality and interface modification are crucial to further improving the performance of large-area devices. Considering the drawbacks of ITO, the meal mesh based large-area PSCs may find wider applications in the near future.
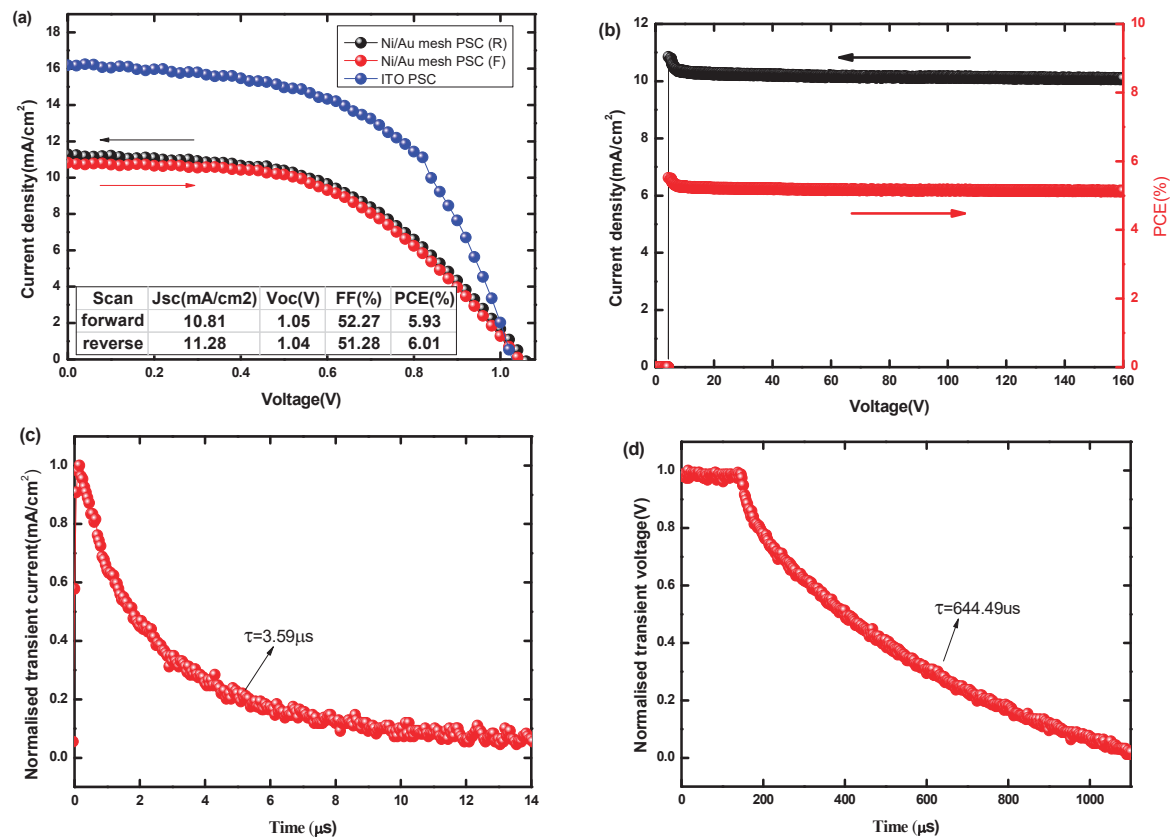

Figure 8. (a) J-V curves in forward and reverse scans for large-area PSCs based metal mesh, (b) steady output characteristics curve, (c) TPC and (d) TPV decay curves.

\section{Conclusions}

In summary, we carefully designed and deposited hexagon Ni/Au metal mesh transparent electrodes with high transmittance and low resistance by photolithography and the e-beam evaporation process. To be an efficient electrode for PSCs, the Ni was used to improve the adhesion of metal mesh to glass substrate and the Au was used to increase the conductivity of the metal mesh. The conductive polymer PH1000 not only smooths the raised surface of metal mesh but also enhances the charge collection ability of metal mesh. The optimal hexagonal Ni (30 nm)/Au (10 nm)/PH1000 electrodes were employed to fabricate ITO-free PSCs. The champion PSC $\left(0.09 \mathrm{~cm}^{2}\right)$, with a typical planar structure, obtained a PCE of $13.88 \%$, negligible current hysteresis, steady current density and PCE outputs, good repeatability and storing stability. The comparable performance to the ITO based 
reference PSC demonstrates that the Ni/Au mesh transparent electrodes are a promising ITO alternative to fabricate efficient PSCs. Further, we tried to fabricate the large area $\left(1 \mathrm{~cm}^{2}\right)$ devices under the same low-temperature process, and achieved a PCE over $6 \%$ with negligible hysteresis and stable steady outputs. And the perovskite film quality and interface modification are crucial to further improving the performance of large-area devices. Considering the drawbacks of ITO, the meal mesh-based PSCs may find wider applications in the near future.

Supplementary Materials: The following are available online at http://www.mdpi.com/2079-4991/9/7/932/s1, Figure S1: Photos of ITO-free PSCs $\left(0.09 \mathrm{~cm}^{2}\right)$ based on Ni/Au mesh electrode (a) light incident surface (b) backlight surface, Figure S2: Photos of large-area ITO-free PSCs $\left(1 \mathrm{~cm}^{2}\right)$ based on Ni/Au mesh electrode (a) light incident surface (b) backlight surface., Figure S3: J-V curves of ITO-free PSCs $\left(0.09 \mathrm{~cm}^{2}\right)$ based on Ni $(30 \mathrm{~nm}) \mathrm{square}, \mathrm{Ni}(20$ $\mathrm{nm}) / \mathrm{Au}(10 \mathrm{~nm})$ square, and $\mathrm{Ni}(20 \mathrm{~nm}) / \mathrm{Au}(10 \mathrm{~nm})$ hexagon mesh electrodes. The sheet resistance of pure $\mathrm{Ni}$ and $\mathrm{Ni} / \mathrm{Au}$ meshes are about $58 \Omega / \mathrm{sq}, 30.7 \Omega / \mathrm{sq}$, and $22.6 \Omega / \mathrm{sq}$, thus the PSC with Ni/Au hexagon electrode obtains higher Jsc, FF, and PCE values, Figure S4: Semi-log plots of dark JV curves for PSC based on Ni/Au mesh and ITO electrodes, Figure S5: JV curves under AM 1.5G illumination for PSC based on Ni/Au mesh and ITO electrodes. Here the symbols represent the experimental data and the solid lines indicate the fitting curves, Figure S6: Nyquist curves of PSCs based on Ni/Au mesh and ITO electrodes. The insert is the equivalent circuit for the fittings, where $R_{\mathrm{s}}$ represents the series resistive elements related to connections and devices, $R_{\text {rec }}$ the carrier recombination resistance and, $C_{P E}$ the constant phase element.; Table $S 1: R_{S}, R_{s h}$, saturation current, and ideality factor extracted from JV curves under AM 1.5G illumination, Table S2: EIS parameters extracted from Nyquist curves. The electron lifetime is the reciprocal of the frequency of the maximum point of the semi-circular response.

Author Contributions: D.C. and C.Z. conceived the idea, designed the experiment and guided the experiment. G.F., H.Z. and L.Z. conducted most of the electrode preparation, device fabrication, data collection and wrote the manuscript; D.C. and C.Z. revised the manuscript; W.Z., H.X. helped the device measurement, X.H. and Z.L. helped the film characterization, H.D. and S.P. helped the data analysis. J.Z. and Y.H. supervised the group. All authors read and approved the manuscript.

Funding: This work is partly supported by the Fundamental Research Funds for the National 111 Center (Grant No.B12026), Fundamental Research Funds for the Central Universities (XJS191107), Shaanxi Postdoctoral Research Grant Program (30102180038), Class General Financial Grant from the China Postdoctoral Science Foundation (2016M602771), and Natural Science Foundation of China (61804113, 61704128, 61704131, and 61604119).

Conflicts of Interest: The authors declare no conflict of interest.

\section{References}

1. Jiang, Q.; Zhao, Y.; Zhang, X.; Yang, X.; Chen, Y.; Chu, Z.; Ye, Q.; Li, X.; Yin, Z.; You, J. Surface passivation of perovskite film for efficient solar cells. Nat. Photonics 2019, in press. [CrossRef]

2. Green, M.A.; Hishikawa, Y.; Warta, W.; Dunlop, E.D.; Levi, D.H.; Hohl-Ebinger, J.; Ho-Baillie, A.W.H. Solar cell efficiency tables (version 50). Prog. Photovolt. Res. Appl. 2017, 25, 668-676. [CrossRef]

3. Liu, Z.; Chang, J.; Lin, Z.; Zhou, L.; Yang, Z.; Chen, D.; Zhang, C.; Liu, S.; Hao, Y. High-performance planar perovskite solar cells using low temperature, solution-combustion-based nickel oxide hole transporting layer with efficiency exceeding 20\%. Adv. Energy Mater. 2018, 8, 1703432. [CrossRef]

4. Pang, S.; Chen, D.; Zhang, C.; Chang, J.; Lin, Z.; Yang, H.; Sun, X.; Mo, J.; Xi, H.; Han, G.; et al. Efficient bifacial semitransparent perovskite solar cells with silver thin film electrode. Sol. Energy Mater. Sol. Cells 2017, 170, 278-286. [CrossRef]

5. Li, Y.; Meng, L.; Yang, Y.; Xu, G.; Hong, Z.; Chen, Q.; You, J.; Li, G.; Yang, Y.; Li, Y. High-efficiency robust perovskite solar cells on ultrathin flexible substrates. Nat. Commun. 2016, 7, 10214. [CrossRef] [PubMed]

6. Li, L.; Zhang, S.; Yang, Z.; Berthold, E.E.S.; Chen, W. Recent advances of flexible perovskite solar cells. J. Energy Chem. 2018, 27, 673-689. [CrossRef]

7. Fu, F.; Feurer, T.; Jäger, T.; Avancini, E.; Bissig, B.; Yoon, S.; Buecheler, S.; Tiwari, A.N. Low-temperatureprocessed efficient semi-transparent planar perovskite solar cells for bifacial and tandem applications. Nat. Commun. 2015, 6, 1-9. [CrossRef]

8. McMeekin, D.P.; Sadoughi, G.; Rehman, W.; Eperon, G.E.; Saliba, M.; Hörantner, M.T.; Haghighirad, A.; Sakai, N.; Korte, L.; Rech, B.; et al. A mixed-cation lead mixed-halide perovskite absorber for tandem solar cells. Science 2016, 351,3-8. [CrossRef] 
9. Cardinaletti, I.; Vangerven, T.; Nagels, S.; Cornelissen, R.; Schreurs, D.; Hruby, J.; Vodnik, J.; Devisscher, D.; Kesters, J.; D'Haen, J.; et al. Organic and perovskite solar cells for space applications. Sol. Energy Mater. Sol. Cells 2018, 182, 121-127. [CrossRef]

10. Heo, J.H.; Lee, D.S.; Shin, D.H.; Im, S.H. Recent advancements in and perspectives on flexible hybrid perovskite solar cells. J. Mater. Chem. A 2019, 7, 888-900. [CrossRef]

11. Loh, K.P.; Tong, S.W.; Wu, J. Graphene and graphene-like molecules: Prospects in solar cells. J. Am. Chem. Soc. 2016, 138, 1095-1102. [CrossRef] [PubMed]

12. Tang, H.; Jiang, Y.; Tang, C.W.; Kwok, H.S. Grid optimization of large-area OLED lighting panel electrodes. J. Disp. Technol. 2016, 12, 605-609. [CrossRef]

13. Dou, B.; Whitaker, J.B.; Bruening, K.; Moore, D.T.; Wheeler, L.M.; Ryter, J.; Breslin, N.J.; Berry, J.J.; Garner, S.M.; Barnes, F.S.; et al. Roll-to-roll printing of perovskite solar cells. ACS Energy Lett. 2018, 3, 2558-2565. [CrossRef]

14. Han, T.H.; Lee, Y.; Choi, M.R.; Woo, S.H.; Bae, S.H.; Hong, B.H.; Ahn, J.H.; Lee, T.W. Extremely efficient flexible organic light-emitting diodes with modified graphene anode. Nat. Photonics 2012, 6, 105-110. [CrossRef]

15. Kang, J.; Jang, Y.; Kim, Y.; Cho, S.H.; Suhr, J.; Hong, B.H.; Choi, J.B.; Byun, D. An Ag-grid/graphene hybrid structure for large-scale, transparent, flexible heaters. Nanoscale 2015, 7, 6567-6573. [CrossRef] [PubMed]

16. Chan, J.; Venugopal, A.; Pirkle, A.; McDonnell, S.; Hinojos, D.; Magnuson, C.W.; Ruoff, R.S.; Colombo, L.; Wallace, R.M.; Vogel, E.M. Reducing extrinsic performance-limiting factors in graphene grown by chemical vapor deposition. ACS Nano 2012, 6, 3224-3229. [CrossRef] [PubMed]

17. Ye, S.; Rathmell, A.R.; Chen, Z.; Stewart, I.E.; Wiley, B.J. Metal nanowire networks: The next generation of transparent conductors. Adv. Mater. 2014, 26, 6670-6687. [CrossRef]

18. Wu, J.; Que, X.; Hu, Q.; Luo, D.; Liu, T.; Liu, F.; Russell, T.P.; Zhu, R.; Gong, Q. Multi-length scaled silver nanowire grid for application in efficient organic solar cells. Adv. Funct. Mater. 2016, 26, 4822-4828. [CrossRef]

19. Song, J.; Kulinich, S.A.; Li, J.; Liu, Y.; Zeng, H. A general one-pot strategy for the synthesis of high-performance transparent-conducting-oxide nanocrystal inks for all-solution-processed devices. Angew. Chem. Int. Ed. 2015, 127, 472-476. [CrossRef]

20. Xiao, Y.; Han, G.; Wu, J.; Lin, J.Y. Efficient bifacial perovskite solar cell based on a highly transparent poly(3,4-Ethylenedioxythiophene) as the P-type hole-transporting material. J. Power Sour. 2016, 306, 171-177. [CrossRef]

21. Sun, K.; Li, P.; Xia, Y.; Chang, J.; Ouyang, J. Transparent conductive oxide-free perovskite solar cells with PEDOT:PSS as transparent electrode. ACS Appl. Mater. Interfaces 2015, 7, 15314-15320. [CrossRef] [PubMed]

22. Abachi, T.; Cattin, L.; Louarn, G.; Lare, Y.; Bou, A.; Makha, M.; Torchio, P.; Fleury, M.; Morsli, M.; Addou, M.; et al. Highly flexible, conductive and transparent $\mathrm{MoO}_{3} / \mathrm{Ag} / \mathrm{MoO}_{3}$ multilayer electrode for organic photovoltaic cells. Thin Solid Films 2013, 545, 438-444. [CrossRef]

23. Pang, S.; Li, X.; Dong, H.; Chen, D.; Zhu, W.; Chang, J.; Lin, Z.; Xi, H.; Zhang, J.; Zhang, C.; et al. Efficient bifacial semitransparent perovskite solar cells using Ag/V $2 \mathrm{O} 5$ as transparent anodes. ACS Appl. Mater. Interfaces 2018, 10, 12731-12739. [CrossRef] [PubMed]

24. Chang, C.-Y.; Chang, Y.-C.; Huang, W.-K.; Liao, W.-C.; Wang, H.; Yeh, C.; Tsai, B.-C.; Huang, Y.-C.; Tsao, C.-S. Achieving high efficiency and improved stability in large-area ito-free perovskite solar cells with thiol-functionalized self-assembled monolayers. J. Mater. Chem. A 2016, 4, 7903-7913. [CrossRef]

25. Mao, L.; Chen, Q.; Li, Y.; Li, Y.; Cai, J.; Su, W.; Bai, S.; Jin, Y.; Ma, C.Q.; Cui, Z.; et al. Flexible silver grid/PEDOT: PSS hybrid electrodes for large area inverted polymer solar cells. Nano Energy 2014, 10, 259-267. [CrossRef]

26. Sam, F.L.M.; Mills, C.A.; Rozanski, L.J.; Silva, S.R.P. Thin film hexagonal gold grids as transparent conducting electrodes in organic light emitting diodes. Laser Photonics Rev. 2014, 8, 172-179. [CrossRef]

27. Kim, W.; Kim, S.; Kang, I.; Jung, M.S.; Kim, S.J.; Kim, J.K.; Cho, S.M.; Kim, J.H.; Park, J.H. Hybrid silver mesh electrode for ITO-free flexible polymer solar cells with good mechanical stability. ChemSusChem 2016, 9, 1042-1049. [CrossRef] [PubMed]

28. Suh, Y.D.; Kwon, J.; Lee, J.; Lee, H.; Jeong, S.; Kim, D.; Cho, H.; Yeo, J.; Ko, S.H. Maskless fabrication of highly robust, flexible transparent $\mathrm{Cu}$ conductor by random crack network assisted $\mathrm{Cu}$ nanoparticle patterning and laser sintering. Adv. Electron. Mater. 2016, 7, 5024-5031. [CrossRef] 
29. Kim, W.K.; Lee, S.; Hee Lee, D.; Hee Park, I.; Seong Bae, J.; Woo Lee, T.; Kim, J.Y.; Hun Park, J.; Chan Cho, Y.; Ryong Cho, C.; et al. Cu mesh for flexible transparent conductive electrodes. Sci. Rep. 2015, 5, 10715-10722. [CrossRef]

30. Guo, C.F.; Sun, T.; Liu, Q.; Suo, Z.; Ren, Z. Highly stretchable and transparent nanomesh electrodes made by grain boundary lithography. Nat. Commun. 2014, 5, 3121. [CrossRef]

31. Galagan, Y.; Rubingh, J.E.J.; Andriessen, R.; Fan, C.C.; Blom, P.W.; Veenstra, S.C.; Kroon, J.M. ITO-free flexible organic solar cells with printed current collecting grids. Sol. Energy Mater. Sol. Cells 2011, 17, 349-354. [CrossRef]

32. Available online: https://en.wikipedia.org/wiki/Photolithography (accessed on 8 June 2019).

33. Abdollahi Nejand, B.; Nazari, P.; Gharibzadeh, S.; Ahmadi, V.; Moshaii, A. All-inorganic large-area low-cost and durable flexible perovskite solar cells using copper foil as a substrate. Chem. Commun. 2017, 53, 747-750. [CrossRef] [PubMed]

34. Chen, L.; Xie, X.; Liu, Z.; Lee, E.C. A transparent poly(3,4-ethylenedioxylenethiophene):poly(styrene sulfonate) cathode for low temperature processed, metal-oxide free perovskite solar cells. J. Mater. Chem. A 2017, 5, 6974-6980. [CrossRef]

35. Troughton, J.; Bryant, D.; Wojciechowski, K.; Carnie, M.J.; Snaith, H.; Worsley, D.A.; Watson, T.M. Highly efficient, flexible, indium-free perovskite solar cells employing metallic substrates. J. Mater. Chem. A 2015, 3, 9141-9145. [CrossRef]

36. Zhang, H.X.; Chen, D.Z.; Zhang, C.F. ITO-free perovskite solar cells using photolithography processed metal grids as transparent anodes. In Proceedings of the 2016 13th IEEE International Conference on Solid-State and Integrated Circuit Technology (ICSICT 2016), Hangzhou, China, 25-28 October 2016; pp. 1026-1028.

37. Lai, W.C.; Lin, K.W.; Wang, Y.T.; Chiang, T.Y.; Chen, P.; Guo, T.F. Oxidized Ni/Au transparent electrode in efficient $\mathrm{CH}_{3} \mathrm{NH}_{3} \mathrm{PbI}_{3}$ perovskite/fullerene planar heterojunction hybrid solar cells. Adv. Mater. 2016, 28, 3290-3297. [CrossRef] [PubMed]

38. Zhang, C.; Zhang, J.; Hao, Y.; Lin, Z.; Zhu, C. A simple and efficient solar cell parameter extraction method from a single current-voltage curve. J. Appl. Phys. 2011, 110, 064504. [CrossRef]

39. Macdonald, T.J.; Batmunkh, M.; Lin, C.-T.; Kim, J.; Tune, D.D.; Amboz, F.; Li, X.; Xu, S.; Sol, C.; Papakonstantinou, I.; et al. Origin of performance enhancement in $\mathrm{TiO}_{2}$-carbon nanotube composite perovskite solar cells. Small Methods 2019, 1900164, Early View. [CrossRef]

40. Chen, D.; Pang, S.; Zhou, L.; Li, X.; Su, A.; Zhu, W.; Chang, J.; Zhang, J.; Zhang, C.; Hao, Y. Efficient TeO $2 / \mathrm{Ag}$ transparent top electrode for $20 \%$-efficiency bifacial perovskite solar cells with a bifaciality factor exceeding 80\%. J. Mater. Chem. A 2019. accepted manuscript. [CrossRef]

(C) 2019 by the authors. Licensee MDPI, Basel, Switzerland. This article is an open access article distributed under the terms and conditions of the Creative Commons Attribution (CC BY) license (http://creativecommons.org/licenses/by/4.0/). 

Article

\title{
Dopant-Free Hole Transport Materials with a Long Alkyl Chain for Stable Perovskite Solar Cells
}

\author{
Kai Wang ${ }^{1,+}$, Haoran Chen ${ }^{1,+}$, Tingting Niu ${ }^{1}$, Shan Wang ${ }^{1}$, Xiao Guo ${ }^{1}$ and Hong Wang ${ }^{2, *}$ \\ 1 Key Laboratory of Flexible Electronics (KLOFE) \& Institute of Advanced Materials (IAM), Jiangsu National \\ Synergetic Innovation Center for Advanced Materials (SICAM), Nanjing Tech University (Nanjing Tech), \\ Nanjing 211816, China \\ 2 Zhongshan Institute of Modern industrial Technology, South China University of Technology, Zhongshan \\ 528437, China \\ * Correspondence: phhwang@scut.edu.cn; Tel.: +86-136-0006-6193 \\ + These authors contributed equally to this work.
}

Received: 22 May 2019; Accepted: 24 June 2019; Published: 28 June 2019

\begin{abstract}
Hole transport materials are indispensable to high efficiency perovskite solar cells. Two new hole transporting materials (HTMs), named 4,4'-(9-nonyl-9H-carbazole-3,6-diyl)bis ( $N, N$-bis(4-methoxyphenyl)aniline) (CZTPA-1) and 4,4'-(9-methyl-9H-carbazole-3,6-diyl)bis (N,N-bis(4-methoxyphenyl)aniline)(CZTPA-2), were developed by different alkyl substitution methods. The two compounds, containing a carbazole core and triphenylamine (TPA) groups with different lengths of the alkyl chain, were designed and synthesized through a two-step synthesis approach. The power conversion efficiency (PCE) was found to be affected by the length of the alkyl chain, reaching $7 \%$ for CZTPA- 1 and $11 \%$ for CZTPA-2. Furthermore, the CZTPA- 2 still maintained $89.7 \%$ of its original performance after $400 \mathrm{~h}$. The proposed results demonstrate the effect of carbon chain substituents on the efficiency of perovskite solar cells (PSCs).
\end{abstract}

Keywords: perovskite solar cell; alkyl chain; hole transporting materials; stable

\section{Introduction}

Perovskite solar cells (PSCs) have attracted much attention in recent years owing to their excellent optoelectronic properties, high absorption coefficients, easy solution processability, high carrier mobility, and so on [1-5]. Many efforts have been made to increase the efficiency of PSCs. Surprisingly, it has increased dramatically from $3.8 \%$ [1] to $24.2 \%$ [6] in a short period of time.

As is well-known, 2,2',7,7'-Tetrakis[N,N-di(4-methoxyphenyl)amino]-9, $9^{\prime}$-spirobifluorene (Spiro-OMeTAD) $[7,8]$ is a common hole transporting material (HTM) with good performance. However, it is still a formidable challenge to develop this material due to various drawbacks, such as a complicated synthesis process and high cost. Therefore, new HTMs with a simple synthesis process and low cost need urgently to be developed.

HTMs construct the hole transport layer (HTL) that is needed to block electron transport, enhance hole transport, and prevent direct contact between the perovskite layer and the electrode, which causes annihilation. An ideal HTM should have such characteristics as good hole mobility, good hydrophobicity, suitable energy levels, and the ability to be prepared in solution [9-11]. Currently, common HTMs can be classified as inorganic substances, organic polymers, or organic small molecules depending on the type of material. Low cost, high stability, and hole mobility are among the many advantages that HTMs based on inorganic materials have. Kamat and co-workers first introduced copper iodide as an HTM and achieved an average PCE of $6 \%$ [12]. Then, inorganic semiconductors (CuSCN, NiO, CuI) as HTMs were developed [13,14]. In addition to inorganic HTMs, polymer-based HTMs have been explored in PSCs. Poly-[bis(4-phenyl)(2,4,6-trimethylphenyl)amine] (PTAA) was 
the first conjugated polymer to be used as an HTM in PSCs [15] and maintained the highest PCE of any reported polymeric HTM [16]. Accompanied by the development of conjugated polymer HTMs, Poly(3-hexylthiophene-2,5-diyl (P3HT) [17] was originally used in organic solar cells (OSCs) as the active layer was introduced into the hole transport layer. Compared to polymeric HTMs, small molecule HTMs have the advantages of a determined molecular weight and simple purification for PSCs. As a group with good stability and solubility, triphenylamine (TPA) is widely used in organic small molecule HTMs [18-20]. The TPA group in particular can influence the optoelectrical properties of HTMs due to its non-planar geometry. Furthermore, the carbazole group has a high carrier mobility in OSCs and as good a performance as HTMs; thus, it is currently regarded as a core in PSCs [21-27].

In 2014, Sun and co-workers [27] designed a series of HTMs based on carbazole, named X19 and X51. The X51 realized a PCE of $9.8 \%$ due to a higher charge-carrier mobility and conductivity than X19. Subsequently, Nazeeruddin and co-workers [28] studied bridged carbazole with biphenyl, by using silolothiophene as the bridge, which obtained a PCE of $13.1 \%$. They found that compared to the spirofluorene-linked triphenylamine HTMs, novel silolothiophene-linked methoxy triphenylamines (Si-OMeTPAs) enable more stable PSCs. In the same year, Tang and co-workers [29] used carbazole as a core with four TPAs as the side groups to achieve a PCE of up to $18.32 \%$.

Recently, Khaja Nazeeruddin and co-workers [30] used anthra[1,2-b:4,3-b':5,6-b':8,7$b^{\prime \prime \prime}$ ]tetrathiophene as the core, by changing the alkyl chain length of the methoxy groups on the triarylamine sites, to develop a series of materials. The device based on a methyl substitute named ATT-OMe was found to have the best PCE of $18.13 \%$, which was better than that of the device based on other longer alkyl chain HTMs. They believed that the presence of alkyl chains decreased the hole-transport properties. However, the performance of PSCs based on carbazole is far from that of the classical Spiro-OMeTAD. Therefore, more efforts are needed to develop new small molecule HTMs that match with perovskite instead of the Spiro-OMeTAD.

In this work, we developed two HTMs-4,4'-(9-nonyl-9H-carbazole-3,6-diyl)bis ( $N, N$-bis(4-methoxyphenyl)aniline) (CZTPA-1) and 4,4'-(9-methyl-9H-carbazole-3,6-diyl)bis ( $N, N$-bis(4-methoxyphenyl)aniline) (CZTPA-2)-based on TPA as the end group. They both have the advantage of simple synthesis steps and low cost. Both HTMs are synthesized by one-step Suzuki coupling. The cost of the raw material 3,6-Dibromocarbazole ( $\$ 0.3 / \mathrm{g})$ plus 4-methoxy- $N$-(4-methoxyphenyl)- $N$-(4-(4,4,5,5-tetramethyl-1,3,2-dioxaborolan-2-yl)phenyl)aniline $(\$ 15 / \mathrm{g})$ is clearly lower than that of Spiro-OMeTAD (\$220/g). Notably, the CZTPA-2 with the longer alkyl chain achieved a better PCE of $11.79 \%$ with a short current density $\left(J_{\text {sc }}\right)$ of $21.80 \mathrm{~mA} / \mathrm{cm}^{2}$, an open circuit voltage $\left(V_{\mathrm{oc}}\right)$ of $0.99 \mathrm{~V}$, and a fill factor $(\mathrm{FF})$ of $54.59 \%$. This is attributed to the significantly improved hole mobility of CZTPA-2, resulting in a significant increase in device efficiency.

\section{Materials and Methods}

\subsection{Materials}

Unless otherwise noted, all reagents used in the experiments were purchased from commercial sources and used without further purification. 3,6-Dibromo-9H-carbazole, $\mathrm{N}, \mathrm{N}$-bis(4-Methoxyphenyl)-4-(4,4,5,5-tetraMethyl-1,3,2-dioxaborolan-2-yl)-BenzenaMine, lead iodide $\left(\mathrm{PbI}_{2}\right)$, methylammonium iodide (MAI), acetonitrile $(99.8 \%)$, chlorobenzene (99.9\%), and dimethylformamide (DMF) (99\%) were purchased from Sigma-Aldrich. 4-tert-butylpyridine (TBP) and Li-bis-(trifluoromethanesulfonyl) imide (Li-TFSI) were purchased from TCI. 2,2',7,7'-tetrakis-( $N, N$-di-p-methoxyphenylamine)-9,9's-spirobifluorene (Spiro-OMeTAD) (99.0\%) was purchased from Xi'an Polymer Light Technology Co., Ltd.

Perovskite precursor: The perovskite precursor was obtained by mixing $\mathrm{PbI}_{2}$ and $\mathrm{MACl}$ (in a molar ratio of 1:1) in DMF with a concentration of $350 \mathrm{mg} / \mathrm{mL}$, and was then stirred at $60{ }^{\circ} \mathrm{C}$ overnight in a glovebox. 
Spiro-OMeTAD: The 2,2',7,7'-Tetrakis( $N, N^{\prime}$-di-p-methoxyphenylamine)-9,9'-spirobifluorene (Spiro-OMeTAD) was doped with TBP and Li-TFSI. A total of $73.2 \mathrm{mg}$ of Spiro-OMeTAD (Xi'an Polymer Light Technology Co., Ltd., Xi'an, China) was dissolved in $1 \mathrm{~mL}$ of chlorobenzene (CB) with $28.8 \mu \mathrm{L}$ of 4-tert-butylpyridine (TBP) and $17.6 \mu \mathrm{L}$ of Li-bis-(trifluoromethanesulfonyl) imide (Li-TFSI).

\subsection{Device Fabrication}

The $\mathrm{SnO}_{2}$ layer was spin-coated on an ITO substrate at $3000 \mathrm{rpm}$ for $30 \mathrm{~s}$, which was cleaned in UV-ozone and then annealed at $150{ }^{\circ} \mathrm{C}$ for $30 \mathrm{~min}$. The perovskite layer was spin-coated at $4000 \mathrm{rpm}$ for $30 \mathrm{~s}$ by an anti-solvent method. The details of the operation are as follows: $100 \mu \mathrm{L} \mathrm{CB}$ was rapidly added after $5 \mathrm{~s}$ of spin-coating with perovskite solution; and the perovskite films were annealed at $100{ }^{\circ} \mathrm{C}$ for $5 \mathrm{~min}$. All of the above processes were performed in the nitrogen glovebox. Then, Spiro-OMeTAD and two HTMs were dissolved in the CB $(10 \mathrm{mg} / \mathrm{mL})$, and then spin-coated upon the perovskite layer at $3000 \mathrm{rpm}$ for $30 \mathrm{~s}$. Then, molybdenum trioxide $\left(\mathrm{MoO}_{3}\right)$ and gold $(\mathrm{Au})$ were thermally evaporated on the hole transporting layer. The effective area of the cell is $0.05 \mathrm{~cm}^{2}$.

\subsection{Device Characterization}

The cross-sectional images of PSC were taken by scanning electron microscopy (SEM) (ZEISS Merlin, Carl Zeiss Microscopy, Jena, Germany). The UV-visible absorption spectra were measured using a UV Spectrophotometer (SHIMADZU UV-1750, East Test Technology Co., Ltd, Shenzhen, China). Photoluminescence (PL) spectra were obtained using a spectrofluorometer (HitachiF-7000, Hitachi High-Technologies Corporation, Shenzhen, China). Thermogravimetric (TGA) analysis was performed on a Mettler Toledo TGA2.

The device was measured under AM $1.5 \mathrm{G}$ solar irradiation with an intensity of $100 \mathrm{~mW} / \mathrm{cm}^{2}$ through an Enlitech SS-F5-3A solar simulator. The instrument was calibrated on standard solar cells. $J-V$ properties were measured by the method of Enlitech Ltd. (Kaohsiung, Taiwan) and a Keithley (Cleveland, OH, USA) 2400 source meter under dark conditions. The external quantum efficiency (EQE) spectra were measured using a solar cell IPCE test system (CROWNTECH Inc., model QTEST HIFINITY (Macungie, PA, USA)).

The synthesis method and details of the experimental procedure are shown in the supporting information (SI).

\section{Results}

The details of the experimental procedure are shown in the Supplementary Information (SI). The design principle was to improve planarity as well as increase solubility. The carbazole group with simple structures has good hole transporting ability. By inserting $\mathrm{N}$ atoms with different alkyl chain lengths, the optoelectronic properties and solubility can be adjusted. Herein, we chose 4-methoxy- $N$-(4-methoxyphenyl)- $N$-(4-(4,4,5,5-tetramethyl-1,3,2-dioxaborolan-2-yl)phenyl)aniline units as the raw material, used Suzuki coupling, and substituted the carbazole core with different lengths of alkyl chains. The aimed-for materials were obtained by simple column chromatography separation and recrystallization.

Figure 1a shows the absorption spectra of CZTPA-1 and CZTPA- 2 in chloroform and as a coating on quartz substrates. Absorption peaks at $335 \mathrm{~nm}$ for CZTPA- 1 and $327 \mathrm{~nm}$ for CZTPA-2 in the solution were observed. Relative to the solution, the CZTPA-1 film exhibits a redshift of $2 \mathrm{~nm}$ with an onset of $409 \mathrm{~nm}$, corresponding to an optical bandgap of $3.03 \mathrm{eV}$, whereas CZTPA-2 aligns to a narrower bandgap of $2.98 \mathrm{eV}$ (onset of $416 \mathrm{~nm}$ ). Both HTMs have a slight redshift in the film compared with the solution, suggesting that aggregation exists in the films. 
a

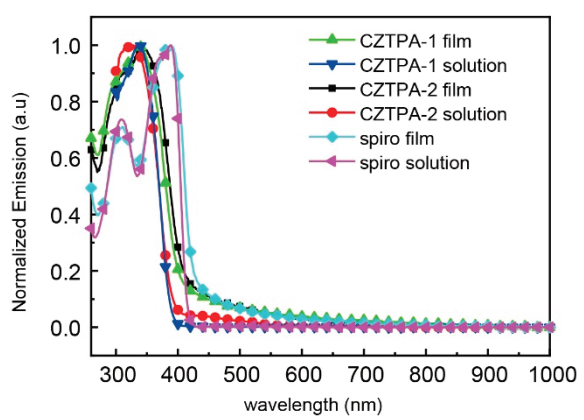

b

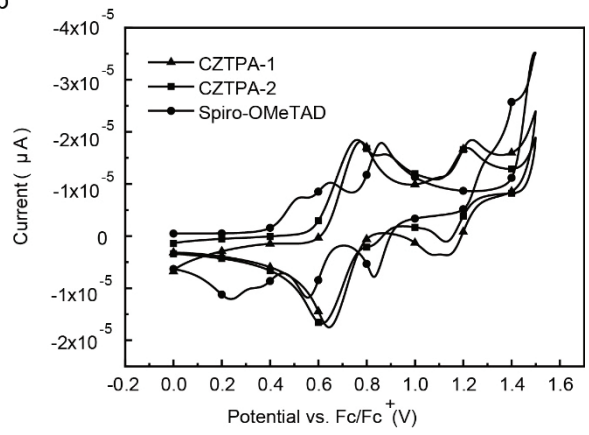

Figure 1. (a) Optical absorption spectra of 4,4'-(9-nonyl-9H-carbazole-3,6-diyl)bis ( $N, N$-bis(4-methoxyphenyl)aniline) (CZTPA-1) and 4,4'-(9-methyl-9H-carbazole-3,6-diyl)bis ( $N, N$-bis(4-methoxyphenyl)aniline) (CZTPA-2) in chloroform and thin films spin-coated from chloroform. (b) Cyclic voltammetry of CZTPA-1 and CZTPA-2.

From Figure 1b, the highest occupied molecular orbital (HOMO) level of CZTPA-1 is $-4.89 \mathrm{eV}$, while in the CZTPA-2 there is a higher $\mathrm{HOMO}$ of $-4.83 \mathrm{eV}$ (the energy level of Ferroceneis is $-0.54 \mathrm{eV}$ by the cyclic voltammetry method). Compared to the two HTMs, the Spiro-OMeTAD has the higher energy level as the $\mathrm{HOMO}$ is $-4.64 \mathrm{eV}$. Based on the relationship of $E_{\mathrm{LUMO}}=E_{\mathrm{HOMO}}+E_{\mathrm{g}}$, the lowest unoccupied molecular orbital (LUMO) level value was calculated to be $-1.86 \mathrm{eV}$ for CZTPA-1, -1.85 eV for CZTPA-2, and -1.74 eV for Spiro-OMeTAD (Table 1). CZTPA-2 has similar electrochemical properties compared with CZTPA-1, which indicates that the electrochemical properties of the molecule remain stable with a change in the alkyl chain length.

Table 1. Optical and electrochemical properties of CZTPA-1 and CZTPA-2.

\begin{tabular}{|c|c|c|c|c|c|c|}
\hline & $\begin{array}{c}\lambda_{\max } \text { Sol (a) } \\
\text { (nm) }\end{array}$ & $\begin{array}{c}\lambda_{\max } \text { Film (b) } \\
(\mathrm{nm})\end{array}$ & $\begin{array}{c}\lambda_{\text {onset }} \\
(\mathrm{nm})\end{array}$ & $\begin{array}{c}E_{\mathrm{g}}{ }^{\text {opt }}(\mathrm{c}) \\
(\mathrm{eV})\end{array}$ & $\begin{array}{c}E_{\text {HOMO }} \\
(\mathrm{eV})\end{array}$ & $\begin{array}{c}E_{\text {LUMO }}(\mathrm{d}) \\
(\mathrm{eV})\end{array}$ \\
\hline CZTPA-1 & 335 & 337 & 409 & 3.03 & -4.89 & -1.86 \\
\hline CZTPA-2 & 327 & 339 & 416 & 2.98 & -4.83 & -1.85 \\
\hline Spiro-OMeTAD & 386 & 390 & 428 & 2.90 & -4.64 & -1.74 \\
\hline
\end{tabular}

(a) Maximum absorption peak in $\mathrm{CH}_{2} \mathrm{Cl}_{3}$ solution; (b) Maximum absorption peak of films on quartz glass; (c) Optical bandgap calculated from the absorption onset of films: $E_{\mathrm{g}}{ }^{\mathrm{opt}}=1240 / \lambda_{\text {onset }} \mathrm{eV} ;(\mathrm{d}) E_{\mathrm{LUMO}}=E_{\mathrm{HOMO}}+E_{\mathrm{g}}{ }^{\text {opt }}$.

We then found that CZTPA-1 and CZTPA-2 match well with the energy level of the perovskite from Figure 2a. Furthermore, the thermal stability of the two HTMs was measured by thermogravimetric analysis (TGA) (Figure 2b). Both CZTPA-1 and CZTPA-2 exhibit good thermal stability with decomposition temperatures $\left(\mathrm{T}_{\mathrm{d}}, 5 \%\right.$ weight loss) at $391.8^{\circ} \mathrm{C}$ and $384.6{ }^{\circ} \mathrm{C}$, respectively. As we expected, increasing the length of the alkyl chains reduces the thermal stability.

The photoluminescence (PL) spectra in Figure 2c show the maximum emission peak at $431 \mathrm{~nm}$ for CZTPA-1 and at $425 \mathrm{~nm}$ for CZTPA-2 in film. CZTPA-2 was slightly more blue-shifted than CZTPA-1, caused by the increase in the length of the alkyl chains.

Figure $2 \mathrm{~d}$ shows the PL spectra of the perovskite, perovskite with Spiro-OMeTAD, perovskite with CZTPA-1, and perovskite with CZTPA-2. Strong PL quenching was observed after the HTMs were coated on perovskite films. Respectively, compared with the original perovskite film, the PL intensity was reduced to $7 \%, 22 \%$, and $18 \%$ after coating with Spiro-OMeTAD, CZTPA-1, and CZTPA-2. Thus, we think that CZTPA-2 has better charge separation than CZTPA-1 and a smaller $J_{S C}$ and FF in the PSCs compared to Spiro-OMeTAD devices. In short, this means that the hole transfer capabilities of CZTPA-2 are superior because of their better charge transfer capability. 


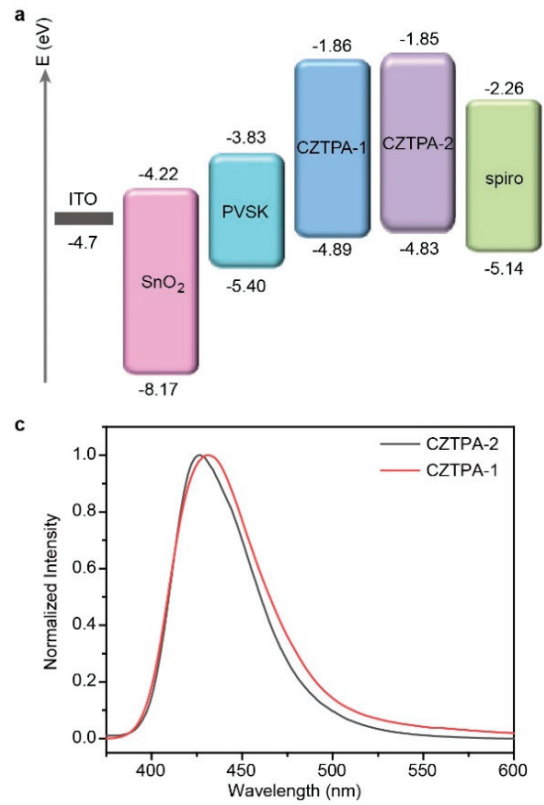

b
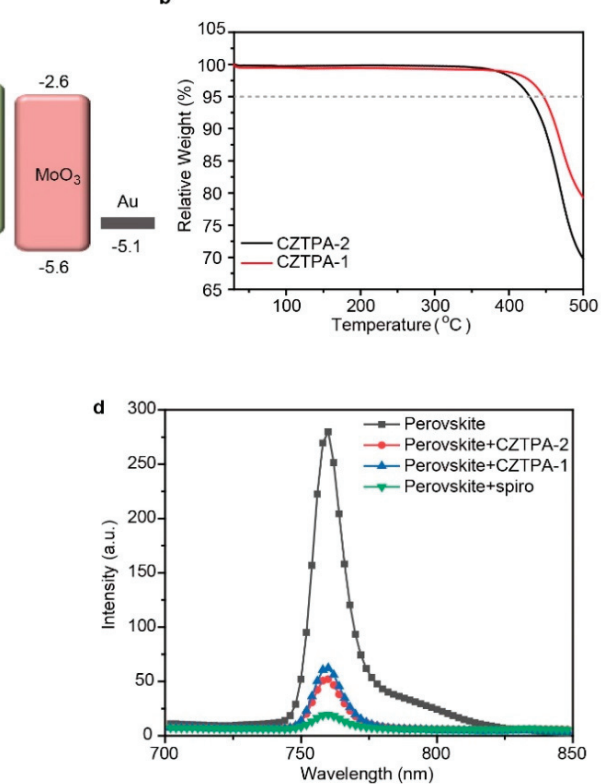

Figure 2. (a) Energy level diagram of a perovskite solar cell (PSC) with CZTPA-1, CZTPA-2, and 2,2',7,7'-Tetrakis[N,N-di(4-methoxyphenyl)amino]-9,9'-spirobifluorene (Spiro-OMeTAD). (b) Thermogravimetric analysis (TGA) diagrams of CZTPA-1 and CZTPA-2. (c) Photoluminescence (PL) spectra of CZTPA-1 and CZTPA-2 thin film, excitation at $350 \mathrm{~nm}$. (d) Photoluminescence spectra of perovskite, perovskite with Spiro-OMeTAD, perovskite with CZTPA-1, and perovskite with CZTPA-2, excitation at $500 \mathrm{~nm}$.

Figure 3 shows two cross-sectional scanning electron microscopy (SEM) images of the PSC with the structure of ITO/SnO $2 /$ perovskite/HTMs/Au. The PSC includes an $\approx 460 \mathrm{~nm}$ perovskite capping layer and an $\approx 35 \mathrm{~nm}$ HTM layer (CZTPA-1 or CZTPA-2). From the SEM image, we found that the HTM layer deposited on the perovskite layer and the boundaries of each layer are clear. Atomic force microscopy (AFM) images of the two materials spin-coated onto perovskite films are shown in Figure S7, which represent the perovskite/CZTPA-2 (a) and the perovskite/CZTPA-1 (b) films, respectively. The roughness of both samples is slightly high, which may be due to the lower thickness of the HTMs. After a comparison, it was found that the roughness of the film in which the HTM is CZTPA-2 (RMS = $20.968 \mathrm{~nm}$ ) is significantly lower than that of CZTPA-1 (RMS = $28.662 \mathrm{~nm}$ ); this is attributed to the solubility of CZTPA-2 being higher such that it could better cover the film and further improve the carrier transport of the device.
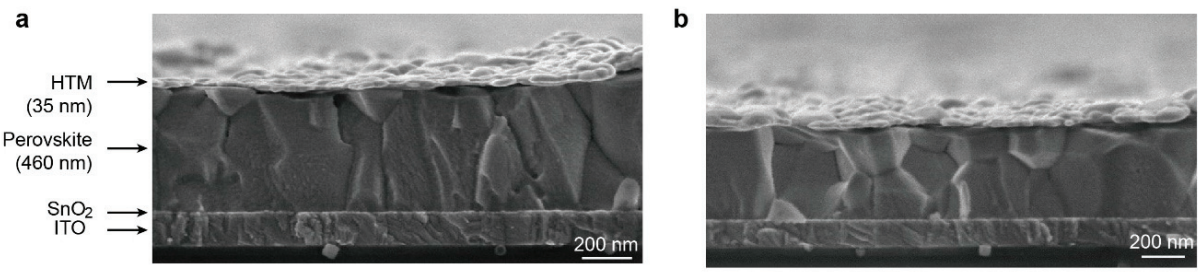

Figure 3. (a) A cross-sectional SEM image of the CZTPA-1 PSC. The scale bar is $200 \mathrm{~nm}$. (b) A cross-sectional SEM image of the CZTPA-2 PSC. The scale bar is $200 \mathrm{~nm}$. 
In order to compare the properties of the two HTMs, we used them as the hole transport layer of perovskite solar cells to compare device performance. Between them, the effective area of the cells is $0.05 \mathrm{~cm}^{2}$, and the scanning rate is $0.02 \mathrm{~V} / \mathrm{s}$. As shown in Figure 4a,b, the PSCs with CZTPA-2 achieve a PCE of $11.79 \%$ with an open-circuit voltage $\left(V_{\mathrm{oc}}\right)$ of $0.99 \mathrm{~V}$, a short-circuit current density $\left(J_{\mathrm{sc}}\right)$ of $21.8 \mathrm{~mA} \mathrm{~cm}^{-2}$, and a fill factor (FF) of $54.59 \%$, while the PSCs with CZTPA-1 achieve a lower PCE of $6.05 \%$ under the condition of no doping. In contrast, the best cell is based on Spiro-OMeTAD, as the HTM achieves the PCE of $16.77 \%$. We also compared the Spiro-OMeTAD PSC without any doping, which achieved a PCE of $11.74 \%$. The photovoltaic performance of the PSCs based on the two HTMs (dopant-free) and the Spiro-OMeTAD were investigated under AM 1.5 illumination $\left(100 \mathrm{~mW} \mathrm{~cm}^{-2}\right)$. The champion device performance plots of CZTPA-1 and CZTPA-2 are shown in Table 2. The device fabricated with CZTPA-1 as the HTM yielded a promising PCE of $6.05 \%$ with a $J_{\mathrm{sc}}$ of $20.58 \mathrm{~mA} \mathrm{~cm}^{-2}$, a $V_{\mathrm{oc}}$ of $0.77 \mathrm{~V}$, and an FF of $38.01 \%$. We calculated the average PCE of the CZTPA-2 devices to be $10.15 \% \pm 0.90$. The CZTPA-1 devices own an average PCE of $5.27 \% \pm 0.57$. The average PCE of the Spiro-OMeTAD (dopant-free) is $10.02 \% \pm 0.98$, and the corresponding PCE of Spiro-OMeTAD is $15.65 \% \pm 0.71$. All data are based on the values obtained from 20 devices. From these, we can speculate that CZTPA-2 exhibits better performance compared with CZTPA-1. The FF and $V_{\text {oc }}$ of CZTPA-1 are obviously lower than those of CZTPA-2 in the PSC devices. Furthermore, CZTPA-2 obtains a slightly higher PCE compared with the dopant-free Spiro-OMeTAD, which is attributed to the higher $J_{\mathrm{sc}}$.
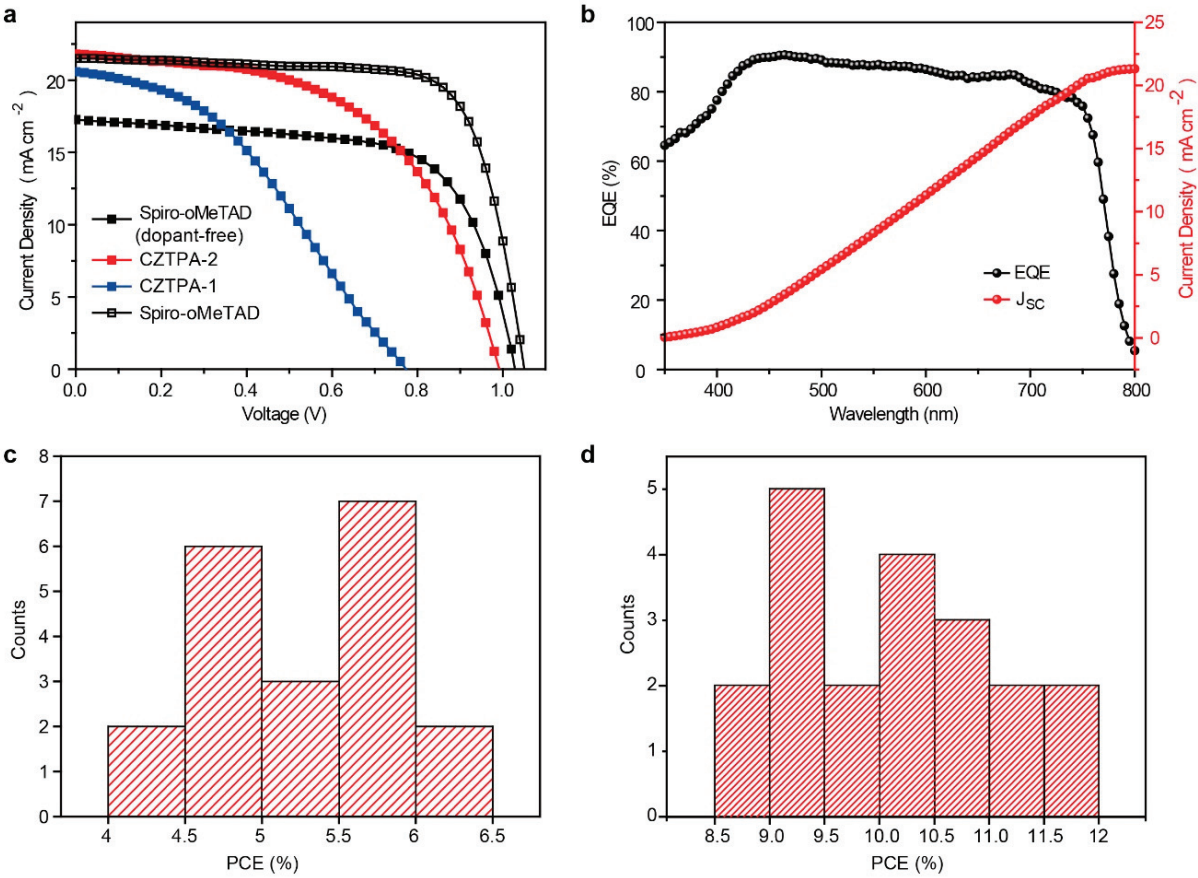

Figure 4. (a) $J-V$ characteristics of PSCs based on the two hole transport materials (HTMs), the Spiro-OMeTAD, and the Spiro-OMeTAD (dopant-free). (b) External quantum efficiency (EQE) and $J_{\text {sc }}$ spectra of PSCs with CZTPA-2. (c) Histograms of PCEs measured in 20 cells of CZTPA-1. (d) Histograms of PCEs measured in 20 cells of CZTPA-2. 
Table 2. Photovoltaic data of PSCs based on the two HTMs, the Spiro-OMeTAD, and the Spiro-OMeTAD (dopant-free).

\begin{tabular}{cccccc}
\hline & $V_{\text {OC }}(\mathbf{V})$ & $J_{\text {SC }}\left(\mathbf{m A} \cdot \mathbf{c m}^{-2}\right)$ & FF (\%) & PCE (\%) & PCE Ave (\%) \\
\hline Spiro-OMeTAD (dopant-free) & 1.02 & 17.26 & 66.14 & 11.74 & $10.02 \% \pm 0.98$ \\
CZTPA-2 & 0.99 & 21.80 & 54.59 & 11.79 & $10.15 \% \pm 0.90$ \\
CZTPA-1 & 0.77 & 20.58 & 38.01 & 6.05 & $5.27 \% \pm 0.57$ \\
Spiro-OMeTAD & 1.05 & 21.51 & 74.24 & 16.77 & $15.65 \% \pm 0.71$ \\
\hline
\end{tabular}

When preparing the solution, we found the CZTPA-1 dissolution rate to be slower than the CZTPA-2 dissolution rate. What is more, the solubility of CZTPA-2 was found to be better than that of CZTPA-1 with an increasing alkyl chain length and CZTPA-2 deposits in perovskite with better crystallization. These results also demonstrate that CZTPA-2 achieves better performance.

To test the reproducibility of the devices, we fabricated 20 devices in several different batches. The devices are shown in Figure 4c,d. As shown in the PCE histogram of the corresponding device data, the average PCE of CZTPA-2 and CZTPA-1 is $10.15 \%$ and $5.27 \%$, respectively.

Moreover, the EQE spectrum of PSCs with CZTPA-2 is also shown in Figure 4b. The integral of the current densities calculated from the EQE spectra is $21.32 \mathrm{~mA} \mathrm{~cm}^{-2}$ for CZTPA-2 according predominantly to the experimental data.

To calculate the hole mobility of the two HTMs, we constructed a device with a configuration of ITO/PEDOT:PSS/HTM/Au using the space-charge-limited current (SCLC) method, and the $J-V$ characteristics of this device were studied in the dark. Hole mobility is calculated by the Mott-Gurney equation of $J=9 \varepsilon_{\mathrm{r}} \varepsilon_{0} \mu \mathrm{Va}^{2} / 8 \mathrm{~L}^{3}$, so we change the form of the formula to obtain $\mu=8 \mathrm{~d}^{3} / 9 \varepsilon_{\mathrm{r}} \varepsilon_{0}\left(J^{1 / 2} / \mathrm{Va}\right)^{2}$, where $\varepsilon_{\mathrm{r}}$ is the relative dielectric constant of the transport medium $\left(\varepsilon_{\mathrm{r}}=3\right.$ for organic materials), $\varepsilon_{0}$ is the permittivity of free space $\left(8.85 \times 10^{-12} \mathrm{C} \mathrm{V}^{-1} \mathrm{~m}^{-1}\right)$, $J$ is the dark current density $\left(\mathrm{mA} \mathrm{cm}^{-2}\right)$, and $\mathrm{d}$ is the thickness of the active layer [31]. $\mathrm{d}$ is $48 \mathrm{~nm}$ for CZTPA-1 and $56 \mathrm{~nm}$ for CZTPA-2. Figure 5 shows that the hole mobility of Spiro-OMeTAD (doped) is $1.01 \times 10^{-3} \mathrm{~cm}^{2} \mathrm{~V}^{-1} \mathrm{~s}^{-1}$. The hole mobility of CZTPA-1 is $4.68 \times 10^{-5} \mathrm{~cm}^{2} \mathrm{~V}^{-1} \mathrm{~s}^{-1}$, and CZTPA-2 has the higher hole mobility of $8.06 \times 10^{-5} \mathrm{~cm}^{2}$ $\mathrm{V}^{-1} \mathrm{~s}^{-1}$. However, they are all lower than the hole mobility of Spiro-OMeTAD (doped). Compared to CZTPA-1, CZTPA-2 has a higher hole mobility, which leads to good hole transport and enhances the charge transport in a planar PSC. CZTPA-2's higher hole mobility can be attributed to its high hole transport capability. These results suggest that both a fast charge transfer and high hole transport capability contribute to a high PCE.
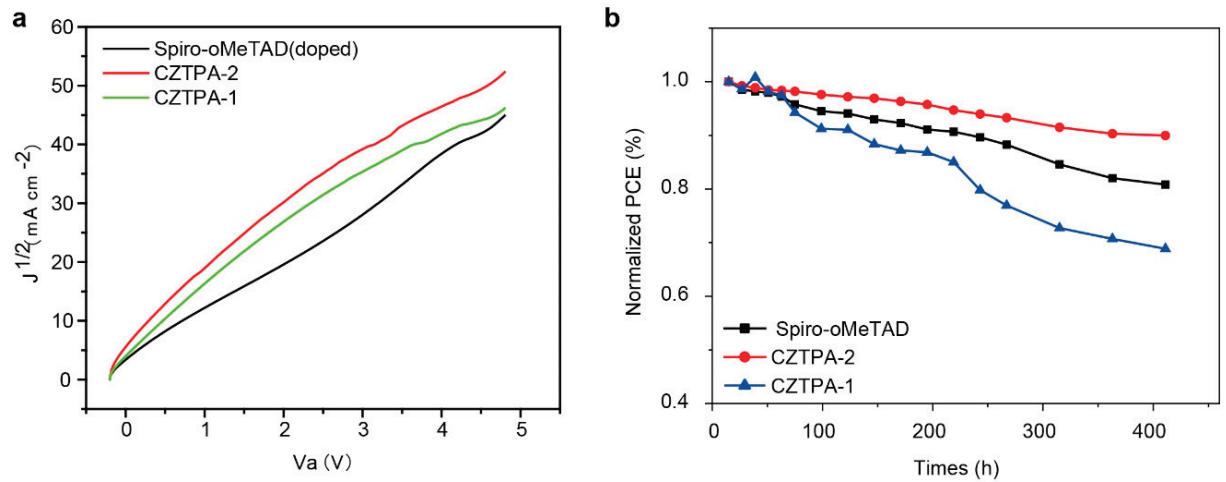

Figure 5. (a) Space-charge-limited current (SCLC) $J^{1 / 2}-V$ characteristics of CZTPA-1-, CZTPA-2-, and Spiro-OMeTAD-based hole-only devices measured in the dark. (b) Stability of CZTPA-1, CZTPA-2, and Spiro-oMeTAD (dopant-free) without encapsulation. 
We tested the stability of the three HTM devices without encapsulation by storing them in the dark under air conditions for at least $400 \mathrm{~h}$. The PCE over time curve was plotted and is shown in Figure 5b. The PCE of the CZTPA-2 device was still over 10\%. In comparison, the PCE of Spiro-OMeTAD (dopant-free) device dropped below 10\%. CZTPA-1 exhibited low performance, with $68.2 \%$ of the original PCE. CZTPA-2 and Spiro-OMeTAD (dopant-free) maintained $89.7 \%$ and $81.6 \%$ of their initial PCE, respectively. This test verified that the device based on CZTPA-2 has the best stability of the three HTMs. The long alkyl chain, which has good morphology, may influence the stability of a PSC device.

Finally, we also tested the capacitance of the three HTMs. The capacitance versus frequency was plotted and is shown in Figure 6. The capacitance is mainly caused by charge or ion accumulation at the perovskite interface, which leads to interfacial recombination. We can see the capacitance of the device based on CZTPA-2 is obviously smaller than that of CZTPA-1 and Spiro-oMeTAD (dopant-free), which confirms that the CZTPA-2 device has less interfacial recombination and a higher PCE.

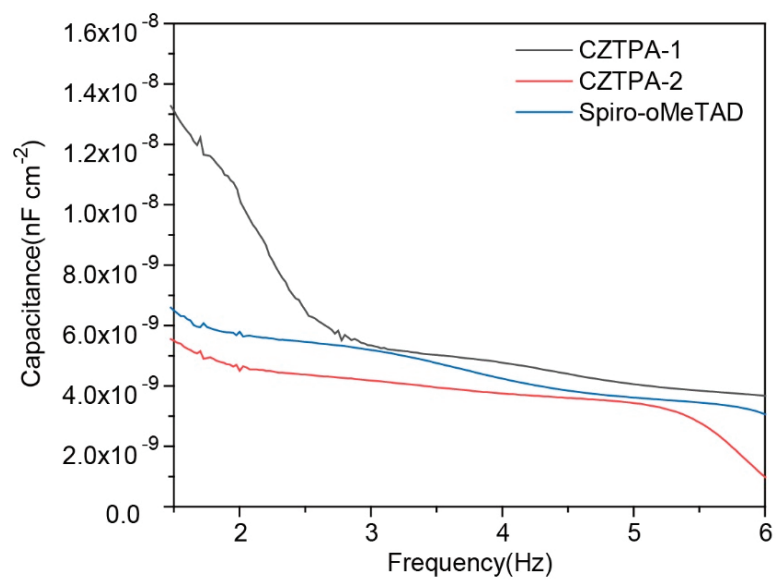

Figure 6. Capacitance versus frequency based on the devices of $\mathrm{ITO} / \mathrm{SnO}_{2} /$ perovskite/HTMs/Au.

\section{Conclusions}

Two new and low-cost hole transporting materials based on a carbazole core were designed and synthesized using a simple synthesis process. CZTPA-2 (dopant-free) achieved the best performance, with a PCE of $11.79 \%$, a $J_{\mathrm{sc}}$ of $21.80 \mathrm{~mA} / \mathrm{cm}^{2}$, a $V_{\mathrm{oc}}$ of $0.99 \mathrm{~V}$, and a FF of $54.59 \%$, which was slightly higher than that of Spiro-OMeTAD (dopant-free) and CZTPA-1 (dopant-free) and attributed to its higher hole transport mobility. The PL spectra, scanning electron microscopy images, and photoelectric properties indicate that CZTPA-2 with a longer alkyl chain has better optoelectrical properties. The CZTPA-2 (dopant-free) device also had the best stability, which remained at $89.7 \%$ of its original PCE after $400 \mathrm{~h}$ compared to CZTPA-1 and Spiro-OMeTAD (dopant-free). Besides this, its hole transport layer thickness is $35 \mathrm{~nm}$. Therefore, we think that CZTPA-2 can also be used to modify an interface when compared to traditional HTMs (above $100 \mathrm{~nm}$ ). The device based on CZTPA-2 exhibited good stability. We conclude that a longer alkyl chain may promote solubility and enhance the perovskite layer's crystallinity.

Supplementary Materials: The following are available online at http://www.mdpi.com/2079-4991/9/7/935/s1, Figure S1: ${ }^{1} \mathrm{H}$ NMR spectrum for compound 1. Figure S2: ${ }^{1} \mathrm{H}$ NMR spectrum for compound 2. Figure S3: ${ }^{1} \mathrm{H}$ NMR spectrum for CZTPA-1. Figure S4: ${ }^{1} \mathrm{H}$ NMR spectrum for CZTPA-2. Figure S5: ${ }^{13} \mathrm{C}$ NMR spectrum for CZTPA-1. Figure S6: ${ }^{13} \mathrm{C}$ NMR spectrum for CZTPA-2. Figure S7: AFM images ( $\left.4 \mu \mathrm{m} \times 5 \mu \mathrm{m}\right)$ of CZTPA-2 (a) and CZTPA-1 (b) films. 
Author Contributions: K.W. conceived the idea; K.W. designed the experiment; H.C. conducted device fabrication; X.G. and T.N. helped in device measurement; K.W. conducted device fabrication and data collection and wrote the manuscript; K.W. and S.W. revised the manuscript; Writing-review \& editing, H.W.; Supervision, H.W.

Funding: This work was supported by the Key Technologies R\&D Plan Projects of Guangdong Province (Nos. 2015B010127013, 2016B010124004, 2017B010112003), by the Science and Technologies Plan Projects of Guangzhou City (Nos.201604046021, 201905010001), and by the Science and Technology Development Special Fund Projects of Zhongshan City (Nos. 2017F2FC0002, 2017A1009).

Conflicts of Interest: The authors declare no conflicts of interest.

\section{References}

1. Kojima, A.; Teshima, K.; Shirai, Y.; Miyasaka, T. Organometal Halide Perovskites as Visible-Light Sensitizers for Photovoltaic Cells. J. Am. Chem. Soc. 2009, 131, 6050-6051. [CrossRef]

2. Michael, M.; Lee, J.L.T.T. Efficient Hybrid Solar Cells Based on Meso-Superstructured Organometal Halide Perovskites. Science 2012, 338, 643-647.

3. Kim, H.; Lee, C.; Im, J.; Lee, K.; Moehl, T.; Marchioro, A.; Moon, S.; Humphry-Baker, R.; Yum, J.; Moser, J.E.; et al. Lead Iodide Perovskite Sensitized All-Solid-State Submicron Thin Film Mesoscopic Solar Cell with Efficiency Exceeding 9\%. Sci. Rep. 2012, 2, 591. [CrossRef] [PubMed]

4. Laura Calil, S.K.M.G. Hole-Transport Materials for Perovskite Solar Cells. Angew. Chem. Int. Ed. 2016, 55, 14522-14545.

5. Bi, D.; Tress, W.; Dar, M.I.; Gao, P.; Luo, J.; Renevier, C.M.; Schenk, K.; Abate, A.; Giordano, F.; Correa Baena, J.; et al. Efficient luminescent solar cells based on tailored mixed-cation perovskites. Sci. Adv. 2016, 2, 1501170-1501176. [CrossRef] [PubMed]

6. NREL Best Research Cell Efficiency Chart. Available online: https://www.nrel.gov/pv/assets/pdfs/bestresearch-cell-efficiencies-190416.pdf (accessed on 27 June 2019).

7. Bach, U.; Lupo, D.; Comte, P.; Moser, J.E.; Weissortel, F.; Salbeck, J.; Spretzer, H.; Gratzel, M. Solid-state dye-sensitized mesoporous $\mathrm{TiO} 2$ solar cells with high photon-to-electron conversion efficiencies. Nature 1998, 395, 583-585. [CrossRef]

8. Jeon, N.J.; Lee, H.G.; Kim, Y.C.; Seo, J.; Noh, J.H.; Lee, J.; Seok, S.I. o-Methoxy Substituents in Spiro-OMeTAD for Efficient Inorganic-Organic Hybrid Perovskite Solar Cells. J. Am. Chem. Soc. 2014, 136, 7837-7840. [CrossRef]

9. Gatti, T.; Menna, E.; Meneghetti, M.; Maggini, M.; Petrozza, A.; Lamberti, F. The Renaissance of fullerenes with perovskite solar cells. Nano Energy 2017, 41, 84-100. [CrossRef]

10. Wang, R.; Mujahid, M.; Duan, Y.; Wang, Z.; Xue, J.; Yang, Y. A Review of Perovskites Solar Cell Stability. Adv. Funct. Mater. 2019, 1808843. [CrossRef]

11. Castro, E.; Murillo, J.; Fernandez-Delgado, O.; Echegoyen, L. Progress in fullerene-based hybrid perovskite solar cells. J. Mater. Chem. C 2018, 6, 2635-2651. [CrossRef]

12. Christians, J.A.; Fung, R.C.M.; Kamat, P.V. An Inorganic Hole Conductor for Organo-Lead Halide Perovskite Solar Cells. Improved Hole Conductivity with Copper Iodide. J. Am. Chem. Soc. 2014, 136, 758-764. [CrossRef] [PubMed]

13. Kim, J.H.; Liang, P.; Williams, S.T.; Cho, N.; Chueh, C.; Glaz, M.S.; Ginger, D.S.; Jen, A.K.Y. High-Performance and Environmentally Stable Planar Heterojunction Perovskite Solar Cells Based on a Solution-Processed Copper-Doped Nickel Oxide Hole-Transporting Layer. Adv. Mater. 2015, 27, 695-701. [CrossRef] [PubMed]

14. Qin, P.; Tanaka, S.; Ito, S.; Tetreault, N.; Manabe, K.; Nishino, H.; Nazeeruddin, M.K.; Gr tzel, M. Inorganic hole conductor-based lead halide perovskite solar cells with $12.4 \%$ conversion efficiency. Nat. Commun. 2014, 5, 3834. [CrossRef] [PubMed]

15. Heo, J.H.; Im, S.H.; Noh, J.H.; Mandal, T.N.; Lim, C.; Chang, J.A.; Lee, Y.H.; Kim, H.; Sarkar, A.; Nazeeruddin, M.K.; et al. Efficient inorganic-organic hybrid heterojunction solar cells containing perovskite compound and polymeric hole conductors. Nat. Photonics 2013, 7, 486-491. [CrossRef]

16. Huang, X.; Zhao, Z.; Cao, L.; Chen, Y.; Zhu, E.; Lin, Z.; Li, M.; Yan, A.; Zettl, A.; Wang, Y.M.; et al. High-performance transition metal-doped Pt3Ni octahedra for oxygen reduction reaction. Science 2015, 348, 1230-1234. [CrossRef] 
17. Edri, E.; Kirmayer, S.; Cahen, D.; Hodes, G. High Open-Circuit Voltage Solar Cells Based on Organic?-CInorganic Lead Bromide Perovskite. J. Phys. Chem. Lett. 2013, 4, 897-902. [CrossRef] [PubMed]

18. Cabau, L.; Garcia-Benito, I.; Molina-Ontoria, A.; Montcada, N.F.; Martin, N.; Vidal-Ferran, A.; Palomares, E. Diarylamino-substituted tetraarylethene (TAE) as an efficient and robust hole transport material for $11 \%$ methyl ammonium lead iodide perovskite solar cells. Chem. Commun. 2015, 51, 13980-13982. [CrossRef]

19. Li, H.; Fu, K.; Hagfeldt, A.; Gr tzel, M.; Mhaisalkar, S.G.; Grimsdale, A.C. A Simple 3,4-Ethylenedioxythiophene Based Hole-Transporting Material for Perovskite Solar Cells. Angew. Chem. Int. Ed. 2014, 53, 4085-4088. [CrossRef]

20. Li, H.; Fu, K.; Boix, P.P.; Wong, L.H.; Hagfeldt, A.; Gr tzel, M.; Mhaisalkar, S.G.; Grimsdale, A.C. Hole-Transporting Small Molecules Based on Thiophene Cores for High Efficiency Perovskite Solar Cells. ChemSusChem 2014, 7, 3420-3425. [CrossRef]

21. Park, S.H.; Roy, A.; Beaupr, S.; Cho, S.; Coates, N.; Moon, J.S.; Moses, D.; Leclerc, M.; Lee, K.; Heeger, A.J. Bulk heterojunction solar cells with internal quantum efficiency approaching 100\%. Nat. Photonics 2009, 3, 297-302. [CrossRef]

22. Qin, R.; Li, W.; Li, C.; Du, C.; Veit, C.; Schleiermacher, H.; Andersson, M.; Bo, Z.; Liu, Z.; Ingana s, O.; et al. A Planar Copolymer for High Efficiency Polymer Solar Cells. J. Am. Chem. Soc. 2009, 131, 14612-14613. [CrossRef] [PubMed]

23. Blouin, N.; Leclerc, M. Poly(2,7-carbazole)s: Structure-Property Relationships. Acc. Chem. Res. 2008, 41, 1110-1119. [CrossRef] [PubMed]

24. Blouin, N.; Michaud, A.; Leclerc, M. A Low-Bandgap Poly(2,7-Carbazole) Derivative for Use in High-Performance Solar Cells. Adv. Mater. 2007, 19, 2295-2300. [CrossRef]

25. Zhu, X.D.; Ma, X.J.; Wang, Y.K.; Li, Y.; Gao, C.H.; Wang, Z.K.; Jiang, Z.Q.; Liao, L.S. Hole-Transporting Materials Incorporating Carbazole into Spiro-Core for Highly Efficient Perovskite Solar Cells. Adv. Funct. Mater. 2018, 29, 1807094. [CrossRef]

26. Chen, Z.; Li, H.; Zheng, X.; Zhang, Q.; Li, Z.; Hao, Y.; Fang, G. Low-Cost Carbazole-Based Hole-Transport Material for Highly Efficient Perovskite Solar Cells. ChemSusChem 2017, 10, 3111-3117. [CrossRef] [PubMed]

27. Xu, B.; Sheibani, E.; Liu, P.; Zhang, J.; Tian, H.; Vlachopoulos, N.; Boschloo, G.; Kloo, L.; Hagfeldt, A.; Sun, L. Carbazole-Based Hole-Transport Materials for Efficient Solid-State Dye-Sensitized Solar Cells and Perovskite Solar Cells. Adv. Mater. 2014, 26, 6629-6634. [CrossRef] [PubMed]

28. Abate, A.; Paek, S.; Giordano, F.; Correa-Baena, J.P.; Saliba, M.; Gao, P.; Matsui, T.; Ko, J.; Zakeeruddin, S.M.; Dahmen, K.H.; et al. Silolothiophene-linked triphenylamines as stable hole transporting materials for high efficiency perovskite solar cells. Energy Environ. Sci. 2015, 8, 2946-2953. [CrossRef]

29. Yin, X.; Guan, L.; Yu, J.; Zhao, D.; Wang, C.; Shrestha, N.; Han, Y.; An, Q.; Zhou, J.; Zhou, B.; et al. One-step facile synthesis of a simple carbazole-cored hole transport material for high-performance perovskite solar cells. Nano Energy 2017, 40, 163-169. [CrossRef]

30. Zimmermann, I.; Urieta-Mora, J.; Gratia, P.; Arag, J.; Grancini, G.; Molina-Ontoria, A.N.; Ort, E.; Mart n, N.; Nazeeruddin, M.K. High-Efficiency Perovskite Solar Cells Using Molecularly Engineered, Thiophene-Rich, Hole-Transporting Materials: Influence of Alkyl Chain Length on Power Conversion Efficiency. Adv. Funct. Mater. 2017, 7, 1601674. [CrossRef]

31. Wang, Y.; Su, T.; Tsai, H.; Wei, T.; Chi, Y. Spiro-Phenylpyrazole/Fluorene as Hole-Transporting Material for Perovskite Solar Cells. Sci. Rep. 2017, 7, 7859-7867. [CrossRef] 
Article

\title{
Solution-Processed PEDOT:PSS/MoS 2 Nanocomposites as Efficient Hole-Transporting Layers for Organic Solar Cells
}

\author{
Madeshwaran Sekkarapatti Ramasamy, Ka Yeon Ryu, Ju Won Lim, Asia Bibi, Hannah Kwon, \\ Ji-Eun Lee, Dong Ha Kim * and Kyungkon Kim * \\ Deprtment of Chemistry and Nanoscience, Ewha Womans University, 52 Ewhayeodae-gil, Seodaemun-gu, \\ Seoul 03760, Korea \\ * Correspondence: dhkim@ewha.ac.kr (D.H.K.); kimkk@ewha.ac.kr (K.K.)
}

Received: 6 July 2019; Accepted: 11 September 2019; Published: 16 September 2019

\begin{abstract}
An efficient hole-transporting layer (HTL) based on functionalized two-dimensional (2D) $\mathrm{MoS}_{2}$-poly(3,4-ethylenedioxythiophene):poly(styrenesulfonate) (PEDOT:PSS) composites has been developed for use in organic solar cells (OSCs). Few-layer, oleylamine-functionalized $\mathrm{MoS}_{2}\left(\mathrm{FMoS}_{2}\right)$ nanosheets were prepared via a simple and cost-effective solution-phase exfoliation method; then, they were blended into PEDOT:PSS, a conducting conjugated polymer, and the resulting hybrid film (PEDOT:PSS/FMoS 2 ) was tested as an HTL for poly(3-hexylthiophene):[6,6]-phenyl-C 61 -butyric acid methyl ester (P3HT:PCBM) OSCs. The devices using this hybrid film HTL showed power conversion efficiencies up to $3.74 \%$, which is $15.08 \%$ higher than that of the reference ones having PEDOT:PSS as HTL. Atomic force microscopy and contact angle measurements confirmed the compatibility of the PEDOT:PSS/FMoS 2 surface for active layer deposition on it. The electrical impedance spectroscopy analysis revealed that their use minimized the charge-transfer resistance of the OSCs, consequently improving their performance compared with the reference cells. Thus, the proposed fabrication of such HTLs incorporating 2D nanomaterials could be further expanded as a universal protocol for various high-performance optoelectronic devices.
\end{abstract}

Keywords: organic solar cells; $\mathrm{MoS}_{2}$; hole-transporting layer; oleylamine

\section{Introduction}

Organic solar cells (OSCs) have many striking properties such as flexibility, solution processability, light weight, and simple manufacturing, especially if compared with their inorganic counterparts. To enhance their performance, numerous strategies have been proposed, including novel photoactive materials, morphology control, interfacial engineering, plasmonic nanoparticles incorporation, and alternative buffer layers and electrodes [1-6]. Their power conversion efficiency (PCE) has been recently improved up to $>13 \%$ with rapid advances in new photovoltaic materials [7]. In the typical bulk heterojunction (BHJ) OSCs configuration, a photoactive blend layer consisting of acceptor/donor pairs is sandwiched between a bottom transparent anode and a top low-work-function cathode, combined with the corresponding interlayers. Such interlayers are crucial for determining the overall PCE and stability of OSCs because they reduce the potential energy barrier between photoactive layer and electrodes, enhancing the extraction of holes and electrons at the anode and cathode, respectively.

Until now, many hole-transporting layer (HTL) materials, such as conducting conjugated polymers [8-10], conjugated polyelectrolytes [11,12] metal oxides/sulfides [13-17], and graphene oxide and its hybrid films [18-21], have been explored for use in OSCs. Among them, the conjugated polymer poly(3,4 ethylenedioxythiophene):poly(styrenesulfonate) (PEDOT:PSS) has been the most widely used due to its adequate work function for creating a good ohmic contact between active 
layer and anode, solution processability, and high conductivity. However, its hygroscopic and acidic nature often induces chemical instability between active layers and indium tin oxide (ITO) anodes, affecting the device stability and efficiency [22,23]. Moreover, there is a clear surface energy mismatch between PEDOT:PSS (hydrophilic nature) and the active layer (hydrophobic and made of, e.g., poly(3-hexylthiophene) (P3HT)) [24,25]. To overcome such drawbacks, various PEDOT:PSS modification strategies, such as incorporating metal nanoparticles [26-28], modification by metal salts [29,30], polymer doping [31,32], and hybridization with graphene [33,34], have been developed. Interfacial engineering with long alkyl chains is an alternative but attractive method to reduce the surface energy mismatch between HTL and active layer and also to accomplish desirable molecular orientation in the active layer for enhancing the charge transport in OSCs [35].

Single and few-layer molybdenum disulfide, a two-dimensional (2D) transition metal dichalcogenide (TMDC), has recently received much interest in electronics and optoelectronics research due to its excellent optical (bandgap: $1.8 \mathrm{eV}$ ), electrical (device mobility: $10-130 \mathrm{~cm}^{2} \mathrm{~V}^{-1} \mathrm{~S}^{-1}$ ), and mechanical (Young modulus: $270 \mathrm{GPa}$ ) properties [36,37]. Among the key preparation/exfoliation methods for TMDCs, namely, micromechanical cleavage [38], chemical vapor deposition [39], and liquid-phase exfoliation (LPE) [40], the latter is more attractive because it is scalable and cost-effective. $\mathrm{MoS}_{2}$ has been tested as HTL for OSCs [41-43] to exploit its extraordinary optical and electrical properties in photovoltaics; nevertheless, the results have revealed that neat $\mathrm{MoS}_{2}$ is not sufficient to replace PEDOT:PSS as OSC HTL, possibly because of its work function mismatch and unexpected phase transition. Hence, Xing et al. fabricated PEDOT:PSS/WS ${ }_{2}$ hybrid films and demonstrated their applicability as effective OSC HTLs [44]. However, the long-time (48 h) sonication they adopted for TMDC exfoliation in the PEDOT:PSS aqueous dispersion may affect the structure of both PEDOT:PSS and $\mathrm{MoS}_{2}$ in the final product; therefore, innovative strategies for effectively integrating these materials in OSCs are still highly demanded.

Here, we report the fabrication of oleylamine-functionalized $\mathrm{MoS}_{2}\left(\mathrm{FMoS}_{2}\right)$ combined with PEDOT:PSS as an effective hybrid HTL (PEDOT:PSS/FMoS 2 ) for use in conventional P3HT:[6,6]-phenyl- $\mathrm{C}_{61}$-butyric acid methyl ester (PCBM)-based OSCs. The so-obtained OSCs exhibited better PCE and short-circuit current density $\left(\mathrm{J}_{\mathrm{sc}}\right)$ values compared with the reference cell having simple PEDOT:PSS as HTL. FMoS 2 was characterized by various spectroscopic techniques including Raman spectroscopy, ultraviolet-visible (UV-Vis) absorption and transmittance, photoluminescence (PL), and transmission electron microscopy (TEM); the active layer microstructure and the surface properties of the hybrid HTL were analyzed by grazing-incidence wide-angle X-ray scattering (GIWAXS), atomic force microscopy (AFM), and contact angle measurements. Electrochemical impedance spectroscopy (EIS) measurements were carried out using an electrochemical analyzer (IVIUMSTAT.XR, IVIUM Technologies) under illumination at $0.1 \mathrm{~V}$.

\section{Experimental}

\subsection{Materials and Methods}

The following chemicals were used in our experiment: molybdenum (IV) sulfide ( $<2 \mu \mathrm{m}, 99 \%)$ and oleylamine (Sigma-Aldrich, Gyeonggi-do, Korea), P3HT (1-Material, Gyeonggi-do, Korea), PEDOT:PSS (Heraeus Deutschland GmbH \& Co., Leverkusen, Germany), isopropyl alcohol (IPA) (Dae-Jung Chemicals \& Metals Co., Ltd., Gyeonggi-do, Korea), and methanol (Samchun Chemicals, Seoul, Korea).

\subsection{Synthesis of FMoS 2 Nanosheets and PEDOT:PSS/FMoS 2 Hybrids}

$\mathrm{FMoS}_{2}$ nanosheets were synthesized according to the liquid-phase exfoliation method reported in literature [45], with small modifications. Briefly, bulk $\mathrm{MoS}_{2}$ powder $(200 \mathrm{mg})$ was bath-sonicated in oleylamine $(2 \mathrm{~mL})$ by using a Branson ultrasonic bath for $20 \mathrm{~min}$ and successively stirred at $60^{\circ} \mathrm{C}$ for $12 \mathrm{~h}$ in an $\mathrm{N}_{2}$-filled glove box. Then, 1,2-dichlorobenzene (DCB) $(18 \mathrm{~mL})$ was added, and the dispersion was further bath-sonicated for $5 \mathrm{~h}$. The resulting suspension was centrifuged at $4000 \mathrm{rpm}$, 
and the top $80 \%$ dark-green color supernatant, which contains excess oleylamine, DCB, and FMOS 2 was collected. Then, the $\mathrm{FMoS}_{2}$ nanosheets were separated by adding excess acetone, followed by sonication for $2 \mathrm{~min}$ and high-speed centrifugation (10000 rpm). The separated $\mathrm{FMoS}_{2}$ nanosheets were settled at the bottom of the centrifuge tube, which was re-dispersed in a small amount of IPA by mild sonication, and different concentrations $(5,20$, and $50 \mu \mathrm{L})$ of the resulting dispersion were added into PEDOT:PSS:methanol (1:1 V\%) aqueous solutions, which were successively ultrasonicated for 30 min to obtain PEDOT:PSS/FMoS 2 hybrid solutions.

\subsection{Fabrication of OSCS}

The OSCs having device architectures of ITO/PEDOT:PSS/P3HT:PCBM/LiF/Al and ITO/(PEDOT:PSS/FMoS 2 )/P3HT:PCBM/LiF/Al were fabricated as follows. ITO-coated glass substrates were cleaned via sequential ultrasonication in acetone, IPA, and distilled water, followed by oxygen plasma treatment for $10 \mathrm{~min}$; then, they were spin-coated with a PEDOT:PSS (Clevios P VP Al 4083) or PEDOT:PSS/FMoS 2 solution at $4000 \mathrm{rpm}$ for $40 \mathrm{~s}$ and dried at $130{ }^{\circ} \mathrm{C}$ for $30 \mathrm{~min}$ to complete the HTL deposition. Next, an active layer consisting of a P3HT:PCBM (1:0.6 wt\%) binary blend solution was spin-coated on the resulting HTL layer at $2500 \mathrm{rpm}$ for $40 \mathrm{~s}$ inside an $\mathrm{N}_{2}$-filled glove box and annealed at $150{ }^{\circ} \mathrm{C}$. Finally, $\mathrm{LiF}$ and $\mathrm{Al}$ layers were deposited by thermal evaporation. The active area of the fabricated OSCs was $0.06 \mathrm{~cm}^{2}$.

\subsection{Characterization}

The absorption properties of the samples were analyzed using a UV-Vis absorption spectrometer (Cary 5000, Varian, Inc.). Raman spectra were recorded on a Horiba Jobin-Yvon spectrometer. The emission properties were investigated with a luminescence spectrometer (LS55 Perkin Elmer). The TEM measurements were carried out on a JEOL JSM-2100-F system. The surface morphologies were investigated using a tapping-mode atomic force microscope (Veeco D3100). The water contact angles of the samples were measured with a KSV CAM 101 instrument. The GIWAXS analysis was conducted at the PLS-II 9A U-SAXs beamline of the Pohang Accelerator Laboratory (Korea) at the following operating conditions: incidence angle of $\sim 0.12^{\circ}$, wavelength of $1.12 \AA$, and sample-to-detector distance of $224 \mathrm{~nm}$. The GIWAXS patterns were recorded using a 2D charge-coupled device camera (Rayonix, SX-165, USA) with an exposure time of 10-30 s. The JV properties of the solar cells were measured with a Keithley 2400 solar cell IV measurement system under AM 1.5 G illumination at $100 \mathrm{~mW} \mathrm{~cm}^{-2}$.

\section{Results and Discussion}

OSCs having two different device architectures, ITO/(PEDOT:PSS/FMoS 2 )/P3HT:PCBM/LiF/Al and ITO/PEDOT:PSS/P3HT:PCBM/LiF/Al (for comparison), were fabricated as schematized in Figure 1.

First, we synthesized $\mathrm{FMoS}_{2}$ nanosheets via the solution-phase ultrasonic exfoliation of bulk $\mathrm{MoS}_{2}$ in the presence of oleylamine and 1,2-dichlorobenzene as a solvent; then, they were incorporated in different concentrations $(5,20$, and $50 \mu \mathrm{L}$ ) into PEDOT:PSS, and the resulting PEDOT:PSS/FMoS 2 (denoted as PEDOT:PSS/FMoS 2 (5), PEDOT:PSS/FMoS 2 (20), and PEDOT:PSS/FMoS 2 (50) according to the $\mathrm{FMoS}_{2}$ loading) was used as HTL for conventional OSCs.

Raman spectroscopy is a powerful nondestructive technique for monitoring structural changes in 2D materials [46]. The Raman spectrum of bulk $\mathrm{MoS}_{2}$ showed two characteristic peaks at 374.83 and $402.05 \mathrm{~cm}^{-1}$ corresponding, respectively, to the $\mathrm{E}_{2 \mathrm{~g}}{ }_{\mathrm{g}}$ and $\mathrm{A}_{1 \mathrm{~g}}$ vibrational modes (Figure $2 \mathrm{a}$ ); the first arose from the in-plane vibration of Mo and $S$ atoms, while the second resulted from the out-of-plane vibrations of sulfur $[47,48]$. As regards $\mathrm{FMoS}_{2}$, the peaks for both the $\mathrm{E}_{2 \mathrm{~g}}^{1}$ and $\mathrm{A}_{1 \mathrm{~g}}$ vibrational modes were blue-shifted toward higher wavenumbers (respectively, 382.66 and $405.66 \mathrm{~cm}^{-1}$ ), suggesting interactions between oleylamine and $\mathrm{MoS}_{2}$. Moreover, the wavenumber difference between these two vibrational modes is closely related to the layer number present in the $\mathrm{MoS}_{2}$ nanosheets [49], and in 
our case, this difference decreased from $27.2 \mathrm{~cm}^{-1}$ for bulk $\mathrm{MoS}_{2}$ to $23 \mathrm{~cm}^{-1}$ for $\mathrm{FMoS}_{2}$ nanosheets, demonstrating the successful exfoliation of $\mathrm{MoS}_{2}$ nanosheets during the oleylamine treatment.

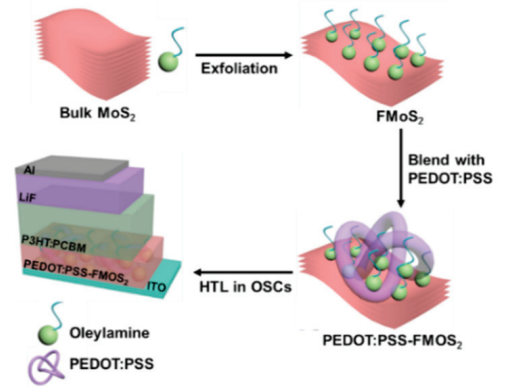

Figure 1. Fabrication process for poly(3,4-ethylenedioxythiophene):poly(styrenesulfonate) (PEDOT:PSS)/oleylamine-functionalized $\mathrm{MoS}_{2}\left(\mathrm{FMoS}_{2}\right)$ hybrid hole-transporting layer (HTL) for organic solar cells.

The absorption properties of the $\mathrm{FMoS}_{2}$ nanosheets were further investigated via UV-Vis absorption spectroscopy; their spectrum (Figure 2b) clearly showed two characteristic absorption peaks of $\mathrm{MoS}_{2}$ at 618 and $677 \mathrm{~cm}^{-1}$ corresponding, respectively, to the A1 and B1 direct excitonic transitions with the energy split from valence band spin-orbital coupling [50]. Furthermore, unlike bulk $\mathrm{MoS}_{2}, \mathrm{FMoS}_{2}$ yielded dark-greenish dispersion in 1,2-dichlorobenzene. These results clearly indicate some alteration in the surface properties of $\mathrm{MoS}_{2}$ due to the oleylamine treatment [51].

Bulk $\mathrm{MoS}_{2}$ is an indirect bandgap semiconductor that does not exhibit any photoluminescence; however, upon exfoliation, its luminescence increases with decreasing its layer thickness, so that single-layer $\mathrm{MoS}_{2}$ shows the highest photoluminescence due to its transition into a direct bandgap semiconductor [52,53]. As expected, $\mathrm{FMoS}_{2}$ exhibited significant photoluminescence (see the PL spectra in Figure S1, Electronic Supporting Information (ESI)), which clearly proves the successful layer thinning of $\mathrm{MoS}_{2}$ during the functionalization process.
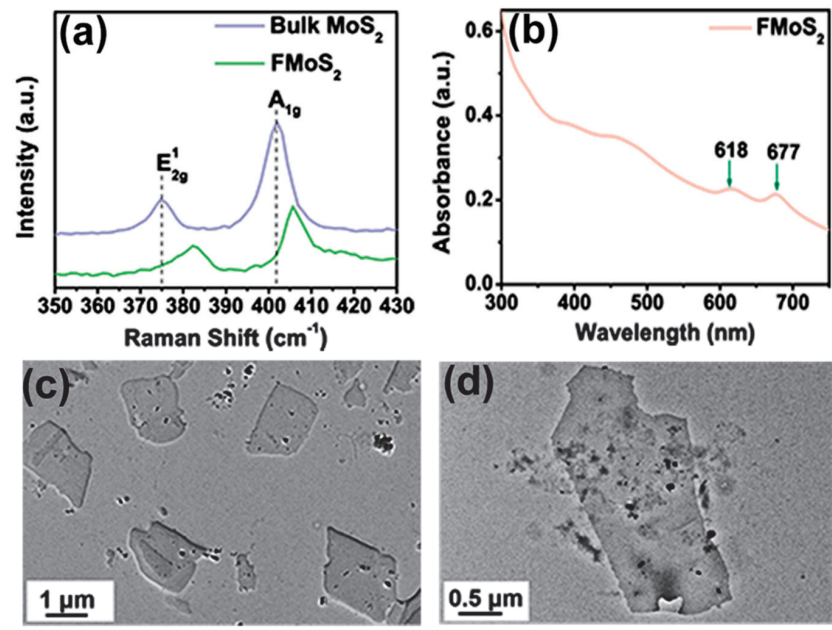

Figure 2. (a) Raman spectra of bulk and oleylamine-functionalized $\mathrm{MoS}_{2}\left(\mathrm{FMoS}_{2}\right)$. (b) Ultravioletvisible light absorption spectrum of $\mathrm{FMoS}_{2}$. (c,d) Transmission electron microscopy images of $\mathrm{FMoS}_{2}$ nanosheets. 
The TEM images of the FMoS 2 nanosheets are displayed in Figure 2c,d, showing a thin nanosheet morphology with sizes of several hundred nanometers. A careful observation of the nanosheet edges reveals the presence of few-layer nanosheets, confirming the effectiveness of the liquid-based exfoliation with oleylamine. AFM measurements were carried out (Figure S2, ESI) to further evaluate the layer thickness; that of $\mathrm{FMoS}_{2}$ was $\sim 6.7 \mathrm{~nm}$, suggesting the existence of few-layer nanosheets, while the reported thickness of monolayer $\mathrm{MoS}_{2}$ ranges between 0.9 and $1.2 \mathrm{~nm}$ [54].

To improve the performance of conventional PEDOT:PSS-based HTL for OSCs, we incorporated it with $\mathrm{FMoS}_{2}$ via a simple solution-blending method because we believed that the introduction of 2D sheet-like $\mathrm{MoS}_{2}$ functionalized with a long-chain primary alkyl amine (oleylamine) would have made the PEDOT:PSS surface more hydrophobic, facilitating the following deposition of the hydrophobic active layer. In addition, the amine group of oleylamine tends to be located near Mo atoms in $\mathrm{MoS}_{2}$ due to metal-amine interactions, while its long alkyl chain with $-\mathrm{CH}_{3}$ groups is oriented toward the active layer, and this kind of configuration should enforce the active layer with a desirable molecular orientation for efficient charge transport in OSCs; P3HT thin films deposited on insulator substrates modified with $-\mathrm{CH}_{3}$ groups formed face-on orientation because of $\pi-\mathrm{H}$ interactions $[55,56]$.

The contact angles of ITO with PEDOT:PSS and PEDOT:PSS/FMoS 2 containing 5, 20, and $50 \mu \mathrm{L}$ of $\mathrm{FMoS}_{2}$ were $30^{\circ}, 47^{\circ}, 54^{\circ}$, and $56^{\circ}$, respectively (Figure S3, ESI), which indicates that the hydrophobicity of PEDOT:PSS was slightly increased by the $\mathrm{FMoS}_{2}$ addition and, hence, the hydrophobic active layer solution was more compatible on hybrid HTL than that of the hydrophilic PEDOT:PSS one.

The surface morphology of the various samples was compared via tapping-mode AFM analysis (Figure S4, ESI); the root-mean-square (rms) roughness value of PEDOT:PSS was $1 \mathrm{~nm}$ and decreased down to $0.69 \mathrm{~nm}$ for PEDOT:PSS/FMoS 2 (5), suggesting a smooth surface morphology in the hybrid HTL. However, PEDOT:PSS/FMoS 2 (50) exhibited an rms roughness value of $0.97 \mathrm{~nm}$, indicating that the addition of higher $\mathrm{FMoS}_{2}$ concentrations would decrease the film smoothness.

All the synthesized PEDOT:PSS and PEDOT:PSS/FMoS ${ }_{2}$ hybrid films exhibited similar UV-Vis transmittance values (Figure S5a, ESI), showing that the $\mathrm{FMoS}_{2}$ addition did not affect any absorption property of the PEDOT:PSS matrix. As regards the P3HT:PCBM (active layer) films spin-coated on glass substrates predeposited with PEDOT:PSS or PEDOT:PSS/FMoS 2 HTLs (Figure S5b), for all the samples, their absorbance ranged from 400 to $650 \mathrm{~nm}$, with a maximum at $512 \mathrm{~nm}$, and two shoulders around 550 and $600 \mathrm{~nm}$. The existence of vibronic feature at $600 \mathrm{~nm}$ suggests that the P3HT film existed in a high degree of ordered crystalline lamella due to strong interchain interactions [57].

The current-voltage (JV) characteristics of the fabricated P3HT:PCBM OSCs having PEDOT:PSS/FMoS 2 as HTL are shown in Figure 3a. Their performance is compared with that of reference devices having PEDOT:PSS as HTL in Table 1. The reference cells showed PCE $=3.25 \%$, $\mathrm{J}_{\mathrm{sc}}=7.92 \mathrm{~mA} \mathrm{~cm}^{-2}, \mathrm{~V}_{\mathrm{OC}}=0.671 \mathrm{~V}$, and FF $=0.61$. The FMoS 2 incorporation led to significant PCE and $\mathrm{J}_{\mathrm{SC}}$ improvements; in particular, the device based on PEDOT:PSS/FMoS 2 (5) exhibited the highest PCE, $\mathrm{J}_{\mathrm{sc}}$, and FF.

The external quantum efficiency (EQE) measurements (Figure 3b) showed improved EQE for the hybrid HTL-based OSCs compared with the reference cells and confirmed also their increased $\mathrm{J}_{\mathrm{sc}}$, demonstrating the enhanced charge extraction at the HTL/active layer interface and the charge collection at the electrodes [58,59]. The photovoltaic parameters such as PCE, $\mathrm{J}_{\mathrm{sc}}, \mathrm{FF}$ and $\mathrm{V}_{\mathrm{oc}}$ as a function of $\mathrm{FMoS}_{2}$ in PEDOT:PSS HTLs are plotted in Figure $3 \mathrm{c}$, d, e and $\mathrm{f}$ respectively. 

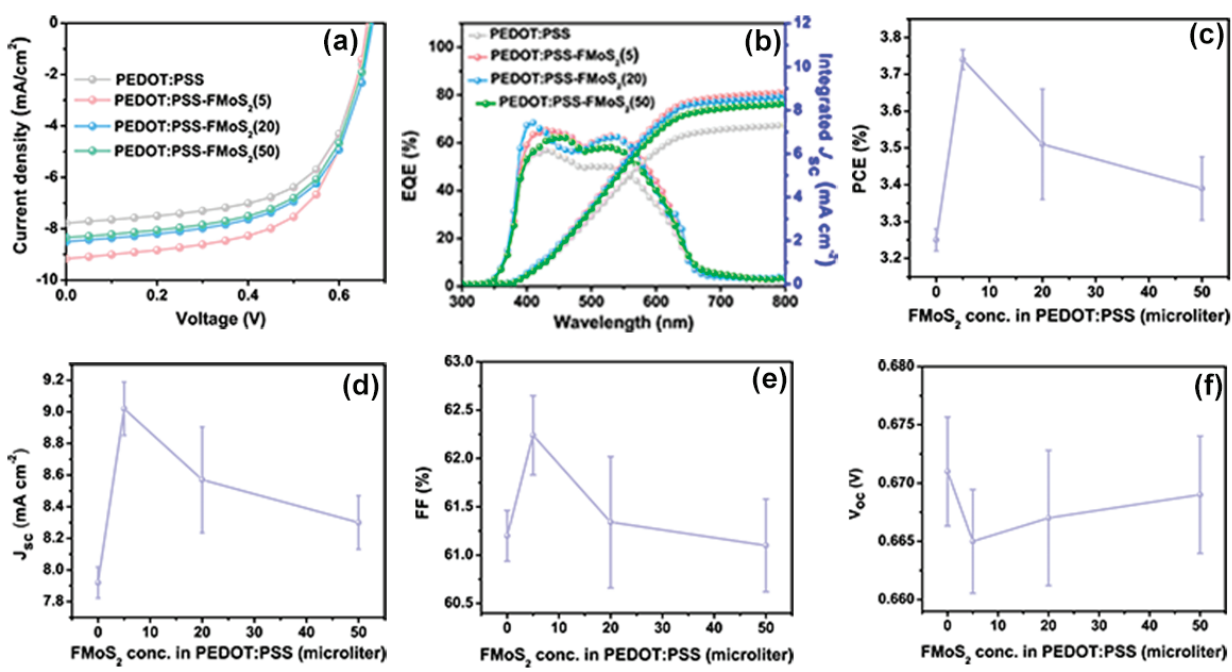

Figure 3. (a) Current density-voltage curves, (b) external quantum efficiency (EQE) profiles, (c) power conversion efficiencies (PCE), (d) short-circuit current density $\left(\mathrm{J}_{\mathrm{sc}}\right)$, (e) fill factor, and (f) open-circuit voltage $\left(\mathrm{V}_{\mathrm{oc}}\right)$ values of organic solar cells based on poly(3,4-ethylenedioxythiophene):poly(styrenesulfonate) (PEDOT:PSS) and PEDOT:PSS/oleylamine-functionalized $\mathrm{MoS}_{2}\left(\mathrm{FMoS}_{2}\right)$ as hole-transporting layers. The reported average PCE values are extracted from nine identical cells for each sample.

Table 1. Photovoltaic performance of poly(3-hexylthiophene):[6,6]-phenyl-C61-butyric acid methyl ester-based organic solar cells having poly(3,4-ethylenedioxythiophene):poly(styrenesulfonate) (PEDOT:PSSS) and PEDOT:PSS/oleylamine-functionalized $\mathrm{MoS}_{2}\left(\mathrm{FMoS}_{2}\right)$ as hole-transportation layers.

\begin{tabular}{ccccc}
\hline $\begin{array}{c}\text { FMoS }_{2} \text { Concentration }(\mu \mathrm{L}) \text { in } \\
\text { PEDOT:PSS }\end{array}$ & PCE (\%) & $\mathbf{V}_{\mathbf{~ o c}}(\mathbf{V})$ & $\mathbf{J}_{\mathbf{s c}}\left(\mathbf{m A ~ c m} \mathbf{~ c}^{-2}\right)$ & FF (\%) \\
\hline 0 (Reference) & $3.25 \pm 0.03$ & $0.671 \pm 0.004$ & $7.92 \pm 0.09$ & $61.2 \pm 0.26$ \\
5 & $3.74 \pm 0.02$ & $0.665 \pm 0.004$ & $9.02 \pm 0.17$ & $62.24 \pm 0.41$ \\
20 & $3.51 \pm 0.15$ & $0.667 \pm 0.006$ & $8.57 \pm 0.33$ & $61.34 \pm 0.68$ \\
50 & $3.39 \pm 0.08$ & $0.669 \pm 0.005$ & $8.30 \pm 0.17$ & $61.10 \pm 0.48$ \\
\hline
\end{tabular}

To understand the charge transport, we analyzed the microstructure (chain-orientation and crystallinity) of the active layer (P3HT:PCBM) on both the PEDOT:PSS and PEDOT:PSS/FMoS 2 samples by GIWAXS (Figures 4 and 5). Charge transport in conjugated polymers occurs either in the $\pi-\pi$ staking direction or the chain backbone one, which is the fastest but its vertical alignment of chains backbones along the $\mathrm{z}$ direction is rarely observed [60,61]. In general, P3HT crystallizes into two main configurations, namely, edge-on and face-on orientations; in the former, both chain backbone and $\pi-\pi$ staking directions lie parallel to the substrate; in the latter, $\pi-\pi$ staking occurs perpendicular to the substrate, which is a desirable orientation in OSCs for vertical charge transport [62]. Figure 4 shows the GIWAXS diffraction patterns of P3HT:PCBM thin films deposited on PEDOT:PSS and PEDOT:PSS/FMoS 2 HTLs. In both cases, the thin films exhibited strong (100), (200), and (300) diffractions along the $\mathrm{z}$ axis, confirming the existence of the strong edge-on lamellae configuration of P3HT [63]. In addition, the absence of $\pi-\pi$ staking peak (010), corresponding to the face-on orientation near the $\mathrm{z}$ axis, indicates that P3HT preferentially adopted the edge-on configuration in both PEDOT:PSS and PEDOT:PSS/FMoS 2 HTLs. Since the use of $-\mathrm{CH}_{3}$ group-functionalized substrates tends to promote the face-on orientation of P3HT $[55,56]$, we aimed to improve such configuration of the active layer by incorporating the described oleylamine (having $-\mathrm{CH}_{3}$ groups)-functionalized 
$\mathrm{MoS}_{2}$ into PEDOT:PSS, but we did not observe any significant difference in its molecular orientation, maybe because the low $\mathrm{FMoS}_{2}$ concentrations used were not sufficient for such change. Thus, we can conclude that the PCE and $\mathrm{J}_{\mathrm{sc}}$ enhancement in the OCSs having PEDOT:PSS/FMoS 2 as HTL may be due to its surface compatibility for the active layer deposition, as observed in the AFM and contact angle measurements.
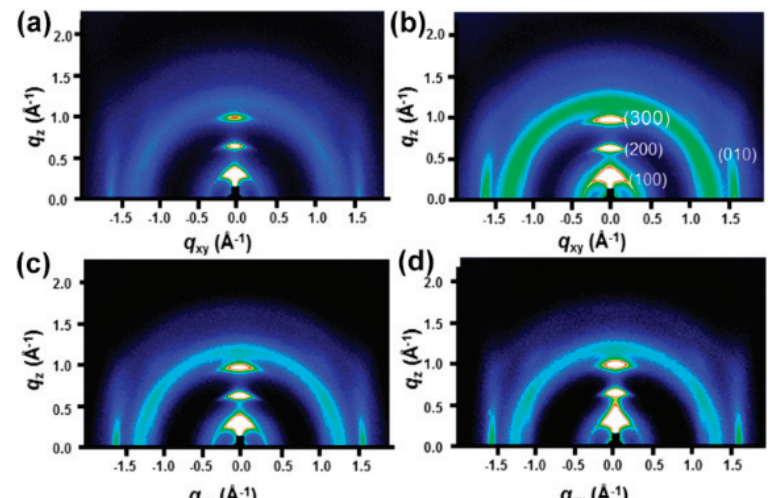

Figure 4. Grazing-incidence wide-angle $\mathrm{X}$-ray scattering diffraction patterns of poly(3-hexylthiophene):[6,6]-phenyl- $\mathrm{C}_{61}$-butyric acid methyl ester thin films deposited on (a) poly(3,4-ethylenedioxythiophene):poly(styrenesulfonate) (PEDOT:PSS) and PEDOT:PSS combined with (b) 5, (c) 20, and (d) $50 \mu \mathrm{L}$ of oleylamine-functionalized $\mathrm{MoS}_{2}$.
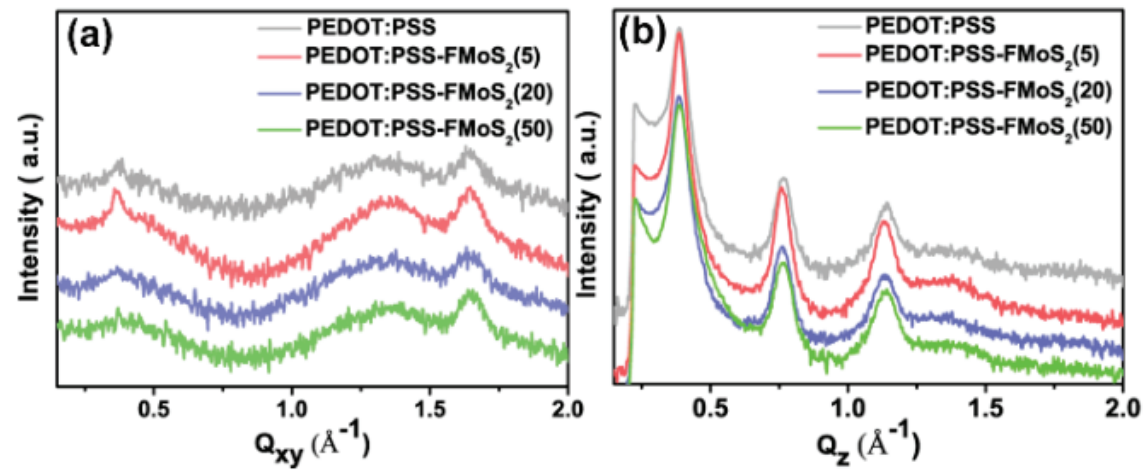

Figure 5. (a) In-plane and (b) out-of-plane spectra of poly(3-hexylthiophene):[6,6]-phenyl-C61-butyric acid methyl ester thin films deposited on poly (3,4-ethylendioxythiophene): poly(styrenesulfonate) (PEDOT:PSS) and PEDOT:PSS combined with 5, 20, and $50 \mu \mathrm{L}$ of oleylamine-functionalized $\mathrm{MoS}_{2}$ samples obtained from grazing-incidence wide-angle $\mathrm{X}$-ray scattering.

Electrical impedance spectroscopy (EIS) was performed to investigate the charge transport dynamics of the OSCs fabricated with PEDOT:PSS and PEDOT:PSS/FMoS 2 (5) as HTL (Figure 6). This analysis allowed us to observe the current response by applying alternating current voltage as a function of frequency; the OSCs with PEDOT:PSS/FMoS 2 (5) demonstrated slightly lower charge transfer resistance, revealing that the holes were effectively transported from the active layer to the anode (ITO). In order to elucidate the origin of the improvement in the photovoltaic performance, especially both FF and $\mathrm{J}_{\mathrm{sc}}$ for PEDOT:PSS/FMoS 2 (5), we further calculated the resistance of the devices. In general, it is well known that lower series resistance $\left(R_{S}\right)$ and higher shunt resistance $\left(R_{S H}\right)$ are required to achieve higher FF in the solar cell device [64]. Based on the J-V curves obtained from the 
devices, it is clearly revealed that the device with PEDOT:PSS/FMoS 2 (5) as HTL showed the lowest $R_{S}$ while maintaining higher $\mathrm{R}_{\mathrm{SH}}$, leading to enhancement in charge extraction. The corresponding $\mathrm{R}_{\mathrm{S}}$ value of cells employing PEDOT:PSS/FMoS 2 (5) as HTL was $134.8 \Omega \cdot \mathrm{cm}^{2}$, while the reference showed $180.0 \Omega \cdot \mathrm{cm}^{2}$. Lower $\mathrm{R}_{\mathrm{S}}$ indicates that better interfacial contact and charge collection efficiency were obtained due to the addition of the conducting $\mathrm{FMoS}_{2}$ layer. In the case of the $\mathrm{R}_{\mathrm{SH}}$, no significant changes in the shunt resistance were observed for the devices. In the point of view of the identical $\mathrm{R}_{\mathrm{SH}}$, barrier resistance at the interface and the leakage current level flowing across the photoactive layer is similar. Therefore, the addition of $\mathrm{FMoS}_{2}$ might contribute to extract photoexcited charges efficiently by lowering the $R_{S}$.

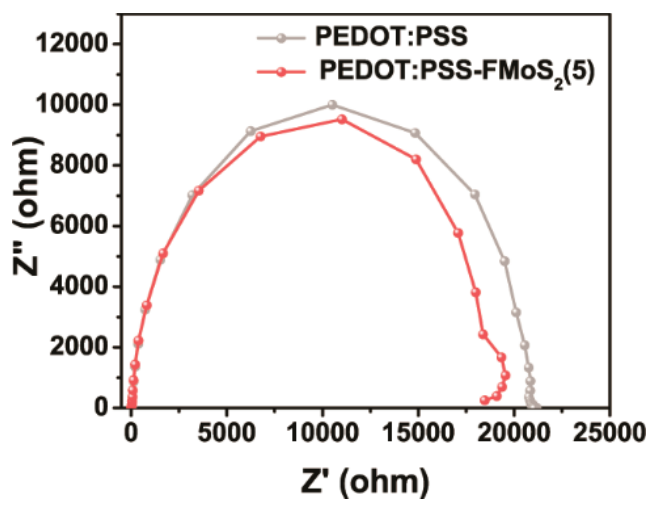

Figure 6. Electrical impedance spectra of organic solar cells based on poly(3,4-ethylenedioxythiophene):poly(styrenesulfonate) (PEDOT:PSS) and PEDOT:PSS/oleylamine-functionalized $\mathrm{MoS}_{2}(5 \mu \mathrm{L})($ PEDOT:PSS/FMoS $2(5))$ as hole-transportation layer.

\section{Conclusions}

The application of solution-processed PEDOT:PSS/FMoS 2 hybrids as effective HTLs for OSCs has been successfully demonstrated. Raman, UV-Vis, PL, TEM, and AFM analyses confirmed the successful exfoliation of bulk $\mathrm{MoS}_{2}$ into few-layer nanosheets in the presence of oleylamine via a simple and cost-effective solution-based method. The OSCs fabricated with the synthesized PEDOT:PSS/FMoS 2 hybrids as HTL exhibited PCE values up to $3.74 \%$, which is $15.08 \%$ higher than that of the reference cells having simple PEDOT:PSS as HTL. The hybrid HTL films showed better surface properties for the deposition of the hydrophobic active layer, consequently, the charge-transfer resistance was minimized for OSCs fabricated with hybrid HTL compared with reference cells, improving the OSC performance. Due to their simple preparation method, 2D FMoS 2 -incorporated PEDOT:PSS-based HTL provides valuable alternative HTL for OSCs.

Supplementary Materials: The following are available online at http://www.mdpi.com/2079-4991/9/9/1328/s1, Figures S1 and S2: PL spectra and AFM image of oleylamine-functionalized $\mathrm{MoS}_{2}\left(\mathrm{FMoS}_{2}\right)$ respectively, Figures S3 and S4: Contact angles and AFM images of PEDOT:PSS and PEDOT:PSS combined with FMoS ${ }_{2}$ respectively, Figure S5: (a) UV-Vis transmittance spectra of PEDOT:PSS and PEDOT:PSS combined with FMoS ${ }_{2}$, (b) UV-Vis absorbance spectra of P3HT:PCBM thin film spin-coated on PEDOT:PSS and PEDOT:PSS FMoS ${ }_{2}$.

Author Contributions: M.S.R., prepared the content of this research, carried out device fabrication, analysis of results and wrote the manuscript. K.Y.R. performed GIWAXS measurements and interpreted the data. J.W.L. performed IPCE measurements and guided for manuscript revisions. A.B., H.K., J.-E.L. performed the design of device configuration, performed AFM and PL measurements. D.H.K. and K.K. guided the overall scope of this research and wrote the manuscript.

Funding: This work was supported by National Research Foundation of Korea Grant funded by the Korean Government (2017R1A2A1A05022387 and 2016M1A2A2940914) and by the Korea Institute of Energy Technology Evaluation and Planning (KETEP) and the Ministry of Trade, Industry \& Energy (MOTIE) of the Republic of Korea (No. 20173010013340 and 20163030013900). 
Conflicts of Interest: There are no conflicts to declare.

\section{References}

1. Jang, Y.H.; Jang, Y.J.; Kim, S.; Quan, L.N.; Chung, K.; Kim, D.H. Plasmonic solar cells: From rational design to mechanism overview. Chem. Rev. 2016, 116, 14982-15034. [CrossRef] [PubMed]

2. Oh, Y.; Lim, J.W.; Kim, J.G.; Wang, H.; Kang, B.H.; Park, Y.W.; Kim, H.; Jang, Y.J.; Kim, J.; Kim, D.H.; et al. Plasmonic periodic nanodot arrays via laser interference lithography for organic photovoltaic cells with $>10 \%$ efficiency. ACS Nano 2016, 10, 10143-10151. [CrossRef] [PubMed]

3. Xie, L.; Lee, J.S.; Jang, Y.; Ahn, H.; Kim, Y.H.; Kim, K. Organic photovoltaics utilizing a polymer nanofiber/fullerene interdigitated bilayer prepared by sequential solution deposition. J. Phys. Chem. C 2016, 120, 12933-12940. [CrossRef]

4. Zhu, M.; Kim, H.; Jang, Y.J.; Park, S.; Ryu, D.Y.; Kim, K.; Tang, P.; Qiu, F.; Kim, D.H.; Peng, J. Toward high efficiency organic photovoltaic devices with enhanced thermal stability utilizing P3HT-b-P3PHT block copolymer additives. J. Mater. Chem. A 2016, 4, 18432-18443. [CrossRef]

5. Kim, Y.; Son, J.; Shafian, S.; Kim, K.; Hyun, J.K. Semitransparent blue, green, and red organic solar cells Using Color Filtering Electrodes. Adv. Opt. Mater. 2018, 6, 1800051. [CrossRef]

6. Xie, L.; Yoon, S.; Cho, Y.J.; Kim, K. Effective protection of sequential solution-processed polymer/fullerene bilayer solar cell against charge recombination and degradation. Org. Electron. 2015, 25, 212-218. [CrossRef]

7. Zhao, W.; Li, S.; Yao, H.; Zhang, S.; Zhang, Y.; Yang, B.; Hou, J. Molecular optimization enables over 13\% efficiency in organic solar cells. J. Am. Chem. Soc. 2017, 139, 7148-7151. [CrossRef] [PubMed]

8. Ahn, S.; Jeong, S.H.; Han, T.H.; Lee, T.W. Conducting polymers as anode buffer materials in organic and perovskite optoelectronics. Adv. Opt. Mater. 2017, 5, 1600512. [CrossRef]

9. Zhang, S.; Yu, Z.; Li, P.; Li, B.; Isikgor, F.H.; Du, D.; Sun, K.; Xia, Y.; Ouyang, J. Poly(3,4-ethylenedioxythiophene): Polystyrene sulfonate films with low conductivity and low Acidity through a treatment of their solutions with probe ultrasonication and their application as hole transport layer in polymer solar cells and perovskite solar cells. Org. Electron. 2016, 32, 149-156.

10. Lee, J.J.; Lee, S.H.; Kim, F.S.; Choi, H.H.; Kim, J.H. Simultaneous enhancement of the efficiency and stability of organic solar cells using PEDOT: PSS grafted with a PEGME buffer layer. Org. Electron. 2015, 26, 191-199. [CrossRef]

11. Zhou, H.; Zhang, Y.; Mai, C.K.; Seifter, J.; Nguyen, T.Q.; Bazan, G.C.; Heeger, A.J. Solution-processed $\mathrm{pH}$-neutral conjugated polyelectrolyte improves interfacial contact in organic solar cells. ACS Nano 2015, 9, 371-377. [CrossRef] [PubMed]

12. Zhou, H.; Zhang, Y.; Mai, C.K.; Collins, S.D.; Nguyen, T.Q.; Bazan, G.C.; Heeger, A.J. Conductive conjugated polyelectrolyte as hole-transporting layer for organic bulk heterojunction solar cells. Adv. Mater. 2014, 26, 780-785. [CrossRef] [PubMed]

13. Jasieniak, J.J.; Seifter, J.; Jo, J.; Mates, T.; Heeger, A.J. A solution-processed MoOx anode interlayer for use within organic photovoltaic devices. Adv. Funct. Mater. 2012, 22, 2594-2605. [CrossRef]

14. Xie, F.; Choy, W.C.H.; Wang, C.; Li, X.; Zhang, S.; Hou, J. Low-temperature solution-processed hydrogen molybdenum and vanadium bronzes for an efficient hole-transport layer in organic electronics. Adv. Mater. 2013, 25, 2051-2055. [CrossRef] [PubMed]

15. Bao, X.; Zhu, Q.; Wang, T.; Guo, J.; Yang, C.; Yu, D.; Wang, N.; Chen, W.; Yang, R. Simple O 2 plasma-processed $\mathrm{V}_{2} \mathrm{O}_{5}$ as an anode buffer layer for high performance polymer solar cells. ACS Appl. Mater. Interfaces 2015, 7, 7613-7618. [CrossRef] [PubMed]

16. Bai, S.; Jin, Y.; Dai, X.; Liang, X.; Ye, Z.; Li, M.; Cheng, J.; Xiao, X.; Wu, Z.; Xia, Z.; et al. Low-temperature combustion-synthesized nickel oxide thin films as hole-transport interlayers for solution processed optoelectronic devices. Adv. Energy Mater. 2014, 4, 1301460. [CrossRef]

17. Yin, Z.; Wei, J.; Zheng, Q. Interfacial materials for organic solar cells: Recent advances and perspectives. Adv. Sci. 2016, 3, 1500362. [CrossRef] [PubMed]

18. Liu, J.; Xue, Y.; Dai, L. Sulfated graphene oxide as a hole-extraction layer in high-performance polymer solar cells. J. Phys. Chem. Lett. 2012, 3, 1928-1933. [CrossRef]

19. Li, S.S.; Tu, K.H.; Lin, C.C.; Chen, C.W.; Chhowalla, M. Solution-processable graphene oxide as an efficient hole transport layer in polymer solar cells. ACS Nano 2010, 4, 3169-3174. [CrossRef] 
20. Yun, J.M.; Yeo, J.S.; Kim, J.; Jeong, H.G.; Kim, D.Y.; Noh, Y.J.; Kim, S.S.; Ku, B.C.; Na, S.I. Solution-processable reduced graphene oxide as a novel alternative to PEDOT:PSS hole transport layers for highly efficient and stable polymer solar cells. Adv. Mater. 2011, 23, 4923-4928. [CrossRef]

21. Niu, J.; Yang, D.; Ren, X.; Yang, Z.; Liu, Y.; Zhu, X.; Zhao, W.; Liu, S. Graphene-oxide doped PEDOT: PSS as a superior hole transport material for high-efficiency perovskite solar cell. Org. Electron. 2017, 48, 165-171. [CrossRef]

22. Drakonakis, V.M.; Savva, A.; Kokonou, M.; Choulis, S.A. Investigating electrodes degradation in organic photovoltaics through reverse engineering under accelerated humidity lifetime conditions. Sol. Energy Mater. Sol. Cells 2014, 130, 544-550. [CrossRef]

23. Kawano, K.; Pacios, R.; Poplavskyy, D.; Nelson, J.; Bradley, D.D.C.; Durrant, J.R. Degradation of organic solar cells due to air exposure. Sol. Energy Mater. Sol. Cells 2006, 90, 3520-3530. [CrossRef]

24. Lim, F.J.; Ananthanarayanan, K.; Luther, J.; Ho, G.W. Influence of a novel fluorosurfactant modified PEDOT: PSS hole transport layer on the performance of inverted organic solar cells. J. Mater. Chem. 2012, 22, 25057-25064. [CrossRef]

25. Arulkashmir, A.; Krishnamoorthy, K. Disassembly of micelles to impart donor and acceptor gradation to enhance organic solar cell efficiency. Chem. Commun. 2016, 52, 3486-3489. [CrossRef]

26. Lim, D.C.; Kim, K.D.; Park, S.Y.; Hong, E.M.; Seo, H.O.; Lim, J.H.; Lee, K.W.; Jeong, Y.J.; Song, C.; Lee, E.; et al. Towards fabrication of high-performing organic photovoltaics: New donor polymer, atomic layer deposited thin buffer layer and plasmonic effects. Energy Environ. Sci. 2012, 5, 9803-9807. [CrossRef]

27. Wang, K.; Yi, C.; Hu, X.; Liu, C.; Sun, Y.; Hou, J.; Li, Y.; Zheng, J.; Chuang, S.; Karim, A.; et al. Enhanced performance of polymer solar cells using PEDOT:PSS doped with $\mathrm{Fe}_{3} \mathrm{O}_{4}$ magnetic nanoparticles aligned by an external magnetostatic field as an anode buffer layer. ACS Appl. Mater. Interfaces 2014, 6, 13201-13208. [CrossRef]

28. Yao, K.; Salvador, M.; Chueh, C.C.; Xin, X.K.; Xu, Y.X.; de Quilettes, D.W.; Hu, T.; Chen, Y.; Ginger, D.S.; Jen, A.K.Y. A general route to enhance polymer solar cell performance using plasmonic nanoprisms. Adv. Energy Mater. 2014, 4, 1400206. [CrossRef]

29. Zhao, Z.; Wu, Q.; Xia, F.; Chen, X.; Liu, Y.; Zhang, W.; Zhu, J.; Dai, S.; Yang, S. Improving the conductivity of PEDOT: PSS hole transport layer in polymer solar cells via copper(II) bromide salt doping. ACS Appl. Mater. Interfaces 2015, 7, 1439-1448. [CrossRef]

30. Kadem, B.; Cranton, W.; Hassan, A. Metal salt modified PEDOT: PSS as anode buffer layer and its effect on power conversion efficiency of organic solar cells. Org. Electron. 2015, 24, 73-79. [CrossRef]

31. Kang, D.J.; Cho, H.H.; Lee, I.; Kim, K.H.; Kim, H.J.; Liao, K.; Kim, T.S.; Kim, B.J. Enhancing mechanical properties of highly efficient polymer solar cells using size-tuned polymer nanoparticles. ACS Appl. Mater. Interfaces 2015, 7, 2668-2676. [CrossRef]

32. Hossain, J.; Liu, Q.; Miura, T.; Kasahara, K.; Harada, D.; Ishikawa, R.; Ueno, K.; Shirai, H. Nafion-modified PEDOT: PSS as a transparent hole-transporting layer for high-performance crystalline-Si/organic heterojunction solar cells with improved light soaking stability. ACS Appl. Mater. Interfaces 2016, 8, 31926-31934. [CrossRef]

33. Hilal, M.; Han, J.I. Significant improvement in the photovoltaic stability of bulk heterojunction organic solar cells by the molecular level interaction of graphene oxide with a PEDOT: PSS composite hole transport layer. Sol. Energy 2018, 167, 24-34. [CrossRef]

34. HDehsari, S.; Shalamzari, E.K.; Gavgani, J.N.; Taeomi, F.A.; Ghanbary, S. Efficient preparation of ultralarge graphene oxide using a PEDOT: PSS/GO composite layer as hole transport layer in polymer-based optoelectronic devices. RSC Adv. 2014, 4, 55067-55076. [CrossRef]

35. Walker, B.; Choi, H.; Kim, J.Y. Interfacial engineering for highly efficient organic solar cells. Curr. Appl. Phys. 2017, 17, 370-391. [CrossRef]

36. Pham, V.P.; Yeom, G.Y. Recent advances in doping of molybdenum disulfide: Industrial applications and future prospects. Adv. Mater. 2016, 28, 9024-9059. [CrossRef]

37. Chhowalla, M.; Shin, H.S.; Eda, G.; Li, L.J.; Loh, K.P.; Zhang, H. The chemistry of two-dimensional layered transition metal dichalcogenide nanosheets. Nat. Chem. 2013, 5, 263-275. [CrossRef]

38. Li, H.; Wu, J.; Yin, Z.; Zhang, H. Preparation and Applications of Mechanically Exfoliated Single-Layer and Multilayer $\mathrm{MoS}_{2}$ and $\mathrm{WSe}_{2}$ Nanosheets. Acc. Chem. Res. 2014, 47, 1067-1075. [CrossRef] 
39. Lee, Y.H.; Zhang, X.Q.; Zhang, W.; Chang, M.T.; Lin, C.T.; Chang, K.D.; Yu, Y.C.; Wang, J.T.W.; Chang, C.S.; Li, L.J.; et al. Synthesis of large-area $\mathrm{MoS}_{2}$ atomic layers with chemical vapor deposition. Adv. Mater. 2012, 24, 2320-2325. [CrossRef]

40. Zhang, X.; Lai, Z.; Tan, C.; Zhang, H. Solution-processed two-Dimensional $\mathrm{MoS}_{2}$ nanosheets: Preparation, hybridization, and applications. Angew. Chem. Int. Ed. 2016, 55, 8816-8838. [CrossRef]

41. Le, Q.V.; Nguyen, T.P.; Jang, H.W.; Kim, S.Y. The use of UV/ozone-treated $\mathrm{MoS}_{2}$ nanosheets for extended air stability in organic photovoltaic cells. Phys. Chem. Chem. Phys. 2014, 16, 13123-13128. [CrossRef]

42. Yun, J.M.; Noh, Y.J.; Yeo, J.S.; Go, Y.J.; Na, S.I.; Jeong, H.G.; Kim, J.; Lee, S.; Kim, S.S.; Koo, H.Y.; et al. Efficient work-function engineering of solution-processed $\mathrm{MoS}_{2}$ thin-films for novel hole and electron transport layers leading to high-performance solar cells. J. Mater. Chem. C 2013, 1, 3777-3783. [CrossRef]

43. Yang, X.; Fu, W.; Liu, W.; Hong, J.; Cai, Y.; Jin, C.; Xu, M.; Wang, H.; Yang, D.; Chen, H. Engineering crystalline structures of two-dimensional $\mathrm{MoS}_{2}$ sheets for high-performance organic solar cells. J. Mater. Chem. A 2014, 2, 7727-7733. [CrossRef]

44. Xing, W.; Chen, Y.; Wu, X.; Xu, X.; Ye, P.; Zhu, T.; Guo, Q.; Yang, L.; Li, W.; Huang, H. PEDOT: PSS-assisted exfoliation and functionalization of 2D nanosheets for high-performance organic solar cells. Adv. Funct. Mater. 2017, 27, 1701622. [CrossRef]

45. Ahmad, R.; Srivastava, R.; Yadav, S.; Chand, S.; Sapra, S. Functionalized 2D-MoS 2 -incorporated polymer ternary solar cells: Role of nanosheet-induced long-range ordering of polymer chains on charge transport. ACS Appl. Mater. Interfaces 2017, 9, 34111-34121. [CrossRef]

46. Wu, J.B.; Lin, M.L.; Cong, X.; Liu, H.N.; Tan, P.H. Raman spectroscopy of graphene-based materials and its applications in related devices. Chem. Soc. Rev. 2018, 47, 1822-1873. [CrossRef]

47. Cho, K.; Min, M.; Kim, T.Y.; Jeong, H.; Pak, J.; Kim, J.K.; Jang, J.; Yun, S.J.; Lee, Y.H.; Hong, W.K.; et al. Electrical and optical characterization of $\mathrm{MoS}_{2}$ with Sulfur vacancy passivation by treatment with alkanethiol molecules. ACS Nano 2015, 9, 8044-8053. [CrossRef]

48. Yao, Y.; Tolentino, L.; Yang, Z.; Song, X.; Zhang, W.; Chen, Y.; Wong, C. High-concentration aqueous dispersions of $\mathrm{MoS}_{2}$. Adv. Funct. Mater. 2013, 23, 3577-3583. [CrossRef]

49. Luo, S.; Qi, X.; Ren, L.; Hao, G.; Fan, Y.; Liu, Y.; Han, W.; Zang, C.; Li, J.; Zhong, J. Photoresponse properties of large-area $\mathrm{MoS}_{2}$ atomic layer synthesized by vapor phase deposition. J. Appl. Phys. 2014, 116, 164304. [CrossRef]

50. Zhou, K.G.; Mao, N.N.; Wang, H.X.; Peng, Y.; Zhang, H.L. A Mixed-solvent strategy for efficient exfoliation of inorganic graphene analogues. Angew. Chem. Int. Ed. 2011, 50, 10839-10842. [CrossRef]

51. Chen, X.; Berner, N.C.; Backes, C.; Duesberg, G.S.; McDonald, A.R. Functionalization of two-dimensional $\mathrm{MoS}_{2}$ : On the reaction between $\mathrm{MoS}_{2}$ and organic thiols. Angew. Chem. Int. Ed. 2016, 55, 5803-5808. [CrossRef]

52. Splendiani, A.; Sun, L.; Zhang, Y.; Li, T.; Kim, J.; Chim, C.Y.; Galli, G.; Wang, F. Emerging photoluminescence in monolayer $\mathrm{MoS}_{2}$. Nano Lett. 2010, 10, 1271-1275. [CrossRef]

53. Eda, G.; Yamaguchi, H.; Voiry, D.; Fujita, T.; Chen, M.; Chhowalla, M. Photoluminescence from chemically exfoliated $\mathrm{MoS}_{2}$. Nano. Lett. 2011, 11, 5111-5116. [CrossRef]

54. Qi, Y.; Wang, N.; Xu, Q.; Li, H.; Zhou, P.; Lu, X.; Zhao, G. A green route to fabricate $\mathrm{MoS}_{2}$ nanosheets in water-ethanol- $\mathrm{CO}_{2}$. Chem. Commun. 2015, 51, 6726-6729. [CrossRef]

55. Kim, D.H.; Park, Y.D.; Jang, Y.; Yang, H.; Kim, Y.H.; Han, J.I.; Moon, D.G.; Park, S.; Chang, T.; Chang, C.; et al. Enhancement of field-effect mobility due to surface-mediated molecular ordering in regioregular polythiophene thin film transistors. Adv. Funct. Mater. 2005, 15, 77-82. [CrossRef]

56. Kim, D.H.; Jang, Y.; Park, Y.D.; Cho, K. Surface-induced conformational changes in poly(3-hexylthiophene) monolayer films. Langmuir 2005, 21, 3203-3206. [CrossRef]

57. Huang, J.S.; Goh, T.; Li, X.; Sfeir, M.Y.; Bielinski, E.A.; Tomasulo, S.; Lee, M.L.; Hazari, N.; Taylor, A.D. Polymer bulk heterojunction solar cells employing Forster resonance energy transfer. Nat. Photonics 2013, 7, 479-485. [CrossRef]

58. Liu, Y.; Renna, L.A.; Page, Z.A.; Thompson, H.B.; Kim, P.Y.; Barnes, M.D.; Emrick, T.; Venkataramanan, D.; Russell, T.P. A polymer hole extraction layer for inverted perovskite solar cells from aqueous solutions. Adv. Energy Mater. 2016, 6, 1600664. [CrossRef] 
59. Choi, H.; Kim, H.B.; Ko, S.J.; Kim, J.Y.; Heeger, A.J. An organic surface modifier to produce a high work function transparent electrode for high performance polymer solar cells. Adv. Mater. 2015, 27, 892-896. [CrossRef]

60. Noriega, R.; Rivnay, J.; Vandewal, K.; Koch, F.P.V.; Stingelin, N.; Smith, P.; Toney, M.F.; Salleo, A. A general relationship between disorder, aggregation and charge transport in conjugated polymers. Nat. Mater. 2013, 12, 1038-1044. [CrossRef]

61. Lan, Y.K.; Huang, C. A theoretical study of the charge transfer behavior of the highly regioregular poly-3-hexylthiophene in the ordered state. J. Phys. Chem. B 2008, 112, 14857-14862. [CrossRef]

62. Skrypnychuk, V.; Boulanger, N.; Yu, V.; Hilke, M.; Mannsfeld, S.C.B.; Toney, M.F.; Barbero, D.R. Enhanced vertical charge transport in a semiconducting P3HT thin Film on single layer grapheme. Adv. Funct. Mater. 2015, 25, 664-670. [CrossRef]

63. Boulanger, N.; Yu, V.; Hilke, M.; Toney, M.F.; Barbero, D.R. In situ probing of the crystallization kinetics of rr-P3HT on single layer graphene as a function of temperature. Phys. Chem. Chem. Phys. 2017, 19, 8496-8503. [CrossRef]

64. Lim, J.W.; Wang, H.; Choi, C.H.; Quan, L.N.; Chung, K.; Park, W.T.; Noh, Y.Y.; Kim, D.H. Polyethylenimine ethoxylated interlayer-mediated $\mathrm{ZnO}$ interfacial engineering for high-performance and low-temperature processed flexible perovskite solar cells: A simple and viable route for one-step processed $\mathrm{CH}_{3} \mathrm{NH}_{3} \mathrm{PbI}_{3}$. J. Power Sources 2019, 438, 226956. [CrossRef]

(C) 2019 by the authors. Licensee MDPI, Basel, Switzerland. This article is an open access article distributed under the terms and conditions of the Creative Commons Attribution (CC BY) license (http://creativecommons.org/licenses/by/4.0/). 
Article

\title{
Carboxylic Acid Functionalization at the Meso-Position of the Bodipy Core and Its Influence on Photovoltaic Performance
}

\author{
Filip Ambroz, Joanna L. Donnelly, Jonathan D. Wilden, Thomas J. Macdonald * and \\ Ivan P. Parkin * \\ Department of Chemistry, University College London 20 Gordon St., London WC1H 0AJ, UK; \\ filip.ambroz.16@ucl.ac.uk (F.A.); joanna.donnelly.15@ucl.ac.uk (J.L.D.); j.wilden@ucl.ac.uk (J.D.W.) \\ * Correspondence: tom.macdonald@ucl.ac.uk (T.J.M.); i.p.parkin@ucl.ac.uk (I.P.P.)
}

Received: 18 August 2019; Accepted: 17 September 2019; Published: 20 September 2019

\begin{abstract}
Two bodipy dyes with different carboxylic acids on the meso-position of the bodipy core were prepared and used to sensitize $\mathrm{TiO}_{2}$ photoelectrodes. On the basis of spectroscopic characterization, the photoelectrodes were used to fabricate photoelectrochemical cells (PECs) for solar light harvesting. Photovoltaic measurements showed that both bodipy dyes successfully sensitized PECs with short-circuit current densities $\left(J_{S C}\right)$ two-fold higher compared to the control. The increase in generated current was attributed to the gain in spectral absorbance due to the presence of bodipy. Finally, the influence of co-sensitization of bodipy and N719 dye was also investigated and photovoltaic device performance discussed.
\end{abstract}

Keywords: Dye-sensitized solar cells; bodipy dye; co-sensitization; N719 dye; photoelectrochemical cells

\section{Introduction}

Over the last few decades numerous types of photoelectrochemical cells (PECs) that convert sunlight to electricity have been extensively explored as an alternative photovoltaic technology to silicon [1,2]. The most promising include, dye-sensitized solar cells (DSSCs) [3,4], metal chalcogenide solar cells [5,6], organic/polymer solar cells [7-9], and perovskite solar cells [10,11]. While significant research has been conducted for their progress, they all have drawbacks in certain aspects that hinder large scale market employment [12]. For DSSCs in particular, the main efforts have been related to improving cell efficiencies where investigations have focused on two main components, such as the dye sensitizer and semiconducting electrode $[13,14]$. The foremost step in achieving high efficiencies is the light absorption by the dye molecules that should ideally cover as much of the visible spectrum as possible. To complement this, ruthenium-based dyes such as Di-tetrabutylammonium cis-bis(isothiocyanato)bis(2,2'-bipyridyl-4,4'-dicarboxylato)ruthenium(II) (best known as N719) and other ruthenium-based derivatives have been the most successful candidates thus far [15-17]. While N719 dye has been extensively used in DSSCs research since it shows promise of high efficiency, the limited supply, fluctuation in price, and environmental impact of ruthenium have all prompted investigations into other alternatives [18] Possible choices to replace ruthenium-based dyes include porphyrin $[19,20]$, squaraine [21,22], and boron dipyrromethene (bodipy) dye complexes $[23,24]$. As a result of many unique features that bodipy dyes possess, they have emerged as an attractive class of functional dyes that can be used for a variety of applications $[25,26]$. They are known to exhibit characteristics such as ease of structural modification, minimum triplet state formation, photostability, low rates of intersystem crossing, and more [27], which renders them promising for use in the future [28]. In the past decade, a variety of bodipy dyes have been synthesized for use in solar cell applications, however most attempts were not prosperous since the efficiencies were shown to be 
poor [29]. This was mostly a result of insufficient light harvesting since efforts to design a metal free organic dye that would achieve panchromatic absorption proved to be rather ambitious [30]. Therefore, bodipy dyes were separately engineered to cover a particular absorption spectral range and co-sensitized together in a PEC with the aim to obtain high efficiency [31]. In addition, structural modifications and functionalization of the bodipy core was also shown to have a notable influence on the photovoltaic performance of PECs. For instance, by replacing fluorine on the bodipy core with long alkoxy groups, losses due to charge recombination can be minimized resulting in efficiencies in the range of $5.75 \%$ as reported by Ziessel et al [32].

Herein, we report the details of the synthesis and characterization of two bodipy sensitizers with different carboxylic acids at the meso-position [29] of the bodipy core. In addition, spectroscopy results of bodipy-sensitized $\mathrm{TiO}_{2}$ photoelectrodes are discussed followed by PEC fabrication and characterization using simulated sunlight. Finally, the influence of bodipy and N719 dye co-sensitization on the performance of PECs is also investigated.

\section{Experimental Section}

\subsection{Materials}

All chemicals used in this study were obtained from Sigma Aldrich (St. Louis, MO, USA), Acros Organics (Geel, Belgium), Alfa Aesar (Haverhill, MA, USA) or Thermo Fischer Scientific (Waltham, MA, USA). They were used as received unless otherwise stated.

\subsection{Synthesis of Bodipy Dye 1 and 2}

2,4-dimethylpyrrole $(0.120 \mathrm{~mL}, 1.20 \mathrm{mmol}, 2$ eq. $)$ and glutaric or succinic anhydride $(0.600 \mathrm{mmol}$, 1 eq.) were dissolved in dry dichloromethane $(\mathrm{DCM}, 10.0 \mathrm{~mL})$ under argon. $\mathrm{BF}_{3} \cdot \mathrm{Et}_{2} \mathrm{O}(0.500 \mathrm{~mL}$, $4.00 \mathrm{mmol})$ and TEA $(0.420 \mathrm{~mL}, 3.00 \mathrm{mmol})$ were added and the reaction was heated under reflux for five hours. The organic material was washed with water, dried over $\mathrm{MgSO}_{4}$, filtered and concentrated in vacuo before purification by flash column chromatography on silica gel; eluent: Hexane/EtOAc/AcOH:50/50/0 to 0/97/3.

\subsubsection{Bodipy Dye 1}

4-(5,5-difluoro-1,3,7,9-tetramethyl-5H-414,5l4-dipyrrolo[1,,2-c:2',1'-f][1,3,2]diazaborinin-10-yl) butanoic acid $(22.0 \mathrm{mg}, 0.066 \mathrm{mmol}, 11 \%) .{ }^{1} \mathrm{H}$ NMR $\left(600.130 \mathrm{MHz}, \mathrm{CDCl}_{3}\right) \delta_{\mathrm{H}} 6.06(\mathrm{~s}, 2 \mathrm{H}, \mathrm{ArH})$, 2.82-2.78 (m, 2H, CH$), 2.57-2.54\left(\mathrm{~m}, 2 \mathrm{H}, \mathrm{CH}_{2}\right), 2.52\left(\mathrm{~s}, 6 \mathrm{H}, 2 \mathrm{CH}_{3}\right), 2.43\left(\mathrm{~s}, 6 \mathrm{H}, 2 \mathrm{CH}_{3}\right), 2.04-1.99(\mathrm{~m}, 2 \mathrm{H}$, $\left.\mathrm{CH}_{2}\right)$ ppm; $\mathrm{R}_{\mathrm{f}}(\mathrm{EtOAc})=0.1$ (stained with bromocresol green)

\subsubsection{Bodipy Dye 2}

3-(5,5-difluoro-1,3,7,9-tetramethyl-5H-414,514-dipyrrolo[1,2-c:2',1'-f][1,3,2]diazaborinin-10-yl) propanoic acid $(27.0 \mathrm{mg}, 0.084 \mathrm{mmol}, 14 \%) .{ }^{1} \mathrm{H}$ NMR $\left(600.130 \mathrm{MHz}, \mathrm{CDCl}_{3}\right) \delta_{\mathrm{H}} 6.06(\mathrm{~s}, 2 \mathrm{H}, \mathrm{ArH})$, 3.36-3.33 (m, 2H, CH$), 2.71-2.69\left(\mathrm{~m}, 2 \mathrm{H}, \mathrm{CH}_{2}\right), 2.52\left(\mathrm{~s}, 6 \mathrm{H}, 2 \mathrm{CH}_{3}\right), 2.45\left(\mathrm{~s}, 6 \mathrm{H}, 2 \mathrm{CH}_{3}\right) \mathrm{ppm}$; $\mathrm{R}_{\mathrm{f}}(\mathrm{EtOAc})=0.1$ (stained with bromocresol green).

\subsection{Preparation of Photoelectrochemical Cells (PECs)}

PEC fabrication followed the procedures already reported in our previous work [14]. Briefly, $\mathrm{TiO}_{2}$ photoelectrodes were prepared by doctor blading commercially available $\mathrm{TiO}_{2}$ paste (GreatCell Solar, DSL-18NRT, Queanbeyan, Australia) onto pre-cleaned fluorine-doped tin oxide (FTO) glass followed by sintering at $500{ }^{\circ} \mathrm{C}$ for $30 \mathrm{~min}$ which resulted in a uniform layer of anatase $\mathrm{TiO}_{2}$ nanoparticles (NPs) labelled as a transparent layer. On this layer, an additional layer of bigger-sized $\mathrm{TiO}_{2} \mathrm{NPs}$ (WER2-0 paste, GreatCell Solar, Queanbeyan, Australia) was deposited (doctor blading technique) followed by another sintering at $500{ }^{\circ} \mathrm{C}$ for $30 \mathrm{~min}$. The second layer was labelled as light-scattering layer. The photoelectrodes were then subject to treatment with an aqueous solution of titanium 
tetrachloride $\left(\mathrm{TiCl}_{4}, 40 \mathrm{mM}\right.$ ) for $30 \mathrm{~min}$ at $\approx 70{ }^{\circ} \mathrm{C}$ followed by another sintering at $500{ }^{\circ} \mathrm{C}$ for $30 \mathrm{~min}$. It should be noted that the active solar cell area of the photoelectrodes was $0.1256 \mathrm{~cm}^{2}$. Control (unsensitized) PECs (see procedures below for dye sensitization), were directly eclipsed with counter electrodes (Pt-coated FTO glass, GreatCell Solar, Queanbeyan, Australia) with a thermoplastic sealant (GreatCell Solar, MS004610, Queanbeyan, Australia) following by heating at $\approx 100{ }^{\circ} \mathrm{C}$ for $10 \mathrm{~min}$ to seal the sealant. An electrolyte consisting of iodine $\left(\mathrm{I}_{2}, 0.05 \mathrm{M}\right), 1$,2-dimethyl-3-propylimidazolium iodide (DMPII, 0.6 M), guanidium thiocyanate $(0.10 \mathrm{M})$ and 4-tert-Butylpyridine (TBP, $0.5 \mathrm{M})$ in a mixture of acetonitrile and valeronitrile (volume ratio, 85:15) was injected between the sealed electrode via vacuum filling.

\subsection{Dye Sensitization}

Bodipy dye 1 and 2 sensitized photoelectrodes underwent dye sensitization with a solution of a relevant dye $(0.5 \mathrm{mM})$ in acetonitrile for $20 \mathrm{~h}$ in the dark.

Control (sensitized only with N719) photoelectrodes underwent dye sensitization with a solution of ruthenizer 535-bisTBA (Solaronix 0.5 mM, Aubonne, Switzerland) in absolute ethanol for $20 \mathrm{~h} \mathrm{in}$ the dark.

Bodipy dye 1 and 2 co-sensitized photoelectrodes underwent dye sensitization with a solution that was a mixture of bodipy dye 1 or 2 solution in absolute ethanol $(0.5 \mathrm{mM})-5 \mathrm{vol} \%$ and a solution of ruthenizer 535-bisTBA ( $0.5 \mathrm{mM}$, Solaronix, Aubonne, Switzerland) in absolute ethanol for $20 \mathrm{~h}$ in the dark.

\section{Characterisation}

Monitoring of all reactions was achieved using 60 F254 silica coated aluminium TLC plates by Merck. Visualisation of these was carried out using UV light of wavelength of 254 and/or $365 \mathrm{~nm}$. Purification was achieved by flash column chromatography using silica gel $(43-60 \mu \mathrm{m})$ from Merck.

All ${ }^{1} \mathrm{H},{ }^{13} \mathrm{C},{ }^{11} \mathrm{~B}$ and ${ }^{19} \mathrm{~F}$ nuclear magnetic resonance spectra were recorded at $600 \mathrm{MHz}$ using the Bruker Avance III 600 Cryo or at $700 \mathrm{MHz}$ with the Bruker Avance Neo 700. Instruments clearly indicated for each spectra. Chemical shifts are reported in ppm relative to the internal standard TMS as follows: chemical shift, multiplicity ( $\mathrm{s}=$ singlet, $\mathrm{d}=$ doublet, $\mathrm{t}=$ triplet, $\mathrm{q}=$ quartet, $\mathrm{sep}=$ septet, $\mathrm{m}=$ multiplet), coupling constant(s), integration, and assignment using either $\mathrm{CDCl}_{3}$ or DMSO- $d^{6}$ as a solvent and TMS as an internal standard.

X-Ray photoelectron spectroscopy (XPS) analysis was carried out using a Thermo Scientific $\mathrm{K}$-alpha photoelectron spectrometer with monochromatic $\mathrm{Al}-\mathrm{K}_{\alpha}$ radiation. Peak positions were calibrated to carbon $(284.8 \mathrm{eV})$ and plotted using the CasaXPS software. The measurements were performed on control and sensitized photoelectrodes. X-Ray diffraction (XRD) analysis was performed with a Bruker D8 discovery X-Ray diffractometer using monochromatic $\mathrm{Cu} \mathrm{K}_{\alpha 1}$ and $\mathrm{Cu} \mathrm{K}_{\alpha 2}$ radiation of wavelengths 1.54056 and $1.54439 \AA$, respectively.

The UV/Vis absorption spectra were taken on a Perkin Elmer Lambda 950 instrument with a measurement interval of $1 \mathrm{~nm}$.

The photoluminescence (PL) spectra were recorded using Horiba FluoroMax-4 spectrofluorometer equipped with a PMT detector.

Fourier-transform infrared (FTIR) spectra were recorded with a Bruker FTIR Spectrometer Alpha II with an attenuated total reflection (ATR) attachment. Measurements were performed in the mid-IR region $\left(4000-400 \mathrm{~cm}^{-1}\right)$.

$\mathrm{J}-\mathrm{V}$ measurements were performed under one-sun (AM 1.5G) illumination using a LOT calibrated solar simulator with a Xenon lamp. Devices were connected to a Keithley 2400 source meter to output the data. Photocurrent measurements were obtained with a halogen lamp chopped to a frequency of $188 \mathrm{~Hz}$ through a Newport monochromator; a 4-point probe in connection with a lock-in amplifier is used to collect data. The monochromatic beam is calibrated using a Silicon photo-diode. 


\section{Results and Discussion}

\subsection{Synthesis}

The synthesis of bodipy dye 1 and 2 is depicted in Scheme 1 and is based on previously reported synthetic strategies [33,34]. (See Supplementary Materials for more details) Molecular structures of the obtained compounds were characterized by spectroscopic methods, such as NMR which is shown in Supplementary Materials Figure S1 and S2. Singlet peaks integrating to two protons at $6.06 \mathrm{ppm}$ for both compounds confirm the successful construction of the BODIPY scaffold.

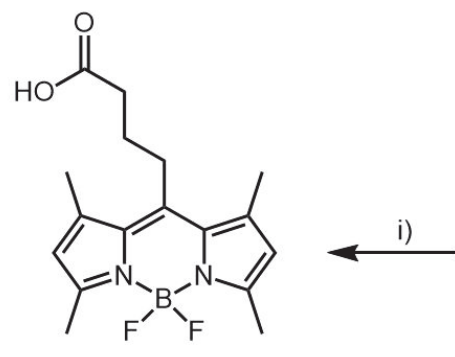

1
2

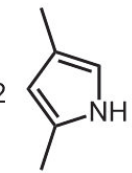

ii)

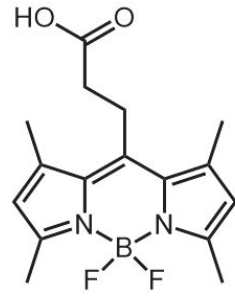

2

Scheme 1. Synthetic routes towards bodipy dyes 1 and 2. (1) Succinic anhydride, dichloromethane $(\mathrm{DCM}), \mathrm{BF}_{3} \cdot \mathrm{Et}_{2} \mathrm{O}$, reflux $5 \mathrm{~h}, \mathrm{BF}_{3} \cdot \mathrm{Et}_{2} \mathrm{O}, \mathrm{TEA}, 16 \mathrm{~h}$. (2) Glutaric anhydride, $\mathrm{DCM}, \mathrm{BF}_{3} \cdot \mathrm{Et}_{2} \mathrm{O}$, reflux $5 \mathrm{~h}$, $\mathrm{BF}_{3} \cdot \mathrm{Et}_{2} \mathrm{O}, \mathrm{TEA}, 16 \mathrm{~h}$.

\subsection{Optical Properties}

The absorption and PL emission spectra of solutions of bodipy dyes 1 and 2 are illustrated in Figure 1a,b. Both dyes exhibit three absorption features (more pronounced for dye 1 due to higher molar attenuation coefficients $(\varepsilon)$ at those particular wavelengths-Table 1 ) with two located in the UV region and one in the visible (green) portion of the electromagnetic spectrum. From the absorption onset of the dyes, their band gap values were determined to be $\approx 2.4 \mathrm{eV}$ (Table 1 ). Due to Stokes shift, where the position of the band maxima of the absorption was at $\approx 495 \mathrm{~nm}$, the emission of the dyes resulted to be $514 \mathrm{~nm}$ for dye 1 and $520 \mathrm{~nm}$ for dye 2. The bodipy dyes were then used for PECs, by sensitizing $\mathrm{TiO}_{2}$ photoelectrodes in a dye solution and their corresponding UV/Vis spectra are shown in Figure 1c,d. To evaluate if the $\mathrm{TiO}_{2}$ photoelectrodes successfully absorbed the dyes, comparison was made to the untreated (unsensitized) $\mathrm{TiO}_{2}$ photoelectrodes. As can be seen in Figure $1 \mathrm{c}$, d, both sensitized $\mathrm{TiO}_{2}$ photoelectrodes exhibited a broad absorption feature in the visible spectrum allowing the harvesting of more energy from photons. This can be attributed to the dye absorption $\left(\lambda_{\max }\right.$ at 502 and $504 \mathrm{~nm}$ for bodipy dyes 1 and 2, respectively). Compared to the bodipy solutions, sensitized $\mathrm{TiO}_{2}$ photoelectrodes exhibited a bathochromic shift that occurred as a result of the interaction, between the dye and $\mathrm{TiO}_{2}$ nanoparticles (suppression of H-aggregation). [35] Moreover, to investigate the molecular packing of dye molecules [36] X-Ray diffraction (XRD) was also performed. Supplementary Materials Figure S4 shows the XRD diffraction patterns for unsensitized and sensitized $\mathrm{TiO}_{2}$ photoelectrodes where no difference between the samples was observed. 
(a)
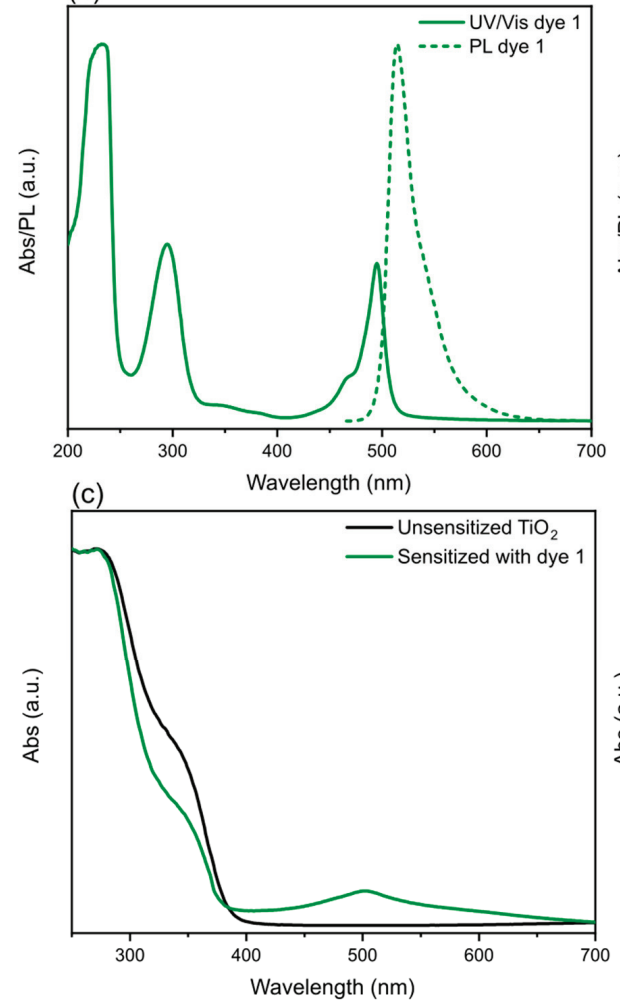

(b)

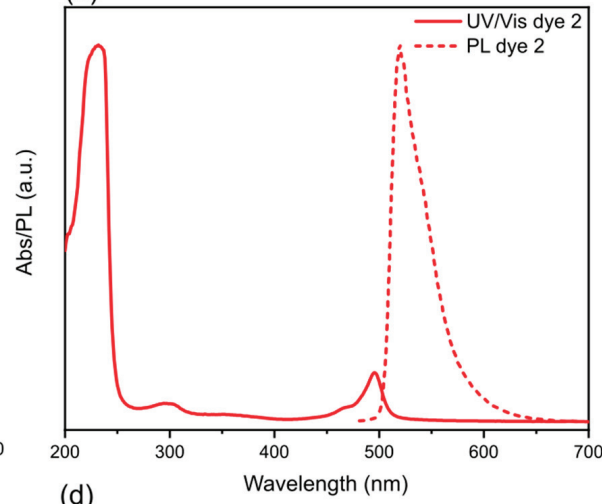

(d)

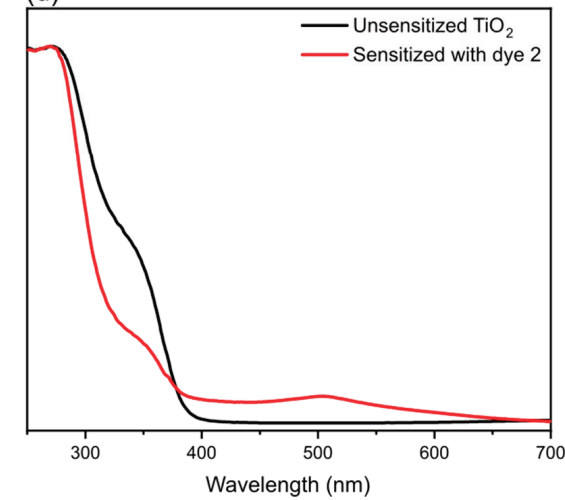

Figure 1. UV/Vis absorption (solid line) and photoluminescence (PL) emission (dotted lines) spectra of bodipy (a) dye 1 and (b) dye 2 solutions. (Excitation wavelength for PL emission was $400 \mathrm{~nm}$ ) UV/Vis absorption spectra of $\mathrm{TiO}_{2}$ sensitized photoelectrodes of bodipy (c) dye 1 and (d) dye 2, respectively. Black lines represent untreated $\mathrm{TiO}_{2}$ photoelectrodes where green (dye 1) and red (dye 2) lines correspond to $\mathrm{TiO}_{2}$ sensitized photoelectrodes.

Table 1. Summary of spectral properties of bodipy dye 1 and 2 in ethanol solution $(0.5 \mathrm{mM})$ and on photoelectrodes. The band gap values $\left(\mathrm{E}_{\mathrm{g}}\right)$ were determined following the procedure reported elsewhere [37] and also from the Tauc plots (Supplementary Materials Figure S3) where the obtained values were comparable.

\begin{tabular}{cccccc}
\hline Sensitizer & $\begin{array}{c}\text { Solution Abs } \\
\lambda_{\max }(\mathbf{n m})\end{array}$ & $\begin{array}{c}\text { Solution PL } \\
\lambda_{\max }(\mathbf{n m})\end{array}$ & $\begin{array}{c}\text { Photoelectrode } \\
\text { Abs } \lambda_{\max }(\mathbf{n m})\end{array}$ & $\mathbf{E}_{\mathrm{g}}(\mathbf{e V})$ & $\left.\varepsilon \mathbf{M}^{-\mathbf{1}} \mathbf{~ c m}^{-\mathbf{1}}\right)$ \\
\hline Dye 1 & $232,295,495$ & 514 & 502 & 2.39 & $6124($ at $495 \mathrm{~nm})$ \\
\hline Dye 2 & $232,295,496$ & 520 & 504 & 2.38 & 1350 (at 496 nm) \\
\hline
\end{tabular}

\subsection{Spectroscopy Characterization}

FTIR spectroscopy was used to obtain infrared spectra (\% transmittance) of synthesized bodipy dyes which can be seen in Figure 2. A broad band in the region of around $3500-2500 \mathrm{~cm}^{-1}$ can be observed (Figure 2a) which is a typical characteristic for compounds containing a carboxyl group $(\mathrm{O}-\mathrm{H}$ stretch) [38]. Since this band is in the same region as the $\mathrm{C}-\mathrm{H}$ stretching bands, a slightly distorted absorption pattern is observed where the former band is superimposed on the sharp $\mathrm{C}-\mathrm{H}$ stretching bands. Furthermore, a strong peak appeared around $1700 \mathrm{~cm}^{-1}$ for both dyes which was assigned to 
$\mathrm{C}=\mathrm{O}$ stretching of the carbonyl group [35]. Additional peaks that were identified for both spectra were located in the regions of around 1400, 1200, and $910 \mathrm{~cm}^{-1}$ (see Supplementary Materials Table S1 for the exact values) and were assigned to $\mathrm{O}-\mathrm{H}$ bend, $\mathrm{C}-\mathrm{O}$ stretch, and $\mathrm{O}-\mathrm{H}$ bend, respectively.
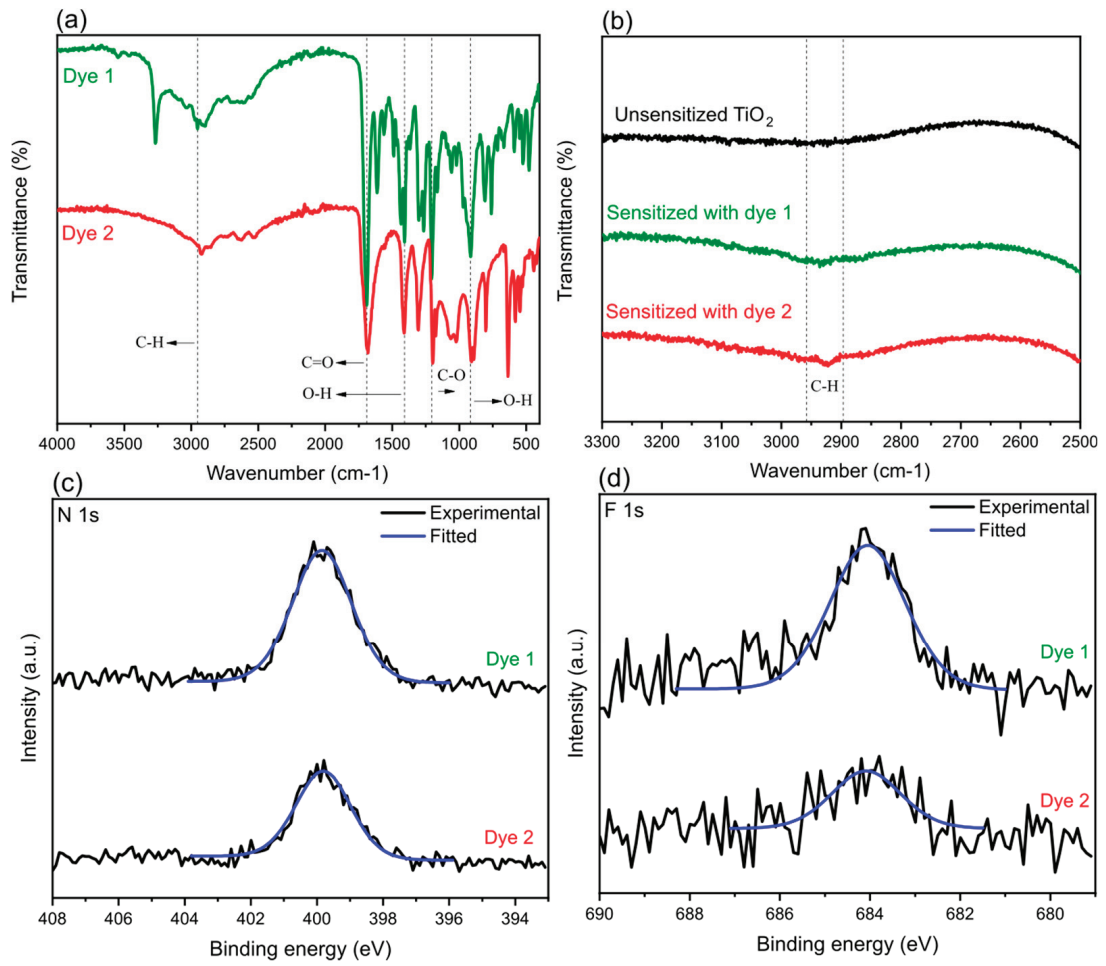

Figure 2. Fourier-transform infrared (FTIR) spectra of bodipy (a) dye 1 (green curve) and dye 2 (red curve) in a powder form along with the inset (b) of untreated (black curve) and sensitized $\mathrm{TiO}_{2}$ photoelectrodes on glass substrate. The whole range for the FTIR spectra of $\mathrm{TiO}_{2}$ photoelectrodes can be seen in Supplementary Materials Figure S5. The high-resolution (c) N 1s and (d) F 1s X-ray photoelectron spectroscopy (XPS) spectra for sensitized $\mathrm{TiO}_{2}$ photoelectrodes.

FTIR measurements were also performed with the intention to investigate interaction of individual dyes on sensitized $\mathrm{TiO}_{2}$ electrodes. However, our results showed that the substrates used for $\mathrm{TiO}_{2}$ deposition strongly absorbed below $2500 \mathrm{~cm}^{-1}$ which prevented characterization in this region (Supplementary Materials Figure S5). Despite this, by comparing regions of around $3000 \mathrm{~cm}^{-1}$ between sensitized and untreated $\mathrm{TiO}_{2}$ photoelectrodes, a slight increase in absorbance was observed for both sensitized $\mathrm{TiO}_{2}$ photoelectrodes. (Figure $2 \mathrm{~b}$ ) These bands were assigned to $\mathrm{C}-\mathrm{H}$ stretching of the dye compounds.

X-Ray photoelectron spectroscopy (XPS) was carried out to identify relevant elements present on the surface of untreated and sensitized $\mathrm{TiO}_{2}$ photoelectrodes. Elements $(\mathrm{N}$ and $\mathrm{F}$ ) associated to the compounds of the dyes were identified on both sensitized $\mathrm{TiO}_{2}$ photoelectrodes (Figure 2c) while only noise was observed in the same binding energy regions for the untreated $\mathrm{TiO}_{2}$ photoelectrode. (Figure S6). It is noteworthy that efforts related to the detection of boron resulted to be negative. However, such results are not surprising since it is notoriously difficult to detect B1's peak due to its very low sensitivity. 


\subsection{Photoelectrochemical Properties}

Photoelectrochemical cells (PECs) were fabricated using bodipy dyes 1 and 2 as photosensitizers for nanocrystalline $\mathrm{TiO}_{2}$ photoelectrodes. Figure 3 a shows the photocurrent-voltage $(J-V)$ curves of PECs and the photovoltaic parameters are summarized in Table 2. Compared to control (unsensitized), PECs sensitized with bodipy dyes showed a significant increase in $J_{\text {SC }}$ values $(\approx 2.5$-fold increase for dye 1 and $\approx 2$-fold increase for dye 2 ). Such a phenomenon is primarily attributed to the improved light harvesting due to the presence of the bodipy dyes. Moreover, the fill factor (FF) also increased for sensitized PECs while $\mathrm{V}_{\mathrm{OC}}$ decreased. The latter can be related to the changes in the band gap energy $\left(E_{g}\right)$ where an $E_{g}$ decrease results in higher $J_{S C}$ and lower $V_{O C}$. Nevertheless, the overall power conversion efficiency (PCE) of bodipy sensitized PECs doubled compared to the control. On the other hand, the results indicate that the proximity of the carboxylic acid group to the bodipy core notably influenced the photovoltaic parameters for PECs. Specifically, PECs sensitized with a bodipy dye 1 (distance of three carbons) were shown to exhibit better $J_{S C}$ as opposed to the bodipy dye 2 (distance of two carbons) sensitized PECs that had higher $V_{O C}$ and FF. Nevertheless, the overall PCE was not influenced by such changes (Table 2). It is noteworthy that the average values of the photovoltaic parameters for different batches of devices, shown in Figure S7, did not show a change in the trends, as discussed herein. Furthermore, the values of PV parameters for bodipy sensitized PECs were low where one of the reasons together with the nature of the absorption onset of the dyes can be related to their aggregation on the $\mathrm{TiO}_{2}$ photoelectrodes, thus increasing charge recombination and reducing electron injection to the n-type layer of the photoelectrode $[39,40]$.
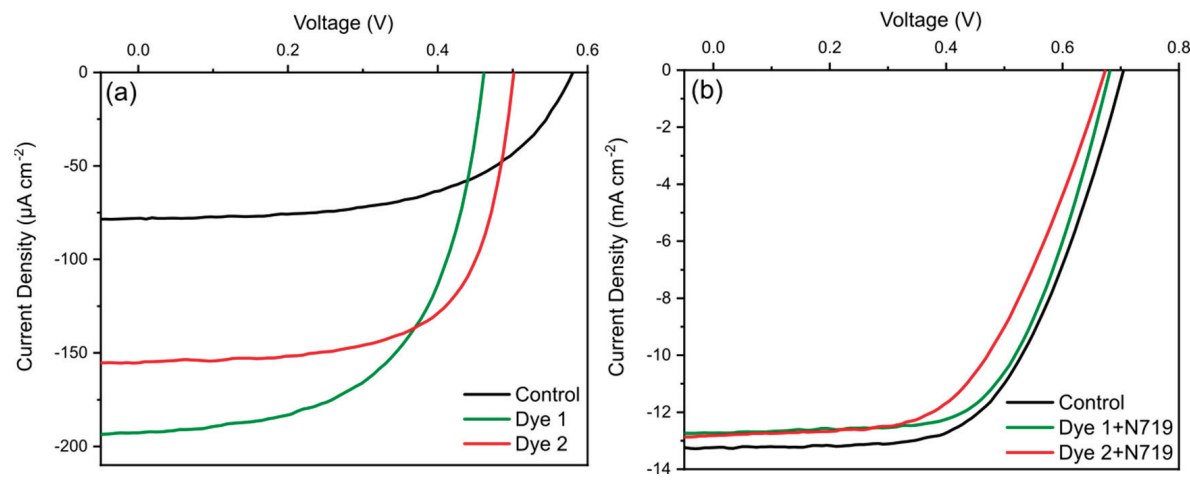

Figure 3. Photocurrent-voltage $(J-V)$ characteristics of photoelectrochemical cells (PECs) sensitized only with (a) dye 1 and 2 including a control (unsensitized) together with (b) N719 co-sensitized. The control PEC in (b) was sensitized only with a dye N719.

Table 2. Summary of photovoltaic parameters for different PECs sensitized with bodipy dye 1 or 2 and co-sensitized with dye $1+$ N719 or dye $2+$ N719 including the corresponding control (unsensitized and N719 sensitized) PECs.

\begin{tabular}{ccccc}
\hline PEC & $J_{\text {SC }}\left(\mu \mathbf{A ~ c m} \mathbf{~ c m}^{-2}\right)$ & $\mathbf{V}_{\mathbf{o c}}(\mathbf{m V})$ & FF (\%) & PCE (\%) \\
\hline Control (unsensitized) & 78.2 & 579.6 & 56.3 & 0.025 \\
\hline Dye 1 & 192.6 & 461.3 & 58.0 & 0.051 \\
\hline Dye 2 & 154.8 & 501.0 & 66.4 & 0.051 \\
\hline Control (N719 sensitized) & 13.2 & 704.7 & 59.2 & 5.5 \\
\hline Dye 1 + N719 & 12.7 & 681.3 & 61.6 & 5.3 \\
\hline Dye 2 + N719 & 12.8 & 673.1 & 55.5 & 4.8
\end{tabular}


Previous reports have shown that the performance of DSSCs containing co-adsorbents, bodipy and N719 can be improved compared to a single sensitizer [35]. Therefore, in an attempt to improve PV parameters bodipy dyes in this study were used and co-sensitized with N719 to investigate if the same conclusions can also be extended to the other combinations of sensitizers. In comparison with the control (sensitized only with N719), both $J_{S C}$ and $V_{O C}$ diminished for bodipy (dye 1 and 2) co-sensitized (5 vol\%) [35] PECs (Figure 3b and Table 2). A particularly noticeable decrease was observed for $\mathrm{V}_{\mathrm{OC}}$ where the parameter is influenced by the recombination rate and adsorption mode of the sensitizer [41] that when compared to the control, negatively influenced the co-sensitized PECs. Therefore, the bodipy dyes used in this study were shown to have a negative effect when implemented together with a N719 dye. We postulate that such an outcome was as a result of an increase in recombination centers which can be attributed to either a mismatch in energy levels or unsuitable molar absorption coefficient. Despite this, the bodipy dyes were shown to successfully sensitize $\mathrm{TiO}_{2}$ photoelectrodes, and further work into modifying the functional groups could lead to improved single sensitized, and co-sensitized PV performance. Specifically, efforts should be made into replacing electronegative elements, for example fluorine, with other functional groups that do not have such tendency to attract a bonding pair of electrons since this characteristic negatively affects the PV performance. In addition, other methods that aim to extend the absorption onset include attachments of an electron donor or acceptor to the C2 and C6 positions [29].

\section{Conclusions}

Two bodipy dyes with different carboxylic acids on the meso-position of the bodipy core have been synthesized. The bodipy dyes were used to sensitize $\mathrm{TiO}_{2}$ photoelectrodes which were characterized using spectroscopic techniques (UV/Vis absorption, FTIR and XPS). On the basis of these results, the $\mathrm{TiO}_{2}$ photoelectrodes were used to fabricate PECs. Their PV parameters were analyzed, and the results showed superior light harvesting and thus higher power conversion efficiencies compared to the control (unsensitized) PECs. Furthermore, the bodipy dyes were co-sensitized (5 vol\%) with a N719 dye to investigate their interactions in a PEC. The results showed a decrease in efficiencies indicating co-sensitization had a negative effect on the photovoltaic performance parameters of co-sensitized PECs. Further improvements in efficiencies are possible by designing/modifying bodipy dyes with different light absorbing groups within the organic framework to tune the absorption spectral range with high molar extinction coefficients and use them as co-sensitizers for solar cell devices.

Supplementary Materials: The following are available online at http:/www.mdpi.com/2079-4991/9/10/1346/s1, Figure S1: ${ }^{1} \mathrm{H}-\mathrm{NMR}$ of bodipy dye 1, Figure S2: ${ }^{1} \mathrm{H}-\mathrm{NMR}$ of bodipy dye 2, Figure S3: Tauc plots for solutions of bodipy (a) dye 1 and (b) dye 2, Figure S4: XRD patterns for $\mathrm{TiO}_{2}$ photoelectrodes, Figure S5: FTIR spectra of untreated and sensitized TiO2 photoelectrodes, Figure S6: The high-resolution (a) N 1s and (b) F 1s XPS spectra for control (unsensitized) TiO2 photoelectrode, Figure S7: Average (a) $J_{\mathrm{SC}}$, (b) $\mathrm{V}_{\mathrm{OC}}$, (c) FF and (d) power conversion efficiency (PCE) of the fabricated PECs sensitized only with bodipy dye 1 or 2 including a control (unsensitized), Table S1: FTIR peak wavenumbers and assignments for bodipy dye 1 and 2 .

Author Contributions: Experiments were designed by T.J.M and I.P.P with contribution from J.D.W. All dyes were synthesized by J.L.D. Materials characterization and PECs fabrication was performed by F.A. The manuscript was written by F.A. with contributions of J.L.D, T.J.M and I.P.P. All authors have given approval to the final version of the manuscript.

Funding: The authors acknowledge financial support from Surface Measurement Systems Ltd. T.J.M would like to thank the Ramsay Memorial Trust for their financial assistance. T.J.M and I.P.P would like to acknowledge the EPSRC for financial support (EP/M015157/1).

Conflicts of Interest: The authors declare no conflict of interest. 


\section{References}

1. Nayak, P.K.; Mahesh, S.; Snaith, H.J.; Cahen, D. Photovoltaic solar cell technologies: Analysing the state of the art. Nat. Rev. Mater. 2019, 4, 269. [CrossRef]

2. Khatri, I.; Shudo, K.; Matsuura, J.; Sugiyama, M.; Nakada, T. Impact of heat-light soaking on potassium fluoride treated CIGS solar cells with CdS buffer layer. Prog. Photovolt. Res. Appl. 2018, 26, 171-178. [CrossRef]

3. Munkhbayar, B.; Nine Md, J.; Jeoun, J.; Ji, M.; Jeong, H.; Chung, H. Synthesis of a graphene-tungsten composite with improved dispersibility of graphene in an ethanol solution and its use as a counter electrode for dye-sensitised solar cells. J. Power Sources 2013, 230, 207-217. [CrossRef]

4. Batmunkh, M.; Shrestha, A.; Bat-Erdene, M.; Nine, M.J.; Shearer, C.J.; Gibson, C.T.; Slattery, A.D.; Tawfik, S.A.; Ford, M.J.; Dai, S.; et al. Electrocatalytic activity of a 2D phosphorene-based heteroelectrocatalyst for photoelectrochemical cells. Angew. Chem. Int. Ed. 2018, 57, 2644-2647. [CrossRef] [PubMed]

5. Stroyuk, O.; Raevskaya, A.; Gaponik, N. Solar light harvesting with multinary metal chalcogenide nanocrystals. Chem. Soc. Rev. 2018, 47, 5354-5422. [CrossRef] [PubMed]

6. Shrestha, A.; Batmunkh, M.; Tricoli, A.; Qiao, S.Z.; Dai, S. Near-infrared active lead chalcogenide quantum dots: Preparation, post-synthesis ligand exchange, and applications in solar cells. Angew. Chem. Int. Ed. 2019, 58, 5202-5224. [CrossRef] [PubMed]

7. Ye, L.; Xiong, Y.; Chen, Z.; Zhang, Q.; Fei, Z.; Henry, R.; Heeney, M.; O'Connor, B.T.; You, W.; Ade, H. Sequential deposition of organic films with eco-compatible solvents improves performance and enables over 12\%-efficiency nonfullerene solar cells. Adv. Mater. 2019, 31, 1808153. [CrossRef] [PubMed]

8. Zhang, J.; Tan, H.S.; Guo, X.; Facchetti, A.; Yan, H. Material insights and challenges for non-fullerene organic solar cells based on small molecular acceptors. Nat. Energy 2018, 3, 720-731. [CrossRef]

9. Ye, L.; Hu, H.; Ghasemi, M.; Wang, T.; Collins, B.A.; Kim, J.-H.; Jiang, K.; Carpenter, J.H.; Li, H.; Li, Z.; et al. Quantitative relations between interaction parameter, miscibility and function in organic solar cells. Nat. Mater. 2018, 17, 253-260. [CrossRef]

10. Jeon, N.J.; Na, H.; Jung, E.H.; Yang, T.-Y.; Lee, Y.G.; Kim, G.; Shin, H.-W.; Seok, S.I.; Lee, J.; Seo, J. A fluorene-terminated hole-transporting material for highly efficient and stable perovskite solar cells. Nat. Energy 2018, 3, 682. [CrossRef]

11. Macdonald, T.J.; Batmunkh, M.; Lin, C.-T.; Kim, J.; Tune, D.D.; Ambroz, F.; Li, X.; Xu, S.; Sol, C.; Papakonstantinou, I.; et al. Origin of performance enhancement in $\mathrm{TiO}_{2}$-carbon nanotube composite perovskite solar cells. Small Methods 2019, 1900164. [CrossRef]

12. Rong, Y.; Hu, Y.; Mei, A.; Tan, H.; Saidaminov, M.I.; Seok, S.I.; McGehee, M.D.; Sargent, E.H.; Han, H. Challenges for commercializing perovskite solar cells. Science 2018, 361, eaat8235. [CrossRef] [PubMed]

13. Ren, Y.; Sun, D.; Cao, Y.; Tsao, H.N.; Yuan, Y.; Zakeeruddin, S.M.; Wang, P.; Grätzel, M. A stable blue photosensitizer for color palette of dye-sensitized solar cells reaching $12.6 \%$ efficiency. J. Am. Chem. Soc. 2018, 140, 2405-2408. [CrossRef] [PubMed]

14. Ambroz, F.; Sathasivam, S.; Lee, R.; Gadipelli, S.; Lin, C.-T.; Xu, S.; Poduval, R.K.; Mclachlan, M.A.; Papakonstantinou, I.; Parkin, I.P.; et al. Influence of lithium and lanthanum treatment on $\mathrm{TiO}_{2}$ nanofibers and their application in n-i-p solar cells. ChemElectroChem 2019, 6, 3590-3598. [CrossRef]

15. Macdonald, T.J.; Ambroz, F.; Batmunkh, M.; Li, Y.; Kim, D.; Contini, C.; Poduval, R.; Liu, H.; Shapter, J.G.; Papakonstantinou, I.; et al. $\mathrm{TiO}_{2}$ nanofiber photoelectrochemical cells loaded with sub-12 nm AuNPs: Size dependent performance evaluation. Mater. Today Energy 2018, 9, 254-263. [CrossRef]

16. Nazeeruddin, M.K.; Klein, C.; Liska, P.; Grätzel, M. Synthesis of novel ruthenium sensitizers and their application in dye-sensitized solar cells. Coord. Chem. Rev. 2005, 249, 1460-1467. [CrossRef]

17. Nazeeruddin, M.K.; Kay, A.; Rodicio, I.; Humphry-Baker, R.; Mueller, E.; Liska, P.; Vlachopoulos, N.; Graetzel, M. Conversion of light to electricity by cis-X2bis(2,2'-bipyridyl-4,4'-dicarboxylate)ruthenium(II) charge-transfer sensitizers ( $\mathrm{X}=\mathrm{Cl}-, \mathrm{Br}-, \mathrm{I}-, \mathrm{CN}-$, and $\mathrm{SCN}-)$ on nanocrystalline titanium dioxide electrodes. J. Am. Chem. Soc. 1993, 115, 6382-6390. [CrossRef]

18. Kolemen, S.; Bozdemir, O.A.; Cakmak, Y.; Barin, G.; Erten-Ela, S.; Marszalek, M.; Yum, J.-H.; Zakeeruddin, S.M.; Nazeeruddin, M.K.; Grätzel, M.; et al. Optimization of distyryl-Bodipy chromophores for efficient panchromatic sensitization in dye sensitized solar cells. Chem. Sci. 2011, 2, 949-954. [CrossRef] 
19. Ji, J.-M.; Zhou, H.; Kim, H.K. Rational design criteria for D- $\pi-$ A structured organic and porphyrin sensitizers for highly efficient dye-sensitized solar cells. J. Mater. Chem. A 2018, 6, 14518-14545. [CrossRef]

20. Song, H.; Liu, Q.; Xie, Y. Porphyrin-sensitized solar cells: systematic molecular optimization, coadsorption and cosensitization. Chem. Commun. 2018, 54, 1811-1824. [CrossRef]

21. Kuang, D.; Walter, P.; Nüesch, F.; Kim, S.; Ko, J.; Comte, P.; Zakeeruddin, S.M.; Nazeeruddin, M.K.; Grätzel, M. Co-sensitization of organic dyes for efficient ionic liquid electrolyte-based dye-sensitized solar cells. Langmuir 2007, 23, 10906-10909. [CrossRef] [PubMed]

22. Chen, Y.; Yang, L.; Wu, J.; Wang, G.; Huang, W.; Melkonyan, F.S.; Lu, Z.; Huang, Y.; Marks, T.J.; Facchetti, A. Performance, morphology, and charge recombination correlations in ternary squaraine solar cells. Chem. Mater. 2018, 30, 6810-6820. [CrossRef]

23. Erten-Ela, S.; Ueno, Y.; Asaba, T.; Kubo, Y. Synthesis of a dibenzo-Bodipy-incorporating phenothiazine dye as a panchromatic sensitizer for dye-sensitized solar cells. New J. Chem. 2017, 41, 10367-10375. [CrossRef]

24. Singh, S.P.; Gayathri, T. Evolution of BODIPY dyes as potential sensitizers for dye-sensitized solar cells. Eur. J. Org. Chem. 2014, 2014, 4689-4707. [CrossRef]

25. He, H.; Ji, S.; He, Y.; Zhu, A.; Zou, Y.; Deng, Y.; Ke, H.; Yang, H.; Zhao, Y.; Guo, Z.; et al. Photoconversion-tunable fluorophore vesicles for wavelength-dependent photoinduced cancer therapy. Adv. Mater. 2017, 29, 1606690. [CrossRef]

26. Turksoy, A.; Yildiz, D.; Akkaya, E.U. Photosensitization and controlled photosensitization with bodipy dyes. Coord. Chem. Rev. 2019, 379, 47-64. [CrossRef]

27. Lee, C.Y.; Hupp, J.T. Dye sensitized solar cells: $\mathrm{TiO}_{2}$ sensitization with a bodipy-porphyrin antenna system. Langmuir 2010, 26, 3760-3765. [CrossRef]

28. Urbani, M.; Grätzel, M.; Nazeeruddin, M.K.; Torres, T. Meso-substituted porphyrins for dye-sensitized solar cells. Chem. Rev. 2014, 114, 12330-12396. [CrossRef]

29. Klfout, H.; Stewart, A.; Elkhalifa, M.; He, H. BODIPYs for dye-sensitized solar cells. ACS Appl. Mater. Interfaces 2017, 9, 39873-39889. [CrossRef]

30. Islam, A.; Chowdhury, T.H.; Qin, C.; Han, L.; Lee, J.-J.; Bedja, I.M.; Akhtaruzzaman, M.; Sopian, K.; Mirloup, A.; Leclerc, N. Panchromatic absorption of dye sensitized solar cells by co-Sensitization of triple organic dyes. Sustain. Energy Fuels 2017, 2, 209-214. [CrossRef]

31. Cheema, H.; Younts, R.; Gautam, B.; Gundogdu, K.; El-Shafei, A. Design and synthesis of BODIPY sensitizers with long alkyl chains tethered to $\mathrm{N}$-carbazole and their application for dye sensitized solar cells. Mater. Chem. Phys. 2016, 184, 57-63. [CrossRef]

32. Qin, C.; Mirloup, A.; Leclerc, N.; Islam, A.; El-Shafei, A.; Han, L.; Ziessel, R. Molecular engineering of new thienyl-bodipy dyes for highly efficient panchromatic sensitized solar cells. Adv. Energy Mater. 2014, 4, 1400085. [CrossRef]

33. Li, Z.; Mintzer, E.; Bittman, R. First synthesis of free cholesterol-BODIPY conjugates. J. Org. Chem. 2006, 71, 1718-1721. [CrossRef] [PubMed]

34. Pakhomov, A.A.; Kononevich, Y.N.; Stukalova, M.V.; Svidchenko, E.A.; Surin, N.M.; Cherkaev, G.V.; Shchegolikhina, O.I.; Martynov, V.I.; Muzafarov, A.M. Synthesis and photophysical properties of a new BODIPY-based siloxane dye. Tetrahedron Lett. 2016, 57, 979-982. [CrossRef]

35. Wanwong, S.; Sangkhun, W.; Wootthikanokkhan, J. The effect of co-sensitization methods between N719 and boron dipyrromethene triads on dye-sensitized solar cell performance. RSC Adv. 2018, 8, 9202-9210. [CrossRef]

36. Krauss, T.N.; Barrena, E.; Zhang, X.N.; de Oteyza, D.G.; Major, J.; Dehm, V.; Würthner, F.; Cavalcanti, L.P.; Dosch, $\mathrm{H}$. Three-dimensional molecular packing of thin organic films of PTCDI-C ${ }_{8}$ determined by surface X-Ray diffraction. Langmuir 2008, 24, 12742-12744. [CrossRef] [PubMed]

37. Dharma, J.; Pisal, A. Simple Method of Measuring the Band Gap Energy Value of TiO2 in the Powder Form Using a UV/Vis/NIR Spectrometer; Perkin Elmer: Shelton, CT, USA, 2012.

38. Jiang, X.; Li, S.; Xiang, G.; Li, Q.; Fan, L.; He, L.; Gu, K. Determination of the acid values of edible oils via FTIR spectroscopy based on the $\mathrm{OH}$ stretching band. Food Chem. 2016, 212, 585-589. [CrossRef]

39. Mao, M.; Song, Q.-H. The structure-property relationships of D- $\pi$-A BODIPY dyes for dye-sensitized solar cells. Chem. Rec. 2016, 16, 719-733. [CrossRef] 
40. Mishra, A.; Fischer, M.K.R.; Bäuerle, P. Metal-free organic dyes for dye-sensitized solar cells: From structure: Property relationships to design rules. Angew. Chem. Int. Ed. 2009, 48, 2474-2499. [CrossRef]

41. Fan, K.; Yu, J.; Ho, W. Improving photoanodes to obtain highly efficient dye-sensitized solar cells: A brief review. Mater. Horiz. 2017, 4, 319-344. [CrossRef]

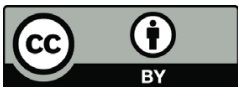

(C) 2019 by the authors. Licensee MDPI, Basel, Switzerland. This article is an open access article distributed under the terms and conditions of the Creative Commons Attribution (CC BY) license (http://creativecommons.org/licenses/by/4.0/). 

Article

\title{
Elucidating the Effect of Etching Time Key-Parameter toward Optically and Electrically-Active Silicon Nanowires
}

\author{
Mariem Naffeti ${ }^{1,2,3, *}$, Pablo Aitor Postigo ${ }^{2}$, Radhouane Chtourou ${ }^{1}$ and Mohamed Ali Zaïbi ${ }^{1,3}$ \\ 1 Laboratory of Nanomaterials and Systems for Renewable Energies (LaNSER), Research and Technology \\ Center of Energy, Techno-Park Borj-Cedria, Bp 95, 2050 Hammam-Lif, Tunis, Tunisia; \\ radhouane.chtourou@crten.rnrt.tn (R.C.); medali.zaibi@ensit.rnu.tn (M.A.Z.) \\ 2 Instituto de Micro y Nanotecnología, IMN-CNM, CSIC (CEI UAM+CSIC) Isaac Newton, 8, E-28760 Tres \\ Cantos, Madrid, Spain; pabloaitor.postigo@imn.cnm.csic.es \\ 3 Tunis University-National High School of Engineering of Tunis, 5 Av Taha Hussein 1008 Tunis, Tunisia \\ * Correspondence: naffeti.mariam@gmail.com
}

Received: 25 November 2019; Accepted: 6 January 2020; Published: 25 February 2020

\begin{abstract}
In this work, vertically aligned silicon nanowires (SiNWs) with relatively high crystallinity have been fabricated through a facile, reliable, and cost-effective metal assisted chemical etching method. After introducing an itemized elucidation of the fabrication process, the effect of varying etching time on morphological, structural, optical, and electrical properties of SiNWs was analysed. The NWs length increased with increasing etching time, whereas the wires filling ratio decreased. The broadband photoluminescence (PL) emission was originated from self-generated silicon nanocrystallites (SiNCs) and their size were derived through an analytical model. FTIR spectroscopy confirms that the PL deterioration for extended time is owing to the restriction of excitation volume and therefore reduction of effective light-emitting crystallites. These SiNWs are very effective in reducing the reflectance to $9-15 \%$ in comparison with $\mathrm{Si}$ wafer. I-V characteristics revealed that the rectifying behaviour and the diode parameters calculated from conventional thermionic emission and Cheung's model depend on the geometry of SiNWs. We deduce that judicious control of etching time or otherwise SiNWs' length is the key to ensure better optical and electrical properties of SiNWs. Our findings demonstrate that shorter SiNWs are much more optically and electrically active which is auspicious for the use in optoelectronic devices and solar cells applications.
\end{abstract}

Keywords: silicon nanowires; metal assisted chemical etching; etching time; optical properties; electrical properties

\section{Introduction}

In recent years, silicon nanowires (SiNWs) have aroused tremendous attention worldwide thanks to the following outstanding features: (1) Environment-friendly as second most earth-abundant materials; (2) unique dimensional structures (1 D); (3) interesting electrical and optical properties compared to bare silicon; (4) affordable fabrication; and (5) potential applications in several fields [1-5]. The various applications of these nanostructures may include lithium-ion batteries [6], biochemical sensors [7,8], electronics [9], catalysis [10], and solar cells [1,11].

Based upon the bottom-up and top down approaches, numerous methods have been used to fabricate SiNWs such as vapor-liquid-solid, thermal evaporation, molecular beam epitaxy, laser ablation, and lithography [12-16]. However, these techniques have some limitations as they generally require expensive and complex equipment, employ hazardous silicon precursors, and involve high vacuum and high temperature [17]. These features make the synthesis expensive and 
time-consuming and therefore hindered their applications for commercialized products. In contrast, an effective and promising synthetic method namely metal assisted chemical etching (MACE) has been proposed [2,4,18-20]. This technique is simple, rapid, low cost, and suitable for both industrial and laboratory scales. Moreover, MACE allows to obtain high crystalline SiNWs quality, as well as an easy control of the different parameters including orientation, doping type, length, and diameter.

The MACE method basically consists of two procedures, the formation of metal catalysts and the subsequent etching process which can be implemented either in a single step (1-MACE) [10,21] or in two steps (2-MACE) [17-20]. Moreover, the formation method, etching time, etching temperature, metal deposition time, and lastly the etchants' concentrations have a crucial influence on the morphology of SiNWs $[2,5,17]$. Ghosh et al. reported that SiNWs grown by MACE are usually covered with silicon nanocrystals due to the side wall etching and which are the origin of quantum confinement $(\mathrm{QC})$ effects owing to their small dimensions [20].

Recently, several research groups have succeeded in the synthesis of optically-active SiNWs exhibiting a significant PL emission and a very low reflectance [3,4,17]. On the other hand, Qi et al. have demonstrated the fabrication of electrically-active SiNWs through heavily doped SiNWs with rough surface where a high Schottky barrier exists at the interface of SiNWs and the metal [22]. Nevertheless, further investigation is required to explore both optically and electrically active SiNWs. Indeed, a number of studies have investigated the optical and electrical properties of SiNWs [23-25]. It has been shown that $\mathrm{SiNWs}$, obtained by 1-MACE in $\mathrm{AgNO}_{3}, \mathrm{HF}$, and $\mathrm{H}_{2} \mathrm{O}_{2}$ solution from a $\mathrm{P}^{+}$type starting $\mathrm{Si}$ wafer, possess such a remarkable low reflectance and the electronic properties are affected by SiNWs' homogeneity [23]. Otherwise, Hutagalung et al. also reported a low reflectance of less than $10 \%$ obtained by SiNW arrays synthesized via 1-MACE in an $\mathrm{AgNO}_{3}$ and $\mathrm{HF}$ solution at $60^{\circ} \mathrm{C}$ from an n-type $\mathrm{Si}$, whereas its I-V characteristics show linear ohmic behavior [24]. Therefore, careful production of SiNWs, by tuning the different parameters such as the etching time, etchant composition and concentration, etching temperature, and the starting $\mathrm{Si}$ wafer characteristics, is important to ensure good physical properties of SiNWs [23-25]. However, these previous works have neglected the PL study, as well as a deeper insight and understanding of the electrical properties via determining the electrical parameters is missing.

In this work, we contribute our recent results on the fabrication of optically and electrically-active SiNWs which exhibit a strong PL emission, remarkable antireflections properties, and interesting electrical properties. First, a detailed explanation of the fabrication process is reported and then vertical aligned SiNWs with relatively high crystallinity were obtained through the 2-MACE method. The effect of etching time key parameter on SiNWs' filling ratio and length, optical, and electrical properties were investigated and evaluated. A broadband PL emission and low reflectance from these wires were obtained. Later on, the I-V characteristics and the electrical parameters were carefully determined and studied. Our findings could consider the optimized SiNWs as a promising candidate in PV and optoelectronic applications due to their unique structural, optical, and electrical properties.

\section{Materials and Methods}

\subsection{Reagents and Materials}

The chemical reagents used in this work for the cleaning or etching process such as acetone, ethanol, isopropanol, hydrofluoric acid ( $\mathrm{HF}, 40 \%)$, silver nitrate $\left(\mathrm{AgNO}_{3}\right)$, hydrogen peroxide $\left(\mathrm{H}_{2} \mathrm{O}_{2}\right.$, $35 \%)$, and nitric acid $\left(\mathrm{HNO}_{3}, 65 \%\right)$ were purchased from Sigma-Aldrich (Madrid, Spain). All of them were used without any purification. The single-side polished p-type silicon wafers were purchased from Siltronics (Archamps, France) and finally deionized water used in all the experiments was supplied by local sources. 


\subsection{Samples Preparation}

SiNW arrays were synthesized by the Ag-assisted chemical etching method of (100) oriented p-type silicon wafers with the resistivity of $1-20 \Omega \mathrm{cm}$. The fabrication process is as follows: (1) The silicon wafers were sequentially cleaned in acetone, ethanol, isopropanol, and deionized water (DI) in an ultrasonic bath for $15 \mathrm{~min}$ each. The cleaned wafers were then immersed in diluted HF for $3 \mathrm{~min}$. (2) Silver nanoparticles were deposited onto the Si substrate using an aqueous solution composed of 4.8 $\mathrm{M} \mathrm{HF}$ and $0.035 \mathrm{M} \mathrm{AgNO}_{3}$ for $1 \mathrm{~min}$. (3) Silicon wafers covered with AgNPs were dipped into the etching solution of $4.8 \mathrm{M} \mathrm{HF}$ and $0.5 \mathrm{M} \mathrm{H}_{2} \mathrm{O}_{2}$ at room temperature during 20 (sample S1), 40 (S2), 60 (S3), 80 (S4), 100 (S5), and $120 \mathrm{~min}$ (S6). (4) The resulting samples were rinsed with DI and then immersed in nitric acid for $15 \mathrm{~min}$ to remove the silver nanoparticles and dendrites. Finally, the as-formed homogeneous black SiNWs were washed again with DI and dried with nitrogen.

\subsection{Characterizations}

The samples were studied using several techniques. The morphologies of the synthesized SiNWs were characterized using scanning electron microscopy (SEM, FEI Verios 460, FEI Europe B.V., Eindhoven, Netherlands). The observations were performed in a top view, cross-section, and $30^{\circ}$ tilt view. X-ray diffraction (XRD) measurements were performed using an automated Bruker D8 advance X-ray diffractometer (Bruker, Karlsruhe, Germany) with $\mathrm{Cu} \mathrm{K} \alpha(\lambda=1.54 \AA)$ in $2 \theta$ ranging from 20 to $80^{\circ}$. Photoluminescence spectroscopic analyses of SiNWs were made with a $405 \mathrm{~nm}$ laser wavelength and all the measurements were done at room temperature (RT). Moreover, we have used an analytical model to deduce the SiNCs size through PL spectra of the fabricated samples. The FTIR analyses were taken on an absorbance mode using Bruker IFS66v/s FTIR spectrometer (Bruker, Karlsruhe, Germany) and investigated in the $400-4000 \mathrm{~cm}^{-1}$ range with a step of $4 \mathrm{~cm}^{-1}$. Reflectance measurements were performed via Perkin Elmer Lambda 950 spectrophotometer (Perkin Elmer, Inc., Waltham, MA, USA). The current-voltage (I-V) measurements were measured via Keithley 2400 source meter (Keithley, Austin, TX, USA) in the dark and at room temperature.

\section{Results and Discussion}

\subsection{Detailed Mechanism of SiNWs' Formation}

Two-step MACE was introduced to prepare vertically aligned SiNWs which is a simple, reproducible, and inexpensive process using Ag catalysts in the $\mathrm{HF} / \mathrm{H}_{2} \mathrm{O}_{2}$ etching agent. To better understand SiNWs' formation mechanism, the properties of $\mathrm{Si}, \mathrm{Ag}^{+}, \mathrm{Ag}$, and $\mathrm{H}_{2} \mathrm{O}_{2}$ in $\mathrm{HF}$ solution should be understood. Figure 1 shows a scheme of the potential distribution of $\mathrm{Si}, \mathrm{Ag}^{+} / \mathrm{Ag}$, and $\mathrm{H}_{2} \mathrm{O}_{2} / \mathrm{H}_{2} \mathrm{O}$ redox pairs in $\mathrm{HF}$ solution when the energy is referred to the standard hydrogen electrode potential (SHE).

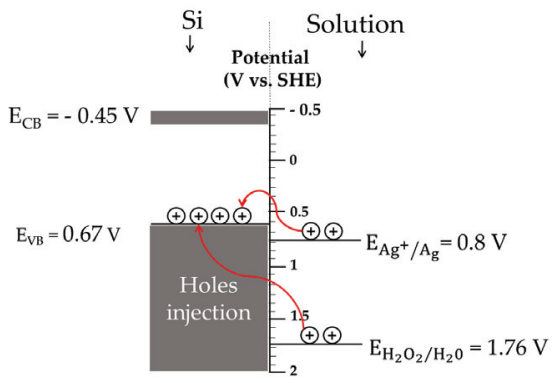

Figure 1. Schematic of the potential relationship between bands in a silicon ( $\mathrm{Si}$ ) substrate, $\mathrm{Ag}^{+} / \mathrm{Ag}$ and $\mathrm{H}_{2} \mathrm{O}_{2} / \mathrm{H}_{2} \mathrm{O}$ redox pairs. 
The energies of the valence band (VB) and conduction band (CB) of Si are 0.67 and $-0.45 \mathrm{eV}$, respectively while the potential energies of the redox pairs of $\mathrm{Ag}^{+} / \mathrm{Ag}$ and $\mathrm{H}_{2} \mathrm{O}_{2} / \mathrm{H}_{2} \mathrm{O}$ are 0.8 and 1.76 $\mathrm{V}$, respectively [26].

The growth mechanism of SiNW arrays was elucidated in this section and depicted in Figure 2.

Step 1

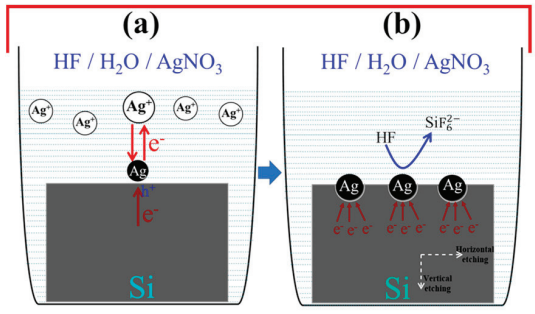

Step 2

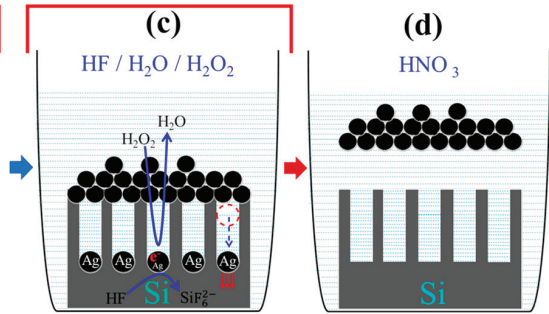

Figure 2. Schematic illustration of the formation mechanism of silicon nanowires (SiNWs) via two-step MACE. (a) Reduction of $\mathrm{Ag}^{+}$ions and formation of $\mathrm{Ag}$ nuclei at the Si surface. (b) Further silver nuclei growth, oxidative dissolution of Silicon atoms, and production of porous layer. (c) Vertical propagation of silver nanoparticles and faster etching leading to SiNWs formation. (d) Silver removal and vertical aligned SiNW arrays production.

After the cleaning stages, 2-MACE consists first of all in dipping the silicon wafers in a $\mathrm{HF} / \mathrm{AgNO}$ aqueous solution producing AgNPs deposition. Indeed, the $\mathrm{AgNO}_{3}$ metallic salt come apart in the HF aqueous solution to yield metal ions $\mathrm{Ag}^{+}$. The $\mathrm{Ag}^{+}$ions close to the Si surface extract electrons from the VB of Si resulting in a small silver nuclei on the surface of the silicon (Figure 2a). These electrons transfer continues to take place as Ag is more electronegative than Si leading to a large silver nuclei growth and then a formation of Ag-nanoclusters or a continuous silver layer. Furthermore, the excess of electrons extract forms an accumulation of holes beneath and around the catalyst.

This leads to silicon oxidation followed by HF dissolution into silicon hexafluoride ions $\left(\mathrm{SiF}_{6}^{2-}\right)$ while unveiling a newly exposed Si coming in contact with the Ag catalysts which will be further etched in the second step of the continuous MACE process. The synchronized mechanism of $\mathrm{Ag}^{+}$ reduction (cathodic process) and silicon oxidation (anodic process) can be described by the following equations:

$$
\begin{aligned}
& \text { cathode reaction } \mathrm{Ag}^{+}+\mathrm{e}^{-} \rightarrow \mathrm{Ag} \quad \mathrm{E}^{0}=0.79 \mathrm{~V} \text { (vs. SHE) } \\
& \text { anode reaction } \mathrm{Si}+6 \mathrm{HF} \rightarrow \mathrm{SiF}_{6}^{2-}+4 \mathrm{e}^{-}+6 \mathrm{H}^{+} \\
& \text {overall reaction } \mathrm{Si}+6 \mathrm{HF}+4 \mathrm{Ag}^{+} \rightarrow \mathrm{SiF}_{6}^{2-}+4 \mathrm{Ag}+6 \mathrm{H}^{+}
\end{aligned}
$$

At a certain while, the hole injection rate attenuates because almost all $\mathrm{Ag}^{+}$ions in the vicinity of the silicon surface are reduced into Ag. Therefore, silicon oxidation slows down causing a decrease in the Si etching rate which requires a complementary hole injection species to permit the continuation of the silicon nanostructuring. Subsequently, $\mathrm{H}_{2} \mathrm{O}_{2}$ is added to the etching solution because it is a strong oxidant allowing a hole injection instead of Ag ions. When the silicon wafer covered with the silver, dendritic layer was put into the $\mathrm{HF} / \mathrm{H}_{2} \mathrm{O}_{2}$ aqueous solution, the second step in MACE mechanism which corresponds to the etching process starts to take place. Since the redox potential of $\mathrm{H}_{2} \mathrm{O}_{2}$ is more positive than that of $\mathrm{Ag}, \mathrm{H}_{2} \mathrm{O}_{2}$ captures electrons from the previously nucleated $\mathrm{Ag}$ particles and reduces to $\mathrm{H}_{2} \mathrm{O}$. Hence, $\mathrm{Ag}$ is oxidized immediately to $\mathrm{Ag}^{+}$, this oxidation allows the solution feeding with $\mathrm{Ag}^{+}$ions which enhances the hole injection. The silicon is then locally oxidized into $\mathrm{SiO}_{2}$ and dissolved simultaneously by HF, so the AgNPs sink downwards vertically along the (100) direction in the pits thus formed leading to the generation of vertical SiNWs (Figure 2c). This is contrary to porous silicon (PS) which displays a porous surface morphology due to the absence of $\mathrm{AgNO}_{3}$ in the etching 
solution and the slow etching rate. The redox reactions taking place during etching process can be described as follows [27,28]:

$$
\begin{aligned}
& \text { cathode reaction } \mathrm{H}_{2} \mathrm{O}_{2}+2 \mathrm{e}^{-}+2 \mathrm{H}^{+} \rightarrow 2 \mathrm{H}_{2} \mathrm{O} \quad \mathrm{E}^{0}=1.76 \mathrm{~V} \text { (vs. SHE) } \\
& \text { anode reaction } \mathrm{Si}+2 \mathrm{H}_{2} \mathrm{O} \rightarrow \mathrm{SiO}_{2}+4 \mathrm{H}^{+}+4 \mathrm{e}^{-} \\
& \qquad \mathrm{SiO}_{2}+6 \mathrm{HF} \rightarrow \mathrm{SiF}_{6}^{2-}+2 \mathrm{H}_{2} \mathrm{O}+2 \mathrm{H}^{+} \\
& \text {Overall reaction } \mathrm{Si}+2 \mathrm{H}_{2} \mathrm{O}_{2}+6 \mathrm{~F}^{-}+4 \mathrm{H}^{+} \rightarrow \mathrm{SiF}_{6}^{2-}+4 \mathrm{H}_{2} \mathrm{O}
\end{aligned}
$$

Using Reaction (7), the potential $\Delta \mathrm{E}$ of etching process is as follows:

$$
\Delta \mathrm{E}=\Delta \mathrm{E}^{0}-\frac{0.059}{4}\left\{\log \frac{\left[5 \mathrm{iF}_{6}^{2-}\right]}{\left[\mathrm{H}_{2} \mathrm{O}_{2}\right]^{2}\left[\mathrm{H}^{+}\right]^{4}\left[\mathrm{~F}^{-}\right]^{6}}\right\}
$$

According to this equation, the increase of $\mathrm{H}_{2} \mathrm{O}_{2}$ and $\mathrm{HF}$ concentrations enhance the reaction potential with an increase in the etching rate. However, the etching rate may not increase infinitely and it is preferable to choose an appropriate range of etchant concentration to ensure good quality SiNWs formation. It is suggested that the self-grown SiNCs on SiNWs form due to sidewall etching such us the extra $\mathrm{Ag}^{+}$ions spread through the nanowires and trap electrons from the sidewalls leading to a lateral etching of SiNWs and consequently formation of porous SiNWs decorated with SiNCs [20]. Ultimately, the removal of AgNPs and dendrites by immersing the samples in an $\mathrm{HNO}_{3}$ aqueous solution reveals highly oriented one-dimensional (1D) SiNWs. The corresponding reaction is expressed as:

$$
3 \mathrm{Ag}+4 \mathrm{HNO}_{3} \rightarrow 3 \mathrm{AgNO}_{3}+\mathrm{NO}+2 \mathrm{H}_{2} \mathrm{O}
$$

\subsection{Etching Time Effect on Morphology of SiNW Arrays}

In order to investigate the effect of etching time on SiNWs morphology and structure, the $\mathrm{AgNO}_{3}$, $\mathrm{HF}$, and $\mathrm{H}_{2} \mathrm{O}_{2}$ concentrations were fixed in both deposition and etching steps. SEM images (top view, cross-section, and tilt view at $30^{\circ}$ ) of the as-prepared SiNWs etched in different times (20-120 min), are shown in Figure 3. The SiNWs dependence on etching time was explored. Forest-like SiNW arrays can be noticed from the top view images (Figure 3a-f). The NWs etched during short etching time are isolated from each other. However, the tips of the nanowires congregate together with time increment to form bundles. This bundle-like structures distribute uniformly on the whole wafers and could be confirmed from the tilt view images. The possible reasons behind this conglomeration may be attributed to Van der Waals attraction between the nanowires [29,30] as well as to the increase in the length of SiNWs that likely causes them to bend to form bouquets under the action of gravity. Otherwise, it was also reported that some nanowires could remain unattached due to inhomogeneous etching induced by a random silver particle distribution [31]. The calculated values of average volume filling ratio (VFR) at the air/SiNW arrays interface versus etching time is plotted in Figure $4 \mathrm{a}$ and it showed the decreasing of VFR when the etching time increase. For example, VFR is 0.45 in dense SiNWs at $20 \mathrm{~min}$ decreases to 0.33 in convergent SiNW arrays at $120 \mathrm{~min}$ of etching time. This is due to the bundle-like structures of the wires in prolonged etching times. Chang et al. [32] reported a similar variation in VFR, however, as a function of $\mathrm{AgNO}_{3}$ concentrations. 
Plan

20

min
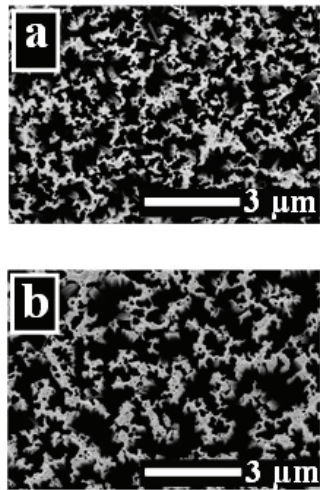

40

min

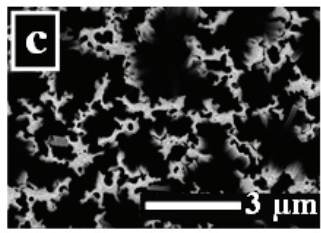

80

min

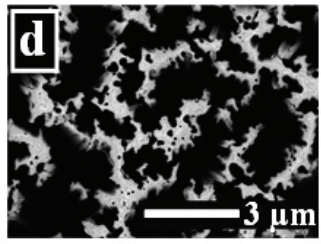

100

min
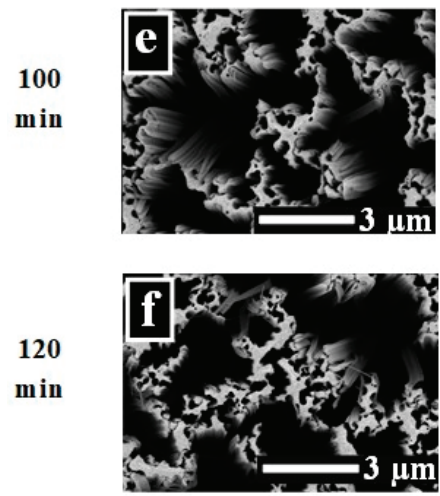

$35^{\circ}$
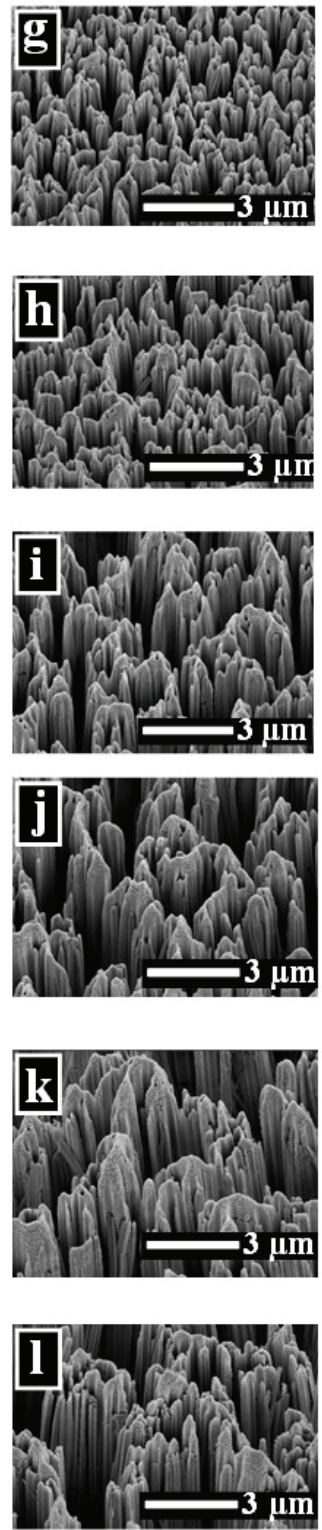

Cross Section
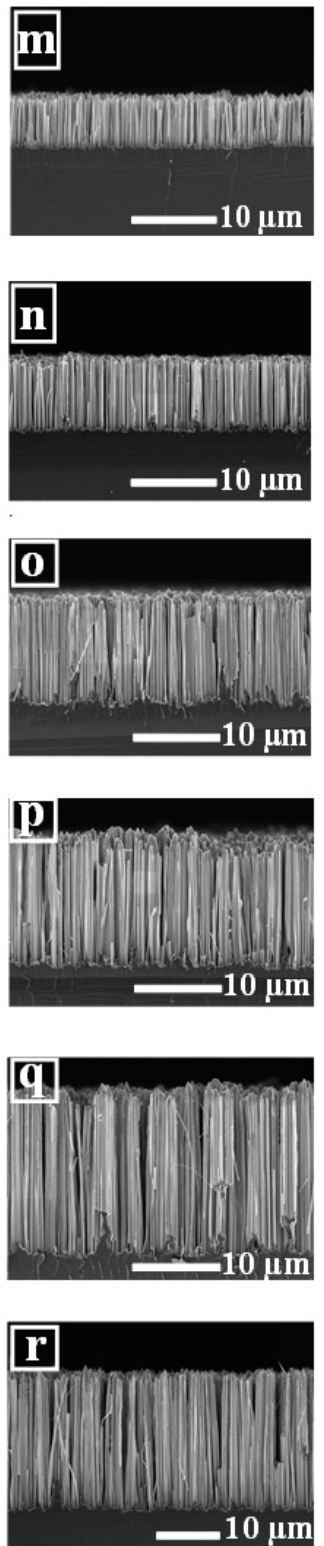

Figure 3. SEM images of SiNWs etched at different durations showing top view surface $(\mathbf{a}-\mathbf{f})$, tilt view $35^{\circ}(\mathbf{g}-\mathbf{1})$, and cross-sectional $(\mathbf{m}-\mathbf{r})$.

Vertically aligned SiNWs with good uniformity were clearly seen in the cross-section images (Figure 3m-r). The length of nanowires significantly increases from 5.48 to $20.84 \mu \mathrm{m}$ with increasing the etching from 20 to $120 \mathrm{~min}$ whereas the wire diameter is approximately in the range of one hundred to a very few hundreds of nanometers. 
Hence, the linear relationship of SiNWs length versus etching time plotted in Figure $4 \mathrm{~b}$ gives an etching rate close to $0.152 \mu \mathrm{m} / \mathrm{min}$.
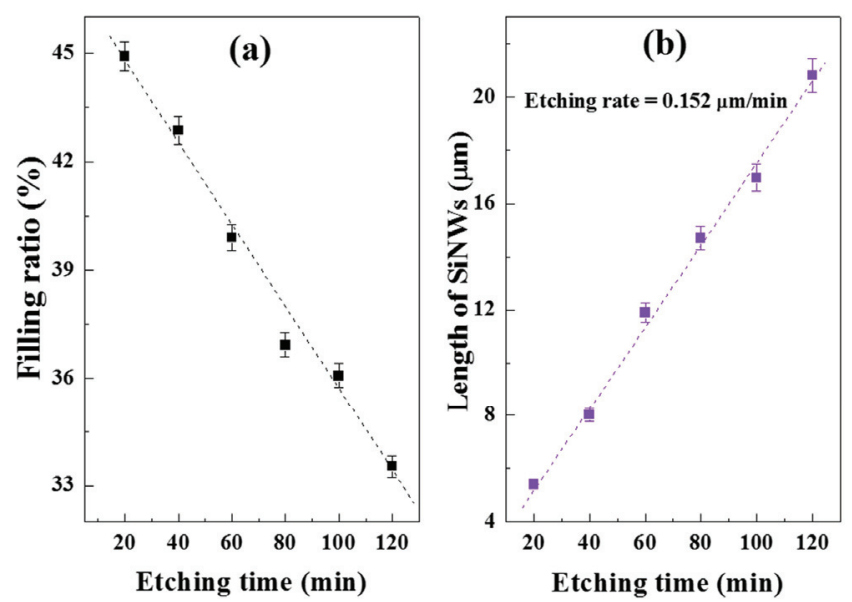

Figure 4. Variation of the (a) filling ratio and (b) length of SiNWs as a function of etching time.

This linear relation has been investigated in literature but with different etching rate values $[2,18,33]$. The possible reasons behind this increase of SiNWs length with etching time was ascribed to the fact that etching was given more time to proceed and the solution had enough oxidizing species to oxidize and dissolve the formed $\mathrm{SiO}_{2}$. We retain that doubling the etching time would not necessarily double the length of SiNW [34,35]. From tilt view images, we can observe that SiNWs are covered by numerous porous structures especially on their tips due to the additional etching pathways via the re-nucleation of the AgNPs throughout the SiNWs.

These porous structures are the origin of quantum confinement effects owing to their small dimensions. SiNW arrays grown by MACE usually show these porous structures called silicon nanocrystals.

Figure 5 displays XRD patterns of untreated Si wafer and SiNWs. A unique sharp peak at $69^{\circ}$ is observed for both samples, which is indexed to a (400) silicon plane. However, the silicon nanowires give a high peak intensity than that of Si wafer. This suggests high quality crystalline nanowires.

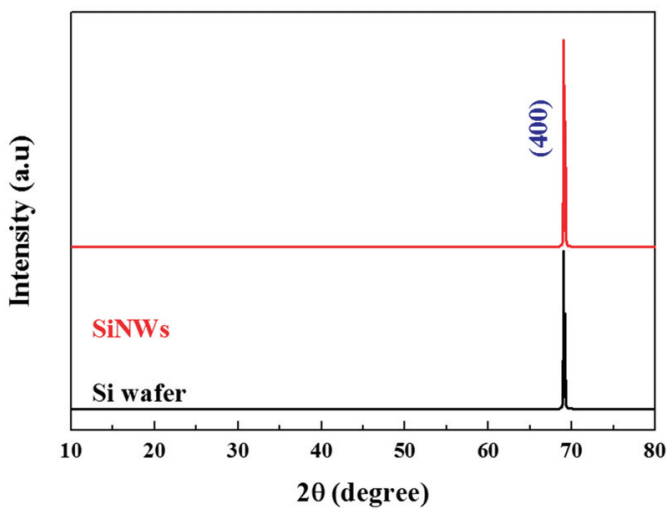

Figure 5. XRD patterns of silicon nanowires and untreated Si wafer. 
On the other hand, no characteristic peaks of silver are observed in the XRD pattern which confirms the completely removal of silver nanoparticles by nitric acid.

\subsection{Photoluminescence Spectroscopy}

The room temperature PL measurements of the as-synthesized samples were carried out in order to study the etching time dependency on photoluminescence properties. The SiNWs PL spectra ranging from 1.4 to $2.3 \mathrm{eV}$ are shown in Figure 6.

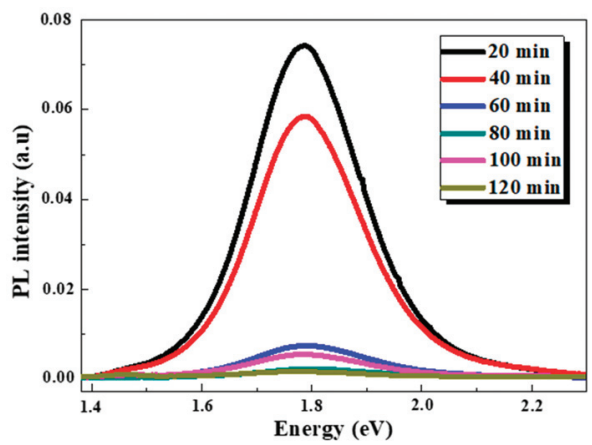

Figure 6. PL spectra of SiNWs synthesized at different etching times.

Broad PL emission bands were recorded with a maximum around $1.78 \mathrm{eV}$ and a full width at half maximum (FWHM) of $0.24 \mathrm{eV}$. Their shape is a gaussian and did not present any significant shift. However, one can see a clear degradation in the PL intensity when increasing etching time.

The highest PL intensity was obtained for 20 and 40 min which are almost 26 times stronger compared to the prolonged etching time. Therefrom, the opposite trend between the integrated PL intensity and etching duration is plotted in Figure 7.

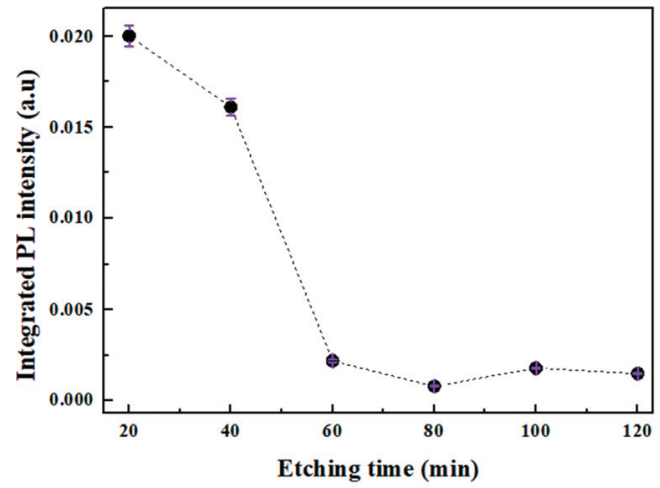

Figure 7. Variation of integrated PL intensities versus etching duration.

To explain the origin of this PL emission, several mechanisms have been proposed including the quantum confinement (QC) effects and the presence of defects in an $\mathrm{SiO}_{\mathrm{x}} / \mathrm{Si}$ interface and/or in the surface of the oxide related to the Si-O-Si bonds [36,37]. However, the QC effects, which enhance the radiative recombination of excitons, remain the most approved model which dictates that the crystallite Si size should be less than the Bohr radius of the free exciton of bulk silicon [17]. In the present work, the SiNW diameters are within one hundred to a very few hundred of nanometers, these values are much larger than the Bohr radius of excitons $(5 \mathrm{~nm})$ present in Si crystals. Taking into account the 
indirect band gap of SiNWs and their large diameters, the observed visible PL is unlikely to originate from the SiNWs and the origin of this light emission must be more complex. This is dissimilar to one earlier report that attribute the visible PL to the radiative recombination at the SiNWs itself [38]. On the other hand, it is widely reported that the SiNWs are decorated with self-grown silicon nanocrystals whose dimensions are smaller than the exciton Bohr diameter in silicon. These SiNCs cause a robust quantum confinement leading to the appearance of observed PL at room temperature [2-4,20]. In the current study, the nanocrystal size resulted from the spectral position of the PL peak by using the equation described below:

$$
\mathrm{E}=\mathrm{E}_{\mathrm{g}}+\frac{\mathrm{C}}{d^{\alpha}}
$$

where $\mathrm{E}$ is PL peak position $(\mathrm{eV}), \mathrm{E}_{\mathrm{g}}$ is the band gap of $\mathrm{c}-\mathrm{Si}(1.12 \mathrm{eV}), d$ is the SiNC size $(\mathrm{nm})$, $\alpha$ and $C$ are constants. Several works have reported different values of these constants from the SiNWs/NCs [19,39-41]. Comparison of SiNCs size values obtained by different parameters from earlier reports of the literature is investigated and the evaluated NC-sizes are summarized in Table 1. One can see clearly that all the estimated NCs diameter values are less than $5 \mathrm{~nm}$ and close to $2 \sim 4 \mathrm{~nm}$ regardless of the formula used (Table 1). According to these below values, we can assert that in these samples, the occurrence of QC in SiNCs is the origin of the recorded PL emission. Note that similar SiNCs size and PL peak position have been recently carried out $[2,3,41]$ due to the known dependence of a SiNC band gap on its size.

Table 1. Comparison of the SiNCs sizes value estimated from Equation (10) for different reports of the literature.

\begin{tabular}{ccccc}
\hline Constants & Valenta et al. [39] & Yan et al. [40] & Gonchar et al. [41] & Bahera et al. [19] \\
\hline $\mathrm{C}\left(\mathrm{eV} \mathrm{n} \mathrm{^{-2 }}\right)$ & 2.49 & 4 & 3.73 & 2.4 \\
$\alpha$ & 0.91 & 1.4 & 1.39 & 1.7 \\
$\mathrm{~d}(\mathrm{~nm})$ & 4.25 & 3.59 & 3.45 & 2.12 \\
\hline
\end{tabular}

Interestingly, the compatibility between the samples (S1-S6) in terms of peak position, FWHM, NCs size, and the variation of the PL intensity indicate that these latter derive from different size distribution and densities of the inseparable set of SiNWs-NCs. This is confirmed by the reduction of SiNWs amount as seen above in the SEM images and more precisely by the reduction of the volume filling ratio over etching time. These latter indicate that the monotonous decrease of the PL intensity over etching duration is interpreted as restriction and diminution of excitation volume which in turn is proportional to the amount of effective light-emitting crystallites [17,41,42].

Therefore, an appropriate geometry is required to ensure PL and our findings demonstrate that shorter SiNWs are much more optically active. It is worth noting that the light emitted from the SiNW arrays upon laser irradiation is visible to the naked eye and appears orange obviously for the samples corresponding to 20 and 40 min etching time. This emission is attributed to the radiative recombination of excitons in small SiNCs present in the nanowire sidewalls in terms of a QC model as explained above.

\subsection{FTIR Analysis}

FTIR spectroscopy was used to study the surface composition of the as prepared SiNWs at different etching durations. An untreated silicon substrate was utilized as background to the measurements and the spectra were taken in absorption mode in the $400-4000 \mathrm{~cm}^{-1}$ spectral range as shown in Figure 8. 


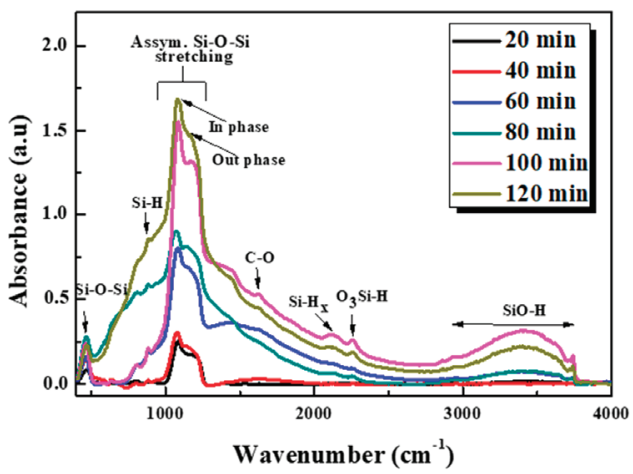

Figure 8. FTIR spectra of SiNWs obtained at different etching time.

All the spectra are closely similar with an increase in the absorbance bands intensity versus increasing etching time or otherwise with increasing SiNWs length. The most intense broad peak appears in the region between $1000-1300 \mathrm{~cm}^{-1}$ and is assigned to the $\mathrm{Si}-\mathrm{O}-\mathrm{Si}$ asymmetric stretching (AS) vibrations. This observed signal can be classified into a strong band at $1080 \mathrm{~cm}^{-1}$ attributed to $A S_{1}$ vibration mode and a shoulder at $1200 \mathrm{~cm}^{-1}$ related to $\mathrm{AS}_{2}$ vibration mode. $\mathrm{AS}_{1}$ results from the motion of the adjacent oxygen atoms moving in phase with one another while at $\mathrm{AS}_{2}$ the oxygen atoms move $180^{\circ}$ out of phase with one another. The appearance of this shoulder is a feature of the IR spectra of $\mathrm{SiO}_{\mathrm{x}}$ material where $\mathrm{x}$ value equals to one or higher [43].

These Si-O-Si bonding, introduced during the electrochemical etching, were found to be more popular with increasing etching time. Hence, Figure 9 presents the evolution of peaks intensity of dominant bands existing in the spectra.

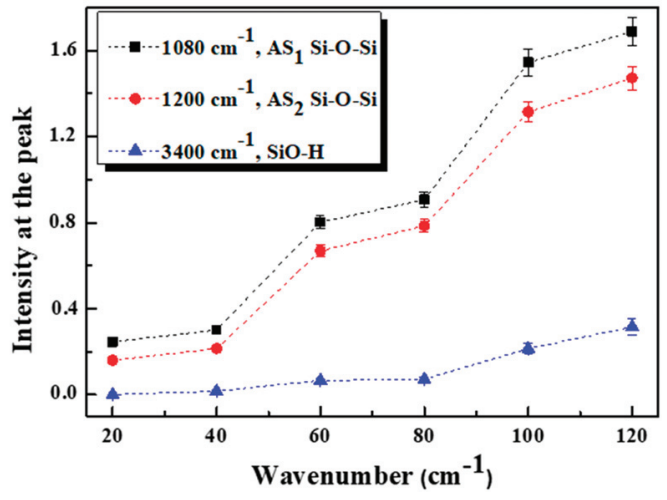

Figure 9. Evolution of peaks intensity of dominant FTIR bands versus etching time.

This increase of intensities indicates the continuity of chemical etching even during extended durations and then the formation of $\mathrm{Si}-\mathrm{O}$ radicals becomes consistent when rising the immersion duration in $\mathrm{HF} / \mathrm{H}_{2} \mathrm{O}_{2}$. Here, it involves that the charge transfer faces some difficulty in order to establish an electrical equilibrium leading to a decay in etching rate [44]. This behavior is in accordance with PL results and hence we could say that PL deterioration in higher etching time is related to the change in the distribution and density of the inseparable set of SiNWs-NCs owing to this etching rate decay leading to a restriction of excitation volume and therefore reduction of luminescent crystallites' density.

The broad peak at $465 \mathrm{~cm}^{-1}$ was related to $\mathrm{Si}-\mathrm{O}-\mathrm{Si}$, while the broad band within $3000-3700 \mathrm{~cm}^{-1}$ is attributed to the stretching of the $\mathrm{O}-\mathrm{H}$ bonds in $\mathrm{SiOH}$ groups and surface adsorbed $\mathrm{H}_{2} \mathrm{O}$. Whereas the 
narrow band at $3747 \mathrm{~cm}^{-1}$, is attributed to the stretching mode of surface free $\mathrm{OH}$ groups. The weak IR absorption peaks situated at around 900,2125 , and $2258 \mathrm{~cm}^{-1}$ corresponds to $\mathrm{Si}-\mathrm{H}$ bending vibrations, $\mathrm{Si}-\mathrm{H}_{\mathrm{x}}$ bonds and to $\mathrm{Si}-\mathrm{H}$ stretching mode in $\mathrm{O}_{3}-\mathrm{SiH}$, respectively. Finally, the tiny absorption band barely detectable at $1630 \mathrm{~cm}^{-1}$ is attributed to $\mathrm{C}-\mathrm{O}$ bonds which mainly came from the SiNWs surface contamination from environment and can hardly be avoided [2,21,28,43]. We notice that the surface states assigned to $\mathrm{Si}-\mathrm{O}$ and $\mathrm{Si}-\mathrm{H}$ chemical bonds are popular in all samples.

\subsection{Reflectance Analysis}

Figure 10 shows the reflectance spectra of the untreated Si wafer and the synthesized SiNWs with various heights over the wavelength range of 250-700 nm which covers the main spectral irradiance of sunlight that is useful for Si solar cells.

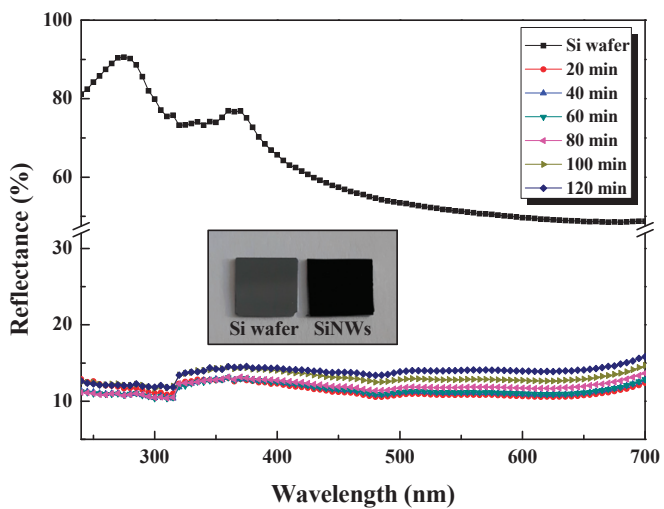

Figure 10. Reflectance spectra of SiNWs with various lengths etched during different times and corresponding $\mathrm{Si}$ wafer. The inset displays images of Si wafer and SiNWs.

When compared to the untreated bulk Si, all the etched samples show a significant lower reflectivity which is consistent with the colour changes from metallic grey to dark black as shown in the inset. The average reflectance for bulk Si is about 50\% 90\% in the UV-visible range while it reaches less than $15 \%$ for all the etched samples. Hence, such nanowires reduce reflection losses and further enhance the carrier collection which is extremely beneficial for developing high efficiency solar cells requiring good antireflective properties.

The sharp suppression in the reflectance is ascribed to three important factors: (i) The gradual variation towards the refractive index from air $(n \approx 1)$ to SiNWs and to Si substrate $(n \approx 3.42)$, (ii) the tapered morphology of silicon wires leading to light trapping due to the multiple reflections back and forth in the inner surface and (iii) the sub-wavelength structures for additional light trapping within the NWs $[17,33,45]$. The observed peaks of Si wafer at 275 and $367 \mathrm{~nm}$ come from the inter-band transitions of $\mathrm{Si}[32,45]$. In addition, as readily seen in the figure, all the reflectance values of SiNW arrays with various lengths are almost close and low (9-15\%) owing to the tapered NWs structure. The slightly higher reflectance observed for prolonged etching time is attributed to the coalescence of NWs at the apex and bundles formation as shown above in SEM images [33,45].

\subsection{I-V Measurements}

Electrical properties of SiNWs samples with various lengths of nanowires are studied through measurement of current-voltage (I-V) characteristics at room temperature and in the dark. First, Schottky contact was formed between metal and semiconductors (Al/Si and Ag/SiNWs). The I-V measurements of $\mathrm{Ag} / \mathrm{SiNWs} / \mathrm{Si} / \mathrm{Al}$ structure from -4 to $4 \mathrm{~V}$ are depicted in Figure 11. 


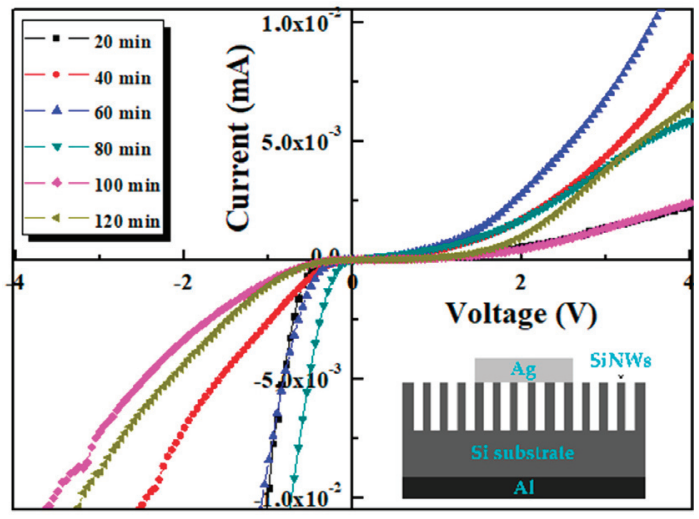

Figure 11. Curves of the as-prepared heterojunction based on SiNWs synthesised at various etching times. The inset displays a schematic illustration of $\mathrm{Ag} / \mathrm{SiNWs} / \mathrm{Si} / \mathrm{Al}$ device.

All the curves corresponding to NWs show a diode-like nature with an obvious rectifying behaviour. Interestingly, the junctions based on these SiNWs etched at different etching time display considerably the same properties at different areas on the junction. This latter observation highlights the uniformity of the junctions and could be supported by the distribution of a uniform large area of SiNWs on the whole wafers as shown above in the SEM images. On the other hand, the fabrication of other devices with maintaining the same conditions pointed out an electrical reproducibility property of the junctions. One can note that SiNWs fabrication with good uniformity/reproducibility are a MACE feature $[4,34]$. It is worth noting that the observed rectifying behaviour of these SiNWs is similarly shown in the literature for porous silicon [42,46-48]. Importantly, the nonlinear I-V characteristics and the rectifying event are mainly controlled by the SiNW layers and ascribed to Ag/SiNWs:p-Si since the $\mathrm{Si} / \mathrm{Al}$ interface was proved to be ohmic [47,48]. The electron flow into the SiNW layers from Ag and recombine with holes, leaving negatively charged electrons in SiNWs which leads to the N-type role of $\mathrm{SiNWs}$ with respect to Si. Thus, the formed depletion layer causes the rectifying behaviour. Another reason is that the quantum confinement coming from the SiNCs in the SiNWs increases the band gap in the SiNWs side which creates a potential barrier leading to the diodic behaviour [49,50]. It is clear to notice from the I-V curves the increase of rectification extent (current intensity) in the forward bias with etching time or in other words with SiNWs' length until reaching a threshold time (length) which corresponds to $60 \mathrm{~min}(\approx 12 \mu \mathrm{m})$, then the current intensity decreases. Therefore, we can assume that the electrical transport properties of the device are governed by SiNWs' contribution. The current decrease for samples with higher etching times is attributed to the increase of SiNWs length. The wires, acting as carries trapped, will increase and form a high resistive region which lead to the decrease of the current flowing through the SiNW layers.

Therefore, a well-defined moderate length of SiNWs is required to ensure better electrical properties. Electrical parameters of the device are obtained using the conventional thermionic emission model (TE) as expressed:

$$
I=I_{S}\left(\exp \left(\frac{q\left(v-R_{s}\right)}{\eta k T}\right)-1\right)
$$

where $q$ is the electronic charge, $\eta$ is the ideality factor, $R_{S}$ is the series resistance, $k$ is the Boltzmann constant, $\mathrm{T}$ is the absolute temperature, and $\mathrm{I}_{\mathrm{S}}$ is the reverse saturation current given by:

$$
\mathrm{I}_{\mathrm{s}}=\mathrm{aA}^{*} \mathrm{~T}^{2} \exp \left(\frac{-\mathrm{q} \varphi_{\mathrm{b}}}{\mathrm{kT}}\right)
$$


Herein, a is the diode area, $\mathrm{A}^{*}$ is Richardson constant $\left(\approx 32 \mathrm{~A} \mathrm{~cm}^{-2} \mathrm{~K}^{-1}\right.$ for $\mathrm{p}$-type $\left.\mathrm{Si}\right)$ and $\varphi_{\mathrm{b}}$ is barrier height. As eV $>>\eta \mathrm{KT}$ at room temperature, Equation (11) can be rewritten as:

$$
I=I_{s} \exp \left(\frac{q V}{\eta k T}\right)
$$

The ideality factor $\eta$ was estimated from the slope of the linear region of the plot of $\ln (\mathrm{I}) \mathrm{vs}$. V (Figure 12) based on Equation (13). The saturation current was derived by extrapolating $\ln (\mathrm{I}) \mathrm{vs}$. V plot to $\mathrm{V}=0$ while $\varphi_{\mathrm{b}}$ was calculated through Equation (12).

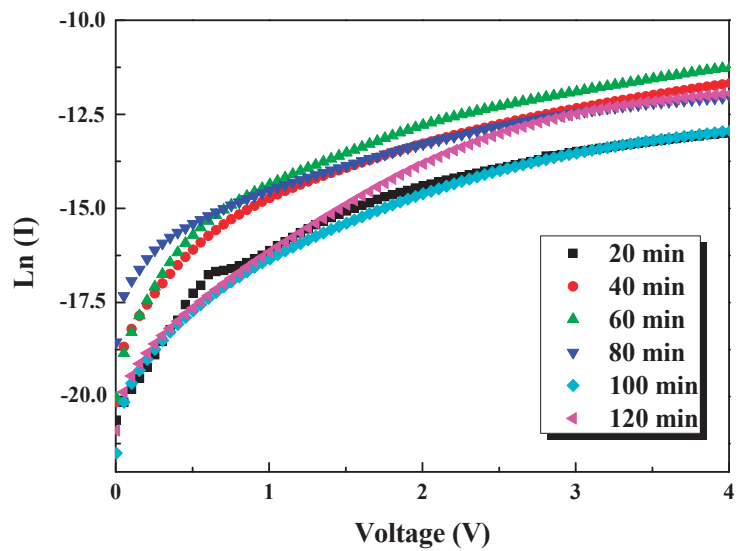

Figure 12. Logarithm of forward current versus voltage (Ln (I) vs. V) curves of SiNWs synthesized at different etching times.

In order to have more accurate ideality factor values owing to the non-linear part of $\ln (\mathrm{I}) \mathrm{vs}$. V plots and to determine the series resistance $\left(R_{s}\right)$, the Cheung's functions were utilized [51,52]. Thus,

$$
\frac{\mathrm{dV}}{\mathrm{d}(\mathrm{LnI})}=\mathrm{R}_{\mathrm{s}} \mathrm{I}+\frac{\eta \mathrm{kT}}{\mathrm{q}}
$$

Figure 13 presents the experimental $\frac{d V}{d(\operatorname{LnI})}$ vs. I plots, the $R_{S}$ and $\eta$ were determined as the slope and y axis intercept, respectively.

The deduced values of Is, $\eta, \varphi_{\mathrm{b}}$, and $\mathrm{R}_{\mathrm{s}}$ for samples S1-S6 are summarized in Table 2 and show a notable dependence of SiNWs' length. According to the formula in Equation (11), high I require high Is and small $\eta$ and $R_{s}$. The ideality factor values estimated from Cheung's functions are nearly matched with I-V method values. These relatively high values could be attributed to series resistance, barrier inhomogeneities, interfacial defects, or existence of an oxide layer spontaneously produced during the synthesis [51,52]. These latter give sense to the deviation from ideality and $\eta$ deterioration especially for higher etching times. A similar trend is noticed for barrier height. The results point out that the electrical parameters depend upon the thicknesses of SiNWs and the use of shorter SiNWs not exceeding $12 \mu \mathrm{m}$ (corresponding to $40 \mathrm{~min}$ etching time) can result in better electrical properties. One can note that these $\eta$ values are lower compared to those reported on porous silicon [47]. This is suggested to be related to the unique properties of SiNWs compared to PS which is promising for optoelectronic devices application. 

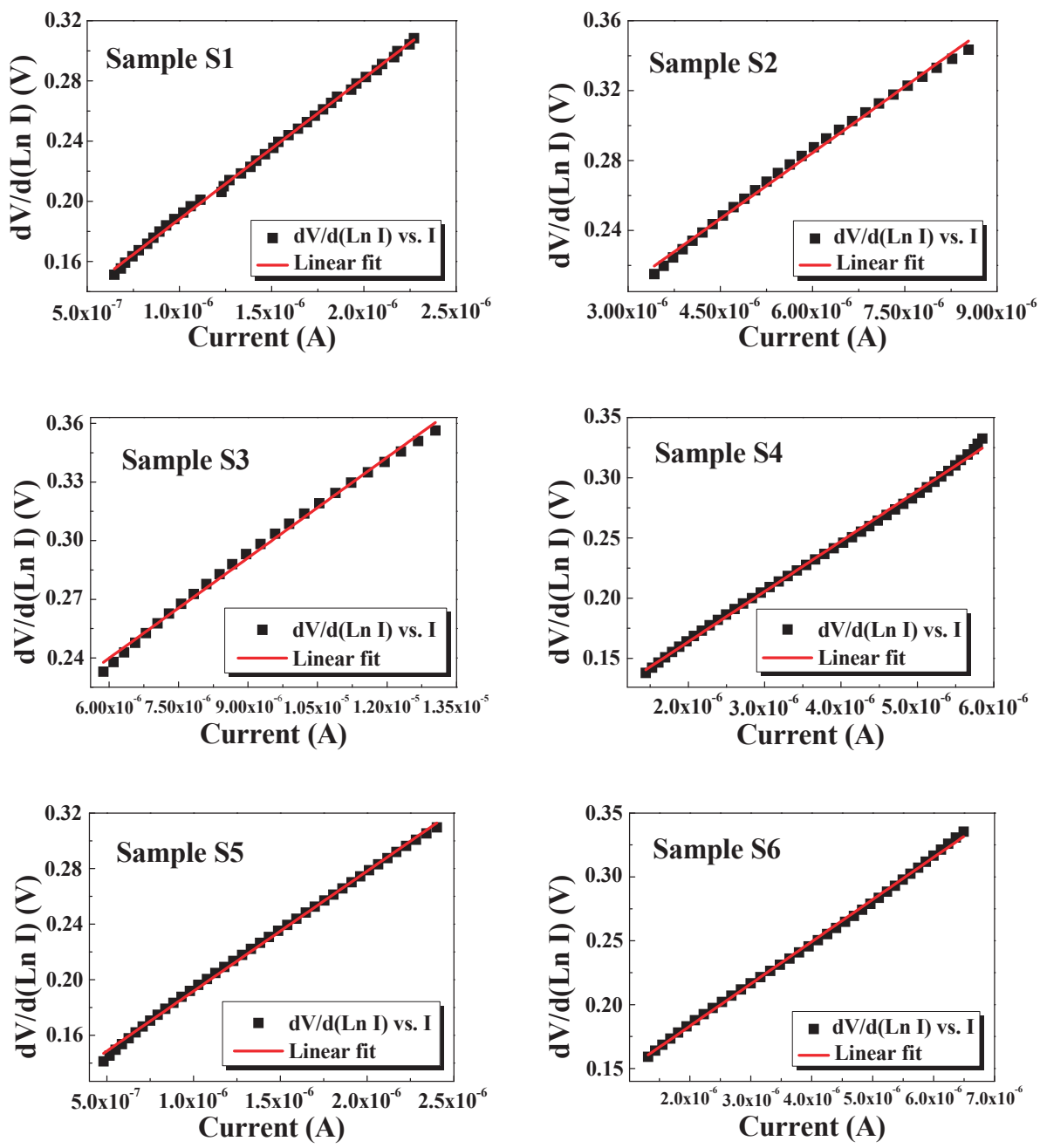

Figure 13. Plots of $d V / d(L n I)$ vs. I of SiNWs samples (S1-S6).

Table 2. Various electrical parameters determined by conventional TE and Cheung's model.

\begin{tabular}{cccccc}
\hline & \multicolumn{2}{c}{ Ln (I) vs. V (TE model) } & \multicolumn{2}{c}{$\begin{array}{c}\text { Cheung's } \\
\text { Functions }\end{array}$} \\
\hline Etching Time & $\mathbf{I}_{\mathbf{s}}(\boldsymbol{\mu} \mathbf{A})$ & $\eta$ & $\boldsymbol{\varphi}_{\mathbf{b}}(\mathbf{e V})$ & $\mathbf{R}_{\mathbf{S}}(\mathbf{k} \boldsymbol{\Omega})$ & $\eta$ \\
\hline $20 \mathrm{~min}$ & 0.211 & 5.91 & 0.806 & 93.65 & 3.65 \\
$40 \mathrm{~min}$ & 0.495 & 5.31 & 0.790 & 32.10 & 3.56 \\
$60 \mathrm{~min}$ & 0.695 & 4.38 & 0.771 & 25.06 & 2.60 \\
$80 \mathrm{~min}$ & 0.566 & 6.17 & 0.768 & 41.75 & 3.10 \\
$100 \mathrm{~min}$ & 0.239 & 6.05 & 0.801 & 86.33 & 4.08 \\
$120 \mathrm{~min}$ & 0.224 & 6.41 & 0.804 & 33.01 & 4.53 \\
\hline
\end{tabular}




\section{Conclusions}

In summary, optically and electrically-active SiNWs with strong PL emission, remarkable antireflections properties, and interesting electrical properties are successfully synthesized via 2-MACE method. First, an expanded explanation of the fabrication process is reported and then a systematic study is presented to visualize the effect of varying etching times on morphological, structural, optical, and electrical properties of SiNWs. The NWs length was increased by increasing etching time with a rate about $152 \mathrm{~nm} / \mathrm{min}$, whereas the wires filling ratio decreased. An analytical model is utilized to calculate the sizes of the self-grown silicon nanocrystallites which are the origin of the observed photoluminescence emission. FTIR spectroscopy supports PL results and confirms that the PL intensity degradation for expanded durations is owing to the restriction of excitation volume and therefore reduction of luminescent SiNCs. Therefore, appropriate SiNWs in terms of length and geometry is strongly required to ensure good PL. When compared to the silicon wafer, the formed SiNWs demonstrate a strong decrease of the reflectance to $9-15 \%$. This strong reduction of reflectance certifies that SiNWs are an excellent candidate for photovoltaic cells. I-V characteristics revealed that the rectifying behaviour of the uniform-reproducible junctions and the diode parameters (Is, n, $\varphi_{\mathrm{b}}$, and $R_{S}$ ) calculated from conventional thermionic emission and Cheung's model are found to depend significantly on the geometry of SiNWs. In brief, we deduce that etching time or otherwise SiNWs' length plays a key role on optical and electrical properties of SiNWs. Hence, judicious optimisation of these latter parameters is robustly required for better SiNWs' physical properties. Our findings demonstrate that shorter SiNWs are much more optically and electrically effective which pave the way for its application in the field of optoelectronic devices and solar cells.

Author Contributions: All authors have read and agree to the published version of the manuscript. M.N. performed the experiments, undertook the analysis, and wrote the manuscript. M.A.Z. and P.A.P. contributed to the analysis and supervised the progress of the research. P.A.P. and R.C. contributed reagents/materials/analysis tools.

Funding: This research received no external funding.

Acknowledgments: The authors would like to acknowledge the Tunisian Ministry of Higher Education and Scientific Research as well as University of Tunis. P.A. Postigo acknowledge the service from the X-SEM Laboratory at IMN and funding from MINECO under project CSIC13-4E-1794 with support from EU (FEDER, FSE).

Conflicts of Interest: The authors declare no conflict of interest.

\section{References}

1. Sahoo, M.K.; Kale, P. Integration of silicon nanowires in solar cell structure for efficiency enhancement: A review. J. Mater. 2019, 5, 34-48. [CrossRef]

2. Cong, L.T.; Ngoc Lam, N.T.; Giang, N.T.; Kien, P.T.; Dung, N.D.; Ha, N.N. N-type silicon nanowires prepared by silver metal-assisted chemical etching: Fabrication and optical properties. Mater. Sci. Semicond. Process. 2019, 90, 198-204. [CrossRef]

3. Ashrafabadi, S.; Eshghi, H. Single-crystalline Si nanowires fabrication by one-step metal assisted chemical etching: The effect of etching time and resistivity of Si wafer. Superlattices Microstruct. 2018, 120, 517-524. [CrossRef]

4. Lajvardi, M.; Eshghi, H.; Izadifard, M.; Ghazi, M.E.; Goodarzi, A. Effects of silver and gold catalytic activities on the structural and optical properties of silicon nanowires. Phys. E Low-Dimens. Syst. Nanostruct. 2016, 75, 136-143. [CrossRef]

5. Amri, C.; Ouertani, R.; Hamdi, A.; Chtourou, R.; Ezzaouia, H. Effect of porous layer engineered with acid vapor etching on optical properties of solid silicon nanowire arrays. Mater. Des. 2016, 111, 394-404. [CrossRef]

6. Baek, S.-H.; Park, J.-S.; Jeong, Y.-M.; Kim, J.H. Facile synthesis of Ag-coated silicon nanowires as anode materials for high-performance rechargeable lithium battery. J. Alloy. Compd. 2016, 660, 387-391. [CrossRef]

7. Schwartz, M.; Nguyen, T.C.; Vu, X.T.; Wagner, P.; Thoelen, R.; Ingebrandt, S. Impedimetric Sensing of DNA with Silicon Nanowire Transistors as Alternative Transducer Principle. Phys. Status Solidi A 2018, 215, 1700740. [CrossRef] 
8. Mirzaei, A.; Kang, S.Y.; Choi, S.-W.; Kwon, Y.J.; Choi, M.S.; Bang, J.H.; Kim, S.B.; Kim, H.W. Fabrication and gas sensing properties of vertically aligned Si nanowires. Appl. Surf. Sci. 2018, 427, 215-226. [CrossRef]

9. Borgne, B.L.; Salaün, A.C.; Pichon, L. Electrical properties of self-aligned gate-allaround polycrystalline silicon nanowires field-effect transistors. Microelectron. Eng. 2016, 150, 32-38. [CrossRef]

10. Amdouni, S.; Cherifi, Y.; Coffinier, Y.; Addad, A.; Zaiibi, M.A.; Oueslati, M.; Boukherroub, R. Gold nanoparticles coated silicon nanowires for efficient catalytic and photocatalytic applications. Mater. Sci. Semicond. Process. 2018, 75, 206-213. [CrossRef]

11. Yu, P.; Wu, J.; Liu, S.; Xiong, J.; Jagadish, C.; Wang, Z.M. Design and fabrication of silicon nanowires towards efficient solar cells. Nanotoday 2016, 11, 704-737. [CrossRef]

12. Latu-Romain, L.; Mouchet, C.; Cayron, C.; Rouviere, E.; Simonato, J.P. Growth parameters and shape specific synthesis of silicon nanowires by the VLS method. J. Nanopart. Res. 2008, 10, 1287-1291. [CrossRef]

13. Pan, H.; Lim, S.; Poh, C.; Sun, H.; Wu, X.; Feng, Y.; Lin, J. Growth of Si nanowires by thermal evaporation. Nanotechnology 2005, 16, 417-421. [CrossRef]

14. Fuhrmann, B.; Leipner, H.S.; Hoche, H.-R. Ordered arrays of silicon nanowires produced by nanosphere lithography and molecular beam epitaxy. Nano Lett. 2005, 5, 2524-2527. [CrossRef] [PubMed]

15. Kokai, F.; Inoue, S.; Hidaka, H.; Uchiyama, K.; Takahashi, Y.; Koshio, A. Catalyst-free growth of amorphous silicon nanowires by laser ablation. Appl. Phys. 2013, 112, 1-7. [CrossRef]

16. Hamdana, G.; Südkamp, T.; Descoins, M.; Mangelinck, D.; Caccamo, L.; Bertke, M.; Wasisto, H.S.; Bracht, H.; Peiner, E. Towards fabrication of 3D isotopically modulated vertical silicon nanowires in selective areas by nanosphere lithography. Microelectron. Eng. 2017, 179, 74-82. [CrossRef]

17. Lajvardi, M.; Eshghi, H.; Ghazi, M.E.; Izadifard, M.; Goodarzi, A. Structural and optical properties of silicon nanowires synthesized by Ag-assisted chemical etching. Mater. Sci. Semicond. Process. 2015, 40, 556-563. [CrossRef]

18. Vinzons, L.U.; Shu, L.; Yip, S.; Wong, C.-Y.; Chan, L.L.H.; Ho, J.C. Unraveling the Morphological Evolution and Etching Kinetics of Porous Silicon Nanowires During Metal-Assisted Chemical Etching. Nanoscale Res. Lett. 2017, 12, 1872. [CrossRef]

19. Behera, A.K.; Viswanath, R.N.; Lakshmanan, C.; Madapu, K.K.; Kamruddin, M.; Mathews, T. Synthesis, microstructure and visible luminescence properties of vertically aligned lightly doped porous silicon nanowalls. Microporous Mesoporous Mater. 2019, 273, 99-106. [CrossRef]

20. Ghosh, R.; Pal, A.; Giri, P.K. Quantitative analysis of the phonon confinement effect in arbitrarily shaped $\mathrm{Si}$ nanocrystals decorated on Si nanowires and its correlation with the photoluminescence spectrum. J. Raman Spectrosc. 2015, 7, 624-631. [CrossRef]

21. Leontis, I.; Othonos, A.; Nassiopoulou, A.G. Structure, morphology, and photoluminescence of porous $\mathrm{Si}$ nanowires: Effect of different chemical treatments. Nanoscale Res. Lett. 2013, 1, 383. [CrossRef] [PubMed]

22. Qi, Y.; Wang, Z.; Zhang, M.; Wang, X.; Ji, A.; Yang, F. Electron transport characteristics of silicon nanowires by metal-assisted chemical etching. AIP Adv. 2014, 3, 031307. [CrossRef]

23. Nafie, N.; Lachiheb, M.; Bouaicha, M. Effect of etching time on morphological, optical, and electronic properties of silicon nanowires. Nanoscale Res. Lett. 2012, 1, 393. [CrossRef]

24. Hutagalung, S.D.; Fadhali, M.M.; Areshi, R.A.; Tan, F.D. Optical and Electrical Characteristics of Silicon Nanowires Prepared by Electroless Etching. Nanoscale Res. Lett. 2017, 12, 425. [CrossRef]

25. Hasan, M.; Huq, M.F.; Mahmood, Z.H. A review on electronic and optical properties of silicon nanowire and its different growth techniques. SpringerPlus 2013, 2, 151. [CrossRef]

26. Huang, Z.; Geyer, N.; Werner, P.; de Boor, J.; Gösele, U. Metal-Assisted Chemical Etching of Silicon: A Review. Adv. Mater. 2010, 2, 285-308. [CrossRef] [PubMed]

27. Yang, C.; Wang, J.; Mei, L.; Wang, X. Enhanced Photocatalytic Degradation of Rhodamine B by $\mathrm{Cu}_{2} \mathrm{O}$ Coated Silicon Nanowire Arrays in Presence of $\mathrm{H}_{2} \mathrm{O}_{2}$. J. Mater. Sci. Technol. 2014, 11, 1124-1129. [CrossRef]

28. Lin, L.; Guo, S.; Sun, X.; Feng, J.; Wang, Y. Synthesis and Photoluminescence Properties of Porous Silicon Nanowire Arrays. Nanoscale Res. Lett. 2010, 11, 1822-1828. [CrossRef]

29. Brahiti, N.; Hadjersi, T.; Amirouche, S.; Menari, H.; ElKechai, O. Photocatalytic degradation of cationic and anionic dyes in water using hydrogen-terminated silicon nanowires as catalyst. J. Hydrog. Energy 2018, 43, 11411-11421. [CrossRef]

30. Bai, F.; Li, M.; Song, D.; Yu, H.; gosh, B.; Li, Y. One-step synthesis of lightly doped porous silicon nanowires in $\mathrm{HF} / \mathrm{AgNO}_{3} / \mathrm{H}_{2} \mathrm{O}_{2}$ solution at room temperature. J. Solid State Chem. 2012, 96, 596-600. [CrossRef] 
31. Qiu, T.; Wu, X.L.; Mei, Y.F.; Wan, G.J.; Chu, P.K.; Siu, G.G. From Si nanotubes to nanowires: Synthesis, characterization, and self-assembly. J. Cryst. Growth 2005, 277, 143-148. [CrossRef]

32. Chang, H.-C.; Lai, K.-Y.; Dai, Y.-A.; Wang, H.-H.; Lin, C.-A.; He, J.-H. Nanowire arrays with controlled structure profiles for maximizing optical collection efficiency. Energy Environ. Sci. 2011, 4, 2863. [CrossRef]

33. Li, S.; Ma, W.; Chen, X.; Xie, K.; Li, Y.; He, X.; Yang, X.; Lei, Y. Structure and antireflection properties of SiNWs arrays form mc-Si wafer through Ag-catalyzed chemical etching. Appl. Surf. Sci. 2016, 369, 232-240. [CrossRef]

34. Srivastava, S.K.; Kumar, D.; Schmitt, S.W.; Sood, K.N.; Christiansen, S.H.; Singh, P.K. Large area fabrication of vertical silicon nanowire arrays by silver-assisted single-step chemical etching and their formation kinetics. Nanotechnology 2014, 25, 175601. [CrossRef] [PubMed]

35. Ozdemir, B.; Kulakci, M.; Turan, R.; Unalan, H.E. Effect of electroless etching parameters on the growth and reflection properties of silicon nanowires. Nanotechnology 2011, 22, 155606. [CrossRef] [PubMed]

36. Najar, A.; Slimane, A.B.; Hedhili, M.N.; Anjum, D.; Sougrat, R. Effect of hydrofluoric acid concentration on the evolution of photoluminescence characteristics in porous silicon nanowires prepared by Ag-assisted electroless etching method. J. Appl. Phys. 2012, 112, 33502-33506. [CrossRef]

37. Vladimir, S.; Voigt, F.; Berger, A.; Bauer, G.; Christiansen, S. Roughness of silicon nanowire sidewalls and room temperature photoluminescence. Phys. Rev. B 2010, 82, 125446.

38. Chern, W.; Hsu, K.; Chun, I.S.; Azeredo BP, D.; Ahmed, N.; Kim, K.-H.; Zuo, J.-M.; Fang, N.; Ferreira, P.; Li, X. Nonlithographic Patterning and Metal-Assisted Chemical Etching for Manufacturing of Tunable Light-Emitting Silicon Nanowire Arrays. Nano Lett. 2010, 10, 1582-1588. [CrossRef]

39. Valenta, J.; Bruhn, B.; Linnros, J. Coexistence of 1D and Quasi-0D Photoluminescence from Single Silicon Nanowires, Coexistence of 1D and Quasi-0D. Nano Lett. 2011, 7, 3003-3009. [CrossRef]

40. Yan, J.-A.; Yang, L.; Chou, M.Y. Size and orientation dependence in the electronic properties of silicon nanowires. Phys. Rev. B 2007, 76, 115318. [CrossRef]

41. Gonchar, K.A.; Zubairova, A.A.; Schleusener, A.; Osminkina, L.A.; Sivakov, V. Optical Properties of Silicon Nanowires Fabricated by Environment-Friendly Chemistry. Nanoscale Res. Lett. 2016, 1, 357. [CrossRef] [PubMed]

42. Kulathuran, K.; Mohanraj, K.; Natarajan, B. Structural, optical and electrical characterization of nanostructured porous silicon: Effect of current density. Spectrochim. Acta Part A Mol. Biomol. Spectrosc. 2016, 152, 51-57. [CrossRef] [PubMed]

43. Zamchiy, A.O.; Baranov, E.A.; Khmel, S.Y.; Maximovskiy, E.A.; Gulyaev, D.V.; Zhuravlev, K.S. Deposition time dependence of the morphology and properties of tin-catalyzed silicon oxide nanowires synthesized by the gas-jet electron beam plasma chemical vapor deposition method. Thin Solid Films 2018, 654, 61-68. [CrossRef]

44. Moumni, B.; Jaballah, A.B. Correlation between oxidant concentrations, morphological aspects and etching kinetics of silicon nanowires during silver-assist electroless etching. Appl. Surf. Sci. 2017, 425, 1-7. [CrossRef]

45. Chaliyawala, H.A.; Ray, A.; Pati, R.K.; Mukhopadhyay, I. Strong light absorption capability directed by structured profile of vertical Si nanowires. Optical Mater. 2017, 73, 449-458. [CrossRef]

46. Garzon-Roman, A.; Cuate-Gomez, D.H. Graphene nanoflakes and carbon nanotubes on porous silicon layers by spin coating, for possible applications in optoelectronics. Sens. Actuators A Phys. 2019, 292, 121-128. [CrossRef]

47. Das, M.; Nath, P.; Sarkar, D. Influence of etching current density on microstructural, optical and electrical properties of porous silicon (PS):n-Si heterostructure. Superlattices Microstruct. 2016, 90, 77-86. [CrossRef]

48. Al Mortuza, A.; Hafijur, M.; Sinthia, R.; Mou, S.; Islam, M.J.; Ismail, A.B.M. Electrical and optical characteristics of porous silicon impregnated with LaF3 by a novel chemical bath technique. Curr. Appl. Phys. 2012, 12, 565-569. [CrossRef]

49. Dariani, R.S.; Zabihipour, M. Effect of electrical behavior of $\mathrm{ZnO}$ microparticles grown on porous silicon substrate. Appl. Phys. A 2016, 122, 1047. [CrossRef]

50. Haditale, M.; Zabihipour, A.; Koppelaar, H. A comparison of I-V characteristics of graphene silicon and graphene-porous silicon hybrid structures. Superlattices Microstruct. 2018, 122, 387-393. [CrossRef] 
51. Somvanshi, D.; Jit, S. Analysis of I-V Characteristics of Pd/ZnO Thin Film/n-Si Schottky Diodes with Series Resistance. J. Nanoelectron. Optoelectron. 2014, 9, 1-6. [CrossRef]

52. Kumar, Y.; Kumr, H.; Rawat, G.; Kumar, C.; Pal, B.N.; Jit, S. Electrical and Optical Characteristics of Pd/ZnO Quantum Dots Based Schottky Photodiode on n-Si. In Proceedings of the 2016 IEEE International Symposium on Nanoelectronic and Information Systems (iNIS), Gwalior, India, 19-21 December 2016.

(C) 2020 by the authors. Licensee MDPI, Basel, Switzerland. This article is an open access article distributed under the terms and conditions of the Creative Commons Attribution (CC BY) license (http://creativecommons.org/licenses/by/4.0/). 
MDPI

St. Alban-Anlage 66

4052 Basel

Switzerland

Tel. +41616837734

Fax +41 613028918

www.mdpi.com

Nanomaterials Editorial Office

E-mail: nanomaterials@mdpi.com www.mdpi.com/journal/nanomaterials

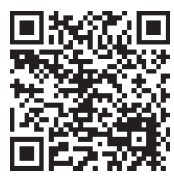



MDPI

St. Alban-Anlage 66

4052 Basel

Switzerland

Tel: +41 616837734

Fax: +41 613028918

www.mdpi.com 